PNNL-18120

WTP-RPT-170, Rev. 0

U.S. DEPARTMENT OF

ENERGY

Prepared for the U.S. Department of Energy under Contract DE-AC05-76RL01830

\title{
Characterization, Leaching, and Filtration Testing of Ferrocyanide Tank Sludge (Group 8) Actual Waste Composite
}

SK Fiskum

JM Billing

JV Crum

RC Daniel

February 2009
MK Edwards

RW Shimskey

RA Peterson

PJ MacFarlan
EC Buck

KE Draper

AE Kozelisky 


\title{
DISCLAIMER
}

This report was prepared as an account of work sponsored by an agency of the United States Government. Neither the United States Government nor any agency thereof, nor Battelle Memorial Institute, nor any of their employees, makes any warranty, express or implied, or assumes any legal liability or responsibility for the accuracy, completeness, or usefulness of any information, apparatus, product, or process disclosed, or represents that its use would not infringe privately owned rights. Reference herein to any specific commercial product, process, or service by trade name, trademark, manufacturer, or otherwise does not necessarily constitute or imply its endorsement, recommendation, or favoring by the United States Government or any agency thereof, or Battelle Memorial Institute. The views and opinions of authors expressed herein do not necessarily state or reflect those of the United States Government or any agency thereof.

\author{
PACIFIC NORTHWEST NATIONAL LABORATORY \\ operated by \\ BATTELLE \\ for the \\ UNITED STATES DEPARTMENT OF ENERGY \\ under Contract DE-AC05-76RL01830
}

Printed in the United States of America
Available to DOE and DOE contractors from the
Office of Scientific and Technical Information,
P.O. Box 62, Oak Ridge, TN 37831-0062;
ph: (865) 576-8401
fax: (865) 5765728
email: reports@adonis.osti.gov

\footnotetext{
Available to the public from the National Technical Information Service, U.S. Department of Commerce, 5285 Port Royal Rd., Springfield, VA 22161 ph: (800) 553-6847 fax: (703) 605-6900

email: orders@nits.fedworld.gov online ordering: http://www.ntis.gov/ordering.htm
} 
PNNL-18120

WTP-RPT-170, Rev. 0

\section{Characterization, Leaching, and Filtration Testing of Ferrocyanide Tank Sludge (Group 8) Actual Waste Composite}

\author{
SK Fiskum \\ JM Billing \\ JV Crum \\ RC Daniel
}

\author{
MK Edwards \\ RW Shimskey \\ RA Peterson \\ PJ MacFarlan
}

EC Buck

KE Draper

AE Kozelisky

February 2009

Test specification: 24590-PTF-TSP-RT-06-003, Rev. 1

Test plan: TP-RPP-WTP-467, Rev. 1

Test exceptions: None

R\&T focus area: Pretreatment

Test Scoping Statement(s): N/A

Pacific Northwest National Laboratory

Richland, Washington 99352 


\section{COMPLETENESS OF TESTING}

This report describes the results of work and testing specified by Test Specification 24590-PTF-TSP-RT-06-003, Rev. 1 "Characterization and Small Scale Testing of Hanford Wastes to Support the Development and Demonstration of Leaching and Ultrafiltration Pretreatment Processes" and Test Plan TP-RPP-WTP-467, Rev. I "Characterization and Small Scale Testing of Hanford Wastes to Support the Development and Demonstration of Leaching and Ultrafiltration Pretreatment Processes." The work and any associated testing followed the quality assurance requirements outlined in the Test Specification/Plan. The descriptions provided in this test report are an accurate account of both the conduct of the work and the data collected. Test plan results are reported. Also reported are any unusual or anomalous occurrences that are different from expected results. The test results and this report have been reviewed and verified.

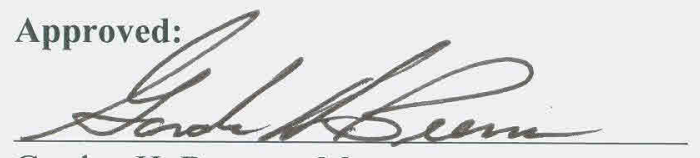

Gordon H. Beeman, Manager WTP R\&T Support Project

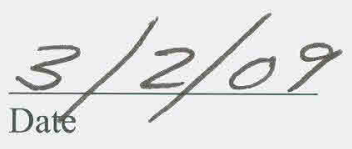




\section{Contents}

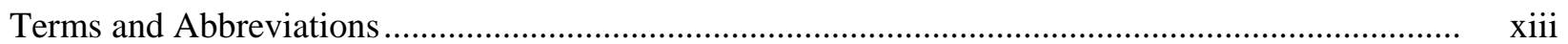

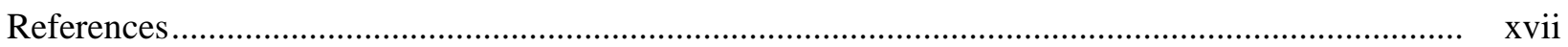

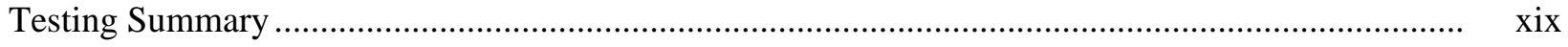

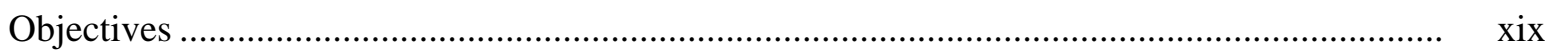

Test Exceptions........................................................................................................... $\quad$ xxii

Results and Performance Against Success Criteria ............................................................. xxii

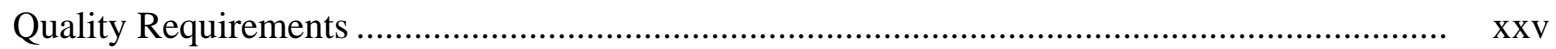

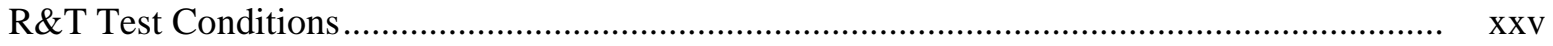

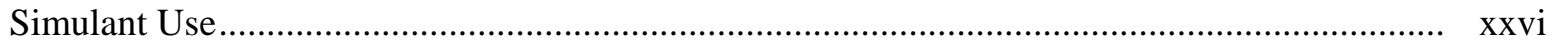

Discrepancies and Follow-on Tests ..................................................................................... xxvii

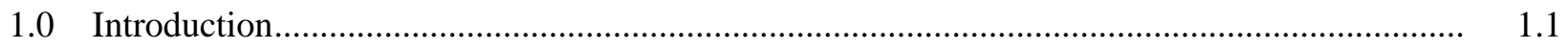

1.1 Overview of Tank Waste Pretreatment Operations at the WTP .................................... 1.1

1.2 Issues Identified by the External Flowsheet Review Team .............................................. 1.3

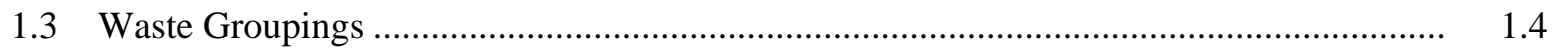

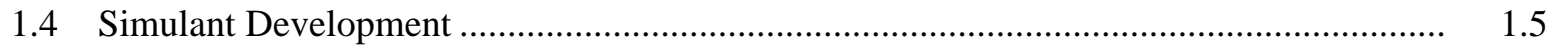

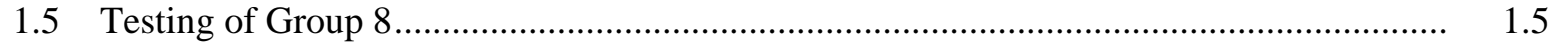

2.0 Test Sample Selection, Compositing, and Homogenization................................................ 2.1

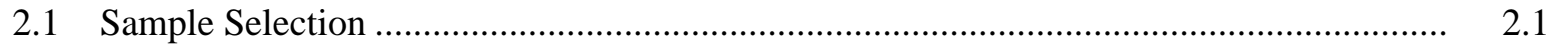

2.2 Group 8 Sample Compositing, Homogenization, and Sub-Sampling .............................. 2.5

3.0 Initial Characterization Results for Ferrocyanide Waste Sludge Group 8 .............................. 3.1

3.1 Physical Properties of the Composite Group 8 FeCN Slurry ......................................... 3.3

3.2 Rheology of the Composite Group 8 FeCN Slurry ......................................................... 3.5

3.2.1 Shear Strength...................................................................................................... 3.5

3.2.2 Flow Curve ................................................................................................... 3.6

3.3 Chemical and Radiochemical Composition of the Group 8 Slurry .................................. 3.9

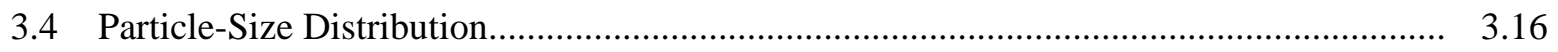

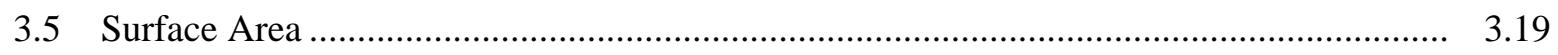

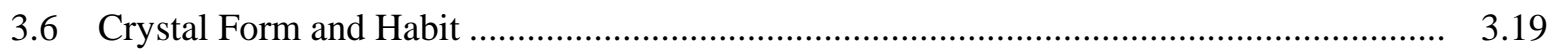

3.6.1 X-Ray Diffraction Pattern Evaluation.................................................................... 3.20

3.6.2 Scanning Electron Microscopy ….................................................................. 3.23

3.6.3 Transmission Electron Microscopy …............................................................... 3.29

4.0 Group 8 CUF Testing and Results .................................................................................

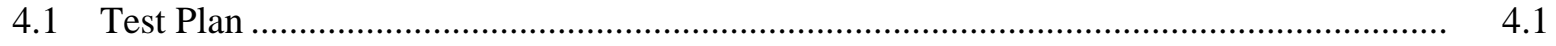


4.2 Low-Solids Slurry Characterization ............................................................................... 4.4

4.3 Filter Flux Test Matrix and Initial Dewater.............................................................. 4.10

4.3.1 Low-Solids Slurry Test Matrix .................................................................... 4.11

4.3.2 Dewatering of Group 8 Waste ......................................................................... 4.16

4.3.3 High-Solids Matrix ........................................................................................ 4.17

4.4 High-Solids Slurry Characterization................................................................................ 4.23

4.5 Caustic Leaching/Washing ........................................................................................... 4.30

4.5.1 Caustic Batch Leaching Results..................................................................... 4.31

4.5.2 Caustic-Leach Dewatering ........................................................................... 4.33

4.5.3 Dewatered Leached Slurry Physical Characterization ......................................... 4.35

4.5.4 Caustic Batch Rinsing Results ......................................................................... 4.41

4.5.5 Dewatering Caustic-Wash Solutions ................................................................ 4.48

4.6 Leached Material Characterization .................................................................................... 4.50

4.6.1 Chemical Characterization ................................................................................ 4.51

4.6.2 Crystal Form and Habit...................................................................................... 4.55

4.6.3 Particle Size and Rheology …........................................................................... 4.59

4.7 Final Filter Flux Test Matrix ...................................................................................... 4.63

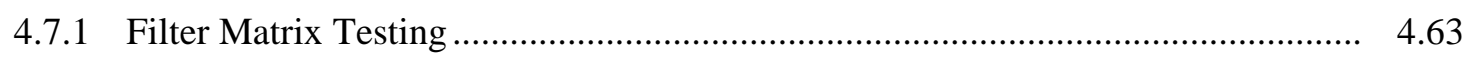

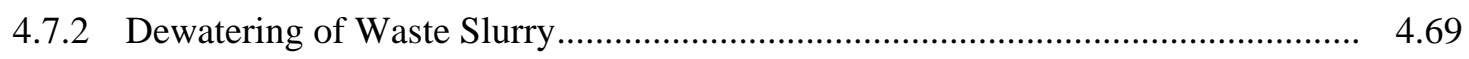

5.0 Summary and Conclusions ............................................................................................... 5.1

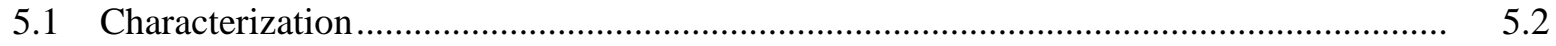

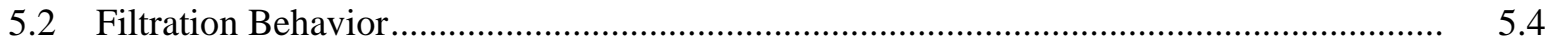

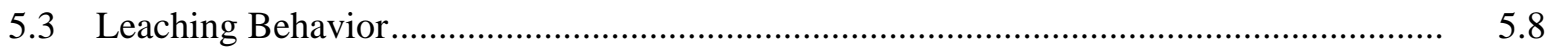

Appendix A: Homogenization Vessel.................................................................................. A.1

Appendix B: Analysis Methods ............................................................................................ B.1

Appendix C: Quality Assurance and Quality Control............................................................. C.1

Appendix D: CUF Filtration/Leaching Apparatus, Experimental Methods, Sampling, and Sample

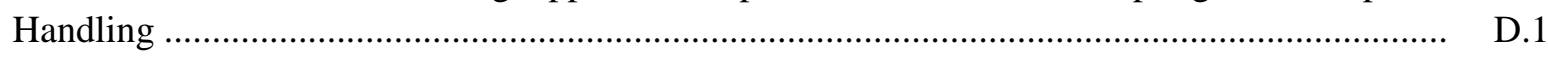

Appendix E: Calculations Supporting CUF Filtration/Leaching .................................................. E.1

Appendix F: Group 8 CUF Rheology …................................................................................ F.1

Appendix G: Group 8 PSD Report .......................................................................................... G.1

Appendix H: CUF Process Request ............................................................................................... H.1

Appendix I: Group 8 CUF Analytical Results .................................................................................. I.1 


\section{Figures}

1.1. Schematic Representation of the Key Processes to be Performed in the PTF.

2.1. Estimated Tank Waste Composition of Selected Analytes for Ferrocyanide Sludge Wastes in the Hanford Tank Farm (BBI Source) Containing > 70wt\% Ferrocyanide Waste.................. $\quad 2.2$

2.2. Selection Decision Process $1 \mathrm{C}$ and 2C Sludge Samples ........................................................ 2.3

2.3. Representative Photographs of As-Received Group 8 Waste Samples ................................... 2.7

2.4. Contribution of the Individual Tank Materials to the Group 8 Composite Sample .................. 2.11

2.5. Group 8 Confirmation of Successful Material Composite Based on Volume Percent of 5-Day Settled Solids and Gross Density....

3.1. Composite Group 8 Slurry Processing and Analysis Scheme....

3.2. Group 8 FeCN Solids Settling Test (AR-S1, -S2, -S3)

3.3. Shear Strength Versus Shear Rate for Group 8 FeCN Sludge Initial Characterization Sample (TI516-G8-AR-P1) at $25^{\circ} \mathrm{C}, 40^{\circ} \mathrm{C}$, and $60^{\circ} \mathrm{C}(11.4 \mathrm{wt} \%$ UDS), Measured Using the MV1 Smooth Cup and Rotor

3.4. Wash Sequence of Group 8 FeCN Sludge Supporting Initial Characterization ......

3.5. Selected Analyte Phase Distribution for Group 8 FeCN Sludge.....

3.6. Volume Distribution Results for the Primary Washed Group 8 Sample as a Function of Pump Speed

3.7. Volume Distribution Result for the Duplicate Washed Group 8 Sample as a Function of Pump Speed

3.8. Comparison of Primary and Duplicate Sample Differential Volume PSD of Group 8 Initial Characterization Sample at 3000 RPM without Sonication

3.9. Raw Data XRD Pattern of Washed Group 8 FeCN Sludge with Rutile (Internal Standard)......

3.10. Background-Subtracted Pattern with Stick-Peak Identification of Washed Group 8 FeCN Sludge

3.11. SEM Images of Washed Group 8 FeCN Sludge

3.12. Electron Imaging of Washed Group 8 FeCN Sludge Showing U-Rich Particle

3.13. SEM Images of Washed Group 8 FeCN Sludge

3.14. SEM Images with EDS Evaluation of Group 8 FeCN Washed Sludge, 4000×

3.15. SEM Imaging of Washed Group 8 FeCN Sludge with EDS Analysis, 2000×

3.16. Low Magnification STEM-HAADF View of Washed Group 8 Particles (left) and High Magnification Image Showing Iron-, Strontium-, and Uranium-Bearing Particles (right) ........

3.17. High Resolution Image of Uranium Phase in Washed Group 8 Sludge; Inset is a Selected Area Electron Diffraction Pattern and the EDS Analysis is Shown to the Right

3.18. Electron Diffraction Pattern Along the B[111] Zone Axis of Iron Oxide Phase in Washed Group 8 Solids. 
3.19. STEM-HAADF Image and EDS Analyses of an Agglomerate of Particles.

3.20. Electron Energy-Loss Spectra of the Oxygen K-Edge from Three Phases in the Washed Group 8 Tank Sludge.

3.21. TEM Images of G8-S-WL Tank Sludge Showing the Heterogeneous Nature of the Particles

3.22. Energy-Filtered TEM Images Showing Strontium and Uranium Distribution in Sludge Particles

3.23. High-Resolution TEM Image of Sr-P Phase in Group 8

3.24. Electron Energy-Loss Spectrum of the Sr-P Phase

3.25. Rotational Average of an Electron Diffraction Pattern from the Sr-P Phase

4.1. Group 8 Testing Flowchart.

4.2. Process Flow Diagram of Creating Low-Solids Slurry ...

4.3. Volume Distribution PSD Results for the Group 8 Low-Solids Matrix Sample as a Function of Pump Speed.

4.4. Influence of Circulation in the CUF for Group 8 PSD

4.5. Flow Curves for Group 8 CUF Low Solids Slurry (Measured UDS of 5.9 wt\%)......

4.6. Filter Flux Data for Low-Solids Slurry Matrix (Measured UDS of 5.9 wt\%).

4.7. Filter Flux Performance for Low-Solids Slurry (Measured UDS of $5.9 \mathrm{wt} \%$ ).

4.8. Correlation of Average Flux as a Function of TMP for the Low-Solids Slurry (Measured UDS of $5.9 \mathrm{wt} \%$ ).

4.9. Process Flow for Dewatering Group 8 Slurry

4.10. Filter Flux During Dewatering of Group 8 Low-Solids Slurry from 5.9 wt $\%$ to 14 wt\% UDS (Dewatering paused to restore TMP and AV conditions)

4.11. Dilution of Dewatered Slurry for High-Solids Matrix Test...

4.12. Filter-Flux Data for High Solids Matrix (Measured UDS of $13 \mathrm{wt} \%$ ).

4.13. Filter-Flux Performance for High-Solids Slurry (Measured UDS of $13 \mathrm{wt} \%$ ).

4.14. Least Square Fit to High-Solids Matrix Test Results to Linear Model (Measured UDS of $13 \mathrm{wt} \%)$.

4.15. Process Flow Through the High-Solids Matrix

4.16. Particle-Size Volume Distribution Results for the Group 8 High-Solids Matrix as a Function of Pump Speed (Measured at 13 wt\% UDS).

4.17. Influence of Filtration and Shear on the PSD of Group 8 Solids on PSD

4.18. Flow Curves for the CUF High Solids Slurry (Measured at $13 \mathrm{wt} \%$ UDS)

4.19. Process Flow for Caustic Leach Preparation

4.21. Temperature Profile/Aluminum Leach Factor During Batch Caustic Leaching of the Group 8 Slurry (3.7 M free hydroxide) 
4.22. Process Flow of Dewatering Group 8 Caustic Leached Slurry

4.23. Dewatering Leached Group 8 Slurry at Standard Conditions

4.24. Sampling of Dewatered Caustic Leached Slurry 4.36

4.25. Flow Curves for Group 8 CUF Caustic Leached Dewatered Slurry

4.28. Total Phosphorus in Group 8 CUF Slurry

4.29. Total Chromium in Group 8 CUF Slurry

4.30. Total 137Cs in Group 8 CUF Slurry

4.31. Al, Cr, P, 137Cs Removed from the Group 8 CUF Slurry

4.32. Sodium and Free-Hydroxide Molarity in Group 8 CUF Slurry

4.33. TMP and AV as Functions of Process Time During Slurry Washing

4.34. Filter Flux of Dewatered Wash Supernate

4.35. Process Flow for Sampling of the Washed and Caustic-Leached Group 8 Slurry .....

4.36. Radionuclides/Total Solids in CUF 8 Slurry, Adjusted for Sampling.....

4.37. Raw X-Ray Diffraction Pattern of the Caustic-Leached and Washed Group 8 Solids .....

4.38. Background-Subtracted XRD Patterns Comparing Initial Characterization Group 8 Solids with Caustic-Leached and Washed Group 8 Solids

4.39. SEM Image with EDS Evaluation of Group 8 Leached and Washed Particle

4.40. SEM Image with EDS Evaluation of Group 8 Leached and Washed Particle

4.41. Volume Distribution Result for the Group 8 Caustic-Leached and Washed Slurry as a Function of Pump Speed

4.42. Flow Curves for the Group 8 Leached, Washed Slurry.

4.43. Filter Matrix Test Results of Blended Wash Leached Slurries (Group 8 with Group 7/ AY102) at a Measured UDS of $15 \mathrm{wt} \%$

4.44. Filtration Performance of the Blended Group 8 Solids and AY-102 Solids (measured UDS of $15 \mathrm{wt} \%)$

4.45. Least Square Fit of Leached Solid Test Matrix Results with Linear Model; Blended Waste (measured UDS of $15 \mathrm{wt} \%$ )

4.46. Dewatering Curve for the Blended Waste.

4.47. Flow Curve of the Dewatered Blended Washed Leached Slurry 


\section{Tables}

Table

Caption

Page

1.1. Projected Distribution of Water-Insoluble Components in the Tank Waste Groupings ............ 1.4

2.1. Selection of Ferrocyanide Sludge Tanks ............................................................................... 2.4

2.2. Group 8 Expected Samples and Masses from 222S Archive ................................................. 2.5

2.3. Group 8 Ferrocyanide Sludge Samples ............................................................................... 2.9

2.4. Group 8 Sub-Sample Mass Density and Settling Data....................................................... 2.12

3.1. Physical-Property Measurements of Homogenized Group 8 FeCN Slurry …............................ 3.4

3.2. Supplemental Physical Properties from Chemical Characterization Samples............................ 3.5

3.3. Shear Strength of Group 8 Initial Characterization (Sample TI516-G8-AR-P1) ..................... 3.6

3.4. Best Fit Newtonian Viscosities for Group 8 FeCN Sludge Slurries.......................................

3.5. Radionuclide Characterization of the Group 8 FeCN Sludge ............................................... 3.11

3.6. Chemical Characterization of the Group 8 FeCN Sludge .................................................... 3.12

3.7. Phase Distribution of Selected Analytes in Group 8 FeCN Sludge ......................................... 3.15

3.8. PSD Analysis Percentile Results of the Washed Group 8 Sample (Primary and Duplicate) ..... 3.18

3.9. Percentile RPD Between Primary and Duplicate Washed Group 8 Samples ........................... 3.18

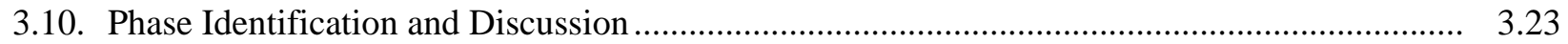

3.11. Measured Electron Diffraction Reflections from the Uranium Phase Compared Against Possible Candidate Phases

3.12. EDS Analysis of Strontium to Phosphorus Content (Relative Atom Fraction)........................ 3.36

3.13. Electron Diffraction Data from Cancrinite Phase in Washed Group 8 Solids.......................... 3.37

4.1. Mass Balance Overview of Group 8 Low-Solids Slurry ........................................................

4.2. Simulated Supernate Addition to Group 8 Composite ............................................................... 4.5

4.3. Low-Solids Slurry Physical Property Measurements (Slurry Circulation Loop) ...................... 4.6

4.4. Group 8 Low-Solids Slurry Composition Based on Overall Mass Balance (Mass Includes

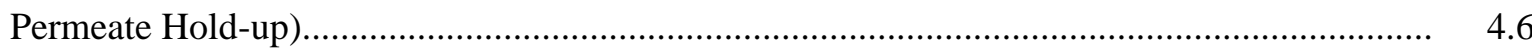

4.5. Particle-Size Analysis Percentile Results from the Group 8 Low-Solids Matrix Sample .......... $\quad 4.7$

4.6. Cumulative Undersize Percentiles Showing the Influence of Circulation in the CUF on Group 8 PSD at Measurement Condition 1 (3000 RPM) ......................................................

4.7. Results of Fitting Analysis for Group 8 CUF Low Solids Slurry (Measured UDS of

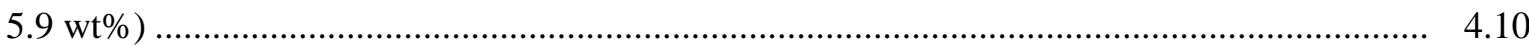

4.8. Average Operating Conditions and Permeate Flux for Low-Solids Slurry Matrix Test ............ 4.12

4.9. Mass Balance Overview of Dewatering ….......................................................................... 4.16

4.10. Mass Balance Overview of Dilution of Dewatered Slurry to 13 wt\% UDS............................ 4.18

4.12. High-Solids Slurry Physical-Property Measurements (Inside Slurry Loop) ............................ 4.23 
4.13. Group 8 High-Solids Slurry Composition Based on Mass-Balance Calculation (Mass Calculation Included Permeate Hold-up)

4.14. Group 8 High-Solids Slurry Composition Based on ICP-OES/Radionuclide Characterization. 4.25

4.15. Particle Size Analysis Percentile Results of the Group 8 High-Solids Matrix Sample..... 4.26

4.16. Cumulative Undersize Percentiles Showing the Influence of Filtration and Shear on the PSD of Group 8 Solids at PSD Measurement Condition 1 (3000 RPM) ......................................... 4.28

4.17. Results of Fitting Analysis for the CUF High Solids Matrix ................................................ 4.29

4.18. Selected Analyte Concentrations During Caustic Leaching of Group 8 ................................. 4.33

4.19. Comparison of Slurry Supernate Attributes to Filter Flux ..................................................... 4.35

4.20. Dewatered Caustic Leached Slurry Physical Property Measurements ...................................... 4.36

4.21. Dewatered Leached Slurry Composition (including permeate hold-up) .................................. 4.37

4.22. Dewatered Leached Slurry Composition and Calculated Solids Leach Factors ...................... 4.38

4.23. Results of Fitting Analysis for the Group 8 CUF Leached Dewatered Slurry …..................... 4.41

4.24. Overall Mass Balance Results after Washing of Caustic Leached Slurry ............................... 4.47

4.25. Comparison of Washed Slurry Supernate Attributes to Filter Flux ....................................... 4.49

4.26. Final Leached and Washed Slurry Physical-Property Measurements ..................................... 4.51

4.27. Group 8 Washed Caustic Leached Slurry Composition Based on Overall Mass Balance (Mass Includes Permeate Holdup Fraction) ................................................................... 4.52

4.28. Washed Leach Slurry Composition and Caustic Leach Factor Calculations ........................... 4.53

4.29. PSD Percentile Results for the Group 8 Caustic-Leached and Washed Sample ....................... 4.60

4.30. Results of Fitting Analysis for the Group 8 Leached and Washed Slurry ................................ 4.62

4.31. Physical-Property Measurements of the Initial Blended Slurry .............................................. 4.63

4.32. Average Flux Values for Washed Leached Group 8 Slurry Blended with the Washed Leached Group 7/AY-102 Slurry (Measured UDS of 15 wt\%) .............................................. 4.64

4.33. Final Leached and Washed Slurry Physical-Property Measurements ....................................... 4.69

4.34. Results of Fitting Analysis for the Dewatered Blended Washed Leached Slurry .................... 4.72

5.1. Radionuclide Content in Group 8 Before and After Caustic Leach ....................................... 5.3

5.2. Inductively Coupled Plasma (ICP) Analyte Content in Group 8 Before and After Caustic Leach ................................................................................................................ 5.4

5.3. Summary of Group 8 Filtration Results …...................................................................

5.4. Caustic Leaching Summary of Group 8 Slurry ........................................................... 



\section{Terms and Abbreviations}

\begin{tabular}{|c|c|}
\hline ASO & Analytical Support Operations \\
\hline ASR & analytical services request \\
\hline ASTM & American Society for Testing and Materials \\
\hline ATL & Advanced Technologies and Laboratories International \\
\hline AV & axial velocity \\
\hline BBI & Best Basis Inventory \\
\hline BET & $\begin{array}{l}\text { term used to describe a surface-area measurement technique developed by Stephen } \\
\text { Brunauer, Paul Hugh Emmett, and Edward } \underline{\text { Teller }}\end{array}$ \\
\hline BNI & Bechtel National, Inc. \\
\hline BS & blank spike \\
\hline CCD & charged-coupled device \\
\hline $\mathrm{CF}$ & concentration factor \\
\hline CS & centrifuged solids \\
\hline CUF & crossflow filtration apparatus (which specifically contains the cell unit filter) \\
\hline CWP & PUREX cladding waste \\
\hline CWR & REDOX cladding waste \\
\hline CS & centrifuged solids \\
\hline DACS & data acquisition system \\
\hline DI & deionized (water) \\
\hline DOE & U.S. Department of Energy \\
\hline EDS & energy dispersive spectrometry \\
\hline EELS & electron energy-loss spectroscopy \\
\hline EFRT & External Flowsheet Review Team \\
\hline EFTEM & energy filtered transmission electron microscopy \\
\hline EQL & estimated quantitation limit \\
\hline $\mathrm{FeCN}$ & ferrocyanide tank waste sludge \\
\hline GEA & gamma energy analysis \\
\hline HAADF & high angle annular dark field \\
\hline HLRF & High-Level Radiochemistry Facility \\
\hline HLW & high-level waste \\
\hline
\end{tabular}




\begin{tabular}{|c|c|}
\hline HP & hot persulfate \\
\hline IC & ion chromatography \\
\hline ICDD & International Centre for Diffraction Data \\
\hline ICP & inductively coupled plasma \\
\hline $\mathrm{KOH}$ & potassium hydroxide fusion \\
\hline KPA & kinetic phosphorescence analysis \\
\hline LAW & low-activity waste \\
\hline LCS & laboratory control standard \\
\hline MS & matrix spike \\
\hline MDL & minimum detection limit \\
\hline na & not applicable \\
\hline $\mathrm{n} / \mathrm{a}$ & not analyzed \\
\hline NIST & National Institute for Science and Technology \\
\hline NQA & nuclear quality assurance \\
\hline OES & optical emission spectrometry \\
\hline ORP & Office of River Protection (DOE) \\
\hline PB & preparation blank \\
\hline PNNL & Pacific Northwest National Laboratory \\
\hline PSD & particle-size distribution \\
\hline PTF & Pretreatment Facility \\
\hline PTFE & polytetrafluoroethylene \\
\hline PUREX & plutonium-uranium extraction \\
\hline QA & quality assurance \\
\hline QAM & Quality Assurance Manual \\
\hline QAP & Quality Assurance Plan \\
\hline QAPjP & Quality Assurance Project Plan \\
\hline QARD & Quality Assurance Requirements and Descriptions \\
\hline QC & quality control \\
\hline REDOX & reduction oxidation \\
\hline RIR & relative intensity ratio \\
\hline RPD & relative percent difference \\
\hline RPL & Radiochemical Processing Laboratory \\
\hline
\end{tabular}


RSD

RPP-WTP

R\&T

RTD

SAED

SEM

STEM

TBP

TEM

TI

TIC

TMP

TOC

TP

TRU

TSS

TWINS

UDS

WCS

WTP

XRD relative standard deviation

River Protection Project-Waste Treatment Plant Support Program

research and technology

resistance temperature detector

selected area electron diffraction

scanning electron microscopy

scanning transmission electron microscopy

tributyl phosphate

transmission electron microscopy

test instruction

total inorganic carbon

trans-membrane pressure

total organic carbon

test plan

transuranic

technical scoping statement

Tank Waste Information Network System

undissolved solids

wet centrifuged solids

Hanford Tank Waste Treatment and Immobilization Plant

X-ray diffraction 


\section{Terms of Measurement}

\begin{tabular}{ll}
$\mu \mathrm{Ci}$ & microcurie \\
$\mu \mathrm{g}$ & microgram \\
$\AA$ & angstrom \\
${ }^{\circ} \mathrm{C}$ & degrees centrigrade \\
$\mathrm{cP}$ & centiPoise, equivalent to mPa·s \\
$\mathrm{eV}$ & electron volt \\
$\mathrm{ft} / \mathrm{s}$ & feet per second \\
$\mathrm{g}$ & gram \\
$\mathrm{g} / \mathrm{mL}$ & density \\
$\mathrm{GPM} / \mathrm{ft}^{2}$ & gallons per minute per foot squared \\
$\mathrm{h}$ & hour \\
$\mathrm{KeV}$ & kiloelectron volt \\
$\mathrm{kg}$ & kilogram \\
$\mathrm{L}$ & liter \\
$\mathrm{M}$ & molarity \\
$\mathrm{min}$ & minute \\
$\mathrm{mL}$ & milliliter \\
$\mathrm{mm}$ & millimeter \\
$\mathrm{mPa} \cdot \mathrm{s}$ & millipascals-sec, equivalent to cP \\
$\mathrm{nm}$ & nanometer \\
$\mathrm{Pa}$ & Pascal \\
$\mathrm{psid}$ & pounds per square inch differential \\
$\mathrm{vol} \%$ & revolutions per minute \\
$\mathrm{wt} \%$ & volume percent \\
\hline &
\end{tabular}


WTP-RPT-170, Rev. 0

\section{References}

Brooks KP, PR Bredt, SK Cooley, GR Golcar, LK Jagoda, KG Rappe, and MW Urie. 2000a.

Characterization, Washing, Leaching and Filtration of AZ-102 Sludge. PNWD 3045 (BNFL-RPT-038, Rev. 0), Battelle-Pacific Northwest Division, Richland, WA.

Brooks KP, PR Bredt, GR Golcar, SA Hartley, LK Jagoda, KG Rappe, and MW Urie. 2000b.

Characterization, Washing, Leaching and Filtration of C-104 Sludge. PNWD 3024 (BNFL-RPT-030, Rev. 0), Battelle-Pacific Northwest Division, Richland, WA.

Buck EC, and BK McNamara. 2004. "Precipitation of Nitrate-Cancrinite in Hanford Tank Sludge." Environ. Sci. Technol. 38:4432-4438.

Buhl JC, F Stief, M Fechtelkord, TM Gesing, U Taphorn, and C Taake. 2000. "Synthesis, X-ray diffraction and MAS NMR characteristics of nitrate cancrinite $\mathrm{Na}_{7.6}\left[\mathrm{AlSiO}_{4}\right]_{6}\left(\mathrm{NO}_{3}\right)_{1.6}\left(\mathrm{H}_{2} \mathrm{O}\right)_{2}$." J. Alloys Compds. 305:93-102.

Burger LL, DA Reynolds, WW Schulz, and DM Strachan. 1991. A Summary of Available Information on Ferrocyanide Tank Wastes. PNL-7822, Battelle Northwest Laboratory, Richland, WA.

Deutsch WJ, KM Krupka, KJ Cantrell, CF Brown, MJ Lindberg, HT Schaef, SM Heald, BW Arey, and RK Kukkadapu. 2005. Advances in Geochemical Testing of Key Contaminants in Residual Hanford Tank Waste. PNNL-15372, Pacific Northwest National Laboratory, Richland, WA.

Finch RJ, and RC Ewing. 1997. “Clarkeite: New chemical and structural data.” American Mineralogist 82:607-619.

Finch RJ, FC Hawthorne, ML Miller, and RC Ewing. 1997. "Distinguishing among schoepite, $\left.\left[\mathrm{UO}_{2}\right)_{8} \mathrm{O}_{2}(\mathrm{OH})_{12}\right]\left(\mathrm{H}_{2} \mathrm{O}\right)_{12}$, and related minerals by X-ray powder diffraction.” Powder Diffraction 12:230-238.

Fiskum SK, EC Buck, RC Daniel, K Draper, MK Edwards, TL Hubler, LK Jagoda, ED Jenson, AE Kozelisky, GJ Lumetta, PJ MacFarlan, BK McNamara, RA Peterson, SI Sinkov, LA Snow, and RG Swoboda. 2008. Characterization and Leaching Testing for REDOX Sludge and S-Saltcake Actual Waste Sample Composites. PNNL-17368 (WTP-RPT-157), Pacific Northwest National Laboratory, Richland, WA.

Geeting, JGH, RT Hallen, LK Jagoda, AP Poloski, RD Scheele, and DR Weier. 2003. Filtration, Washing, and Caustic Leaching of Hanford Tank AZ-101 Sludge. PNWD-3206, Rev. 1 (WTP-RPT-043, Rev. 1), Battelle-Pacific Northwest Division, Richland, WA.

Li H, J Addai-Mensah, JC Thomas, and AR Gerson. 2005. “The Influence of Al(III) Supersaturation and $\mathrm{NaOH}$ Concentration on the Rate of Crystallization of $\mathrm{Al}(\mathrm{OH})_{3}$ Precursor Particles From Sodium Aluminate Solutions.” J. Colloid and Interface Science 286:511-519. 
Lumetta GL, and RT Hallen. 2007. Review of Caustic Leaching Testing With Hanford Tank Waste Sludges. WTP-RPT-151, Battelle-Pacific Northwest Division, Richland, WA.

Poirier MR, P Burket, and JL Siler. 2003. Filtration, Washing, and Leaching of a Hanford AY-102/C106 Sample. WSRC-TR-2003-00240, Rev. B (SRT-RPP-2003-00110, Rev. B). Savannah River Technology Center, Westinghouse Savannah River Company, Aiken, SC.

Peterson RA, JGH Geeting, and RC Daniel. 2007. "Estimation of Ultrafiltration Performance Based on Characterization Data.” Chemical Eng. Technology 30(9):1050-1054. 
WTP-RPT-170, Rev. 0

\section{Testing Summary}

This is the final report in a series of eight reports summarizing the characterization, leach, and filtration testing of a wide variety of Hanford tank waste sludges. The information generated from this series is intended to supplement the Waste Treatment and Immobilization Plant (WTP) project understanding of actual waste behaviors associated with tank waste sludge processing through the pretreatment portion of the WTP. The work described in this report presents information on a high-iron waste form, specifically the ferrocyanide tank waste sludge. Iron hydroxide has been shown to pose technical challenges during filtration processing; the ferrocyanide tank waste sludge represented a good source of the high-iron matrix to test the filtration processing. Specifically discussed in this report are:

- selection and compositing of tank waste sludge samples

- chemical and physical characterization of the composited tank waste feed (solids and supernatant)

- solids crossflow ultrafiltration testing

- caustic leaching for Al removal

- solids crossflow filtration

- stepwise solids washing using decreasing concentrations of sodium hydroxide with filtration

- chemical and physical characterization of the product solids

- chemical composition of the leaching solution and solids washing solutions.

The effectiveness of each pretreatment process step was evaluated by following mass balances of key components (such as B, Cd, Cr, Pu, Ni, Mn, and Fe), demonstrating component ( $\mathrm{Al}, \mathrm{P}, \mathrm{Cr}$, Cs) removal, demonstrating filterability by evaluating filter-flux rates under various processing conditions (transmembrane pressure [TMP], crossflow velocities, and wt\% undissolved solids [UDS]), filter fouling, and identifying potential issues for WTP.

\section{Objectives}

The test objectives delineated in the controlling test plan (TP-RPP-WTP-467 $7^{(\mathrm{a})}$ ) are provided in Table S.1 along with discussions of how the objectives were met. Several objectives (in gray shading lighter than header shading) did not specifically apply to the scope provided in this report; they have been reported in companion reports as indicated in the controlling test plan.

(a) SK Fiskum, Characterization and Small Scale Testing of Hanford Wastes to Support the Development and Demonstration of Leaching and Ultrafiltration Pretreatment Processes, 2007. 
Table S.1. Test Objectives

\begin{tabular}{|c|c|c|}
\hline Test Objective & $\begin{array}{c}\text { Objective } \\
\text { Met? (Y/N) }\end{array}$ & Discussion \\
\hline $\begin{array}{l}\text { 1) Determine the physical and } \\
\text { chemical characteristics } \\
\text { (summarized in } \\
\text { Section 6.2.2 of the test } \\
\text { plan) relevant to leaching } \\
\text { and ultrafiltration } \\
\text { behaviors of actual waste } \\
\text { samples required for the } \\
\text { validation of simulants. }\end{array}$ & $\mathrm{Y}$ & $\begin{array}{l}\text { The following characterizations were conducted on the } \\
\text { Group } 8 \text { washed solids: } \\
\text { - solids chemical composition } \\
\text { - mineral composition } \\
\text { - particle-size distribution } \\
\text { - crystal habit and morphology. } \\
\text { The following characterizations were conducted on the } \\
\text { Group } 8 \text { initial slurry: } \\
\text { - slurry density } \\
\text { - slurry rheology, flow curve, and shear strength } \\
\text { - settling rate, fraction of settled solids, and fraction } \\
\text { of centrifuged solids. } \\
\text { The following characterizations were conducted on the } \\
\text { Group } 8 \text { aqueous portion and solids wash solution: } \\
\text { - chemical composition } \\
\text { - density. } \\
\text { The characterization results are summarized in } \\
\text { Section } 3 \text {. }\end{array}$ \\
\hline $\begin{array}{l}\text { 2) Determine the dissolution } \\
\text { rate of aluminum in the } \\
\text { actual waste samples, } \\
\text { present predominantly as } \\
\text { gibbsite, as a function of } \\
\text { temperature and free- } \\
\text { hydroxide concentration, } \\
\text { and over a range of sodium } \\
\text { concentrations of interest } \\
\text { to the caustic-leaching } \\
\text { process. }\end{array}$ & $\mathrm{Y}$ & $\begin{array}{l}\text { The total Al present in Group } 8 \text { only represented } \\
9.0 \mathrm{wt} \% \text { (dry mass basis) of washed solids; the amount } \\
\text { of Al present as gibbsite was approximately half this } \\
\text { quantity, representing } \sim 4.5 \mathrm{wt} \% \text { as } \mathrm{Al} \text { or } \sim 13 \mathrm{wt} \% \text { as } \\
\text { gibbsite of the total solids composition. Caustic-leach } \\
\text { testing was conducted in the crossflow filtration } \\
\text { apparatus (CUF) at one condition ( } 3.7 \mathrm{M} \text { free hydroxide } \\
\text { and } 5.2 \mathrm{M} \text { sodium at } 60^{\circ} \mathrm{C} \text { ) to confirm gibbsite leach } \\
\text { behavior. The dissolution rate was addressed by taking } \\
\text { samples as a function of process time. } \\
\text { Parametric caustic leaching for Al removal was not an } \\
\text { objective for Group } 8 \text { testing. Characterization of } \\
\text { gibbsite leaching behavior was intended to be } \\
\text { established with Group 3, plutonium-uranium extraction } \\
\text { (PUREX) cladding waste sludge and Group } 4 \text { reduction- } \\
\text { oxidation (REDOX) cladding waste sludge. }\end{array}$ \\
\hline $\begin{array}{l}\text { 3) Determine the dissolution } \\
\text { rate of aluminum in the } \\
\text { actual waste samples, } \\
\text { present predominantly as } \\
\text { boehmite, as a function of } \\
\text { temperature and free- } \\
\text { hydroxide concentration, } \\
\text { and over a range of sodium } \\
\text { concentrations of interest } \\
\text { to the caustic-leaching } \\
\text { process. }\end{array}$ & NA & $\begin{array}{l}\text { Parametric caustic leaching was not an objective of the } \\
\text { Group } 8 \text { testing. Boehmite was not identified from } \\
\text { X-ray Diffraction (XRD) analysis in Group 8, nor was } \\
\text { the Al concentration particularly significant (see } \\
\text { discussion for item 2). (The characterization of } \\
\text { boehmite leaching behavior was intended to be } \\
\text { established with Group 5, REDOX sludge.) }\end{array}$ \\
\hline
\end{tabular}


Table S.1 (Contd)

\begin{tabular}{|c|c|c|c|}
\hline \multicolumn{2}{|c|}{ Test Objective } & $\begin{array}{c}\text { Objective } \\
\text { Met? (Y/N) }\end{array}$ & Discussion \\
\hline & $\begin{array}{l}\text { Determine the dissolution } \\
\text { rate of chromium and the } \\
\text { extent of dissolution of } \\
\text { plutonium and other } \\
\text { safety-related constituents } \\
\text { (U, Fe, } \mathrm{Mn}, \mathrm{Ni} \text {, and } \mathrm{Zn} \text { ) in } \\
\text { the actual waste samples as } \\
\text { functions of temperature } \\
\text { and over a range of } \mathrm{NaOH} \\
\text { concentrations of interest } \\
\text { for oxidative leaching. } \\
\text { (The NaMnO} \mathrm{N}_{4} \text { dosage will } \\
\text { be predetermined for the } \\
\text { oxidation of the chromium } \\
\text { in the waste solids.) }\end{array}$ & NA & $\begin{array}{l}\text { Parametric oxidative leaching was not an objective of } \\
\text { the Group } 8 \text { testing. This waste form was not } \\
\text { anticipated to be a high-Cr waste. The Cr concentration } \\
\text { in the dry washed solids represented } 0.2 \mathrm{wt} \% \text {. (The } \\
\text { characterization of chromium leaching behavior was } \\
\text { intended to be established with Group 6, S-saltcake } \\
\text { solids, and Group 1, bismuth phosphate saltcake solids.) }\end{array}$ \\
\hline 5) & $\begin{array}{l}\text { Determine the } \\
\text { dissolution/reaction rate of } \\
\text { phosphates in the actual } \\
\text { waste samples as a } \\
\text { function of temperature } \\
\text { and over a range of } \mathrm{NaOH} \\
\text { concentrations of interest } \\
\text { for the caustic leaching } \\
\text { process as well as the } \\
\text { extent of dissolution during } \\
\text { post-leaching wash. }\end{array}$ & $\mathrm{Y}$ & $\begin{array}{l}\text { The total phosphorus present in Group } 8 \text { only } \\
\text { represented } 3.7 \text { wt } \% \text { (dry mass basis) of washed solids. } \\
\text { Caustic leach testing was conducted in the CUF at one } \\
\text { condition ( } 3.7 \mathrm{M} \text { free hydroxide and } 5.2 \mathrm{M} \text { sodium at } \\
60^{\circ} \mathrm{C} \text { ) to confirm phosphorous leach behavior. The } \\
\text { dissolution rate was addressed by taking samples as a } \\
\text { function of process time. } \\
\text { Parametric phosphate leaching was not an objective of } \\
\text { the Group } 8 \text { testing. The characterization of phosphate } \\
\text { leaching behavior was intended to be established with } \\
\text { Group } 1 \text { and Group 2, bismuth phosphate sludge and } \\
\text { saltcake, and Group 7, tributyl phosphate sludge. }{ }^{\text {(a) }}\end{array}$ \\
\hline 6) & $\begin{array}{l}\text { Determine ultrafiltration } \\
\text { flux before and after } \\
\text { caustic and oxidative } \\
\text { leaching over the operating } \\
\text { range of solids } \\
\text { concentrations during the } \\
\text { leaching processes at } 25^{\circ} \mathrm{C} \\
\text { when sufficient actual } \\
\text { waste sample is available } \\
\text { for testing of the filtration } \\
\text { behavior. }\end{array}$ & $Y$ & $\begin{array}{l}\text { Filter matrix testing was performed before leaching } \\
\text { using slurries with both low ( } 5.9 \text { wt\%) and high } \\
\text { (13 wt\%) solids contents. Further filter matrix testing at } \\
\text { high-solids ( } 15 \text { wt\%) content was performed after } \\
\text { caustic leaching and washing of Group } 8 \text { solids. In this } \\
\text { case, the leached and washed Group } 8 \text { solids were } \\
\text { combined with caustic leached and washed solids from } \\
\text { Group 7, tributyl phosphate sludge mixed with solids } \\
\text { from AY-102. During these tests, the ultrafiltration flux } \\
\text { was determined as a function of TMP and axial velocity. } \\
\text { The filtration tests were conducted at ambient } \\
\text { temperature. } \\
\text { Dewatering curves were generated before and after } \\
\text { caustic leaching and after each of four washes. An } \\
\text { additional dewatering curve was generated after filter } \\
\text { matrix testing in combination with Group 7/AY-102 } \\
\text { solids to define filter flux as a function of wt } \% \text { UDS and }\end{array}$ \\
\hline
\end{tabular}


Table S.1 (Contd)

\begin{tabular}{|c|c|c|}
\hline Test Objective & $\begin{array}{c}\text { Objective } \\
\text { Met? (Y/N) }\end{array}$ & Discussion \\
\hline & & $\begin{array}{l}\text { estimation of the gel-point. } \\
\text { The Group } 8 \text { FeCN sludge did not require oxidative } \\
\text { leaching. } \\
\text { All the CUF testing results are discussed in Section } 4 .\end{array}$ \\
\hline $\begin{array}{l}\text { 7) Scanning electron } \\
\text { microscopy (SEM), } \\
\text { transmission electron } \\
\text { microscopy (TEM), energy } \\
\text { dispersive spectroscopy } \\
\text { (EDS), and XRD will be } \\
\text { used to determine the } \\
\text { primary mineral forms } \\
\text { present for Al, Cr, and P } \\
\text { and provide information to } \\
\text { enable the correlation of } \\
\text { these mineral forms to } \\
\text { dissolution behavior. }\end{array}$ & $\mathrm{Y}$ & $\begin{array}{l}\text { SEM and TEM coupled with EDS and XRD were } \\
\text { performed on the washed Group } 8 \text { solids before caustic } \\
\text { leaching. XRD and SEM/EDS analyses were applied to } \\
\text { the post-CUF processing waste. Evaluation of the XRD } \\
\text { imaging showed that, except for gibbsite removal, the } \\
\text { mineral forms did not change. The XRD diffraction } \\
\text { patterns were complex and difficult to deconvolute. } \\
\text { The solids characterization results are provided in } \\
\text { Section } 3 \text { (before CUF testing) and Section } 4 \text { (after CUF } \\
\text { testing). }\end{array}$ \\
\hline \multicolumn{3}{|c|}{$\begin{array}{l}\text { Shading indicates that the objective was outside of the current report subject area; objectives were } \\
\text { addressed in companion reports as indicated in the controlling test plan. } \\
\text { (a) While aluminum and phosphorus quantities were too small in the Group } 8 \text { sample to warrant resources } \\
\text { for parametric testing, a single CUF leach was used to confirm the fast kinetics of aluminum as } \\
\text { gibbsite and compare the dissolution of phosphorus to that found for Group 1/2, reported separately in } \\
\text { support of the controlling test plan. }\end{array}$} \\
\hline
\end{tabular}

\section{Test Exceptions}

No test exceptions were applied to the test scope.

\section{Results and Performance against Success Criteria}

The test plan delineated several success criteria, which are listed in Table S.2. Selected criteria were relevant to the test scope included in this report; the other criteria that are outside of this report scope are shaded (lighter than the header shading). 
Table S.2. Test Success Criteria

\begin{tabular}{|c|c|c|}
\hline \multicolumn{2}{|c|}{ List Success Criteria } & \multirow{2}{*}{$\begin{array}{l}\text { Explain How the Tests Did or Did Not } \\
\text { Meet the Success Criteria } \\
\text { Letter report number RPP-WTP-07-705 } \\
\text { (GJ Lumetta and RT Hallen, WTP-RPT-151, } \\
\text { Review of Caustic Leaching Testing With Hanford } \\
\text { Tank Waste Sludges), which addressed this success } \\
\text { criterion, was delivered to WTP on 1/24/2007. }\end{array}$} \\
\hline & $\begin{array}{l}\text { A summary (letter report format) of the } \\
\text { available information (including published } \\
\text { literature) is provided on the characteristics } \\
\text { (both known characteristics and those needed } \\
\text { to be determined) relevant to leaching and } \\
\text { filtration behaviors of the tank farm waste } \\
\text { groupings identified for testing. }\end{array}$ & \\
\hline & $\begin{array}{l}\text { The physical and chemical characteristics for } \\
\text { each of the actual waste-sample composites } \\
\text { selected for testing are provided (including a } \\
\text { format in conformance with the presentation } \\
\text { protocols [24590-WTP-GPG-RTD-001]). The } \\
\text { relevant physical and chemical characteristics } \\
\text { are elaborated in Section 6.0, Test Conditions, } \\
\text { of the test plan. }\end{array}$ & $\begin{array}{l}\text { All physical and chemical characterization testing, } \\
\text { as defined in the test plan, were completed. This } \\
\text { included extensive physical and chemical } \\
\text { characterization of the homogenized slurry } \\
\text { materials and extensive chemical characterization of } \\
\text { caustic-leached solids from CUF processing. The } \\
\text { analytical results for each test group are reported in } \\
\text { Sections } 3 \text { and } 4 \text {. }\end{array}$ \\
\hline & $\begin{array}{l}\text { The dissolution rate and the extent of } \\
\text { dissolution of aluminum present } \\
\text { predominantly as gibbsite in actual waste } \\
\text { solids are determined as a function of } \\
\text { temperature, free-hydroxide, and sodium } \\
\text { concentrations. The associated uncertainties in } \\
\text { test results are provided. }\end{array}$ & $\begin{array}{l}\text { Group } 8 \text { material contained a small amount of } \\
\text { gibbsite. Supernatant samples were taken during } \\
\text { CUF processing to evaluate } \mathrm{Al}, \mathrm{P} \text {, and } \mathrm{Cr} \\
\text { concentrations as a function of time. Aluminum } \\
\text { concentration reached equilibrium by the time the } \\
\text { first sample was taken during the heat ramp (at } \\
40^{\circ} \mathrm{C} \text { ). No additional dissolution was apparent in } \\
\text { succeeding samples, indicating that gibbsite } \\
\text { dissolution was very fast, requiring only modest } \\
\text { heat. } \\
\text { Parametric caustic leaching was not an objective of } \\
\text { the Group } 8 \text { testing. }\end{array}$ \\
\hline 4) & $\begin{array}{l}\text { The dissolution rate and the extent of } \\
\text { dissolution of aluminum present } \\
\text { predominantly as boehmite in actual waste } \\
\text { solids are determined as a function of } \\
\text { temperature, free-hydroxide, and sodium } \\
\text { concentrations. The associated uncertainties in } \\
\text { test results are provided. }\end{array}$ & $\begin{array}{l}\text { Not applicable. Parametric caustic leaching was not } \\
\text { an objective of the Group } 8 \text { testing. Group } 8 \\
\text { material had no significant amount of boehmite. }\end{array}$ \\
\hline 5) & $\begin{array}{l}\text { The dissolution rate and the extent of } \\
\text { dissolution of chromium in the actual waste } \\
\text { solids are determined as a function of } \\
\text { temperature and over a range of } \mathrm{NaOH} \\
\text { concentrations of interest to oxidative } \\
\text { leaching. The } \mathrm{NaMnO}_{4} \text { dosage will be } \\
\text { predetermined for the oxidation of the } \\
\text { chromium in the waste solids. The associated } \\
\text { uncertainties in the test results are provided. }\end{array}$ & $\begin{array}{l}\text { Not applicable. Parametric oxidative leaching was } \\
\text { not an objective of the Group } 8 \text { testing. Group } 8 \\
\text { material had no significant amount of chromium. }\end{array}$ \\
\hline
\end{tabular}


Table S.2 (Contd)

\begin{tabular}{|c|c|c|}
\hline \multicolumn{2}{|c|}{ List Success Criteria } & $\begin{array}{l}\text { Explain How the Tests Did or Did Not } \\
\text { Meet the Success Criteria }\end{array}$ \\
\hline & $\begin{array}{l}\text { The dissolution rate and the extent of } \\
\text { dissolution of phosphates in the actual waste } \\
\text { solids are determined as a function of } \\
\text { temperature and } \mathrm{NaOH} \text { concentration along } \\
\text { with the uncertainty in these estimates. }\end{array}$ & $\begin{array}{l}\text { Group } 8 \text { material contained a small amount of } \\
\text { insoluble phosphorus. Supernatant samples were } \\
\text { taken during CUF processing to evaluate Al, P, and } \\
\text { Cr concentrations as a function of time. No } \\
\text { phosphorus dissolution was apparent during the } \\
\text { entire caustic-leaching process. In fact, a small } \\
\text { amount of phosphate from the supernatant appeared } \\
\text { to precipitate as sodium phosphate when the caustic } \\
\text { was added. The sodium phosphate precipitate re- } \\
\text { dissolved during the slurry washing steps. } \\
\text { Parametric caustic leaching was not an objective of } \\
\text { the Group } 8 \text { testing. }\end{array}$ \\
\hline & $\begin{array}{l}\text { The ultrafiltration flux before and after caustic } \\
\text { and, as applicable, oxidative leaching } \\
\text { (reconcentration, if sufficient solids are } \\
\text { available) over the operating range of solids } \\
\text { concentrations with the actual waste samples } \\
\text { at } 25^{\circ} \mathrm{C} \text { is defined when available sample size } \\
\text { is adequate for the testing. }\end{array}$ & $\begin{array}{l}\text { During CUF testing using the Group } 8 \text { slurry with a } \\
\text { UDS concentration of } 5.9 \text { wt\%, the filter flux was } \\
\text { found to be directly proportional to the TMP; axial } \\
\text { velocity (AV) had no significant impact, and time } \\
\text { had a slight negative impact indicating slight filter } \\
\text { fouling over time. The filter flux with high-solids } \\
\text { (13 wt\% UDS) concentration was impacted by both } \\
\text { TMP and AV; the time dependence was not a factor, } \\
\text { indicting that the filter had been conditioned during } \\
\text { the low-solids filter matrix testing. } \\
\text { The Group } 8 \text { solids combined with caustic leached } \\
\text { and washed Group 7/AY-102 solids demonstrated a } \\
\text { filter flux dependency on TMP, AV, and time. } \\
\text { Final dewatering of the Group 8/Group7/AY-102 } \\
\text { slurry showed decreasing flux with increasing wt\% } \\
\text { UDS. The gel point was extrapolated to } 46 \text { wt\%, } \\
\text { which was equivalent to the wt\% UDS in the } \\
\text { centrifuged solids. }\end{array}$ \\
\hline & $\begin{array}{l}\text { Determination of the primary mineral forms } \\
\text { present for } \mathrm{Al}, \mathrm{Cr} \text {, and } \mathrm{P} \text {, and a qualitative } \\
\text { correlation of the dissolution behavior of these } \\
\text { waste elements to the mineral forms identified. }\end{array}$ & $\begin{array}{l}\text { The multiplicity of phases present in Group } 8 \\
\text { confounded deconvolution of the XRD pattern. } \\
\text { Using XRD in conjunction with SEM- and } \\
\text { scanning transmission electron microscopy } \\
\text { (STEM)-EDS evaluations, the Group } 8 \text { solids were } \\
\text { identified as mainly sodium uranium oxide } \\
\left(\mathrm{Na}_{2} \mathrm{U}_{2} \mathrm{O}_{7}\right) \text {, hematite }\left(\mathrm{Fe}_{2} \mathrm{O}_{3}\right) \text {, hydroxycancrinite } \\
\left(1.06 \mathrm{Na}_{2} \mathrm{O} \cdot \mathrm{Al}_{2} \mathrm{O}_{3} \cdot 1.60 \mathrm{SiO}_{2} \cdot 1.60 \mathrm{H}_{2} \mathrm{O}\right) \text {, gibbsite } \\
\left(\mathrm{Al}[\mathrm{OH}]_{3}\right), \text { sodium aluminum iron oxide, } \\
\mathrm{Na}_{2} \mathrm{Al}_{0.5} \mathrm{Fe} \mathrm{S}_{9.5} \mathrm{O}_{15} \text {, sodium uranyl carbonate, } \\
\mathrm{Na}_{4}\left(\mathrm{UO} \mathrm{O}_{2}\right)(\mathrm{CO} 3)_{3} \text {, and other possible/unconfirmed } \\
\text { minor phases. Following the caustic leach and wash } \\
\text { in the CUF, only the XRD diffraction peaks } \\
\text { characteristic of the gibbsite phase were absent. }\end{array}$ \\
\hline
\end{tabular}




\section{Quality Requirements}

PNNL implemented the RPP-WTP quality requirements by performing work in accordance with the River Protection Project - Waste Treatment Plant Support Program (RPP-WTP) Quality Assurance Plan (RPP-WTP-QA-001, QAP). Work was performed to the quality requirements of NQA-1-1989 Part I, Basic and Supplementary Requirements, NQA-2a-1990, Part 2.7, and DOE/RW-0333P, Rev 13, Quality Assurance Requirements and Descriptions (QARD). These quality requirements were implemented through the River Protection Project - Waste Treatment Plant Support Program (RPP-WTP) Quality Assurance Manual (RPP-WTP-QA-003, QAM). The quality assurance requirements of DOE/RW-0333P, Rev 13, Quality Assurance Requirements and Descriptions (QARD) and DOE Order 414.1C were not identified as a requirement for this work in the test specification.

A matrix that cross-references the NQA-1, NQA-2a, and QARD requirements with the procedures for RPP-WTP work was provided in the test plan TP-RPP-WTP-467. It included justification for those requirements not implemented.

Experiments that were not method-specific were performed in accordance with RPP-WTP's procedures QA-RPP-WTP-1101 “Scientific Investigations” and QA-RPP-WTP-1201 “Calibration and Control of Measuring and Testing Equipment” so that sufficient data were taken with properly calibrated measuring and test equipment to obtain quality results.

Pacific Northwest National Laboratory (PNNL) addressed internal verification and validation activities by conducting an Independent Technical Review of the final data report in accordance with PNNL's procedure QA-RPP-WTP-604, part of PNNL's RPP-WTP Quality Assurance Manual. This review verified that the reported results were traceable, inferences and conclusions were soundly based, and the reported work satisfied the Test Plan objectives.

\section{R\&T Test Conditions}

Table S.3 briefly summarizes the various R\&T test conditions and briefly discusses how the test condition was followed. 
WTP-RPT-170, Rev. 0

Table S.3. R\&T Test Conditions

\begin{tabular}{|c|c|}
\hline List R\&T Test Conditions & Were Test Conditions Followed? \\
\hline $\begin{array}{l}\text { 1) Selection of actual wastes for testing: the waste } \\
\text { samples selected for testing will be from the } \\
\text { groupings identified in the resolution of Issue } \\
\text { M4. }\end{array}$ & $\begin{array}{l}\text { Yes. One of the eight waste groupings identified in } \\
\text { resolution to Issue M4 was tested: Group } 8 \\
\text { (ferrocyanide sludge). }\end{array}$ \\
\hline $\begin{array}{l}\text { 2) Physical and chemical characterization } \\
\text { properties shall be stated and carried out } \\
\text { according to the Guideline document } \\
\text { 24590-WTP-GPG-RTD-001. }\end{array}$ & $\begin{array}{l}\text { Yes. Physical characterizations, including specific } \\
\text { gravity (density), settling rate, rheology, volume- } \\
\text { percent settled solids, and volume-percent } \\
\text { centrifuged solids, were determined according to the } \\
\text { requirements document. } \\
\text { Chemical characterization was conducted on the } \\
\text { supernatant (water used to dissolve soluble solids } \\
\text { and slurry the solids into a workable homogenized } \\
\text { composite) on the solids rinsed with three contacts } \\
\text { of } 3: 1 \text { volume ratios of } 0.01 \mathrm{M} \mathrm{NaOH} \text { :solids and on } \\
\text { the rinse solution composite. }\end{array}$ \\
\hline $\begin{array}{l}\text { Actual determinations of waste leach kinetics } \\
\text { will be carried out in well-mixed conditions. A } \\
\text { test matrix will be forwarded to the research } \\
\text { and technology (R\&T) M12 Issue manager for } \\
\text { concurrence before testing. Residual leached } \\
\text { and washed solids will be characterized. }\end{array}$ & $\begin{array}{l}\text { Yes. This was conducted as part of the CUF testing } \\
\text { at one process condition (i.e., not a parametric test } \\
\text { matrix). The process test conditions were } \\
\text { forwarded to, and approved by, the Bechtel National } \\
\text { Inc. (BNI) R\&T M12 Issue Manager (see Appendix } \\
\text { H). Actual test conditions are given in Sections } 4.0 \\
\text { and were compliant with the targeted test } \\
\text { parameters. }\end{array}$ \\
\hline $\begin{array}{l}\text { 4) Testing for filtration behavior will be } \\
\text { performed. Actual conditions are too numerous } \\
\text { to delineate and are found in the controlling test } \\
\text { plan. }\end{array}$ & $\begin{array}{l}\text { Yes. CUF matrix testing was performed on a low- } \\
\text { solids (5.9 wt\%) slurry and a high-solids slurry } \\
\text { (13 wt\%) of Group } 8 \text { solids before caustic leaching. } \\
\text { Following caustic leaching and washing, the } \\
\text { Group } 8 \text { solids slurry was combined with Group } 7 \\
\text { solids (tributyl phosphate [TBP] sludge plus } \\
\text { AY-102 sludge) for another high-solids (15 wt\%) } \\
\text { filtration matrix test. } \\
\text { Dewatering curves were collected during initial } \\
\text { slurry dewatering, after caustic leaching, and after } \\
\text { each of four solids washings at baseline conditions } \\
\text { of } 40 \text { psid TMP and } 13 \mathrm{ft} / \mathrm{s} \text { AV. Due to volume } \\
\text { restrictions, the wash solution dewatering was } \\
\text { difficult to maintain at the baseline condition. }\end{array}$ \\
\hline
\end{tabular}

\section{Simulant Use}

Most testing used actual Hanford tank wastes. Simulated supernatant was prepared to mimic the Group 8 supernatant phase and added to the solids for CUF processing. This simulant was expected to result in dilution of radionuclides and non-oxalate organic materials. The simulant 
was not expected to have a negative impact on test results or interpretations. The simulant was required because insufficient aqueous phase was available to run the CUF at the low solids matrix, and it was not feasible within the budget and time constraints to obtain additional supernatant from actual Hanford storage tanks.

\section{Discrepancies and Follow-on Tests}

The phosphorus in the Group 8 solids did not metathesize during caustic leaching to a watersoluble form. This was in direct contrast with the behavior observed for Group 1 (bismuth phosphate sludge) where most of the phosphorus was bound to Fe as a phosphate. In that case, the sodium was reported to exchange for iron forming $\mathrm{Na}_{3} \mathrm{PO}_{4}$ and $\mathrm{Fe}(\mathrm{OH})_{3}$. Group 7 (TBP sludge; where the phosphorus was bound in a variety of Fe and U phases) also displayed ready removal of phosphorus during caustic leaching. 

WTP-RPT-170, Rev. 0

\subsection{Introduction}

This report is one in a series that summarizes the findings from the characterization, leaching, and filtration testing of actual Hanford tank wastes in support of the Hanford Waste Treatment and Immobilization Plant (WTP) pretreatment process development and demonstration. The tests reported here were conducted according to test plan TP-RPP-WTP-467, ${ }^{(a)}$ which was written in response to the Bechtel National Inc. (BNI) Test Specification 24590-PTF-TSP-RT-06-003 Rev. 1. ${ }^{\text {(b) }}$ The ferrocyaniderich tank waste type is the subject of this report.

\subsection{Overview of Tank Waste Pretreatment Operations at the WTP}

Figure 1.1 provides a schematic illustration of the primary functions to be performed in the WTP. Tank waste will enter the Pretreatment Facility (PTF) as a slurry. Initially, the bulk of the low-activity waste (LAW) liquid phase will be removed from the high-level waste (HLW) solids phase by ultrafiltration in the PTF. Specific pretreatment operations will depend on the specific composition of the HLW solids. The solids will be washed and routed directly to HLW vitrification or pretreated with caustic and/or oxidative leaching processes to dissolve and remove materials (aluminum, chromium, phosphates, and sulfates) that would otherwise limit HLW loading in the immobilized waste glass. Caustic leaching effectively dissolves common aluminum phases (gibbsite and boehmite), and washing effectively removes dissolved aluminum and water-soluble components such as sodium salts of oxalate, sulfate, and phosphate. Oxidative leaching effectively oxidizes the chromium from insoluble $\mathrm{Cr}$ (III) to soluble $\mathrm{Cr}(\mathrm{VI})$ with a sodium permanganate $\left(\mathrm{NaMnO}_{4}\right)$ solution, allowing the chromium to be routed to the LAW stream. Note, however, that the oxidative leachate and wash solutions from the oxidative leaching process must be evaporated before subsequent re-introduction into the system. Ultimately, these evaporated solutions are blended with incoming feed, and any leached components are sent to LAW. The HLW solids will be re-concentrated after each leaching and washing operation using ultrafiltration.

Before starting the current testing program, only a limited number of integrated filtration tests had been performed (Brooks et al. 2000a, 2000b; Geeting et al. 2003; Poirer et al. 2003). These tests represented a very narrow range of waste types and reflected only the first several batches of feed expected to be processed at the WTP. One of the primary intents of this research program was to expand the understanding of filtration behavior for a wider range of actual waste samples. As had been demonstrated in simulant testing, ${ }^{(c)}$ slurries containing primarily precipitated iron hydroxide solids resulted in significantly lower filter fluxes than those for more crystalline slurries (containing primarily gibbsite or boehmite). The primary objective of the work described in this report was to assess the filtration performance of a slurry expected to contain a significant fraction of precipitated iron solids.

(a) SK Fiskum, TP-RPP-WTP-467, Rev. 0, 2/2/07 and Rev. 1 7/31/07, Characterization and Small Scale Testing of Hanford Wastes to Support the Development and Demonstration of Leaching and Ultrafiltration Pretreatment Processes.

(b) PS Sundar. 2006. 24590-PTF-TSP-RT-06-003 Rev. 1, Characterization and Small Scale Testing of Hanford Wastes to Support the Development and Demonstration of Leaching and Ultrafiltration Pretreatment Processes.

(c) RL Russell, HD Smith, JM Billing, RA Peterson, DE Rinehart. Draft report. Development and Demonstration of Ultrafiltration Simulants. WTP-RPT-183, Pacific Northwest National Laboratory, Richland, WA. 


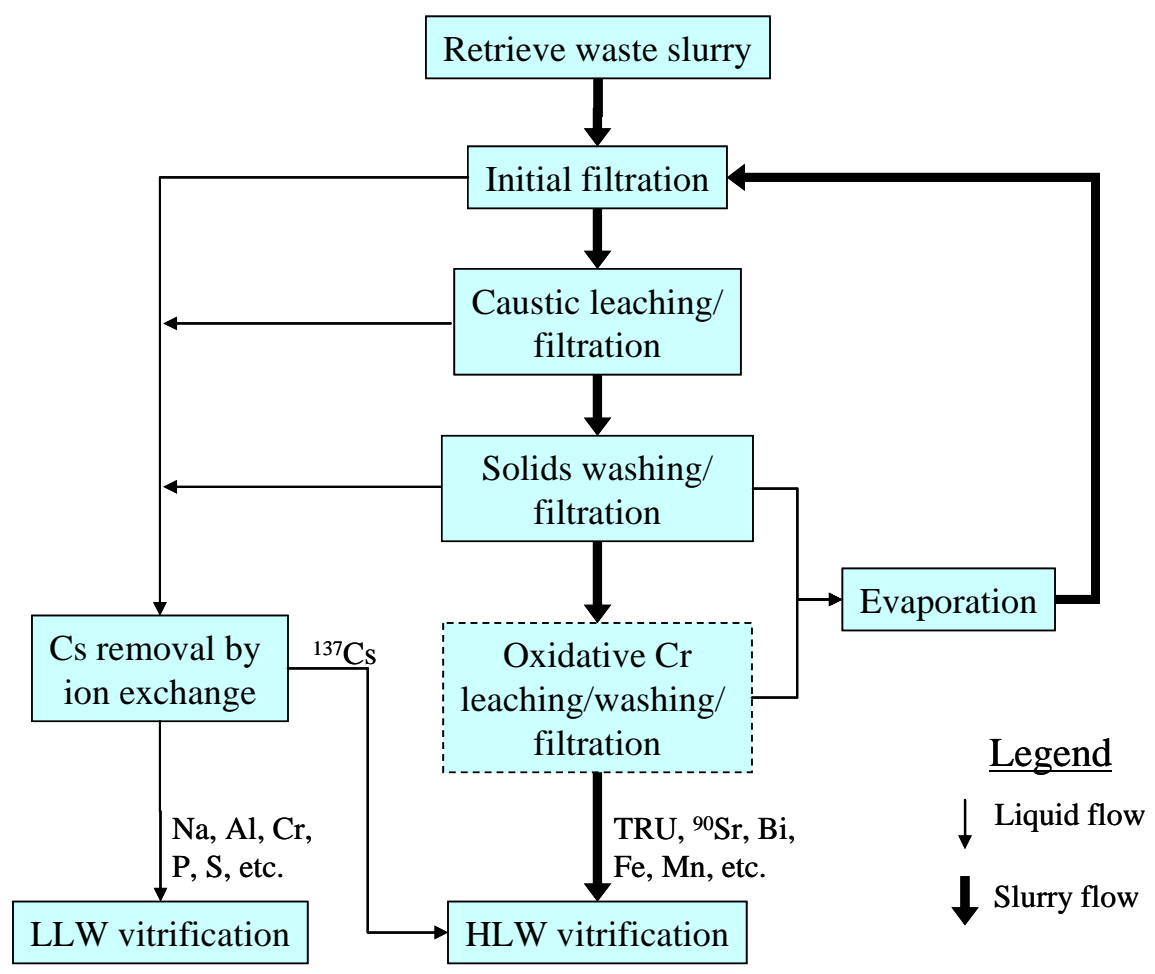

Figure 1.1. Schematic Representation of the Key Processes to be Performed in the PTF

(Note: This is for illustrative purposes only; it is not meant to be a comprehensive view of the functions performed within the WTP.)

Secondary objectives of the research program were to expand the knowledge base of the tank waste characteristics relevant to the plant operation. These included:

- chemical and radiochemical characterization of the feed material

- characterize solids crystal form and habit, particle size distribution (PSD), and surface area

- characterize rheological properties

- evaluate leach factors as a result of caustic leaching.

Assessment of these factors was expected to enhance the interpretation and understanding of the filtration performance of the high-iron-bearing solids. 
WTP-RPT-170, Rev. 0

\subsection{Issues Identified by the External Flowsheet Review Team}

A team of experts from industry, national laboratories, and universities (referred to as the External Flowsheet Review Team or EFRT) was assembled by BNI in October of 2005 to conduct an in-depth review of the process flowsheet supporting the design of the WTP. The EFRT identified several issues from the critical review of the process flowsheet, ${ }^{(\mathrm{a}, \mathrm{b})}$ including

- Issue M4: The WTP had not demonstrated that its design is sufficiently flexible to reliably process all of the Hanford tank farm wastes at the design throughputs.

- Issue M12: Neither the caustic leaching nor the oxidative leaching process had been demonstrated at greater than bench scale. The small-scale experiments are capable of defining the leaching chemistry. However, they are limited in their capability to predict the effectiveness of these processes without a scale-up demonstration.

- Issue M13: For wastes requiring leaching, a combination of inadequate filter flux and area would likely limit throughput to the HLW or LAW vitrification facilities.

The work scope defined in TP-RPP-WTP-467 represented the initial actual waste-testing part of Task 4 from the M-12 EFRT issue response plan. ${ }^{(\mathrm{c})}$ The actual tank waste testing was interfaced with responses developed to resolve EFRT Issue M4. In this case, a family of waste groupings representing the behavior of $\sim 75 \%$ of the tank-farm inventory was developed to assist in designing subsequent tests that would assess the adequacy of the overall flowsheet design in treating the tank-farm wastes. These waste groupings were the basis for selecting actual wastes for the current scope of testing.

Additional EFRT-defined issues were identified that likely will also benefit from the actual waste testing reported herein, including:

- Issue M1: Piping that transports slurries will plug unless it is properly designed to minimize this risk. This design approach has not been followed consistently, which will lead to frequent shutdowns due to line plugging.

- Issue M2: Large, dense particles will accelerate erosive wear in mixing vessels. The effects of such particles on vessel life must be re-evaluated.

- Issue M3: Issues were identified related to mixing-system designs that would result in insufficient mixing and/or extended mixing times. These issues include a design basis that discounts the effects of large particles and of rapidly settling Newtonian slurries. There is also insufficient testing of the

(a) WTP Doc. No. 24590-WTP-PL-ENG-06-0008, Rev 0, "Hanford Waste Treatment and Immobilization Plant (WTP) Project Response Plan for Resolution of Issues Identified by the Comprehensive Review of the WTP Flowsheet and Throughput.” L Lucas, March 2006.

(b) WTP Project Doc. No. CCN 132846 "Comprehensive Review of the Hanford Waste Treatment Plant Flowsheet and Throughput - Assessment Conducted by an Independent Team of External Experts.” March 2006, chartered by the Hanford Waste Treatment and Immobilization Plant Project at the Direction of the U.S. Department of Energy, Office of Environmental Management, Washington DC.

(c) SM Barnes, and R Voke, September 2006, 24590-WTP-PL-ENG-06-0024 Rev. 0, "Issue Response Plan for Implementation of External Flowsheet Review Team (EFRT) Recommendations - M12: Undemonstrated Leaching Process." 
selected designs.

- Issue M6: Many of the process operating limits have not been defined. Further testing is required to define process limits for WTP unit operations. Without this more complete understanding of each process, it will be difficult or impossible to define a practical operating range for each unit operation.

\subsection{Waste Groupings}

The available information regarding tank history and tank waste characterization was analyzed. This analysis revealed eight groupings of waste tanks that represent $~ 75 \%$ of the inventory of those components that are most significant with respect to leaching in the WTP; i.e., Al, Cr, phosphate, and sulfate (Fiskum et al. 2008). Table 1.1 summarizes the eight waste groups along with the estimated water-insoluble fractions (with respect to the entire tank farm inventory) of selected components contained in each group. Group 8, the specific topic of this report, is a moderate source of the iron and phosphate feed vector to the WTP and was of particular interest relative to the caustic leaching of phosphate and filtration behavior.

Table 1.1. Projected Distribution of Water-Insoluble Components in the Tank Waste Groupings (Fiskum et al. 2008)

\begin{tabular}{|c|c|c|c|c|c|c|c|c|}
\hline Group ID & Type & $\begin{array}{c}\text { Al } \\
(\%)\end{array}$ & $\begin{array}{l}\mathrm{Cr} \\
(\%)\end{array}$ & $\begin{array}{c}F \\
(\%)\end{array}$ & $\begin{array}{l}\text { Fe } \\
(\%)\end{array}$ & $\begin{array}{c}\text { Oxalate } \\
(\%)\end{array}$ & $\begin{array}{c}\text { Phosphate } \\
\text { (\%) }\end{array}$ & $\begin{array}{c}\text { Sulfate } \\
(\%)\end{array}$ \\
\hline 1 & Bi Phosphate sludge & 4 & 4 & 22 & 22 & 0.5 & 36 & 7 \\
\hline 2 & $\begin{array}{l}\text { Bi Phosphate saltcake } \\
(\mathrm{BY}, \mathrm{T})\end{array}$ & 13 & 18 & 24 & 8 & 37 & 23 & 42 \\
\hline 3 & $\begin{array}{l}\text { CWP, PUREX Cladding } \\
\text { Waste sludge }\end{array}$ & 17 & 1 & 1.3 & 5 & 1 & 2 & 0.4 \\
\hline 4 & $\begin{array}{l}\text { CWR, REDOX Cladding } \\
\text { Waste sludge }\end{array}$ & 10 & 1 & $<0.1$ & 1 & 0.4 & 0.1 & $<0.1$ \\
\hline 5 & REDOX sludge & 29 & 6 & 0.1 & 4 & 3 & 1 & 0.4 \\
\hline 6 & S - Saltcake (S) & 8 & 46 & 0.6 & 4 & 27 & 4 & 14 \\
\hline 7 & TBP Waste sludge & 1 & 0.4 & 0.5 & 7 & 0.1 & 17 & 3 \\
\hline 8 & FeCN Waste sludge & 1 & 1 & 0.4 & 7 & 1 & 6 & 1 \\
\hline & Balance & 17 & 24 & 51 & 41 & 30 & 10 & 32 \\
\hline $\begin{array}{l}\text { Note: The } \\
\text { BY = repre } \\
\text { CWP = PU } \\
\text { CWR = RE } \\
\text { FeCN = fer } \\
\text { PUREX = } \\
\text { REDOX = } \\
\mathrm{S}=\text { represe } \\
\text { T = represe } \\
\text { TBP = tribu } \\
\text { The bolded }\end{array}$ & $\begin{array}{l}\text { omponent values were rour } \\
\text { ent tanks in the Hanford B } \\
\text { EX cladding waste } \\
\text { OOX cladding waste } \\
\text { ocyanide } \\
\text { lutonium uranium extractio } \\
\text { eduction oxidation } \\
\text { t tanks in the Hanford S tan } \\
\text { t tanks in the Hanford T tar } \\
\text { yl phosphate } \\
\text { and highlighted Group } 8 \text { sig }\end{array}$ & $\begin{array}{l}\text { farm } \\
\text { k farm }\end{array}$ & $\mathrm{m}$ & 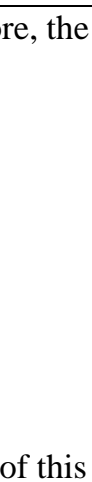 & 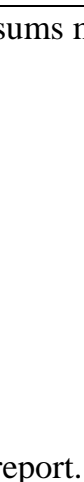 & & & \\
\hline
\end{tabular}

A history of ferrocyanide waste production in the Hanford tank farms has been previously described (Burger et al. 1991). In essence, a ferrocyanide salt such as potassium ferrocyanide $\left(\mathrm{K}_{4} \mathrm{Fe}[\mathrm{CN}]_{6}\right)$ or sodium ferrocyanide $\left(\mathrm{Na}_{4} \mathrm{Fe}[\mathrm{CN}]_{6}\right)$ was added to the metal waste recovery process stream and to 
underground storage tanks with $\mathrm{NiSO}_{4}$ in an effort to scavenge ${ }^{137} \mathrm{Cs}$ from the aqueous phase as a precipitate (e.g., as $\mathrm{Cs}_{2} \mathrm{NiFe}[\mathrm{CN}]_{6}$ ). ${ }^{\text {(a) }}$ The ferrocyanide treatment program lasted from 1954 to 1957. This waste type is characterized by high iron concentration accompanied with relatively high nickel and

${ }^{137}$ Cs concentrations.

\subsection{Simulant Development}

BNI plans to carry out process development and scale-up testing to demonstrate the design effectiveness of both the caustic- and the oxidative-leaching processes over the entire applicable range of Hanford tank farm wastes. ${ }^{\text {(b) }}$ Scale-up testing will require substantial volumes of feed. Therefore, the development of simulants that mimic the chemical, leaching, and ultrafiltration behaviors over the range observed for actual waste groups is necessary to the process development and demonstration. The characterization and leaching performance data obtained from the actual waste testing will serve as benchmarks for defining the simulant characteristics and behaviors and as a basis for revising the parameters used in evaluating WTP process performance using the appropriate process models.

\subsection{Testing of Group 8}

The Group 8 waste-type definition, sample identification, archived sample conditions, and homogenization activities are discussed in this report. Chemical and radioisotope compositions, mechanical properties, and particle morphology before and after caustic leach processing are presented. Additionally, crossflow ultrafiltration tests before, during, and after caustic leach and washing are described and the results presented.

The results from these tests refine the knowledge base of the tank waste chemical and mineralogical characteristics. Caustic leach testing provides leaching kinetics and leach factors of phosphate and aluminum phases in Group 8 as well as filtration performance parameters for the high iron-containing solids supporting simulant development work.

(a) Reducing the ${ }^{137} \mathrm{Cs}$ concentration (along with ${ }^{90} \mathrm{Sr}$ as a $\mathrm{SrSO}_{4}$ precipitate) allowed the aqueous phase to be discharged to the cribs (in compliance with then-current regulations and policies), thus freeing up more underground tank storage space for new process wastes.

(b) WTP Doc. No. 24590-WTP-PL-ENG-06-0008, Rev 0, "Hanford Waste Treatment and Immobilization Plant (WTP) Project Response Plan for Resolution of Issues Identified by the Comprehensive Review of the WTP Flowsheet and Throughput.” L Lucas, March 2006. 

WTP-RPT-170, Rev. 0

\subsection{Test Sample Selection, Compositing, and Homogenization}

Retrieving ferrocyanide tank waste material from the source tanks to support testing was deemed to be prohibitively expensive and time intensive and therefore was not considered. To support the actual waste testing, sample materials identified as representing the ferrocyanide sludge (Group 8) were obtained from the archives at the Hanford 222S Laboratory all of which had aged $~ 13$ years in the hot-cell storage facility. The archived samples were composited to construct a reasonable representation of Group 8 (as practical). The sample selection rationale, sample compositing and homogenization, and sub-sampling of the composite material are described in this section.

\subsection{Sample Selection}

Tank waste sludge samples obtained from tanks with known ferrocyanide process history were targeted to construct the Group 8 composite. The Tank-Waste Information Network System (TWINS) database ${ }^{\text {(a) }}$ was queried in 2007 to identify the tanks containing $>70 \%$ ferrocyanide waste type identified as:

- 1CFeCN-ferrocyanide sludge from in-farm scavenging of 1C (bismuth phosphate first cycle decontamination waste) supernatants in TY-Farm (1955-1958)

- PFeCN—ferrocyanide sludge from in-plant scavenged supernatant (1954-1955)

- TFeCN-ferrocyanide sludge produced by in-tank or in-farm scavenging (no date provided).

The tanks identified as containing $>70$-wt\% ferrocyanide-related tank waste sludge were further queried in the Best Basis Inventory (BBI; available through the TWINS database) for the major inorganic components (phosphate, $\mathrm{Fe}, \mathrm{Al}, \mathrm{U}, \mathrm{Ni}$, sulfate, $\mathrm{Si}$, and $\mathrm{Bi}$ ) in the solid and sludge phases. Figure 2.1 shows the relative mass distributions of these analytes in each of the identified tanks. (Note that major elemental and anionic mass contributions from sodium, nitrate, nitrite, and oxalate are excluded from the data in Figure 2.1.) The Fe mass fractions were fairly consistent across the identified ferrocyanide tanks. The two TY tanks contained significantly more Bi than the BY tanks. Uranium appeared to have been well-removed (in the U recovery operations) from the TY-101 tank. The arrows in the figure point to the tanks that were actually represented in the Group 8 composite; the weight of each arrow is approximately proportionate to the weight fraction of that tank material in the Group 8 composite.

(a) The TWINS database is a U.S. Department of Energy (DOE) owned resource. It is a web-based interface providing access to information about a wide variety of Hanford tank waste information. It is available at URL http://twins/twins3/twins.htm. 


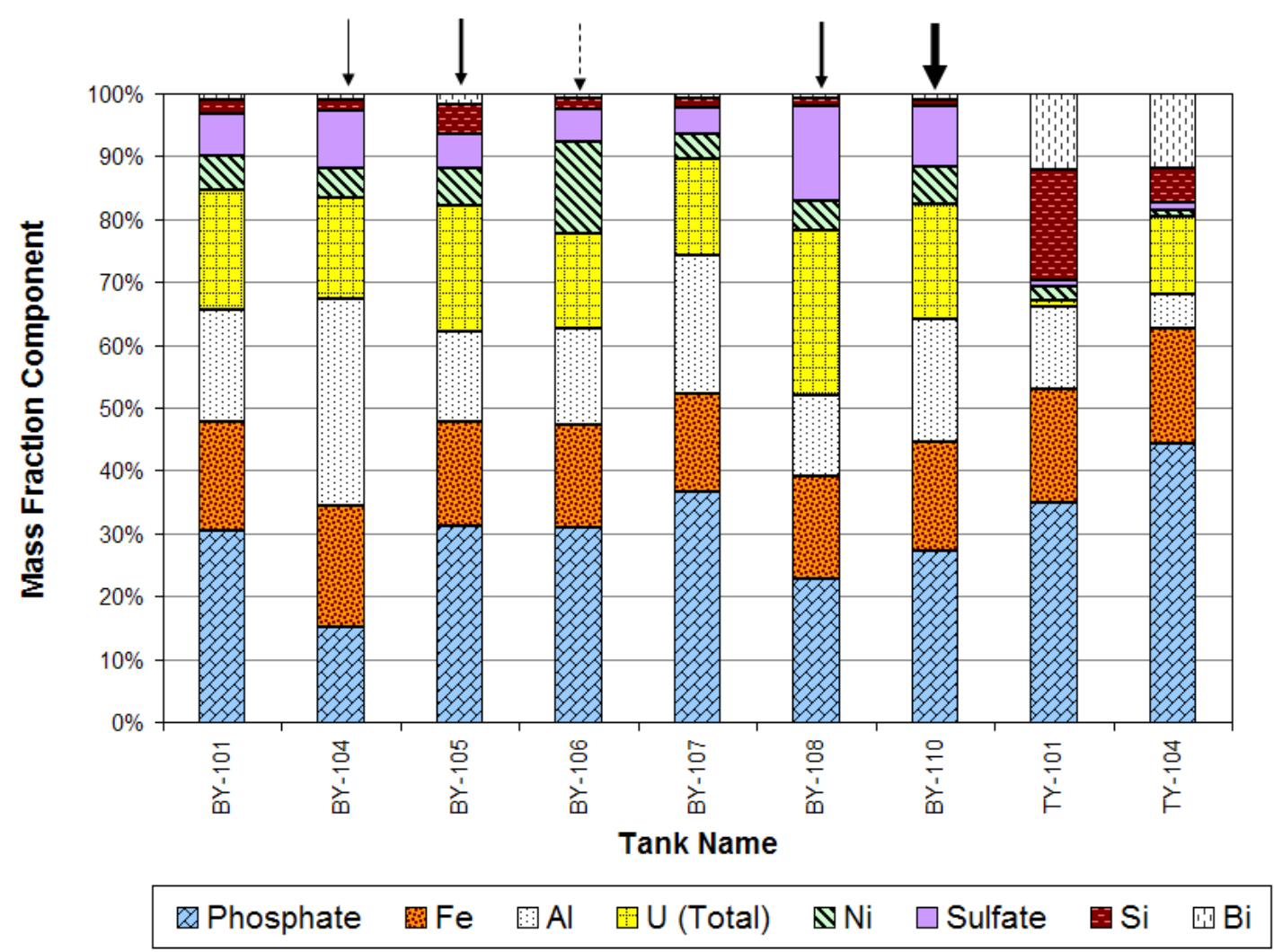

Figure 2.1. Estimated Tank Waste Composition of Selected Analytes for Ferrocyanide Sludge Wastes in the Hanford Tank Farm (BBI Source) Containing > 70wt\% Ferrocyanide Waste.

Note: arrows point to the tanks actually used to prepare the Group 8 composite; arrow thickness indicates relative fraction in the Group 8 composite.

The decision process flowchart for selecting tank waste samples from the sample archive is summarized in Figure 2.2. The 222S archive sample inventory ${ }^{(a)}$ was searched for sludge samples from the tanks identified as containing ferrocyanide waste. The samples were then cross-referenced to the TWINS database to determine if analytical data from the specific samples were available. Samples identified as containing $>1 \mathrm{mg}$ Fe per g sludge (reported on a wet-mass basis) were carried forward in the selection process. Of these samples, those with $<10 \mathrm{~g}$ material were omitted. The final list of samples was submitted to $\mathrm{CH} 2 \mathrm{MHill}$ personnel ${ }^{(\mathrm{b})}$ for a two-step evaluation process: 1) the samples were confirmed to represent the ferrocyanide sludge waste based on the tank strata, core segment, and corresponding characterization results, and 2) the samples were not held for other activities and could be released from the archive.

(a) Personal communication of the inventory database, file "Vials May18," provided from P Brackenbury, Bechtel, June 2006.

(b) David Place and Bruce Higley, Process Engineers, Process Analysis Organization, CH2MHill. 
WTP-RPT-170, Rev. 0

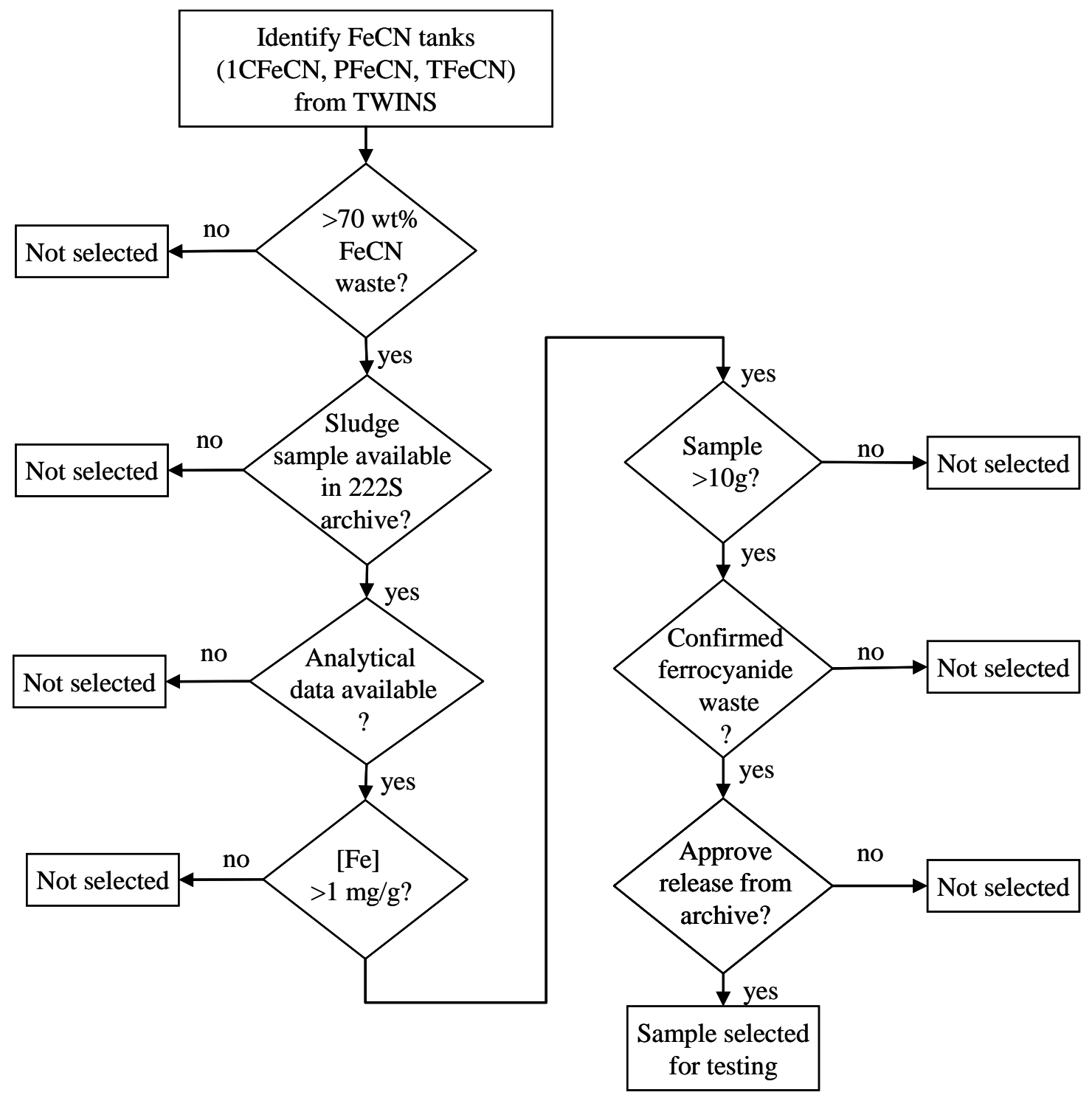

Figure 2.2. Selection Decision Process 1C and 2C Sludge Samples

Table 2.1 summarizes the tank sources evaluated and shows how the tank or samples met or failed the selection criteria. Tanks highlighted in bold in the table were those determined to meet all of the selection criteria (these tanks are indicated in Figure 2.1 with an arrow). 
Table 2.1. Selection of Ferrocyanide Sludge Tanks

\begin{tabular}{|c|c|c|c|c|c|c|}
\hline \multirow[b]{2}{*}{ Tank } & \multirow[b]{2}{*}{$\begin{array}{c}\text { FeCN } \\
\text { Sludge, } k L\end{array}$} & \multirow[b]{2}{*}{$\begin{array}{c}\text { Total } \\
\text { Sludge, } \mathbf{k L}\end{array}$} & \multirow[b]{2}{*}{$\begin{array}{c}\text { Fraction } \\
\text { FeCN } \\
\text { Sludge }\end{array}$} & \multicolumn{3}{|c|}{ 222S Archive } \\
\hline & & & & $\begin{array}{c}\text { Available } \\
\text { Samples }\end{array}$ & $\begin{array}{l}\text { Identified } \\
\text { as Sludge }\end{array}$ & $\begin{array}{c}\text { Analytical } \\
\text { Results }\end{array}$ \\
\hline 241-BY-101 & 140 & 140 & 1 & no & & \\
\hline 241-BY-104 & 172 & 172 & 1 & & & yes \\
\hline 241-BY-105 & 151 & 181 & 0.83 & & & yes \\
\hline 241-BY-106 & 120 & 120 & 1 & & & yes \\
\hline 241-BY-107 & 58 & 58 & 1 & & no & \\
\hline 241-BY-108 & 151 & 151 & 1 & & & yes \\
\hline 241-BY-110 & 162 & 162 & 1 & & & yes \\
\hline 241-TY-101 & 273 & 273 & 1 & no & & \\
\hline 241-TY-104 & 114 & 163 & 0.70 & & no & \\
\hline
\end{tabular}

Table 2.2 summarizes the individual samples (sampling date from the tank, tank ID, sample core, and segment) from the archive that met the selection criteria. These samples had been in storage at 222-S for $\sim 12$ to 15 years. The long storage time could potentially cause the sample characteristics to be altered relative to the as-retrieved sample condition through aging and drying. However, as stated previously, obtaining fresh core samples from the Hanford waste tanks was outside the scope of the project budget and schedule. Also shown in Table 2.2 are the anticipated iron concentrations (wet sample basis) and the sample masses assumed available based on the archive inventory taken 2002 . A total of $1.58 \mathrm{~kg}$ of ferrocyanide sludge was assumed to be available and sufficient for the testing scope. 
Table 2.2. Group 8 Expected Samples and Masses from 222S Archive

\begin{tabular}{|c|c|c|c|c|c|c|}
\hline $\begin{array}{c}\text { Tank Sampling } \\
\text { Date }^{(a)}\end{array}$ & Jar \# & Tank & Core & Segment & $\begin{array}{l}\text { Estimated } \\
\mathrm{Fe}, \mathrm{mg} / \mathbf{g}^{(\mathbf{b})}\end{array}$ & $\begin{array}{l}\text { Expected } \\
\text { Net Sample } \\
{\text { Weight }(g)^{(c)}}\end{array}$ \\
\hline \multirow[t]{2}{*}{ 10/31/1995 } & 8782 & BY-104 & 116 & 8 & $12-40$ & 40.1 \\
\hline & 8784 & BY-104 & 116 & 8 & $12-40$ & 82.9 \\
\hline \multirow{5}{*}{$7 / 23 / 98$} & 15012 & BY-105 & 246 & 9 & 26-31 & 73.3 \\
\hline & 10767 & BY-105 & 246 & Comp & 30 & 17.81 \\
\hline & 14987 & BY-105 & $246 \mathrm{R}$ & 9R & 30 & 113.1 \\
\hline & 14758 & BY-105 & $246 \mathrm{R}$ & 9R & 13 & 130.72 \\
\hline & 14992 & BY-105 & 250 & 9B & $7-10$ & 17.5 \\
\hline $1 / 24 / 95$ & 6403 & BY-106 & 65 & 13 & 25 & 31.13 \\
\hline \multirow[t]{6}{*}{$8 / 1 / 95$} & 7454 & BY-108 & 99 & 4 & $20-40$ & 26.9 \\
\hline & 7455 & BY-108 & 99 & 4 & $20-40$ & 28.3 \\
\hline & 7456 & BY-108 & 99 & 4 & $20-40$ & 37.2 \\
\hline & 7457 & BY-108 & 99 & 4 & $20-40$ & 28.2 \\
\hline & 13529 & BY-108 & 99 & 4 & $20-40$ & 38.1 \\
\hline & 18770 & BY-108 & 99 & 4 & $20-40$ & 108.7 \\
\hline \multirow[t]{2}{*}{$8 / 16 / 95$} & 7695 & BY-108 & 104 & 5 & $2-40$ & 38.3 \\
\hline & 13160 & BY-108 & 104 & 5 & $2-40$ & 69.11 \\
\hline \multirow[t]{5}{*}{ 8/29/95 } & 7967 & BY-110 & 101 & 8 & $1-17$ & 47.38 \\
\hline & 7964 & BY-110 & 101 & 9 & $20-40$ & 68.67 \\
\hline & 7971 & BY-110 & 101 & 9 & $20-40$ & 67.1 \\
\hline & 7970 & BY-110 & 101 & 9 & $20-40$ & 46.7 \\
\hline & 7969 & BY-110 & 101 & 9 & $20-40$ & 58.54 \\
\hline $8 / 15 / 95$ & 7650 & BY-110 & 103 & 9 & $8-38$ & 46.47 \\
\hline \multirow[t]{4}{*}{$8 / 24 / 95$} & 7713 & BY-110 & 107 & 9 & $30-60$ & 54.08 \\
\hline & 7714 & BY-110 & 107 & 9 & $30-60$ & 54.28 \\
\hline & 7715 & BY-110 & 107 & 9 & $30-60$ & 64.6 \\
\hline & 7712 & BY-110 & 107 & 9 & $30-60$ & 27.37 \\
\hline \multirow[t]{4}{*}{$10 / 28 / 95$} & 8485 & BY-110 & 113 & 8 & $2-31$ & 39.3 \\
\hline & 8486 & BY-110 & 113 & 8 & $2-31$ & 56.4 \\
\hline & 8487 & BY-110 & 113 & 8 & $2-31$ & 49.1 \\
\hline & 8488 & BY-110 & 113 & 8 & $2-31$ & 22.4 \\
\hline \multicolumn{7}{|c|}{\begin{tabular}{ll|l|} 
& Sum & 1,584 \\
\end{tabular}} \\
\hline \multicolumn{7}{|c|}{$\begin{array}{l}\text { (a) Tank sampling date is defined in TWINS database. } \\
\text { (b) Iron concentration was provided on a wet-mass basis, as defined in TWINS database. } \\
\text { (c) The anticipated mass was determined based on the sample mass inventory in the } 222 \mathrm{~S} \text { sample } \\
\text { inventory database "Vials May 18" (2002) provided by P Brackenbury. }\end{array}$} \\
\hline
\end{tabular}

\subsection{Group 8 Sample Compositing, Homogenization, and Sub-Sampling}

Twenty-nine Group 8 ferrocyanide sludge samples were shipped from the Hanford 222-S laboratory to Pacific Northwest National Laboratory (PNNL). Gross masses for these archived samples were provided by Advanced Technologies and Laboratories International (ATL) in the shipping letter report. The gross masses were compared to the 2002 inventory records and sample history and indicated that most of the 
samples had dried out before the 2002 inventory during the years spent in archived storage. Photographs, as received weights, and detailed sample descriptions were recorded in test instruction TI-RPP-WTP516. ${ }^{\text {(a) }}$ The samples' appearance and color ranged from gray dry crystals, to gray pastes, to brown sludge. One sample, BY-108 Jar \# 18770, had a distinct, yellowish aqueous phase above white solids. Figure 2.3 shows some photographs of the as-received samples.

The Group 8 sample materials fell into the following general categories:

- dry solid sample-monolithic

- dry solid sample-broken chunks

- moist solids

- solids with clearly visible liquid layer on top.

Table 2.3 lists the individual samples added to the homogenizer (see Appendix A for a description of the homogenizer). The gross masses (expected and found), the net mass of waste transferred to the homogenizer, and the calculated net mass residual in the sample container (or loss) are also provided in Table 2.3. Several cases were observed where the measured gross mass exceeded the expected gross mass; these deviations were probably associated with replacing deteriorated lightweight vial lids with heavier more robust lids. Obvious foreign material, such as pieces of broken caps, were picked out with stainless steel tweezers and weighed when possible. In some cases, the thin Teflon liner pieces often disintegrated in the tweezers, so no weights could be obtained for these. It is important to note that very small pieces of these foreign materials probably remained in the sample and became part of the eventual composite.

Wet and moist solids were removed from the sample jar by a process of scraping and rinsing with deionized (DI) water using a gentle water jet. Dry samples were added directly to the compositing container if they could be poured out of the container. For samples "cemented" in place, water was added in an effort to re-hydrate the solids and soften them. In this fashion, nearly all residues were removed from the sample jars. The contents of BY-108 Jar \#7456 could not be removed from the vial; it was essentially cemented in place, impervious to hydration and softening as well as attempts at scraping.

(a) RG Swoboda, Test Instruction Group 8 - Ferrocyanide Sludge Hanford Tank Waste Sample Compositing, Homogenization, and Sub-Division, January 2008. 


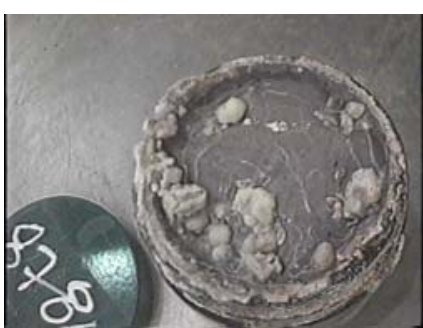

BY-104 Jar \# 8784

(dry)

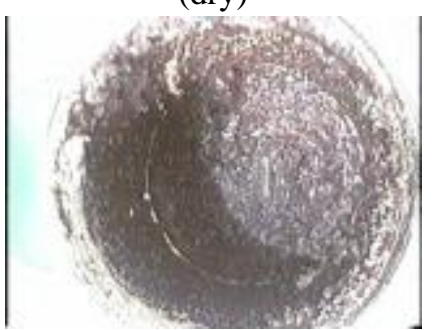

BY-105 Jar \#14758

(dry)

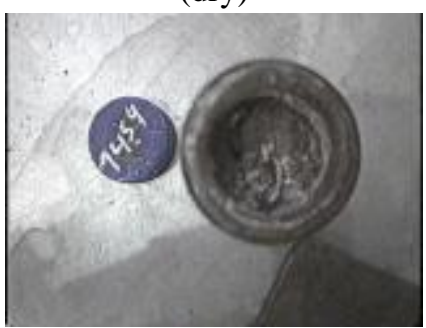

BY-108 Jar \#7454

(dry)

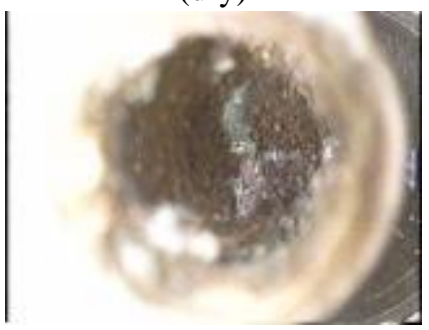

BY-108 Jar \#7457

(dry)

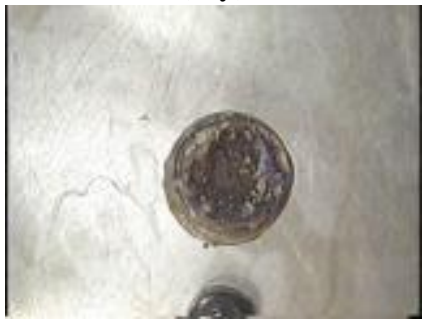

BY-108 Jar \#7695

(moist)

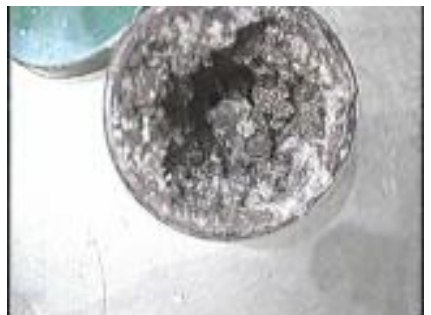

BY-105 Jar \#15012

(dry)

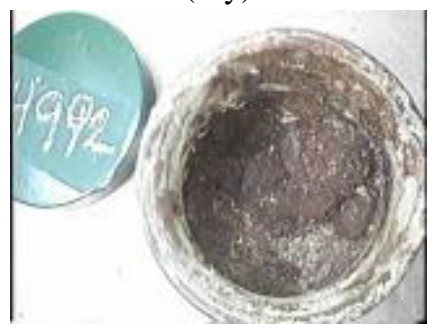

BY-105 Jar \#14992

(dry)

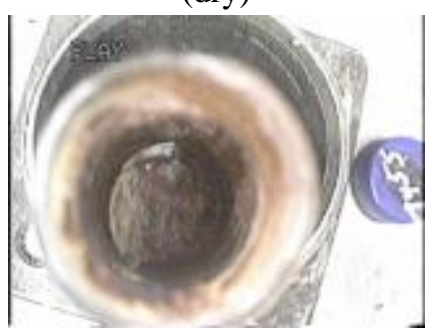

BY-108 Jar \#7455

(dry)

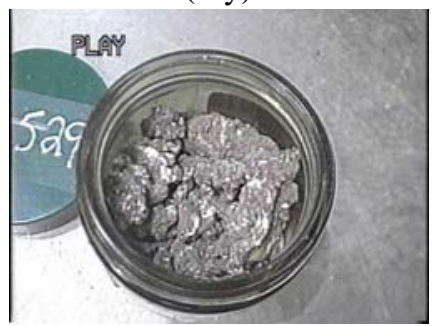

BY-108 Jar \#13529

(dry)

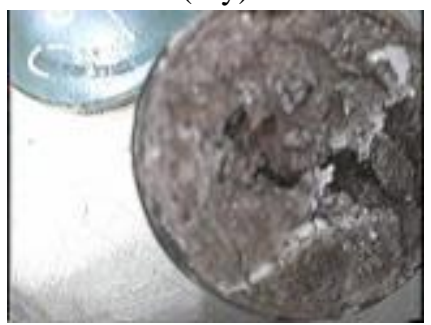

BY-108 Jar \#13160

(dry)

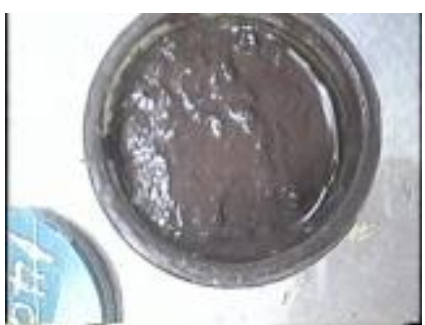

BY-105 Jar \#14987 (moist)

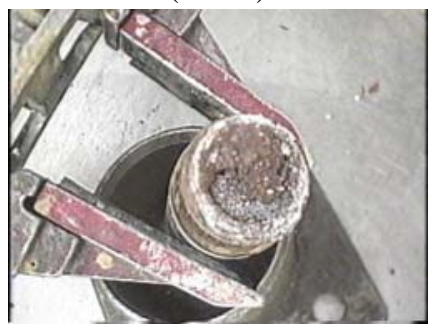

BY-106 Jar \#6403 (dry)

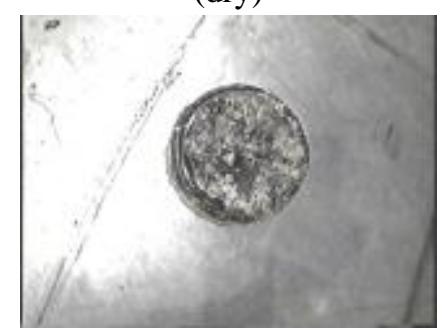

BY-108 Jar \#7456

(dry, sample could not be removed)

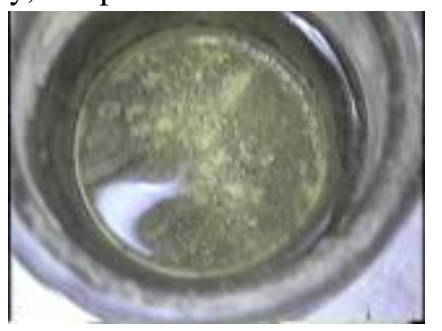

BY-108 Jar \# 18770

(wet, yellow liquid, white solids)

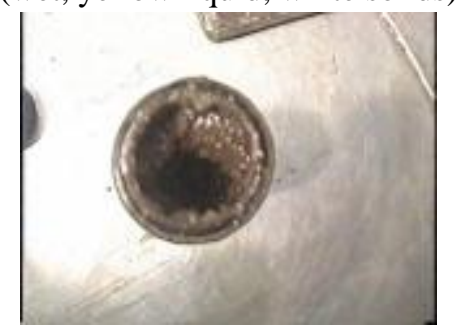

BY-110 Jar \#7967

(bottom moist, top dry)

Figure 2.3. Representative Photographs of As-Received Group 8 Waste Samples Notes: Photographs of BY-104 Jar \#8782 and BY-110 Jar \#7964 were not taken. 


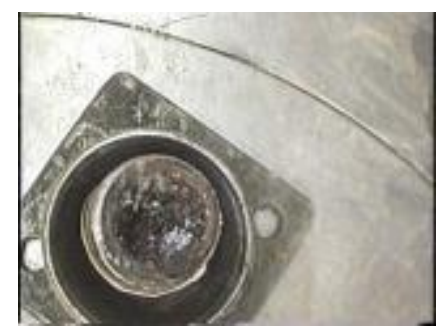

BY-110 Jar \#7971

(moist)

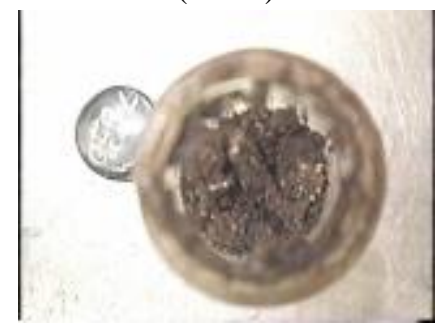

BY-110 Jar \#7650

(dry)

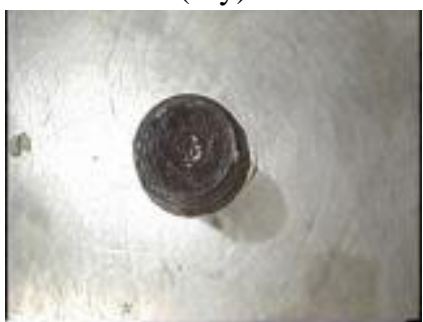

BY-110 Jar \# 7715

(moist)

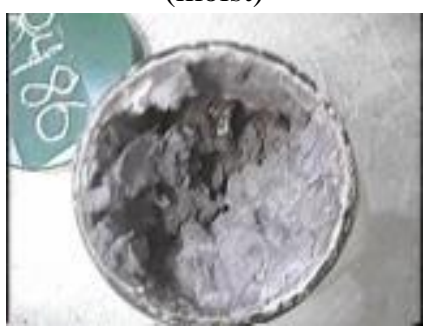

BY-110 Jar \# 8486

(dry)

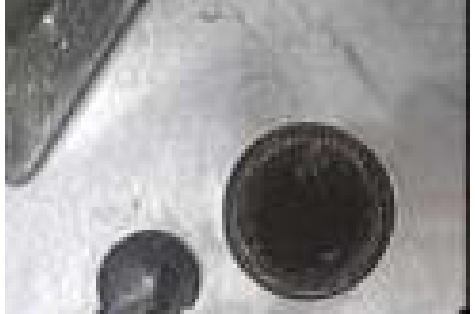

BY-110 Jar \# 7970

(dry, best available picture)

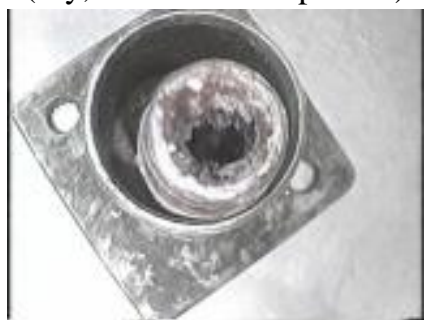

BY-110 Jar \#7713

(condition not recorded)

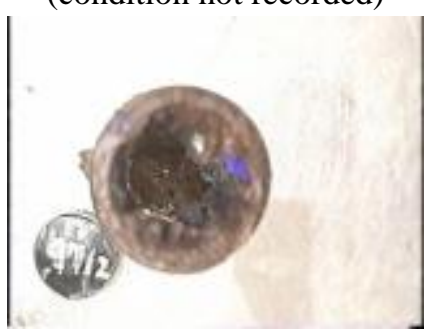

BY-110 Jar \# 7712

(dry)

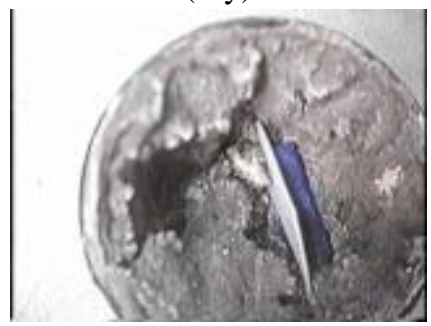

BY-110 Jar \#8487

(dry, shows fragment of lid)

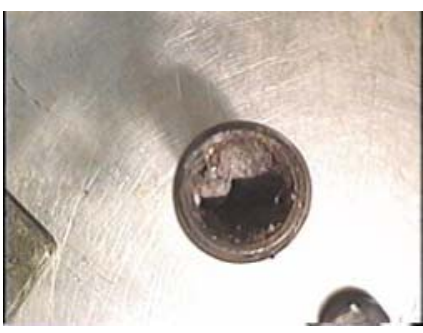

BY-110 Jar \#7969

(dry)

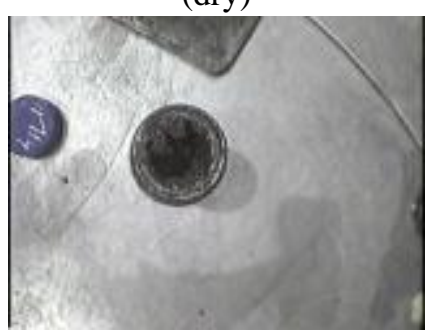

BY-110 Jar \#7714

(dry)

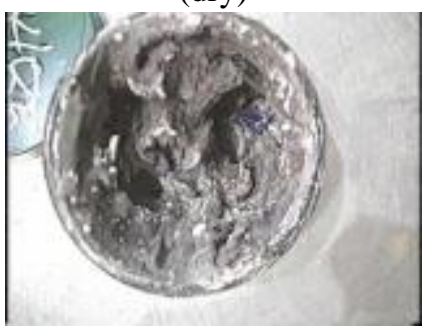

BY-110 Jar \#8485

(dry)

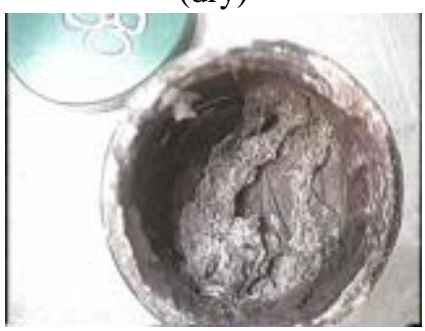

BY-110 Jar \# 8488

(dry)

Figure 2.3 (contd) 
Table 2.3. Group 8 Ferrocyanide Sludge Samples

\begin{tabular}{|c|c|c|c|c|c|c|c|}
\hline & $\begin{array}{l}\text { Hanford } \\
\text { Tank ID }\end{array}$ & $\begin{array}{l}\text { 222-S } \\
\text { Jar ID }\end{array}$ & \begin{tabular}{l}
\multicolumn{1}{c}{$222 \mathrm{~S}$} \\
Expected \\
Gross \\
Mass (g)
\end{tabular} & $\begin{array}{l}\text { PNNL } \\
\text { As-found } \\
\text { Gross } \\
\text { Mass (g) }\end{array}$ & $\begin{array}{c}\text { Expected } \\
\text { Net } \\
\text { Mass (g) }\end{array}$ & $\begin{array}{c}\text { PNNL } \\
\text { Mass } \\
\text { Transferred } \\
\text { (g) }\end{array}$ & \begin{tabular}{l}
\multicolumn{1}{c}{ Difference } \\
Transferred \\
from Expected \\
mass (g)
\end{tabular} \\
\hline & BY-104 & 8782 & 131.5 & 138.00 & 46.0 & 46.07 & -0.1 \\
\hline & BY-104 & 8784 & 182.5 & 186.29 & 95.9 & 94.07 & 1.8 \\
\hline & BY-105 & $10767^{(\mathrm{a})}$ & -- & -- & 17.8 & -- & -- \\
\hline & BY-105 & 14758 & 334.3 & 345.69 & 117.9 & 115.86 & 2.0 \\
\hline & BY-105 & 14987 & 198.7 & 195.73 & 112.1 & 103.30 & 8.8 \\
\hline & BY-105 & 14992 & 102.6 & 107.54 & 16.9 & 15.59 & 1.3 \\
\hline & BY-105 & 15012 & 145.4 & 145.53 & 58.5 & 49.57 & 8.9 \\
\hline & BY-106 & 6403 & 55.4 & 54.83 & 30.4 & 28.01 & 2.4 \\
\hline & BY-108 & 7454 & 48.9 & 48.90 & 23.6 & 22.69 & 0.9 \\
\hline & BY-108 & 7455 & 46.7 & 46.66 & 21.5 & 18.30 & 3.2 \\
\hline & BY-108 & 7456 & 62.4 & 63.08 & 37.1 & 0.00 & $37.1^{(\mathrm{b})}$ \\
\hline & BY-108 & 7457 & 48.7 & 48.44 & 23.5 & 18.86 & 4.6 \\
\hline & BY-108 & 7695 & 56.2 & 56.40 & 30.2 & 29.45 & 0.8 \\
\hline & BY-108 & 13160 & 149.4 & 149.30 & 63.5 & 61.04 & 2.5 \\
\hline & BY-108 & 13529 & 125.4 & 131.22 & 37.4 & 37.48 & -0.1 \\
\hline & BY-108 & 18770 & 242.5 & 242.21 & 114.0 & $112.33^{(\mathrm{c})}$ & 1.7 \\
\hline & BY-110 & 7650 & 66.0 & 48.24 & 40.0 & 21.62 & 18.4 \\
\hline & BY-110 & 7712 & 48.8 & 48.68 & 23.4 & 20.33 & 3.1 \\
\hline & BY-110 & 7713 & 73.1 & 72.71 & 47.1 & 46.43 & 0.7 \\
\hline & BY-110 & 7714 & 80.0 & 79.83 & 54.2 & 51.28 & 2.9 \\
\hline & BY-110 & 7715 & 86.1 & 85.71 & 60.5 & 55.50 & 5.0 \\
\hline & BY-110 & 7964 & 93.2 & 90.43 & 67.5 & 64.01 & 3.5 \\
\hline & BY-110 & 7967 & 73.2 & 73.16 & 47.3 & 46.85 & 0.5 \\
\hline & BY-110 & 7969 & 75.7 & 75.84 & 50.2 & 37.64 & $12.6^{(\mathrm{d})}$ \\
\hline & BY-110 & 7970 & 72.8 & 72.72 & 47.1 & 42.21 & 4.9 \\
\hline & BY-110 & 7971 & 90.6 & 89.02 & 65.5 & 62.26 & 3.2 \\
\hline & BY-110 & 8485 & 123.6 & 129.76 & 38.6 & 38.22 & 0.4 \\
\hline & BY-110 & 8486 & 140.2 & 146.46 & 55.6 & 55.58 & 0.0 \\
\hline & BY-110 & 8487 & 128.2 & 134.70 & 43.9 & 44.25 & -0.3 \\
\hline \multirow{2}{*}{\multicolumn{2}{|c|}{ BY-110 }} & 8488 & 106.3 & 112.20 & 21.5 & 19.98 & 1.5 \\
\hline & & & & sum & 1508.7 & 1358.8 & \\
\hline \multicolumn{8}{|c|}{$\begin{array}{l}\text { (a) Sample \#10767 had been depleted between the } 2002 \text { inventory and the shipping date. } \\
\text { (b) Sample \#7456 could not be removed from the vial; it was essentially cemented in place. } \\
\text { (c) Sample \#18770 contained yellow liquid with white solids; the liquid phase significantly contributed } \\
\text { to the large net sample mass. } \\
\text { (d) Sample \#7969 vial broke during transfer; the transferred mass is the best estimate. }\end{array}$} \\
\hline
\end{tabular}


The sample-transfer to the homogenizer was conducted in a stepwise process. The sample removal from the multitude of small fragile vials (mostly $40-\mathrm{mL}$ vials) was time consuming and required finesse to avoid breakage of the containers. Therefore, to minimize evaporative water loss from the composite in the homogenizer, the collected sample materials were staged into one of three composite glass jars. These could be sealed during non-sample collection times (e.g., overnight). After all sample materials were collected in the composite jars, the jar contents were transferred to the homogenizer. This process maintained the solids in a wetted manner and avoided the potential of the solids drying in the homogenizer over the several days required to empty the smaller jars.

Solids and semi-solids were forced through the sieve (used to collect objects $>3 \mathrm{~mm}$ diameter) set above the homogenizer using DI water, rubber spatulas, and a stainless steel mashing tool that also was used in breaking up some chunks of solid materials so they could pass though the sieve. No significant amount of sample remained trapped on the sieve.

After all of the recoverable sample materials were transferred to the homogenizer tank, the sample jars were allowed to dry, and they were then reweighed. These masses were used to calculate sample recovery and the actual amount of sample added to the homogenizer (Table 2.3). A few jars had significant differences between the expected net mass and the measured net mass. These larger differences were probably due to loss of water from the sample over time during storage at 222S and/or sample depletion from sub-sampling activities conducted after the 2002 inventory. The jar lids tend to become brittle in the radiological environment over time, so some of these likely cracked, and the water evaporated. Some tare masses were based on vials with blue lids; lids had been replaced with green lids for shipping. The mass difference associated with the change in lids was $\sim 4.6 \mathrm{~g}$, and net masses of affected samples were appropriately adjusted.

There was $~ 5 \%$ mass loss from the expected mass (from 2002 archive records), and the received mass indicated that virtually no evaporation occurred since 2002. A total of $95 \%$ of the received sample mass was recovered from the sample jars and transferred to the composite. The received mass was calculated by subtracting the 222S-supplied tare weights for the sample jars from the total mass measured in the HLRF before transferring the sample materials. The recovered mass was determined by subtracting the mass of the emptied jar from the gross mass. Approximately 5\% of the material could not be removed from the jars because of spillage and intractable solids. Uncertainties in mass transfers stemmed from container tare mass discrepancies (replaced lid) and potential unrecorded sub-sampling events. Figure 2.4 depicts the best estimate of tank source materials contributing to the final composite based on the mass balance. 
WTP-RPT-170, Rev. 0

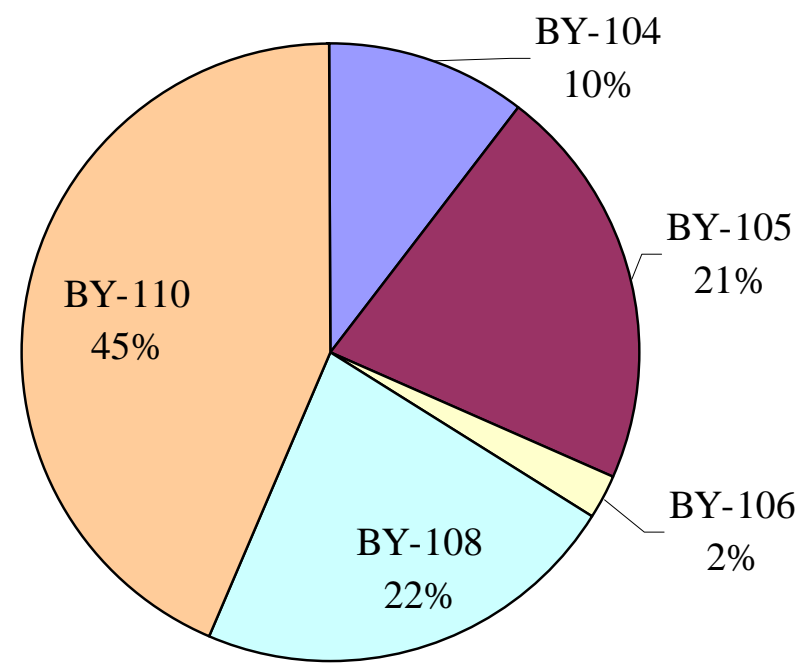

Figure 2.4. Contribution of the Individual Tank Materials to the Group 8 Composite Sample

The sieve screen was removed after all samples had been added to the homogenizer tank, and all equipment (spatula, sieve, mashing tool) had been rinsed free of sample. A total of $\sim 960 \mathrm{~g}$ of DI water was added during the compositing process. A mechanical stirrer with stainless steel impeller was lowered into the tank, the fitted lid was placed on the tank, and the material was mixed thoroughly. The temperature in the hot cell was $\sim 32^{\circ} \mathrm{C}$ at the start of mixing. The goal of this step was to homogenize the sample using as little force as possible. The stirrer speed was slowly increased until the solids were mobilized. The positions and arrangements for the height of the mixer relative to the support rod and impeller were predetermined during the preliminary non-radioactive testing, and the proper alignments marked onto the impeller and support rod correctly aligned. While operating the vessel agitator, material was extracted from the collection port at the bottom of the tank and returned through the top of the vessel so that all the material was mixed well.

The test plan defined a minimum required mixing time of 1 hour. The total mixing time for the Group 8 composite slurry was 1 hour and 5 minutes before sub-sampling began. The sub-samples were removed in a specific order to pre-determined target volumes. Pre-weighed and labeled jars and centrifuge tubes were staged in collection vessels in the order provided in Table 2.4.

At the start of sub-sampling, while operating the vessel agitator, one sub-sample of sufficient size (minimum of $100 \mathrm{~mL}$ ) was extracted through the sample valve into sample jar TI516-G8-AR-J1 to clear material from the lowest portion of the vessel. This material was then added back to the mixing vessel before sub-sampling began. 
Table 2.4. Group 8 Sub-Sample Mass Density and Settling Data

\begin{tabular}{|l|c|c|c|c|c|c||}
\hline $\begin{array}{l}\text { Sample ID in Order } \\
\text { of Collection }\end{array}$ & $\begin{array}{c}\text { Target } \\
\text { Collection } \\
\text { Volume }\end{array}$ & $\begin{array}{c}\text { Sample } \\
\text { Net Wt, g }\end{array}$ & $\begin{array}{c}\text { Total } \\
\text { Slurry } \\
\text { Volume, } \\
\text { mL }\end{array}$ & $\begin{array}{c}\text { Settled } \\
\text { Solids } \\
\text { Volume, mL }\end{array}$ & $\begin{array}{c}\text { Gross } \\
\text { Slurry } \\
\text { Density, } \\
\text { g/mL }\end{array}$ & $\begin{array}{c}\text { Vol\% } \\
\text { Settled } \\
\text { Solids }\end{array}$ \\
\hline TI516-G8-AR-J1 & $300-400 \mathrm{~mL}$ & 451.369 & 365 & 130 & 1.24 & $35.6 \%$ \\
\hline TI516-G8-AR-S1 & $10-15 \mathrm{~mL}$ & 11.068 & 8.7 & 3.2 & 1.27 & $36.8 \%$ \\
\hline TI516-G8-AR-J2 & $300-400 \mathrm{~mL}$ & 464.179 & 375 & 135 & 1.24 & $36.0 \%$ \\
\hline TI516-G8-AR-J3 & $300-400 \mathrm{~mL}$ & 409.596 & 340 & 125 & 1.20 & $36.8 \%$ \\
\hline TI516-G8-AR-C1 & $25 \mathrm{~mL}$ & 14.345 & 11.5 & 3.75 & 1.25 & $32.6 \%$ \\
\hline TI516-G8-AR-RH1 & $50 \mathrm{~mL}$ & 82.116 & 70 & 27 & 1.17 & $38.6 \%$ \\
\hline TI516-G8-AR-S2 & $10-15 \mathrm{~mL}$ & 10.075 & 8.2 & 3.1 & 1.23 & $37.8 \%$ \\
\hline TI516-G8-AR-Arch1 & $10 \mathrm{~mL}$ & 11.088 & 9 & 3.0 & 1.23 & $33.3 \%$ \\
\hline TI516-G8-AR-P1 & $150 \mathrm{~mL}$ & 202.622 & 165 & 55 & 1.23 & $33.3 \%$ \\
\hline TI516-G8-AR-C2 & $25 \mathrm{~mL}$ & 14.453 & 12 & 3.8 & 1.20 & $31.7 \%$ \\
\hline TI516-G8-AR-S3 & $10-15 \mathrm{~mL}$ & 9.965 & 8.0 & 3.0 & 1.25 & $37.5 \%$ \\
\hline TI516-G8-AR-J4 & $300-400 \mathrm{~mL}$ & 462.208 & 385 & 135 & 1.20 & $35.1 \%$ \\
\hline TI516-G8-AR-J5 & $300-400 \mathrm{~mL}$ & 436.142 & 360 & 115 & 1.21 & $31.9 \%$ \\
\hline & & & & Average & 1.22 & $35.2 \%$ \\
& & &
\end{tabular}

For compositing to be considered successful, the standard deviations of the average sample density and settled solids data were targeted to be less than $5 \%$, and trends in settled solids and density variation due to subsample removal order needed to be statistically insignificant. Figure 2.5 shows the Group 8 density and vol\% settled solids as a function of sub-sampling order. A slight downward trend in slurry density and vol\% settled solids was noted. However, within the measurement uncertainties, the parameters of the initial and final samples taken were not statistically different from those of the initial samples. The initial density of $1.24 \pm 0.02 \mathrm{~g} / \mathrm{mL}$ was within the error of measurement of the final density of $1.21 \pm 0.02 \mathrm{~g} / \mathrm{mL}$; the initial vol\% settled solids of $35.6 \pm 4.1 \%$ was within the error of measurement of the final vol\% settled solids of $31.9 \pm 4.6 \%$. 
WTP-RPT-170, Rev. 0

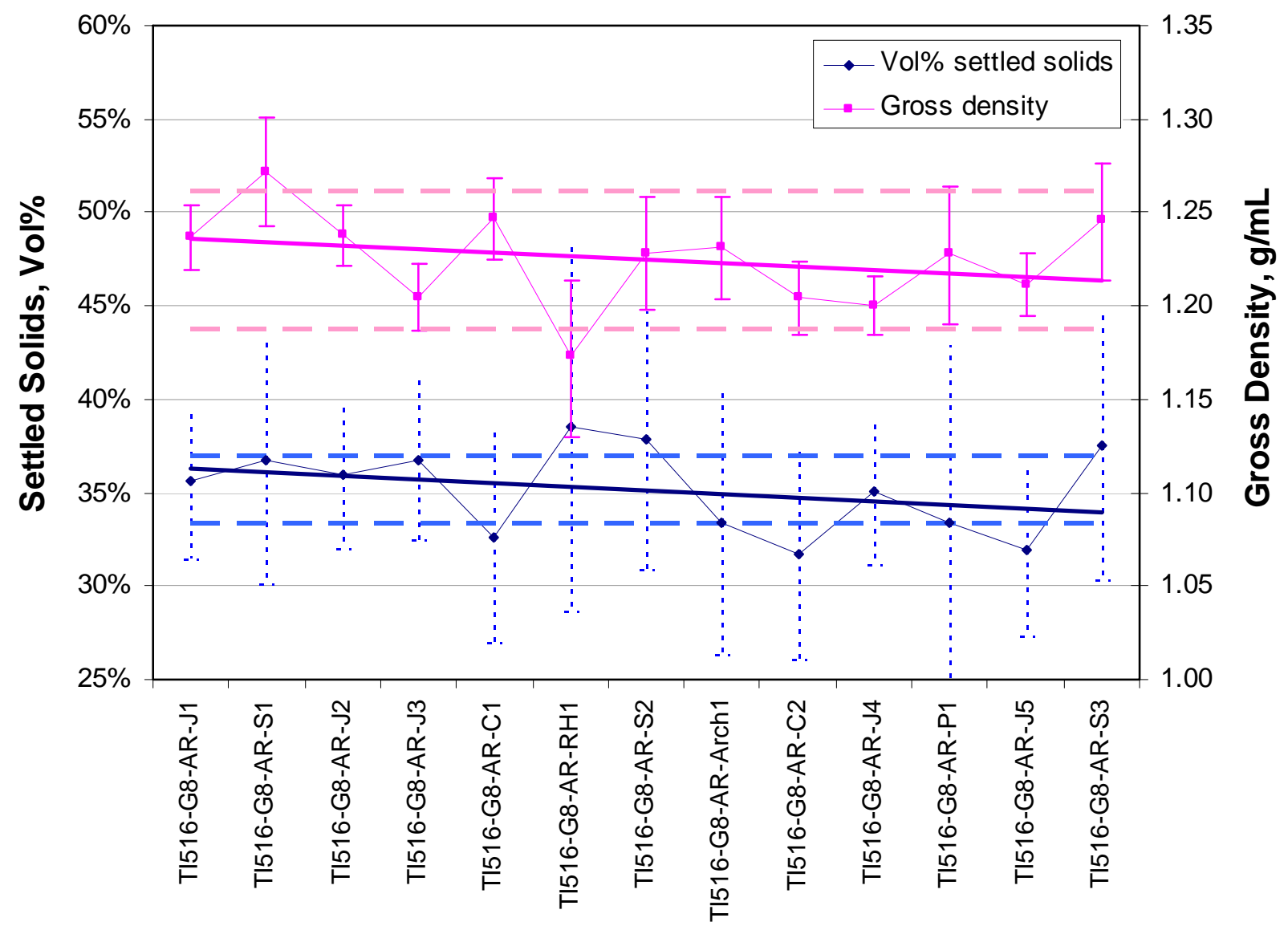

Figure 2.5. Group 8 Confirmation of Successful Material Composite Based on Volume Percent of 5-Day Settled Solids and Gross Density

Note: the gross sample density is shown with bounds set at $\pm 3 \%$ of the average $1.22 \mathrm{~g} / \mathrm{mL}$; the volume percent settled solids is shown with bounds set at $\pm 5 \%$ of the average 35.2 vol\%. 



\subsection{Initial Characterization Results for Ferrocyanide Waste Sludge Group 8}

This section reports and discusses the initial characterization results for the Group 8 Ferrocyanide (FeCN) sludge slurry composite, supernatant, and washed solids. The initial characterization activities included physical-property testing and chemical analysis as shown in Figure 3.1. ${ }^{\text {(a) }}$ The supernatant results represent the equilibrated aqueous phase in contact with the solids; the solids characterization results were obtained after washing with $0.01 \mathrm{M} \mathrm{NaOH}$. Solids washing was considered crucial to better understand the nature of the solids, free of complications associated with supernatant entrainment. The solids wash solutions were separately collected and then combined as a total wash composite. Descriptions of the characterization processes and methods are provided in Appendix B.

(a) The physical property testing was conducted according to TI-RPP-WTP-516, Ferrocyanide Sludge Hanford Tank Waste Sample Compositing, Homogenization and Sub-Division, R. Swoboda, 1/22/08; the solids washing and sample handling was conducted according to TI-RPP-WTP-609, Initial Characterization of Group 8 Tank Waste: FeCN Wastes, M Edwards, 3/25/08. 


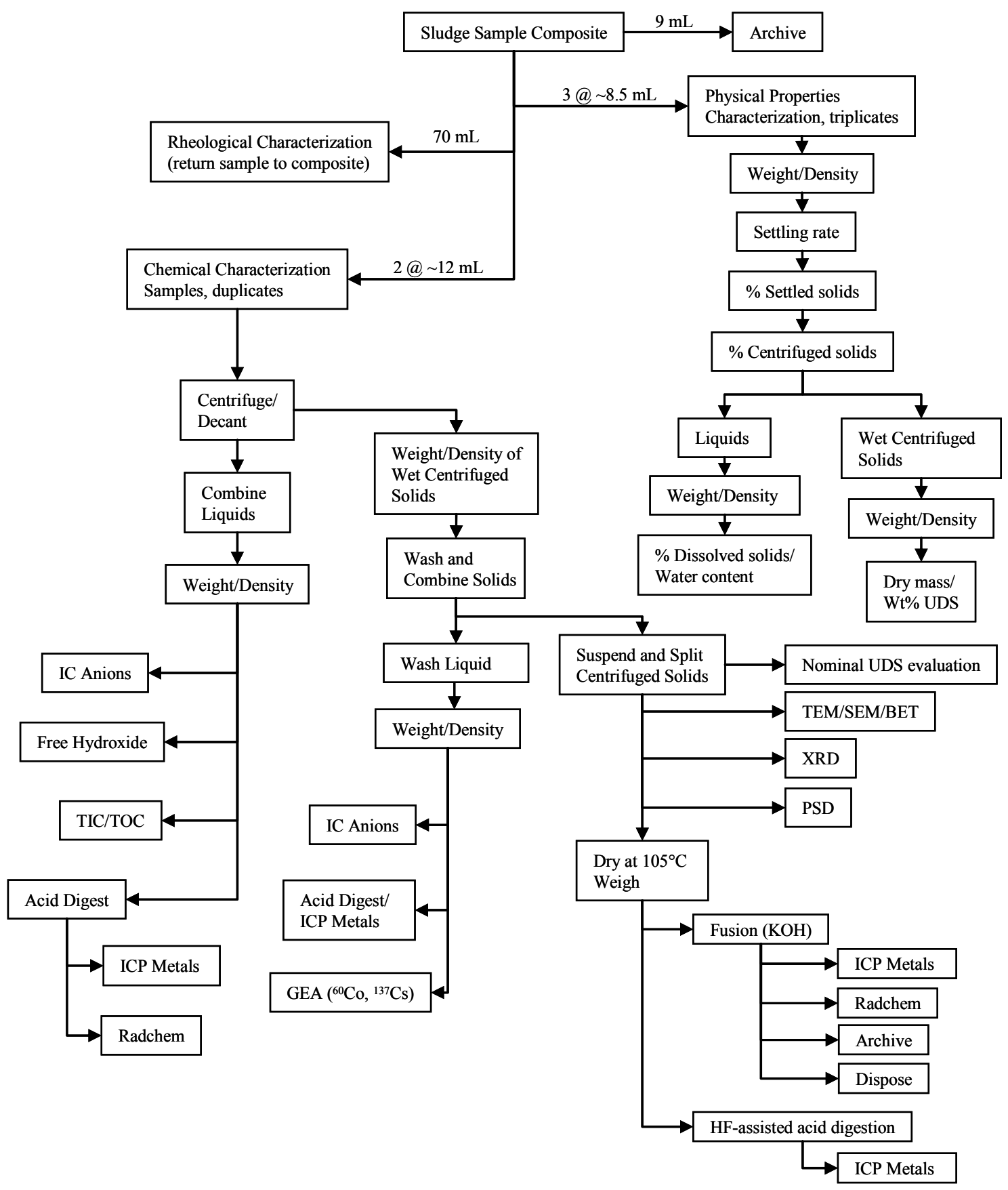

Figure 3.1. Composite Group 8 Slurry Processing and Analysis Scheme

\section{Acronyms used in Figure 3.1:}

BET Brunauer, Emmett, and Teller

GEA gamma energy analysis

HF hydrofluoric acid

IC ion chromatography

ICP inductively coupled plasma

$\mathrm{KOH}$ potassium hydroxide fusion

PSD particle-size distribution
SEM scanning electron microscopy

TEM transmission electron microscopy

TIC total inorganic carbon

TOC total organic carbon

UDS undissolved solids

XRD X-ray diffraction 


\subsection{Physical Properties of the Composite Group 8 FeCN Slurry}

The settling curves of the triplicate samples of Group 8 composited solids are shown in Figure 3.2. Results are shown in two ways: 1) volume-percent settled solids as a function of time and 2) height of settled solids as a function of time. The settling curves for samples AR-S1, -S2, and -S3 showed overall good agreement. The solids settling proceeded rapidly, requiring nominally $6 \mathrm{~h}$ to reach $\sim 50 \mathrm{vol} \%$ settled solids. However, an additional $50 \mathrm{~h}$ was required to reach $\sim 40 \mathrm{vol} \%$ settled solids.

a)

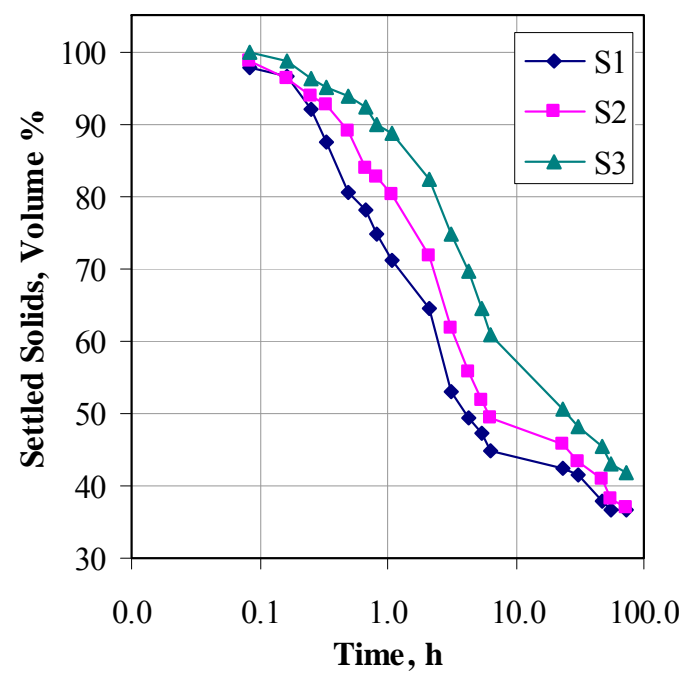

b)

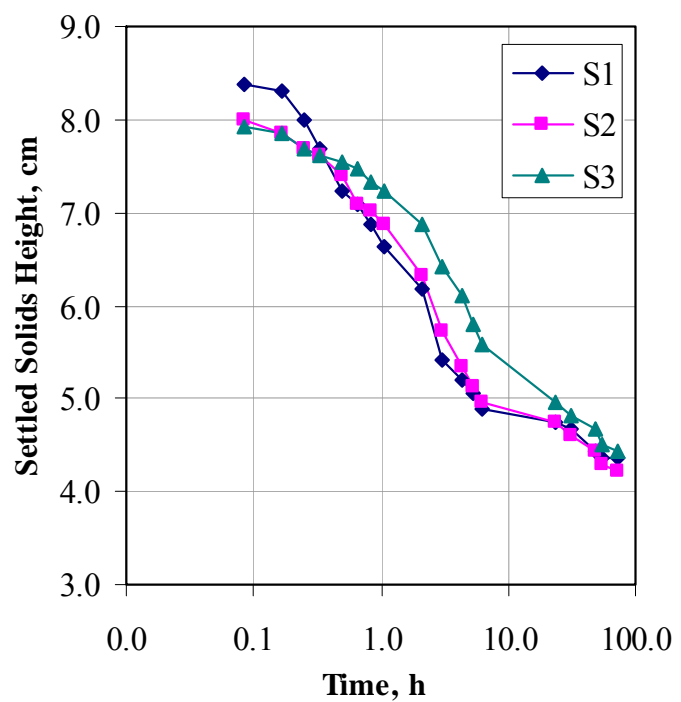

Figure 3.2. Group 8 FeCN Solids Settling Test (AR-S1, -S2, -S3)

Physical-property results for the Group $8 \mathrm{FeCN}$ sludge are summarized in Table 3.1 along with the propagated 1- $\sigma$ errors, averages, and relative standard deviations. Good precision was obtained for the sample set. Density and vol\% values associated with this testing were limited to 2 significant figures because of the small sample size $(<10 \mathrm{~mL})$ and volume measure uncertainty in the graduated centrifuge tubes and cylinders $(\sim 0.2 \mathrm{~mL})$; the third significant figure is shown for indication only. Supernatant density was also determined to more significant figures as part of the chemical analysis processing. 
WTP-RPT-170, Rev. 0

Table 3.1. Physical-Property Measurements of Homogenized Group 8 FeCN Slurry

\begin{tabular}{|c|c|c|c|c|c|c|}
\hline Description & AR-S1 & AR-S2 & AR-S3 & $\begin{array}{l}\text { Nominal } \\
1 \sigma \text { error }\end{array}$ & Avg. & $\operatorname{RSD}^{(a)}(\%)$ \\
\hline \multicolumn{7}{|c|}{ Bulk Sample } \\
\hline Sample Size (mL) & 8.7 & 8.1 & 7.9 & 0.2 & na & na \\
\hline Sample Size (g) & 10.836 & 9.800 & 9.504 & 0.003 & na & na \\
\hline Density $(\mathrm{g} / \mathrm{mL})^{(\mathrm{b})}$ & 1.25 & 1.23 & 1.24 & 0.03 & 1.24 & 0.8 \\
\hline Total Solids (wt $\%)$ & 25.9 & 28.9 & 30.6 & 0.034 & 28.5 & 8.3 \\
\hline Total Undissolved Solids (wt\%) & 11.2 & 11.0 & 12.1 & 0.030 & 11.4 & 5.0 \\
\hline \multicolumn{7}{|c|}{ Settled Solids } \\
\hline Density $(\mathrm{g} / \mathrm{mL})^{(\mathrm{b})}$ & 1.42 & 1.34 & 1.25 & 0.08 & 1.34 & 6.3 \\
\hline $\mathrm{Vol}^{\left({ }^{(\mathrm{b})}\right.}$ & 36.8 & 37.5 & 42.3 & 2.8 & 38.9 & 7.7 \\
\hline $\mathrm{Wt} \%$ & 42.1 & 43.2 & 46.2 & 3.5 & 43.8 & 4.8 \\
\hline Total Undissolved Solids (wt\%) & 26.6 & 26.2 & 26.9 & 2.1 & 26.6 & 1.3 \\
\hline \multicolumn{7}{|c|}{ Wet Centrifuged Solids } \\
\hline Density $(\mathrm{g} / \mathrm{mL})^{(\mathrm{b})}$ & 1.354 & 1.359 & 1.277 & 0.10 & 1.33 & 3.4 \\
\hline Vol $\%{ }^{(b)}$ & 32.2 & 32.1 & 34.2 & 2.7 & 32.8 & 3.6 \\
\hline $\mathrm{Wt} \%$ & 35.0 & 36.1 & 36.3 & 0.03 & 35.8 & 1.9 \\
\hline Total Undissolved Solids (wt\%) & 29.6 & 29.4 & 32.0 & 2.7 & 30.3 & 4.7 \\
\hline Total Solids (wt\%) & 43.3 & 44.2 & 47.1 & 0.07 & 44.9 & 4.5 \\
\hline \multicolumn{7}{|c|}{ Supernatant } \\
\hline Density $(\mathrm{g} / \mathrm{mL})^{(\mathrm{b})}$ & 1.14 & 1.13 & 1.17 & 0.02 & 1.15 & 1.6 \\
\hline Total Dissolved Solids (wt\%) & 16.5 & 19.7 & 20.7 & 0.04 & 19.0 & 12 \\
\hline Water Content $(\mathrm{g} / \mathrm{g})$ & 0.8354 & 0.8025 & 0.7929 & 0.0006 & 0.8102 & 2.8 \\
\hline
\end{tabular}

The two $\sim 10$-mL samples taken for chemical characterization were evaluated for density, $\mathrm{wt} \%$, and vol $\%$ centrifuged solids as part of the initial phase separation providing supplemental physical-property results (see Table 3.2). In this case, the centrifuged solids densities varied significantly between the duplicates, but the results bracketed the values obtained with the physical-property samples. Both wt $\%$ and vol $\%$ wet centrifuged solids were lower than the values observed with the physical-property testing samples (AR$\mathrm{S} 1,-\mathrm{S} 2$, and -S3) whereas the bulk density measures were equivalent to those observed from the physicalproperty testing. The differences associated with these parameters suggest that the solids may have packed more densely in the characterization samples. Even though the centrifuging conditions were similar in each case $(1 \mathrm{~h}$ at $1000 \mathrm{G})$, the aspect ratio of the centrifuged solids was significantly different (closer to 1 in the case of $\mathrm{C} 1$ and $\mathrm{C} 2$ chemical characterization samples) and may have contributed to the observed difference. 
WTP-RPT-170, Rev. 0

Table 3.2. Supplemental Physical Properties from Chemical Characterization Samples

\begin{tabular}{|c|c|c|c|c|c|c|}
\hline Description & AR-C1 & AR-C2 & $\begin{array}{l}\text { Nominal } \\
1 \sigma \text { error }\end{array}$ & Avg. & $\begin{array}{c}\text { RPD }^{(a)} \\
(\%)\end{array}$ & $\begin{array}{c}\text { Comparison to } \\
\text { Table } 3.1 \\
\text { Results } \\
\end{array}$ \\
\hline Sample Size $(\mathrm{mL})^{(\mathrm{b})}$ & 11.5 & 10.0 & 0.2 & na & na & na \\
\hline Sample Size (g) & 14.344 & 12.407 & 0.003 & na & na & na \\
\hline Bulk Density $(\mathrm{g} / \mathrm{mL})^{(\mathrm{b})}$ & 1.25 & 1.24 & 0.03 & 1.24 & 0.5 & equivalent \\
\hline $\begin{array}{l}\text { Wet Centrifuged Solids } \\
\text { Density }(\mathrm{g} / \mathrm{mL})^{(\mathrm{b})}\end{array}$ & 1.20 & 1.38 & 0.20 & 1.29 & 14 & $-3.0 \%$ \\
\hline Vol\% Centrifuged Solids ${ }^{(b)}$ & 30.4 & 31.0 & 1.5 & 30.7 & 1.8 & $-6.4 \%$ \\
\hline $\mathrm{Wt} \%$ Centrifuged Solids & 29.4 & 34.5 & 0.03 & 31.9 & 16 & $-11 \%$ \\
\hline Supernatant Density $(\mathrm{g} / \mathrm{mL})$ & \multicolumn{2}{|c|}{1.151} & 0.001 & na & na & equivalent \\
\hline \multicolumn{7}{|c|}{$\begin{array}{l}\text { (a) RPD = relative percent difference } \\
\text { (b) The density and vol\% values are only valid to two significant figures since the volume measures were } \\
\text { determined to two significant figures; the third significant figure is provided for indication only. } \\
\text { Bolded values indicated differences exceeding the uncertainties. }\end{array}$} \\
\hline
\end{tabular}

\subsection{Rheology of the Composite Group 8 FeCN Slurry}

The rheology (i.e., flow behavior) of Group $8 \mathrm{FeCN}$ slurry was characterized with respect to 1) incipient motion in settled tank waste solids and 2) non-elastic flow. Incipient motion is characterized by shearstrength testing, which determines the force required to initiate motion in a bed of settled solids (after a given settling time). Non-elastic flow is characterized by rotational viscometry (also referred to as flowcurve testing) and provides information on how the waste slurry responds to applied shear or deformation. The experimental requirements, instrumentation, and measurement protocols for flow-curve and shearstrength testing are described in Appendix B of this report.

Before flow-curve testing, the thermocouple attached to the water jacket failed. Because of this failure, the temperature could not be verified during flow-curve testing of sample TI516-G8-AR-P1. As a result, all flow-curve data and any information derived from these data are marked "For Information Only." Additional details are provided in NCR 38963.1. Shear-strength measurements conducted at ambient cell temperature were not affected by this failure because the temperature could be verified using calibrated thermocouples on the crossflow ultrafiltration (CUF) slurry reservoir. As such, flow-curve and shearstrength analyses produced the following reportable data for the Group 8 initial characterization sample:

- three measurements of settled solids shear strength after 72 hours

- flow-curve data for Group 8 slurries at $25^{\circ} \mathrm{C}, 40^{\circ} \mathrm{C}$, and $60^{\circ} \mathrm{C}$ (For Information Only-See NCR 38963.1)

- best-fit Newtonian viscosities at $25^{\circ} \mathrm{C}, 40^{\circ} \mathrm{C}$, and $60 \mathrm{C}$ (For Information Only-See NCR 38963.1)

\subsubsection{Shear Strength}

Three separate measurements of shear strength were made on settled solids in sample jar TI516-G8-ARP1. The Group 8 slurry jar had been stored undisturbed, and during storage, the sludge solids had settled 
to the bottom of the sample jar. Before shear-strength testing, settled slurry solids were dispersed uniformly by vigorously shaking the jar by remote manipulator. The dispersion was then allowed to settle for 72 hours. After this period of time, the shear strength of the settled solids was measured.

Because the height of settled solids in the test jar was limited, it was not possible to satisfy the geometric constraints outlined for vane immersion depth (see Appendix B). The total height of settled solids was $\sim 20 \mathrm{~mm}$. To avoid contact with the bottom of the container, the vane was inserted until the top of the vane blades was just below the surface of the settled solids. Because of the proximity of the vane to both the floor of the test jar and the surface of the settled solids, the shear-strength results for this sample are not independent of container geometry. As such, reported shear strengths should be taken as an estimate of actual Group 8 settled-solids strength.

The results of Group 8 initial characterization shear-strength testing are shown in Table 3.3. Three separate observations after 72 hours of settling time indicated a shear strength ranging from 11 to $13 \mathrm{~Pa}$. The single measurement at the central location suggests a shear strength of approximately $11 \mathrm{~Pa}$. Slightly higher shear strengths of $\sim 13 \mathrm{~Pa}$ were encountered during measurements made near the container walls. Radial measurements were likely influenced by vane-wall interactions, yielding the observed increase in shear strength at these test locations.

These results should be approached with some caution. The geometric constraints required for shearstrength testing could not be met because of limited settled-solids volume. As a result, all reported values are likely influenced by container geometry. The proximity of the vane to the floor of the container may cause an increase in the measurement shear strength similar to that observed in the radial measurements. This increase would be driven by the coupling of stress interactions, such as the formation of linked stress chains between the vane tool, waste particles, and container floor. On the other hand, the proximity of the vane to the surface tends to reduce the measured value of the shear strength. Reduction is a result of the vane no longer having to shear the volume of material above the top of the blades.

Table 3.3. Shear Strength of Group 8 Initial Characterization (Sample TI516-G8-AR-P1)

\begin{tabular}{||c|c|c||}
\hline Test Number & $\begin{array}{c}\text { Relative Vane Location } \\
\text { in Container }\end{array}$ & $\begin{array}{c}\text { Shear Strength } \\
\text { [Pa] }\end{array}$ \\
\hline 1 & Center & 11 \\
\hline 2 & Radial (Near Wall) & 13 \\
\hline 3 & Radial (Near Wall) & 13 \\
\hline Average & --- & $\sim 13$ \\
\hline $\begin{array}{l}\text { Notes: } \\
\text { Solids were subjected to a 72-h settling time before measurement. } \\
\text { Measurements were taken at ambient cell temperature of } 27.6^{\circ} \mathrm{C} .\end{array}$ \\
\hline
\end{tabular}

\subsubsection{Flow Curve}

Flow-curve testing for slurry sample TI516-G8-AR-P1 was performed at $25^{\circ} \mathrm{C}, 40^{\circ} \mathrm{C}$, and $60^{\circ} \mathrm{C}$. Two measurements (an initial and replicate) were performed at $25^{\circ} \mathrm{C}$ to assess reproducibility. The Group 8 slurry jar had been stored undisturbed, and during storage, the sludge solids had settled to the bottom of 
the sample jar. Immediately before flow-curve testing, these solids were dispersed uniformly by vigorously shaking the jar by remote manipulator. Immediately after shaking, a sub-sample of the slurry was transferred to the rheometer measuring cup to minimize the potential for settling. Visual inspection of the slurry during and after transfer found no immediately observable solids settling.

Figure 3.3 shows the results of flow-curve measurements for the Group 8 initial characterization slurry sample, TI516-G8-AR-P1, at $25^{\circ} \mathrm{C}, 40^{\circ} \mathrm{C}$, and $60^{\circ} \mathrm{C}$. Flow-curve data indicated Newtonian flow behavior. The response over shear rates of 0 to $\sim 500 \mathrm{~s}^{-1}$ was linear at all temperatures. At higher shear rates, flow-curve data showed an increase in the slope of the stress response curve that is indicative of Taylor vortex formation onset (i.e., unstable/turbulent flow). As such, flow-curve data beyond $500 \mathrm{~s}^{-1}$ were unusable. Apart from Taylor vortex formation, the flow-curve data were relatively free of data anomalies such as hysteresis. However, there was significant overlap between flow-curve data at $25^{\circ} \mathrm{C}$, $40^{\circ} \mathrm{C}$, and $60^{\circ} \mathrm{C}$, and as a result, no temperature trends were immediately identifiable through visual inspection of the valid flow-curve data (i.e., those over 0 to $500 \mathrm{~s}^{-1}$ ). Analyses of flow-curve data (discussed on the pages that follow) indicated a decrease in viscosity with increasing temperature. Overall, the stress response of the Group 8 slurry was weak ( $\left.1 \mathrm{~Pa}^{2} 500 \mathrm{~s}^{-1}\right)$ and indicative of a lowviscosity slurry. Because of the weak response, the signal-to-noise ratio observed for these flow-curve measurements was low over 0 to $500 \mathrm{~s}^{-1}$.

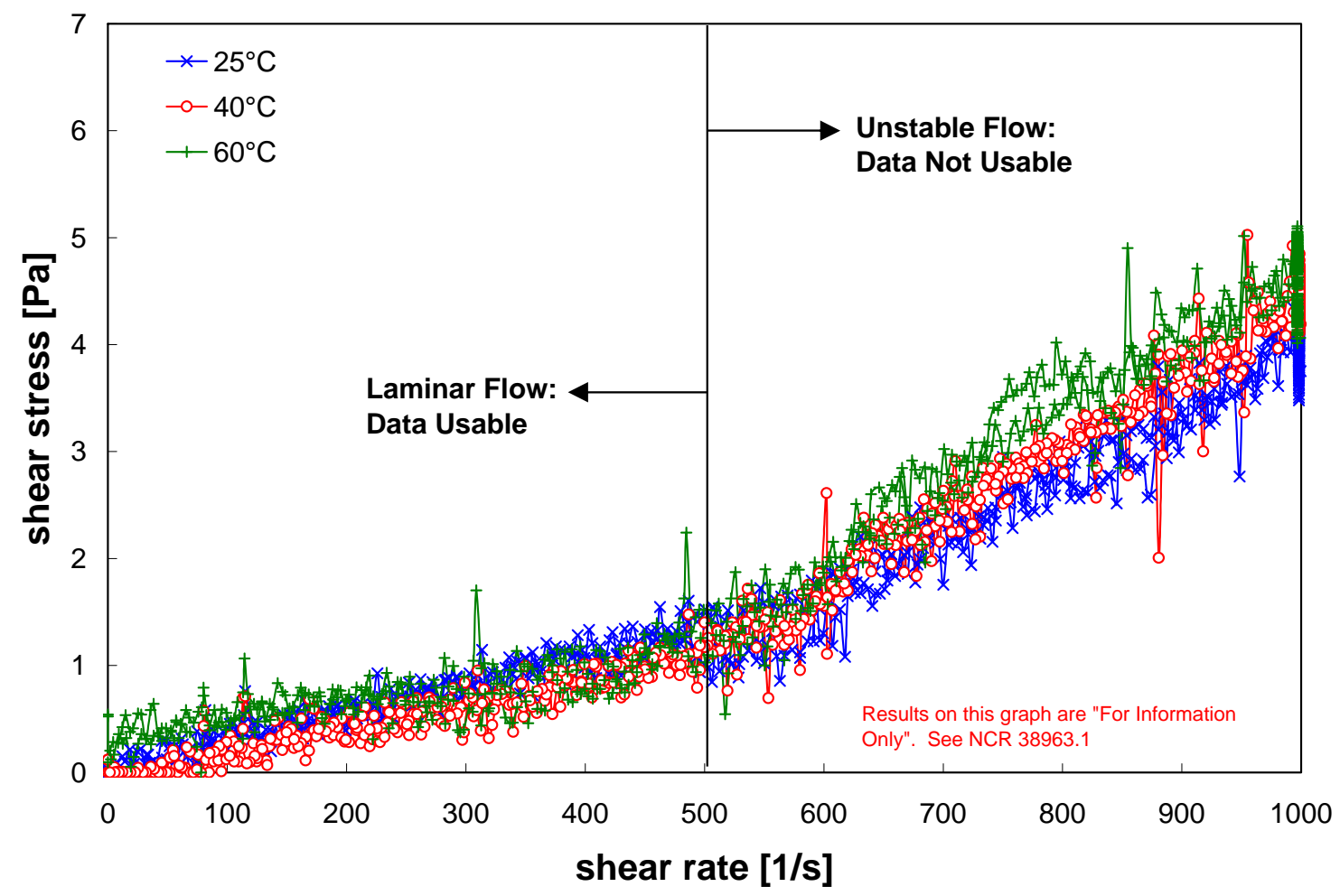

Figure 3.3. Shear Strength Versus Shear Rate for Group 8 FeCN Sludge Initial Characterization Sample (TI516-G8-AR-P1) at $25^{\circ} \mathrm{C}, 40^{\circ} \mathrm{C}$, and $60^{\circ} \mathrm{C}(11.4 \mathrm{wt} \%$ UDS), Measured Using the MV1 Smooth Cup and Rotor

To quantify the stress-response behavior shown in Figure 3.3, the viscosity for slurry sample TI516-G8AR-P1 was determined as a function of temperature by regression analysis of the flow-curve data. The 
analysis was complicated by two factors: 1) Taylor vortex formation and 2) weak stress response coupled with small (but finite) stress offset. To exclude data affected by Taylor vortex formation, a limited shearrate range was used for fitting analysis. For the initial $25^{\circ} \mathrm{C}$ measurement, the range was restricted to 0 to $500 \mathrm{~s}^{-1}$. For the replicate $25^{\circ} \mathrm{C}$ measurement and the $60^{\circ} \mathrm{C}$ measurement, the range was limited to 0 to $400 \mathrm{~s}^{-1}$. Finally, the fit of the $40^{\circ} \mathrm{C}$ measurement data was limited to 100 to $500 \mathrm{~s}^{-1}$. The lower bound of $100 \mathrm{~s}^{-1}$ in the latter fit excluded data affected by a negative torque correction (i.e., a negative stress offset).

The flow-curve data showed a minor stress offset (about $\pm 0.2 \mathrm{~Pa}$ ). This offset resulted from the difficulty in zeroing the initial torque reading on the M5-system. Although this $\pm 0.2 \mathrm{~Pa}$ stress offset is not significant in terms of the limits of accuracy of the instrument $( \pm 0.5 \mathrm{~Pa})$, it is significant in terms of the overall stress response of this slurry $(\sim 1 \mathrm{~Pa})$. As such, neglecting the offset can bias the regressed viscosity. The offset was present in the flow-curve measurements to varying degrees. The replicate $25^{\circ} \mathrm{C}$ measurement data showed little offset, whereas the $60^{\circ} \mathrm{C}$ measurement data showed an offset of $\sim 0.3 \mathrm{~Pa}$. The $40^{\circ} \mathrm{C}$ measurement data appear to exhibit a negative stress offset, which the RheoWin software (rheometer operating software) corrected by zeroing all stress less than zero to zero. The fitting analysis accounted for the offset by using a Bingham-Plastic model to fit the flow-curve data. It was assumed that the slurry behavior was Newtonian, and the Newtonian viscosity was associated with the regressed value for Bingham-Plastic consistency. The Bingham-Plastic yield stress was neglected.

Table 3.4 summarizes the Newtonian viscosity results derived from flow-curve data for sample TI516G8-AR-P1. It is emphasized that these results are "For Information Only"-NCR 38963.1 provides additional details regarding the quality status for these data. Table 3.4 indicates that Group 8 slurry viscosity fell between 1.4 and $3.3 \mathrm{mPa} \cdot \mathrm{s}$, depending on temperature. An increased temperature appeared to yield a decrease in the slurry viscosity, likely as a result of decreased suspending phase viscosity. This decrease in viscosity with increasing temperature was consistent with Group 8 waste slurry behaviors measured during CUF testing (see Section 4 of this report). However, the initial and replicate viscosity measurement at $25^{\circ} \mathrm{C}$ do not compare, showing a significant $0.7 \mathrm{~Pa}$ difference or $20 \%$ relative percent change between initial and replicate measurements. The replicate measurement at $25^{\circ} \mathrm{C}$ occurred at the end of the measurement series, after both $40^{\circ} \mathrm{C}$ and $60^{\circ} \mathrm{C}$ measurements. Observation of lower viscosity could be a result of 1) changes in the slurry structure that occurred after prolonged slurry shearing (i.e., thixotropy) or 2) settling of slurry solids. The lack of flow-curve hysteresis in Figure 3.3 suggested that the time-dependent behavior was not a result of shear. As such, the decreased viscosity between the initial and repeat measurements at $25^{\circ} \mathrm{C}$ was likely caused by the settling of slurry solids. Likewise, because of the decrease observed in the replicate measurement, it is difficult to ascertain if the decreases observed at $40^{\circ} \mathrm{C}$ and $60^{\circ} \mathrm{C}$ are attributable to temperature alone or include both temperature and settling effects. 
Table 3.4. Best Fit Newtonian Viscosities for Group 8 FeCN Sludge Slurries

\begin{tabular}{|c|c|c|c|c|}
\hline Model & $\begin{array}{c}\text { Temperature } \\
{\left[{ }^{\circ} \mathrm{C}\right]}\end{array}$ & $\begin{array}{c}\text { Shear Rate Range } \\
{\left[\mathrm{s}^{-1}\right]^{(\mathrm{a})}}\end{array}$ & $\begin{array}{l}\text { Viscosity } \\
\text { [mPa·s] }\end{array}$ & $\mathbf{R}^{(\mathbf{b})}$ \\
\hline \multirow{4}{*}{$\begin{array}{l}\text { Newtonian } \\
\text { (Flow Curve) }\end{array}$} & $25(1$ of 2$)$ & $0-500$ & 3.3 & 0.89 \\
\hline & $25(2$ of 2$)$ & $0-400$ & 2.6 & 0.94 \\
\hline & 40 & $100-500$ & 2.2 & 0.89 \\
\hline & 60 & $0-400$ & 1.4 & 0.69 \\
\hline \multicolumn{5}{|c|}{$\begin{array}{l}\text { Results are flagged "For Information Only" because of calibrated thermocouple failure. } \\
\text { See NCR } 38963.1 \\
\text { (a) Shear rates }>500 \mathrm{~s}^{-1} \text { resulted in Taylor vortex formation and were thus excluded from } \\
\text { the viscosity calculation. } \\
\text { (b) } \mathrm{R} \text { is the correlation coefficient. } \\
\text { Note } 1 \mathrm{mPa} \cdot \mathrm{s}=1 \mathrm{cP} \text {. }\end{array}$} \\
\hline
\end{tabular}

Test Plan TP-RPP-WTP-467 requested determination of apparent viscosity at $33 \mathrm{~s}^{-1}$. For the current measurement, measurement noise and the low slurry viscosity $(<5 \mathrm{mPa} \cdot \mathrm{s})$ makes determination of apparent viscosity at this shear rate difficult and subject to significant error. In terms of calculated apparent viscosities, the Newtonian results reported in Table 3.4 represent the apparent viscosity over the entire range of shear and should provide a reasonable estimation of the apparent viscosity at $33 \mathrm{~s}^{-1}$. Thus, the determination of apparent viscosity from measurement data is forgone in favor for the results in Table 3.3.

In summary, flow-curve analysis for Group 8 Initial Characterization slurry sample, TI516-G8-AR-P1, suggested Newtonian rheology. Regression analysis of the flow-curve data resulted in slurry viscosities of $2.6-3.3 \mathrm{mPa} \cdot \mathrm{s}$ at $25^{\circ} \mathrm{C}, 2.2$ at $40^{\circ} \mathrm{C}$, and $1.4 \mathrm{mPa} \cdot \mathrm{s}$ at $60^{\circ} \mathrm{C}$. A decrease in slurry viscosity was observed at higher temperatures; however, part of this decrease may have resulted from settling of slurry solids over the course of the temperature series.

\subsection{Chemical and Radiochemical Composition of the Group 8 Slurry}

A summary of the solids washing and steps and the chemical and radionuclide characterizations of the Group 8 solids, wash solution, and supernatant are provided in this section. Opportunistically, additional physical-property data were collected and compared with data provided in Section 3.1.

The supernatant density was determined to be $1.151 \mathrm{~g} / \mathrm{mL}\left(\mathrm{T}=28^{\circ} \mathrm{C}\right)$ based on the average masses of four $1-\mathrm{mL}$ volume deliveries. This value agreed well with that determined from the physical-property testing shown in Table 3.1.

The specific washing scheme for the FeCN sludge is provided in Figure 3.4. The centrifuged solids (CS) volumes were estimated based on the centrifuge-tube graduations. Within the uncertainty of the volume measurement, there was no change in the centrifuged solids volume with each successive washing step. The free-hydroxide concentration in the final wash solution was $\sim 0.01 \mathrm{M}$. 
WTP-RPT-170, Rev. 0

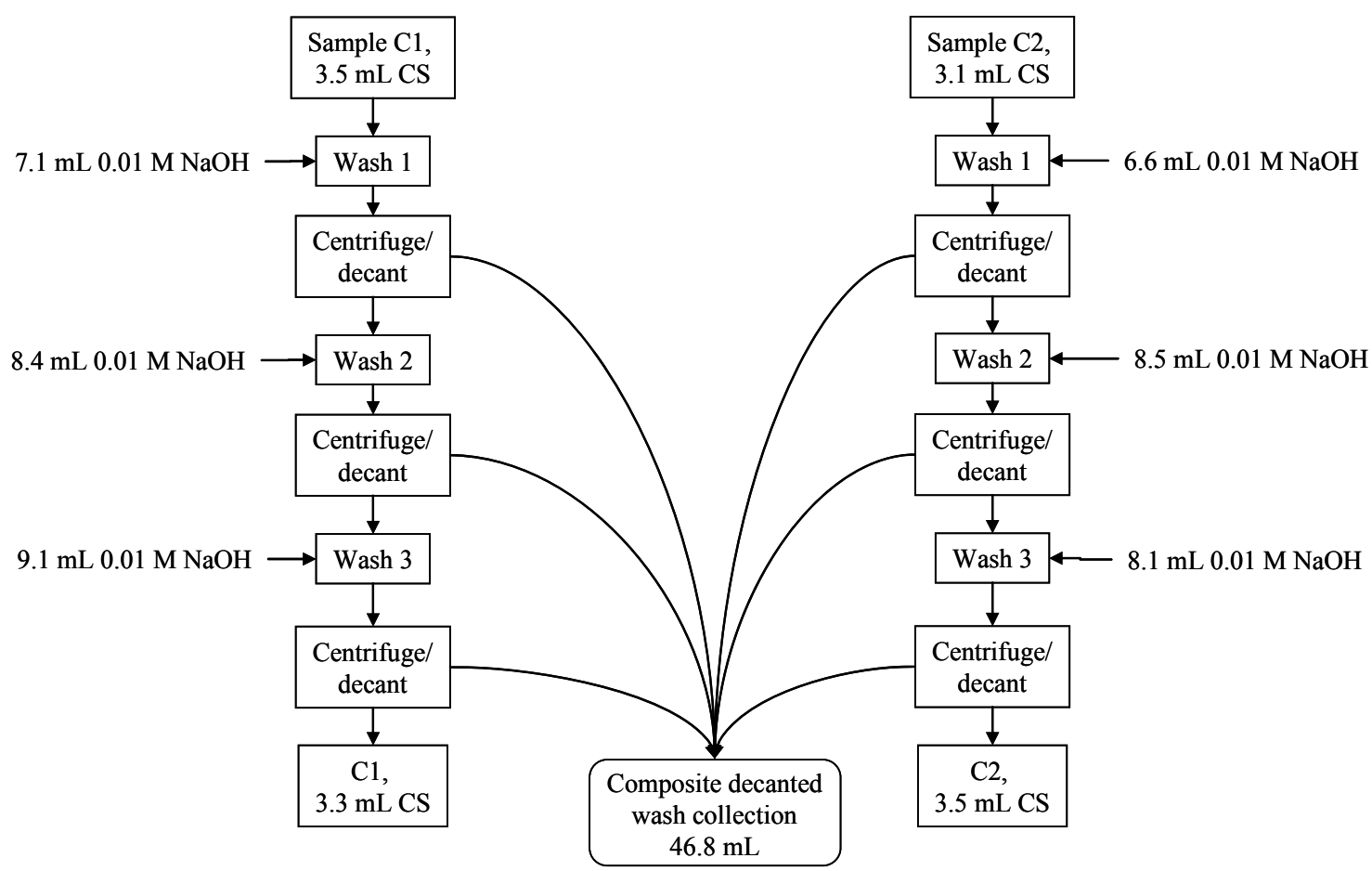

Figure 3.4. Wash Sequence of Group 8 FeCN Sludge Supporting Initial Characterization (CS $=$ centrifuged solids)

The average radioanalytical results for the supernatant, composite wash solution, and washed solids are provided in Table 3.5 along with the applicable relative percent differences (RPD, measure of precision) between duplicate results. The concentrations of the gross-beta results and the sum of beta emitters, ${ }^{137} \mathrm{Cs}$ and ${ }^{90} \mathrm{Sr}$ (in secular equilibrium with ${ }^{90} \mathrm{Y}$ ), were equivalent ( ratio $=1.0$ ). The good agreement between these values indicated that no other major source of beta activity was present. The gross alpha activity in the solids was $14 \%$ higher than the summation of alpha emitters $\left({ }^{238} \mathrm{Pu},{ }^{239+240} \mathrm{Pu}\right.$, and detected $\left.{ }^{241} \mathrm{Am}\right)$; this difference was within the overall experimental uncertainty but may also indicate that another source of alpha activity may have been present. In this waste, the ${ }^{137} \mathrm{Cs}$ concentration was very high in the solids component, which was characteristic of the Cs scavenging effect of the nickel ferrocyanide precipitation reaction (Burger et al. 1991). 
WTP-RPT-170, Rev. 0

Table 3.5. Radionuclide Characterization of the Group 8 FeCN Sludge

\begin{tabular}{|c|c|c|c|c|c|}
\hline \multirow{3}{*}{$\begin{array}{l}\text { Sample ID }> \\
\text { Analyte } \\
\end{array}$} & \multicolumn{2}{|c|}{ Supernatant } & \multirow{3}{*}{$\begin{array}{c}\text { Composite Wash } \\
08-01944 \\
\mu \mathrm{Ci} / \mathrm{mL} \\
\end{array}$} & \multirow{2}{*}{\multicolumn{2}{|c|}{$\begin{array}{c}\text { Washed solids }^{(\mathbf{a})} \\
08-01946 \\
\end{array}$}} \\
\hline & \multicolumn{2}{|c|}{ 08-01943 } & & & \\
\hline & $\mu \mathrm{Ci} / \mathbf{m L}$ & RPD & & $\mu \mathrm{Ci} / \mathrm{g}$ & RPD \\
\hline${ }^{137} \mathrm{Cs}$ & $4.53 \mathrm{E}+1$ & 0.66 & $4.11 \mathrm{E}+0$ & $3.85 \mathrm{E}+2$ & 0.26 \\
\hline${ }^{60} \mathrm{Co}$ & $<1$. E-4 & na & $<2$.E-5 & $9.94 \mathrm{E}-3^{(\mathrm{b})}$ & $\mathrm{na}^{(\mathrm{c})}$ \\
\hline${ }^{241} \mathrm{Am}$ & $<7 . \mathrm{E}-3$ & na & $<1 . \mathrm{E}-3$ & $1.91 \mathrm{E}-1$ & 12 \\
\hline${ }^{238} \mathrm{Pu}$ & $5.58 \mathrm{E}-6$ & 24 & \multirow{9}{*}{$\mathrm{n} / \mathrm{a}$} & $1.41 \mathrm{E}-2$ & 26 \\
\hline${ }^{239+240} \mathrm{Pu}$ & $7.69 \mathrm{E}-5$ & 8.2 & & $5.63 \mathrm{E}-1$ & 2.8 \\
\hline Gross alpha & $<4$.E-3 & na & & $8.77 \mathrm{E}-1$ & 7.3 \\
\hline Gross beta & $4.54 \mathrm{E}+1$ & 2.0 & & $2.97 \mathrm{E}+3$ & 1.7 \\
\hline${ }^{90} \mathrm{Sr}$ & $8.12 \mathrm{E}-2$ & 3.0 & & $1.29 \mathrm{E}+3$ & 2.3 \\
\hline Alpha sum & $<7$. E-3 & 0.11 & & $7.68 \mathrm{E}-1$ & 0.44 \\
\hline$\alpha$ gross/sum & na & na & & 1.14 & na \\
\hline Beta sum & $4.54 \mathrm{E}+1$ & 0.67 & & $2.95 \mathrm{E}+3$ & 2.0 \\
\hline$\beta$ gross/sum & 1.00 & na & & 1.00 & na \\
\hline \multicolumn{6}{|l|}{ Opportunistic } \\
\hline${ }^{154} \mathrm{Eu}$ & $<5$.E-4 & na & $<7 . \mathrm{E}-5$ & $1.41 \mathrm{E}-1$ & 11 \\
\hline${ }^{155} \mathrm{Eu}$ & $<8 . \mathrm{E}-3$ & na & $<1 . \mathrm{E}-3$ & $<1$.E-1 & na \\
\hline \multicolumn{6}{|c|}{$\begin{array}{l}\text { (a) Analyte concentrations are calculated on a dry-mass basis. } \\
\text { (b) The primary sample resulted in } 9.94 \mathrm{E}-3 \text {, and the duplicate resulted in }<3 \mathrm{E}-3 \text {. } \\
\text { (c) Not calculated-the duplicate sample was a "less-than" value, }<3 \mathrm{E}-3 \text {; the result of the primary } \\
\text { sample is reported. } \\
\text { Notes: } \\
\text { ASR } 8150\end{array}$} \\
\hline
\end{tabular}

The chemical compositions of the Group $8 \mathrm{FeCN}$ supernatant, composite wash solution, and washed solids are provided in Table 3.6. Results for both solids preparation methods (fusion and HF-assisted acid digestion) are shown. The analysis results from the solids prepared by the HF-assisted acid-digestion method showed good agreement with the results from the fusion-preparation method. The Si and B values were only relevant for the fusion method; these elements are potentially lost as volatile fluorides during acid digestion. The $\mathrm{Ni}$ and $\mathrm{K}$ values were only relevant for the HF-assisted acid digestion; the fusion method used a $\mathrm{KOH} / \mathrm{KNO}_{3}$ fusion flux in Ni crucibles.

The supernatant was composed primarily of sodium salts (nitrate, carbonate, nitrite, hydroxide, phosphate, sulfate, and oxalate). The anionic and cationic charge balance was evaluated for the supernatant, resulting in a $6.5 \%$ difference, well within analytical uncertainties. The TOC concentration $(1.75 \mathrm{E}-1 \mathrm{M})$ was significantly higher than twice the oxalate concentration $(6.62 \mathrm{E}-2 \mathrm{M})$, indicating that an equivalent of 1.1E-1 $\mathrm{M}$ organic carbon in the supernatant phase was associated with material other than the oxalate.

The wash solution was generally diluted supernatant with a typical ratio of 0.10 (wash solution analyte concentration divided by the supernatant solution analyte concentration). Notable exceptions included $\mathrm{Si}$, Fe, and oxalate, where the wash/supernatant analyte ratios were $0.40,0.25$, and 0.18 , respectively. This 
indicated that a small amount of silicon, iron, and oxalate was dissolved from the solids phase during washing as water-soluble compounds.

The washed water-insoluble solids were dominated by U (12 wt \%), Fe (10 wt \%), $\mathrm{Al}(9 \mathrm{wt} \%), \mathrm{Ca}$ (6.4 wt\%), $\mathrm{Na}(5 \mathrm{wt} \%)$, $\mathrm{Ni}$ and $\mathrm{P}(3.6 \mathrm{wt} \%)$, and $\mathrm{Sr}(4.2 \mathrm{wt} \%)$ (dry mass basis). The presence of Ni is characteristic of ferrocyanide waste sludge; the Fe:Ni mole ratio in the Group 8 solids was 3:1.

Table 3.6. Chemical Characterization of the Group 8 FeCN Sludge

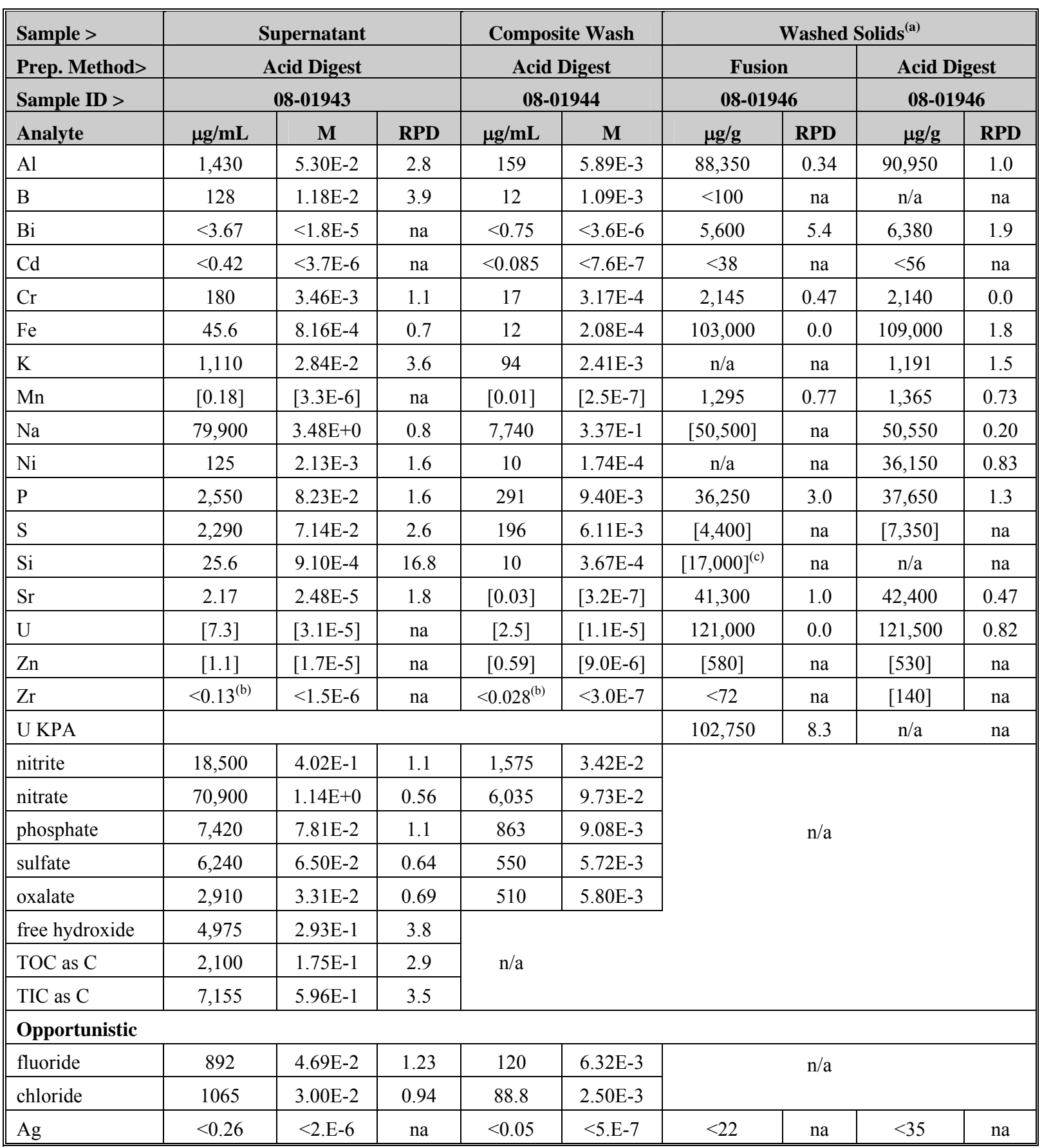


WTP-RPT-170, Rev. 0

Table 3.6 (Contd)

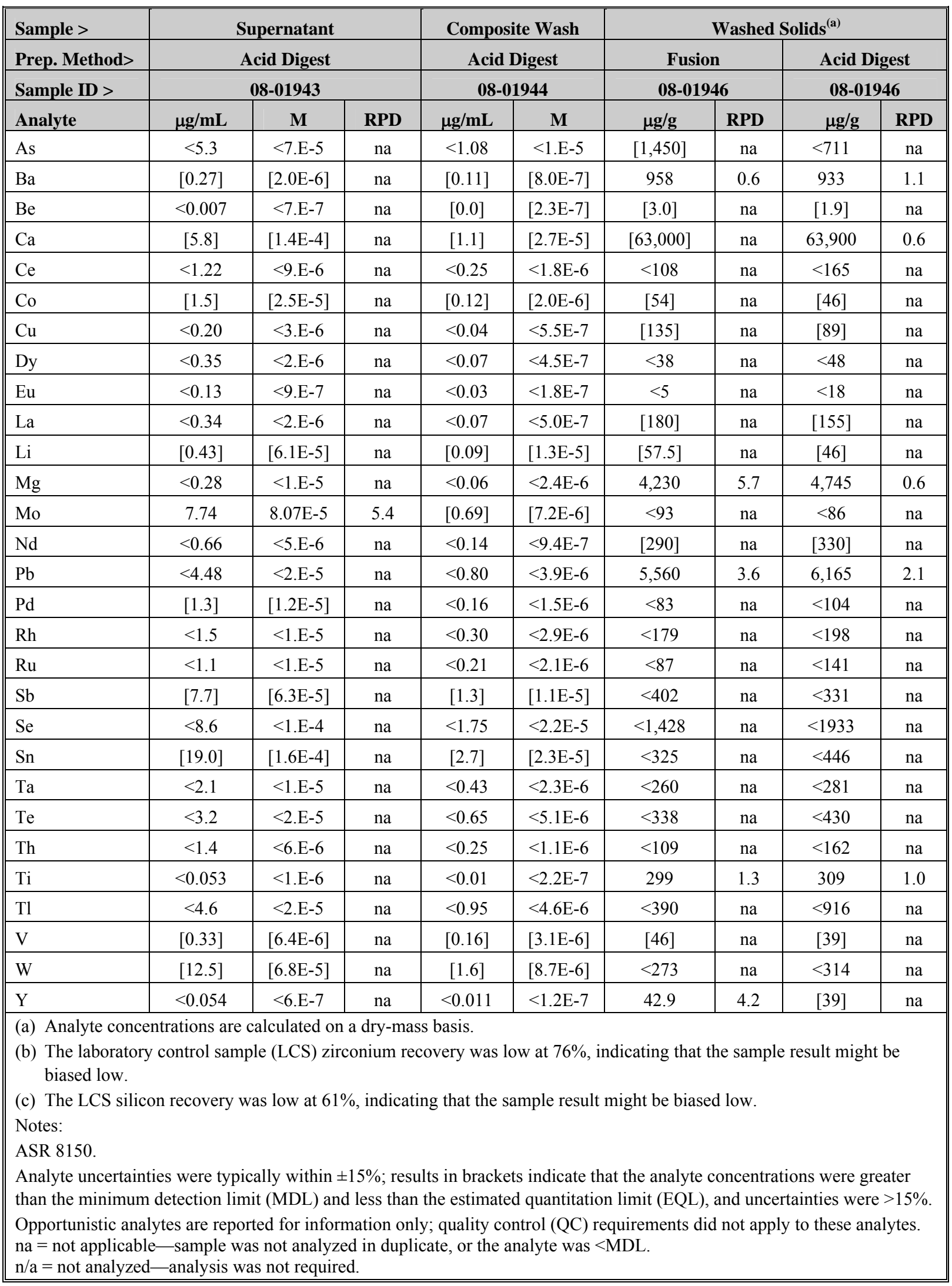


Analyte water-wash factors were calculated from the mass distribution in the combined supernatant and wash solutions relative to the total analyte mass according to Equation 3.1.

$$
F_{i}=\frac{S_{i}+W_{i}}{S_{i}+W_{i}+U D S_{i}}
$$

where $\quad \mathrm{F}_{\mathrm{i}}=$ analyte fraction removed during washing

$\mathrm{S}_{\mathrm{i}}=$ analyte mass in supernatant fraction

$\mathrm{W}_{\mathrm{i}}=$ analyte mass in wash solution

$\mathrm{UDS}_{\mathrm{i}}=$ analyte mass in the undissolved solids.

The fractional distributions of selected analytes in the supernatant, combined wash, and solids phases are shown in Table 3.7 and Figure 3.5. A large portion (>85\%) of the $\mathrm{Na}$ and $\mathrm{K}$ partitioned to the aqueous phase. Washing removed much smaller amounts of $\mathrm{Cr}(38 \mathrm{wt} \%), \mathrm{Al}(10 \mathrm{wt} \%)$, and $\mathrm{P}(34 \mathrm{wt} \%)$. Well over half of the ${ }^{137} \mathrm{Cs}$ remained in the solids phase. The water-wash factors obtained from the current testing were compared with the weighted mean of the water-wash factors obtained from the TWINS database. The weighting factors were calculated from the relative masses of tank wastes that were used to create the composite. The experimentally obtained $\mathrm{Na}$ and $\mathrm{K}$ wash factors resulted in fairly good correspondence with the TWINS water-wash factors. The experimentally obtained $\mathrm{Al}, \mathrm{Cr}, \mathrm{P}, \mathrm{S}$, and ${ }^{137} \mathrm{Cs}$ wash factors were significantly lower than the predicted wash factors. The Fe and Ni wash factors were expected to be very low; observed differences from the TWINS factors may not be statistically significant. Direct cross comparison of these water-wash factors with those in the TWINS database may be confounded by the sample selection process; only the available FeCN sludge samples containing high Fe concentrations in the $222 \mathrm{~S}$ archive were selected for processing, and these had aged $\sim 10 \mathrm{y}$. These factors may have resulted in a slightly different mineral suite than materials previously tested and entered in the TWINS database. 
Table 3.7. Phase Distribution of Selected Analytes in Group 8 FeCN Sludge

\begin{tabular}{|c|c|c|c|c|c||}
\hline Analyte & $\begin{array}{c}\text { Supernatant } \\
\text { wt\% }\end{array}$ & $\begin{array}{c}\text { Composite } \\
\text { Wash Solution } \\
\text { wt\% }\end{array}$ & $\begin{array}{c}\text { Observed Water- } \\
\text { Wash Factor } \\
\text { wt\% }\end{array}$ & $\begin{array}{c}\text { TWINS Water- } \\
\text { Wash Factor } \\
\text { wt\% }\end{array}$ & $\begin{array}{c}\text { Solids } \\
\text { wt\% }\end{array}$ \\
\hline $\mathrm{Al}$ & 8.5 & 2.1 & $\mathbf{1 0 . 6}$ & 77.6 & 89.4 \\
\hline $\mathrm{Cr}$ & 31.6 & 6.6 & $\mathbf{3 8 . 0}$ & 54.8 & 62.0 \\
\hline $\mathrm{Na}$ & 75.4 & 167 & 92.1 & 94.3 & 7.9 \\
\hline $\mathrm{K}$ & 72.9 & 14.1 & 87.0 & 94.8 & 13.0 \\
\hline $\mathrm{P}$ & 27.0 & 7.0 & $\mathbf{3 4 . 0}$ & $81.5^{(\mathrm{c})}$ & 66.0 \\
\hline $\mathrm{S}$ & 61.7 & 12.0 & $\mathbf{7 3 . 7}$ & $97.2^{(\mathrm{d})}$ & {$[26]$} \\
\hline${ }^{137} \mathrm{Cs}$ & 38.2 & 7.9 & $\mathbf{4 6 . 1}$ & 62.1 & 53.9 \\
\hline $\mathrm{Fe}$ & 0.25 & 0.15 & $\mathbf{0 . 4 0}$ & 4.6 & 99.6 \\
\hline $\mathrm{Ni}$ & 2.0 & 0.38 & $\mathbf{2 . 4}$ & 9.1 & 97.6 \\
\hline
\end{tabular}

(a) Bolded values indicate significant deviation from the predicted water-wash values based on the TWINS database query (see note b).

(b) The water-wash factors represent the weighted mean of the five represented tank-waste sources from the Best Basis Inventory (BBI) in the Tank Waste Information Network System (TWINS) database (search date 10/28/08).

(c) Reported in TWINS as phosphate; phosphorous wash factor was not available.

(d) Reported in TWINS as sulfate; sulfur water wash factor was not available.

Result in brackets indicates that the analyte concentration was $>$ MDL and $<$ EQL.

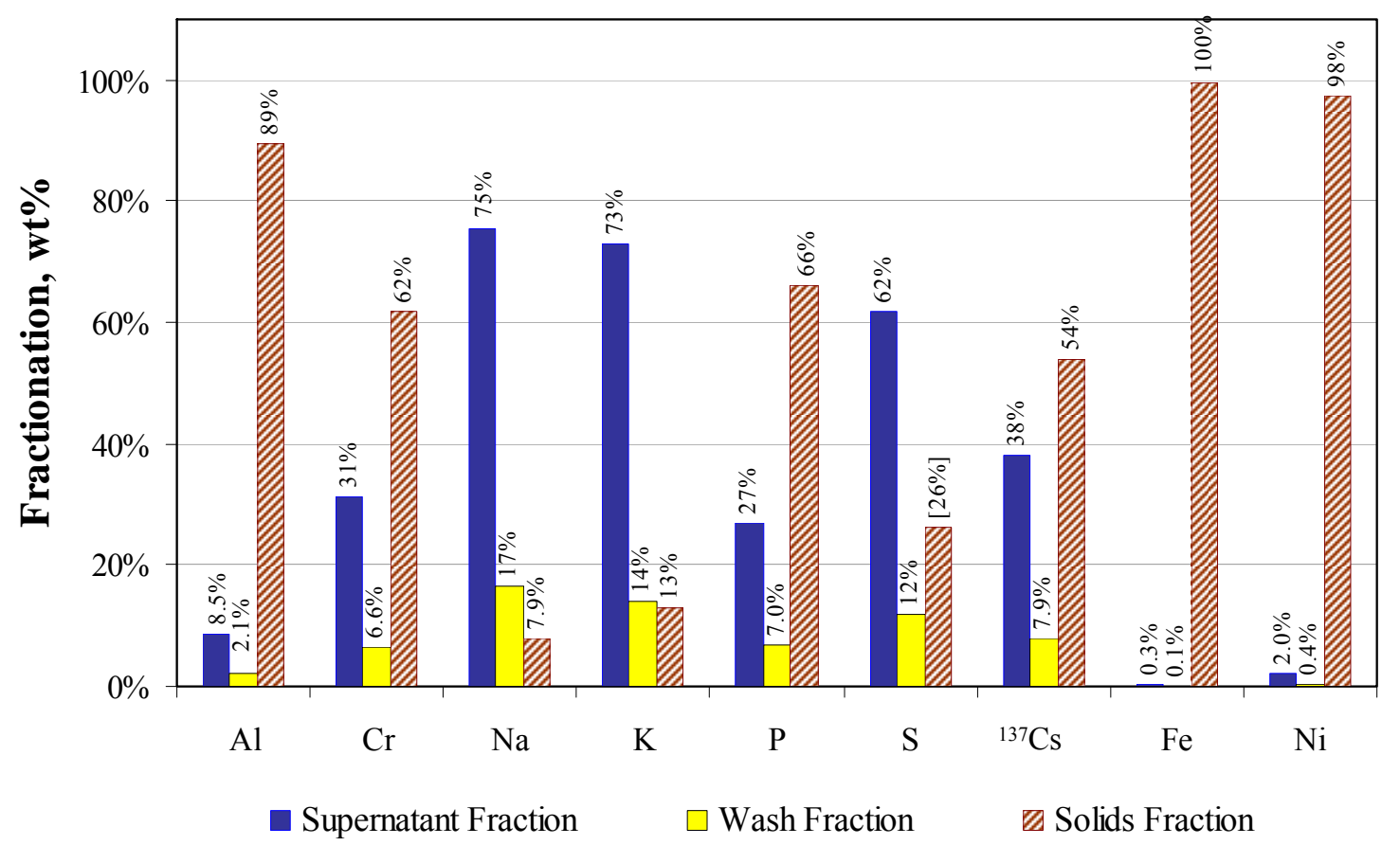

Figure 3.5. Selected Analyte Phase Distribution for Group 8 FeCN Sludge 
WTP-RPT-170, Rev. 0

\subsection{Particle-Size Distribution}

The PSDs of the washed Group 8 solids (primary and duplicate samples) are discussed in the following sections. The samples were measured as a function of pump speed ${ }^{(\mathrm{a})}$ using a Malvern Mastersizer MS2000 in a $0.01 \mathrm{M} \mathrm{NaOH}$ suspending solution (test run conditions are provided in Appendices B and G). The PSDs are shown as volume distribution plots; comparison of the PSD population profiles allows a qualitative examination of the PSD behavior with respect to pump speed and sub-sampling.

Figure 3.6 shows the PSD for the primary Group 8 initial characterization sample as a function of pump speed. At 2000 RPM, the distribution was continuous and relatively uni-modal; the PSD ranged from 0.2 to $40 \mu \mathrm{m}$ with a peak centered at $10 \mu \mathrm{m}$ and a shoulder over 0.2 to $2 \mu \mathrm{m}$. At $3000 \mathrm{RPM}$, the distribution was comprised of three separate populations that formed a tri-modal range spanning 0.2 to $750 \mu \mathrm{m}$ with peaks at 6,110 , and $500 \mu \mathrm{m}$ and a shoulder from 0.2 to $2 \mu \mathrm{m}$. At $4000 \mathrm{RPM}$, the distribution was continuous and bi-modal, ranging from 0.2 to $150 \mu \mathrm{m}$ with peaks at 5 and $60 \mu \mathrm{m}$ and a shoulder from 0.2 to $1 \mu \mathrm{m}$. As the pump speed was increased from 3000 RPM to 4000 RPM, there was a relative decrease in particles $>100 \mu \mathrm{m}$.

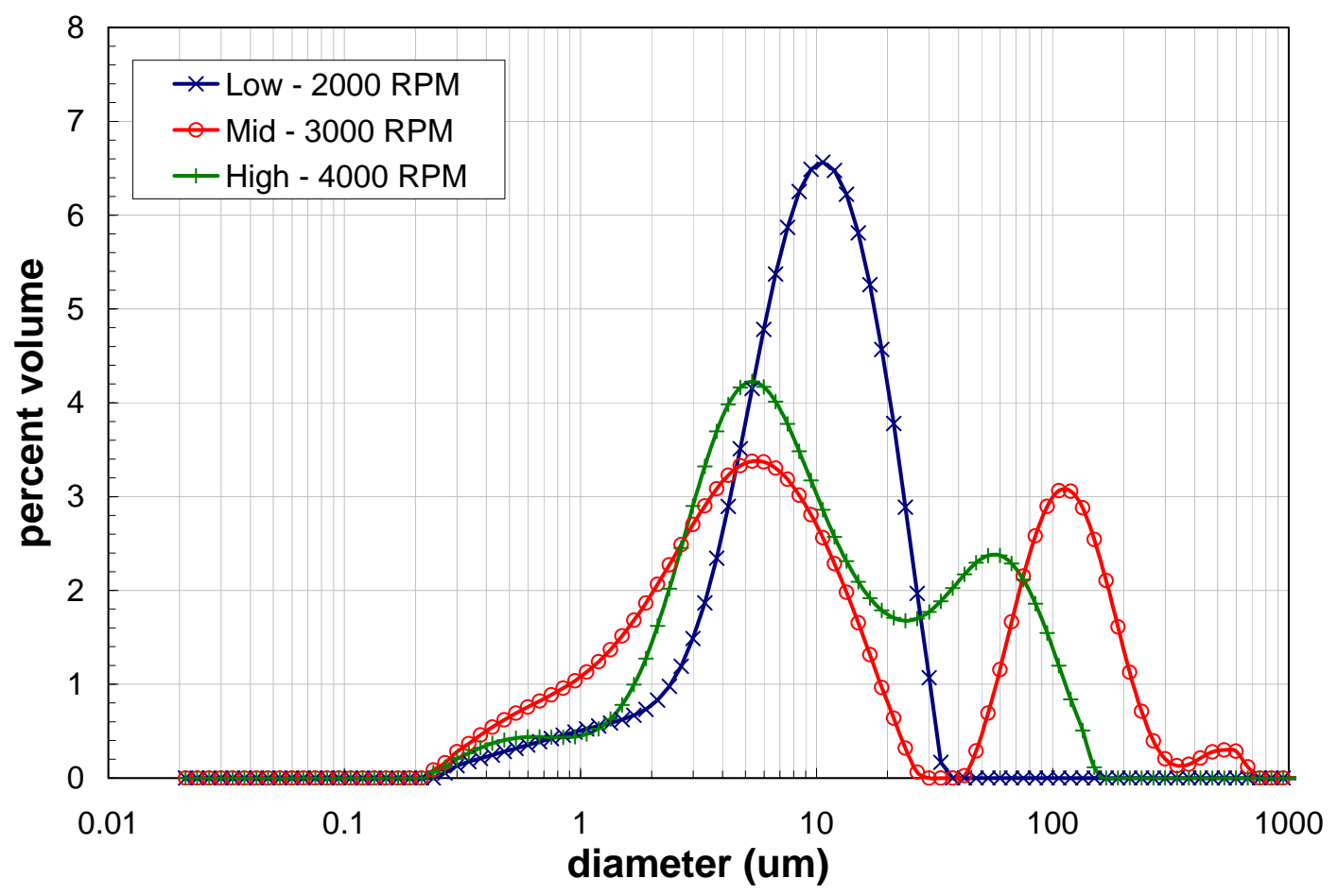

Figure 3.6. Volume Distribution Results for the Primary Washed Group 8 Sample as a Function of Pump Speed

Figure 3.7 shows the PSD for the duplicate washed Group 8 sample as a function of pump speed. Unlike the primary sample, the PSD distribution for all pump speeds was continuous and uni-modal with a range of 0.2 to $170 \mu \mathrm{m}$ with peak maxima at 30,10 , and $7 \mu \mathrm{m}$ for 2000,3000 , and 4000 RPM, respectively. As

(a) Agitation from various levels of sonication could not be assessed because the sonicator was out of service. 
the pump speed was increased from 3000 to 4000 RPM, a relative increase was seen in the 20 - to $170-\mu \mathrm{m}$ population with a corresponding decrease in the peak diameter.

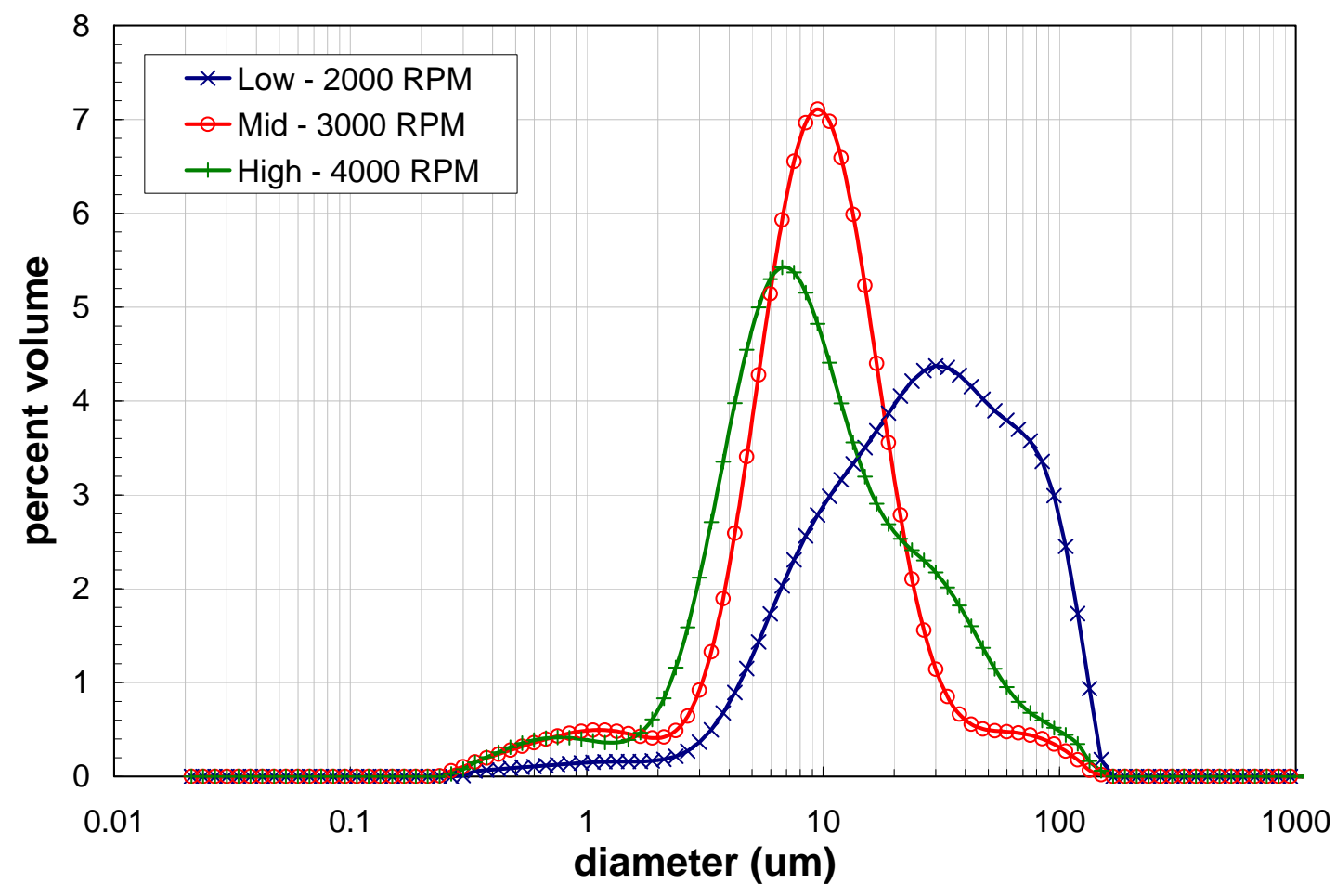

Figure 3.7. Volume Distribution Result for the Duplicate Washed Group 8 Sample as a Function of Pump Speed

Table 3.8 presents cumulative oversize diameters corresponding to the $10^{\text {th }}, 50^{\text {th }}$, and $90^{\text {th }}$ volume percentiles, hereafter referred to as $\mathrm{d}(10), \mathrm{d}(50)$, and $\mathrm{d}(90)$, respectively, of the washed Group 8 solids (primary and duplicate sample dispersions). The behavior of the washed Group 8 particle-size percentile as a function of pump speed was evaluated with the following observations:

- The primary sample d(10) fell between 1.3 and $2.8 \mu \mathrm{m}$, the $\mathrm{d}(50)$ fell between 7.5 and $9.5 \mu \mathrm{m}$, and the $\mathrm{d}(90)$ fell between 20 and $140 \mu \mathrm{m}$.

- The listed diameter percentiles appeared to be sensitive to changes in pump speed. For example, a decrease between 4000 and 2000 RPM increased the d(50) in the primary sample from 8.1 to $9.5 \mu \mathrm{m}$. This was an increase of $17 \%$, which was greater than the overall measurement uncertainty $(\sim \pm 10 \%)$ and thus was significant (and not merely random noise or measurement error).

- The behavior of the duplicate sample PSD with respect to pump speed showed it favored larger diameters for the $\mathrm{d}(10)$ and $\mathrm{d}(50)$ than that of the primary sample at equivalent measurement conditions. 
WTP-RPT-170, Rev. 0

Table 3.8. PSD Analysis Percentile Results of the Washed Group 8 Sample (Primary and Duplicate)

\begin{tabular}{||c|c|c|c|c|c|c|c||}
\hline \hline \multirow{2}{*}{$\begin{array}{c}\text { Measurement } \\
\text { Condition }\end{array}$} & \multirow{2}{*}{$\begin{array}{c}\text { Pump } \\
\text { Speed }\end{array}$} & $\begin{array}{c}\mathbf{d}(\mathbf{1 0}) \\
{[\boldsymbol{\mu m}]}\end{array}$ & $\begin{array}{c}\mathbf{d}(\mathbf{5 0}) \\
{[\boldsymbol{\mu m}]}\end{array}$ & $\begin{array}{c}\mathbf{d}(\mathbf{9 0}) \\
{[\boldsymbol{\mu m}]}\end{array}$ & $\begin{array}{c}\mathbf{d}(\mathbf{1 0}) \\
{[\boldsymbol{\mu m}]}\end{array}$ & $\begin{array}{c}\mathbf{d}(\mathbf{5 0}) \\
{[\boldsymbol{\mu m}]}\end{array}$ & $\begin{array}{c}\mathbf{d}(\mathbf{9 0}) \\
{[\boldsymbol{\mu m}]}\end{array}$ \\
\hline 1 & 3000 & 1.3 & 7.5 & 140 & 3.5 & 9.4 & 23 \\
\hline 2 & 4000 & 2.2 & 8.1 & 65 & 2.9 & 8.4 & 37 \\
\hline 3 & 2000 & 2.6 & 9.5 & 110 & 4.5 & 17 & 67 \\
\hline 4 & 2000 & 2.8 & 9.1 & 20 & 6.6 & 27 & 84 \\
\hline
\end{tabular}

Table 3.9 provides the RPD of the primary and duplicate washed Group 8 samples at $\mathrm{d}(10)$, $\mathrm{d}(50)$, and $\mathrm{d}(90)$. The RPDs were determined according to Equation 3.1,

$$
R P D=\left|\frac{d_{d}(n)-d_{p}(n)}{d_{p}(n)}\right|
$$

where $d_{p}(n)$ and $d_{d}(n)$ are the primary and duplicate cumulative oversize diameters corresponding to the $n^{\text {th }}$ percentile. The listed RPDs indicate that there is a significant difference between samples.

Table 3.9. Percentile RPD Between Primary and Duplicate Washed Group 8 Samples

\begin{tabular}{||c|c|c|c|c||}
\hline \hline \multirow{2}{*}{$\begin{array}{c}\text { Measurement } \\
\text { Condition }\end{array}$} & \multirow{2}{*}{ Pump Speed } & \multicolumn{3}{|c||}{ RPD } \\
\cline { 3 - 5 } & 3000 & $\mathbf{d}(\mathbf{1 0})$ & $\mathbf{d}(\mathbf{5 0})$ & $\mathbf{d}(\mathbf{9 0})$ \\
\hline 1 & 4000 & $35 \%$ & $26 \%$ & $84 \%$ \\
\hline 2 & 2000 & $71 \%$ & $79 \%$ & $42 \%$ \\
\hline 3 & 2000 & $140 \%$ & $190 \%$ & $320 \%$ \\
\hline 4 & \multicolumn{3}{|l}{} \\
\hline
\end{tabular}

For particle-size measurements on the Malvern Mastersizer 2000, RPDs of up to $10 \%$ were generally expected given the overall measurement uncertainty. The results for the washed Group 8 samples showed RPDs that ranged from 3.9 to $320 \%$ depending on the measurement condition and percentile examined. Based on the large number of RPDs greater than $10 \%$ in Table 3.9, there appeared to be a significant difference in the size or size fractionation of the solid species in the primary and duplicate samples. The most significant RPDs occurred in the measurements at 2000 and 3000 RPM, and the RPDs observed in the repeat measurement at 2000 RPM were substantially higher than that in the first measurement at 2000 RPM. These trends indicated that the differences were driven by pump speeds, which indicated that 2000 and 3000 RPM may not have suspended sample solids adequately. In addition, the lower RPD at the highest pump setting of 4000 RPM could have indicated that differences in the state of particle aggregation led to differences in the apparent particle size distribution. High pump speed may have sheared apart aggregates, yielding a more comparable PSD for primary and replicate samples.

Figure 3.8 shows how the differences in the primary and duplicate PSDs described in the preceding paragraphs manifested in differential volume distributions (3000-RPM pump speed). The primary sample displayed a larger $>40-\mu \mathrm{m}$ population with an extended range compared to the duplicate sample. The 
duplicate distribution was uni-modal with its primary peak shifted to higher diameters than the primary sample.

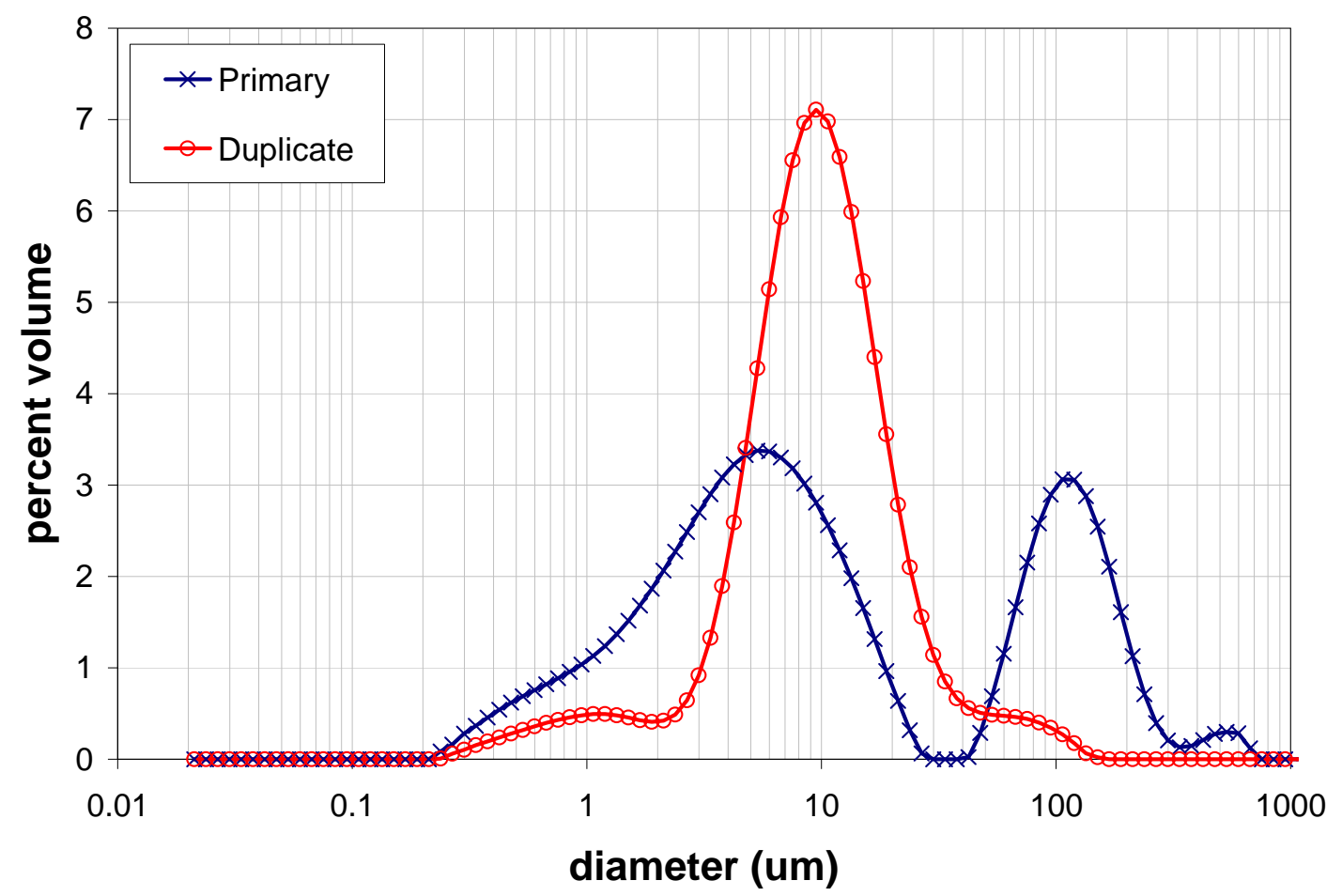

Figure 3.8. Comparison of Primary and Duplicate Sample Differential Volume PSD of Group 8 Initial Characterization Sample at 3000 RPM without Sonication

The washed Group 8 PSD had a broad PSD ranging from $\sim 0.25 \mu \mathrm{m}$ to $>100 \mu \mathrm{m}$. Overall, there appeared to be some large difficult-to-suspend species. These species may have been flocculants, as indicated by larger diameter peak populations in the low pump speeds, which were broken apart at higher pump speeds. There was an apparent size-distribution difference between the primary and duplicate sample. This may have been a result of sub-sampling difficulties due to large, difficult-to-suspend species, such as U-rich particles or influences of flocculation and/or agglomeration.

\subsection{Surface Area}

Testing of duplicate samples $(0.2802 \mathrm{~g}$ and $0.3236 \mathrm{~g})$ for surface area (BET) resulted in $70.7 \pm 4.5 \mathrm{~m}^{2} / \mathrm{g}$. The overall experimental uncertainty was estimated to be $\pm 10 \%$.

\subsection{Crystal Form and Habit}

The crystal form and habit of the washed solids were evaluated from the XRD pattern, SEM imaging, and TEM imaging as discussed in the following sections. 


\subsubsection{X-Ray Diffraction Pattern Evaluation}

The XRD mount of the washed Group 8 solids was prepared with rutile as the internal standard. The raw XRD pattern is shown in Figure 3.9. The broad hump from about 10 to 35 degrees 2-theta in Figure 3.9 indicated that the washed Group 8 solids probably contained some amount of amorphous materials.

The background-subtracted pattern with phase identification using stick figures to identify associated peaks is shown in Figure 3.10. In this case, the phase showing the greatest peak intensity is at the top of the stick figures display (except the internal standard, which is shown topmost). Phases present at a lower peak area/height are shown in decreasing order down the display. The International Centre for Diffraction Data (ICDD) card identification is also shown with each identified phase in the figure. 


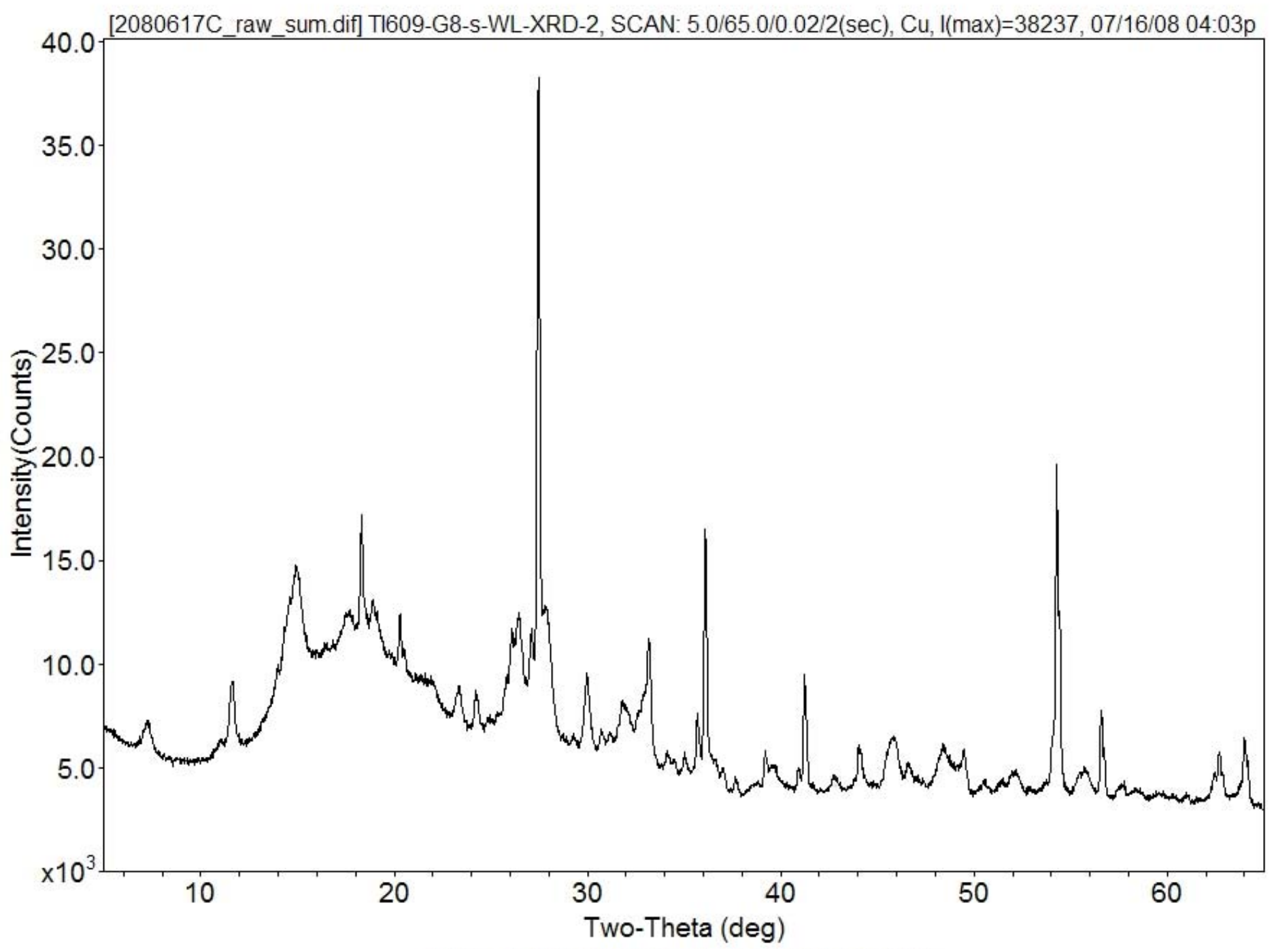

Figure 3.9. Raw Data XRD Pattern of Washed Group 8 FeCN Sludge with Rutile (Internal Standard) 


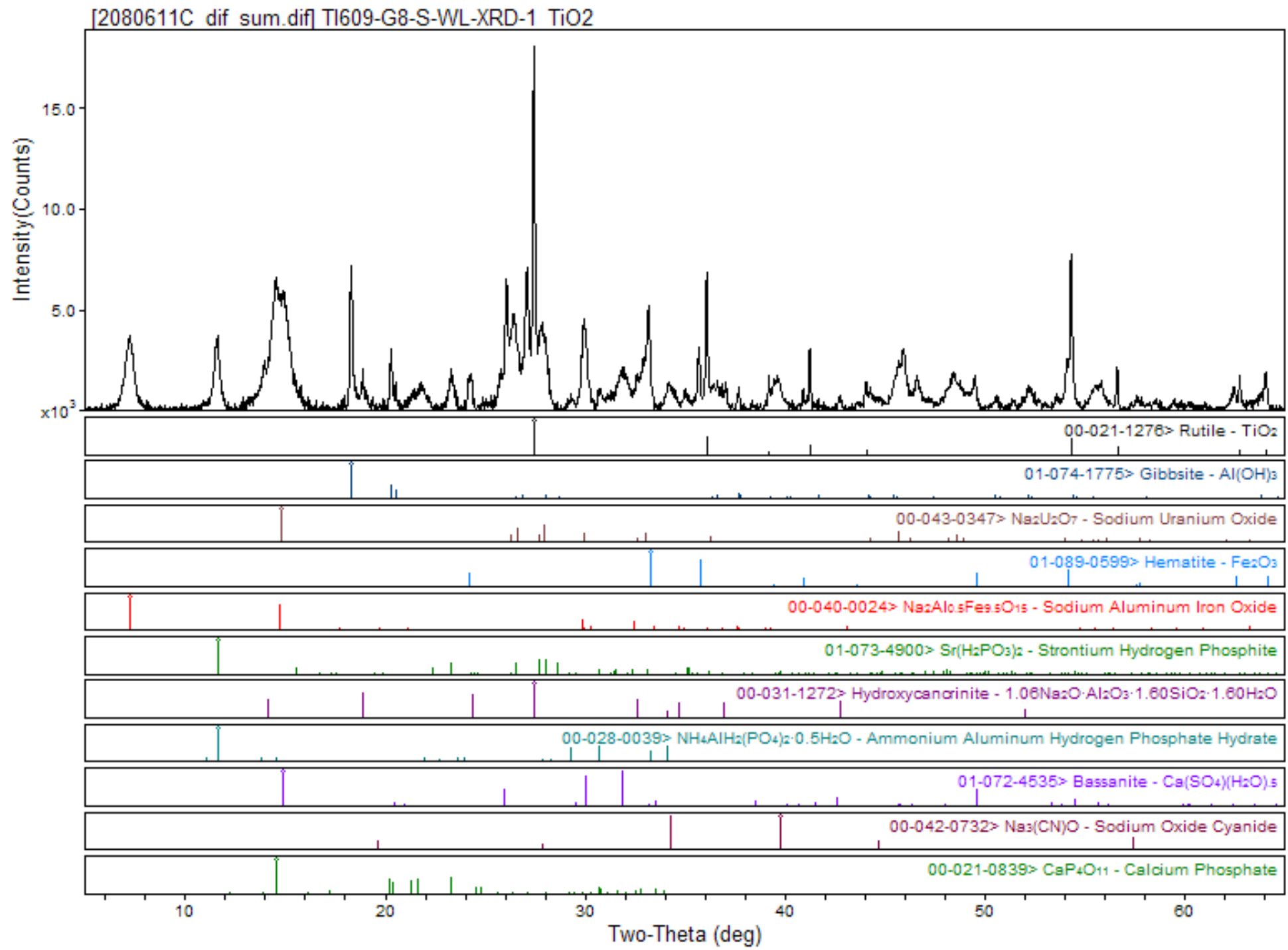

Figure 3.10. Background-Subtracted Pattern with Stick-Figure Peak Identification of Washed Group 8 FeCN Sludge 
The phases shown in Figure 3.10 are also provided in Table 3.10 with a brief discussion of how the reference diffraction pattern fit the observed Group 8 diffraction pattern. Overall, the combined phases matched the observed diffraction pattern well. Phases containing nickel could not be identified; NiO and $\mathrm{Ni}(\mathrm{OH})_{2}$ were specifically evaluated and were excluded as possible forms in Group 8.

Table 3.10. Phase Identification and Discussion

\begin{tabular}{|c|c|c|c|}
\hline Phase & Formula & Discussion & ICDD Card \\
\hline Gibbsite & $\mathrm{Al}(\mathrm{OH})_{3}$ & $\begin{array}{l}\text { Good match to major and } \\
\text { minor peaks }\end{array}$ & $74-1775$ \\
\hline Sodium Uranium Oxide & $\mathrm{Na}_{2} \mathrm{U}_{2} \mathrm{O}_{7}$ & $\begin{array}{l}\text { Excellent match to major } \\
\text { and minor peaks }\end{array}$ & $43-347$ \\
\hline Hematite & $\mathrm{Fe}_{2} \mathrm{O}_{3}$ & $\begin{array}{l}\text { Excellent match to major } \\
\text { and minor peaks }\end{array}$ & $89-599$ \\
\hline $\begin{array}{l}\text { Sodium Aluminum Iron } \\
\text { Oxide }\end{array}$ & $\mathrm{Na}_{2} \mathrm{Al}_{0.5} \mathrm{Fe}_{9.5} \mathrm{O}_{15}$ & $\begin{array}{l}\text { Only possible match, given } \\
\text { chemistry restrictions, for } \\
\text { low angle peak at } 7.1^{\circ} \\
\text { 2-theta }\end{array}$ & $40-0024$ \\
\hline $\begin{array}{l}\text { Strontium Hydrogen } \\
\text { Phosphite }\end{array}$ & $\mathrm{Sr}\left(\mathrm{H}_{2} \mathrm{PO}_{3}\right)_{2}$ & Acceptable match & $73-4900$ \\
\hline Hydroxycancrinite & $\begin{array}{l}1.06 \mathrm{Na}_{2} \mathrm{O} \cdot \mathrm{Al}_{2} \mathrm{O}_{3} \cdot 1.60 \mathrm{SiO}_{2} \\
1.60 \mathrm{H}_{2} \mathrm{O}\end{array}$ & $\begin{array}{l}\text { Good match to all minor } \\
\text { peaks }\end{array}$ & $31-1272$ \\
\hline $\begin{array}{l}\text { Ammonium Aluminum } \\
\text { Hydrogen Phosphate } \\
\text { Hydrate }\end{array}$ & $\mathrm{NH}_{4} \mathrm{AlH}_{2}\left(\mathrm{PO}_{4}\right)_{2} \cdot 0.5 \mathrm{H}_{2} \mathrm{O}$ & Possible fit & $28-0039$ \\
\hline Bassanite $^{(\mathrm{a})}$ & $\mathrm{Ca}\left(\mathrm{SO}_{4}\right)\left(\mathrm{H}_{2} \mathrm{O}\right)_{0.5}$ & Good match as minor phase & $72-4535$ \\
\hline Sodium Oxide Cyanide & $\mathrm{Na}_{3}(\mathrm{CN}) \mathrm{O}$ & $\begin{array}{l}\text { Good fit; unable to } \\
\text { determine if it can form in } \\
\text { the given conditions }\end{array}$ & $42-0732$ \\
\hline $\begin{array}{l}\text { Sodium Uranyl } \\
\text { Carbonate }^{(\mathrm{b})}\end{array}$ & $\mathrm{Na}_{4}\left(\mathrm{UO}_{2}\right)\left(\mathrm{CO}_{3}\right)_{3}$ & Good fit as minor phase & $40-8052$ \\
\hline Calcium Phosphate & $\mathrm{CaP}_{4} \mathrm{O}_{11}$ & Possible fit & 21-0839 \\
\hline \multicolumn{4}{|c|}{$\begin{array}{l}\text { (a) Sample was dried over Drierite, which is a calcium sulfate compound; therefore, this could be an } \\
\text { impurity from the sample preparation process. } \\
\text { (b) Sodium uranyl carbonate is not shown in Figure 3.10, but was found on a duplicate preparation of } \\
\text { the sample and in the product from leaching in the CUF. }\end{array}$} \\
\hline
\end{tabular}

\subsubsection{Scanning Electron Microscopy}

Several SEM images of the washed Group 8 solids are shown in Figure 3.11 through Figure 3.15. The washed FeCN sludge particles tended to agglomerate into multi-component masses. Figure 3.11c clearly shows bundled hexagonal and bladed rods bound with smaller $<1-\mu \mathrm{m}$ particles. Figure 3.13 shows a population of spherical composites composed of spherical components. 

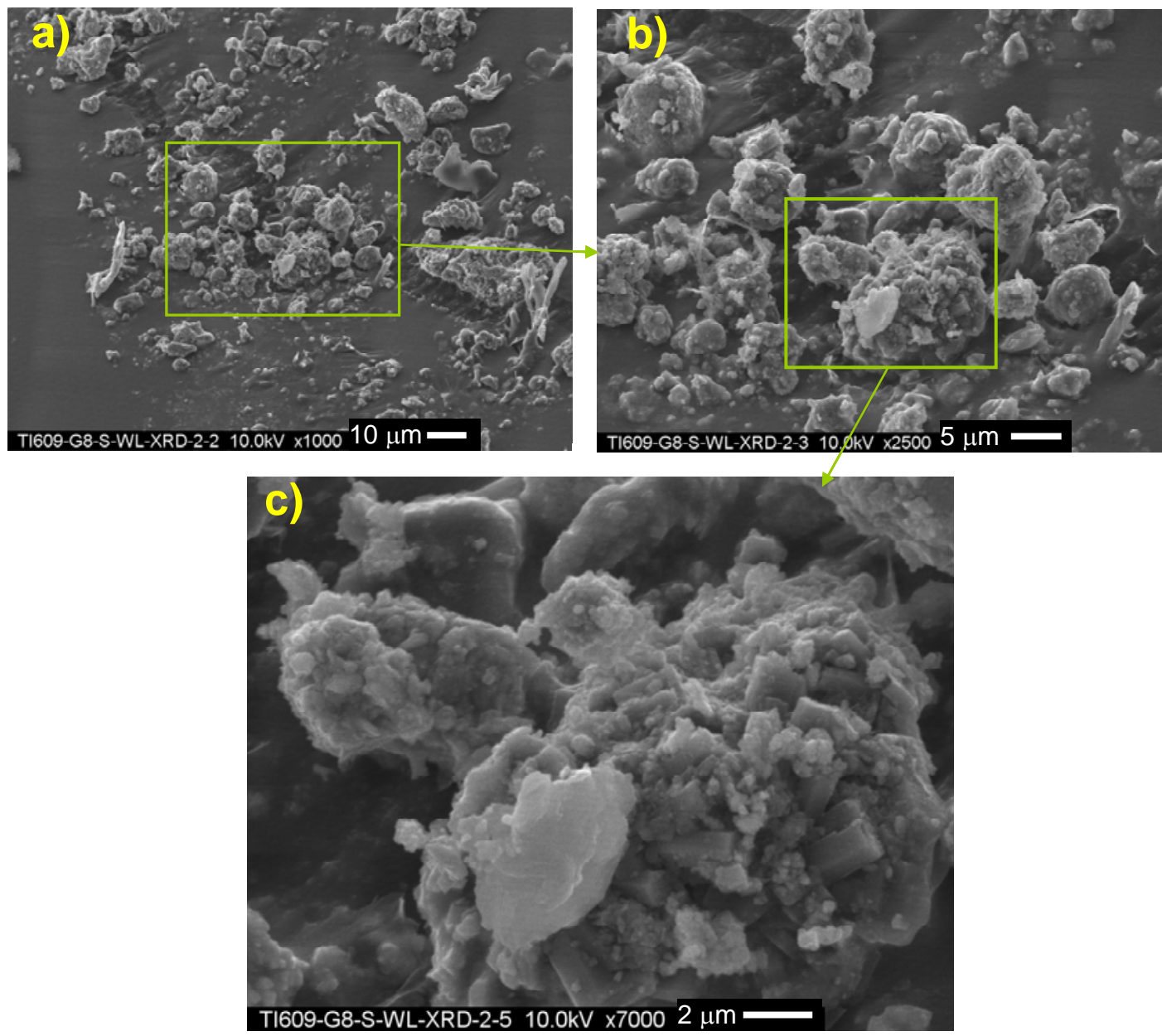

Figure 3.11. SEM Images of Washed Group 8 FeCN Sludge

(a) $1000 \times$; (b) $2500 \times$; (c) $7000 \times$

The images shown in Figure 3.12 were taken in a normal secondary electron imaging (image a and c) and back-scattered electron imaging (image b). The high-Z (high atomic mass) particles are well manifested as very bright spots in the backscattered image. Several bright spots were identified as U-rich particles using electron-dispersive spectroscopy (EDS); the large U-rich particle measured 25.8 microns in one dimension. Another moderately bright spot was identified as primarily Sr. These are indicated in Figure 3.12b. 


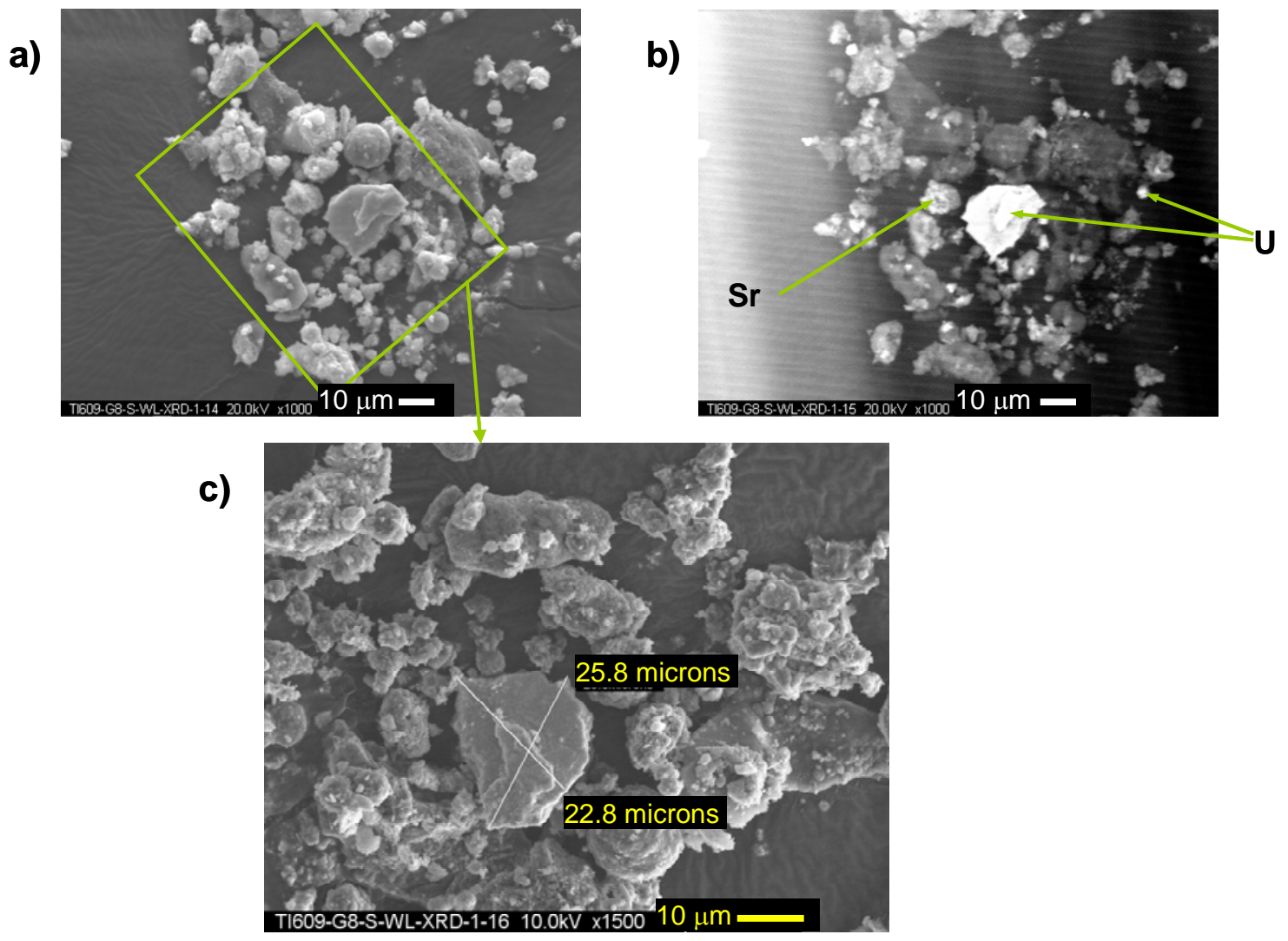

Figure 3.12. Electron Imaging of Washed Group 8 FeCN Sludge Showing U-Rich Particle

(a) Secondary electron imaging, 1000×

(b) Backscatter electron imaging (bright spots indicate high-Z materials), 1000×

(c) Secondary electron imaging, $1500 \times$

Selected samples were further analyzed using EDS. Evaluation of the spheres (e.g., as in Figure 3.13e) with EDS resulted in high $\mathrm{C}$ and $\mathrm{O}$ signals with virtually no other elemental information apparent. Therefore, their identities could not be determined. Other particles showed a rich diversity of structure and complexity as indicated in Figure 3.14. Spot 3 contained $\mathrm{O}>\mathrm{Al} \sim \mathrm{Na} \geq \mathrm{Si}$ (consistent with hydroxycancrinite) $>>\mathrm{Fe}>\mathrm{Ca}>\mathrm{U} \sim \mathrm{P}$. Spot 10 in this figure shows the following elements in order of decreasing atomic percent: $\mathrm{O}>\mathrm{Al}>>\mathrm{Ca}>\mathrm{Fe} \sim \mathrm{P} \geq \mathrm{Na} \sim \mathrm{U} \geq \mathrm{Ni}$. Spot 5 contained $\mathrm{O}>>\mathrm{Al}>\mathrm{Na} \geq \mathrm{Fe}>$ $\mathrm{Ca}>\mathrm{P}>\mathrm{Ni}=\mathrm{Si}>\mathrm{U}$. Spot 9 contained $\mathrm{O}>\mathrm{Fe}>\mathrm{Sr}>\mathrm{Ca} \sim \mathrm{Al} \sim \mathrm{Ni}>\mathrm{P}>\mathrm{U}$. In contrast, spot 12 was composed of $\mathrm{O} \geq \mathrm{Fe}$ (consistent with lepidocrocite and hematite) $>>\mathrm{Ca}=\mathrm{Ni} \sim \mathrm{Al}>\mathrm{Si}>\mathrm{P} \sim \mathrm{U}>\mathrm{Bi}$.

Figure 3.15 was similarly evaluated with respect to component atom percent. Spot 1 was clearly dominated by $\mathrm{Fe} \sim \mathrm{O} \gg \mathrm{Ca} \gg \mathrm{Na} \sim \mathrm{Al}, \sim \mathrm{U} \sim \mathrm{Ni} \sim \mathrm{P} \sim \mathrm{Sr}$. Spot 4 was composed of $\mathrm{O}>>\mathrm{Ca}>>\mathrm{P}>\mathrm{Na}$ $>\mathrm{U}>\mathrm{Sr}$; the XRD did not identify a major or minor phase containing Ca. Spot 8 was essentially composed of $\mathrm{O}$ and $\mathrm{Al}$, consistent with gibbsite. Spot 11 resulted in $\mathrm{O}>>\mathrm{Na}>\mathrm{Al} \sim \mathrm{Si}$ (consistent with hydroxycancrinite or zeolite) $>>\mathrm{Fe} \sim \mathrm{U} \sim \mathrm{P} \sim \mathrm{Ca}$.

A specific phase containing $\mathrm{Na}$ and $\mathrm{U}$ (sodium uranium oxides as identified by XRD) was not identified in the SEM-EDS analysis. The U-bearing phases identified by XRD were either obscured by other 
phases, randomly not mounted on the SEM stub, or were more complex (incorporating other minerals in the lattice structure) yet fitting the sodium uranium oxide diffraction patterns.

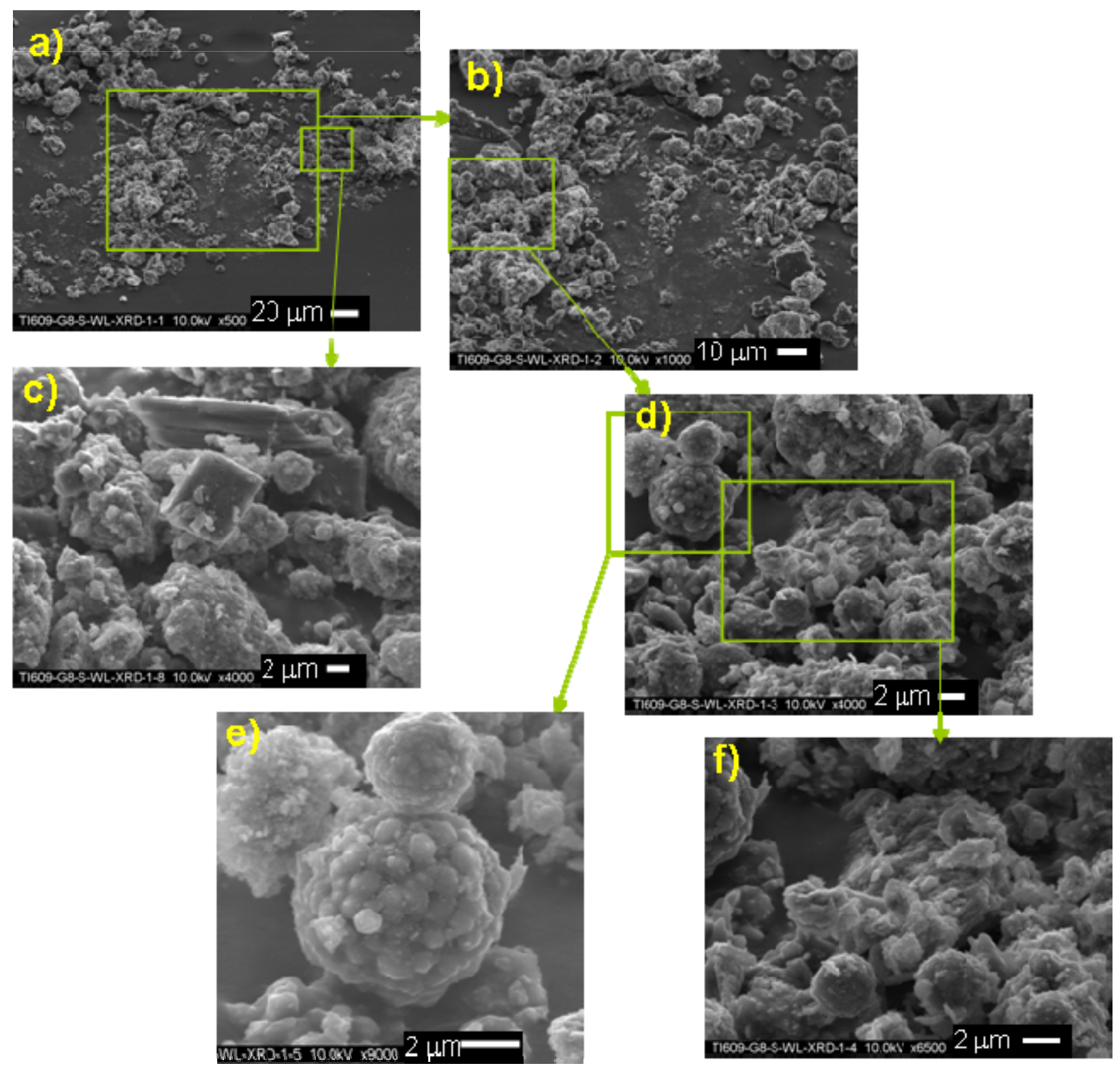

Figure 3.13. SEM Images of Washed Group 8 FeCN Sludge
(a) $500 \times$
(b) $1000 \times$; (c)
c) $4000 \times$; (d)
(d) $4000 \times$; (e) $9000 \times$; (f) $6500 \times$ 

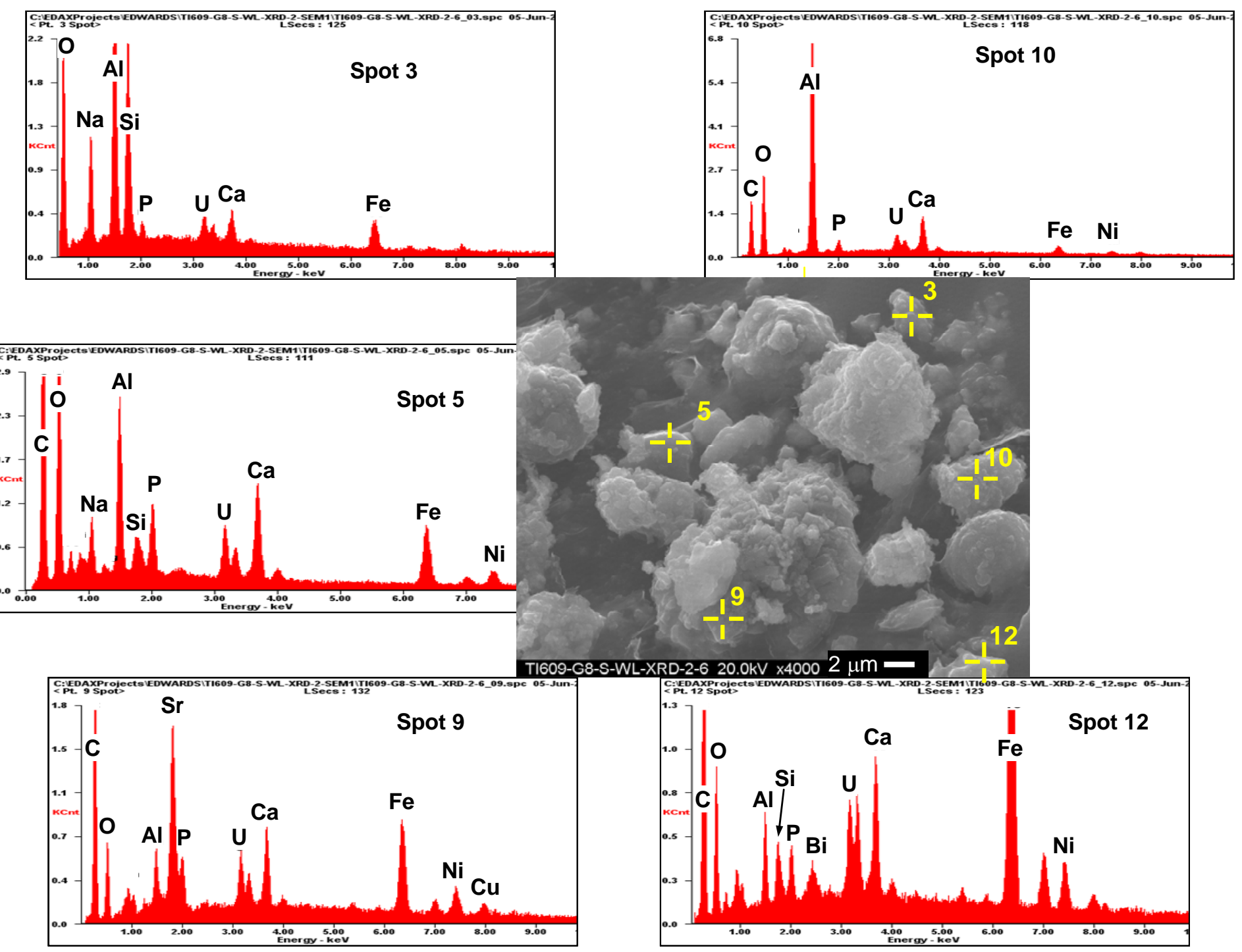

Figure 3.14. SEM Images with EDS Evaluation of Group 8 FeCN Washed Sludge, 4000× 

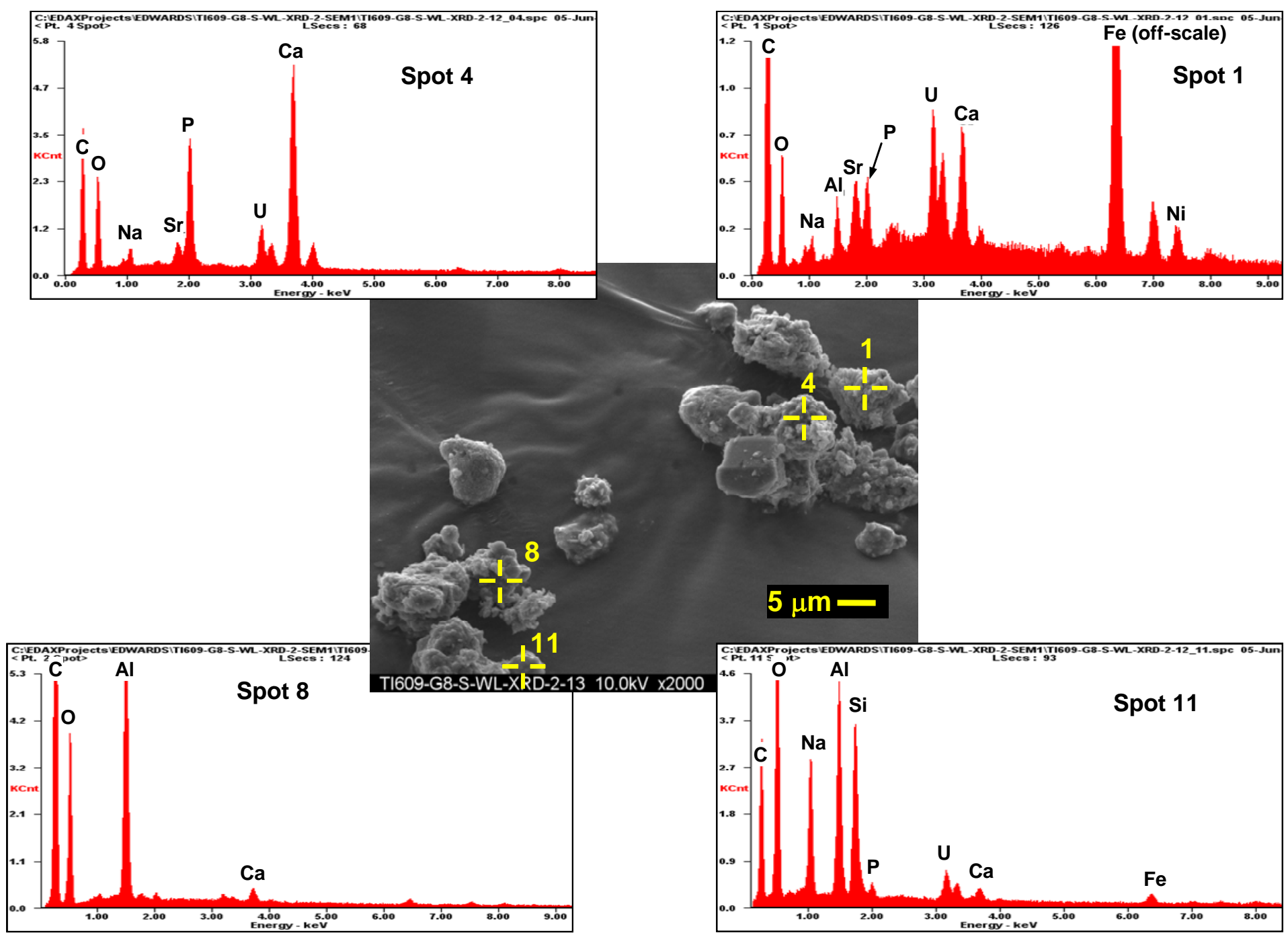

Figure 3.15. SEM Imaging of Washed Group 8 FeCN Sludge with EDS Analysis, 2000×

Note: EDS examination was conducted at $20 \mathrm{kV}$; the $10 \mathrm{kV}$ SEM image is shown for better clarity of the particle morphology. 


\subsubsection{Transmission Electron Microscopy}

The major advantage of TEM over XRD and SEM-EDS analyses is that TEM more effectively isolates a particular phase such that compositional and structural information specific to the phase can be better resolved. Conventional TEM imaging and spectroscopic analysis has been used previously on Hanford tank waste samples. In this series of studies, much more advanced and modern methods have been brought to bear on the tank sludge samples; including scanning transmission electron microscopy (STEM) and high angle annular dark field (HAADF), which permits easy location of heavy (high Z or high atomic mass) phases, and electron energy loss methods. Electron energy-loss spectroscopy (EELS) and energy filtered TEM (EFTEM) are useful techniques because of the superior energy resolution that permits determination of oxidation states. Subtle variation in the structures of phases can result in changes in the EELS signals.

Several different types of phases were observed in the washed Group 8 sludge sample. These included uranium oxide, iron oxide, strontium phosphate, and cancrinite. In Figure 3.16, a STEM-HAADF image shows a typical particle agglomerate that contains several different phase compositions.
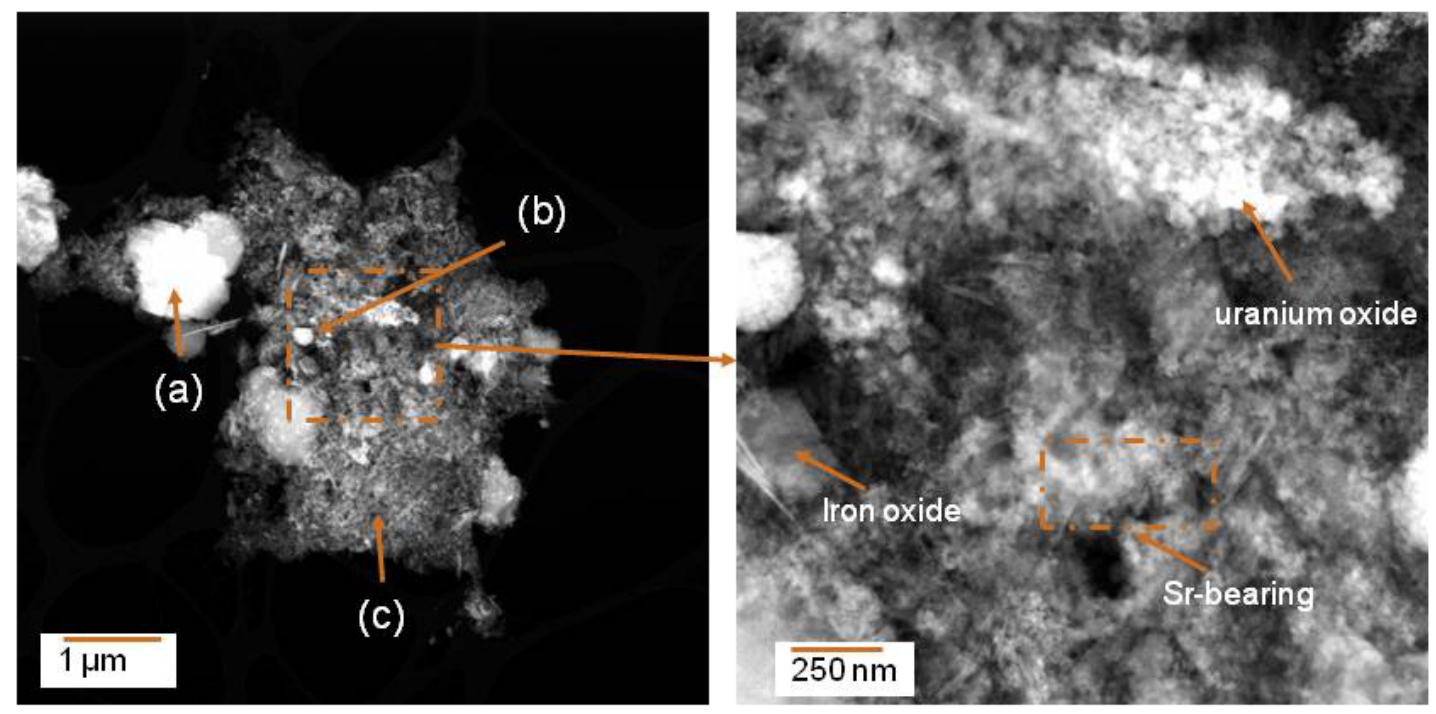

Figure 3.16. Low Magnification STEM-HAADF View of Washed Group 8 Particles (left) and High Magnification Image Showing Iron-, Strontium-, and Uranium-Bearing Particles (right)

The HAADF image in Figure 3.16 shows a highly heterogeneous agglomerate. In the lower magnification image, regions marked as (a) through (c) are iron oxide, uranium oxide, and strontium phosphate, respectively. In the higher magnification image (Figure 3.16 right), iron oxide, strontium-rich, and uranium oxide particles are indicated. The aggregate is highly heterogeneous with individual particles in the nano-meter size range. In the TEM images, the size of the individual particles can be seen more clearly than with other techniques. There is also a wide range of particle densities, surface areas, and particle morphologies in these larger agglomerates. 
Figure 3.17 shows a high-resolution image of a uranium phase together with a selected area electron diffraction (SAED) pattern of a uranium phase particle and EDS analysis. The pattern and image exhibit well-defined features. The lattice spacing in the TEM image may reflect a well-ordered and large unit cell. The EDS analysis does not indicate the presence of sodium or other elements in the phase. Species that would be undetectable and possibly present include carbonate and nitrate. The diffraction pattern was relatively stable, which is generally not indicative of a $\mathrm{U}(\mathrm{VI})$ phase, such as clarkeite. Further analysis of the uranium phases was conducted with EELS, which provided further proof that the uranium phase was not a U(VI) phase. Electron diffraction from the uranium oxide phase was not distinctive. Table 3.11 displays the relative d-spacing in the sample with those from known uranium phases. Neither clarkeite, $\mathrm{U}_{3} \mathrm{O}_{8}$, nor uraninite demonstrated good matching to the d-spacings. Uranium carbonates and nitrates were evaluated but did not provide good matches to the diffraction data (these types of phases are not included in Table 3.11). The best match was with meta-schoepite; however, the electron beam stability and EELS observations tended to refute this identification. The basal plane structures of $\mathrm{U}_{3} \mathrm{O}_{8}$ and the schoepites have strong similarities; hence, it is most likely that the uranium phase is related to $\mathrm{U}_{3} \mathrm{O}_{8}$.
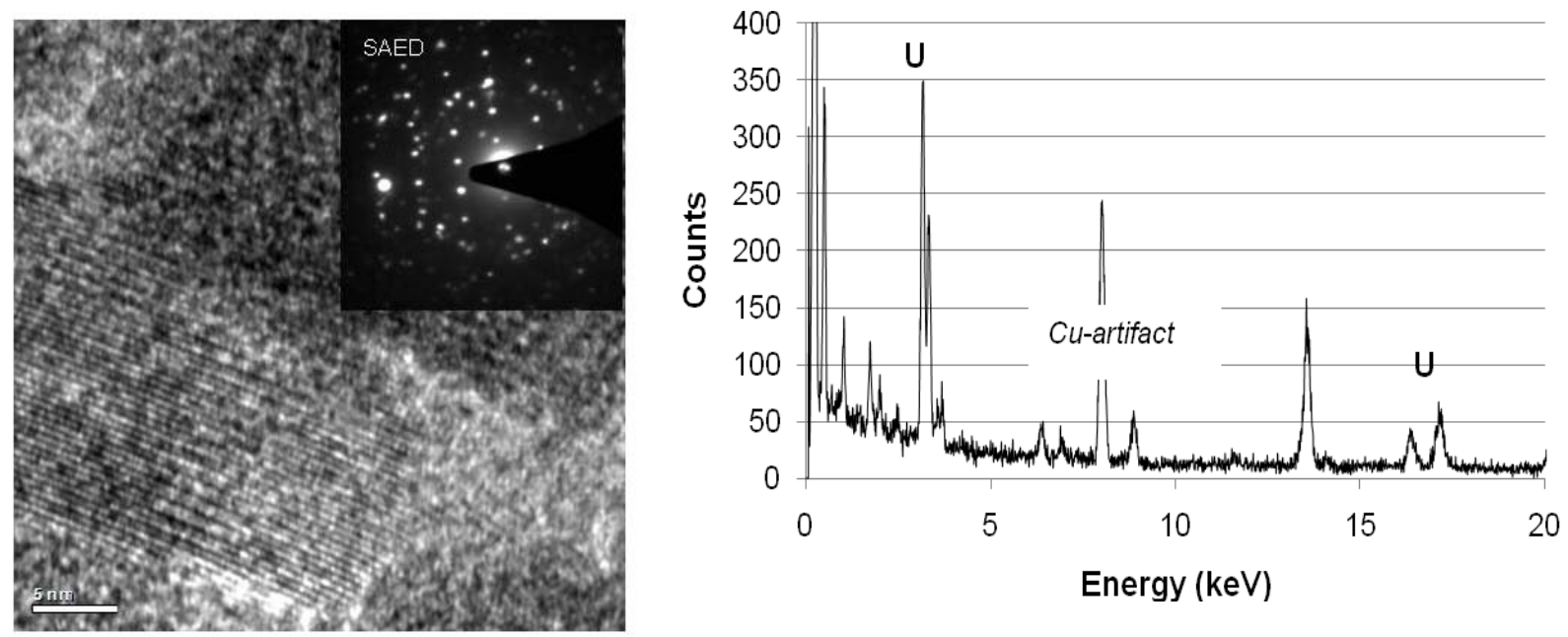

Figure 3.17. High Resolution Image of Uranium Phase in Washed Group 8 Sludge; Inset is a Selected Area Electron Diffraction Pattern and the EDS Analysis is Shown to the Right 
Table 3.11. Measured Electron Diffraction Reflections from the Uranium Phase Compared Against Possible Candidate Phases

\begin{tabular}{|c|c|c|c|c|}
\hline \multicolumn{5}{|c|}{ d-spacing ( $(\AA)$} \\
\hline $\begin{array}{l}\text { Group } 8 \\
\text { Sludge } \\
\text { Observed } \\
\end{array}$ & $\begin{array}{c}\text { Clarkeite } \\
\text { (Finch and } \\
\text { Ewing, 1997) }\end{array}$ & $\begin{array}{c}\text { Jolietite } \\
\text { PDF 29-1378 }\end{array}$ & $\begin{array}{c}\text { Meta-schoepite } \\
\text { (Finch et al. } \\
\text { 1997) }\end{array}$ & $\begin{array}{c}\mathrm{U}_{3} \mathrm{O}_{8} \\
\text { PDF 23-1460 }\end{array}$ \\
\hline 9.709 & & & 8.64 & 8.67 \\
\hline 7.752 & & 8.0947 & $7.33 / 8.33$ & \\
\hline \multicolumn{5}{|l|}{7.57} \\
\hline 6.207 & 5.903 & & 6.439 & \\
\hline 5.473 & & & 5.510 & \\
\hline 5.02 & & & 5.035 & \\
\hline 4.88 & & & 4.871 & \\
\hline 4.695 & & & 4.452 & \\
\hline 3.799 & & 3.7612 & 3.829 & 3.53 \\
\hline 3.080 & 2.945 & & 2.959 & \\
\hline 2.595 & 2.707 & 2.5908 & 2.585 & 2.6 \\
\hline 2.51 & & & 2.529 & \\
\hline 2.44 & 2.46 & & 2.462 & \\
\hline 2.171 & & 2.1799 & 2.1771 & \\
\hline 2.023 & 2.031 & 2.0398 & 2.0342 & 2.0072 \\
\hline 1.860 & 1.86 & 1.8824 & 1.8775 & 1.907 \\
\hline 1.703 & 1.7 & 1.6933 & 1.6998 & 1.734 \\
\hline 1.350 & 1.35 & 1.3281 & & 1.344 \\
\hline
\end{tabular}

The STEM-HAADF image in Figure 3.16 also indicated the presence of an iron oxide. The particles tended to be larger euhedral phases that gave well-defined single-crystal diffraction patterns. A selected area electron diffraction pattern along a major zone axis from one of the iron oxide particles is shown in Figure 3.18. The pattern was indexed as being taken along the $\mathbf{B}[111]$ direction of hematite. Several other STEM-HAADF images were obtained from the Group 8 sludge and all illustrated the highly heterogeneous nature of the sludge sample. In Figure 3.19, the STEM-HAADF image shows two major phases, the uranium oxide and iron oxide. 
WTP-RPT-170, Rev. 0

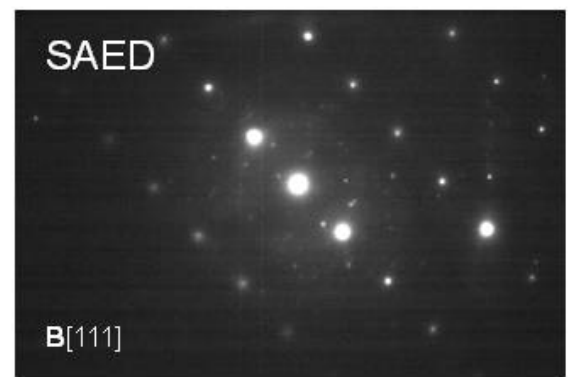

Figure 3.18. Electron Diffraction Pattern Along the $\mathbf{B}[111]$ Zone Axis of Iron Oxide Phase in Washed Group 8 Solids

(Note: The observed diffraction pattern agreed with a simulated diffraction pattern of hematite.)
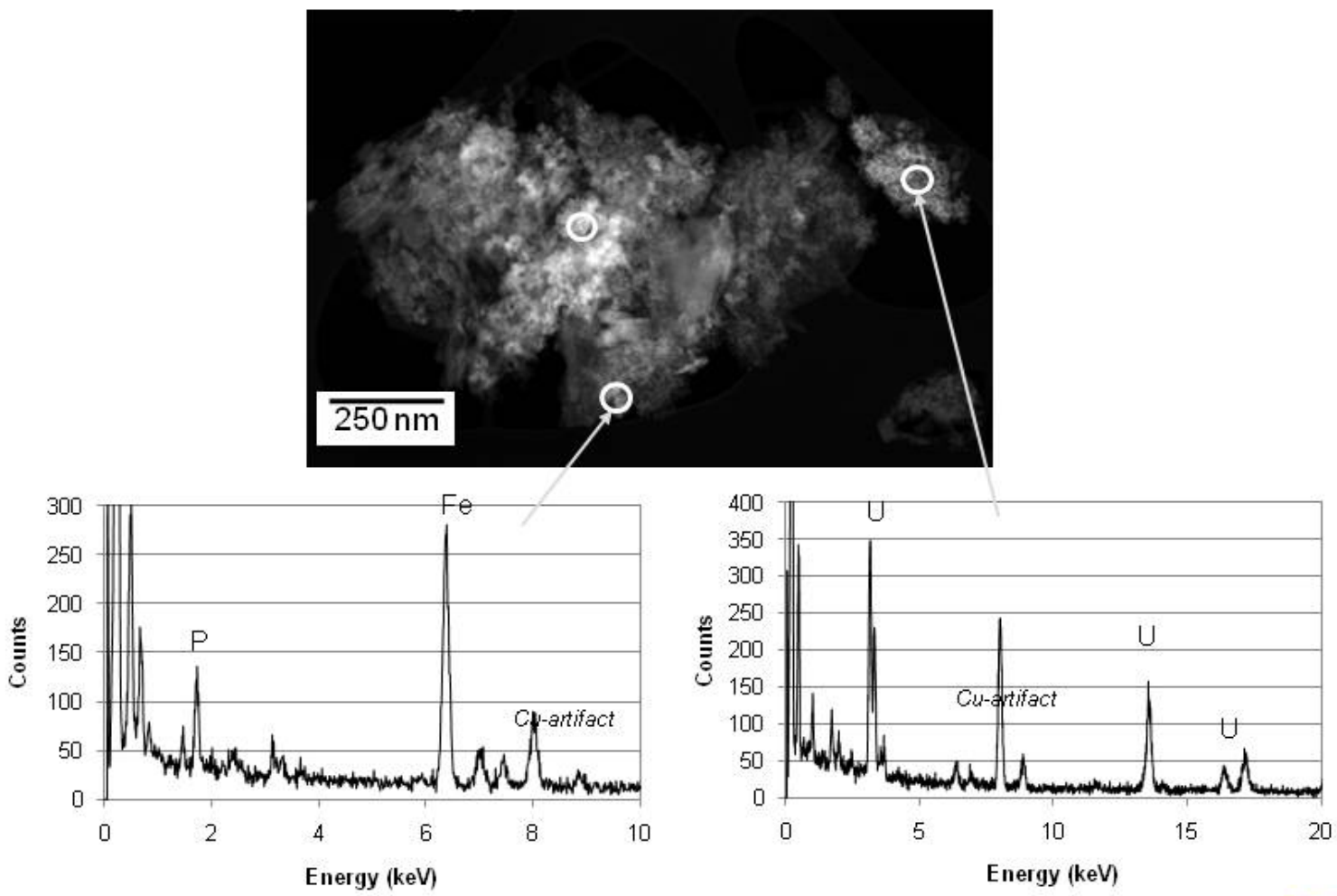

Figure 3.19. STEM-HAADF Image and EDS Analyses of an Agglomerate of Particles

The EDS of two points analyzed are shown in Figure 3.19. These were a uranium oxide and an iron oxide point. Again, the uranium oxide did not indicate the presence of sodium or other elements in high concentrations. The marked point on Figure 3.19 without an indicated EDS analysis was from a mixed iron-nickel phase. Other elements were also detected that may originate from neighboring areas. The iron-nickel phase may be associated with a $\mathrm{NiFe}(\mathrm{CN})_{6}{ }^{2-}$ complex. The electron energy-loss analysis of the three main phases observed in these large agglomerates is shown in Figure 3.20. The plot shows three EELS analyses of oxygen K-edges from the iron, uranium, and strontium phases. Both the strontium and iron spectra exhibit broad edges whereas the uranium edge has two well-defined peaks. 
WTP-RPT-170, Rev. 0

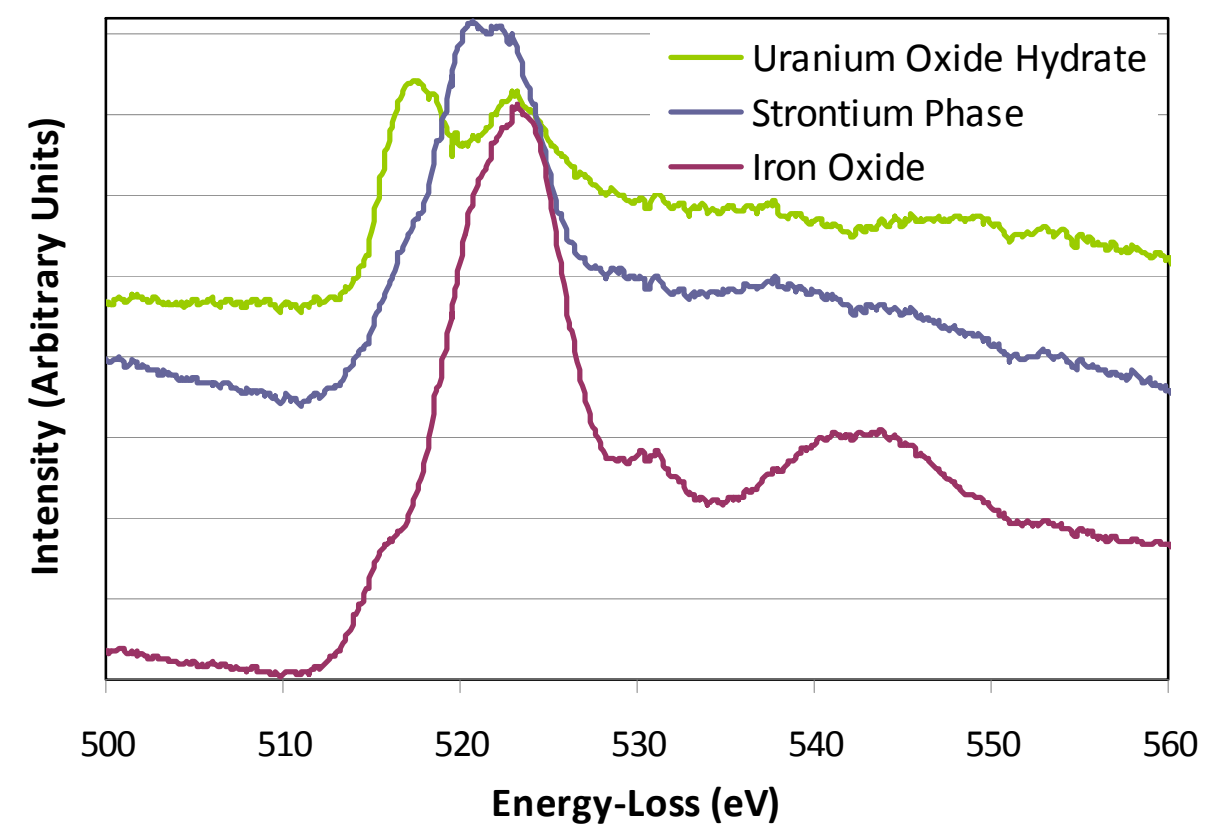

Figure 3.20. Electron Energy-Loss Spectra of the Oxygen K-Edge from Three Phases in the Washed Group 8 Tank Sludge

Theoretically, the oxygen K edge absorption spectra can reveal the nature of the metal-O bond in oxides. For example, in $\mathrm{CeO}_{2}$, the oxygen $\mathrm{K}$-edge is made up of sharp peaks that are from the few $\mathrm{Ce}-\mathrm{O}$ bonds in the structure. Similarly, with $\mathrm{UO}_{2}$, sharp peaks corresponding to distinctive U-O environments can be detected. In contrast, a broad spectral peak is found in U(VI) phases, associated with several different $\mathrm{O}-\mathrm{U}$ bonding environments in the structure and the occurrence of $\mathrm{O}-\mathrm{H}$ bonds due to the presence of bound water and $\mathrm{OH}$ groups in the structure. In Figure 3.20, both the near-edge structures from the $\mathrm{Sr}$ and Fe phases are broad and poorly defined. This may be because oxygen is present in several different environments in these phases. For example, in strontium phosphate, there will be P-O bonds but also $\mathrm{H}-\mathrm{O}$ bonds from hydrated species. The observed uranium phase does not support the occurrence of a hydrated U(VI) phase. Uranyl U(VI) phases have been observed in some sludges. For instance, Deutsch et al. (2005) have reported the occurrence of čejkaite $\left[\mathrm{Na}_{4}\left(\mathrm{UO}_{2}\right)\left(\mathrm{CO}_{3}\right)_{3}\right]$ in Hanford tanks C-203 and C-204, and uranyl phosphates have been observed in the TBP sludge wastes.

The heterogeneous nature of the Group 8 sample can be clearly seen in Figure 3.21, where the individual phases can be identified. The elongated phosphorus-bearing particles are $\sim 50 \mathrm{~nm}$ thick and 100 to $200 \mathrm{~nm}$ in length. In Figure 3.22, the energy-filtered images reveal the strontium and uranium phases. The filtered image for strontium used the Sr-K edge, which is weak but well separated from other edges. The image was obtained by averaging several acquisitions. The uranium edges tend to be sharper as they use the much stronger O-edges at around $100 \mathrm{eV}$. The strontium phase was examined with highresolution imaging and revealed a complex modulated structure (see Figure 3.23). The arrow on Figure 3.23 points to the modulated structure, which suggests superstructure ordering. The phase was fairly stable in the electron beam. The EELS analysis of this phase was used to see if any zirconium could be detected (it might be anticipated that $\mathrm{Zr}$ from the decay of ${ }^{90} \mathrm{Sr}$ might be present if the phase was sufficiently old). Zirconium was not observed; however, the phase clearly contained phosphorus, 
indicating that it was a strontium phosphate or strontium hydrogen phosphite (as possibly indicated by $\mathrm{XRD})$.

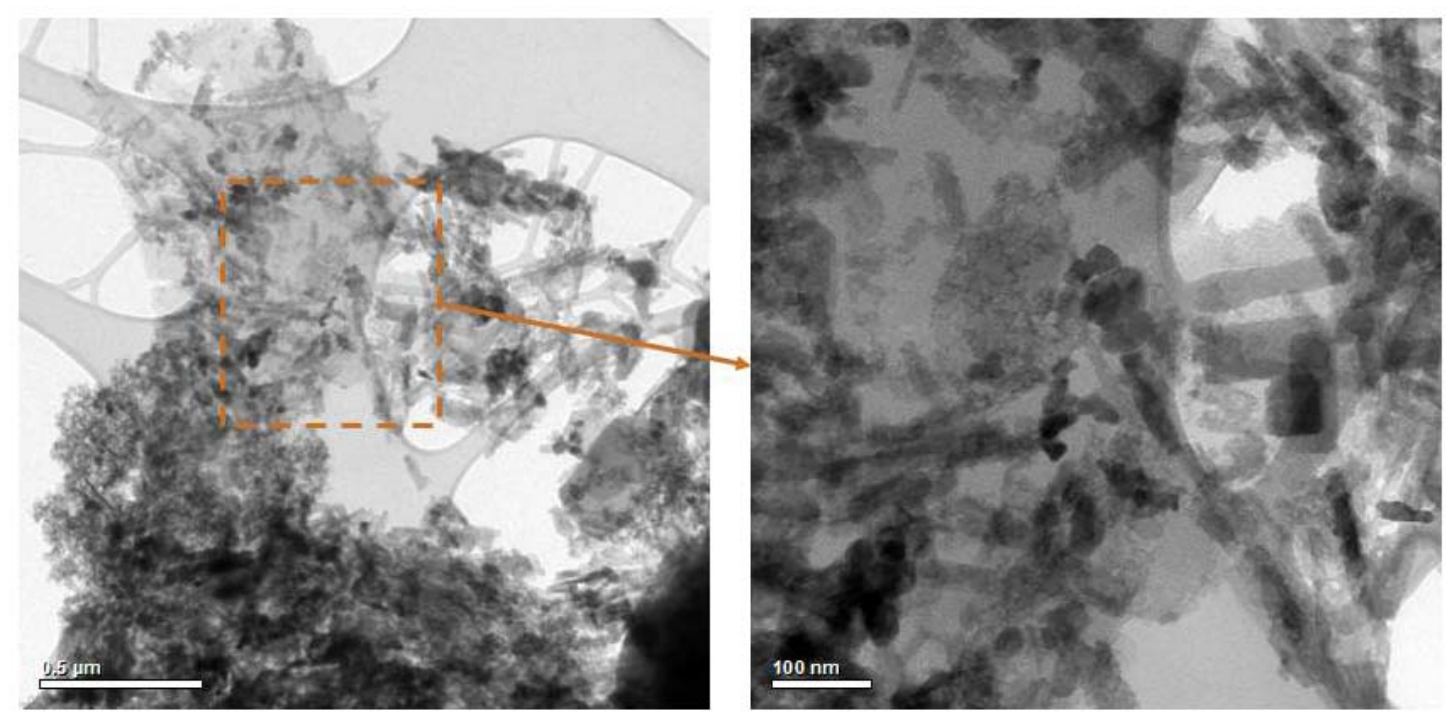

Figure 3.21. TEM Images of G8-S-WL Tank Sludge Showing the Heterogeneous Nature of the Particles
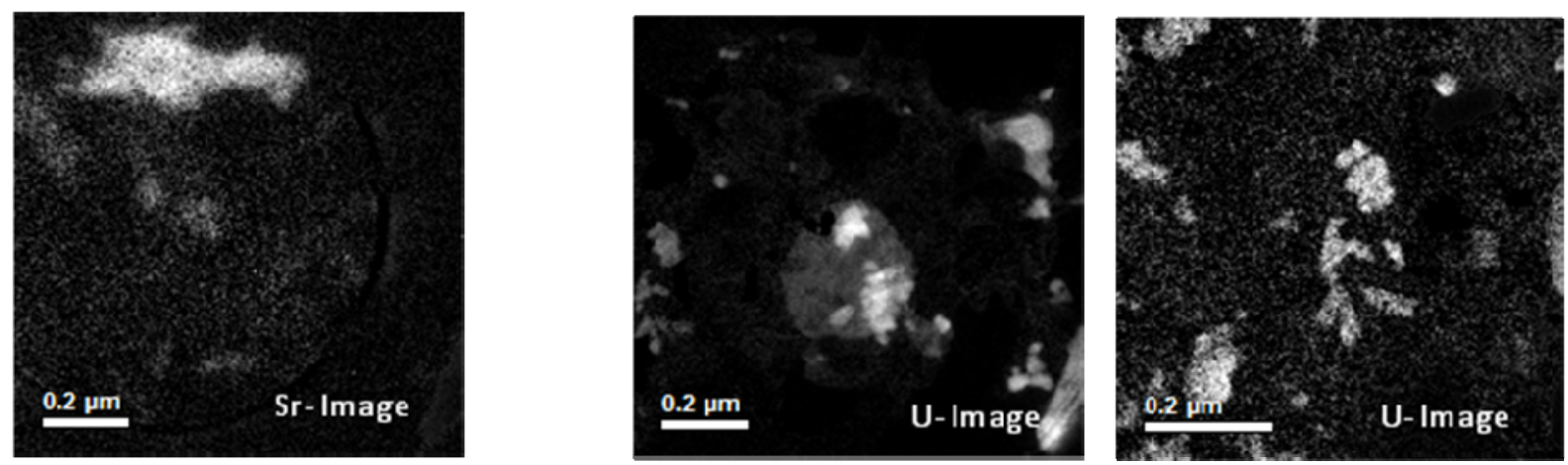

Figure 3.22. Energy-Filtered TEM Images Showing Strontium and Uranium Distribution in Sludge Particles 
WTP-RPT-170, Rev. 0

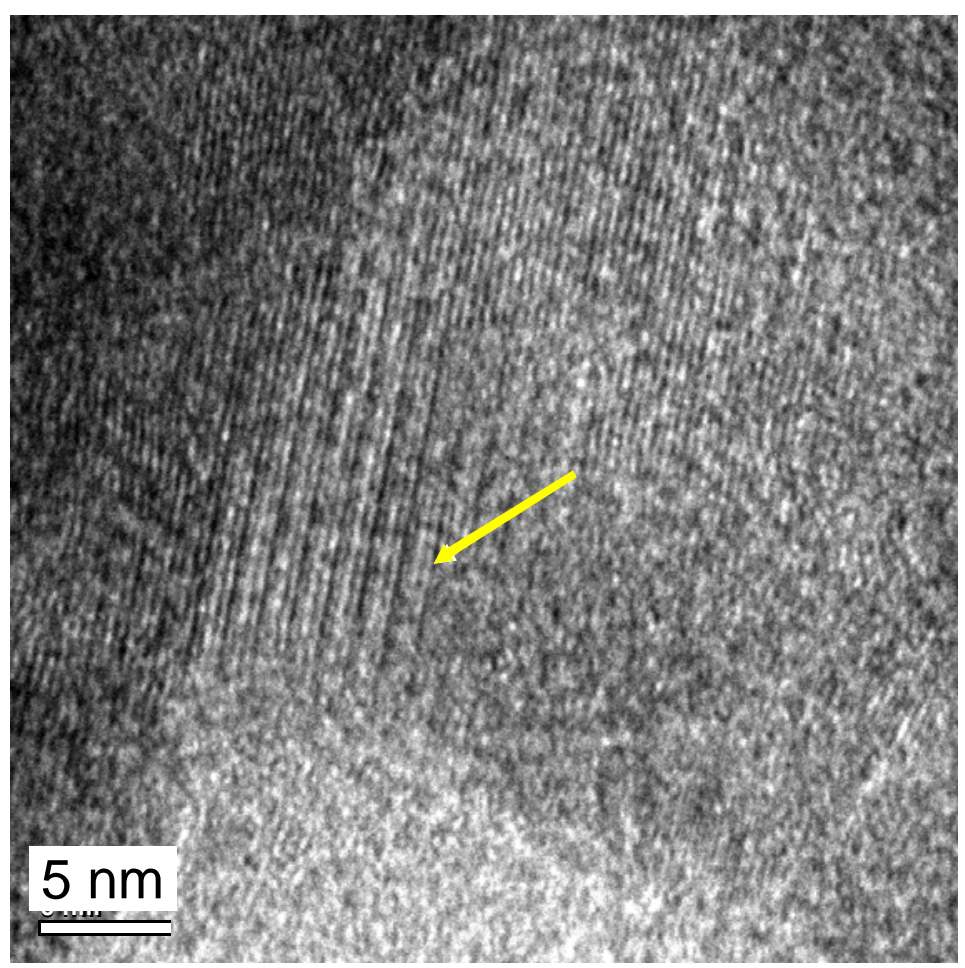

Figure 3.23. High-Resolution TEM Image of Sr-P Phase in Group 8

It was not possible to confirm this result with EDS because of the overlap between $\mathrm{Sr}, \mathrm{P}$, and $\mathrm{Zr}$ at the different characteristic X-ray lines. The higher resolution of the EELS measurement may permit Zr-L edges to be isolated from the P-K. The Sr-L and P-K edges are very well separated in the EELS (see Figure 3.24); however, there remains strong overlap between $\mathrm{Zr}-\mathrm{L}$ and $\mathrm{P}-\mathrm{K}$. The composition of the strontium phase depicted in Figure 3.22 was determined with EDS. The relative $\mathrm{P}$ and $\mathrm{Sr}$ atom fractions in three different areas of this phase are listed in Table 3.12.

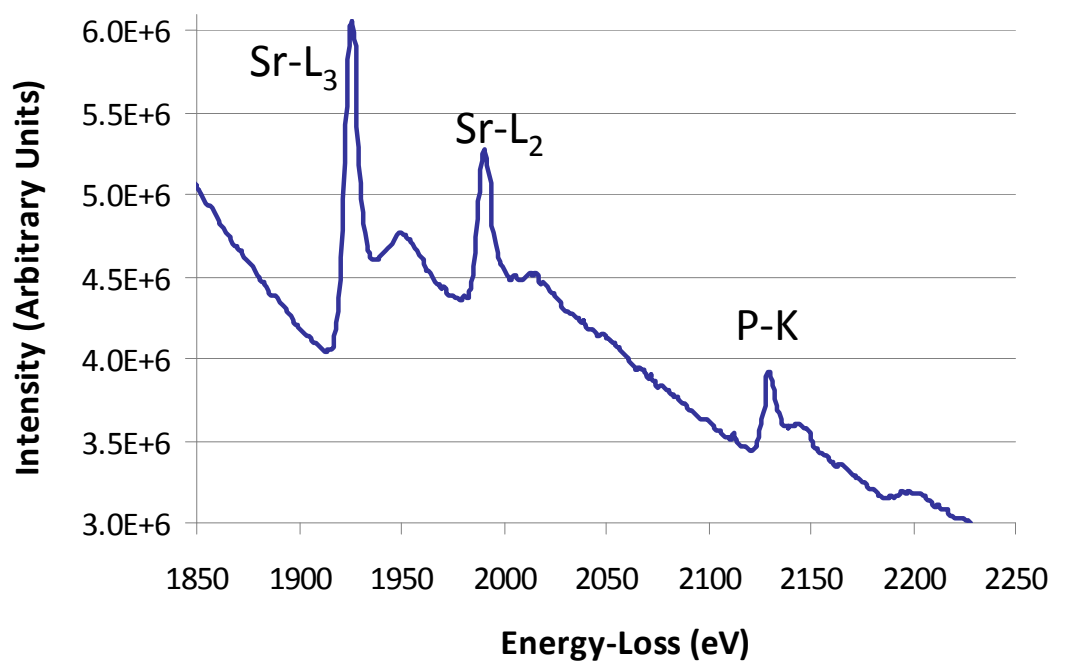

Figure 3.24. Electron Energy-Loss Spectrum of the Sr-P Phase 
WTP-RPT-170, Rev. 0

Table 3.12. EDS Analysis of Strontium to Phosphorus Content (Relative Atom Fraction)

\begin{tabular}{|c|c|c|c||}
\hline Element & EDS-1 & EDS-2 & EDS-3 \\
\hline $\mathrm{P}$ & 0.40 & 0.42 & 0.65 \\
\hline $\mathrm{Sr}$ & 0.33 & 0.58 & 0.92 \\
\hline
\end{tabular}

Electron diffraction from the strontium phase was weak (see Figure 3.25), but a rotational average of the diffraction pattern was obtained, and major reflections were observed at $3.25 \AA, 2.78 \AA, 2.12 \AA, 1.88 \AA$, and $1.62 \AA$. This is in agreement with the apatite mineral phase, strontium phosphate hydroxide (PDF 14691), and $\mathrm{Sr}_{5}\left(\mathrm{PO}_{4}\right)_{3}(\mathrm{OH})$. If the composition was correct, the expected atomic ratio described in Table 3.12 would be 0.375 for $\mathrm{P}$ and 0.625 for Sr. It is also likely that $\mathrm{Al}$ and $\mathrm{Ca}$ are present in this phase based on EDS analyses.

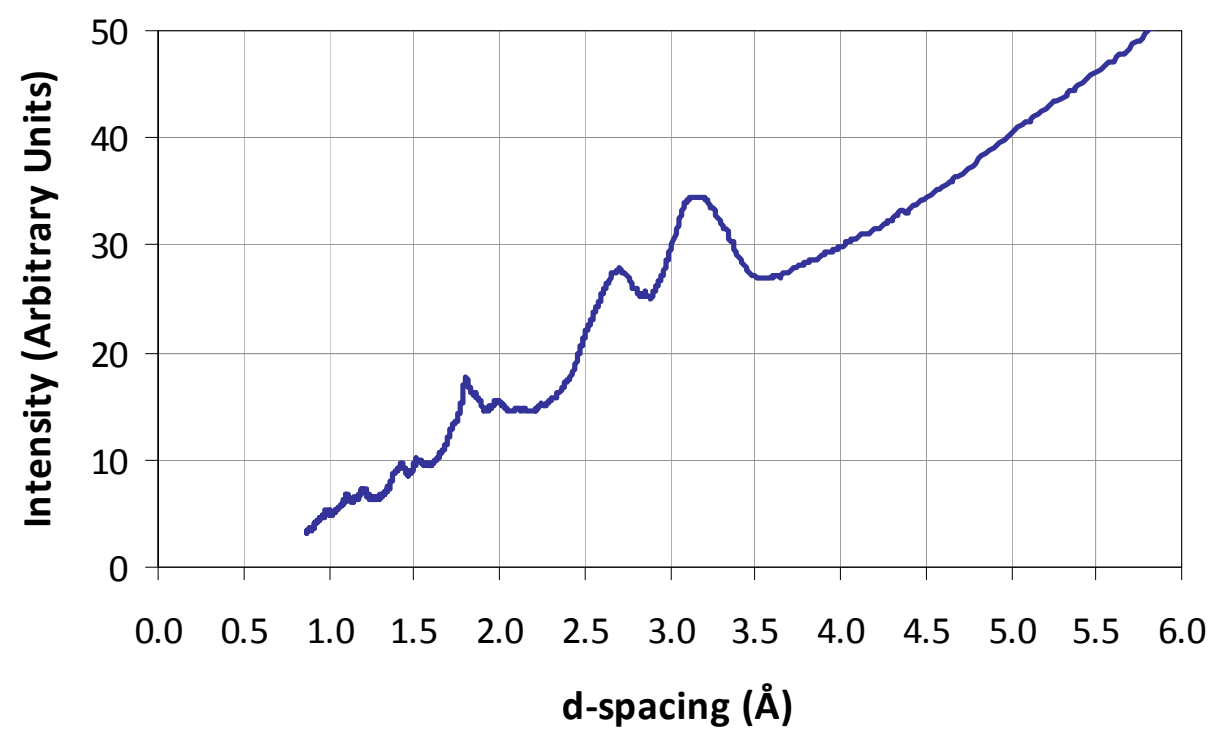

Figure 3.25. Rotational Average of an Electron Diffraction Pattern from the Sr-P Phase

A fourth phase observed in the washed Group 8 sludge sample was an alkali-silicate phase. This phase was thought to be cancrinite based on previous work. Nitrate-cancrinite has been previously identified in Hanford tank waste by Buck and McNamara (2004). Although the presence of this unique composition of cancrinite in the washed $\mathrm{FeCN}$ sludge was not determined (i.e., presence of nitrate or carbonate in the structure), the electron diffraction data listed in Table 3.13 indicated a reasonable match to nitratecancrinite. 
Table 3.13. Electron Diffraction Data from Cancrinite Phase in Washed Group 8 Solids

\begin{tabular}{|c|c|c|c|}
\hline $\begin{array}{c}\text { Observed } \\
\text { d-spacing }(\AA)\end{array}$ & $\begin{array}{c}\text { Cancrinite } \\
\text { d-spacing }(\AA) \\
\text { (Buhl et al. 2000) } \\
\end{array}$ & Intensity & ( h k l) \\
\hline 2.950 & 2.99 & 7 & $\left(\begin{array}{lll}2 & 1 & 1\end{array}\right)$ \\
\hline 2.915 & 2.74 & 58 & $\left(\begin{array}{lll}4 & 0 & 0\end{array}\right)$ \\
\hline 2.591 & 2.59 & 25 & $\left(\begin{array}{lll}0 & 0 & 2\end{array}\right)$ \\
\hline 2.370 & 2.398 & 5 & $(4)$ \\
\hline 2.326 & -- & & \\
\hline 1.595 & 1.5967 & 18 & $(213)$ \\
\hline 1.449 & 1.454 & 14 & $(710)$ \\
\hline 1.372 & -- & & \\
\hline 1.368 & 1.352 & 14 & $(444)$ \\
\hline 1.294 & 1.299 & 9 & $\left(\begin{array}{lll}7 & 2 & 1\end{array}\right)$ \\
\hline 1.285 & -- & & \\
\hline 1.274 & 1.247 & 10 & $\left(\begin{array}{lll}8 & 1 & 1\end{array}\right)$ \\
\hline 0.985 & -- & & \\
\hline \multicolumn{4}{|c|}{$\begin{array}{l}\text { Cancrinite is hexagonal with } \mathbf{a}=12.66 \AA \text { and } \mathbf{c}=5.16 \AA \text {; nitrate-cancrinite } \\
\text { is } 12.675 \AA \text { and } \mathbf{c}=5.19 \AA \text { as reported by Buhl et al. }(2000) \text {. }\end{array}$} \\
\hline
\end{tabular}



WTP-RPT-170, Rev. 0

\subsection{Group 8 CUF Testing and Results}

This section describes the filtration and leaching tests performed on the Group 8 ferrocyanide waste sludge composite in the CUF assembly (see Appendix D for a system and processing description). Testing was performed according to TI-RPP-WTP- $640,{ }^{\text {(a) }}$ which implemented the recommendations defined in a concurrence request (WTP/RPP-MOA-PNNL-00237). ${ }^{(b)}$ The filtration performances in low and high solids matrices are provided along with the caustic leaching behaviors of $\mathrm{Al}, \mathrm{Cr}$, and $\mathrm{P}$. Mass balances of major analyte compositions are presented as well as the solids characterization results of the product with direct comparison to the starting-material composition.

\subsection{Test Plan}

Figure 4.1 outlines the testing that was performed and is reported in this section in order to meet the following goals:

- evaluate the filtration behavior of the iron-rich ferrocyanide sludge waste composite

- evaluate the effectiveness of caustic leaching on aluminum and phosphorus removal from the solids phase in this waste type

- evaluate the filtration behavior of the leached and washed solids.

The first part of the testing was to perform filtration studies on the Group 8 waste sample and understand its dewatering behavior, as outlined in the first column (colored blue) of Figure 4.1. The waste was to be initially evaluated at a target UDS concentration of $\sim 5 \mathrm{wt} \%$, which is the expected solids concentration entering the WTP-Pretreatment UFP2 vessel. To accomplish this, approximately $1.8 \mathrm{~L}$ of Group 8 composite material (measured at $11 \mathrm{wt} \%$ UDS) was diluted with $2 \mathrm{~L}$ of a simulant supernate solution. The simulant solution composition was formulated to match the Group 8 permeate (or aqueous phase) composition (as reported in Section 3). The dilution was targeted to result in $5 \mathrm{wt} \%$ UDS and a predicted slurry volume of $3.8 \mathrm{~L}$. Once the slurry was homogenized, a filtration test matrix was performed (as described in Appendix D) to determine the filtration behavior of the waste at a low UDS concentration. After completing the filtration test matrix, the waste sample was dewatered to the minimum operating volume in the slurry recirculation loop to a predicted concentration of $15 \mathrm{wt} \%$ UDS. At this point, another filtration test matrix was performed to evaluate the change in the filtration behavior after concentrating the waste slurry.

(a) Conducted according to TI-RPP-WTP-640, HLW Filtration and Caustic Leaching of Group 8 Waste, R Shimskey. June, 2008.

(b) Letter WTP/RPP-MOA-PNNL-00237 to HR Hazen from GH Beeman, 6/17/08, Appendix H. 
WTP-RPT-170, Rev. 0

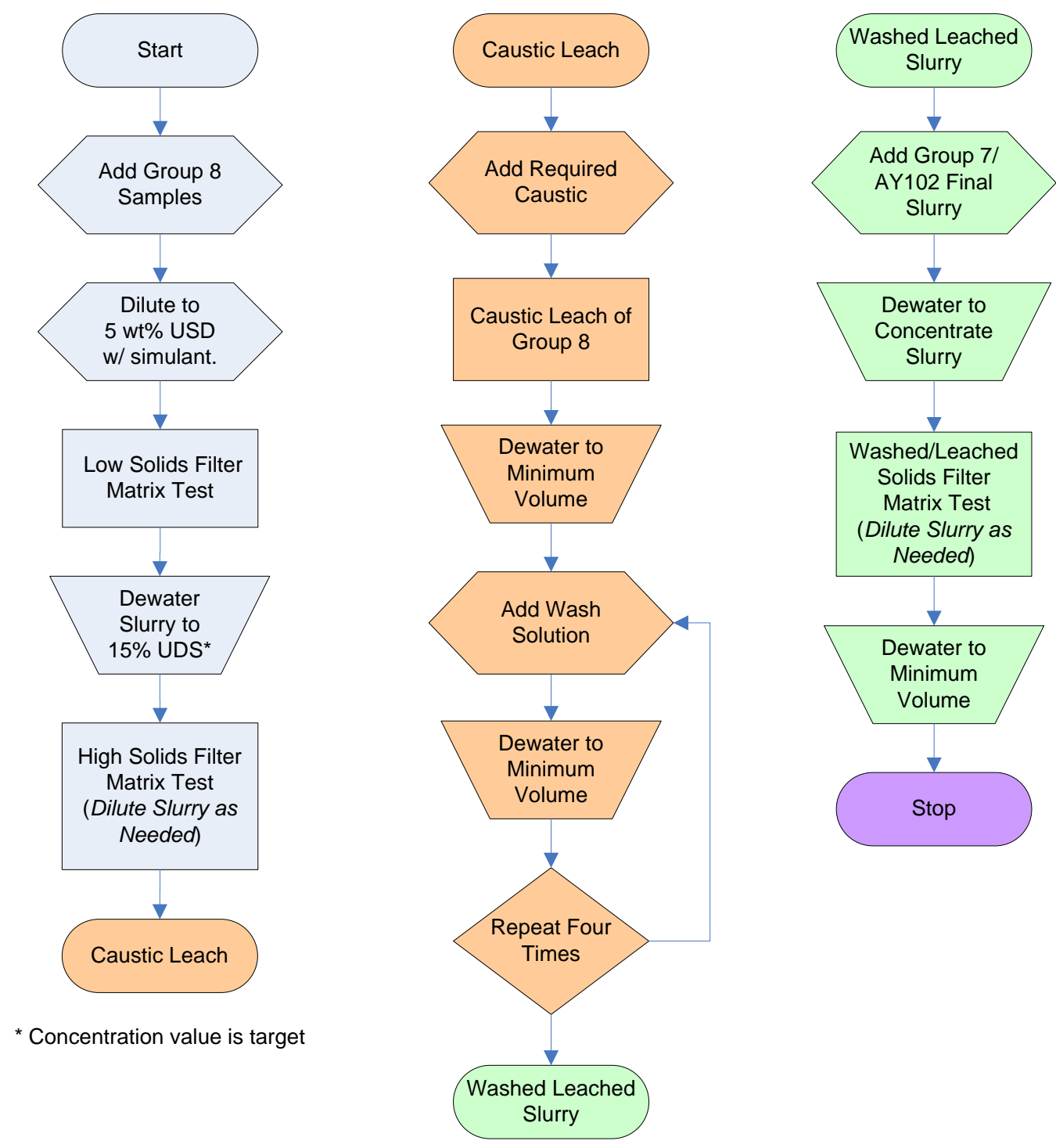

Figure 4.1. Group 8 Testing Flowchart

The second part of the testing was to evaluate the caustic leaching behavior of the Group 8 waste slurry, as outlined in the middle column (colored orange) of Figure 4.1. After completing the high-solids concentration of the filtration test matrix, the sample was drained from the CUF piping and placed back into the slurry reservoir after isolating the tank from the filtration piping. At this point, a known volume and concentration of $\mathrm{NaOH}$ was blended with the concentrated slurry to increase the leach volume to 3.8 L. The caustic addition was based on a stepwise calculation process incorporating the following inputs.

- The Group 8 slurry was calculated to contain $\sim 250 \mathrm{~g}$ of solids material. The mass fractions of aluminum and phosphorus present in the solids were based on the characterization data assembled in Section 3.

- The quantity of hydroxide consumed from $100 \%$ dissolution of the aluminum and phosphorus was calculated assuming that all aluminum was present as gibbsite and all phosphorous was present as sodium phosphate. 
- Using solubility data of aluminum ( $\mathrm{Li}$ et al. 2005), the final free-hydroxide concentration for the leach supernate was estimated iteratively. The estimation accounted for the displacement of P (as phosphate) from the solids phase with hydroxide (3:1 phosphate to hydroxide mole ratio) and the dissolution of $\mathrm{Al}$ (as gibbsite) from the solids phase with additional hydroxide (1:1 mole ratio). The calculated free-hydroxide concentration was then adjusted to be high enough to prevent dissolved aluminum from precipitating after cooling, based on the reported Al solubility. The final molar ratio of free hydroxide to aluminum was predicted to be 10:1.

- Next, the mass of $\mathrm{NaOH}$ required to dissolve both aluminum and phosphorus while maintaining aluminum solubility afterwards was calculated. This mass was to be added as a $19 \mathrm{M} \mathrm{NaOH}$ solution.

- Once the combined volume of dewatered slurry and $19 \mathrm{M} \mathrm{NaOH}$ was estimated, the volume of water to be added to the leach solution representing the leach volume increase due to condensation from heating via steam injection was calculated.

- Because this was a hot cell operation, only one solution addition was desired. Therefore, the $19 \mathrm{M}$ $\mathrm{NaOH}$ addition and water addition for steam condensate were combined into one solution: $1.68 \mathrm{~L}$ of $6.34 \mathrm{M} \mathrm{NaOH}$.

The caustic-leach solution was used to opportunistically rinse residual solids from the CUF piping after the slurry and supernate were drained from the test apparatus and before isolating the slurry reservoir tank for leaching operations. Then the drained slurry, the supernate drained from the permeate loop, and the caustic-addition solution were combined in the isolated slurry reservoir tank with the overhead mixer operating. The reservoir tank system was heated to $60^{\circ} \mathrm{C}$ over a 2.5 -h interval. The slurry was then maintained at $60^{\circ} \mathrm{C}$ for $8 \mathrm{~h}$. The slurry supernate was sampled periodically to evaluate the aluminum, phosphorous, and chromium dissolution rates. Afterwards, the slurry was cooled to $35^{\circ} \mathrm{C}$ at a controlled cooling ramp. At this point, the leached slurry was allowed to enter the piping of the CUF, circulated to reach ambient cell temperature $\left(\sim 25^{\circ} \mathrm{C}\right)$, and dewatered to the minimum operating volume of the circulation pump.

The caustic-leached solids were rinsed four sequential times. After adding a 1.2-L volume of rinse solution, the slurry was mixed by pumping through the slurry recirculation loop for 5 to 10 minutes - note that this resulted in over 50 volume displacements. The slurry was then dewatered to a 1.2- to $1.4-\mathrm{L}$ slurry volume. Each rinse permeate was collected separately. The $\mathrm{NaOH}$ concentration of each added rinse solution was established to provide sufficient free-hydroxide concentration to maintain the solubility of dissolved aluminum (based on the assumed 100\% Al dissolution). The amount of caustic added was determined using the gibbsite solubility data reported by Li et al. (2005). The concentrations of $\mathrm{NaOH}$ in each wash were:

- $0.47 \mathrm{M} \mathrm{NaOH}$ for the first wash

- $0.16 \mathrm{M} \mathrm{NaOH}$ for the second wash

- $0.049 \mathrm{M} \mathrm{NaOH}$ for the third wash

- $0.014 \mathrm{M} \mathrm{NaOH}$ for the fourth wash.

Filtration performance characteristics at a solids concentration approaching $20 \mathrm{wt} \%$ were desired; however, the total solids mass of the Group 8 material was too low to support this testing. The CUF required $\sim 1.2 \mathrm{~L}$ of slurry for successfully processing and dewatering the Group 8 slurry to $22 \mathrm{wt} \%$ UDS 
would have resulted in an $\sim 1.0-\mathrm{L}$ final slurry volume. Therefore, to increase the solids fraction of the slurry, the washed-leached slurry resulting from the Group 7 (mixed with AY-102 solids) CUF test ${ }^{(a)}$ was added to the Group 8 washed-leached slurry. The combined slurry was then mixed and dewatered to an operating volume where the transmembrane pressure (TMP) and axial velocity (AV) test conditions could be reached without disruption from pump cavitation, $\sim 20 \mathrm{wt} \%$ UDS. An 11-point filtration test matrix was performed, as outlined in Appendix D. Afterwards, the slurry was dewatered to a minimum volume to create a dewatering curve where the UDS concentration of the slurry impacted the filter flux. The processing steps performed in support of this final filtration test are outlined in the right column (colored green) of Figure 4.1.

Slurry and supernate samples were periodically collected during the CUF processing to track the analyte mass balances. Samples were submitted such that the solids content in the waste slurry and the chemical composition of the slurry and supernatant could be measured. Appendix D describes the sampling logistics; Appendix E describes the calculation applied to define rheology, filter flux, and solids leach factors; Appendix B describes analytical methods; Appendix I provides the raw analytical results from CUF process samples. These data were used to evaluate the effectiveness of the leach and wash processes in separating LAW waste components from the HLW components in the waste sample.

\subsection{Low-Solids Slurry Characterization}

Figure 4.2 and Table 4.1 outline the activities and materials added to the CUF to produce the low-solids slurry. Initially, $2.21 \mathrm{~kg}$ of Group 8 slurry were added to the slurry reservoir, (sample composites TI516G8-AR-J1 through -J5 as described in Section 2). The Group 8 waste slurry contained 11.4 wt\% UDS. To dilute the waste slurry to near $5 \mathrm{wt} \%$ UDS for the low-solids matrix test, $2.33 \mathrm{~kg}$ of a simulant supernate were added to the reservoir and blended with the actual waste samples. The composition of the simulant (shown in Table 4.2) was based on results of supernate characterization performed on the homogenized Group 8 waste (see Section 3).

Once the actual waste samples and simulant were blended in the slurry reservoir tank, the slurry was circulated through the CUF with permeate from the ultra filter recycling back to the slurry reservoir. The hold-up of slurry supernate in the filter and permeate loop was $\sim 200 \mathrm{~mL}$. Slurry samples were collected for chemical and physical characterization of the slurry inside the slurry circulation loop. Results of physical-property measurements are outlined in Table 4.3. The measured and predicted UDS concentrations of the slurry in the circulation loop agreed at $5.9 \mathrm{wt} \%$. The chemical and radiological composition of the waste slurry is summarized in Table 4.4. Results are expressed as the total amount of components in the CUF slurry (mass balance) and include the supernate present in the permeate loop.

(a) Conducted according to TI-RPP-WTP-624, HLW Filtration and Caustic Leaching of Group 7/AY-102 Composite Waste, R. Shimskey. April, 2008 
WTP-RPT-170, Rev. 0

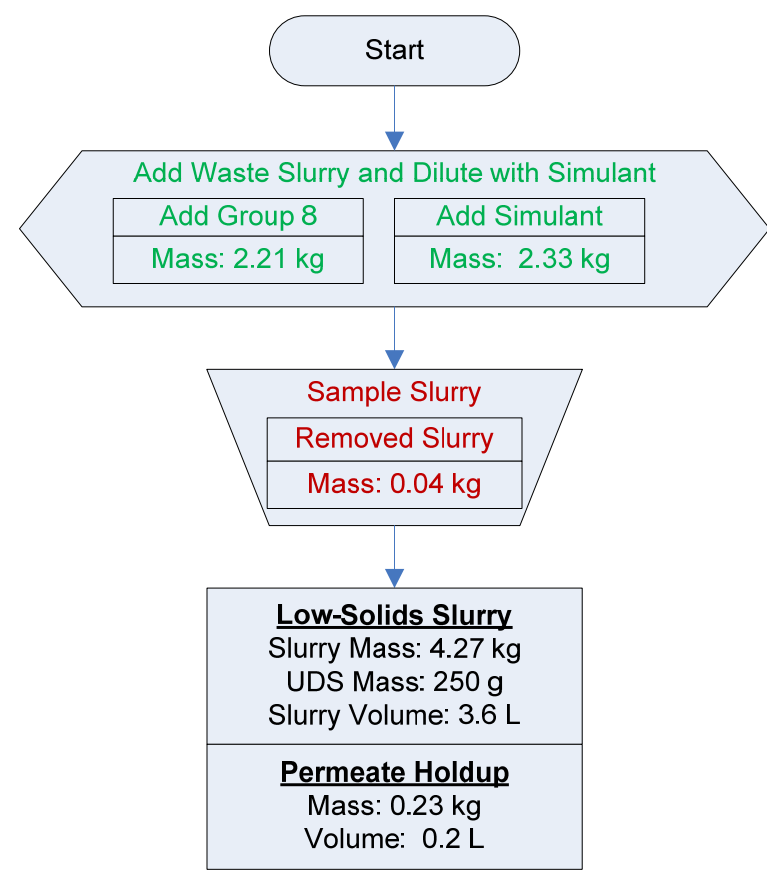

Figure 4.2. Process Flow Diagram of Creating Low-Solids Slurry

Table 4.1. Mass Balance Overview of Group 8 Low-Solids Slurry

\begin{tabular}{|l|c|c|c|c|c|c||}
\hline Step & $\begin{array}{c}\text { Change } \\
\text { in Mass } \\
(\mathbf{g})\end{array}$ & $\begin{array}{c}\text { Total } \\
\text { Mass } \\
(\mathbf{g})\end{array}$ & $\begin{array}{c}\text { Estimated } \\
\text { Solids Mass } \\
\mathbf{( g )}\end{array}$ & $\begin{array}{c}\text { Circulating } \\
\text { Slurry Mass } \\
\mathbf{( g )}\end{array}$ & $\begin{array}{c}\text { Estimated } \\
\text { Slurry UDS } \\
(\mathbf{w t} \%)\end{array}$ & $\begin{array}{c}\text { Measured } \\
\text { Slurry UDS } \\
(\mathbf{w t} \%)\end{array}$ \\
\hline Add Group 8 Slurry & +2210 & 2210 & 250 & na & na & na \\
\hline $\begin{array}{l}\text { Add Simulated } \\
\text { Supernate }\end{array}$ & +2330 & 4540 & 250 & na & na & na \\
\hline Sample Slurry & -40 & 4500 & 250 & 4270 & 5.8 & 5.9 \\
\hline
\end{tabular}

Table 4.2. Simulated Supernate Addition to Group 8 Composite

\begin{tabular}{|c|c|c|c|c||}
\hline \multirow{2}{*}{ Element } & \multicolumn{2}{|c|}{$\begin{array}{c}\text { Simulant Addition } \\
(\mathbf{2 . 0 0} \mathbf{L})\end{array}$} & $\begin{array}{c}\text { Actual Slurry } \\
\text { Waste } \\
(\mathbf{2 . 2 1} \mathbf{~ k g})\end{array}$ & $\begin{array}{c}\text { \% of Slurry } \\
\text { Component Due } \\
\text { to Simulant }\end{array}$ \\
\cline { 2 - 5 } & $\mathbf{m g / L}$ & $\mathbf{g}$ & $\mathbf{g}$ & $\mathbf{w t \%}$ \\
\hline $\mathrm{Na}$ & 80,600 & 161 & 151 & $52 \%$ \\
\hline $\mathrm{Al}$ & 1,360 & 2.7 & 25.1 & $10 \%$ \\
\hline $\mathrm{S}$ & 2,080 & 4.2 & 5.4 & $44 \%$ \\
\hline $\mathrm{P}$ & 2,420 & 4.8 & 13.9 & $26 \%$ \\
\hline Anions & & & & \\
\hline $\mathrm{OH}^{-}$ & 5,650 & 11.3 & 8.4 & $57 \%$ \\
\hline $\mathrm{C}_{2} \mathrm{O}_{4}{ }^{2-}$ & 2,940 & 5.9 & 5.9 & $50 \%$ \\
\hline $\mathrm{NO}_{2}{ }^{-}$ & 18,500 & 37.0 & 31.4 & $54 \%$ \\
\hline $\mathrm{NO}_{3}{ }^{-}$ & 70,300 & 141 & 120 & $54 \%$ \\
\hline $\mathrm{SO}_{4}{ }^{2-}$ & 6,250 & 12.5 & 10.6 & $54 \%$ \\
\hline $\mathrm{PO}_{4}{ }^{3-}$ & 7,420 & 14.8 & 13.4 & $53 \%$ \\
\hline
\end{tabular}


WTP-RPT-170, Rev. 0

Table 4.3. Low-Solids Slurry Physical Property Measurements (Slurry Circulation Loop)

\begin{tabular}{|r|c||}
\hline Slurry Density (g/mL) & 1.2 \\
\hline Supernate Density (g/mL) & 1.2 \\
\hline Settled Solids (vol\%) & 38 \\
\hline Centrifuged Undissolved Solids (wt\%) & 38 \\
\hline Total Solids (wt\%) & 24 \\
\hline Supernate Dissolved Solids (wt\%) & 19 \\
\hline Undissolved Solids (wt\%) & 5.9 \\
\hline
\end{tabular}

Table 4.4. Group 8 Low-Solids Slurry Composition Based on Overall Mass Balance (Mass Includes Permeate Hold-up)

\begin{tabular}{|c|c|c|c|c|c|}
\hline & Slurry $^{(a)}$ & \multicolumn{2}{|c|}{ Liquid Fraction $^{(b)}$} & \multicolumn{2}{|c|}{ Solids Fraction $^{(\mathrm{c})}$} \\
\hline Mass (kg) & 4.50 & \multicolumn{2}{|c|}{4.25} & \multicolumn{2}{|c|}{0.25} \\
\hline Wt\% of Slurry & $100 \mathrm{wt} \%$ & \multicolumn{2}{|c|}{$94.5 \mathrm{wt} \%$} & \multicolumn{2}{|c|}{$5.5 \mathrm{wt} \%$} \\
\hline Metal & g & g & $\mu \mathrm{g} / \mathrm{mL}$ & g & $\mu \mathrm{g} / \mathrm{g}$ \\
\hline Al & $2.8 \mathrm{E}+01$ & $5.4 \mathrm{E}+00$ & $1.5 \mathrm{E}+03$ & $2.2 \mathrm{E}+01$ & $8.9 \mathrm{E}+04$ \\
\hline $\mathbf{B i}$ & $1.5 \mathrm{E}+00$ & $0.0 \mathrm{E}+00$ & $<3.8 \mathrm{E}+00$ & $1.5 \mathrm{E}+00$ & $6.0 \mathrm{E}+03$ \\
\hline $\mathrm{Cr}$ & $8.4 \mathrm{E}-01$ & $2.9 \mathrm{E}-01$ & $8.0 \mathrm{E}+01$ & $5.4 \mathrm{E}-01$ & $2.2 \mathrm{E}+03$ \\
\hline $\mathbf{F e}$ & $2.7 \mathrm{E}+01$ & 8.7E-02 & $2.4 \mathrm{E}+01$ & $2.6 \mathrm{E}+01$ & $1.1 \mathrm{E}+05$ \\
\hline Mn & $3.3 \mathrm{E}-01$ & $3.0 \mathrm{E}-04$ & $8.0 \mathrm{E}-02$ & $3.3 \mathrm{E}-01$ & $1.3 \mathrm{E}+03$ \\
\hline $\mathbf{N a}$ & $3.1 \mathrm{E}+02$ & $2.9 \mathrm{E}+02$ & $7.9 \mathrm{E}+04$ & $1.9 \mathrm{E}+01$ & $7.7 \mathrm{E}+04$ \\
\hline $\mathbf{P}$ & $1.9 \mathrm{E}+01$ & $9.0 \mathrm{E}+00$ & $2.4 \mathrm{E}+03$ & $9.5 \mathrm{E}+00$ & $3.8 \mathrm{E}+04$ \\
\hline $\mathbf{S}$ & $9.4 \mathrm{E}+00$ & $8.2 \mathrm{E}+00$ & $2.2 \mathrm{E}+03$ & $1.2 \mathrm{E}+00$ & $4.8 \mathrm{E}+03$ \\
\hline Si & $4.3 \mathrm{E}+00$ & $6.2 \mathrm{E}-02$ & $1.7 \mathrm{E}+01$ & $4.2 \mathrm{E}+00$ & $1.7 \mathrm{E}+04$ \\
\hline $\mathrm{Sr}$ & $1.0 \mathrm{E}+01$ & $3.9 \mathrm{E}-04$ & $1.1 \mathrm{E}-01$ & $1.0 \mathrm{E}+01$ & $4.2 \mathrm{E}+04$ \\
\hline $\mathbf{U}$ & $3.0 \mathrm{E}+01$ & 4.3E-02 & $1.2 \mathrm{E}+01$ & $3.0 \mathrm{E}+01$ & $1.2 \mathrm{E}+05$ \\
\hline Radionuclides & $\mu \mathbf{C i}$ & $\mu \mathbf{C i}$ & $\mu \mathrm{Ci} / \mathrm{mL}$ & $\mu \mathbf{C i}$ & $\mu \mathrm{Ci} / \mathrm{g}$ \\
\hline${ }^{60} \mathrm{Co}$ & $2.5 \mathrm{E}+00$ & $<5$.E-1 & $<1$. E-4 & $2.5 \mathrm{E}+00$ & $9.9 \mathrm{E}-03$ \\
\hline${ }^{137} \mathrm{Cs}$ & $1.7 \mathrm{E}+05$ & $7.5 \mathrm{E}+04$ & $2.0 \mathrm{E}+01$ & $9.7 \mathrm{E}+04$ & $3.9 \mathrm{E}+02$ \\
\hline${ }^{154} \mathbf{E u}$ & $3.5 \mathrm{E}+01$ & $<1 . \mathrm{E}+0$ & $<4$.E-4 & $3.5 \mathrm{E}+01$ & $1.4 \mathrm{E}-01$ \\
\hline${ }^{241} \mathrm{Am}$ & $4.8 \mathrm{E}+01$ & $<2 . \mathrm{E}+1$ & $<5$.E-3 & $4.8 \mathrm{E}+01$ & $1.9 \mathrm{E}-01$ \\
\hline Gross Alpha & $2.2 \mathrm{E}+02$ & $<8$.E-1 & $<2$.E-4 & $2.2 \mathrm{E}+02$ & 8.7E-01 \\
\hline Gross Beta & $8.2 \mathrm{E}+05$ & $7.6 \mathrm{E}+04$ & $2.0 \mathrm{E}+01$ & $7.4 \mathrm{E}+05$ & $3.0 \mathrm{E}+03$ \\
\hline${ }^{90} \mathrm{Sr}$ & $3.2 \mathrm{E}+05$ & $2.2 \mathrm{E}+01$ & 5.9E-03 & $3.2 \mathrm{E}+05$ & $1.3 \mathrm{E}+03$ \\
\hline${ }^{239+240} \mathrm{Pu}$ & $1.4 \mathrm{E}+02$ & $1.2 \mathrm{E}-01$ & $3.3 \mathrm{E}-05$ & $1.4 \mathrm{E}+02$ & $5.6 \mathrm{E}-01$ \\
\hline${ }^{238} \mathbf{P u}$ & $3.5 \mathrm{E}+00$ & $1.2 \mathrm{E}-02$ & $3.3 \mathrm{E}-06$ & $3.5 \mathrm{E}+00$ & $1.4 \mathrm{E}-02$ \\
\hline $\begin{array}{l}\text { (a) Slurry Mass ce } \\
\text { materials that } \\
\text { (b) Liquid Fractio } \\
\text { TI640-G8-A ( } \\
\text { (c) Solids Fractio } \\
\text { component ma }\end{array}$ & $\begin{array}{l}\text { onents were } \\
\text { e added witl } \\
\text { ass compon } \\
\text { O ID } 08-22 \\
\text { ass compon } \\
\text { and liquid co } \\
\end{array}$ & $\begin{array}{l}\text { dlated from } \\
\text { dlant. Loss } \\
\text { vere calcula } \\
\text { and the pred } \\
\text { jere calcula } \\
\text { nent mass fr } \\
\end{array}$ & $\begin{array}{l}\text { acterization c } \\
\text { ass from sam } \\
\text { sing analytic } \\
\text { mass of sup } \\
\text { om the diffe } \\
\text { n. }\end{array}$ & $\begin{array}{l}\text { Section } 3) \text {, } \\
\text { was incorp } \\
\text { ults from s } \\
\text { in the syst } \\
\text { between th }\end{array}$ & $\begin{array}{l}\text { masses of } \\
\text { te sample }\end{array}$ \\
\hline
\end{tabular}


Particle-size measurements were performed on the slurry sample taken before the filtration testing. Table 4.5 shows select cumulative undersize percentiles for the low-solids slurry as a function of the slurry loop pump speed in the PSD analyzer (the PSD analytical method is described in Appendix B, and the PSD report is provided in Appendix G). Here the $\mathrm{d}(10)$ ranged between 33 and $51 \mu \mathrm{m}$, the $\mathrm{d}(50)$ between 59 and $91 \mu \mathrm{m}$, and the $\mathrm{d}(90)$ between 110 and $160 \mu \mathrm{m}$.

Table 4.5. Particle-Size Analysis Percentile Results from the Group 8 Low-Solids Matrix Sample

\begin{tabular}{||c|c|c|c|c|c|}
\hline $\begin{array}{c}\text { Measurement } \\
\text { Condition }\end{array}$ & Pump Speed & Sonication & $\begin{array}{c}\mathbf{d}(\mathbf{1 0}) \\
(\boldsymbol{\mu m})\end{array}$ & $\begin{array}{c}\mathbf{d}(\mathbf{5 0}) \\
(\boldsymbol{\mu m})\end{array}$ & $\begin{array}{c}\mathbf{d}(\mathbf{9 0}) \\
(\boldsymbol{\mu m})\end{array}$ \\
\hline 1 & 3000 & $\mathrm{n} / \mathrm{a}$ & 50 & 87 & 150 \\
\hline 2 & 4000 & $\mathrm{n} / \mathrm{a}$ & 33 & 59 & 110 \\
\hline 3 & 2000 & $\mathrm{n} / \mathrm{a}$ & 51 & 91 & 160 \\
\hline 4 & 2000 & $\mathrm{n} / \mathrm{a}$ & $\mathrm{n} / \mathrm{a}^{(\mathrm{a})}$ & $\mathrm{n} / \mathrm{a}^{(\mathrm{a})}$ & $\mathrm{n} / \mathrm{a}^{(\mathrm{a})}$ \\
\hline \hline
\end{tabular}

(a) All particles appeared to have settled out of the system after prolonged operation. Sample ID TI640-G8-3-PSD.

Note: The suspending medium was $0.01 \mathrm{M} \mathrm{NaOH}$.

Figure 4.3 shows the PSD for the Group 8 low-solids matrix as a function of pump speed. At 3000 and 4000 RPM, the distribution ranged from approximately 15 to $300 \mu \mathrm{m}$ and was continuous and uni-modal. As the pump speed was increased from 3000 to 4000 RPM, the peak maximum shifted from 90 to $60 \mu \mathrm{m}$. This decrease in particle diameter may have indicated some flocculate or agglomerate disruption at the higher pump speed. The distribution at 2000 RPM was similar to that at 3000 RPM. Essentially no particles were detected in the analyzer, however, for the second 2000-RPM measurement. The most probable explanation for this observation was that the particles settled out at the low 2000-RPM pump speed. This behavior was consistent with dense material. 
WTP-RPT-170, Rev. 0

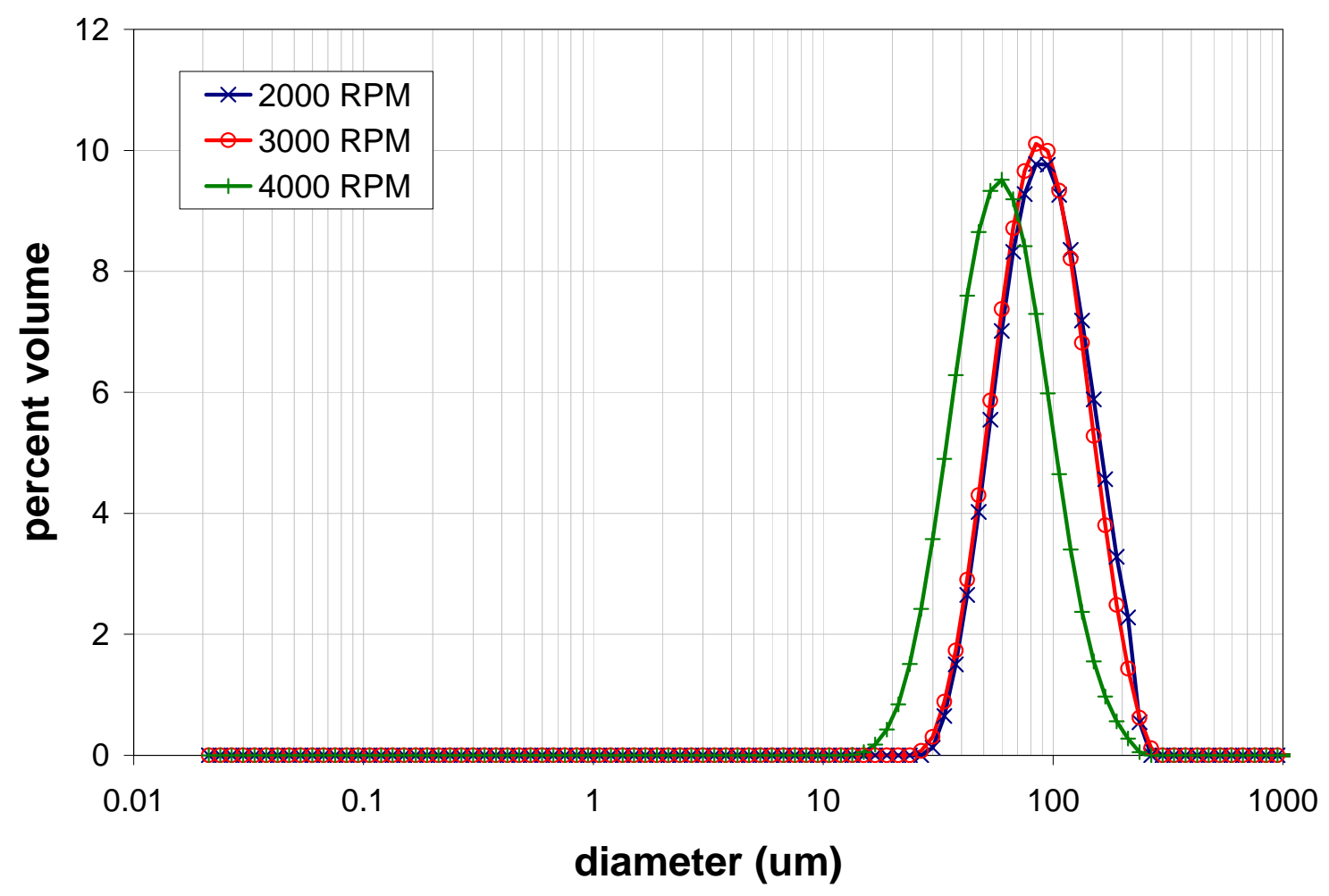

Figure 4.3. Volume Distribution PSD Results for the Group 8 Low-Solids Matrix Sample as a Function of Pump Speed

Table 4.6 and Figure 4.4 show the influence of circulation in the CUF on the PSD of Group 8 waste solids. Here, select cumulative undersize percentiles and PSDs for the initial characterization slurry are compared to the low-solids matrix slurry. Both initial characterization and low-solids matrix PSD samples show a fraction of 30- to 200- $\mu$ m particles/agglomerates. However, the broad distribution of particles spanning 0.2 to $\sim 30 \mu \mathrm{m}$ observed in the initial characterization sample is not present in the CUF testing sample. This observation is difficult to rationalize based on current understanding of particle shear mechanics in the CUF system. Typically, circulation and filtration would be expected to reduce the average size of particles and/or agglomerates. The loss of the $0.2-$ to $30-\mu \mathrm{m}$ population in the CUF testing sample is suggestive of either poor sampling of the material and/or preferential dissolution of particles in the 0.2 - to $30-\mu \mathrm{m}$ range. Of these two possibilities, poor sampling is more likely. As suggested by the loss of sample obscuration in the repeat measurements at 2000 RPM in Table 4.5, the Group 8 low-solids matrix dispersion may be prone to rapid settling. The segregation of large particle solids near the CUF sampling port or segregation during sampling immediately before PSD testing may have yielded a significantly higher percentage of 30 - to $200-\mu \mathrm{m}$ particles/agglomerates relative to that sampled during initial characterization testing. 
Table 4.6. Cumulative Undersize Percentiles Showing the Influence of Circulation in the CUF on Group 8 PSD at Measurement Condition 1 (3000 RPM)

\begin{tabular}{||l|c|c|c||}
\hline \hline \multicolumn{1}{|c|}{ Sample Description } & $\begin{array}{c}\mathbf{d}(\mathbf{1 0}) \\
(\boldsymbol{\mu m})\end{array}$ & $\begin{array}{c}\mathbf{d}(\mathbf{5 0}) \\
(\boldsymbol{\mu m})\end{array}$ & $\begin{array}{c}\mathbf{d}(\mathbf{9 0}) \\
(\boldsymbol{\mu m})\end{array}$ \\
\hline $\begin{array}{l}\text { Group 8 Initial Characterization } \\
\text { (Sample ID TI609-G8-S-WL-PSD-1) }\end{array}$ & 1.3 & 7.5 & 140 \\
\hline $\begin{array}{l}\text { Group 8 Low-Solids Matrix Slurry } \\
\text { (Sample ID TI640-G8-3-PSD) }\end{array}$ & 50 & 87 & 150 \\
\hline \hline
\end{tabular}

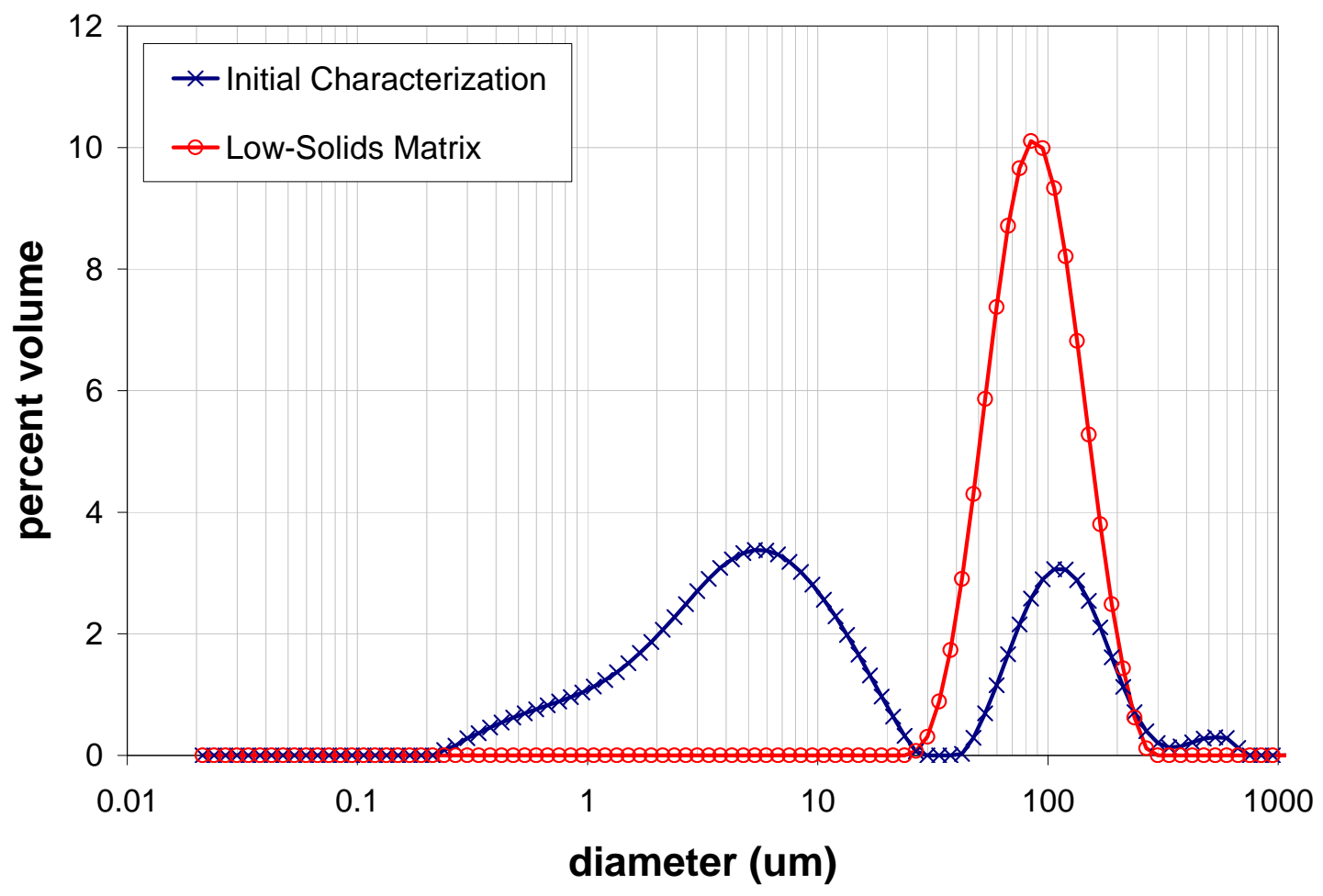

Figure 4.4. Influence of Circulation in the CUF for Group 8 PSD Note: Both PSDs were taken at measurement Condition 1 (3000 RPM)

Rheology measurements of the low-solids slurry were taken before the filtration test (sample TI640-G8R1-Slurry); the flow-curve is shown in Figure 4.5. The data indicated that the low solids-concentration Group 8 slurry was Newtonian. In terms of overall magnitude, the stress response of the slurry was comparable to that observed for the source Group 8 material. The data were subject to significant noise because the stress response of the slurry was approaching the M5-system's limit of measurement accuracy. Although measurement noise yielded significant stress variation, the flow-curve data indicated a decreased slurry stress response at higher temperatures. This was consistent with decreased slurry viscosity and with the temperature trends observed in the initial characterization Group 8 sample (TI516G8-AR-P1, see Section 3.0) flow curve.

Table 4.7 summarizes the best-fit Newtonian viscosities for the low-solids slurry sample. The results indicated that the slurry had a Newtonian viscosity of $3.0 \mathrm{mPa} \cdot \mathrm{s}$ at $25^{\circ} \mathrm{C}, 2.3 \mathrm{mPa} \cdot \mathrm{s}$ at $40^{\circ} \mathrm{C}$, and 1.1 
$\mathrm{mPa} \cdot \mathrm{s}$ at $60^{\circ} \mathrm{C}$. Initial and replicate viscosity measurements at $25^{\circ} \mathrm{C}$ agreed well. The fitting confirmed the decrease in viscosity with increasing temperature observed in Figure 4.5. Because the difference in viscosity between adjacent temperature set-points was greater than the measuring accuracy of $0.5 \mathrm{mPa} \cdot \mathrm{s}$, it was likely that this temperature trend was significant.

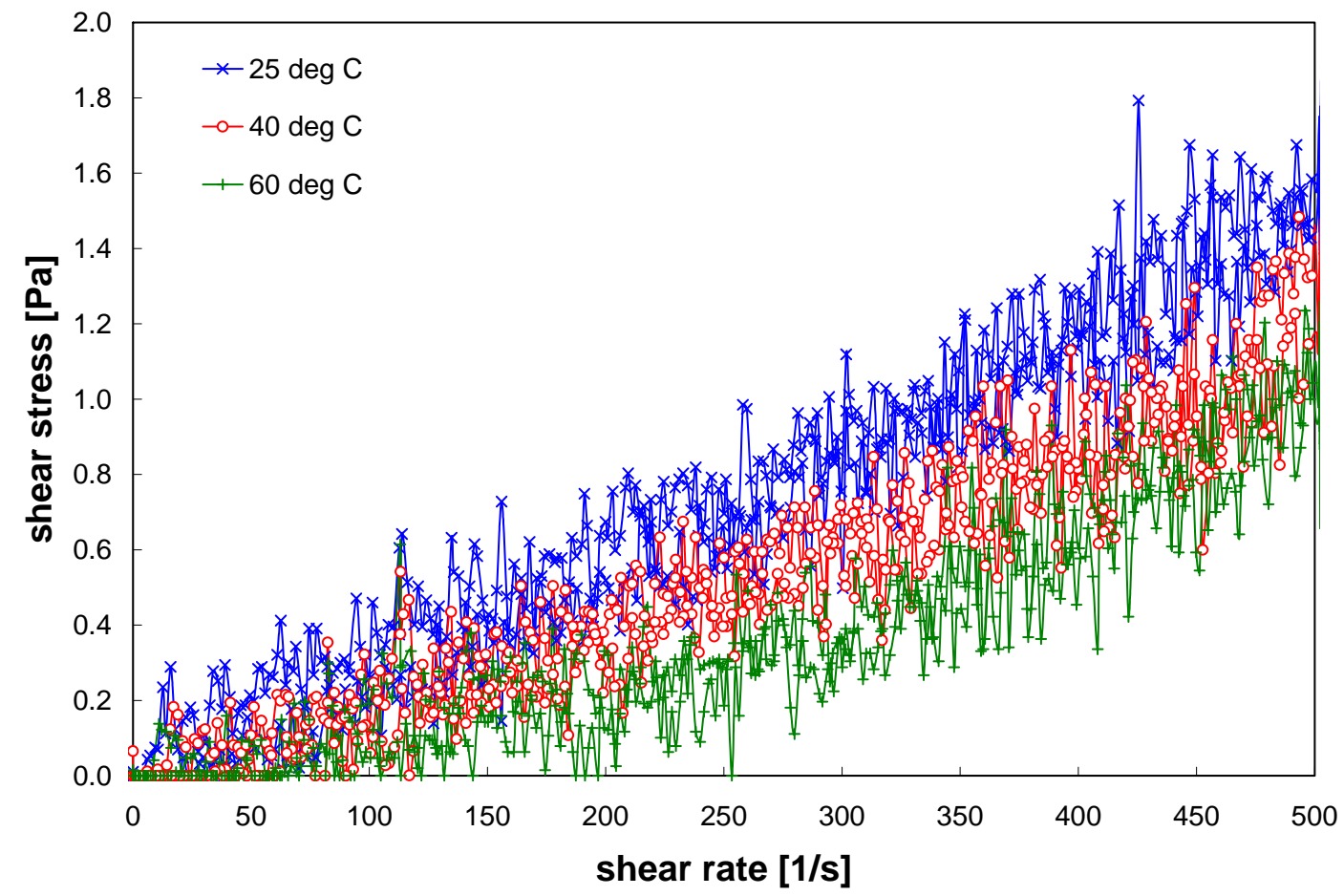

Figure 4.5. Flow Curves for Group 8 CUF Low Solids Slurry (Measured UDS of 5.9 wt $\%$ )

Table 4.7. Results of Fitting Analysis for Group 8 CUF Low Solids Slurry (Measured UDS of 5.9 wt\%)

\begin{tabular}{||c|c|c|c|c||}
\hline \hline \multirow{4}{*}{ Model } & $\begin{array}{c}\text { Temperature } \\
\left({ }^{\circ} \mathbf{C}\right)\end{array}$ & $\begin{array}{c}\text { Range } \\
\left(\mathbf{s}^{-1}\right)\end{array}$ & $\begin{array}{c}\text { Viscosity } \\
(\mathbf{m P a} \cdot \mathbf{s})\end{array}$ & $\mathbf{R}$ \\
\hline \multirow{3}{*}{ Newtonian } & $25(1$ of 2$)$ & $0-500^{(\mathrm{a})}$ & 3.0 & 0.97 \\
\cline { 2 - 5 } & $25(2$ of 2$)$ & $0-500^{(\mathrm{b})}$ & 3.0 & 0.97 \\
\cline { 2 - 5 } & 40 & $0-500^{(\mathrm{c})}$ & 2.3 & 0.96 \\
\cline { 2 - 5 } & 60 & $0-250^{(\mathrm{c})}$ & 1.1 & 0.67 \\
\hline \hline $\begin{array}{l}\text { R is the correlation coefficient. } \\
\text { (a) Viscosity determined from best-fit Bingham-Plastic consistency, up-ramp }\end{array}$ \\
(b) Viscosity determined from best-fit Bingham-Plastic consistency. \\
(c) Viscosity determined from best-fit Newtonian viscosity. \\
\hline
\end{tabular}

\subsection{Filter Flux Test Matrix and Initial Dewater}

This section describes the filtration testing performed using the Group 8 composite sample before leaching, as shown in the left column (colored blue) of Figure 4.1. The following tests were performed. 
- Filtration testing of the composite Group 8 waste slurry at a low-solids concentration as described in Appendix D. Testing compared the effects of TMP, AV, and operation time on filter flux.

- Dewatering of the waste slurry to a higher UDS concentration using a constant TMP and AV to better understand how solids concentration impacted filtration and compare to previous testing of other waste types.

- Filtration testing of the slurry at a high-solids concentration. Like before, testing compared the effects of TMP, AV, and operation time on filter flux.

\subsubsection{Low-Solids Slurry Test Matrix}

After all the slurry samples were collected and the rheology sample was returned to the CUF, the lowsolids filtration test matrix was performed at a measured UDS concentration of $5.9 \mathrm{wt} \%$. The average achieved process parameters and resulting filter fluxes for each filtration test condition are reported in Table 4.8. The measured filter flux over the course of the test matrix is shown in Figure 4.6, where $t=0$ is defined as the starting point of the test matrix.

The achieved experimental test-matrix conditions are mapped in Figure 4.7a as a point of reference. The average filter fluxes from each test condition (shown in Table 4.8) were plotted against TMP, AV, and the median operational time of the test condition to qualitatively gauge their impacts on filtration behavior (see Figure 4.7b-d). The TMP was found to be directly proportional to the filter flux (see Figure 4.7b). The plot for AV (Figure 4.7c) appeared similar to the test-matrix plot (Figure 4.7a), indicating no significant relationship. The plot for filter flux over time (Figure 4.7d) possessed too much scatter to demonstrate any significant trend. Since the TMP was shown to directly affect the filter flux and the AV was shown to have no discernable effect on flux, the effect of time can be evaluated by comparing flux at constant TMP.

Modeling of the data using a least-squares-fit method was then used to quantify the effects of TMP, AV, and relative processing time on filter flux. A linear fit equation with an $\mathrm{R}^{2}$ correlation of 0.98 was developed using TMP and processing time as variables (Figure 4.8). As Figure 4.7b demonstrated, the TMP had a direct impact on filter flux and correlated well with the Darcy equation (Appendix E, Equation E.6), which states that the TMP is linearly proportionally to the filter flux where permeate viscosity and filter resistance are held constant. The model also showed that processing time had a small negative effect on flux, demonstrating that filter resistance was slightly increasing over time by some fouling mechanism occurring with the waste. Due to this transient behavior, the fit for the data shown in Figure 4.8 should be used for general purposes only in that actual results for this waste will be somewhat dependent on filtration time. The AV was shown to have no significant impact on the filter flux from this analysis. This was expected at UDS concentrations well below the gel concentration of the slurry (theoretically equivalent to the measured centrifuged UDS at $\sim 38 \mathrm{wt} \%$; Peterson et al. 2007).

During development of the linear model, a positive offset was created. Therefore, the model does not predict a zero filter flux when the TMP is zero, demonstrating that the input to these models must be bound by the range of TMP used in this filter test, shown in Table 4.8. The use of the model should also be limited to when the test matrix occurred because the filter resistance was not at steady state, and the parameters developed in these models would be expected to change past the 16-hour period that this model predicts. Use of the model should be limited to comparing TMP and AV impacts on filter flux during this test and how filter behavior changed later in the test. 
Table 4.8. Average Operating Conditions and Permeate Flux for Low-Solids Slurry Matrix Test (Slurry UDS Concentration Measured at $5.9 \mathrm{wt} \%$ )

\begin{tabular}{|c|c|c|c|c|c|c|c|}
\hline $\begin{array}{c}\text { Test } \\
\text { Condition }\end{array}$ & $\begin{array}{c}\text { Duration } \\
\text { (h) }\end{array}$ & $\begin{array}{c}\text { Median } \\
\text { Operation } \\
\text { Time }^{(\mathbf{a})} \\
\text { (hh:mm) }\end{array}$ & $\begin{array}{c}\text { Slurry } \\
\text { Temp }^{(b)} \\
\left({ }^{\circ} \mathbf{C}\right)\end{array}$ & $\begin{array}{l}\text { TMP }^{(\mathrm{c})} \\
\text { (psid) }\end{array}$ & $\begin{array}{c}\text { AV } \\
(\mathbf{f t} / \mathbf{s})\end{array}$ & $\begin{array}{c}\text { Corrected } \\
\text { Filter Flux } \\
(\mathbf{d}) \\
\left(\mathbf{G P M} / \mathbf{f t}^{2}\right)\end{array}$ & $\begin{array}{c}\text { Axial } \\
\text { Pressure } \\
\text { Drop }^{(\mathrm{c})} \\
(\mathrm{psid} / \mathrm{ft})\end{array}$ \\
\hline 1 & 3.2 & $1: 34$ & 24.8 & 40.4 & 13.4 & 0.030 & 2.3 \\
\hline 2 & 1.0 & $3: 53$ & 24.6 & 30.9 & 11.1 & 0.028 & 1.7 \\
\hline 3 & 1.0 & $5: 04$ & 24.8 & 29.4 & 15.1 & 0.024 & 2.9 \\
\hline 4 & 1.0 & $6: 18$ & 25.3 & 49.9 & 15.1 & 0.037 & 2.8 \\
\hline 5 & 1.0 & $7: 31$ & 25.0 & 49.6 & 11.1 & 0.036 & 1.7 \\
\hline 6 & 1.0 & $8: 39$ & 25.1 & 41.0 & 12.9 & 0.032 & 2.3 \\
\hline 7 & 1.0 & $9: 50$ & 24.9 & 39.9 & 8.9 & 0.030 & 1.1 \\
\hline 8 & 1.2 & 11:13 & 25.3 & 39.6 & 16.4 & 0.029 & 3.0 \\
\hline 9 & 1.1 & $12: 35$ & 24.4 & 19.9 & 13.0 & 0.016 & 2.2 \\
\hline 10 & 1.0 & 13:44 & 25.4 & 59.3 & 13.1 & 0.041 & 1.9 \\
\hline 11 & 1.1 & $14: 51$ & 25.1 & 39.5 & 13.1 & 0.029 & 2.2 \\
\hline \multicolumn{8}{|c|}{$\begin{array}{l}\text { TMP }=\text { transmembrane pressure } \\
\mathrm{AV}=\text { axial velocity } \\
\text { (a) Median operation time refers to the midpoint in processing time of the specific filtration test condition } \\
\text { relative to the start time of the test }(\mathrm{T}=0) \text {. } \\
\text { (b) Accuracy of thermocouple was } \pm 2^{\circ} \mathrm{C} . \\
\text { (c) Accuracy of pressure transducers was } \pm 1 \text { psig. } \\
\text { (d) The filter flux was calculated from the time-weighted average of the temperature-corrected permeate } \\
\text { flow rate during each test condition and was converted to filter flux by dividing the flow rate by the } \\
\text { surface area of the filter }\left(0.26 \mathrm{ft}^{2}\right) \text {. The corrected permeate flow rate was calculated using Equation E. } 3 \\
\text { in Appendix E to normalize the filter flux data to } 25^{\circ} \mathrm{C} \text {. }\end{array}$} \\
\hline
\end{tabular}




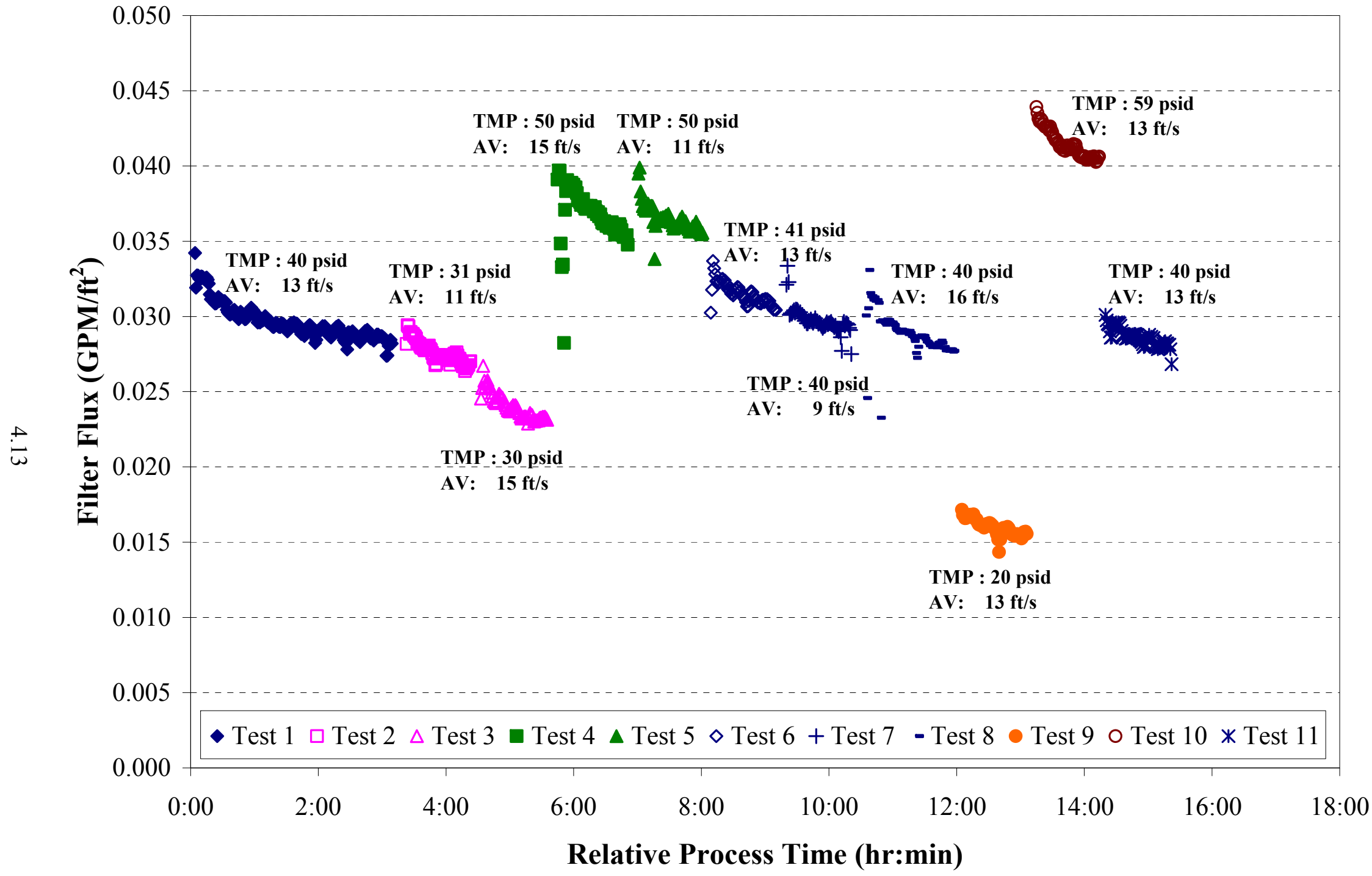

Figure 4.6. Filter Flux Data for Low-Solids Slurry Matrix (Measured UDS of 5.9 wt\%) 


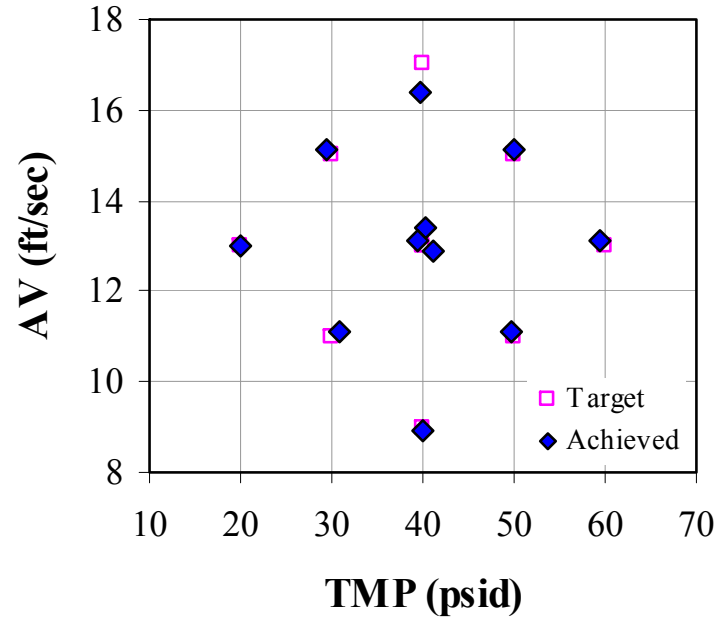

a) Experimental Filter Test Matrix Flux vs. TMP

$\stackrel{+}{+}$

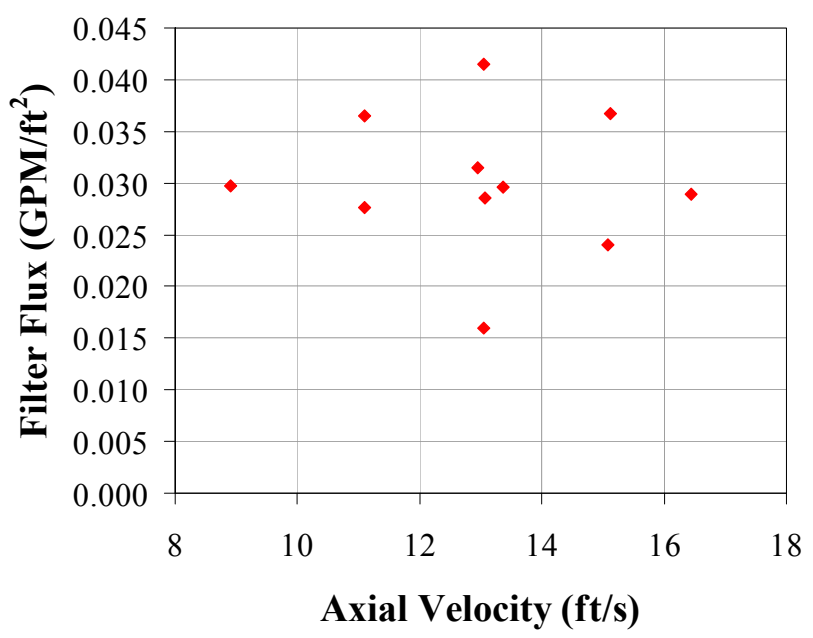

c) Filter Flux vs. Axial Velocity

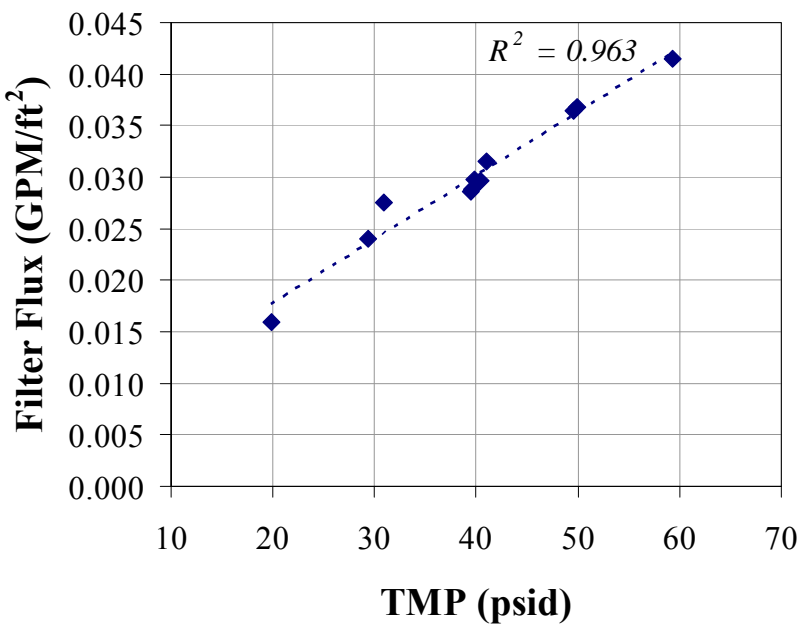

b) Filter Flux vs. TMP

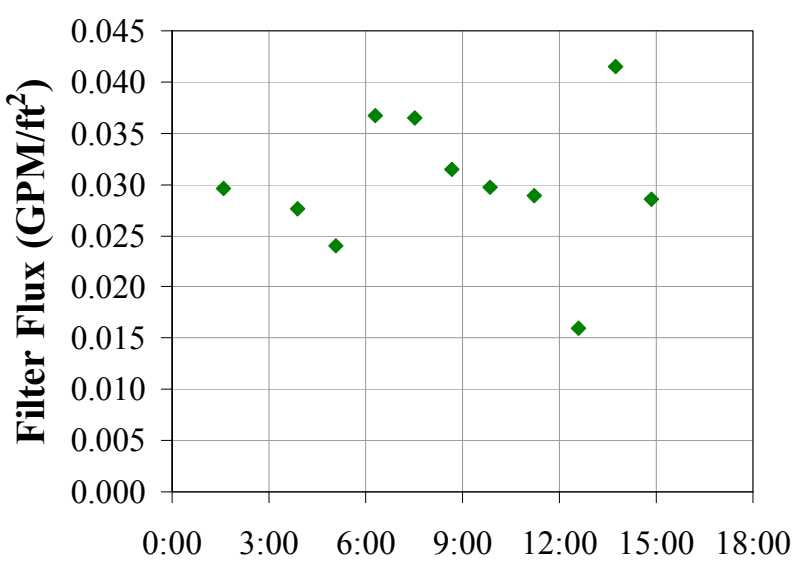

Relative Processing Time (hh:mm)

d) Filter Flux vs Median Operation Time

Figure 4.7. Filter Flux Performance for Low-Solids Slurry (Measured UDS of $5.9 \mathrm{wt} \%$ ) 


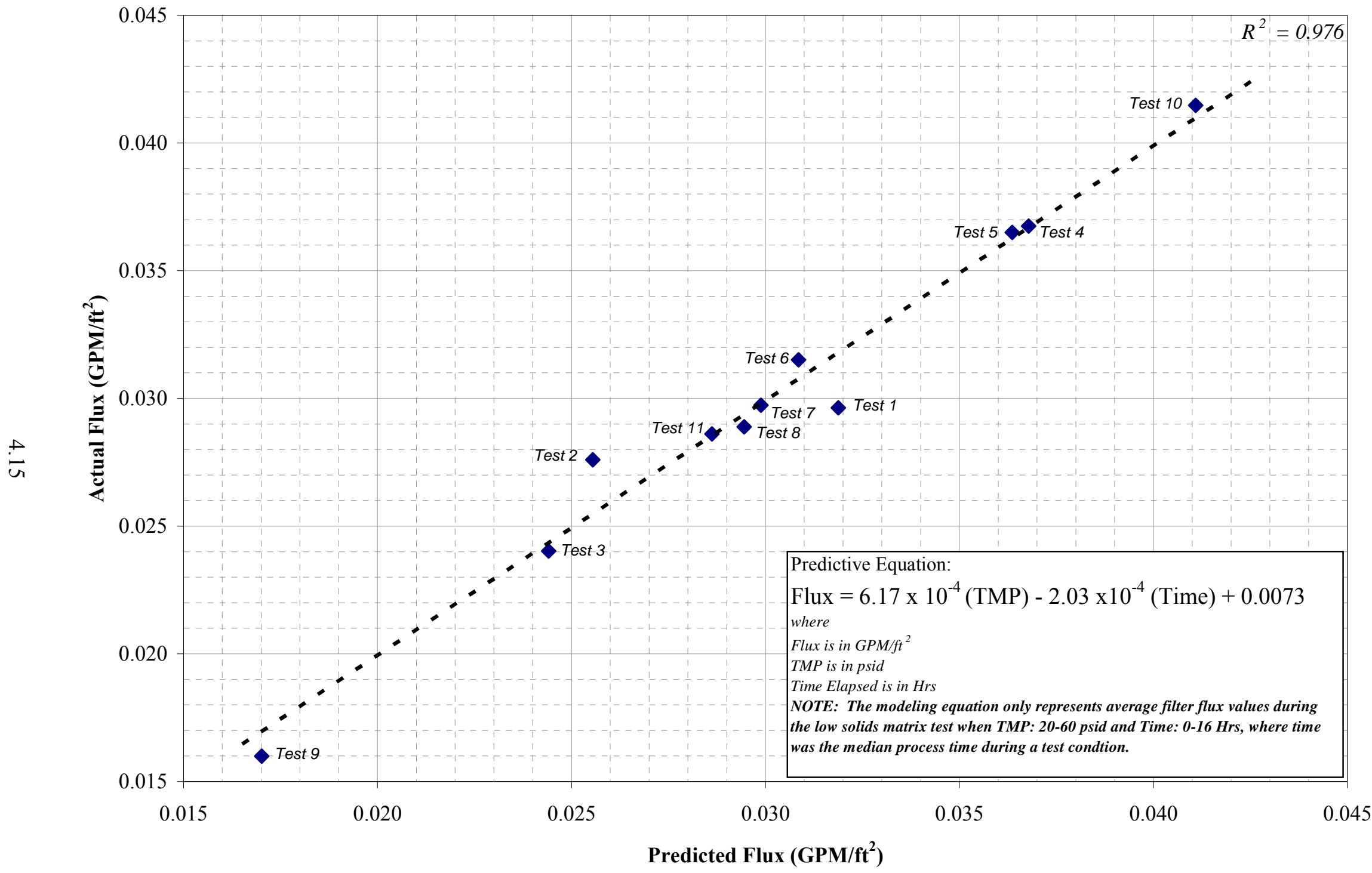

Figure 4.8. Correlation of Average Flux as a Function of TMP for the Low-Solids Slurry (Measured UDS of 5.9 wt\%) 
WTP-RPT-170, Rev. 0

\subsubsection{Dewatering of Group 8 Waste}

After completing the low-solids-filtration matrix test, the slurry was to be dewatered to a target UDS concentration of $\sim 15 \mathrm{wt} \%$. An overview of the test activities and mass balance are shown in Figure 4.9 and Table 4.9. The dewatering occurred over an 80 -min period where approximately $2.1 \mathrm{~L}$ of permeate were collected. The average filter flux was measured as $0.027 \mathrm{GPM} / \mathrm{ft}^{2}$ through the dewatering operation, as shown in Figure 4.10. Increasing the UDS concentration of the slurry to $14 \mathrm{wt} \%$ did not correlate to a significant decrease $(>10 \%)$ in the slurry filter flux. Examination of the physical-property results predicted that the gel concentration of the slurry (taken from the centrifuge UDS concentration) was $38 \mathrm{wt} \%$. Therefore, it was likely that the slurry could be dewatered further before solids concentration effects became significant.

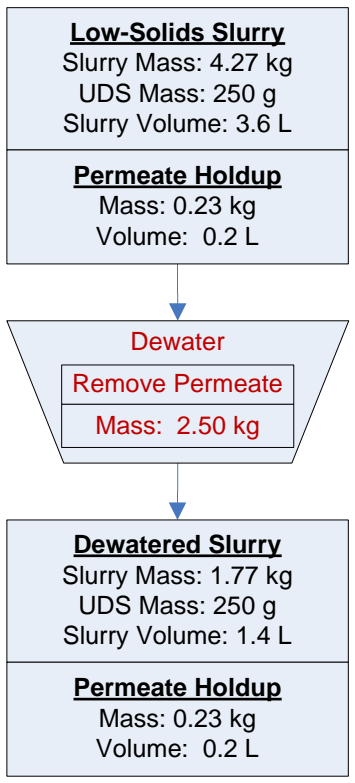

Figure 4.9. Process Flow for Dewatering Group 8 Slurry

Table 4.9. Mass Balance Overview of Dewatering

\begin{tabular}{||l|c|c|c|c|c|c||}
\hline \multicolumn{1}{|c|}{ Step } & $\begin{array}{c}\text { Change in } \\
\text { Mass } \\
(\mathbf{g})\end{array}$ & $\begin{array}{c}\text { Total } \\
\text { Mass } \\
(\mathbf{g})\end{array}$ & $\begin{array}{c}\text { Estimated } \\
\text { Solids Mass } \\
(\mathbf{g})\end{array}$ & $\begin{array}{c}\text { Slurry } \\
\text { Circulating } \\
\text { Mass (g) }\end{array}$ & $\begin{array}{c}\text { Estimated } \\
\text { Slurry UDS } \\
(\mathbf{w t \%})\end{array}$ & $\begin{array}{c}\text { Measured } \\
\text { Slurry UDS } \\
(\mathbf{w t \% )}\end{array}$ \\
\hline Low-Solids Slurry & na & 4500 & 250 & 4270 & 5.8 & 5.9 \\
\hline Dewatered Slurry & -2500 & 2000 & 250 & 1770 & 14 & na \\
\hline
\end{tabular}

Near the end of the dewatering operation, it became difficult to maintain standard filtration conditions (TMP $=40 \mathrm{psid}, \mathrm{AV}=13 \mathrm{ft} / \mathrm{s}$ ), which was inferred to be associated with pump cavitation. Dewatering operations were stopped shortly after 70 minutes to visually examine the slurry level in the slurry reservoir. A layer of foam was observed on top of the slurry with a significant vortex being formed by the mixer. Observed foaming of the waste impacted pumping efficiency, but did not directly impact filtration. The mixer was turned off at this point with the pump still operating. The foam layer on top of the slurry dissipated after 20 minutes, which corresponded to an increase in pumping efficiency. 
Dewatering operations were resumed afterwards for another 7 minutes until the cavitation of the pump was observed again.

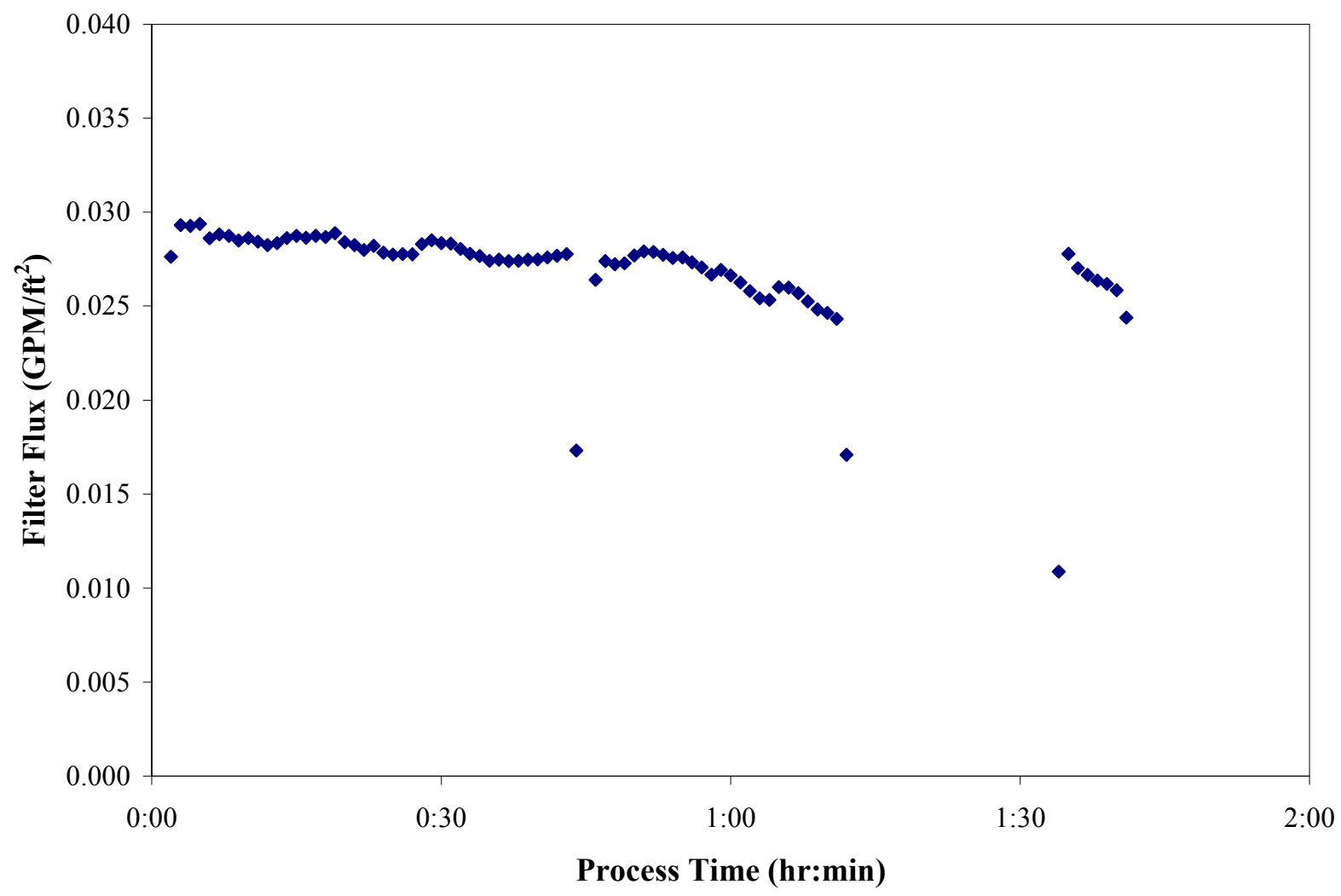

Figure 4.10. Filter Flux During Dewatering of Group 8 Low-Solids Slurry from $5.9 \mathrm{wt} \%$ to $14 \mathrm{wt} \%$ UDS (Dewatering paused to restore TMP and AV conditions)

\subsubsection{High-Solids Matrix}

Initially, the high-solids test-matrix was performed with the estimated $14 \mathrm{wt} \%$ UDS slurry produced from the dewatering operation described in the previous section. However, a majority of test-condition parameters could not be met. At this point, $\sim 0.1 \mathrm{~kg}$ of permeate was returned to the slurry to improve pumping efficiency while decreasing the slurry UDS concentration to $13 \mathrm{wt} \%$ (see Figure 4.11). Physical-property measurements taken after the filtration matrix test confirmed the estimated UDS value (Table 4.10). 
WTP-RPT-170, Rev. 0

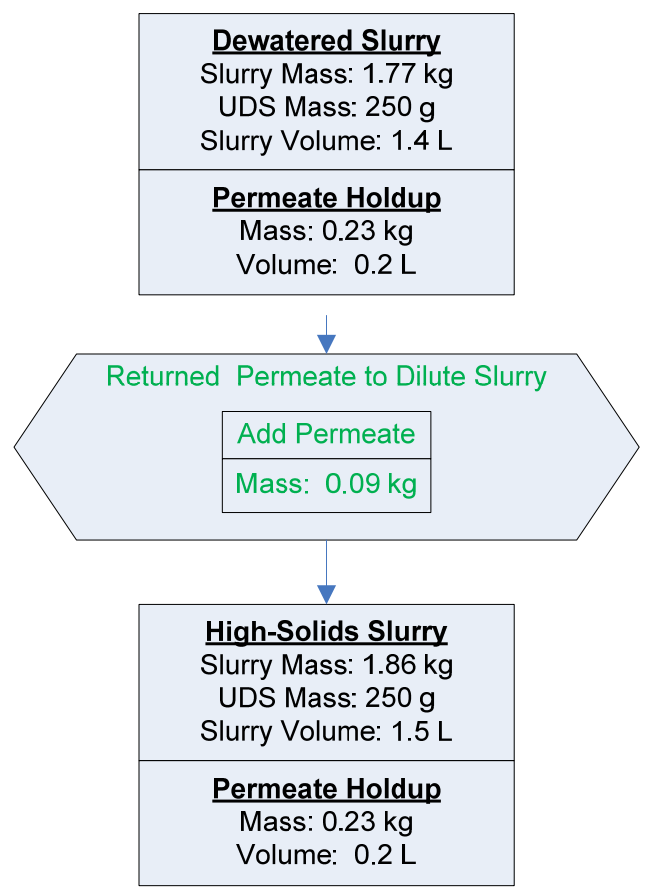

Figure 4.11. Dilution of Dewatered Slurry for High-Solids Matrix Test

Table 4.10. Mass Balance Overview of Dilution of Dewatered Slurry to $13 \mathrm{wt} \%$ UDS

\begin{tabular}{|c|c|c|c|c|c|c|}
\hline Step & $\begin{array}{c}\text { Change in } \\
\text { Mass } \\
(\mathbf{g})\end{array}$ & $\begin{array}{c}\text { Total } \\
\text { Mass } \\
(\mathbf{g})\end{array}$ & $\begin{array}{c}\text { Estimated } \\
\text { Solids Mass } \\
(\mathbf{g})\end{array}$ & $\begin{array}{c}\text { Slurry } \\
\text { Circulating } \\
\text { Mass (g) }\end{array}$ & $\begin{array}{c}\text { Estimated } \\
\text { Slurry UDS } \\
(\mathbf{w t} \%)\end{array}$ & $\begin{array}{c}\text { Measured } \\
\text { Slurry UDS } \\
\text { (wt\%) }\end{array}$ \\
\hline Dewatered Slurry & na & 2000 & 250 & 1770 & 14 & na \\
\hline High Solids Slurry & +90 & 2090 & 250 & 1860 & 13 & na \\
\hline $\begin{array}{c}\text { High Solids Slurry } \\
\text { after Sampling }\end{array}$ & -110 & 1980 & 230 & 1750 & 13 & 13 \\
\hline
\end{tabular}

Table 4.11 summarizes the achieved process parameters and resulting average filter fluxes for each filtration test condition of the high-solids matrix, as shown in Figure 4.12. Despite efforts to improve the pumping efficiency, Test Condition 8 still fell short of the targeted AV; in this case, an AV of $13.8 \mathrm{ft} / \mathrm{s}$ was attained instead of the targeted $17 \mathrm{ft} / \mathrm{s}$. The average flux ranged from $0.014 \mathrm{GPM} / \mathrm{ft}^{2}$ to $0.031 \mathrm{GPM} / \mathrm{ft}^{2}$. The filter fluxes at the standard conditions (TMP $=40 \mathrm{psid}$ and $\mathrm{AV}=13 \mathrm{ft} / \mathrm{s}$ ) were consistently measured as $0.025 \mathrm{GPM} / \mathrm{ft}^{2}$, indicating that the filter was no longer experiencing fouling over time.

The average filter flux from each test condition (Table 4.11) was plotted against TMP, AV, and the median operational time of the test condition to qualitatively gauge their impact, as shown in Figure 4.13. As with the low-solids slurry, the TMP was found to be directly proportional to the filter flux (Figure 4.13b). Trends were difficult to decipher from plots for AV (Figure 4.13c) and processing time (Figure 4.13d). The AV plot did not correlate directly to the achieved test conditions (Figure 4.13a), indicating scatter in the collected data.

Modeling of the data using a least-squares-fit method was used to quantify the effects of TMP, AV, and processing time on filter flux. A linear fit equation with an $\mathrm{R}^{2}$ correlation of 0.93 was developed using 
WTP-RPT-170, Rev. 0

TMP and AV as variables (Figure 4.14). Much like Figure 4.13b, the model demonstrated that the TMP significantly impacted the filter flux. The model also showed that increased AV had a similar positive effect on flux that was not seen in the low-solids matrix test. This indicated that the UDS concentration was high enough to begin impacting filter flux, which was not seen in the dewatering operation.

Modeling confirmed that processing time was no longer influencing filter-flux behavior, indicating that the filter was now "conditioned" after 2 days of operation.

During development of the linear model, a negative offset was created. Therefore, the model does not predict a zero filter flux when the TMP and AV are zero, demonstrating that the input to these models must be bound by the range of TMP and AV used in this filter test, shown in Table 4.11. The model should only be used when comparing TMP and AV impacts on filter flux during this test and demonstrating how filter behavior changed after dewatering the waste slurry.

Table 4.11. Average Operating Conditions and Permeate Fluxes for High-Solids Matrix Test (Measured $13 \mathrm{wt} \%$ UDS)

\begin{tabular}{|c|c|c|c|c|c|c|c|}
\hline $\begin{array}{c}\text { Test } \\
\text { Condition } \\
\end{array}$ & $\begin{array}{c}\text { Duration } \\
\text { (h) }\end{array}$ & $\begin{array}{c}\text { Median } \\
\text { Operation } \\
\text { Time }^{(a)} \\
\text { (hh:mm) } \\
\end{array}$ & $\begin{array}{c}\text { Slurry } \\
\text { Temp }^{(\mathbf{b})} \\
\left({ }^{\circ} \mathrm{C}\right)\end{array}$ & $\begin{array}{l}\text { TMP } \\
\text { (psid) }\end{array}$ & $\begin{array}{l}\text { AV } \\
(\mathbf{f t} / \mathbf{s})\end{array}$ & $\begin{array}{c}\text { Corrected } \\
\text { Filter } \\
\text { Flux }^{(\mathbf{d})} \\
\left(\mathbf{G P M} / \mathbf{f t}^{2}\right) \\
\end{array}$ & $\begin{array}{c}\text { Axial } \\
\text { Pressure } \\
\text { Drop }^{(\mathbf{b})} \\
\text { (psid/ft) }^{\text {pef }} \\
\end{array}$ \\
\hline 1 & 3.0 & $1: 33$ & 25.0 & 39.7 & 13.1 & 0.025 & 2.4 \\
\hline 2 & 1.0 & $3: 39$ & 24.8 & 29.5 & 11.6 & 0.020 & 1.9 \\
\hline 3 & 1.3 & $4: 55$ & 25.1 & 30.3 & 14.8 & 0.019 & 2.8 \\
\hline 4 & 1.1 & $6: 16$ & 28.5 & 49.4 & 14.4 & 0.030 & 2.9 \\
\hline 5 & 1.1 & $7: 34$ & 25.0 & 50.0 & 10.9 & 0.026 & 2.0 \\
\hline 6 & 1.0 & $8: 48$ & 25.2 & 39.8 & 12.9 & 0.025 & 2.3 \\
\hline 7 & 1.0 & $9: 54$ & 24.9 & 38.6 & 9.0 & 0.021 & 1.7 \\
\hline 8 & 1.0 & $11: 05$ & 25.4 & 39.6 & $13.8^{(\mathrm{e})}$ & 0.026 & 2.8 \\
\hline 9 & 1.0 & $12: 16$ & 25.1 & 20.7 & 12.9 & 0.014 & 2.4 \\
\hline 10 & 1.0 & $13: 30$ & 28.9 & 60.1 & 12.5 & 0.031 & 2.6 \\
\hline 11 & 1.1 & $14: 42$ & 25.3 & 39.7 & 13.2 & 0.025 & 2.7 \\
\hline \multicolumn{8}{|c|}{ TMP $=$ transmembrane pressure } \\
\hline \multicolumn{8}{|c|}{$\mathrm{AV}=$ axial velocity } \\
\hline \multicolumn{8}{|c|}{$\begin{array}{l}\text { (a) Median operation time refers to the midpoint in } \mathrm{p} \\
\text { condition relative to the start time of the test }(\mathrm{T}=\end{array}$} \\
\hline \multicolumn{8}{|c|}{ (b) Accuracy of thermocouple was $\pm 2^{\circ} \mathrm{C}$. } \\
\hline \multicolumn{8}{|c|}{ (c) Accuracy of pressure transducers was \pm 1 psig. } \\
\hline \multicolumn{8}{|c|}{ E.3 in Appendix E to normalize the filter flux data to $25^{\circ} \mathrm{C}$. } \\
\hline \multicolumn{8}{|c|}{$\begin{array}{l}\text { (e) The target test condition of } 17 \mathrm{ft} / \mathrm{s} \text { could not be achieved because of pump cavitation. The } 13.8 \mathrm{ft} / \mathrm{s} \\
\text { was the maximum achievable. }\end{array}$} \\
\hline
\end{tabular}




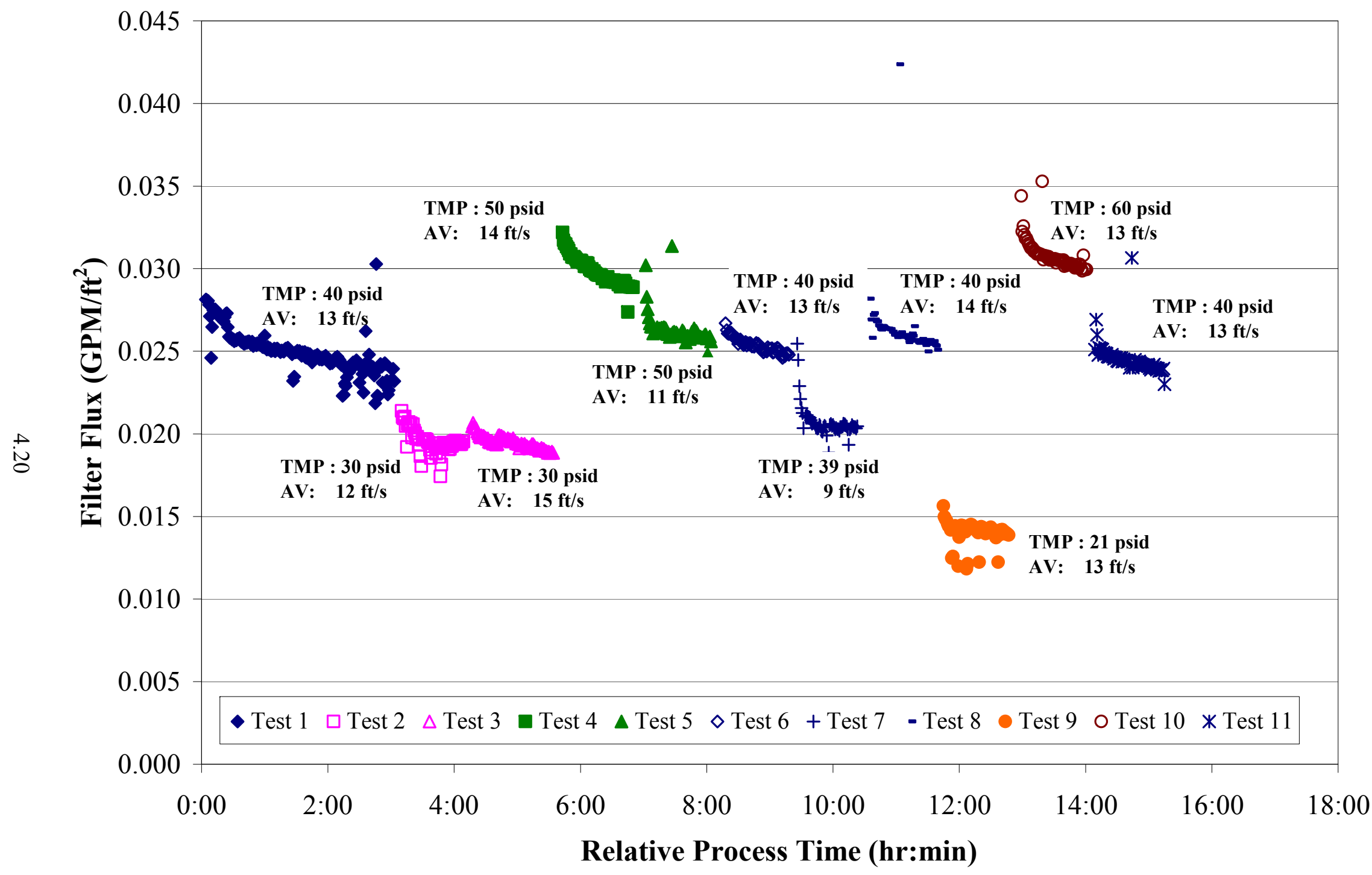

Figure 4.12. Filter-Flux Data for High Solids Matrix (Measured UDS of $13 \mathrm{wt} \%$ ) 


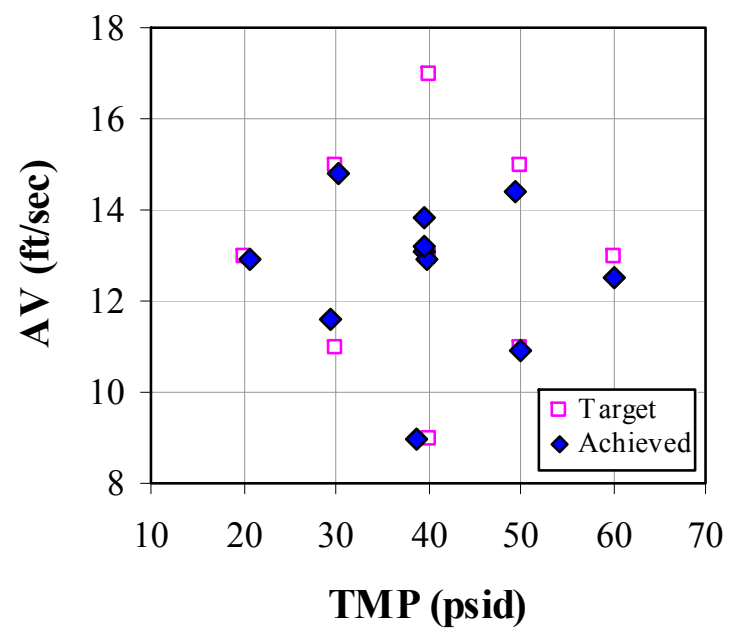

a) Experimental Filter Test Matrix Flux vs. TMP

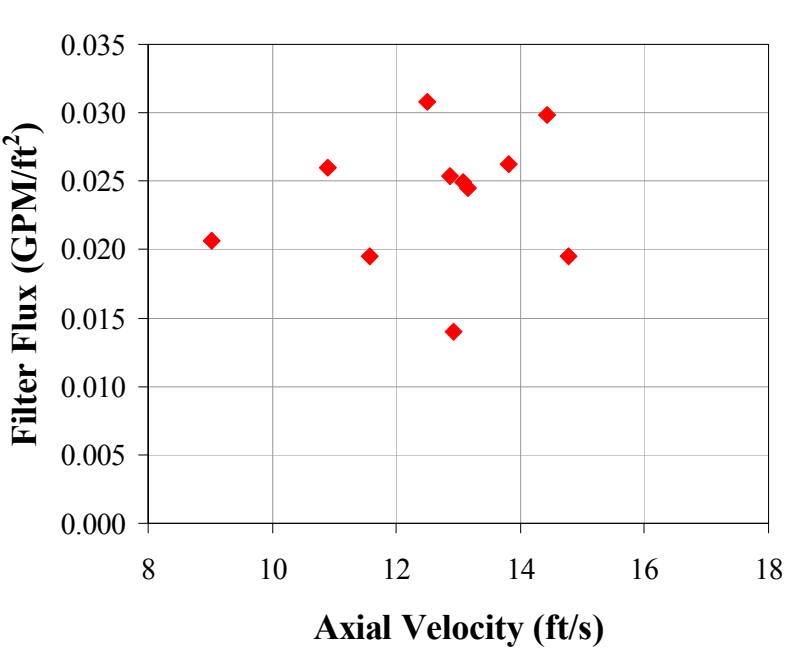

c) Filter Flux vs. Axial Velocity

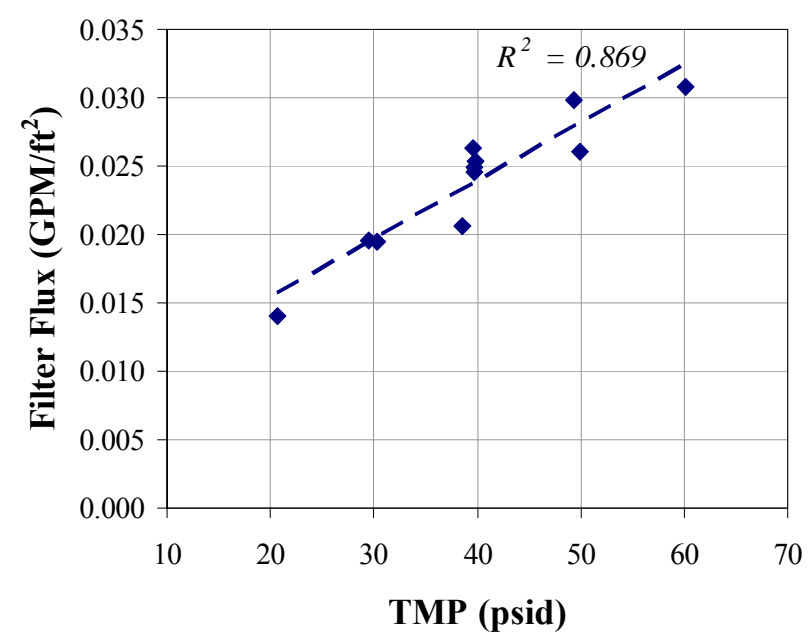

b) Filter Flux vs. TMP

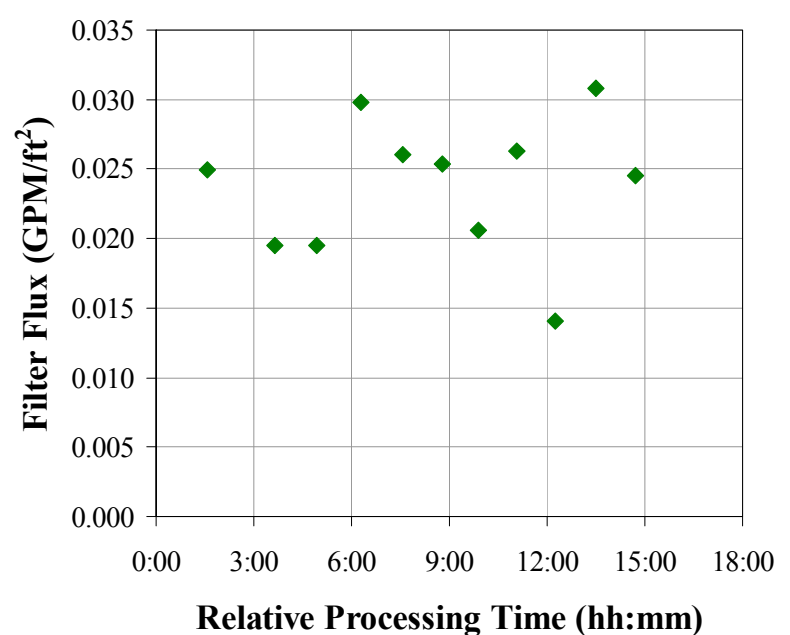

d) Filter Flux vs. Processing Time 


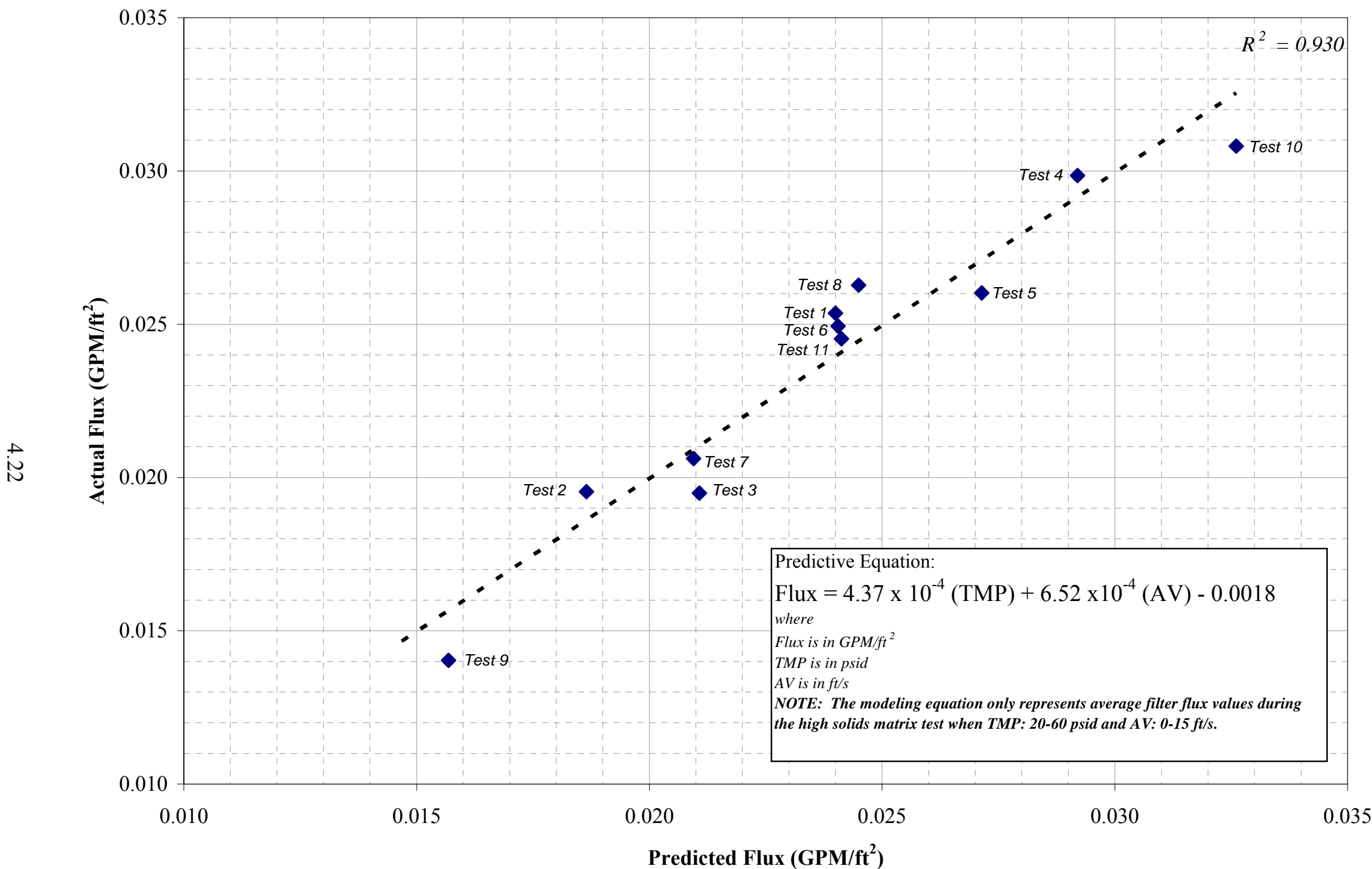

Figure 4.14. Least Square Fit to High-Solids Matrix Test Results to Linear Model (Measured UDS of 13 wt\%) 
WTP-RPT-170, Rev. 0

\subsection{High-Solids Slurry Characterization}

At the completion of the high-solids filtration test matrix, the slurry in the recirculation loop was sampled for physical and chemical analysis (as shown in Figure 4.15). Physical-property measurements of the sample slurry are shown in Table 4.12. Measurements of the UDS concentration matched the predicted concentration $(0.25 \mathrm{~kg} / 1.86 \mathrm{~kg} \sim 13 \mathrm{wt} \%)$.

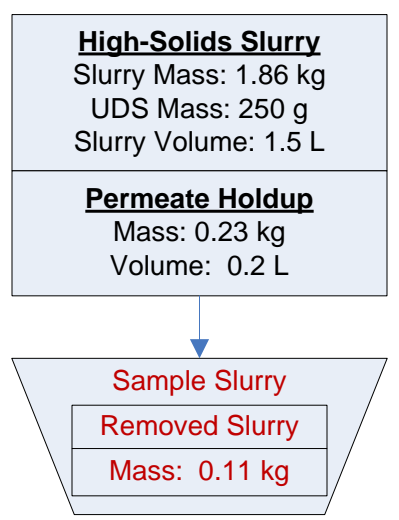

Figure 4.15. Process Flow Through the High-Solids Matrix

Table 4.12. High-Solids Slurry Physical-Property Measurements (Inside Slurry Loop)

\begin{tabular}{|r|c||}
\hline Slurry Density (g/mL) & 1.3 \\
\hline Supernate Density (g/mL) & 1.2 \\
Settled Solids (vol\%) & 64 \\
\hline Centrifuged Undissolved Solids (wt \%) & 44 \\
\hline Total Solids (wt\%) & 31 \\
\hline Supernate Dissolved Solids (wt \%) & 20 \\
\hline Undissolved Solids (wt\%) & 13 \\
\hline
\end{tabular}

The high-solids total slurry and phase-specific compositions before caustic leaching were calculated using two methods.

1) Table 4.13 shows the compositions based on the overall mass balance (Appendix E, Section E.3) in conjunction with the initial characterization results (Appendix E, Equations E.10- E.12).

2) Table 4.14 shows the measured composition of the slurry (dry-mass basis) and supernatant with the calculated dry-solids component composition (Appendix E, Equation E.13).

The majority of analyte concentrations in the solids and aqueous phases calculated using both methods agreed with each other. However, the calculated $\mathrm{S}$ and $\mathrm{Na}$ contents in the solids phase showed significant (factor of 2) discrepancies. Both of these analytes resided primarily in the aqueous phase. The difference of these two large component masses (from the combined slurry and the supernatant, each with $15 \%$ relative uncertainty) will result in a relatively small component mass with a high uncertainty using the methods described above. 
Table 4.13. Group 8 High-Solids Slurry Composition Based on Mass-Balance Calculation (Mass Calculation Included Permeate Hold-up)

\begin{tabular}{|c|c|c|c|c|c|}
\hline & Slurry ${ }^{(a)}$ & \multicolumn{2}{|c|}{ Liquid Fraction $^{(\mathbf{b})}$} & \multicolumn{2}{|c|}{ Solids Fraction ${ }^{(\mathrm{c})}$} \\
\hline Mass (kg) & 1.98 & \multicolumn{2}{|c|}{1.74} & \multicolumn{2}{|c|}{0.23} \\
\hline Wt\% of Slurry & $100 \mathrm{wt} \%$ & \multicolumn{2}{|c|}{$88.2 \mathrm{wt} \%$} & \multicolumn{2}{|c|}{$11.8 \mathrm{wt} \%$} \\
\hline ICP-OES Analyte & g & g & $\mu \mathrm{g} / \mathrm{mL}$ & g & $\mu \mathrm{g} / \mathrm{g}$ \\
\hline Al & $2.3 \mathrm{E}+01$ & $2.2 \mathrm{E}+00$ & $1.5 \mathrm{E}+03$ & $2.1 \mathrm{E}+01$ & $8.8 \mathrm{E}+04$ \\
\hline Bi & $1.4 \mathrm{E}+00$ & $0.0 \mathrm{E}+00$ & $<3.8 \mathrm{E}+00$ & $1.4 \mathrm{E}+00$ & $6.0 \mathrm{E}+03$ \\
\hline $\mathrm{Cr}$ & $6.3 \mathrm{E}-01$ & $1.2 \mathrm{E}-01$ & $8.0 \mathrm{E}+01$ & $5.1 \mathrm{E}-01$ & $2.2 \mathrm{E}+03$ \\
\hline $\mathbf{F e}$ & $2.5 \mathrm{E}+01$ & $3.6 \mathrm{E}-02$ & $2.4 \mathrm{E}+01$ & $2.5 \mathrm{E}+01$ & $1.1 \mathrm{E}+05$ \\
\hline Mn & $3.1 \mathrm{E}-01$ & $1.2 \mathrm{E}-04$ & $8.0 \mathrm{E}-02$ & $3.1 \mathrm{E}-01$ & $1.3 \mathrm{E}+03$ \\
\hline $\mathbf{N a}$ & $1.4 \mathrm{E}+02$ & $1.2 \mathrm{E}+02$ & $7.9 \mathrm{E}+04$ & $1.9 \mathrm{E}+01$ & $8.0 \mathrm{E}+04$ \\
\hline $\mathbf{P}$ & $1.3 \mathrm{E}+01$ & $3.7 \mathrm{E}+00$ & $2.4 \mathrm{E}+03$ & $8.9 \mathrm{E}+00$ & $3.8 \mathrm{E}+04$ \\
\hline $\mathbf{S}$ & $4.6 \mathrm{E}+00$ & $3.4 \mathrm{E}+00$ & $2.2 \mathrm{E}+03$ & $1.2 \mathrm{E}+00$ & $5.1 \mathrm{E}+03$ \\
\hline Si & $4.0 \mathrm{E}+00$ & $2.6 \mathrm{E}-02$ & $1.7 \mathrm{E}+01$ & $3.9 \mathrm{E}+00$ & $1.7 \mathrm{E}+04$ \\
\hline $\mathrm{Sr}$ & $9.7 \mathrm{E}+00$ & $1.6 \mathrm{E}-04$ & $1.1 \mathrm{E}-01$ & $9.7 \mathrm{E}+00$ & $4.2 \mathrm{E}+04$ \\
\hline $\mathbf{U}$ & $2.8 \mathrm{E}+01$ & $1.7 \mathrm{E}-02$ & $1.2 \mathrm{E}+01$ & $2.8 \mathrm{E}+01$ & $1.2 \mathrm{E}+05$ \\
\hline Radionuclides & $\mu \mathbf{C i}$ & $\mu \mathrm{Ci}$ & $\mu \mathrm{Ci} / \mathbf{m L}$ & $\mu \mathbf{C i}$ & $\mu \mathrm{Ci} / \mathrm{g}$ \\
\hline${ }^{60} \mathrm{Co}$ & $2.5 \mathrm{E}+00$ & $<2$.E-1 & $<1$. E-4 & $2.5 \mathrm{E}+00$ & $1.1 \mathrm{E}-02$ \\
\hline${ }^{137} \mathrm{Cs}$ & $1.2 \mathrm{E}+05$ & $3.1 \mathrm{E}+04$ & $2.0 \mathrm{E}+01$ & $9.1 \mathrm{E}+04$ & $3.9 \mathrm{E}+02$ \\
\hline${ }^{154} \mathbf{E u}$ & $3.3 \mathrm{E}+01$ & $<6 . \mathrm{E}-1$ & $<4$.E-4 & $3.3 \mathrm{E}+01$ & $1.4 \mathrm{E}-01$ \\
\hline${ }^{241} \mathrm{Am}$ & $4.4 \mathrm{E}+01$ & $<8 . \mathrm{E}+0$ & $<5$.E-3 & $4.4 \mathrm{E}+01$ & $1.9 \mathrm{E}-01$ \\
\hline Gross Alpha & $2.0 \mathrm{E}+02$ & $<3$.E-1 & $<2$.E-4 & $2.0 \mathrm{E}+02$ & 8.7E-01 \\
\hline Gross Beta & $7.3 \mathrm{E}+05$ & $3.1 \mathrm{E}+04$ & $2.0 \mathrm{E}+01$ & $7.0 \mathrm{E}+05$ & $3.0 \mathrm{E}+03$ \\
\hline${ }^{90} \mathrm{Sr}$ & $3.0 \mathrm{E}+05$ & $8.9 \mathrm{E}+00$ & $5.9 \mathrm{E}-03$ & $3.0 \mathrm{E}+05$ & $1.3 \mathrm{E}+03$ \\
\hline${ }^{239+240} \mathrm{Pu}$ & $1.3 \mathrm{E}+02$ & $5.1 \mathrm{E}-02$ & $3.3 \mathrm{E}-05$ & $1.3 \mathrm{E}+02$ & 5.6E-01 \\
\hline${ }^{238} \mathrm{Pu}$ & $3.1 \mathrm{E}+00$ & 4.9E-03 & $3.3 \mathrm{E}-06$ & $3.1 \mathrm{E}+00$ & $1.3 \mathrm{E}-02$ \\
\hline
\end{tabular}

(a) Slurry component masses were calculated from characterization data (Section 3), added simulant component masses, and removed supernatant component masses. Mass loss from sampling was included.

(b) Liquid Fraction component masses were calculated using analytical results from supernate sample TI640-G8-A (ASO ID 08-2283) and the predicted mass of supernate in the system.

(c) Solids Fraction component masses were calculated from the difference between the slurry and liquid fraction. Solids fraction compositions were then calculated by dividing the mass of the components in the solids phase of the slurry by the estimated mass of solids material in the slurry. 
WTP-RPT-170, Rev. 0

Table 4.14. Group 8 High-Solids Slurry Composition Based on ICP-OES/Radionuclide Characterization

\begin{tabular}{|c|c|c|c|c|}
\hline $\begin{array}{c}\text { Slurry Prep } \\
\text { Method }\end{array}$ & $\begin{array}{c}\text { ICP-OES } \\
\text { Analytes }\end{array}$ & $\begin{array}{c}\text { Dry Slurry } \\
(\mu \mathrm{g} / \mathrm{g})\end{array}$ & $\begin{array}{c}\text { Supernate }_{(\boldsymbol{g})}^{(b)} \\
(\mathrm{mL})\end{array}$ & $\begin{array}{c}\text { Dry Solids }{ }^{(\mathrm{c})} \\
(\mu \mathrm{g} / \mathrm{g})\end{array}$ \\
\hline \multirow{29}{*}{ 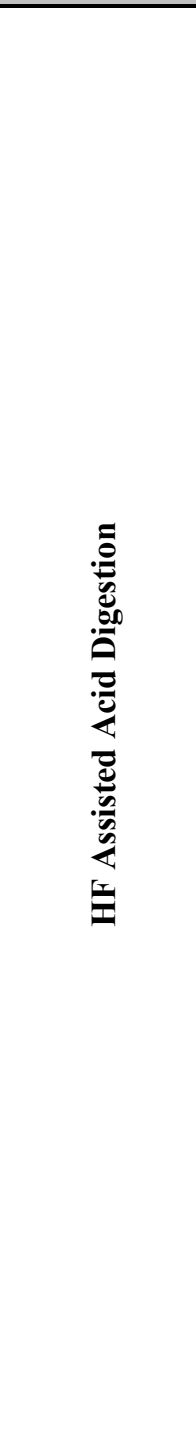 } & $\mathrm{Al}$ & $3.90 \mathrm{E}+04$ & $1.47 \mathrm{E}+03$ & $8.5 \mathrm{E}+04$ \\
\hline & $\mathrm{Bi}$ & $2.43 \mathrm{E}+03$ & $<3.8 \mathrm{E}+0$ & $5.8 \mathrm{E}+03$ \\
\hline & $\mathrm{Cd}$ & $1.20 \mathrm{E}+01$ & {$[1.6 \mathrm{E}+0]$} & $1.9 \mathrm{E}+01$ \\
\hline & $\mathrm{Cr}$ & $1.02 \mathrm{E}+03$ & $8.00 \mathrm{E}+01$ & $2.0 \mathrm{E}+03$ \\
\hline & $\mathrm{Fe}$ & $4.37 \mathrm{E}+04$ & {$[2.4 \mathrm{E}+1]$} & $1.0 \mathrm{E}+05$ \\
\hline & $\mathrm{Mn}$ & $5.68 \mathrm{E}+02$ & [8.7E-2] & $1.4 \mathrm{E}+03$ \\
\hline & $\mathrm{Ni}$ & $1.48 \mathrm{E}+04$ & $5.41 \mathrm{E}+01$ & $3.5 \mathrm{E}+04$ \\
\hline & $\mathrm{P}$ & $2.12 \mathrm{E}+04$ & $2.45 \mathrm{E}+03$ & $3.6 \mathrm{E}+04$ \\
\hline & $\mathrm{S}$ & $6.60 \mathrm{E}+03$ & $2.24 \mathrm{E}+03$ & $2.5 \mathrm{E}+03$ \\
\hline & $\mathrm{Sr}$ & $1.70 \mathrm{E}+04$ & [1.0E-1] & $4.1 \mathrm{E}+04$ \\
\hline & $\mathrm{U}$ & $4.69 \mathrm{E}+04$ & $1.30 \mathrm{E}+01$ & $1.1 \mathrm{E}+05$ \\
\hline & $\mathrm{Zn}$ & $2.35 \mathrm{E}+02$ & {$[1.8 \mathrm{E}+0]$} & $5.5 \mathrm{E}+02$ \\
\hline & $\mathrm{Zr}$ & $1.20 \mathrm{E}+02$ & $<1.4 \mathrm{E}-1$ & $2.9 \mathrm{E}+02$ \\
\hline & $\mathrm{Ag}$ & {$[1.2 E+1]$} & $4.2 E-01$ & {$[2.6 E+1]$} \\
\hline & $B a$ & $3.9 E+02$ & [1.4E-1] & $9.4 E+02$ \\
\hline & $\mathrm{Be}$ & {$[5.0 E-1]$} & $<6.6 E-3$ & {$[1.2 E+0]$} \\
\hline & $C a$ & $2.5 E+04$ & $4.5 E+00$ & $6.0 E+04$ \\
\hline & $\mathrm{Ce}$ & {$[3.5 E+1]$} & $<1.3 E+0$ & {$[7.6 E+1]$} \\
\hline & $\mathrm{Cu}$ & $5.5 E+01$ & $<1.8 E-1$ & $1.3 E+02$ \\
\hline & $L a$ & {$[5.1 E+1]$} & $<3.5 E-1$ & {$[1.2 E+2]$} \\
\hline & $\mathrm{Li}$ & {$[1.2 E+1]$} & 5.0E-01 & {$[2.6 E+1]$} \\
\hline & $M g$ & $1.9 E+03$ & $<2.9 E-1$ & $4.5 E+03$ \\
\hline & Mo & $<1.1 E+1$ & {$[3.2 E+0]$} & $<7.8 E+0$ \\
\hline & $N d$ & {$[6.5 E+1]$} & $<2.5 E+0$ & {$[1.4 E+2]$} \\
\hline & $\mathrm{Pb}$ & $2.3 E+03$ & $<4.1 E+0$ & $5.5 E+03$ \\
\hline & $\mathrm{Ti}$ & $1.3 E+02$ & $<5.4 E-2$ & $3.0 E+02$ \\
\hline & V & {$[2.9 E+0]$} & [5.2E-1] & {$[3.9 E+0]$} \\
\hline & $W$ & $<3.2 E+1$ & $5.0 E+00$ & $<4.8 E+1$ \\
\hline & $Y$ & $1.5 E+01$ & $<5.6 E-2$ & $3.5 E+01$ \\
\hline
\end{tabular}


increased to 4000 RPM, the relative primary peak population decreased slightly, and the $35 \mu \mathrm{m}$ shoulder became a secondary peak. This shift in population may have been a result of increased suspension of larger difficult-to-suspend species at the higher pump speed. Another possibility was shear-induced flocculation and/or agglomeration taking place as a result of increased interaction with other particles. As the speed was reduced from 4000 to 2000 RPM, a further increase in $>10 \mu \mathrm{m}$ population was observed, possibly indicating increased flocculation and/or agglomeration resulting from increased particle interactions with time in the PSD analyzer.

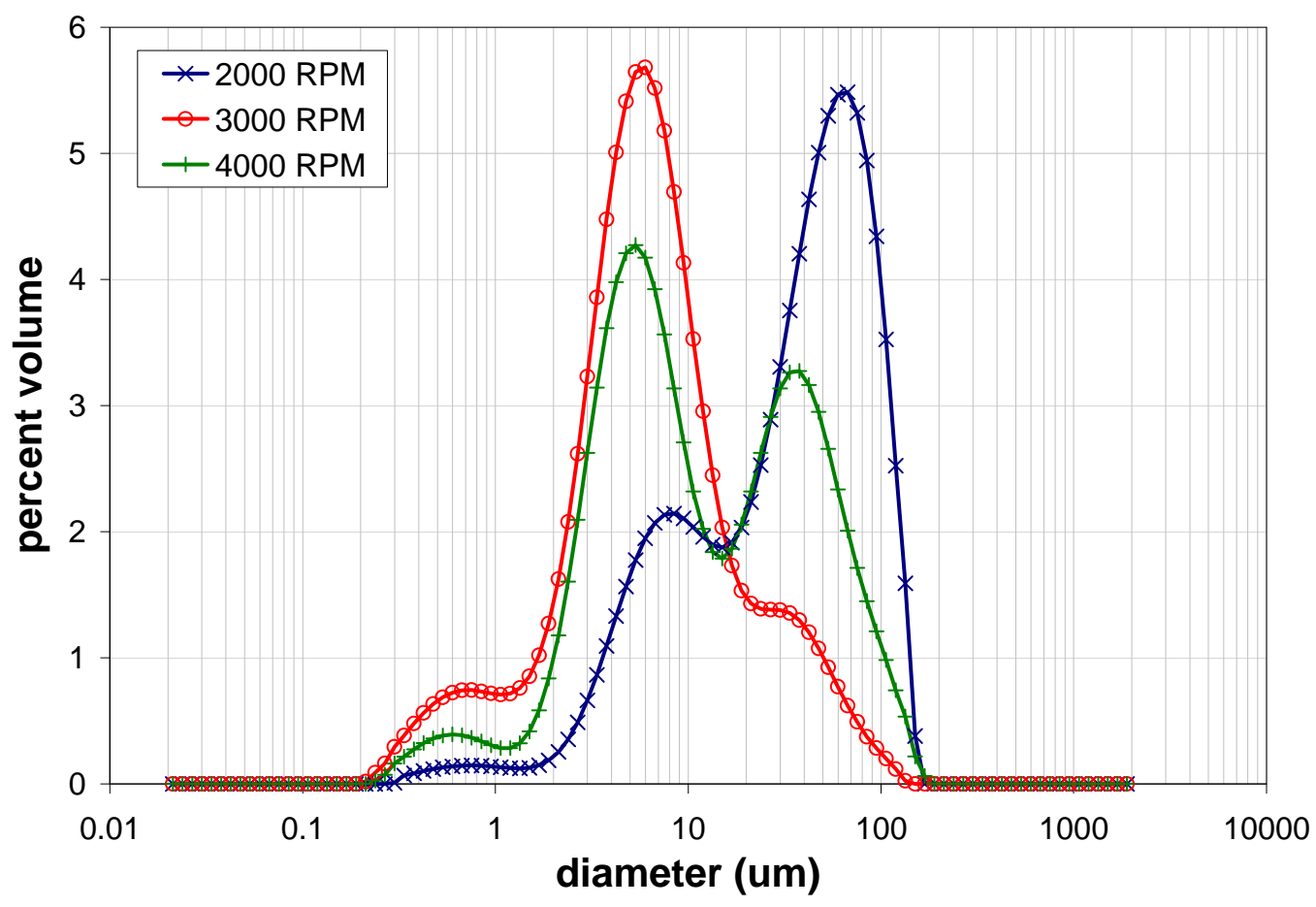

Figure 4.16. Particle-Size Volume Distribution Results for the Group 8 High-Solids Matrix as a Function of Pump Speed (Measured at $13 \mathrm{wt} \%$ UDS)

Table 4.16 and Figure 4.17 show an estimate of the influence of filtration and shearing on the PSD of Group 8 waste solids. The select cumulative undersize percentiles and PSD for the low-solids matrix slurry were compared to that of the high-solids matrix slurry at the first test condition, 3000 RPM. The high-solids matrix slurry showed a decrease in the particle size with a broader distribution. The dewatering and filtration processes may have disrupted the agglomerates and/or flocculates present in the low-solids matrix. The high-solids matrix had a primary peak maximum between 5 and $6 \mu \mathrm{m}$, which was similar to the primary peak in the initial characterization distribution shown in Figure 3.6. 
WTP-RPT-170, Rev. 0

Table 4.16. Cumulative Undersize Percentiles Showing the Influence of Filtration and Shear on the PSD of Group 8 Solids at PSD Measurement Condition 1 (3000 RPM)

\begin{tabular}{||l|c|c|c||}
\hline \hline Sample Description & $\begin{array}{c}\mathbf{d}(\mathbf{1 0}) \\
(\boldsymbol{\mu m})\end{array}$ & $\begin{array}{c}\mathbf{d}(\mathbf{5 0}) \\
(\boldsymbol{\mu m})\end{array}$ & $\begin{array}{c}\mathbf{d}(\mathbf{9 0}) \\
(\boldsymbol{\mu m})\end{array}$ \\
\hline $\begin{array}{l}\text { Low-Solids Matrix Slurry } \\
\text { (TI640-G8-3-PSD) }\end{array}$ & 50 & 87 & 150 \\
\hline $\begin{array}{l}\text { High-Solids Matrix Slurry } \\
\text { (TI640-G8-6-PSD) }\end{array}$ & 1.6 & 6.1 & 29 \\
\hline
\end{tabular}

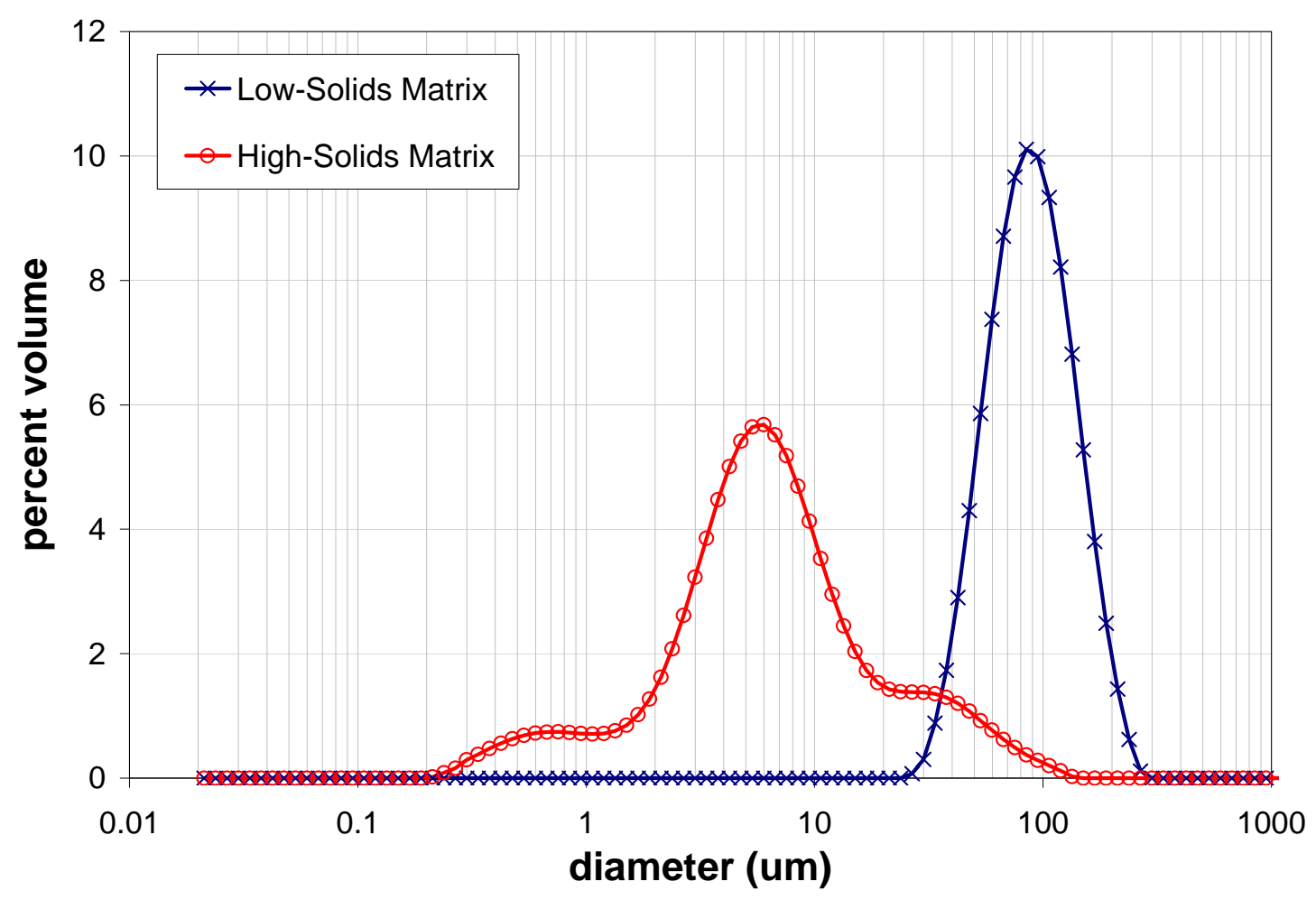

Figure 4.17. Influence of Filtration and Shear on the PSD of Group 8 Solids on PSD Note: All PSDs were taken at measurement condition 1 (3000 RPM).

Figure 4.18 shows the results of flow-curve testing for the high-solids slurry sample collected for rheology analysis. The results suggested a weak non-Newtonian slurry. Specifically, the flow-curve data showed a yield stress of approximately $0.5 \mathrm{~Pa}$ at all temperatures. Because the measured yield stress was near the limit of instrument accuracy $(0.5 \mathrm{~Pa})$, it was difficult to determine if the measured yield was significant. Although, the data were relatively free of hysteresis, both $25^{\circ} \mathrm{C}$ measurements showed a slightly higher stress response during the up-ramp measurement. Such hysteresis was consistent with shear-induced weakening of slurry structure; alternatively, this behavior could be related to solids settling out of the slurry rheology measurement gap.

Flow-curve data in Figure 4.18 also indicated a significant drop in the stress response of the slurry with increasing temperature. The decreased stress response was consistent with a corresponding decrease in the slurry consistency. This behavior was consistent with observed decreased slurry viscosities in both the low solids-concentration slurry and initial characterization materials with increasing temperature. 
Table 4.17 summarizes the best-fit Bingham-Plastic and Casson parameters for the high-solids slurry sample. Analysis of flow-curve data against the Bingham-Plastic flow curve model suggested a yield stress ranging from 0.6 to $0.8 \mathrm{~Pa}$ and a consistency ranging from 2.7 to $5.1 \mathrm{mPa} \cdot \mathrm{s}$. Similar analysis with the Casson model found a yield and consistency that ranged from 0.2 to $0.3 \mathrm{~Pa}$ and 1.6 to $3.9 \mathrm{mPa} \cdot \mathrm{s}$, respectively. Because the magnitude of the best-fit yield stress was either below or approached the limit of instrument accuracy $(0.5 \mathrm{~Pa})$, it was difficult to confidently conclude that the yield stress observed was significant. As such, the rheology was best classified as "weakly" or borderline non-Newtonian. Based on both fitting approaches, it was concluded that the measured yield stress did not vary significantly with temperature but that consistency decreased significantly with temperature.

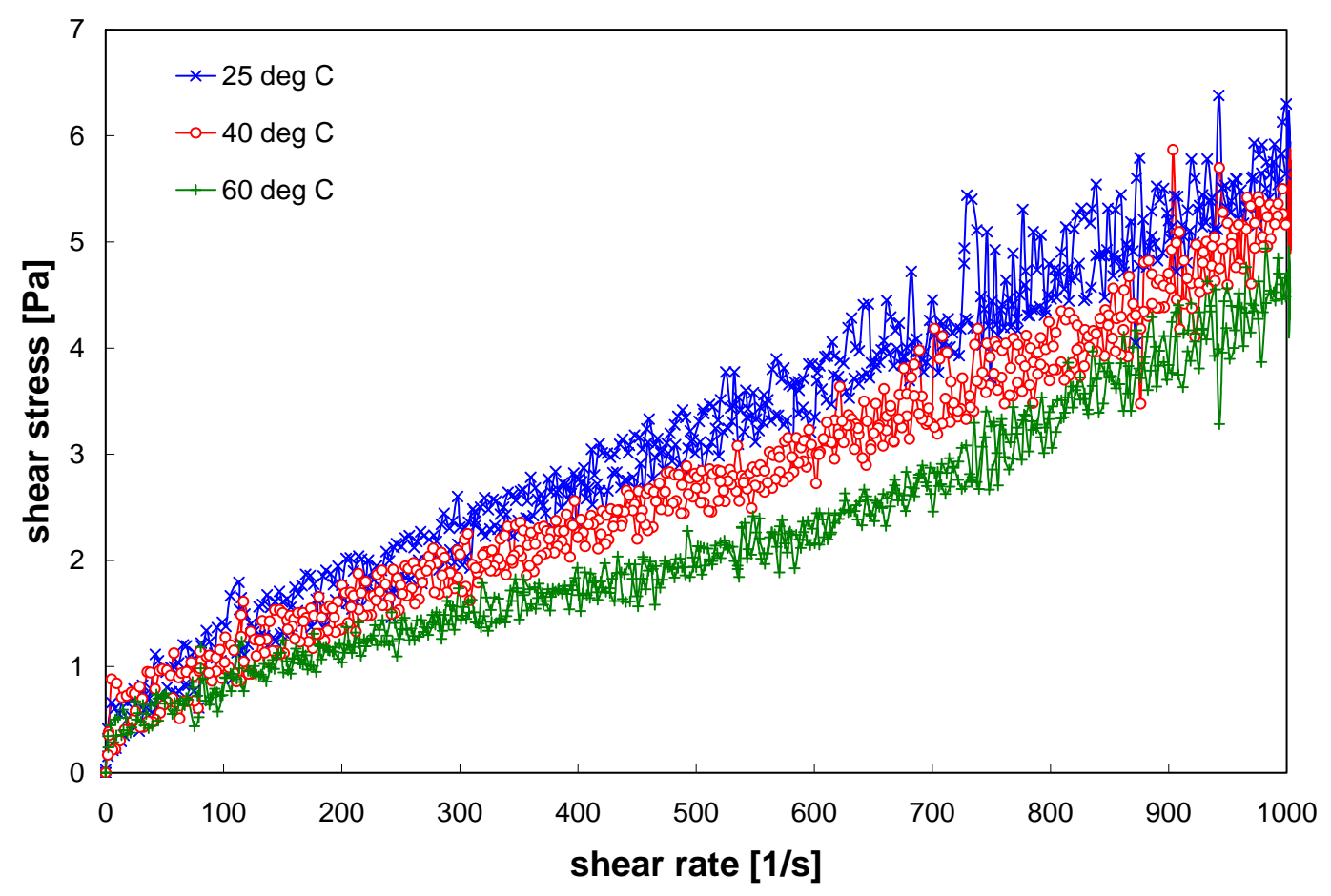

Figure 4.18. Flow Curves for the CUF High Solids Slurry (Measured at $13 \mathrm{wt} \%$ UDS)

Table 4.17. Results of Fitting Analysis for the CUF High Solids Matrix

\begin{tabular}{||c|c|c|c|c|c||}
\hline \multirow{3}{*}{ Model } & $\begin{array}{c}\text { Temperature } \\
\left({ }^{\mathbf{C}} \mathbf{C}\right)\end{array}$ & $\begin{array}{c}\text { Range } \\
\left(\mathbf{s}^{\mathbf{- 1}}\right)\end{array}$ & $\begin{array}{c}\text { Yield Stress } \\
\mathbf{( P a})\end{array}$ & $\begin{array}{c}\text { Consistency } \\
(\mathbf{m P a} \cdot \mathbf{s})\end{array}$ & $\mathbf{R}$ \\
\hline \multirow{4}{*}{ Bingham-Plastic } & $25(1$ of 2$)$ & $100-1000$ & 0.8 & 5.1 & 0.98 \\
\cline { 2 - 6 } & $25(2$ of 2$)$ & $100-1000$ & 0.7 & 4.9 & 0.98 \\
\cline { 2 - 6 } & 40 & $100-800$ & 0.7 & 4.0 & 0.98 \\
\cline { 2 - 6 } & 60 & $100-600$ & 0.6 & 2.7 & 0.96 \\
\hline \multirow{5}{*}{ Casson } & $25(1$ of 2$)$ & $0-1000$ & 0.2 & 3.9 & 0.99 \\
\cline { 2 - 6 } & $25(2$ of 2$)$ & $0-1000$ & 0.2 & 4.0 & 0.99 \\
\cline { 2 - 6 } & 40 & $0-800$ & 0.2 & 2.7 & 0.98 \\
\cline { 2 - 6 } & 60 & $0-600$ & 0.3 & 1.6 & 0.98 \\
\hline
\end{tabular}




\subsection{Caustic Leaching/Washing}

After completing the filtration and rheological testing of the high-solids slurry, the test material was drained from the CUF apparatus (inclusive of the slurry in the slurry reservoir tank, permeate in the permeate flow loop, and slurry in the slurry circulation loop). The slurry circulation loop was rinsed using part of the caustic addition for the leach and additional permeate that was remaining in the backpulse chamber to flush solids out of the system. After the drained slurry, permeate, and caustic solutions were recovered from the system, the slurry reservoir was isolated from the slurry loop. At these points, all the recovered material was placed into the reservoir for caustic leaching. Approximately $0.2 \mathrm{~kg}$ of material containing $\sim 20$ grams of solids was estimated to have been lost during transfer operations and sampling activities used to characterize the slurry before leaching. The best-estimate of the mass balance for these operational steps is shown in Figure 4.19.

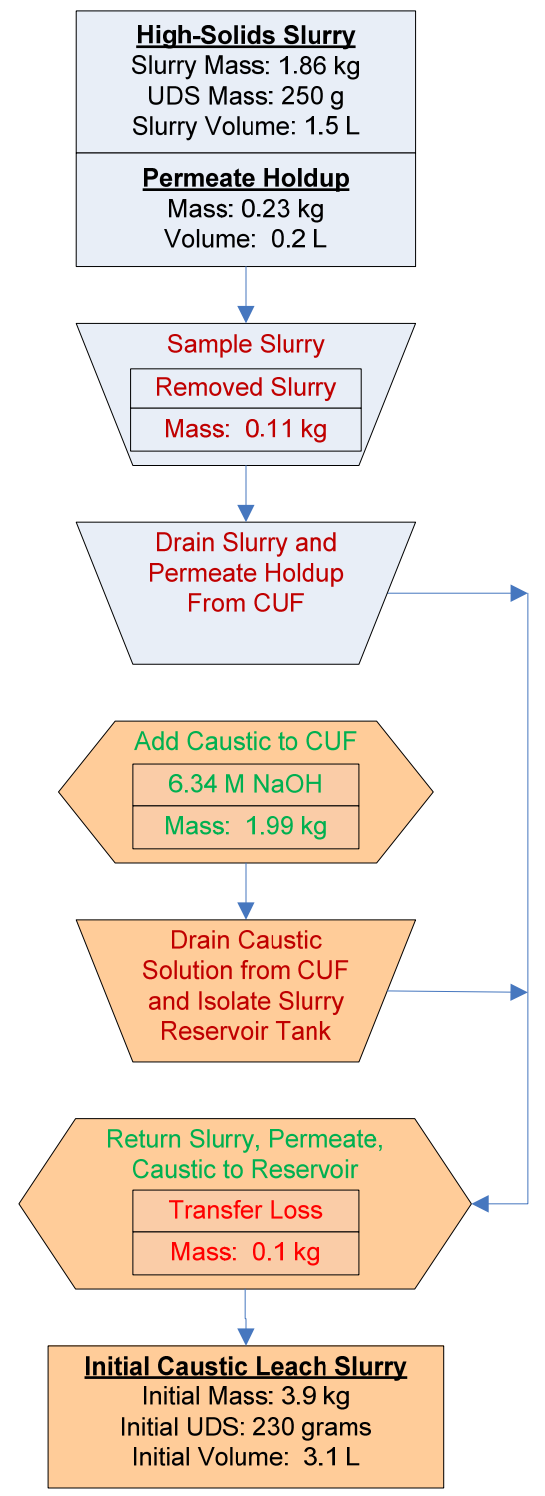

Figure 4.19. Process Flow for Caustic Leach Preparation 
The activities involved in the caustic leach and washing processes, as outlined in the middle column (colored orange) of Figure 4.1, were:

- Batch caustic leaching of the slurry for removing aluminum and phosphorus from UDS in the slurry. Leaching occurred at $60^{\circ} \mathrm{C}$ for an 8 -h period at a free-hydroxide concentration of 3.7 M.

- Dewatering a majority of the leached slurry supernate from the slurry solids.

- Batch washing of the caustic-leached slurry and dewatering of the diluted supernate afterwards. Four total wash solutions were added to the slurry to remove aluminum and phosphorus leached from the UDS in the slurry.

\subsubsection{Caustic Batch Leaching Results}

After the slurry, permeate, and caustic solutions were placed in the slurry reservoir, the lid for the slurry reservoir was placed on the tank, and the overhead mixer was started. An overview of the mass balance of the system during the caustic-leach processing is shown in Figure 4.20.

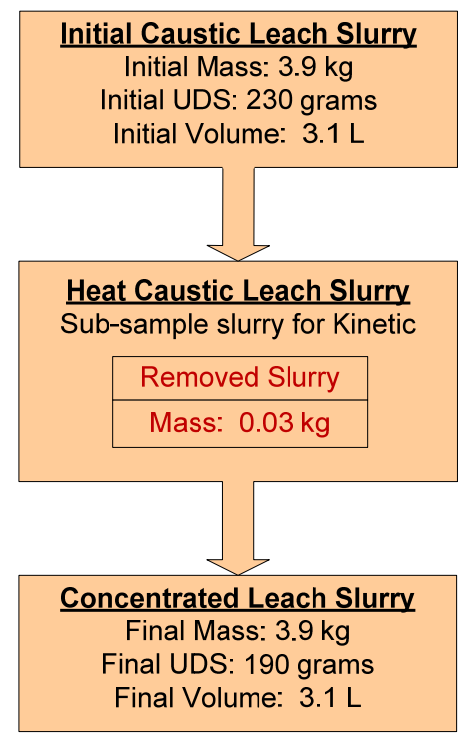

Figure 4.20. Process Flow for the Caustic Leach

The heat controller was started such that the slurry temperature was heated from ambient conditions $\left(26^{\circ} \mathrm{C}\right.$ ) to $60^{\circ} \mathrm{C} \pm 2^{\circ} \mathrm{C}^{(\mathrm{a})}$ over a 2.5 -h period. The slurry temperature was held at $60^{\circ} \mathrm{C}$ for $8 \mathrm{~h}$. Cooling to hot cell ambient temperature was controlled to $\sim 6^{\circ} \mathrm{C} / \mathrm{h}$; as the ambient cell temperature condition was approached, cooling slowed. Additional cooling was obtained by circulating the slurry through the slurry loop, thus taking advantage of cooling offered by the heat exchanger. The temperature profile in the slurry reservoir over the heat ramp, soak, and cool-down periods is shown in Figure 4.21; the cooling associated with slurry loop processing is not shown.

(a) The allowed temperature variability per the test plan was $-10^{\circ} \mathrm{C} / 5^{\circ} \mathrm{C}$. The temperature-controlling system was accurate to $2^{\circ} \mathrm{C}$. 
WTP-RPT-170, Rev. 0

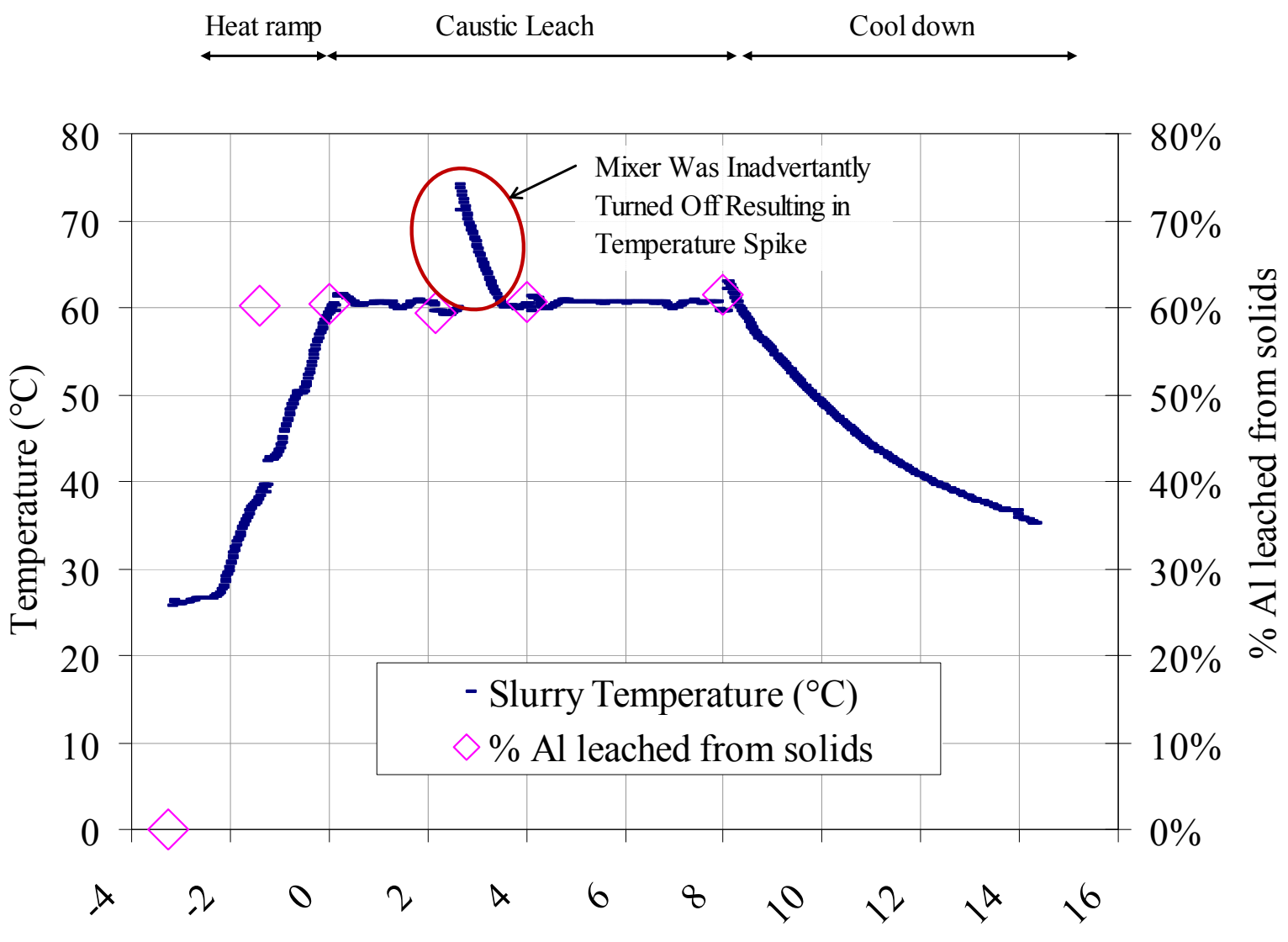

Elapsed Time of Caustic in Hours

Time at 0 is start of leach at $60^{\circ} \mathrm{C}$

Figure 4.21. Temperature Profile/Aluminum Leach Factor During Batch Caustic Leaching of the Group 8 Slurry (3.7 M free hydroxide)

The temperature excursion shown at $2.3 \mathrm{~h}$ in Figure 4.21 was a localized effect associated with the brief shutdown of the overhead mixer during the sub-sampling activity. Heating was supplied to the side walls of the tank; the heat controller's thermocouple was located at the bottom of the tank. If the tank mixer is not turned on immediately after sampling, the bottom of the tank begins to cool, and the controller starts to apply a load to the heaters. When the mixer is turned back on, the heat applied to the sidewall is pulled into the slurry, and a jump in temperature is measured. During normal sampling events, the mixer shutdown time was brief, causing no overall perturbation in the temperature of the tank contents.

The level or volume of the slurry was periodically checked during the leach operation. Unlike the leaching operations performed at $100^{\circ} \mathrm{C}$ with other tank waste Groups where volume decreased as a result of evaporation, no significant change in the system volume was measured.

The supernate portions of the slurry were sampled after mixing at ambient temperature, once during the heat ramp at $40^{\circ} \mathrm{C}$, and four times during the 8 -h soak at $60^{\circ} \mathrm{C}$. The sampling points are indicated in Figure 4.21. The samples were filtered and split for analysis by titration (free hydroxide) and acid digested for ICP-OES analysis. The Al, P, Cr, Na, and free-hydroxide concentrations are shown in 
WTP-RPT-170, Rev. 0

Table 4.18. The sodium and free-hydroxide concentrations of the leach supernate were constant within experimental uncertainties at $5.2 \mathrm{M} \mathrm{Na}$ and $3.7 \mathrm{M} \mathrm{OH}$.

Table 4.18. Selected Analyte Concentrations During Caustic Leaching of Group 8 (3.7 M Free Hydroxide)

\begin{tabular}{|c|c|c|c|c|c|c|}
\hline $\begin{array}{l}\text { Time } \\
\text { (h) }\end{array}$ & $\begin{array}{l}\text { Sampling } \\
\text { Temp. }\left({ }^{\circ} \mathrm{C}\right)\end{array}$ & $\begin{array}{c}\mathrm{Al}, \\
(\mu \mathrm{g} / \mathrm{mL})\end{array}$ & $\begin{array}{c}\mathbf{P} \\
(\mu \mathrm{g} / \mathrm{mL})\end{array}$ & $\begin{array}{c}\mathbf{C r} \\
(\mu \mathrm{g} / \mathrm{mL})\end{array}$ & $\begin{array}{c}\mathrm{Na} \\
(\mu \mathrm{g} / \mathrm{mL})\end{array}$ & $\begin{array}{l}\mathrm{OH} \\
\text { (M) }\end{array}$ \\
\hline (a) & 25 & 697 & $1162^{(\mathrm{b})}$ & 38 & 121,000 & 3.7 \\
\hline-1.5 & 40 & 4,580 & 756 & 63.5 & 119,000 & 3.67 \\
\hline 0 & 60 & 4,600 & 783 & 49.3 & 128,000 & 3.80 \\
\hline 2 & 60 & 4,520 & 774 & 51.3 & 120,000 & 3.68 \\
\hline 4 & 60 & 4,600 & 763 & 54.9 & 120,000 & 3.54 \\
\hline 8 & 60 & 4,650 & 1,040 & 61.3 & 120,000 & 3.63 \\
\hline final & 25 & 4570 & 780 & 63.9 & 119,000 & 3.66 \\
\hline \multicolumn{2}{|c|}{$\begin{array}{l}\text { Estimated caustic-leach } \\
\text { factor for Solids }\end{array}$} & $60 \mathrm{wt} \%$ & $0 \mathrm{wt}^{0} \mathrm{c}^{(\mathrm{c})}$ & $16 \mathrm{wt} \%$ & na & na \\
\hline \multicolumn{7}{|c|}{$\begin{array}{l}\text { (a) Calculated values were based on mass balance. } \\
\text { (b) The P concentration was estimated with the assumption that no phosphate precipitation } \\
\text { occurred when the caustic was added. }\end{array}$} \\
\hline
\end{tabular}

The $\mathrm{Al}$ reached its equilibrium concentration before the first sample was taken at $40^{\circ} \mathrm{C}$. This was attributed to rapid dissolution of the gibbsite phase. Within experimental uncertainty, no additional Al dissolved after this sample was taken. The total Al removed from the solids phase was calculated to be $60 \mathrm{wt} \%$. If the $\mathrm{Al}$ that was leached from the solids phase $(12.2 \mathrm{~g})$ was in the form of gibbsite, the gibbsite mass leached from the solids would be equivalent to $39 \mathrm{~g}$. A 39 -g reduction in solids mass was estimated to reduce the solids inventory mass in the slurry from $230 \mathrm{~g}$ to $191 \mathrm{~g}$, equivalent to a $17-\mathrm{wt} \%$ mass reduction.

The calculated $\mathrm{P}$ concentration after adding the caustic leach solution was $\sim 1200 \mu \mathrm{g} / \mathrm{mL}$; the first sample showed a significantly smaller concentration at $760 \mu \mathrm{g} / \mathrm{mL}$. This indicated that a small amount of the phosphate in the supernate phase precipitated with the increased sodium concentration from caustic addition.

The $\mathrm{Cr}$ concentration was similarly evaluated; it appeared to reach equilibrium concentration in parallel with the Al. The total $\mathrm{Cr}$ released to the aqueous phase as a result of the caustic leach step was $\sim 16 \mathrm{wt} \%$.

\subsubsection{Caustic-Leach Dewatering}

After the cool-down period of the batch leach was complete, the valves isolating the slurry reservoir from the slurry recirculation loop were opened. The circulation pump was then turned on, allowing slurry to recirculate through the filter and allowing permeate to exit the filter and recycle back to the slurry reservoir. Once the density measured by the permeate mass flow meter was stable and the temperature of the slurry was at $25^{\circ} \mathrm{C}$, the back-pulse chamber was filled with permeate, and two back pulses were performed on the filter. At this point, filter permeate was directed away from the slurry reservoir and 
captured in a sample container to dewater the caustic-leached slurry. An overview of the mass balance is shown in Figure 4.22. The dewatering occurred at the standard operating conditions (TMP $=40 \mathrm{psid}$, $\mathrm{AV}=13 \mathrm{ft} / \mathrm{s}$ ) over a 130 -min period. Approximately $1.7 \mathrm{~L}$ of permeate was removed.

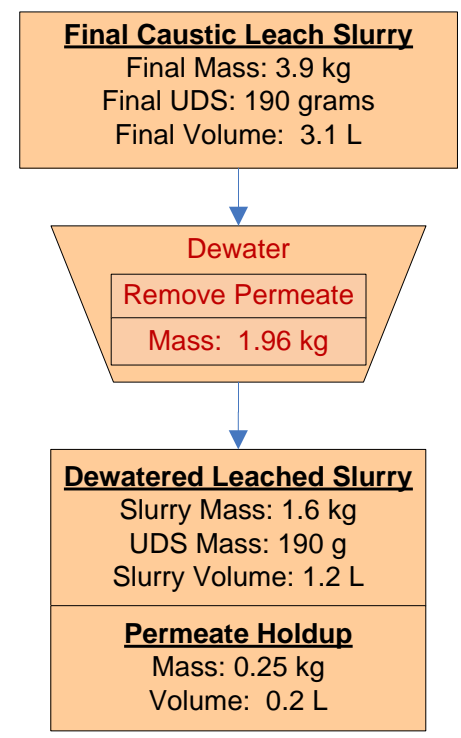

Figure 4.22. Process Flow of Dewatering Group 8 Caustic Leached Slurry

Figure 4.23 is a plot of the permeate flux for the dewatering step. The permeate flux decreased from $0.018 \mathrm{GPM} / \mathrm{ft}^{2}$ to $0.012 \mathrm{GPM} / \mathrm{ft}^{2}$. The decrease appeared to be a result of the filter flux decaying to a steady-state flux after back pulsing the filter and not due to changes in the UDS concentration. The final UDS concentration of the slurry was estimated to be $12 \mathrm{wt} \%$.

Comparison to the average flux of the initial dewatering of Group 8 slurry at the standard conditions $\left(0.27 \mathrm{GPM} / \mathrm{ft}^{2}\right)$ showed that the filter flux after leaching was significantly lower. However, this decrease in the filter flux after leaching was expected from the changes that occurred in the slurry supernate.

Table 4.19 summarizes the changes in the slurry's supernate viscosity and composition before and after caustic leaching and compares these changes to the average filter flux at standard conditions.

Examination of the slurry supernate showed that increases in the sodium and hydroxide concentration of the supernate from the caustic addition increased the supernate viscosity by $50 \%$. This change in viscosity correlated to a decrease in the average filter flux of $\sim 50 \%$. This filter behavior agreed with the Darcy equation (Appendix E, Equation E.6), which predicted that filter flux was inversely proportional to permeate viscosity when TMP and filter resistance are fixed. This also showed that permeate viscosity and TMP were significantly controlling the filter flux and not the corresponding changes in the slurry UDS concentration. 


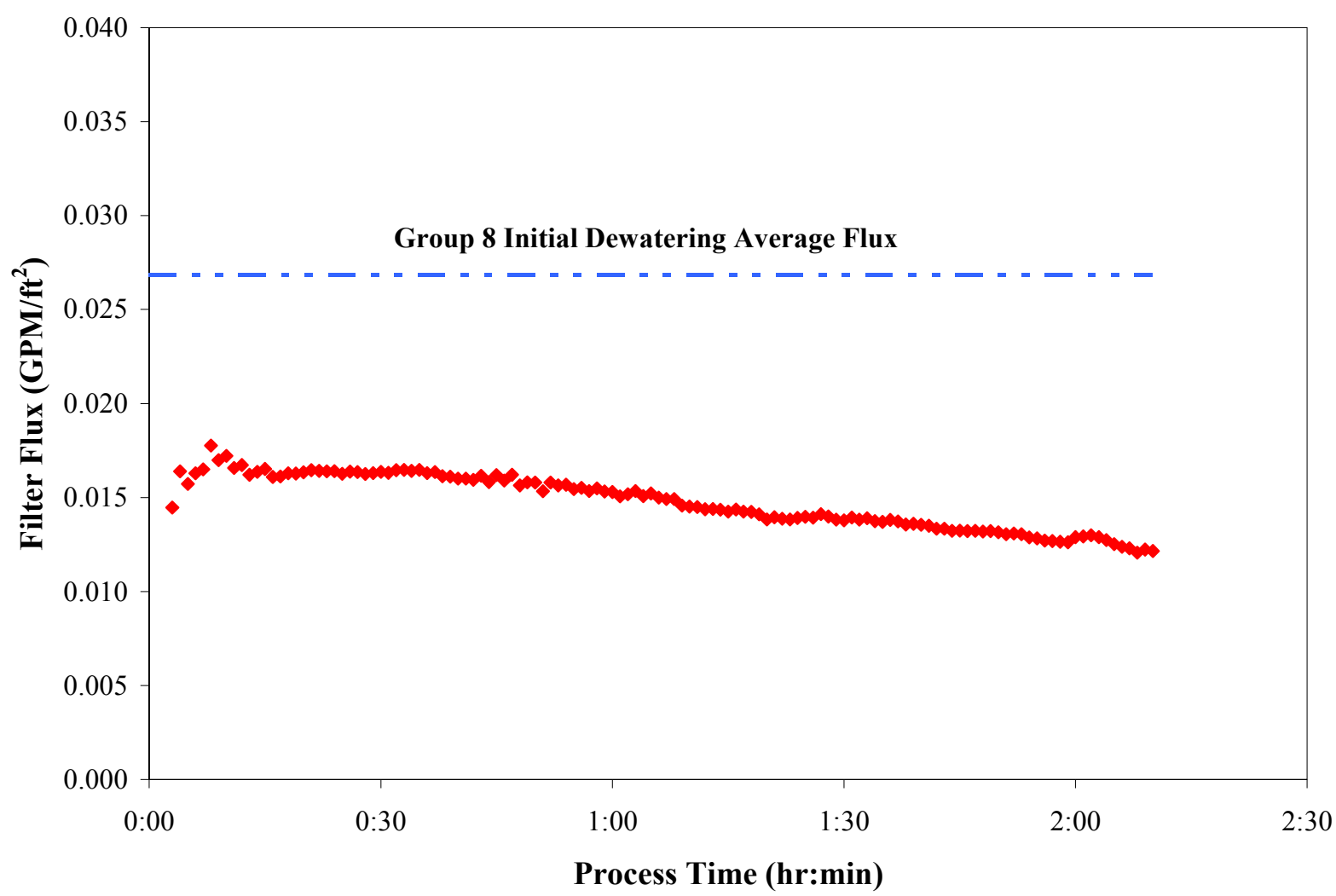

Figure 4.23. Dewatering Leached Group 8 Slurry at Standard Conditions

Table 4.19. Comparison of Slurry Supernate Attributes to Filter Flux

\begin{tabular}{|l|c|c|c|c|c||}
\hline $\begin{array}{c}\text { Slurry } \\
\text { Supernate } \\
\text { Sample }\end{array}$ & $\begin{array}{c}\text { Supernate } \\
\text { Viscosity at } \\
\mathbf{2 5}^{\circ} \mathbf{C}(\mathbf{m P a} \cdot \mathbf{s})\end{array}$ & $\begin{array}{c}{[\mathbf{N a}]} \\
(\mathbf{M})\end{array}$ & $\begin{array}{c}\mathbf{[ O H}] \\
\mathbf{( M )}\end{array}$ & $\begin{array}{c}{[\mathbf{A l}]} \\
\mathbf{( M )}\end{array}$ & $\begin{array}{c}\text { Nominal flux at } \\
\text { standard condition } \\
\left(\mathbf{G P M} / \mathbf{f t}^{\mathbf{2}}\right)\end{array}$ \\
\hline $\begin{array}{l}\text { High-solids } \\
\text { slurry supernate }\end{array}$ & 2.0 & 3.42 & 0.36 & 0.054 & 0.027 \\
\hline $\begin{array}{l}\text { Caustic leached } \\
\text { slurry supernate }\end{array}$ & 3.1 & 5.17 & 3.65 & 0.172 & 0.015 \\
\hline \multicolumn{2}{|l|}{ Note: $1 \mathrm{mPa} \cdot \mathrm{s}=1 \mathrm{cP}}$. \\
\hline
\end{tabular}

\subsubsection{Dewatered Leached Slurry Physical Characterization}

After dewatering the leached slurry, the slurry was sampled for physical properties and chemical analysis (the calculated mass balance is shown in Figure 4.24). The results of physical-property measurements of the leached and dewatered material are shown in Table 4.20. The measured UDS concentration of the slurry $(23 \mathrm{wt} \%)$ was much higher that the predicted concentration $(12 \mathrm{wt} \%)$ and was believed to result from sampling issues. Settling of the slurry during sampling was an ongoing issue for this kind of test in the hot cells. Once a slurry aliquot was collected, transferring slurry using a pipette to a centrifuge cone was problematic. If the measured UDS concentration was correct, the solids inventory of the slurry would be $\sim 370$ grams $(0.23 \times 1.6 \mathrm{~kg}=0.37 \mathrm{~kg})$, which was higher than the initial solids inventory of the characterized slurry. 
WTP-RPT-170, Rev. 0

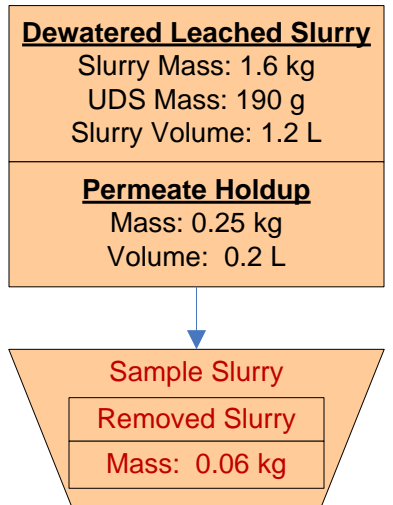

Figure 4.24. Sampling of Dewatered Caustic Leached Slurry

Table 4.20. Dewatered Caustic Leached Slurry Physical Property Measurements (Inside Circulation Loop)

\begin{tabular}{|c|c|}
\hline Slurry Density (g/mL) & 1.3 \\
\hline Supernate Density $(\mathrm{g} / \mathrm{mL})$ & 1.2 \\
\hline Settled Solids (vol\%) & 87 \\
\hline Centrifuged Undissolved Solids (wt\%) & 55 \\
\hline Total Solids (wt\%) & 40 \\
\hline Supernate Dissolved Solids (wt\%) & 24 \\
\hline Undissolved Solids (wt\%) & $23^{(a)}$ \\
\hline \multicolumn{2}{|c|}{$\begin{array}{l}\text { The measured } 23 \mathrm{wt} \% \text { UDS was considered too high; the } \\
\text { calculated } 12 \mathrm{wt} \% \text { UDS was considered more realistic for this } \\
\text { test- see text. }\end{array}$} \\
\hline
\end{tabular}

The total slurry and phase-specific compositions post caustic leaching were calculated using the two methods previously described (see Section 4.4 and Appendix E, Section E.4).

Table 4.21 shows the dewatered leached slurry composition based on the overall mass balance and initial characterization (Section 3). Table 4.22 shows the chemical characterization conducted on the slurry and supernatant samples. The majority of analyte concentrations in the solids and aqueous phases calculated using both methods agreed with each other. As noted previously, the analytes in high concentration in the aqueous phase and low concentration in the solids phase ( $\mathrm{Na}$ and $\mathrm{S}$ ) showed the largest discrepancy.

Solids leach factors were calculated for each of the analytes listed in Table 4.22 by comparing changes in values from those measured before leaching (Table 4.14) and using values of iron and uranium concentrations to estimate the concentration factor of the solids (see Appendix E, Section E.5). As shown previously from the filtered supernate samples taken from the leach (Table 4.18), a little over half of the aluminum (55 wt $\%$ ) was calculated to have leached out of the solids as well as a small fraction of chromium $(10 \mathrm{wt} \%)$. The results also calculated a negative leach factor for phosphorus, indicating that some precipitation of soluble phosphate occurred after increasing the sodium concentration of the slurry supernate. While radioisotopes such as ${ }^{154} \mathrm{Eu},{ }^{90} \mathrm{Sr}$, and $\mathrm{Pu}$ appeared to show no movement from the solids phase after caustic leaching, a solids leach factor for ${ }^{137} \mathrm{Cs}$ was measured at $68 \mathrm{wt} \%$. Note that the calculated leach factor of 0.1 for ${ }^{241} \mathrm{Am}$ was less than the analytical uncertainty of the input factors 
$(\sim 30 \%)$ and as such should not be inferred as indicating Am dissolution, particularly in light of the absence of ${ }^{241} \mathrm{Am}$ in the supernate sample.

Table 4.21. Dewatered Leached Slurry Composition (including permeate hold-up)

\begin{tabular}{|c|c|c|c|c|c|}
\hline & Slurry $^{(a)}$ & \multicolumn{2}{|c|}{ Liquid Fraction ${ }^{(b)}$} & \multicolumn{2}{|c|}{ Solids Fraction $^{(\mathrm{c})}$} \\
\hline Mass (kg) & 1.8 & \multicolumn{2}{|c|}{1.6} & \multicolumn{2}{|c|}{0.19} \\
\hline Wt\% of Slurry & $100 w t \%$ & \multicolumn{2}{|c|}{$90 \mathrm{wt} \%$} & \multicolumn{2}{|c|}{$10 \mathrm{wt} \%$} \\
\hline ICP-OES Analytes & g & g & $\mu \mathrm{g} / \mathrm{mL}$ & g & $\mu \mathrm{g} / \mathrm{g}$ \\
\hline Al & $1.4 \mathrm{E}+01$ & $6.2 \mathrm{E}+00$ & $4.6 \mathrm{E}+03$ & $8.0 \mathrm{E}+00$ & $4.3 \mathrm{E}+04$ \\
\hline $\mathbf{B i}$ & $1.3 \mathrm{E}+00$ & $0.0 \mathrm{E}+00$ & $0.0 \mathrm{E}+00$ & $1.3 \mathrm{E}+00$ & $6.9 \mathrm{E}+03$ \\
\hline $\mathrm{Cr}$ & $4.8 \mathrm{E}-01$ & $8.7 \mathrm{E}-02$ & $6.4 \mathrm{E}+01$ & $3.9 \mathrm{E}-01$ & $2.1 \mathrm{E}+03$ \\
\hline $\mathbf{F e}$ & $2.3 \mathrm{E}+01$ & $1.9 \mathrm{E}-02$ & $1.4 \mathrm{E}+01$ & $2.3 \mathrm{E}+01$ & $1.2 \mathrm{E}+05$ \\
\hline Mn & $2.8 \mathrm{E}-01$ & $2.0 \mathrm{E}-04$ & $1.5 \mathrm{E}-01$ & $2.8 \mathrm{E}-01$ & $1.5 \mathrm{E}+03$ \\
\hline $\mathbf{N a}$ & $1.7 \mathrm{E}+02$ & $1.6 \mathrm{E}+02$ & $1.2 \mathrm{E}+05$ & $3.5 \mathrm{E}+00$ & $1.9 \mathrm{E}+04$ \\
\hline $\mathbf{P}$ & $1.0 \mathrm{E}+01$ & $1.1 \mathrm{E}+00$ & $7.8 \mathrm{E}+02$ & $9.3 \mathrm{E}+00$ & $5.0 \mathrm{E}+04$ \\
\hline $\mathbf{S}$ & $2.6 \mathrm{E}+00$ & $1.4 \mathrm{E}+00$ & $1.1 \mathrm{E}+03$ & $1.2 \mathrm{E}+00$ & $6.2 \mathrm{E}+03$ \\
\hline Si & $3.5 \mathrm{E}+00$ & 7.9E-02 & $5.8 \mathrm{E}+01$ & $3.4 \mathrm{E}+00$ & $1.8 \mathrm{E}+04$ \\
\hline $\mathrm{Sr}$ & $8.9 \mathrm{E}+00$ & $2.4 \mathrm{E}-04$ & $1.8 \mathrm{E}-01$ & $8.9 \mathrm{E}+00$ & $4.8 \mathrm{E}+04$ \\
\hline $\mathbf{U}$ & $2.6 \mathrm{E}+01$ & $1.8 \mathrm{E}-02$ & $1.3 \mathrm{E}+01$ & $2.6 \mathrm{E}+01$ & $1.4 \mathrm{E}+05$ \\
\hline Radionuclides & $\mu \mathrm{Ci}$ & $\mu \mathbf{C i}$ & $\mu \mathrm{Ci} / \mathrm{mL}$ & $\mu \mathrm{Ci}$ & $\mu \mathrm{Ci} / \mathrm{g}$ \\
\hline${ }^{60} \mathrm{Co}$ & $2.4 \mathrm{E}+00$ & $<2$.E-1 & $<1$. E-4 & $2.3 \mathrm{E}+00$ & $1.2 \mathrm{E}-02$ \\
\hline${ }^{137} \mathrm{Cs}$ & $7.3 \mathrm{E}+04$ & $3.7 \mathrm{E}+04$ & $2.7 \mathrm{E}+01$ & $3.6 \mathrm{E}+04$ & $1.9 \mathrm{E}+02$ \\
\hline${ }^{154} \mathrm{Eu}$ & $3.0 \mathrm{E}+01$ & $<6 . \mathrm{E}-1$ & $<4 . \mathrm{E}-4$ & $3.0 \mathrm{E}+01$ & $1.6 \mathrm{E}-01$ \\
\hline${ }^{241} \mathrm{Am}$ & $4.1 \mathrm{E}+01$ & $<7 . \mathrm{E}+0$ & $<5$. E-3 & $3.3 \mathrm{E}+01$ & $1.8 \mathrm{E}-01$ \\
\hline Gross Alpha & $1.9 \mathrm{E}+02$ & $<2$.E-1 & $<2$.E-4 & $1.9 \mathrm{E}+02$ & $1.0 \mathrm{E}+00$ \\
\hline Gross Beta & $6.3 \mathrm{E}+05$ & $3.6 \mathrm{E}+04$ & $2.6 \mathrm{E}+01$ & $5.9 \mathrm{E}+05$ & $3.2 \mathrm{E}+03$ \\
\hline${ }^{90} \mathrm{Sr}$ & $2.8 \mathrm{E}+05$ & $1.3 \mathrm{E}+01$ & $9.6 \mathrm{E}-03$ & $2.8 \mathrm{E}+05$ & $1.5 \mathrm{E}+03$ \\
\hline${ }^{239+240} \mathrm{Pu}$ & $1.2 \mathrm{E}+02$ & $5.8 \mathrm{E}-02$ & $4.3 \mathrm{E}-05$ & $1.2 \mathrm{E}+02$ & $6.5 \mathrm{E}-01$ \\
\hline${ }^{238} \mathrm{Pu}$ & $2.6 \mathrm{E}+00$ & $1.2 \mathrm{E}-02$ & $8.8 \mathrm{E}-06$ & $2.6 \mathrm{E}+00$ & $1.4 \mathrm{E}-02$ \\
\hline \multicolumn{6}{|c|}{$\begin{array}{l}\text { (a) Slurry Mass components were calculated from characterization data (Section 3) and the mass and } \\
\text { composition of materials added and removed. Loss of mass from sampling was included. } \\
\text { (b) Liquid Fraction mass components were calculated using analytical data of supernate sample TI640-G8-D, } \\
\text { (ASO ID 08-2284) and calculating the mass of each component using the predicted mass of supernate in } \\
\text { the system. } \\
\text { (c) Solids Fraction mass components were calculated from the difference between the slurry and liquid mass } \\
\text { component fractions. The solids fraction composition was then calculated by dividing the mass of the } \\
\text { component in the solids phase of the slurry by the estimated mass of solids material in the slurry. }\end{array}$} \\
\hline
\end{tabular}


WTP-RPT-170, Rev. 0

Table 4.22. Dewatered Leached Slurry Composition and Calculated Solids Leach Factors

\begin{tabular}{|c|c|c|c|c|c|}
\hline $\begin{array}{c}\text { Slurry Prep } \\
\text { Method }\end{array}$ & Analyte & $\begin{array}{c}\text { Dry Slurry }{ }^{(a)} \\
(\mu \mathrm{g} / \mathrm{g})\end{array}$ & $\begin{array}{c}\begin{array}{c}\text { Supernate } \\
(\mu \mathrm{g} / \mathrm{mL})\end{array} \\
\end{array}$ & $\begin{array}{c}\begin{array}{c}\text { Dry Solids }{ }^{(c)} \\
(\mu \mathrm{g} / \mathrm{g})\end{array} \\
\end{array}$ & $\begin{array}{c}\text { Solids Leach } \\
\text { Factor }^{(d)}\end{array}$ \\
\hline \multirow{29}{*}{ 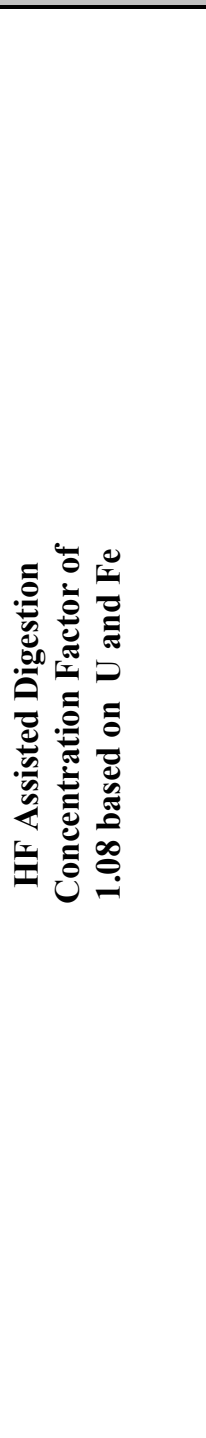 } & $\mathrm{Al}$ & $3.15 \mathrm{E}+04$ & $4.57 \mathrm{E}+03$ & $4.1 \mathrm{E}+04$ & 0.55 \\
\hline & $\mathrm{Bi}$ & $3.76 \mathrm{E}+03$ & $<3.7 \mathrm{E}+0$ & $6.4 \mathrm{E}+03$ & -0.03 \\
\hline & $\mathrm{Cd}$ & $2.10 \mathrm{E}+01$ & {$[1.8 \mathrm{E}+0]$} & $3.1 \mathrm{E}+01$ & -0.50 \\
\hline & $\mathrm{Cr}$ & $1.22 \mathrm{E}+03$ & $6.39 \mathrm{E}+01$ & $1.9 \mathrm{E}+03$ & 0.10 \\
\hline & $\mathrm{Fe}$ & $6.59 \mathrm{E}+04$ & $1.45 \mathrm{E}+01$ & $1.1 \mathrm{E}+05$ & na \\
\hline & $\mathrm{Mn}$ & $8.58 \mathrm{E}+02$ & [1.5E-1] & $1.5 \mathrm{E}+03$ & 0.00 \\
\hline & $\mathrm{Ni}$ & $2.21 \mathrm{E}+04$ & $1.96 \mathrm{E}+01$ & $3.8 \mathrm{E}+04$ & 0.00 \\
\hline & $\mathrm{P}$ & $2.66 \mathrm{E}+04$ & {$[7.8 \mathrm{E}+2]$} & $4.4 \mathrm{E}+04$ & -0.11 \\
\hline & $\mathrm{S}$ & {$[2.2 \mathrm{E}+3]$} & $1.06 \mathrm{E}+03$ & {$[8.4 \mathrm{E}+2]$} & 0.68 \\
\hline & $\mathrm{Sr}$ & $2.56 \mathrm{E}+04$ & [1.8E-1] & $4.4 \mathrm{E}+04$ & 0.00 \\
\hline & $\mathrm{U}$ & $7.06 \mathrm{E}+04$ & $1.30 \mathrm{E}+01$ & $1.2 \mathrm{E}+05$ & na \\
\hline & $\mathrm{Zn}$ & $3.34 \mathrm{E}+02$ & $4.00 \mathrm{E}+00$ & $5.6 \mathrm{E}+02$ & 0.06 \\
\hline & $\mathrm{Zr}$ & $1.85 \mathrm{E}+02$ & $<1.3 \mathrm{E}-1$ & $3.2 \mathrm{E}+02$ & -0.02 \\
\hline & $\mathrm{Ag}$ & {$[1.8 E+1]$} & 5.9E-01 & {$[2.9 E+1]$} & $-[0.03]$ \\
\hline & $B a$ & $5.9 E+02$ & [4.1E-1] & $1.0 E+03$ & 0.00 \\
\hline & $B e$ & [6.3E-1] & $6.4 E-02$ & [9.0E-1] & {$[0.28]$} \\
\hline & $\mathrm{Ca}$ & $3.7 E+04$ & {$[4.2 E+0]$} & $6.4 E+04$ & 0.00 \\
\hline & $\mathrm{Ce}$ & {$[5.7 E+1]$} & $<1.2 E+0$ & {$[9.5 E+1]$} & $-[0.15]$ \\
\hline & $\mathrm{Cu}$ & $8.1 E+01$ & {$[6.0 E-1]$} & $1.4 E+02$ & 0.03 \\
\hline & $L a$ & {$[8.3 E+1]$} & $<3.4 E-1$ & {$[1.4 E+2]$} & $-[0.09]$ \\
\hline & $\mathrm{Li}$ & {$[1.5 E+1]$} & 3.6E-01 & {$[2.5 E+1]$} & {$[0.11]$} \\
\hline & $M g$ & $2.9 E+03$ & $<2.8 E-1$ & $4.9 E+03$ & 0.00 \\
\hline & Mo & $<1.7 E+1$ & {$[1.6 E+0]$} & $<2.5 E+1$ & $n a$ \\
\hline & $N d$ & {$[1.1 E+2]$} & $<2.5 E+0$ & {$[1.8 E+2]$} & $-[0.20]$ \\
\hline & $P b$ & $3.0 E+03$ & $8.3 E+01$ & $5.0 E+03$ & 0.15 \\
\hline & $\mathrm{Ti}$ & $2.0 E+02$ & $<5.3 E-2$ & $3.3 E+02$ & -0.02 \\
\hline & V & {$[3.6 E+0]$} & 5.9E-01 & {$[4.5 E+0]$} & $-[0.09]$ \\
\hline & $W$ & $<5.0 E+1$ & $<1.8 E+0$ & $<8.1 E+1$ & -0.57 \\
\hline & $Y$ & $2.3 E+01$ & $<5.4 E-2$ & $3.9 E+01$ & -0.02 \\
\hline
\end{tabular}


WTP-RPT-170, Rev. 0

Table 4.22 (Contd)

\begin{tabular}{|c|c|c|c|c|c|}
\hline $\begin{array}{c}\text { Slurry Prep } \\
\text { Method }\end{array}$ & Analyte & $\begin{array}{c}\text { Dry Slurry } \\
(\mu \mathrm{g} / \mathrm{g})\end{array}$ & $\begin{array}{c}\text { Supernate }^{(\mathrm{b})} \\
(\mu \mathrm{g} / \mathrm{mL})\end{array}$ & $\begin{array}{c}\text { Dry Solids }{ }^{(c)} \\
(\mu \mathrm{g} / \mathrm{g})\end{array}$ & $\begin{array}{c}\text { Solids Leach } \\
\text { Factor }^{(d)}\end{array}$ \\
\hline \multirow{17}{*}{ 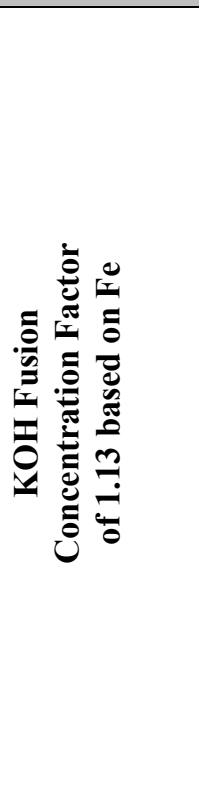 } & $\mathrm{Fe}$ & $6.78 \mathrm{E}+04$ & $6.2 \mathrm{E}+00$ & $1.2 \mathrm{E}+05$ & na \\
\hline & B & $<8.5 \mathrm{E}+1$ & $3.18 \mathrm{E}+01$ & $<5.8 \mathrm{E}+1$ & na \\
\hline & $\mathrm{Na}$ & $2.12 \mathrm{E}+05$ & $1.2 \mathrm{E}+05$ & $3.4 \mathrm{E}+04$ & 0.15 \\
\hline & $\mathrm{Si}$ & {$[1.2 \mathrm{E}+4]$} & $5.0 \mathrm{E}+01$ & {$[2.0 \mathrm{E}+4]$} & {$[0.05]$} \\
\hline & Radionuclide & $(\mu \mathrm{Ci} / \mathrm{g})$ & $(\mu \mathrm{Ci} / \mathrm{mL})$ & $(\mu \mathrm{Ci} / \mathrm{g})$ & \\
\hline & ${ }^{60} \mathrm{Co}$ & $5.36 \mathrm{E}-3$ & $<1 . \mathrm{E}-4$ & $8.9 \mathrm{E}-3$ & na \\
\hline & ${ }^{137} \mathrm{Cs}$ & $1.14 \mathrm{E}+2$ & $2.69 \mathrm{E}+1$ & $1.2 \mathrm{E}+2$ & 0.68 \\
\hline & ${ }^{154} \mathrm{Eu}$ & $9.13 \mathrm{E}-2$ & $<4$.E-4 & $1.6 \mathrm{E}-1$ & -0.04 \\
\hline & ${ }^{155} \mathrm{Eu}$ & $<6$.E-2 & $<6$. E-3 & $<9 . \mathrm{E}-2$ & na \\
\hline & ${ }^{241} \mathrm{Am}$ & [1.08E-1] & $<5$. E-3 & [1.7E-1] & {$[0.10]$} \\
\hline & Total Alpha & $6.08 \mathrm{E}-1$ & $<2$.E-4 & $1.0 \mathrm{E}+0$ & -0.02 \\
\hline & Total Beta & $1.87 \mathrm{E}+3$ & $2.62 \mathrm{E}+1$ & $3.1 \mathrm{E}+3$ & -0.07 \\
\hline & ${ }^{90} \mathrm{Sr}$ & $8.26 \mathrm{E}+2$ & $9.64 \mathrm{E}-3$ & $1.4 \mathrm{E}+3$ & -0.02 \\
\hline & ${ }^{239+240} \mathrm{Pu}$ & $3.58 \mathrm{E}-1$ & $4.29 \mathrm{E}-5$ & $6.2 \mathrm{E}-1$ & -0.08 \\
\hline & ${ }^{238} \mathrm{Pu}$ & $1.89 \mathrm{E}-2$ & $8.76 \mathrm{E}-6$ & $3.2 \mathrm{E}-2$ & -0.11 \\
\hline & KPA & $(\mu \mathrm{g} / \mathrm{g})$ & $(\mu \mathrm{g} / \mathrm{mL})$ & $(\mu \mathrm{g} / \mathrm{g})$ & \\
\hline & $\mathrm{U}$ & $6.59 \mathrm{E}+4$ & $7.42 \mathrm{E}+0$ & $1.1 \mathrm{E}+5$ & 0.02 \\
\hline \multicolumn{6}{|c|}{ (a) Test sample TI640-G8-9, ASO ID 08-2296 } \\
\hline \multicolumn{6}{|c|}{ (b) Test sample TI640-G8-D, ASO ID 08-2284 } \\
\hline \multirow{2}{*}{\multicolumn{6}{|c|}{$\begin{array}{l}\text { (c) Calculated using results from TI640-G8-9 \& TI640-G8-D, as described in Appendix E, Equation E.13. } \\
\text { (d) Calculated using results listed in Table 4.14, as described in Appendix E, Equation E.17. Leach factors for } \\
\text { uranium and iron assumed to be zero. }\end{array}$}} \\
\hline & & & & & \\
\hline \multicolumn{6}{|c|}{$\begin{array}{l}\text { Note: Analytes in italics were measured opportunistically. Values in brackets [ ] are } \geq \text { MDL but }<\text { EQL, with } \\
\text { errors likely to exceed } 15 \% \text {. }\end{array}$} \\
\hline
\end{tabular}

The slurry was sampled for PSD measurement to characterize the average size of solids after caustic leaching. However, the sample was unable to be removed outside of the hot cell due to high radiological dose-rate limitations. The increase in the dose rate was likely due to the increased ${ }^{137} \mathrm{Cs}$ concentration in the sample supernate. A sample of the leached and washed slurry sample was successfully removed from the hot cell and analyzed (see Section 4.6).

The dewatered caustic-leached slurry (sample TI640-G8-R3-Slurry) was also sub-sampled for rheological measurement. Figure 4.25 shows the results of flow-curve testing for this sample. Like the pre-leached high-solids slurry (Section 4.4), the post-leach dewatered slurry showed non-Newtonian behavior. Based on visual inspection of flow-curve data, the yield stress for the slurry appeared to fall between 0.5 and 1.0 Pa. After the slurry's yield point on the flow curve, the stress response of this slurry was linear over the entire range of shear rates tested with the exception of the slight shear-thinning region at low shear (i.e., 0 to $100 \mathrm{~s}^{-1}$ ). At all shear rates, there was significant overlap of flow-curve data between temperatures. Measurement noise and hysteresis both contributed to the observed overlap. Because of the significant data overlap, temperature trends were difficult to discern. The data appeared to indicate a decrease in flow-curve slope (i.e., consistency) from 25 to $40^{\circ} \mathrm{C}$ whereas the flow curves at 40 and $60^{\circ} \mathrm{C}$ appeared statistically similar.

Table 4.23 summarizes the best-fit Bingham-Plastic and Casson parameters for the caustic-leached and dewatered sample (TI640-G8-R3-Slurry). Analysis of flow-curve data against the Bingham-Plastic flow 
curve model suggested a yield stress ranging from 0.9 to $1.1 \mathrm{~Pa}$ and a consistency ranging from $5.4 \mathrm{mPa} \cdot \mathrm{s}$ to $6.7 \mathrm{mPa} \cdot \mathrm{s}$. Similar analysis with the Casson model found a yield stress of $0.3 \mathrm{~Pa}$ and a consistency that ranged from 3.8 to $5.1 \mathrm{mPa} \cdot \mathrm{s}$. Although the regressed Bingham-Plastic yield was significant, the Casson yield still fell below the detection limit of $0.5 \mathrm{~Pa}$. As such, the rheology of the slurry sample was best classified as "weakly" or borderline non-Newtonian.

An increased slurry temperature did not appear to significantly affect yield stress but did impact consistency. The Bingham-Plastic yield stress showed an insignificant 0.2 Pa variation over the range of temperatures tested. Casson yield stress showed no variation. Both Bingham-Plastic and Casson showed decreases of $1.3 \mathrm{mPa} \cdot \mathrm{s}$ between $25^{\circ} \mathrm{C}$ and $60^{\circ} \mathrm{C}$. Most of this decrease occurred over 25 to $40^{\circ} \mathrm{C}$, with little change found between consistency measurements performed at $40^{\circ}$ and $60^{\circ} \mathrm{C}$. This behavior confirmed earlier observations about the slope of the flow-curve data of the sample. Based on both fitting approaches, the measured yield stress did not vary significantly with temperature, but that consistency decreased significantly with increasing temperatures.

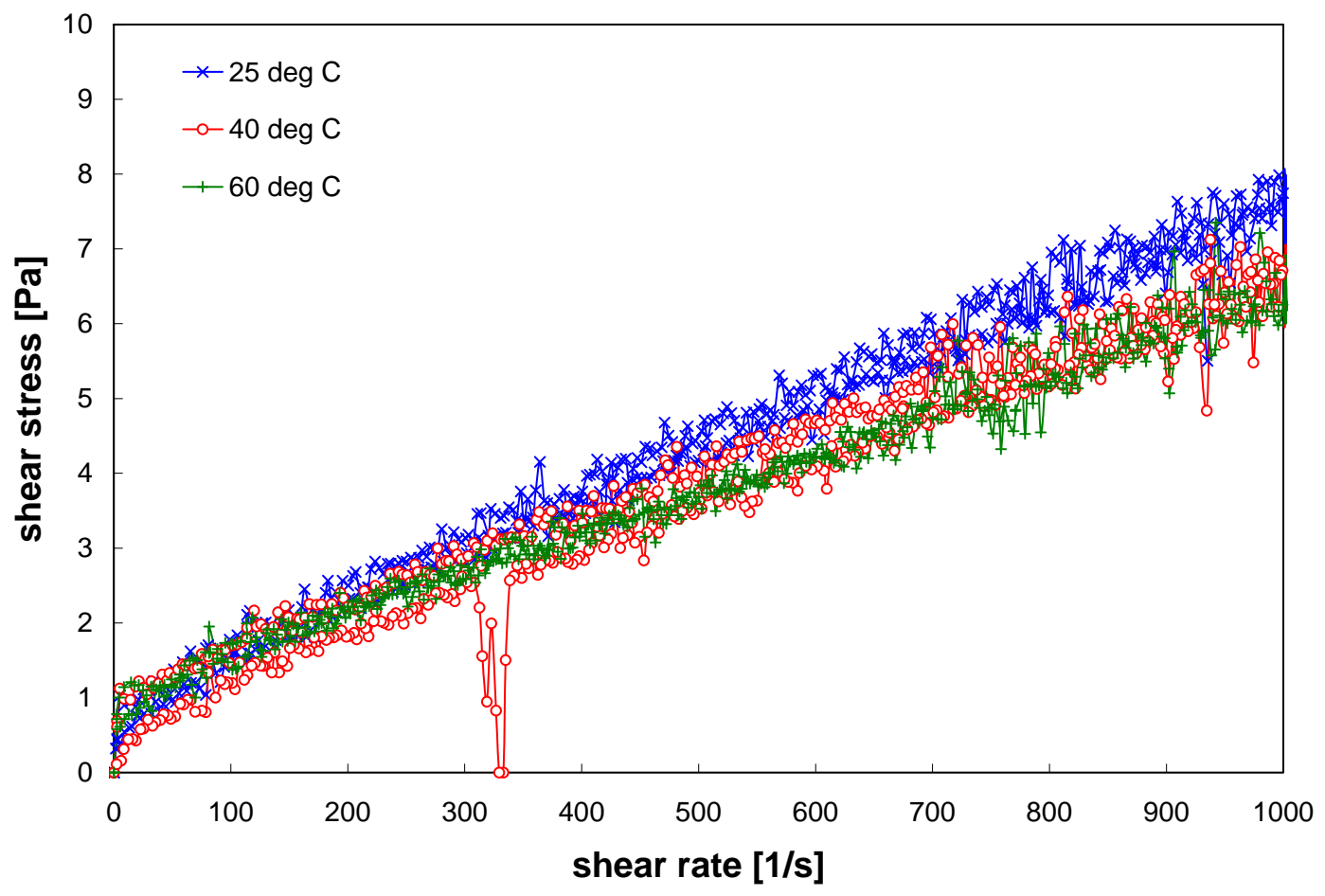

Figure 4.25. Flow Curves for Group 8 CUF Caustic Leached Dewatered Slurry 
WTP-RPT-170, Rev. 0

Table 4.23. Results of Fitting Analysis for the Group 8 CUF Leached Dewatered Slurry

\begin{tabular}{||c|c|c|c|c|c||}
\hline \multirow{3}{*}{ Model } & $\begin{array}{c}\text { Temperature } \\
\left({ }^{\circ} \mathbf{C}\right)\end{array}$ & $\begin{array}{c}\text { Range } \\
\left(\mathbf{s}^{-1}\right)\end{array}$ & $\begin{array}{c}\text { Yield Stress } \\
(\mathbf{P a})\end{array}$ & $\begin{array}{c}\text { Consistency } \\
(\mathbf{m P a} \cdot \mathbf{s})\end{array}$ & $\mathbf{R}$ \\
\hline \multirow{4}{*}{ Bingham-Plastic } & $25(1$ of 2$)$ & $100-1000$ & 1.1 & 6.7 & 0.99 \\
\cline { 2 - 6 } & $25(2$ of 2$)$ & $100-1000$ & 1.1 & 6.6 & 0.99 \\
\cline { 2 - 6 } & 40 & $100-1000$ & 0.9 & 5.6 & 0.98 \\
\cline { 2 - 6 } & 60 & $100-1000$ & 1.0 & 5.4 & 0.99 \\
\hline \multirow{3}{*}{ Casson } & $25(1$ of 2$)$ & $0-1000$ & 0.3 & 5.1 & 0.99 \\
\cline { 2 - 6 } & $25(2$ of 2$)$ & $0-1000$ & 0.3 & 5.0 & 0.99 \\
\cline { 2 - 6 } & 40 & $0-1000$ & 0.3 & 4.2 & 0.99 \\
\cline { 2 - 6 } & 60 & $0-1000$ & 0.3 & 3.8 & 0.99 \\
\hline \hline
\end{tabular}

\subsubsection{Caustic Batch Rinsing Results}

After slurry sampling, the slurry was washed four times with decreasing concentrations of sodium hydroxide, as shown in Figure 4.26. The volume of each wash solution was $1.2 \mathrm{~L}$, approximately the same volume of supernate present in the system after dewatering from caustic leaching. After each solution was added, the slurry was re-circulated in the CUF for $\sim 30$ minutes while filter permeate was recycled back to the slurry reservoir. The slurry was then dewatered at standard conditions to return the slurry back to its original volume. 
WTP-RPT-170, Rev. 0

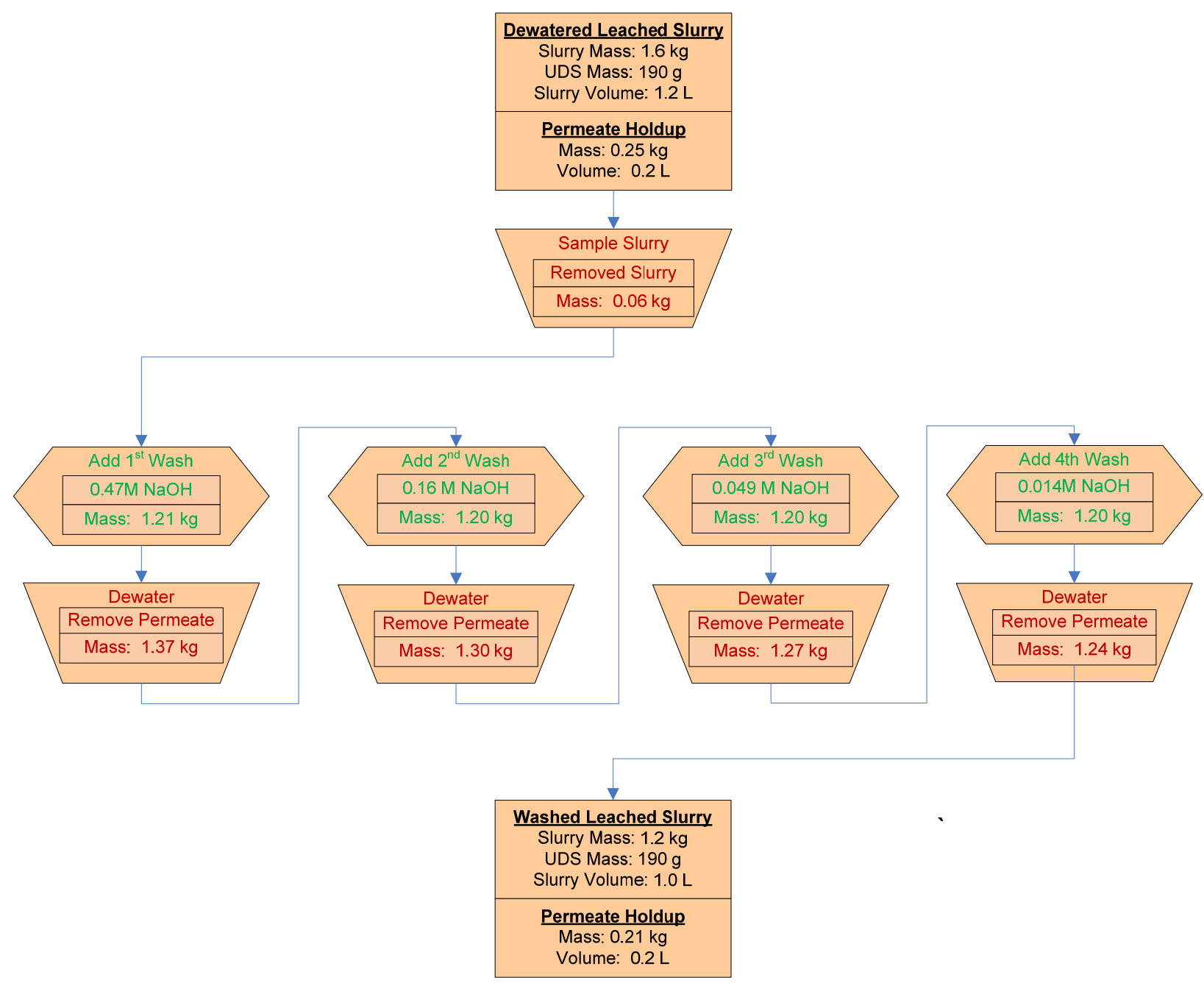

Figure 4.26. Process Flow of Batch Washing Operations

The results of the slurry mass-balance calculations for $\mathrm{Al}, \mathrm{P}, \mathrm{Cr}$, and ${ }^{137} \mathrm{Cs}$ are shown in Figure 4.27 through Figure 4.30, providing a visual representation of the movement of these analytes from the solids phase to the aqueous phase during stepwise processes from the low-solids matrix through the last caustic wash. Sampling losses were taken into account to normalize the mass values to the original solids inventory. Overall, the trends supported the results described in Sections 4.5.1 and 4.5.3. The error bars shown for the solids mass calculations represent $\pm 15 \%$ analytical uncertainty; the error bars for the ${ }^{137} \mathrm{Cs}$ activity concentration uncertainty represented $\pm 6 \%$ analytical uncertainty.

These charts clearly show the incremental dissolution through the leach process of the $\mathrm{Al}, \mathrm{Cs}$, and $\mathrm{Cr}$. The P clearly shows no mobility from the solids phase; removal of $\mathrm{P}$ from the system is only associated with removal of the phosphate already present in the supernate phase. The addition of hydroxide during caustic-leach operations did not result in metathesis of insoluble phosphate compounds to soluble sodium phosphate. Note that there appeared to be an approximately $10 \%$ increase in the insoluble phosphorous content at the start of the caustic leach. This was expected based on the precipitation of sodium phosphate upon the increase in sodium. This precipitated sodium phosphate was then dissolved and removed during subsequent washing. 
WTP-RPT-170, Rev. 0

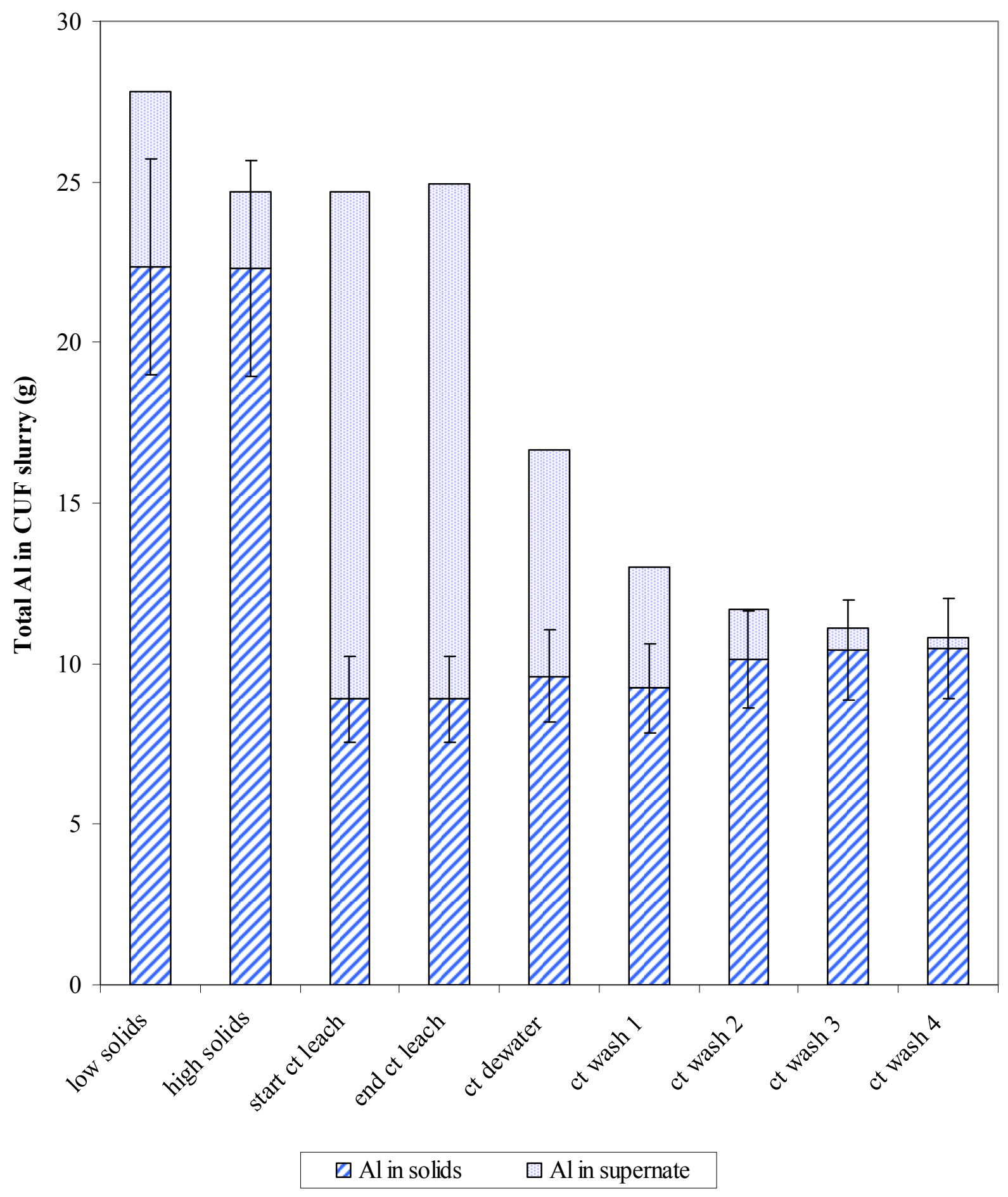

Figure 4.27. Total Aluminum in Group 8 CUF Slurry 
WTP-RPT-170, Rev. 0

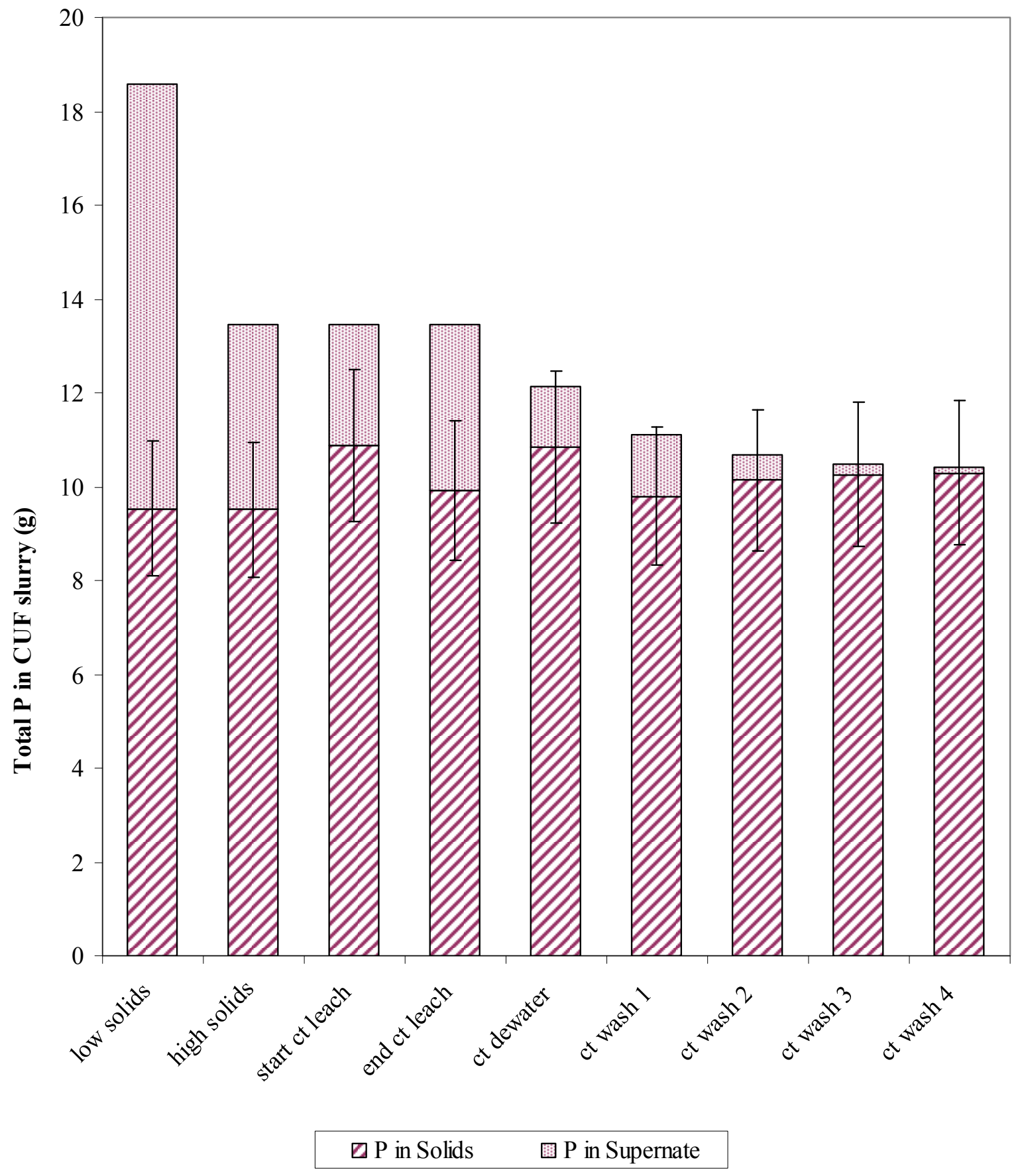

Figure 4.28. Total Phosphorus in Group 8 CUF Slurry 
WTP-RPT-170, Rev. 0

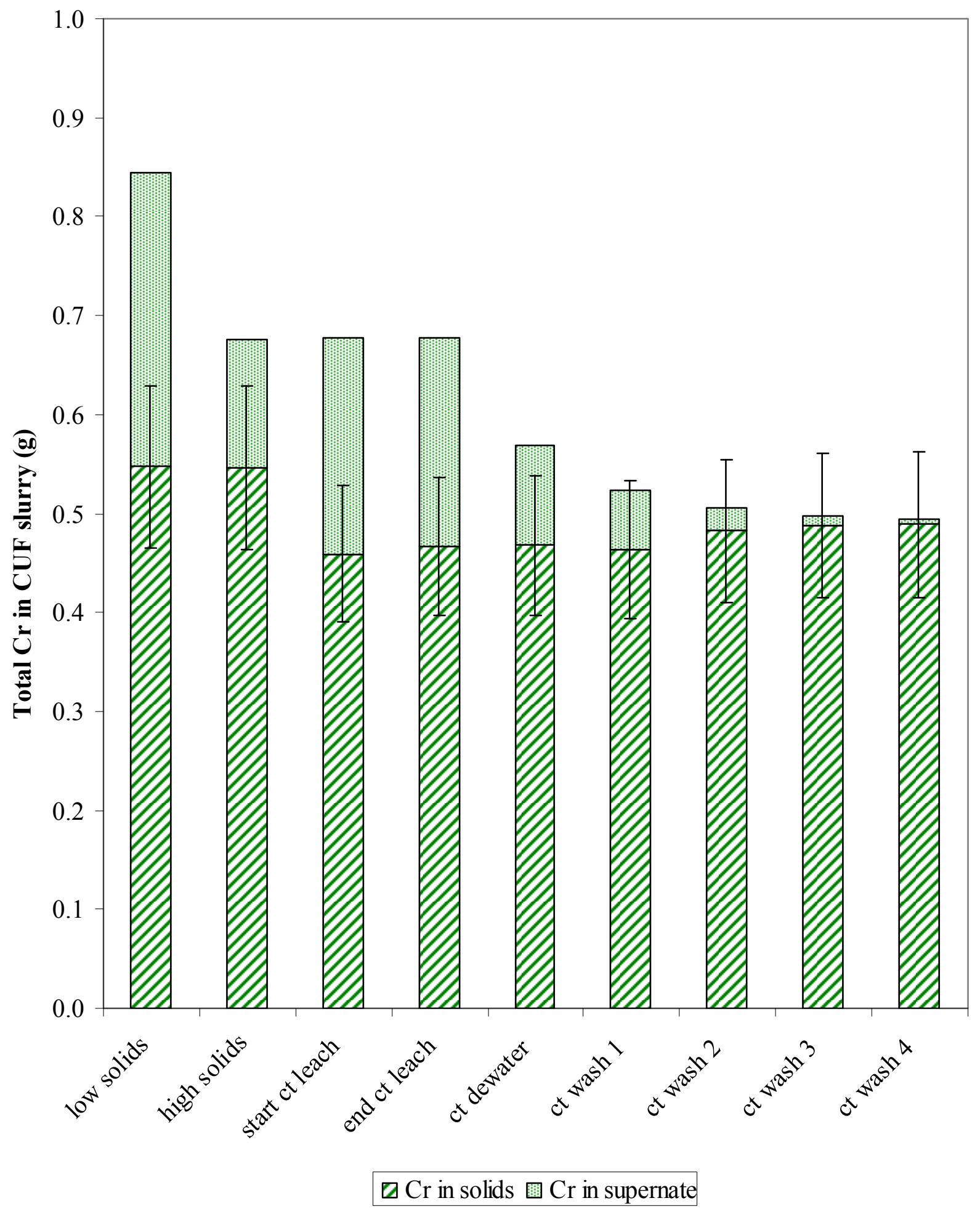

Figure 4.29. Total Chromium in Group 8 CUF Slurry 
WTP-RPT-170, Rev. 0

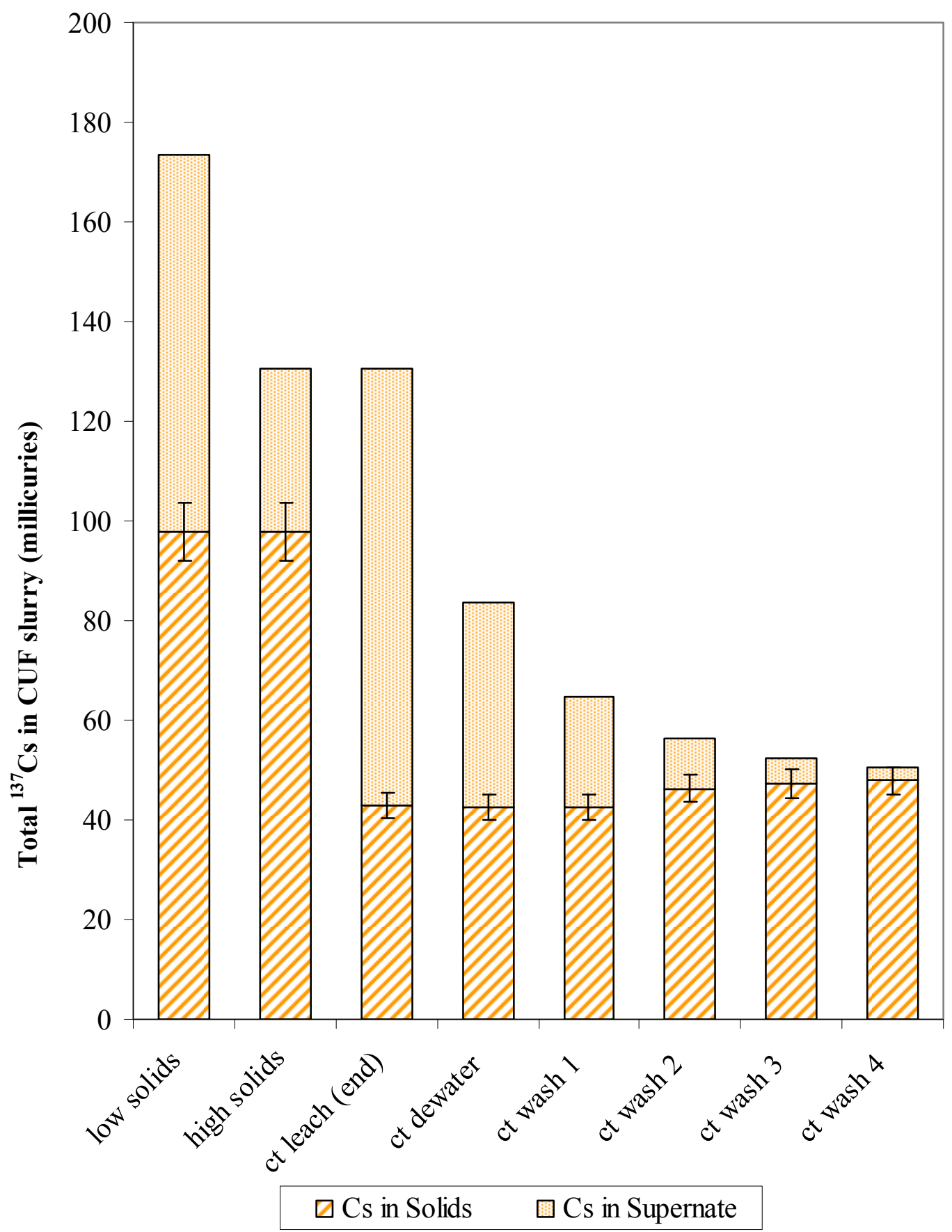

Figure 4.30. Total ${ }^{137} \mathrm{Cs}$ in Group 8 CUF Slurry

Figure 4.31 shows the combined relative analyte removals from the CUF system as a function of processing step. The P removal was attributed solely to the phosphate initially present in the supernatant. All P initially in the solids phase remained in the solids phase; no metathesis with hydroxide appeared to occur. Approximately $11 \%$ of the Cr leached from solids phase and thus showed a slightly higher 
incremental increase relative to the phosphorous. A significant fraction of the $\mathrm{Al}$ and $\mathrm{Cs}$ were leached and removed in the washes.

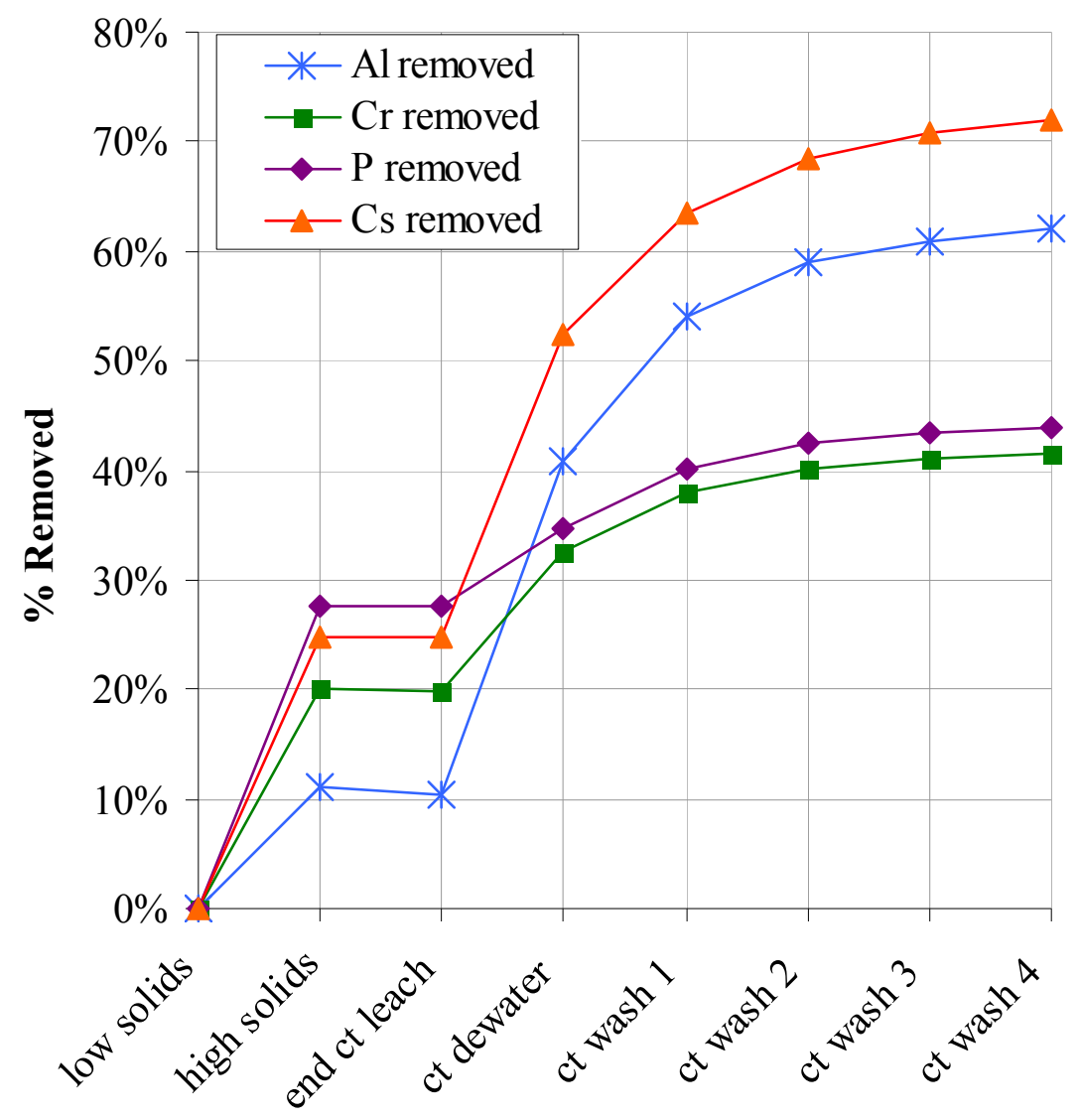

Figure 4.31. Al, Cr, $\mathrm{P},{ }^{137} \mathrm{Cs}$ Removed from the Group 8 CUF Slurry

The overall leach factors and the final inventory removal from the combined CUF process leach and wash steps are shown in Table 4.24.

Table 4.24. Overall Mass Balance Results after Washing of Caustic Leached Slurry

\begin{tabular}{|c|c|c||}
\hline Analyte & $\begin{array}{c}\text { Solids Leach and } \\
\text { Wash Factor } \\
\text { (wt\%) }\end{array}$ & $\begin{array}{c}\text { Total Removal } \\
\text { from Slurry } \\
\text { (wt\%) }\end{array}$ \\
\hline $\mathrm{Al}$ & 54 & 63 \\
\hline $\mathrm{P}$ & $0^{(\mathrm{a})}$ & 44 \\
\hline $\mathrm{Cr}$ & 11 & 41 \\
\hline${ }^{137} \mathrm{Cs}$ & 53 & 72 \\
\hline (a) Actual value calculated was less than zero. \\
\hline
\end{tabular}

Analyte molarities and compositional changes of $\mathrm{Al}, \mathrm{P}, \mathrm{Na}$, and $\mathrm{OH}^{-}$in the slurry supernate over the course of the test are shown in Figure 4.32. Soluble P, present in the initial slurry supernate as phosphate, 
was simply removed by repeated washing (after a slight precipitation during the caustic-leaching step). The molar ratio of free hydroxide to $\mathrm{Al}$ in the aqueous phase was initially 6.6. After adding the caustic solution, the free-hydroxide/Al mole ratio was $\sim 21$. The caustic-wash solutions resulted in a freehydroxide/Al mole ratio of $\sim 26$. A free-hydroxide/Al mole ratio of $\sim 10$ was targeted for leaching and washing this waste. However, only about half of the $\mathrm{Al}$ and none of the $\mathrm{P}$ leached under these process conditions, which resulted in the free-hydroxide matrix being $2 \times$ higher than targeted.

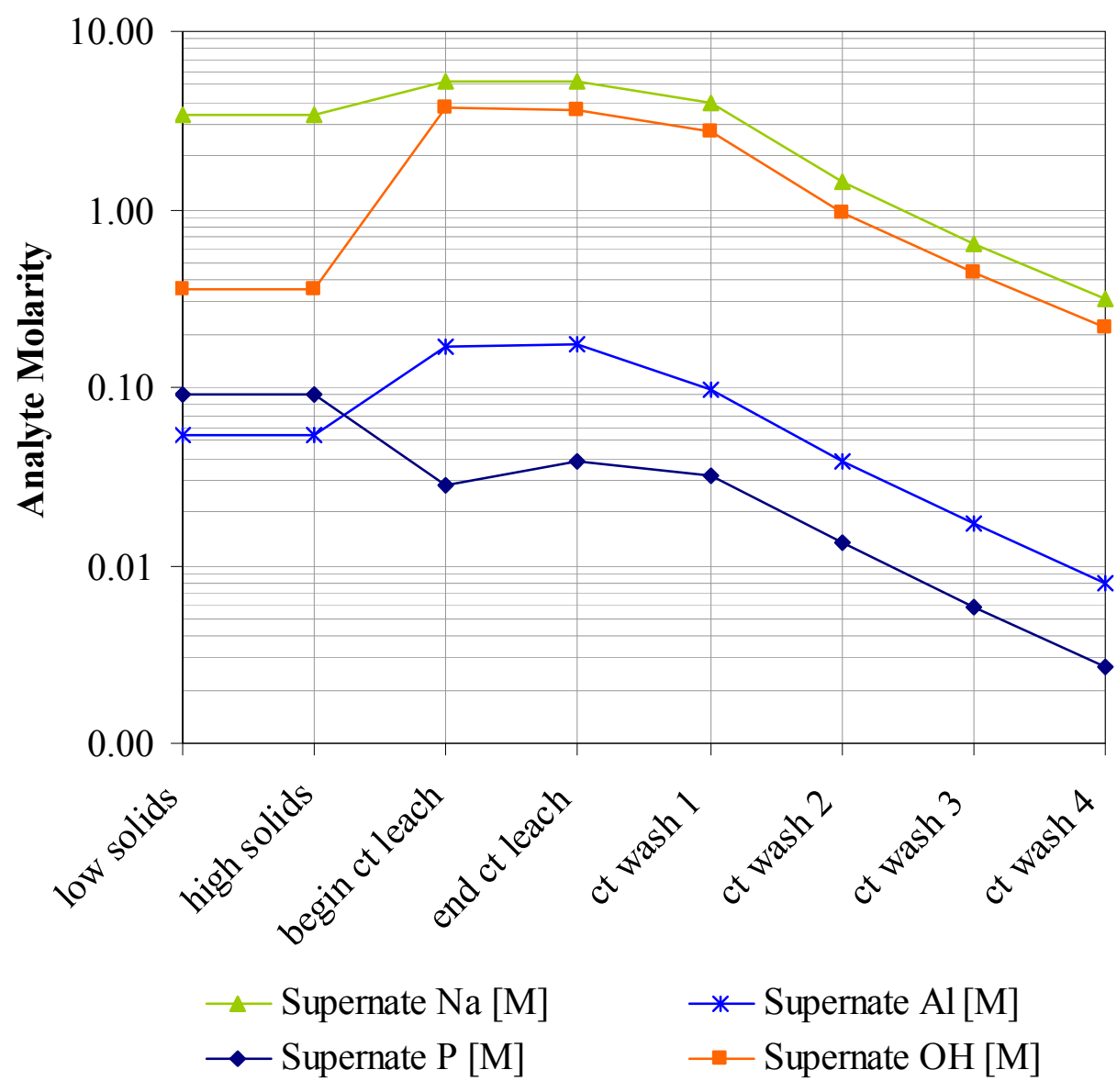

Figure 4.32. Sodium and Free-Hydroxide Molarity in Group 8 CUF Slurry

\subsubsection{Dewatering Caustic-Wash Solutions}

The input $\mathrm{NaOH}$ concentration and volume, equilibrated wash solution $\mathrm{Na}$, free hydroxide, and $\mathrm{Al}$ concentrations, and average filter flux results from dewatering the slurry washes are summarized in Table 4.25. The filtration of the wash solutions occurred rapidly $\left(>0.03 \mathrm{GPM} / \mathrm{ft}^{2}\right)$ with increasing flux with each water wash. The 1.2-L wash volumes required 37, 32, 32, and 28 minutes, sequentially, to filter from the slurry. 
Table 4.25. Comparison of Washed Slurry Supernate Attributes to Filter Flux

\begin{tabular}{|c|c|c|c|c|c|c|}
\hline \multirow[b]{2}{*}{ Process Step } & \multirow{2}{*}{$\begin{array}{c}\text { Added Wash } \\
\text { Volume } \\
\text { (L) }\end{array}$} & \multirow{2}{*}{$\begin{array}{l}\text { Wash Addition } \\
\text { NaOH } \\
\text { (M) }\end{array}$} & \multicolumn{3}{|c|}{ Dewatered Supernate } & \multirow{2}{*}{$\begin{array}{c}\text { Average } \\
\text { Filter Flux } \\
\left(\text { GPM/ft }{ }^{2}\right)\end{array}$} \\
\hline & & & $\begin{array}{l}\mathrm{Na} \\
\text { (M) }\end{array}$ & $\begin{array}{l}\mathrm{OH} \\
(\mathrm{M})\end{array}$ & $\begin{array}{c}\text { Al } \\
\text { (M) }\end{array}$ & \\
\hline Wash 1 & 1.20 & 0.47 & 3.95 & 2.72 & 0.096 & 0.034 \\
\hline Wash 2 & 1.20 & 0.16 & 1.41 & 0.96 & 0.038 & 0.040 \\
\hline Wash 3 & 1.20 & 0.049 & 0.64 & 0.44 & 0.017 & 0.044 \\
\hline Wash 4 & 1.20 & 0.014 & 0.31 & 0.22 & 0.008 & 0.045 \\
\hline Initial slurry & $\overline{\text { na }}$ & $\overline{\text { na }}$ & 3.42 & 0.36 & 0.054 & 0.027 \\
\hline Leach slurry & na & na & 5.17 & 3.65 & 0.172 & 0.015 \\
\hline
\end{tabular}

As expected, the filter flux decreased as the solids concentration in the slurry loop increased. However, the decrease is not necessarily directly related to the changing solids concentration. The standard filtration conditions ( $\mathrm{TMP}=40 \mathrm{psid}$ and $\mathrm{AV}=13 \mathrm{ft} / \mathrm{s}$ ) were difficult to maintain over the filtration operation time period. As the slurry volume decreased, the minimal operating CUF volume was approached, and the pump began to entrain air into the slurry, decreasing pumping efficiency. This caused the TMP at the end of each wash step to drop to $\sim 30$ psid. The AV also was not maintained throughout the dewatering. The AV decreased to $\sim 11 \mathrm{ft} / \mathrm{s}$ for the first two washes, to $\sim 9 \mathrm{ft} / \mathrm{s}$ for the third wash, and to $\sim 8 \mathrm{ft} / \mathrm{s}$ for the fourth wash. Figure 4.33 shows the experimental variation in TMP and AV as functions of process time during the four wash steps.

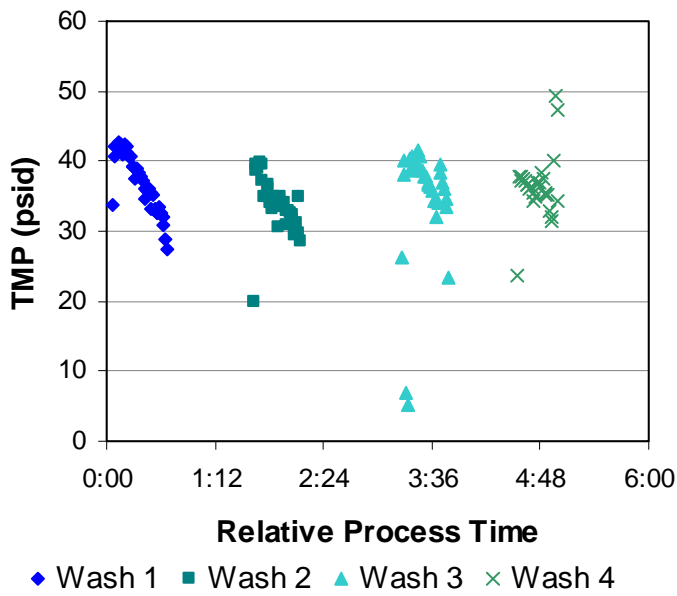

Figure 4.33. TMP and AV as Functions of Process Time During Slurry Washing

The TMP and AV decreases in the filtration conditions were likely the reason for the measurable decreases in the filter flux as a function of time observed for each dewatering operation. Figure 4.34 shows the filter flux as a function of process time and wash step. Also shown for reference are the average filter fluxes for the initial dewatering of Group 8 and the dewatering for the Group 8 leach solution. 
WTP-RPT-170, Rev. 0

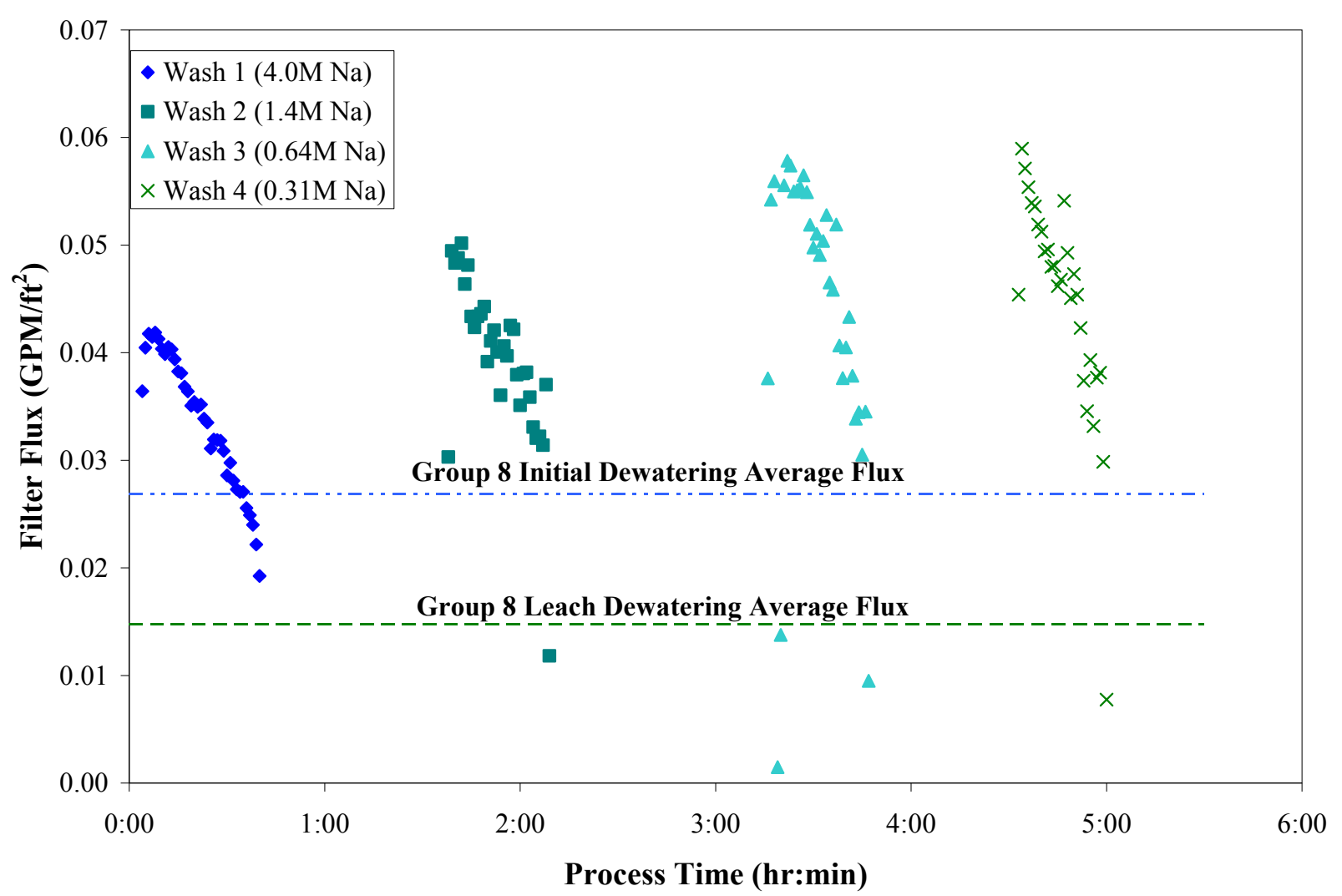

Figure 4.34. Filter Flux of Dewatered Wash Supernate

Comparison of the wash dewatering to the dewatering of the slurry before and after caustic leaching showed a correlation between filter flux and the sodium concentration of the slurry supernate. ${ }^{(a)}$ (For comparison purposes, the flux during wash-solution dewatering conditions should be evaluated where the TMP and AV were sustained at baseline conditions.) For all the dewatering operations, an increase in the filter flux was observed with a decrease in the sodium concentration of the slurry supernate. After the sodium concentration in the slurry supernate decreased below $1 \mathrm{M}$ (wash 3 and wash 4), the estimated supernate viscosity stopped changing and approached $1 \mathrm{mPa} \cdot \mathrm{s}$ (equivalent to water). At the same time, the corresponding filter flux stopped increasing, demonstrating the filter flux dependence on the slurry's supernate composition and viscosity.

\subsection{Leached Material Characterization}

After leaching and washing operations, the slurry was sampled and drained from the CUF as indicated in Figure 4.35. Physical and chemical analyses were performed on the collected samples. The results of physical-property measurements of the leached and dewatered material are shown in Table 4.26. The measured UDS concentration of the slurry $(20 \mathrm{wt} \%)$ was higher than the predicted concentration (15 $\mathrm{wt} \%$ estimated from tracking the mass balance) and was believed to result from sampling issues. As discussed in Section 4.5.4, settling of the slurry during sampling was an ongoing issue for this kind of test in the hot

(a) Sodium concentration is a direct indicator of dissolved salt concentration in the tank waste materials since it is the primary cation in tank waste supernatant. As sodium concentration increases, overall salt loading (from hydroxides, nitrates, aluminates, nitrites, etc.) increases, which is directly related to viscosity. 
cells. Once a slurry aliquot was collected, transferring slurry using a pipette to a centrifuge cone was problematic. If the measured UDS concentration was correct, the solids inventory of the slurry would be $\sim 240$ grams $(0.20 \times 1.2 \mathrm{~kg}=0.24 \mathrm{~kg})$, which was almost equal to the original solids inventory.

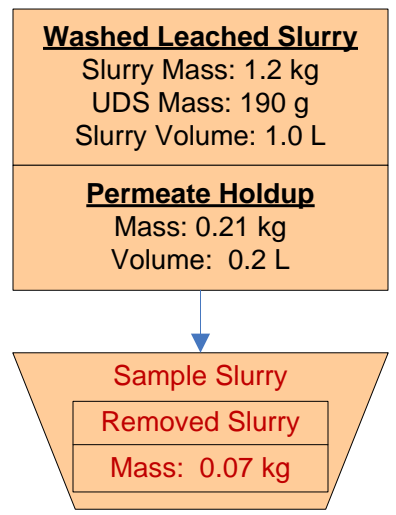

Figure 4.35. Process Flow for Sampling of the Washed and Caustic-Leached Group 8 Slurry

Table 4.26. Final Leached and Washed Slurry Physical-Property Measurements

\begin{tabular}{|r|c||}
\hline Slurry Density (g/mL) & 1.2 \\
\hline Supernate Density (g/mL) & 1.0 \\
\hline Settled Solids (vol\%) & 96 \\
\hline Centrifuged Undissolved Solids (wt\%) & 45 \\
\hline Total Solids (wt\%) & 23 \\
\hline Supernate Dissolved Solids (wt\%) & 3.7 \\
\hline Undissolved Solids (wt\%) & 20 \\
\hline \hline
\end{tabular}

\subsubsection{Chemical Characterization}

The dewatered leached slurry composition, based on tracking the overall mass balance and initial values from characterization, is shown in Table 4.27. Slurry samples were collected and chemically characterized. The slurry composition based on this analysis is provided in Table 4.28. As discussed previously (Section 4.4), analytes that were mostly present in the aqueous phase, such as $\mathrm{S}$ and $\mathrm{Na}$, resulted in large deviations in the calculated solids compositions $(6,200 \mu \mathrm{g} / \mathrm{g}$ vs $769 \mu \mathrm{g} / \mathrm{g}$ for S and a negative concentration vs $61,900 \mu \mathrm{g} / \mathrm{g}$ for $\mathrm{Na}$ ). The negative composition for Na shown Table 4.27 demonstrated the problem of tracking the mass balance over the course of the test for minor analyte components in the solids. Major analyte components such as $\mathrm{U}$ and Fe compared well $(1.2 \mathrm{E}+5 \mu \mathrm{g} / \mathrm{g}$ vs $1.4 \mathrm{E}+5 \mu \mathrm{g} / \mathrm{g}$ for Fe and $1.4 \mathrm{E}+5 \mu \mathrm{g} / \mathrm{g}$ vs. $1.51 \mathrm{E}+5 \mu \mathrm{g} / \mathrm{g}$ for $\mathrm{U})$. 
WTP-RPT-170, Rev. 0

Table 4.27. Group 8 Washed Caustic Leached Slurry Composition Based on Overall Mass Balance (Mass Includes Permeate Holdup Fraction)

\begin{tabular}{|c|c|c|c|c|c|}
\hline & Slurry $^{(\mathbf{a})}$ & \multicolumn{2}{|c|}{ Liquid Fraction $^{(b)}$} & \multicolumn{2}{|c|}{ Solids Fraction ${ }^{(c)}$} \\
\hline Mass (kg) & 1.38 & \multicolumn{2}{|c|}{1.20} & \multicolumn{2}{|c|}{0.18} \\
\hline Wt\% of Slurry & $100 \mathrm{wt} \%$ & \multicolumn{2}{|c|}{$87 \mathrm{wt} \%$} & \multicolumn{2}{|c|}{$13 \mathrm{wt} \%$} \\
\hline ICP-OES Analyte & $\mathbf{g}$ & $\mathbf{g}$ & $\mu \mathrm{g} / \mathrm{mL}$ & g & $\mu \mathrm{g} / \mathrm{g}$ \\
\hline Al & $8.4 \mathrm{E}+00$ & $3.4 \mathrm{E}-01$ & $2.1 \mathrm{E}+02$ & $8.0 \mathrm{E}+00$ & $4.6 \mathrm{E}+04$ \\
\hline $\mathbf{B i}$ & $1.2 \mathrm{E}+00$ & $0.0 \mathrm{E}+00$ & $0.0 \mathrm{E}+00$ & $1.2 \mathrm{E}+00$ & $6.6 \mathrm{E}+03$ \\
\hline $\mathrm{Cr}$ & $3.7 \mathrm{E}-01$ & $5.2 \mathrm{E}-03$ & $3.3 \mathrm{E}+00$ & $3.6 \mathrm{E}-01$ & $2.1 \mathrm{E}+03$ \\
\hline $\mathbf{F e}$ & $2.1 \mathrm{E}+01$ & $5.0 \mathrm{E}-03$ & $3.2 \mathrm{E}+00$ & $2.1 \mathrm{E}+01$ & $1.2 \mathrm{E}+05$ \\
\hline Mn & $2.6 \mathrm{E}-01$ & 4.6E-05 & 2.9E-02 & $2.6 \mathrm{E}-01$ & $1.5 \mathrm{E}+03$ \\
\hline $\mathrm{Na}^{(\mathrm{d})}$ & $9.5 \mathrm{E}+00$ & $1.1 \mathrm{E}+01$ & $7.1 \mathrm{E}+03$ & $-1.8 E+00$ & $-1.0 E+04$ \\
\hline $\mathbf{P}$ & $8.0 \mathrm{E}+00$ & $1.2 \mathrm{E}-01$ & $7.3 \mathrm{E}+01$ & $7.8 \mathrm{E}+00$ & $4.4 \mathrm{E}+04$ \\
\hline $\mathbf{S}^{(d)}$ & $1.2 \mathrm{E}+00$ & $1.0 \mathrm{E}-01$ & $6.5 \mathrm{E}+01$ & $1.1 E+00$ & $6.2 E+03$ \\
\hline Si & $3.1 \mathrm{E}+00$ & $1.2 \mathrm{E}-02$ & $7.6 \mathrm{E}+00$ & $3.0 \mathrm{E}+00$ & $1.7 \mathrm{E}+04$ \\
\hline $\mathbf{S r}$ & $8.1 \mathrm{E}+00$ & $3.5 \mathrm{E}-05$ & $2.2 \mathrm{E}-02$ & $8.1 \mathrm{E}+00$ & $4.6 \mathrm{E}+04$ \\
\hline $\mathbf{U}$ & $2.4 \mathrm{E}+01$ & $1.5 \mathrm{E}-02$ & $9.2 \mathrm{E}+00$ & $2.4 \mathrm{E}+01$ & $1.4 \mathrm{E}+05$ \\
\hline Radionuclides & $\mu \mathrm{Ci}$ & $\mu \mathrm{Ci}$ & $\mu \mathrm{Ci} / \mathbf{m L}$ & $\mu \mathrm{Ci}$ & $\mu \mathrm{Ci} / \mathrm{g}$ \\
\hline${ }^{60} \mathrm{Co}$ & $2.4 \mathrm{E}+00$ & $<$ 9.E-2 & $<7 . \mathrm{E}-5$ & $2.4 \mathrm{E}+00$ & $1.4 \mathrm{E}-02$ \\
\hline${ }^{137} \mathrm{Cs}$ & $4.1 \mathrm{E}+04$ & $1.5 \mathrm{E}+03$ & $1.3 \mathrm{E}+00$ & $4.0 \mathrm{E}+04$ & $2.2 \mathrm{E}+02$ \\
\hline${ }^{154} \mathbf{E u}$ & $2.8 \mathrm{E}+01$ & $<2 . \mathrm{E}-1$ & $<2$.E-4 & $2.8 \mathrm{E}+01$ & $1.6 \mathrm{E}-01$ \\
\hline${ }^{241} \mathrm{Am}$ & $3.8 \mathrm{E}+01$ & $<3 . \mathrm{E}+0$ & $<2 . \mathrm{E}-3$ & $3.8 \mathrm{E}+01$ & $2.1 \mathrm{E}-01$ \\
\hline Total Alpha & $1.9 \mathrm{E}+02$ & $<2$.E-1 & $<2$.E-4 & $1.9 \mathrm{E}+02$ & $1.1 \mathrm{E}+00$ \\
\hline Total Beta & $6.0 \mathrm{E}+05$ & $1.4 \mathrm{E}+03$ & $1.2 \mathrm{E}+00$ & $6.0 \mathrm{E}+05$ & $3.4 \mathrm{E}+03$ \\
\hline${ }^{90} \mathrm{Sr}$ & $2.5 \mathrm{E}+05$ & $7.0 \mathrm{E}-01$ & $6.0 \mathrm{E}-04$ & $2.5 \mathrm{E}+05$ & $1.4 \mathrm{E}+03$ \\
\hline${ }^{239+240} \mathrm{Pu}$ & $1.1 \mathrm{E}+02$ & $7.6 \mathrm{E}-04$ & $6.4 \mathrm{E}-07$ & $1.1 \mathrm{E}+02$ & $6.3 \mathrm{E}-01$ \\
\hline${ }^{238} \mathrm{Pu}$ & $2.2 \mathrm{E}+00$ & $<9 . \mathrm{E}-4$ & $<8 . \mathrm{E}-7$ & $2.2 \mathrm{E}+00$ & $1.2 \mathrm{E}-02$ \\
\hline $\begin{array}{l}\text { (a) Slurry Mass of co } \\
\text { simulant addition } \\
\text { (b) Liquid Fraction c } \\
\text { mass of each com } \\
\text { (c) Solids Fraction co } \\
\text { between the slurry } \\
\text { component in the } \\
\text { (d) Measurements of }\end{array}$ & $\begin{array}{l}\text { nents calcula } \\
\text { ss of mass fr } \\
\text { onents calcul } \\
\text { ent using the } \\
\text { onents calcul } \\
\text { liquid fracti } \\
\text { ds phase of th } \\
\text { and } S \text { in the } n\end{array}$ & $\begin{array}{l}\mathrm{m} \text { characteri } \\
\text { pling includ } \\
\mathrm{m} \text { ICP data } \\
\text { ed mass of } \mathrm{s} \\
\mathrm{m} \text { calculatin } \\
\text { lids fraction } \\
\text { by the esti } \\
\text { ance appear }\end{array}$ & $\begin{array}{l}\text { ata (Section } \\
\text { osition of s } \\
\text { in the syste } \\
\text { ass of each s } \\
\text { ition were tl } \\
\text { ass of solids } \\
\text { significantl }\end{array}$ & $\begin{array}{l}\text { he mass of } \mathrm{n} \\
\text { from testing } \\
\text { mponent by } \\
\text { ulated by div } \\
\text { al in the slurr } \\
\text { m the expec }\end{array}$ & $\begin{array}{l}\text { added from } \\
\text { lculating the } \\
\text { ference } \\
\text { he mass of the } \\
\text { apositions. }\end{array}$ \\
\hline
\end{tabular}


Table 4.28. Washed Leach Slurry Composition and Caustic Leach Factor Calculations Based on ICP-OES/Radiochemical Characterization

\begin{tabular}{|c|c|c|c|c|c|}
\hline $\begin{array}{c}\text { Slurry Prep } \\
\text { Method }\end{array}$ & $\begin{array}{c}\text { ICP-OES } \\
\text { Analyte }\end{array}$ & $\begin{array}{c}\text { Dry Slurry } \\
(\mu \mathrm{g} / \mathrm{g})\end{array}$ & $\begin{array}{c}\text { Supernate } \\
(\mu \mathrm{g} / \mathrm{mL})\end{array}$ & $\begin{array}{c}\text { Dry Solids } \\
(\mu \mathrm{g} / \mathrm{g})\end{array}$ & $\begin{array}{l}\text { Solids Leach } \\
\text { Factor }\end{array}$ \\
\hline \multirow{29}{*}{ 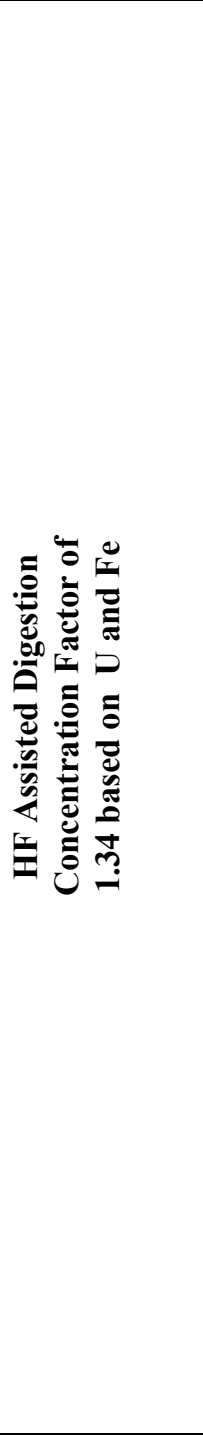 } & $\mathrm{Al}$ & $4.47 \mathrm{E}+04$ & $2.13 \mathrm{E}+02$ & $5.0 \mathrm{E}+04$ & 0.56 \\
\hline & $\mathrm{Bi}$ & $6.79 \mathrm{E}+03$ & $<3.8 \mathrm{E}+0$ & $7.7 \mathrm{E}+03$ & 0.01 \\
\hline & $\mathrm{Cd}$ & {$[1.7 \mathrm{E}+1]$} & {$[1.8 \mathrm{E}+0]$} & {$[1.3 \mathrm{E}+1]$} & 0.51 \\
\hline & $\mathrm{Cr}$ & $2.07 \mathrm{E}+03$ & $3.26 \mathrm{E}+00$ & $2.4 \mathrm{E}+03$ & 0.11 \\
\hline & $\mathrm{Fe}$ & $1.23 \mathrm{E}+05$ & $3.19 \mathrm{E}+00$ & $1.4 \mathrm{E}+05$ & na \\
\hline & $\mathrm{Mn}$ & $1.60 \mathrm{E}+03$ & $<2.9 \mathrm{E}-2$ & $1.8 \mathrm{E}+03$ & 0.00 \\
\hline & $\mathrm{Ni}$ & $4.06 \mathrm{E}+04$ & {$[1.4 \mathrm{E}+0]$} & $4.6 \mathrm{E}+04$ & 0.02 \\
\hline & $\mathrm{P}$ & $4.30 \mathrm{E}+04$ & $7.34 \mathrm{E}+01$ & $4.9 \mathrm{E}+04$ & 0.00 \\
\hline & $\mathrm{S}$ & {$[8.9 \mathrm{E}+2]$} & {$[6.5 \mathrm{E}+1]$} & {$[7.7 \mathrm{E}+2]$} & 0.77 \\
\hline & $\mathrm{Sr}$ & $4.70 \mathrm{E}+04$ & {$[2.2 \mathrm{E}-2]$} & $5.4 \mathrm{E}+04$ & 0.02 \\
\hline & $\mathrm{U}$ & $1.32 \mathrm{E}+05$ & {$[9.2 \mathrm{E}+0]$} & $1.5 \mathrm{E}+05$ & na \\
\hline & $\mathrm{Zn}$ & $5.54 \mathrm{E}+02$ & {$[1.6 \mathrm{E}+0]$} & $6.3 \mathrm{E}+02$ & 0.16 \\
\hline & $\mathrm{Zr}$ & $3.35 \mathrm{E}+02$ & $<1.4 \mathrm{E}-1$ & $3.8 \mathrm{E}+02$ & 0.01 \\
\hline & $\mathrm{Ag}$ & {$[2.4 E+1]$} & $<2.6 E-1$ & {$[2.6 E+1]$} & {$[0.25]$} \\
\hline & $B a$ & $1.08 E+03$ & [3.6E-2] & $1.23 E+03$ & 0.02 \\
\hline & $\mathrm{Be}$ & {$[1.1 E+0]$} & {$[7.9 E-3]$} & {$[1.2 E+0]$} & [0.21] \\
\hline & $\mathrm{Ca}$ & $6.95 E+04$ & {$[2.2 E+0]$} & $7.94 E+04$ & 0.00 \\
\hline & $\mathrm{Ce}$ & {$[1.5 E+2]$} & $<1.3 E+0$ & {$[1.7 E+2]$} & $-[0.63]$ \\
\hline & $\mathrm{Cu}$ & $1.34 E+02$ & $<1.8 E-1$ & $1.52 E+02$ & 0.13 \\
\hline & $L a$ & $1.41 E+02$ & $<3.5 E-1$ & $1.60 E+02$ & {$[0.01]$} \\
\hline & $\mathrm{Li}$ & $1.70 E+01$ & {$[1.7 E-1]$} & $1.88 E+01$ & {$[0.46]$} \\
\hline & $M g$ & $5.35 E+03$ & $<2.9 E-1$ & $6.11 E+03$ & -0.01 \\
\hline & $M o$ & $<1.5 E+1$ & $<6.6 E-1$ & $<1.4 E+1$ & $n a$ \\
\hline & $N d$ & {$[2.9 E+2]$} & $<2.5 E+0$ & {$[3.2 E+2]$} & $-[0.70]$ \\
\hline & $\mathrm{Pb}$ & $5.49 E+03$ & $<4.0 E+0$ & $6.26 E+03$ & 0.14 \\
\hline & $\mathrm{Ti}$ & $3.61 E+02$ & $<5.4 E-2$ & $4.12 E+02$ & -0.01 \\
\hline & $V$ & $<2.1 E+0$ & {$[4.0 E-1]$} & $<8.8 E-1$ & [0.83] \\
\hline & $W$ & {$[4.8 E+1]$} & $<1.9 E+0$ & $4.76 E+01$ & 0.26 \\
\hline & $Y$ & $4.20 E+01$ & $<5.6 E-2$ & $4.78 E+01$ & -0.01 \\
\hline
\end{tabular}


WTP-RPT-170, Rev. 0

Table 4.28 (Contd)

\begin{tabular}{|c|c|c|c|c|c|}
\hline $\begin{array}{c}\text { Slurry Prep } \\
\text { Method }\end{array}$ & $\begin{array}{l}\text { ICP-OES } \\
\text { Analyte }\end{array}$ & $\begin{array}{c}\text { Dry Slurry } \\
(\mu \mathrm{g} / \mathrm{g})\end{array}$ & $\begin{array}{c}\text { Supernate } \\
(\mu \mathrm{g} / \mathrm{mL})\end{array}$ & $\begin{array}{c}\text { Dry Solids } \\
(\mu \mathrm{g} / \mathrm{g})\end{array}$ & $\begin{array}{c}\text { Solids Leach } \\
\text { Factor }\end{array}$ \\
\hline \multirow{17}{*}{ 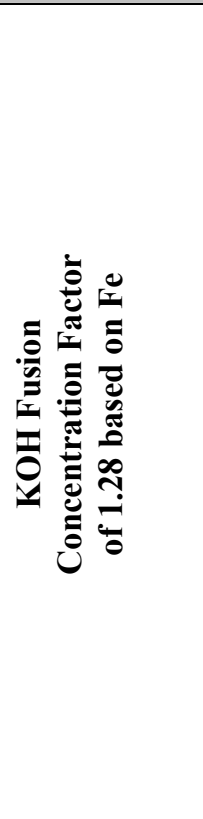 } & $\mathrm{Fe}$ & $1.15 \mathrm{E}+05$ & [3.7E-1] & $1.3 \mathrm{E}+05$ & na \\
\hline & B & $<1.1 \mathrm{E}+2$ & {$[6.1 \mathrm{E}+0]$} & $<1.0 \mathrm{E}+2$ & na \\
\hline & $\mathrm{Na}$ & $7.80 \mathrm{E}+04$ & $7.14 \mathrm{E}+03$ & $6.2 \mathrm{E}+04$ & -0.37 \\
\hline & $\mathrm{Si}$ & {$[2.0 \mathrm{E}+4]$} & $8.35 \mathrm{E}+00$ & {$[2.3 \mathrm{E}+4]$} & {$[0.06]$} \\
\hline & Radionuclide & $(\mu \mathrm{Ci} / \mathrm{g})$ & $(\mu \mathrm{Ci} / \mathrm{mL})$ & $(\mu \mathrm{Ci} / \mathrm{g})$ & \\
\hline & ${ }^{60} \mathrm{Co}$ & $7.10 \mathrm{E}-3$ & $<7 . \mathrm{E}-5$ & $7.8 \mathrm{E}-3$ & na \\
\hline & ${ }^{137} \mathrm{Cs}$ & $1.32 \mathrm{E}+2$ & $1.28 \mathrm{E}+0$ & $1.5 \mathrm{E}+2$ & 0.66 \\
\hline & ${ }^{154} \mathrm{Eu}$ & $1.53 \mathrm{E}-1$ & $<2 . \mathrm{E}-4$ & $1.7 \mathrm{E}-1$ & -0.03 \\
\hline & ${ }^{155} \mathrm{Eu}$ & $<9$.E-2 & $<1$.E-3 & $<9 . \mathrm{E}-2$ & na \\
\hline & ${ }^{241} \mathrm{Am}$ & $1.66 \mathrm{E}-1$ & $<2$.E-3 & $1.8 \mathrm{E}-1$ & 0.16 \\
\hline & Total Alpha & $1.02 \mathrm{E}+0$ & $<2$.E-4 & $1.2 \mathrm{E}+0$ & 0.00 \\
\hline & Total Beta & $3.00 \mathrm{E}+3$ & $1.16 \mathrm{E}+0$ & $3.4 \mathrm{E}+3$ & -0.03 \\
\hline & ${ }^{90} \mathrm{Sr}$ & $1.37 \mathrm{E}+3$ & $5.97 \mathrm{E}-4$ & $1.6 \mathrm{E}+3$ & 0.01 \\
\hline & ${ }^{239 / 240} \mathrm{Pu}$ & $6.01 \mathrm{E}-1$ & $6.44 \mathrm{E}-7$ & $6.9 \mathrm{E}-1$ & -0.07 \\
\hline & ${ }^{238} \mathrm{Pu}$ & $2.50 \mathrm{E}-2$ & $<8 . \mathrm{E}-7$ & $2.9 \mathrm{E}-2$ & 0.13 \\
\hline & KPA & $(\mu \mathrm{g} / \mathrm{g})$ & $(\mu \mathrm{g} / \mathrm{mL})$ & $(\mu \mathrm{g} / \mathrm{g})$ & \\
\hline & $\bar{U}$ & $1.10 \mathrm{E}+5$ & $4.24 \mathrm{E}+0$ & $1.3 \mathrm{E}+5$ & 0.03 \\
\hline \multicolumn{6}{|c|}{ (a) Test sample TI640-G8-12, ASO ID 08-2297 } \\
\hline \multicolumn{6}{|c|}{ b) Test sample TI640-G8-H, ASO ID 08-2285 } \\
\hline \multirow{2}{*}{\multicolumn{6}{|c|}{$\begin{array}{l}\text { Calculated using results from TI640-G8-12 \& TI640-G8-H, as described in Appendix E, Equation E.13. } \\
\text { Calculated using results listed in Table 4.14, and as described in Appendix E, Equation E.17. Leach factors } \\
\text { for uranium and iron assumed to be zero. }\end{array}$}} \\
\hline & & & & & \\
\hline \multicolumn{6}{|c|}{$\begin{array}{l}\text { Note: Analytes in italics were measured opportunistically. Values in brackets [ ] are } \geq \text { MDL but }<\text { EQL, with } \\
\text { errors likely to exceed } 15 \% \text {. }\end{array}$} \\
\hline
\end{tabular}

Solids leach factors were calculated for each of the analytes listed in Table 4.28 by comparing the solids composition measured before leaching (Table 4.14) to the solids composition measured after leaching and washing; the solids concentration factor (as a result of gibbsite dissolution) was estimated from the relative iron and uranium concentrations (see Appendix E, Section E.5). Caustic leach factors for Al, $\mathrm{Cr}$, and ${ }^{137} \mathrm{Cs}$ agreed, within test and analytical variabilities, with results generated from characterization of the dewatered caustic-leached slurry in Table 4.22. The solids leach factor for phosphorus was calculated as zero at this point, which supported previous statements about phosphorus not leaching from the solids phase. The leach factors for ${ }^{241} \mathrm{Am}$ and ${ }^{238} \mathrm{Pu}$ were calculated to be 13 to $16 \mathrm{wt} \%$; however, the analytical results were reported with relatively large propagated uncertainties $\left( \pm 29 \%\right.$ for ${ }^{241} \mathrm{Am}, \pm 11 \%$ for $\left.{ }^{238} \mathrm{Pu}\right)$. Neither component was expected to leach under the experimental conditions. The plutonium processing fate was better ascertained by tracking the ${ }^{239+240} \mathrm{Pu}$ concentrations, which are generally reported with much lower uncertainties and are generally free of potential detection interferences from ${ }^{241} \mathrm{Am}$.

Figure 4.36 shows the pictorial description of the retention of key radionuclide components in the CUF system as a function of process step. Uranium, plutonium, americium, europium, and strontium were shown to be $100 \%$ retained in the solids fraction with no significant migration through the filter. The total solids component removed from the CUF is directly related to the dissolution of gibbsite. A large fraction of the ${ }^{137} \mathrm{Cs}$ removal was associated with supernatant removal (dewatering from low to high solids). Another significant jump in Cs removal was associated with the caustic leach. The mechanism 
of Cs removal from the solids was not determined; however, it is possible that the high Na concentration in the caustic leach solution caused a displacement or metathesis of insoluble Cs with $\mathrm{Na}$.

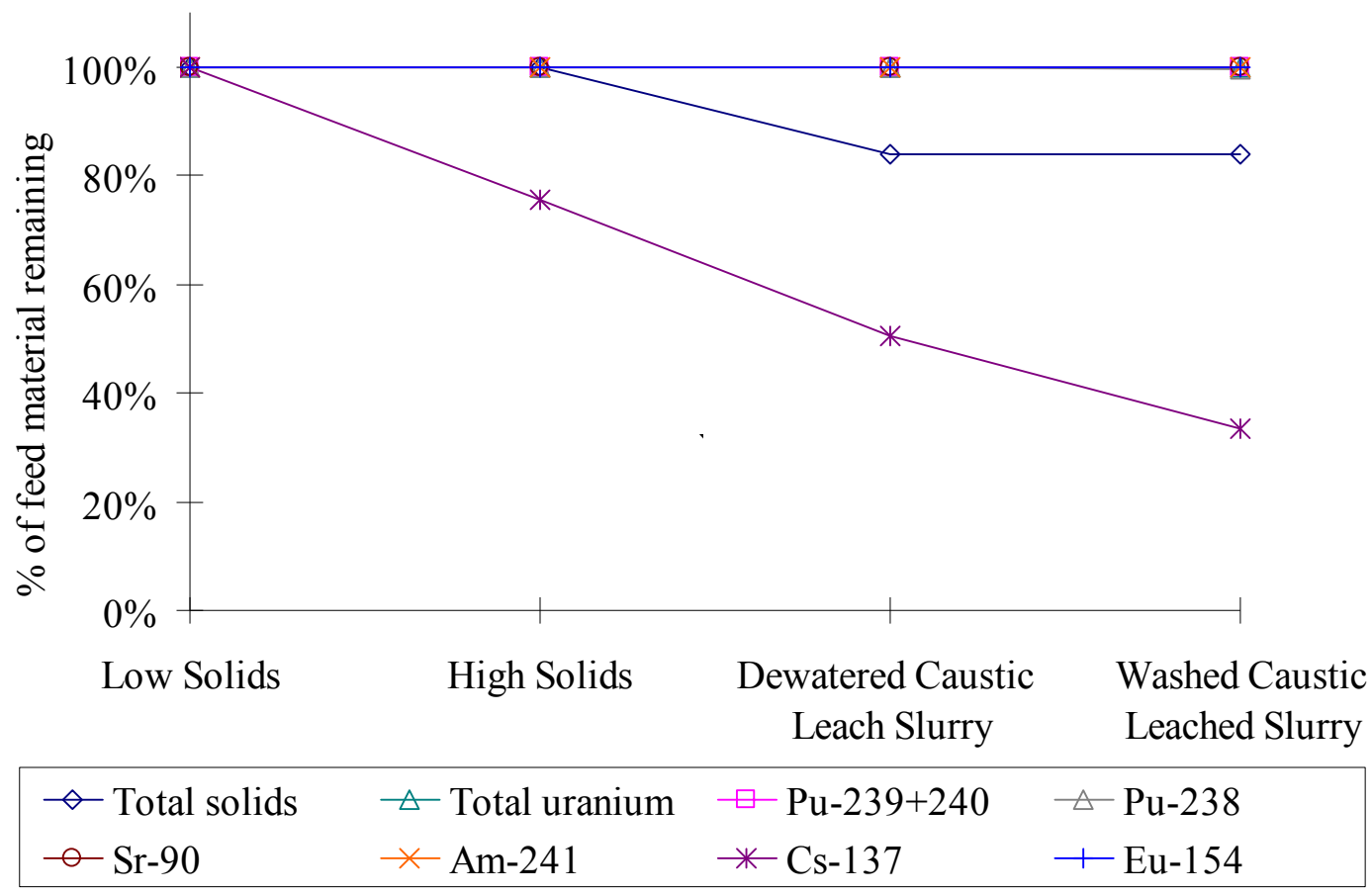

Figure 4.36. Radionuclides/Total Solids in CUF 8 Slurry, Adjusted for Sampling

\subsubsection{Crystal Form and Habit}

Figure 4.37 shows the raw XRD pattern of the caustic-leached and washed solids. The large hump visible in the pattern from $\sim 10$ to 40 degrees 2-theta was indicative of a significant amorphous component(s). The background-subtracted pattern is shown in Figure 4.38 along with the background-subtracted pattern obtained from solids from the initial characterization study. Virtually all diffraction peaks align with respect to position and in relative intensities except for the structure associated with gibbsite. The gibbsite was completely absent from the caustic-leached and washed solids. The phase identifications were identical to those provided for the initial characterization samples (see Section 3.0) with the exception of gibbsite. 
WTP-RPT-170, Rev. 0

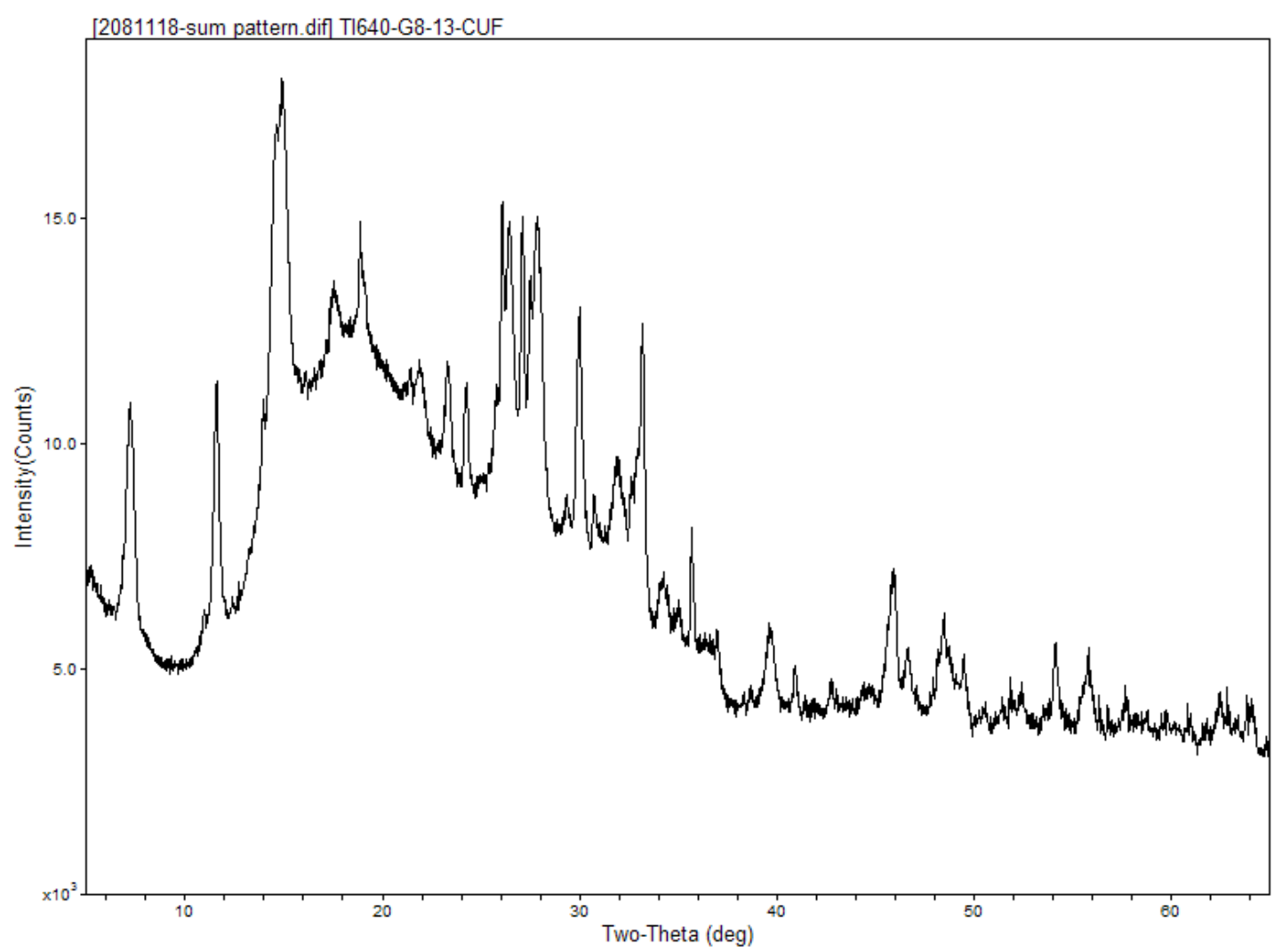

Figure 4.37. Raw X-Ray Diffraction Pattern of the Caustic-Leached and Washed Group 8 Solids 
WTP-RPT-170, Rev. 0

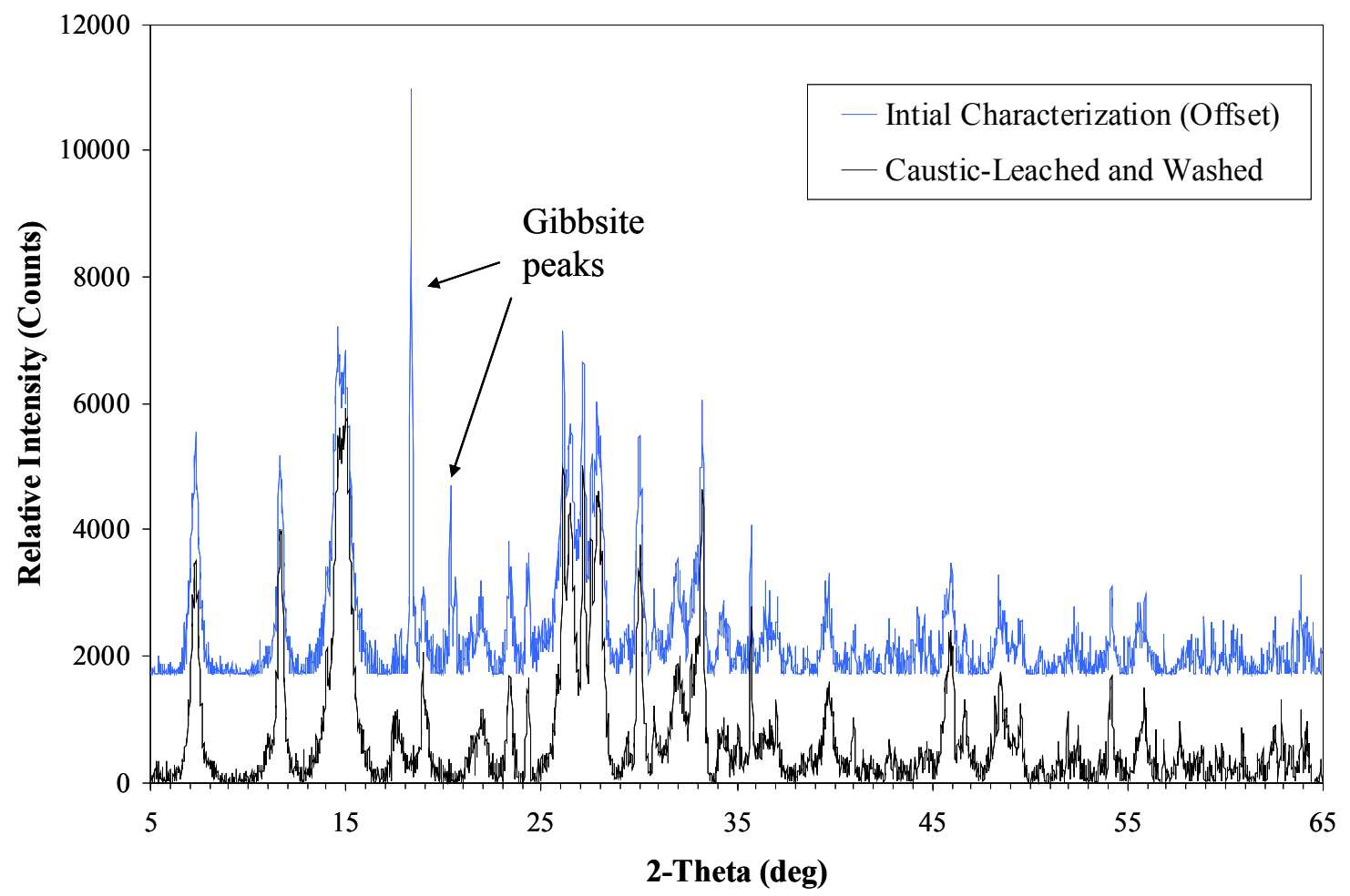

Figure 4.38. Background-Subtracted XRD Patterns Comparing Initial Characterization Group 8 Solids with Caustic-Leached and Washed Group 8 Solids

SEM images of the post-CUF processing Group 8 sample material are shown in Figure 4.39 and Figure 4.40 along with selected EDS examination. Carbon appeared in the EDS examination but was considered primarily an artifact of the carbon-coating process required for SEM analysis to make the sample conductive; therefore, the carbon peak should be ignored.

The crystallinity and morphology of the particles were not as sharp as that found in the initial characterization sample (see Section 3.0). In fact, the particles appeared to form agglomerates with submicron components. EDS analysis of the agglomerates tended to show most analytes present based on the overall chemical composition, indicating that the EDS spot size was large relative to an individual particle and mineral phase. An individual Al-Si-Na-O phase was identified (Figure 4.40, spot 4) which was consistent with the chemistry of hydroxycancrinite. Spot 2 in Figure 4.40 resulted in only a weak Na peak with $\mathrm{O}$ and $\mathrm{C}$ where the phase appeared to be of significant size and structure. Although the chemistry is consistent with sodium oxalate, this compound was not expected to be present after the fourth wash with dilute sodium hydroxide solutions. 
WTP-RPT-170, Rev. 0
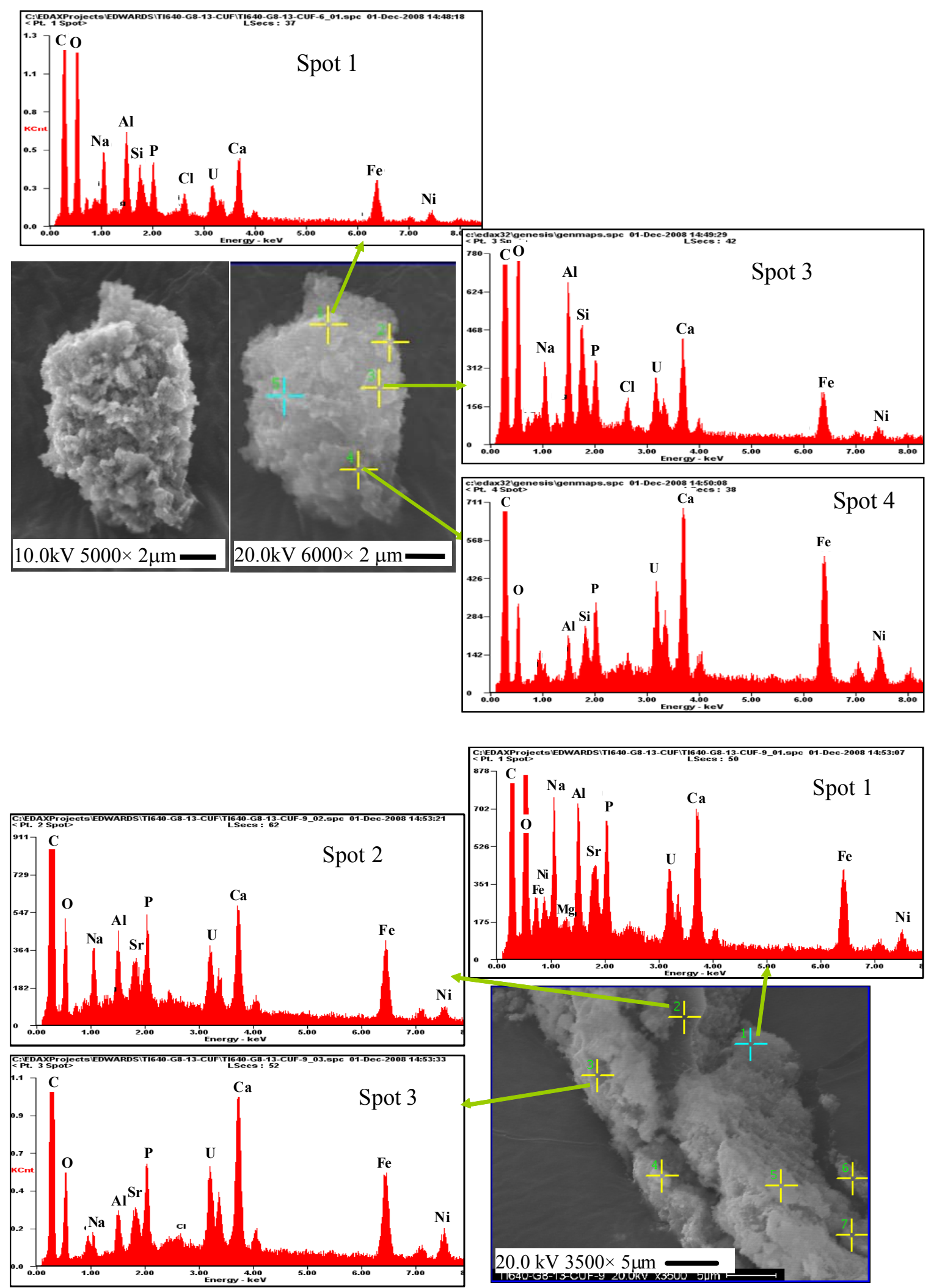

Figure 4.39. SEM Image with EDS Evaluation of Group 8 Leached and Washed Particle 

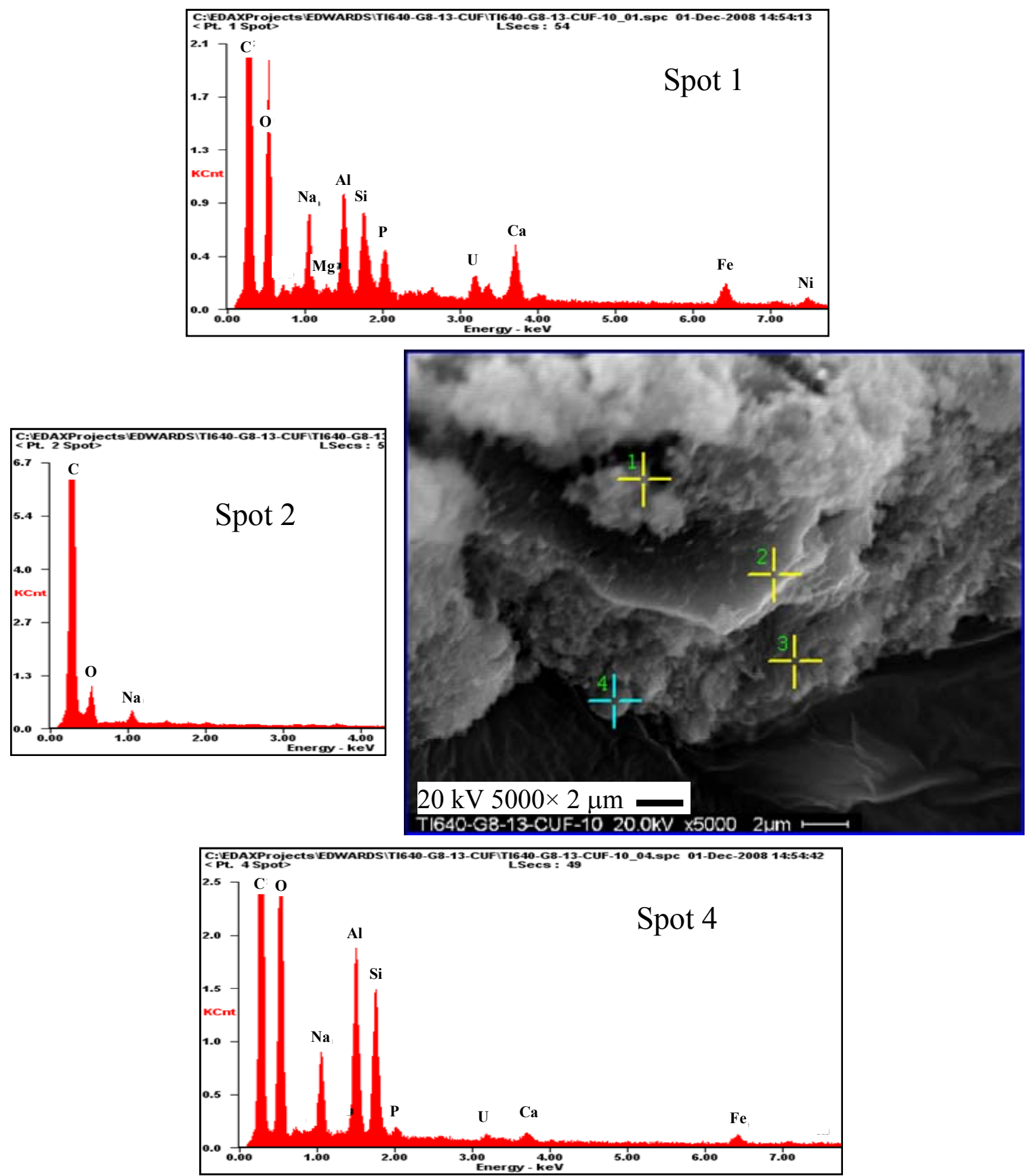

Figure 4.40. SEM Image with EDS Evaluation of Group 8 Leached and Washed Particle

\subsubsection{Particle Size and Rheology}

A PSD measurement was made on the slurry to observe changes in the mean particle size of the UDS after washing. Table 4.29 shows select cumulative undersize percentiles for the leached and washed slurry. Here the $\mathrm{d}(10)$ ranged between 3.2 and $7.3 \mu \mathrm{m}$, the $\mathrm{d}(50)$ between 10 and $38 \mu \mathrm{m}$, and the $\mathrm{d}(90)$ between 54 and $87 \mu \mathrm{m}$. The $\mathrm{d}(10), \mathrm{d}(50)$, and $\mathrm{d}(90)$ percentiles showed a significant increase in size as the condition numbers increased, which may indicate that shear-induced flocculation or agglomeration occurred and increased the measured diameter as time progressed. 
WTP-RPT-170, Rev. 0

Table 4.29. PSD Percentile Results for the Group 8 Caustic-Leached and Washed Sample

\begin{tabular}{||c|c|c|c|c||}
\hline $\begin{array}{c}\text { Measurement } \\
\text { Condition }\end{array}$ & Pump Speed & $\begin{array}{c}\mathbf{d}(\mathbf{1 0 )} \\
(\boldsymbol{\mu m})\end{array}$ & $\begin{array}{c}\mathbf{d}(\mathbf{5 0 )} \\
(\boldsymbol{\mu m})\end{array}$ & $\begin{array}{c}\mathbf{d}(\mathbf{9 0}) \\
(\boldsymbol{\mu m})\end{array}$ \\
\hline 1 & 3000 & 3.3 & 10 & 54 \\
\hline 2 & 4000 & 3.2 & 18 & 63 \\
\hline 3 & 2000 & 4.7 & 30 & 76 \\
\hline 4 & 2000 & 7.3 & 38 & 87 \\
\hline
\end{tabular}

Figure 4.41 shows the PSD for Group 8 caustic-leached, dewatered, and washed slurry as a function of pump speed. The caustic-leached, dewatered, and washed PSD distribution was continuous and ranged from 0.2 to $150 \mu \mathrm{m}$. At $3000 \mathrm{RPM}$, there was a primary peak around $6 \mu \mathrm{m}$, a secondary peak around $30 \mu \mathrm{m}$, and a shoulder between 0.2 and $1.5 \mu \mathrm{m}$. As the pump speed was increased to $4000 \mathrm{RPM}$, the peaks remained centered around similar diameters, although the $30-\mu \mathrm{m}$ peak displayed a relative increase in population. As the pump speed was decreased to $2000 \mathrm{RPM}$, the relative population in the $30-\mu \mathrm{m}$ peak further increased, and the peak diameter shifted slightly to $50 \mu \mathrm{m}$. This most likely indicated that with prolonged circulation in the PSD analyzer, corresponding increases in particle interactions resulted in flocculation and/or agglomeration, producing higher percentages of larger species.

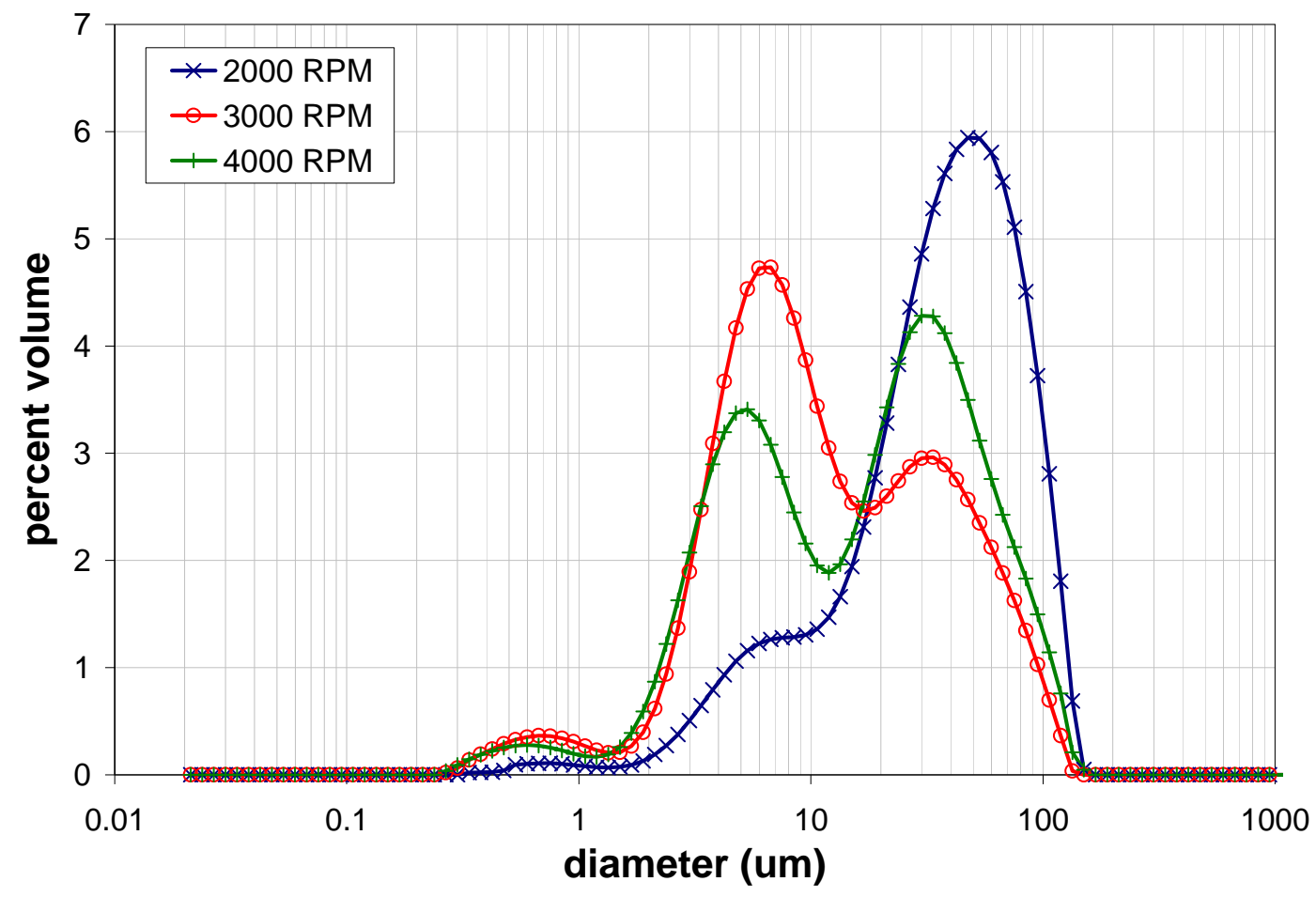

Figure 4.41. Volume Distribution Result for the Group 8 Caustic-Leached and Washed Slurry as a Function of Pump Speed

A slurry sub-sample was also collected for rheology measurements to observe how its flow behavior changed after washing. Rheological characterization of the sample was complicated by significant air entrainment and retention in the waste sample provided. It was suspected that the yield stress of the 
caustic-leached, dewatered, and washed material prevented bubble migration to the surface of the slurry sample during sampling and rheology preparation activities. During testing, entrained air in the waste samples was slowly released from the sample. The release mechanism was suspected to be a combination of shear-induced air-bubble coalescence and yielding of the material, which allowed the bubbles to freely migrate to the surface. Air release was initially evidenced by a slow but significant (nearly a factor of two) decrease in the stress response of the slurry. This decrease was a consequence of the corresponding decrease in the slurry level in the measuring cup that occurred when entrained air left the sample. Visual inspection of the slurry level in the sample cup after initial testing confirmed the volume decrease. Subsequent observation during testing confirmed that bubbles were rising to the surface of the slurry and breaking.

To account for air entrapment, initial measurements affected by air release were discarded. Subsequent measurements included significant pre-shearing of the sample to allow as much bubble release as possible. This involved monitoring torque during steady rotation of the rotor. Bubble release was assumed complete when the torque no longer showed a greater than $0.5 \mathrm{~Pa}$ change over 3 minutes. After the initial measurement at $25^{\circ} \mathrm{C}$, there was insufficient slurry in the cup to refresh the gap at higher temperatures. The measuring system was reloaded with slurry. This slurry was then sheared until most of the air was released, and measurements at $25^{\circ} \mathrm{C}$ (repeat), $40^{\circ} \mathrm{C}$, and $60^{\circ} \mathrm{C}$ were completed. During the 15 -min measurements, a slow transient decrease in the slurry stress response was noted. It was possible that this decrease represented continued air release, but it could also have been a result of shear breakage of slurry structure (i.e., interparticle connections) and/or settling of solids out of the measurement gap.

Figure 4.42 shows the results of flow-curve testing for the sheared slurry sample. Flow-curve data indicated that the slurry was non-Newtonian with a yield stress ranging from 3 to $6 \mathrm{~Pa}$. The stress response was typically non-linear over 0 to $200 \mathrm{~s}^{-1}$ and linear at higher shear rates. In addition, the stress response at higher temperatures appeared to have a larger linear range, with the $60^{\circ} \mathrm{C}$ flow-curve data showing linearity over 100 to $1000 \mathrm{~s}^{-1}$. Flow-curve hysteresis was significant in both $25^{\circ} \mathrm{C}$ and $40^{\circ} \mathrm{C}$ data but absent in the $60^{\circ} \mathrm{C}$ data. Hysteresis was characterized by a higher stress response on the up-ramp portion of the flow-curve measurement relative to the down-ramp portion response. Hysteresis appeared to decrease at higher temperatures. This behavior was consistent with shearing breakage of the sample's internal (i.e., interparticle) structure or could indicate that solids were settling out of the measurement gap. Given that significant air retention and release affected the initial attempts to measure the washedleached slurry sample, the decrease could also result from longer term bubble release. Apart from hysteresis, the measurements showed a relatively high signal-to-noise ratio.

Temperature effects were somewhat difficult to ascertain from the data. Although it was clear that the stress response at $25^{\circ} \mathrm{C}$ was much higher than those at $40^{\circ} \mathrm{C}$ and $60^{\circ} \mathrm{C}$, significant overlap was observed between measurements at $40^{\circ} \mathrm{C}$ and $60^{\circ} \mathrm{C}$. Based on the data, there appeared to be a significant decrease in both yield stress and consistency between $25^{\circ} \mathrm{C}$ and $40^{\circ} \mathrm{C}$. However, this decrease did not appear to continue at higher temperatures. This behavior was consistent with that observed in the leached slurry sample before washing (Section 4.5.3). 


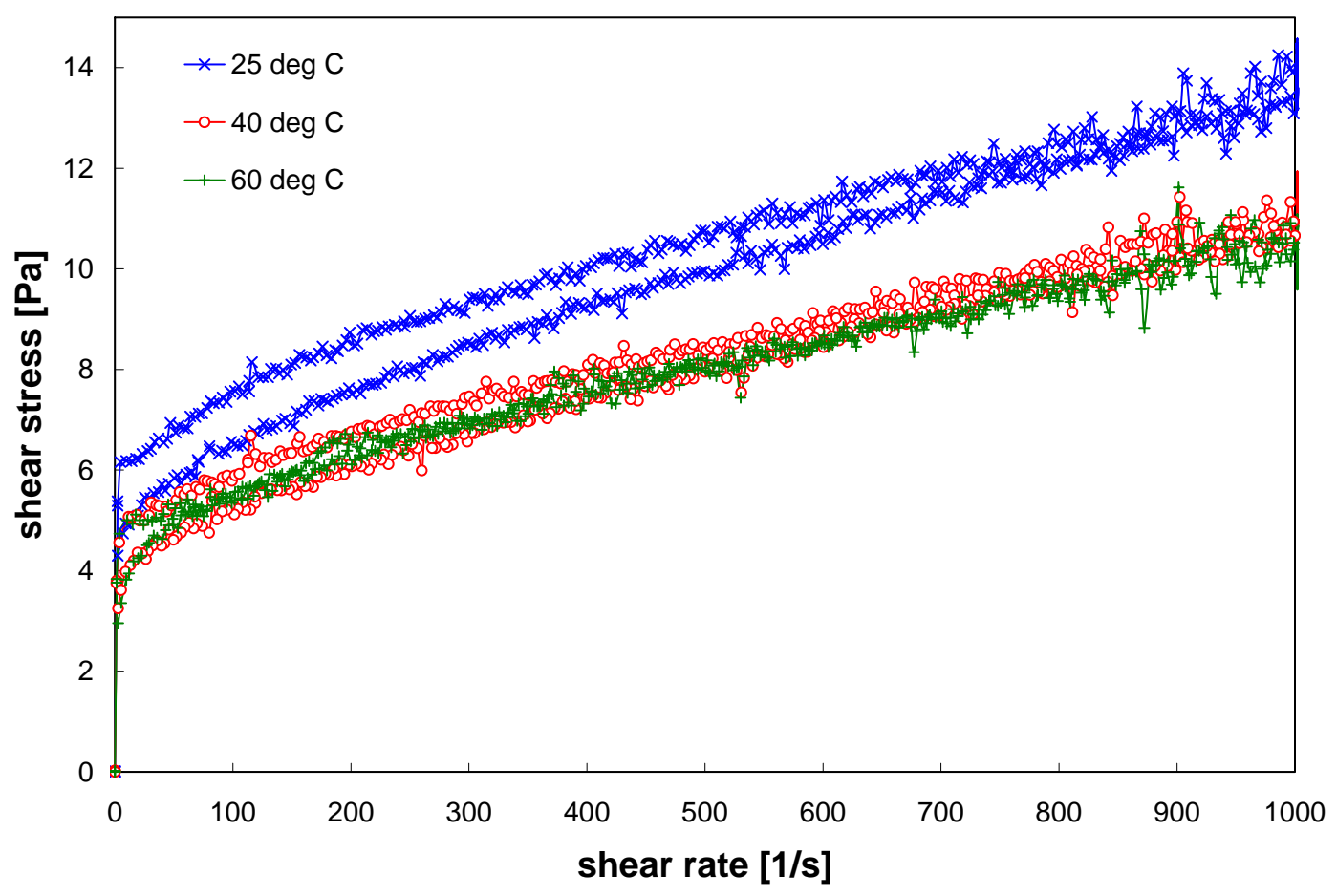

Figure 4.42. Flow Curves for the Group 8 Leached, Washed Slurry

The fitting results in Table 4.30 confirmed a significant yield stress with non-Newtonian rheology. Analysis of flow-curve data against the Bingham-Plastic flow-curve model suggested a yield stress ranging from 5.3 to $6.7 \mathrm{~Pa}$ and a consistency ranging from 5.1 to $6.9 \mathrm{mPa} \cdot \mathrm{s}$. Similar analysis with the Casson model indicated a yield stress ranging from 3.4 to $4.5 \mathrm{~Pa}$ and a consistency ranging from 1.7 to $2.5 \mathrm{mPa} \cdot \mathrm{s}$.

Increases in slurry temperature did not appear to change the slurry yield stress. On the other hand, increased temperature did lower the slurry consistency. The decrease in slurry consistency with increasing temperature was confirmed by both flow-curve data (Figure 4.42) and by both Bingham-Plastic and Casson model fitting results (Table 4.30).

Table 4.30. Results of Fitting Analysis for the Group 8 Leached and Washed Slurry

\begin{tabular}{||c|c|c|c|c|c||}
\hline \multirow{3}{*}{ Model } & $\begin{array}{c}\text { Temperature } \\
\left({ }^{\circ} \mathbf{C}\right)\end{array}$ & $\begin{array}{c}\text { Range } \\
\left(\mathbf{s}^{-1}\right)\end{array}$ & $\begin{array}{c}\text { Yield Stress } \\
(\mathbf{P a})\end{array}$ & $\begin{array}{c}\text { Consistency } \\
(\mathbf{m P a} \cdot \mathbf{s})\end{array}$ & $\mathbf{R}$ \\
\hline \multirow{4}{*}{ Bingham-Plastic } & $25(1$ of 2$)$ & $100-1000$ & 5.4 & 6.5 & 0.98 \\
\cline { 2 - 6 } & $25(2$ of 2$)$ & $100-1000$ & 6.7 & 6.9 & 0.99 \\
\cline { 2 - 6 } & 40 & $100-1000$ & 5.3 & 5.7 & 0.98 \\
\cline { 2 - 6 } & 60 & $100-1000$ & 5.4 & 5.1 & 0.98 \\
\hline \multirow{5}{*}{ Casson } & $25(1$ of 2$)$ & $0-1000$ & 3.4 & 2.5 & 0.98 \\
\cline { 2 - 7 } & $25(2$ of 2$)$ & $0-1000$ & 4.5 & 2.4 & 0.99 \\
\cline { 2 - 7 } & 40 & $0-1000$ & 3.6 & 2.0 & 0.98 \\
\cline { 2 - 7 } & 60 & $0-1000$ & 3.7 & 1.7 & 0.99 \\
\hline
\end{tabular}


WTP-RPT-170, Rev. 0

\subsection{Final Filter Flux Test Matrix}

In an effort to conduct a higher solids-loading filtration test than had yet been achieved, another waste slurry, Group 7/AY-102, was added to the remaining Group 8 solids. The Group 7/AY102 slurry had been previously caustic-leached and washed in the CUF and was expected to have similar filtration behavior to the Group 8 slurry. The estimated UDS from Group 8 testing was $176 \mathrm{~g}$ and from Group 7/AY-102 testing was $227 \mathrm{~g}$. After analytical sampling for physical-property testing, the blended solids component in the CUF was $\sim 400 \mathrm{~g}$. Physical-property measurements of the combined slurry are provided in Table 4.31 .

Table 4.31. Physical-Property Measurements of the Initial Blended Slurry

\begin{tabular}{|r|c||}
\hline Slurry Density (g/mL) & 1.1 \\
\hline Supernate Density (g/mL) & 1.0 \\
\hline Settled Solids (vol\%) & 76 \\
\hline Centrifuged Undissolved Solids (wt\%) & 57 \\
\hline Total Solids (wt\%) & 18 \\
\hline Dissolved Solids (wt\%) & 3.9 \\
\hline Undissolved Solids (wt\%) & 15 \\
\hline
\end{tabular}

\subsubsection{Filter Matrix Testing}

The slurry was to be dewatered before the filtration test matrix was conducted, as described in Section 4.1. However, pump cavitation was observed after dewatering 600 -g permeate; the pump cavitation at this UDS concentration would have precluded some of the matrix test conditions. It was decided that the best course of action was to stop the dewatering operation, return the removed permeate to the CUF, and repeat the dewatering step after the test matrix was completed. Once the test matrix was started, the pump was still cavitating to some degree. Observations of the slurry surface inside the CUF reservoir showed foam formation on the surface, with a vortex forming from the mixer that was entraining air into the slurry. The mixer speed was turned down at this point, and a gradual improvement in pumping efficiency was observed.

The average filter flux and process conditions achieved during the matrix test are summarized in Table 4.32. One of the test conditions (Test 4) was repeated to verify that the targeted AV was achieved. The highest AV achieved at a TMP of $40 \mathrm{psid}$ was $15.5 \mathrm{ft} / \mathrm{s}$. The average flux ranged from 0.022 $\mathrm{GPM} / \mathrm{ft}^{2}$ to $0.060 \mathrm{GPM} / \mathrm{ft}^{2}$. The filter flux at the standard condition $(\mathrm{TMP}=40 \mathrm{psid}$ and $\mathrm{AV}=13 \mathrm{ft} / \mathrm{s}$ ) decreased over the course of the test $\left(0.048,0.040,0.037 \mathrm{GPM} / \mathrm{ft}^{2}\right)$, indicating that some fouling agent was at work. 
WTP-RPT-170, Rev. 0

Table 4.32. Average Flux Values for Washed Leached Group 8 Slurry Blended with the Washed Leached Group 7/AY-102 Slurry (Measured UDS of $15 \mathrm{wt} \%$ )

\begin{tabular}{|c|c|c|c|c|c|c|c|}
\hline $\begin{array}{c}\text { Test } \\
\text { Condition }\end{array}$ & $\begin{array}{c}\text { Duration } \\
\text { (h) }\end{array}$ & $\begin{array}{l}\text { Median } \\
\text { Operation } \\
\text { Time }^{(a)} \\
\text { (hh:mm) }\end{array}$ & $\begin{array}{l}\text { Slurry } \\
\text { Temp }^{(b)} \\
\left({ }^{\circ} \mathrm{C}\right)\end{array}$ & $\begin{array}{c}\operatorname{TMP}^{(\mathbf{c})} \\
\text { (psid) }\end{array}$ & $\begin{array}{c}\text { AV } \\
(\mathbf{f t} / \mathbf{s})\end{array}$ & $\begin{array}{l}\text { Corrected } \\
\text { Filter } \\
\text { Flux } \\
\left(\text { GPM/ } / \mathbf{f t}^{2}\right)\end{array}$ & $\begin{array}{c}\text { Axial } \\
\text { Pressure } \\
\text { Drop } \\
(\mathrm{c}) \\
(\mathrm{psid} / \mathrm{ft})\end{array}$ \\
\hline 1 & 3.0 & $1: 37$ & 25.4 & 40.5 & 13.0 & 0.048 & 2.3 \\
\hline 2 & 1.1 & $3: 53$ & 25.3 & 29.4 & 11.0 & 0.036 & 1.9 \\
\hline 3 & 1.0 & $5: 05$ & 25.3 & 30.3 & 14.4 & 0.036 & 2.4 \\
\hline 4 & 1.0 & $6: 21$ & 25.5 & 49.9 & $12.4^{(\mathrm{e})}$ & 0.051 & 2.2 \\
\hline 5 & 1.0 & $7: 28$ & 25.4 & 50.0 & 11.2 & 0.043 & 1.9 \\
\hline 6 & 1.0 & $8: 33$ & 25.4 & 39.2 & 13.2 & 0.040 & 2.4 \\
\hline 7 & 1.0 & $9: 42$ & 25.0 & 43.1 & 9.1 & 0.033 & 1.7 \\
\hline 8 & 1.0 & $10: 51$ & 25.3 & 39.7 & $15.5^{(\mathrm{f})}$ & 0.038 & 2.6 \\
\hline 9 & 1.1 & 12:02 & 25.1 & 20.4 & 13.0 & 0.022 & 2.1 \\
\hline 10 & 1.0 & $13: 16$ & 28.0 & 59.7 & 13.4 & 0.060 & 2.2 \\
\hline $11^{(\mathrm{e})}$ & 1.0 & $14: 22$ & 27.7 & 49.1 & 15.1 & 0.048 & 2.5 \\
\hline 12 & 1.2 & $15: 34$ & 24.9 & 39.5 & 13.3 & 0.037 & 2.2 \\
\hline \multicolumn{8}{|c|}{$\mathrm{TMP}=$ transmembrane pressure } \\
\hline \multicolumn{8}{|c|}{$\begin{array}{l}\mathrm{AV}=\text { axial velocity } \\
\text { (a) Median operation time refers to the midpoint in processing time of the specific filtration test condition } \\
\text { relative to the start time of the test }(\mathrm{T}=0) \text {. }\end{array}$} \\
\hline \multicolumn{8}{|c|}{ (b) Accuracy of thermocouple was $\pm 2{ }^{\circ} \mathrm{C}$. } \\
\hline \multicolumn{8}{|c|}{ (c) Accuracy of pressure transducers was \pm 1 psig. } \\
\hline \multicolumn{8}{|r|}{$\begin{array}{l}\text { flow } \\
\text { rea of } \\
\text { E to }\end{array}$} \\
\hline \multicolumn{8}{|c|}{$\begin{array}{l}\text { (e) The target test condition of } 15 \mathrm{ft} / \mathrm{s} \text { could not be achieved because of pump cavitation. The } 12.4 \mathrm{ft} / \mathrm{s} \text { was } \\
\text { the maximum achievable at that time. Vortexing of the slurry created by the mixer entrained air into the } \\
\text { pump, reducing pump capacity. Efforts to reduce this problem allowed the test to be repeated } \\
\text { successfully as test condition } 11 \text {. }\end{array}$} \\
\hline
\end{tabular}

The filter-flux test results as a function of time are shown in Figure 4.43. The observed scatter was significantly greater than that noted for the $13 \mathrm{wt} \%$ UDS Group 8 slurry testing (with high supernatant solids loading) shown in Figure 4.12. The scatter in the filter-flux results was attributed to air entrainment still present in the slurry.

The average filter flux from each test condition (shown in Table 4.32) was plotted against TMP, AV, and the median operational time of the test condition to qualitatively gauge their impacts, as shown in Figure 4.44. As with the low-solids and high-solids Group 8 slurry, the TMP was found to be directly proportional to the filter flux (Figure 4.44b). Trends were difficult to decipher from plots for AV (Figure 4.44c) and processing time (Figure 4.44d) for scatter in the data. 
Modeling of the data using a least-squares-fit method was then used to quantify the effects of TMP, AV, and processing time on filter flux. A linear-fit equation with an $\mathrm{R}^{2}$ correlation of 0.93 was developed using all three variables (Figure 4.45). Much like Figure 4.44b, the model demonstrated that TMP significantly impacted filter flux. However, the model also showed that increased AV had a similar positive effect on flux. As with the high-solids Group 8 slurry test, the filter-flux dependence on AV indicated that the UDS concentration was high enough to begin impacting filter flux. Modeling also confirmed that increases in processing time resulted in a negative effect on filter flux. Due to this transient behavior, the fit for the data shown in Figure 4.45 should be used for general purposes only in that actual results for this waste will be somewhat dependent on filtration time.

During development of the linear model, a negative offset was created. Therefore, the model does not predict a zero filter flux when the TMP and AV are both zero, demonstrating that the input to these models must be bound by the range of TMP and AV used in this filter test, shown inTable 4.11. The use of the model should also be limited to when the test matrix occurred because the filter resistance was not at steady state, and the parameters developed in these models would be expected to change past the 16hour period that this model predicts. This model should only be used when comparing TMP and AV impacts on filter flux during this test and demonstrating how filter behavior changed since caustic leaching and washing. 


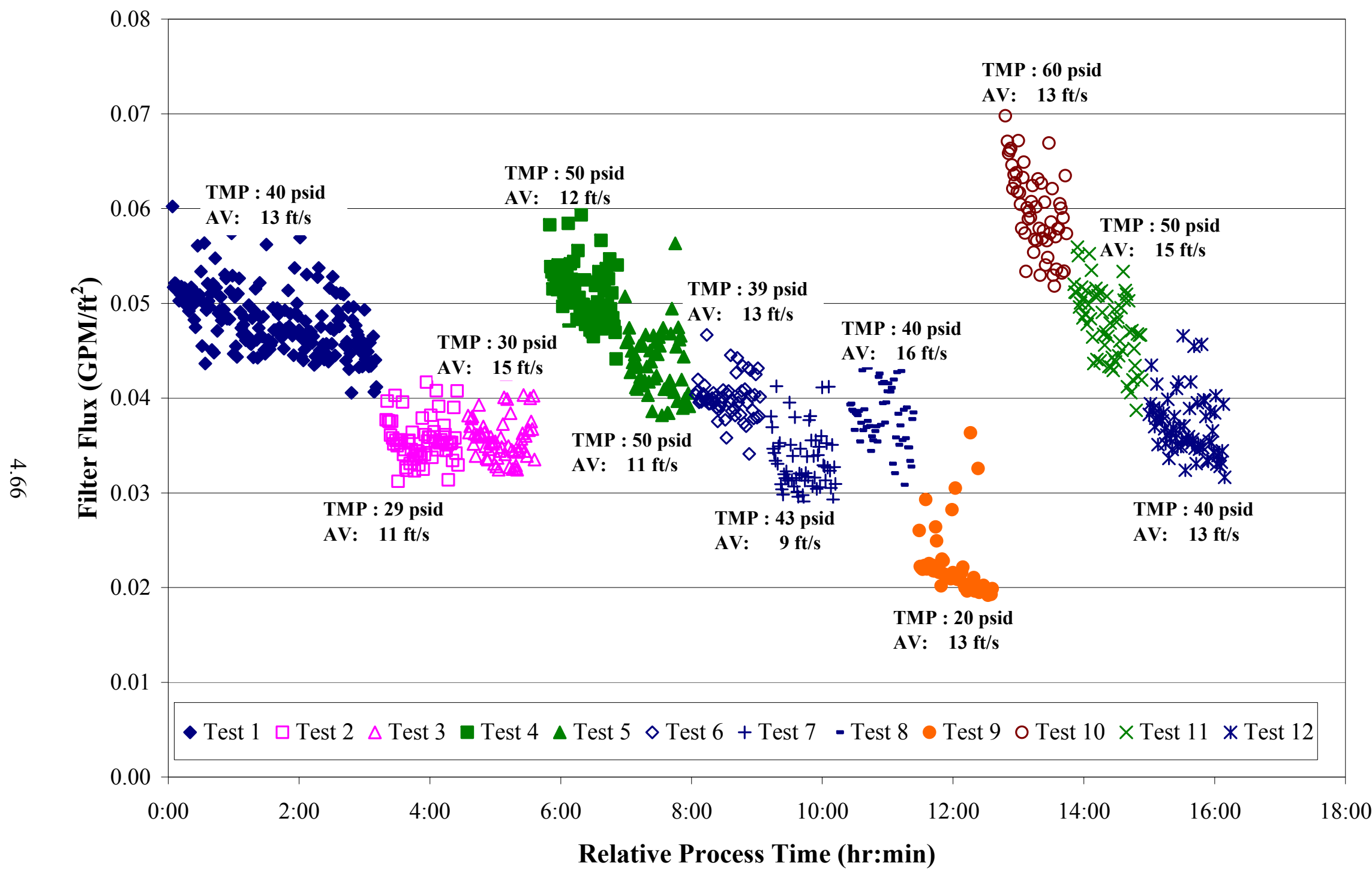

Figure 4.43. Filter Matrix Test Results of Blended Wash Leached Slurries (Group 8 with Group 7/AY102) at a Measured UDS of 15 wt\% 


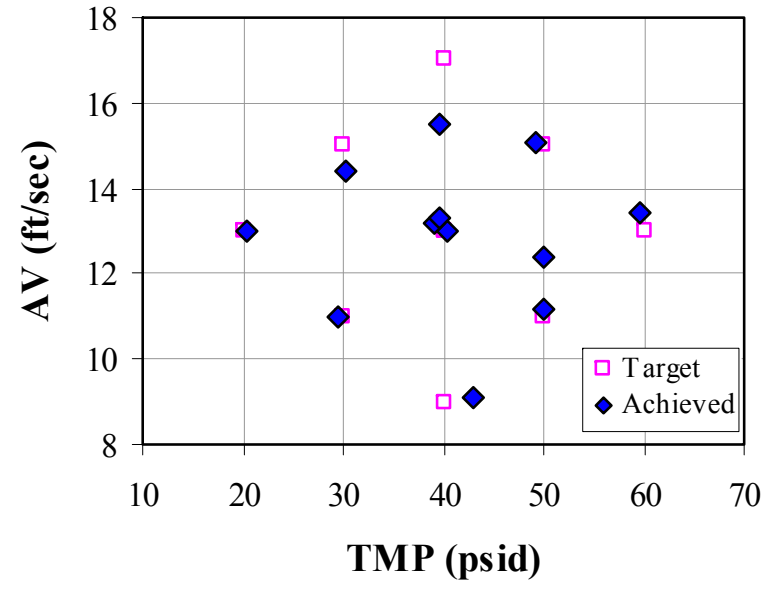

a) Achieved Filtration Test Matrix Conditions

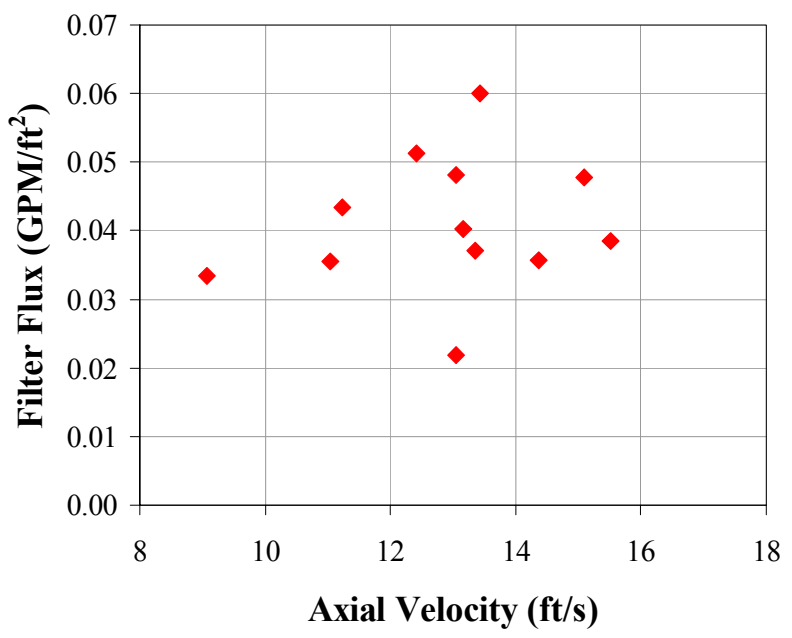

c) Filter Flux vs. Axial Velocity

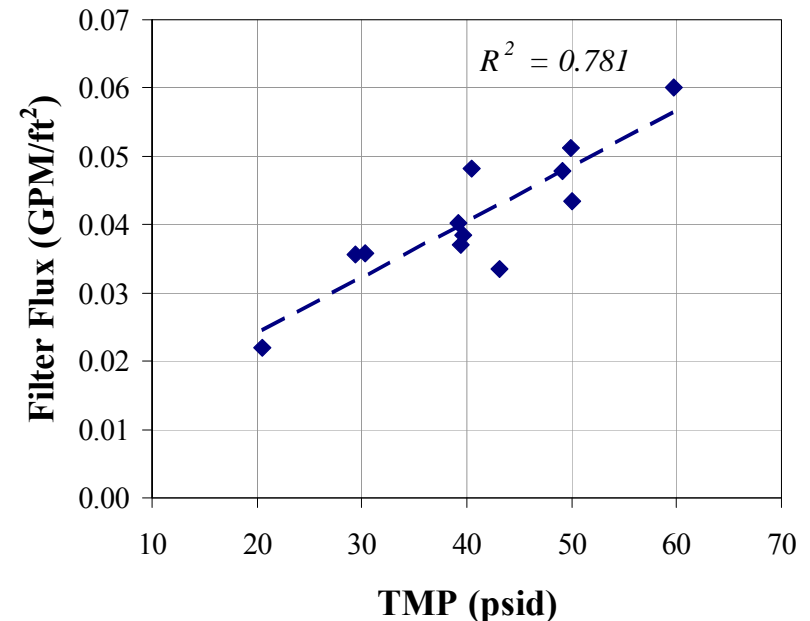

b) Filter Flux vs. TMP

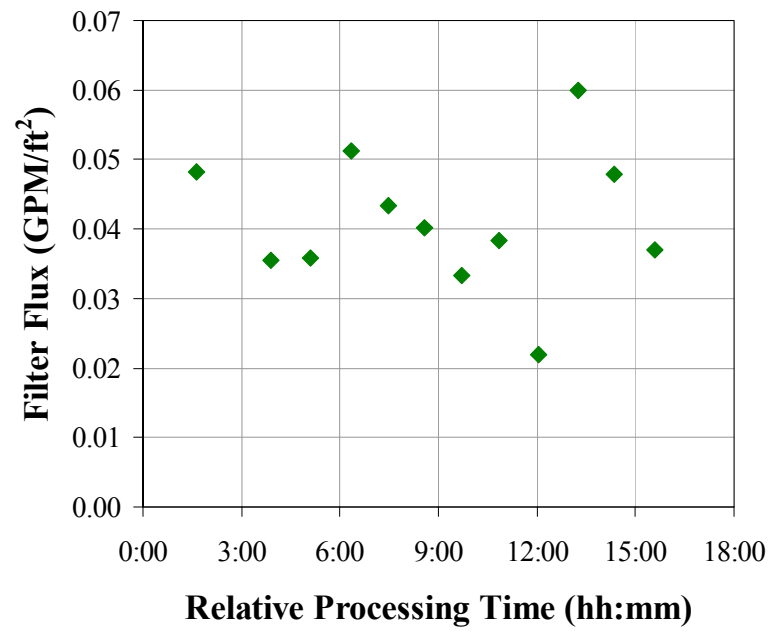

d) Filter Flux vs. Processing Time

Figure 4.44. Filtration Performance of the Blended Group 8 Solids and AY-102 Solids (measured UDS of $15 \mathrm{wt} \%$ ) 


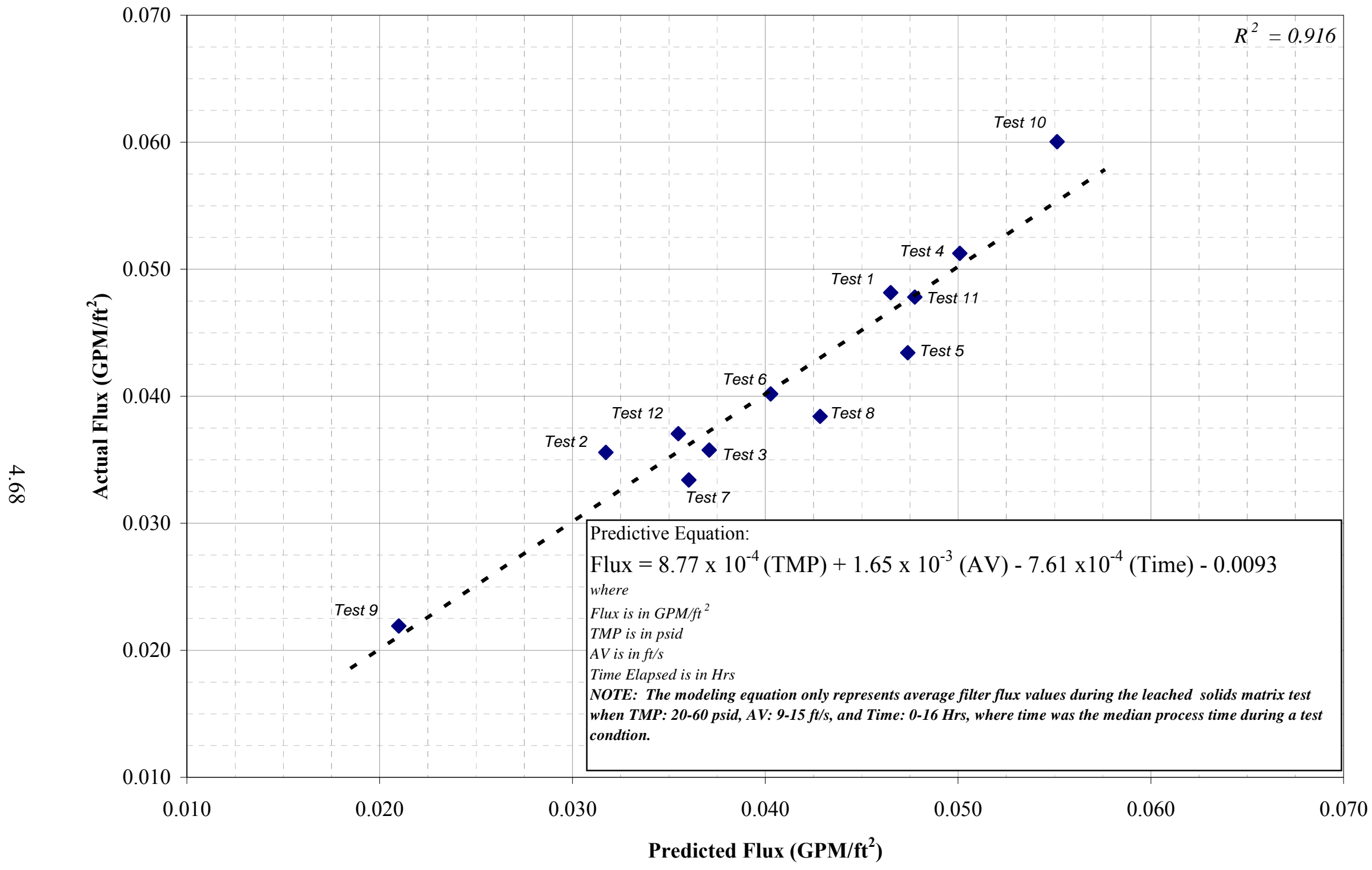

Figure 4.45. Least Square Fit of Leached Solid Test Matrix Results with Linear Model; Blended Waste (measured UDS of 15 wt $\%$ ) 


\subsubsection{Dewatering of Waste Slurry}

After the filter matrix test was completed, the slurry was dewatered by removing $0.9 \mathrm{~L}$ to a measured UDS concentration of $26 \mathrm{wt} \%$ (physical properties are summarized in Table 4.33). Over the course of dewatering, the filter flux decreased from $0.044 \mathrm{GPM} / \mathrm{ft}^{2}$ to $0.022 \mathrm{GPM} / \mathrm{ft}^{2}$. Using the permeate flow data, the change in UDS concentration can be matched with the corresponding filter flux during the dewatering. These data are shown in Figure 4.46 where filter flux is plotted against the logarithm of the UDS concentration of the slurry. A linear trend was found, demonstrating that the decrease in filter flux was explained by changes in the UDS concentration. The linear trend intersected the $\mathrm{x}$-axis at the measured centrifuged UDS concentration of the slurry $(46 \mathrm{wt} \%)$; the intersect point and $\mathrm{wt} \%$ centrifuged UDS are good predictors of the slurry's gel concentration.

Table 4.33. Final Leached and Washed Slurry Physical-Property Measurements

\begin{tabular}{|r|c||}
\hline Slurry Density (g/mL) & 1.3 \\
\hline Supernate Density (g/mL) & 1.0 \\
\hline Settled Solids (vol\%) & 100 \\
\hline Centrifuged Undissolved Solids (wt\%) & 46 \\
\hline Total Solids (wt\%) & 28 \\
\hline Supernate Dissolved Solids (wt\%) & 2.8 \\
\hline Undissolved Solids (wt\%) & 26 \\
\hline
\end{tabular}




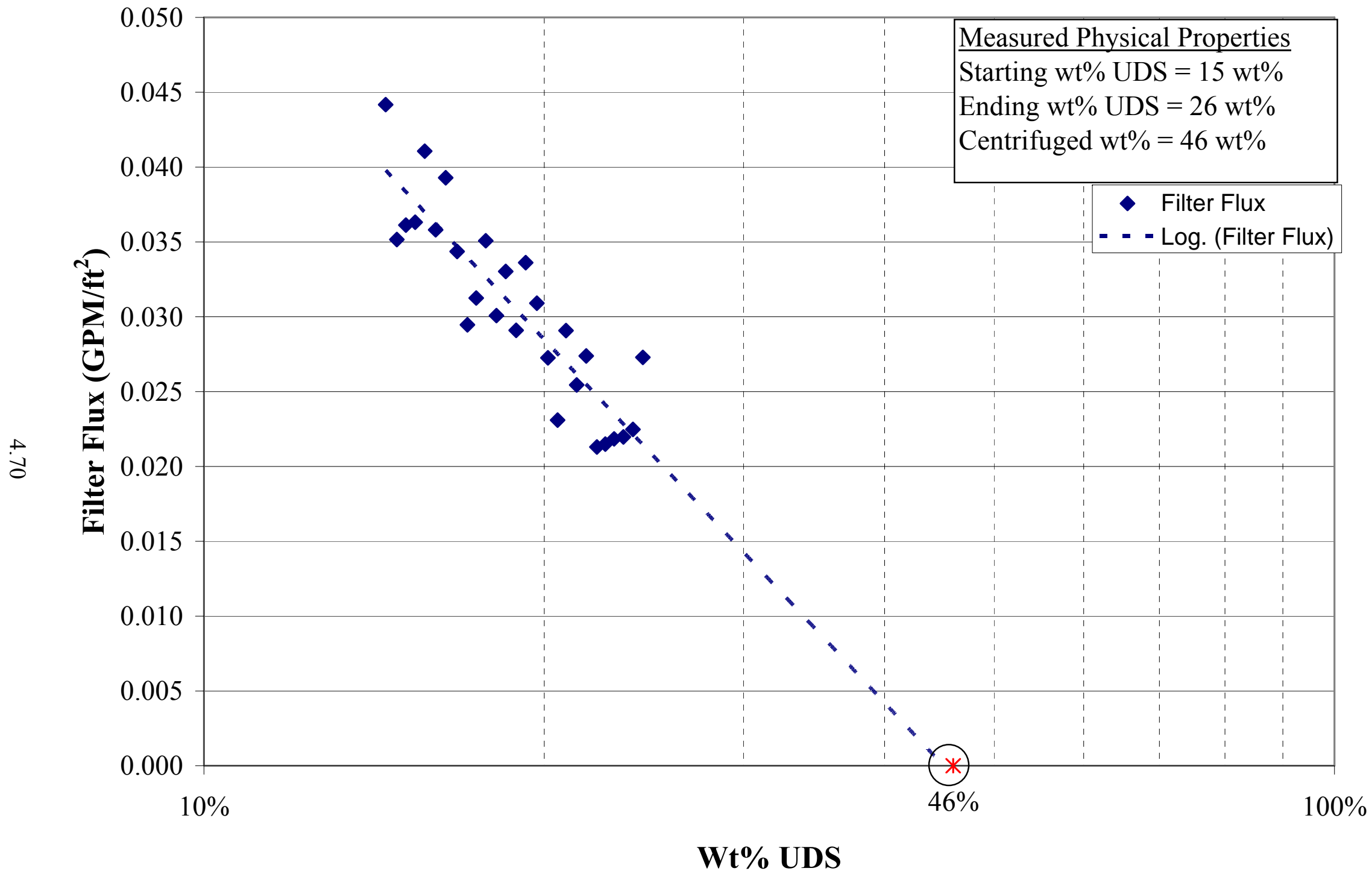

Figure 4.46. Dewatering Curve for the Blended Waste 
The dewatered slurry was sampled for rheology analysis to understand how increases in UDS concentration influence rheology. Like the washed-leached Group 8 slurry (Section 4.6), this sample also exhibited similar difficulties with regard to air entrainment. To prevent gas release during flow-curve measurement, the samples were pre-sheared at a constant rotational rate until the stress response changed less than $0.5 \mathrm{~Pa}$ over $3 \mathrm{~min}$. After this pre-shearing, the sample was measured in accordance with the typical flow-curve procedure, including both the 3-min constant rotation at $470 \mathrm{~s}^{-1}$ (200 RPM) and the 15 -min flow-curve measurements at $25^{\circ} \mathrm{C}, 40^{\circ} \mathrm{C}$, and $60^{\circ} \mathrm{C}$.

Figure 4.47 shows the results of flow-curve testing for this slurry sample. The data indicated a nonNewtonian slurry with significant yield stress. Flow-curve data exhibited hysteresis characterized by a higher stress response during the up-ramp portion of the measurement. The degree of hysteresis appeared to decrease with increasing temperature (i.e., at later times in the measurement). Such hysteresis is suggestive of 1) shear-induced disruption of sample structure, 2) settling of solids in the measurement gap, or 3) degassing of the sample.

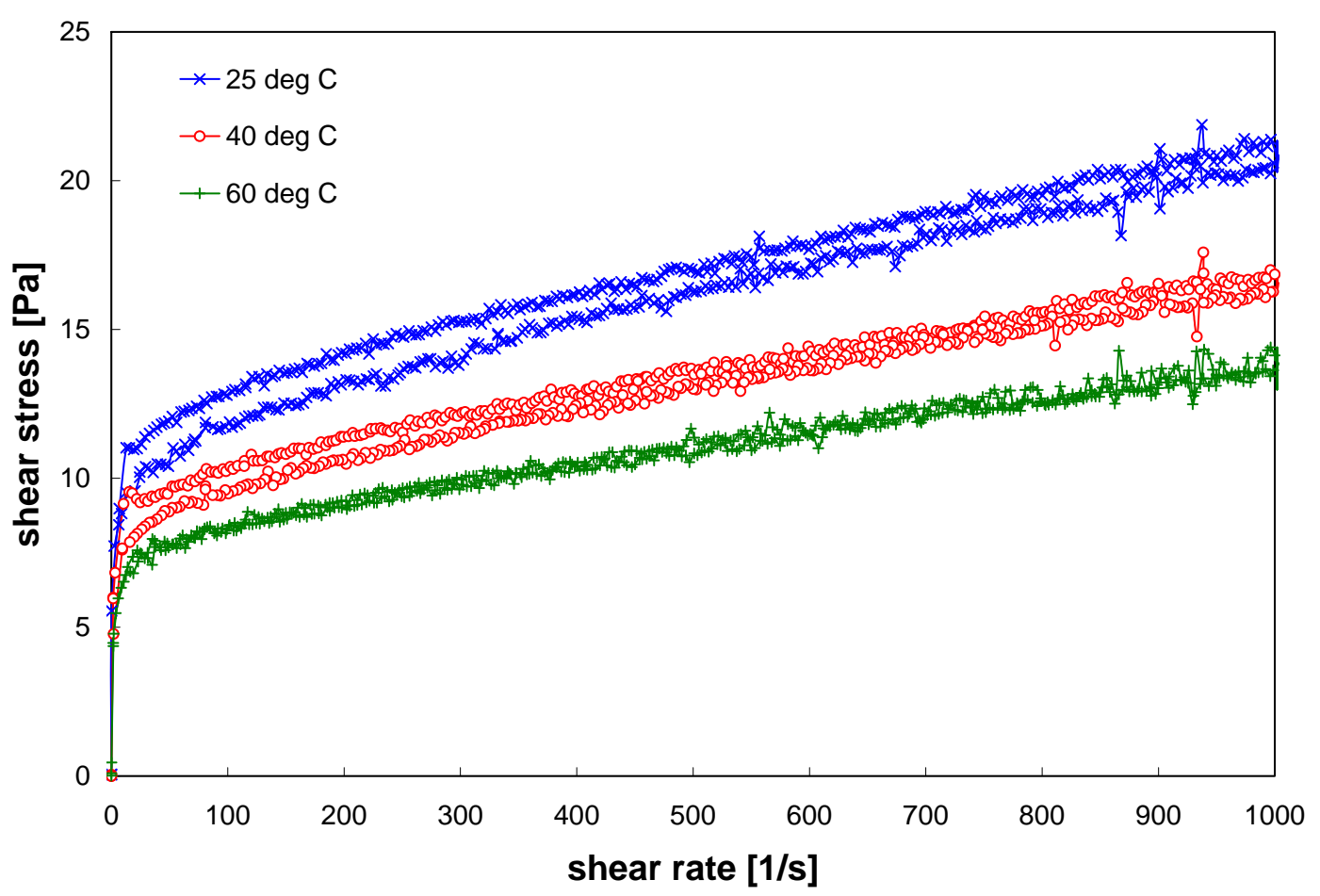

Figure 4.47. Flow Curve of the Dewatered Blended Washed Leached Slurry

(Measured UDS of $26 \mathrm{wt} \%$ )

The data in Figure 4.47 suggested that rheology decreased with increasing temperature. The data showed obvious decreases in yield stress as the temperature was raised to $40^{\circ} \mathrm{C}$ and $60^{\circ} \mathrm{C}$. The slope of the stress response (i.e., the slurry consistency) appeared reduced at $40^{\circ} \mathrm{C}$ relative to that at $25^{\circ} \mathrm{C}$. This decrease might have continued as the temperature was raised from $40^{\circ} \mathrm{C}$ to $60^{\circ} \mathrm{C}$, but this was difficult to tell from visual inspection alone.

To capture and quantify the non-Newtonian rheology of the slurry sample, the flow-curve data were fitted to both Bingham-Plastic and Casson models. Table 4.34 summarizes the best-fit Bingham-Plastic and 
Casson parameters calculated from the data. Both Bingham-Plastic and Casson fits showed nonNewtonian rheology with significant slurry yield stress. Specifically, the Bingham and Casson fits indicated a slurry yield stress of 8.1 to $13 \mathrm{~Pa}$ and 6.0 to $9.5 \mathrm{~Pa}$, respectively. Initial and replicate best-fit yield stresses agreed to within $10 \%$ and as such, were comparable. Both model fits confirmed that the yield stress decreased significantly with temperature. For example, the Bingham-Plastic yield stress decreased from $\sim 12 \mathrm{~Pa}$ to $9.7 \mathrm{~Pa}$ when the temperature was increased from $25^{\circ} \mathrm{C}$ to $40^{\circ} \mathrm{C}$. As the temperature was further increased to $60^{\circ} \mathrm{C}$, the yield decreased again to $8.1 \mathrm{~Pa}$. All decreases were greater than $10 \%$ of the original value and, as such, were likely significant.

Table 4.34. Results of Fitting Analysis for the Dewatered Blended Washed Leached Slurry (Measured UDS of $26 \mathrm{wt} \%$ )

\begin{tabular}{||c|c|c|c|c|c||}
\hline \hline \multirow{3}{*}{ Model } & $\begin{array}{c}\text { Temperature } \\
\left({ }^{\circ} \mathbf{C}\right)\end{array}$ & $\begin{array}{c}\text { Range } \\
\left(\mathbf{s}^{-1}\right)\end{array}$ & $\begin{array}{c}\text { Yield Stress } \\
(\mathbf{P a})\end{array}$ & $\begin{array}{c}\text { Consistency } \\
(\mathbf{m P a} \cdot \mathbf{s})\end{array}$ & $\mathbf{R}$ \\
\hline \multirow{4}{*}{ Bingham-Plastic } & $25(1$ of 2$)$ & $100-1000$ & 13 & 9.5 & 0.99 \\
\cline { 2 - 6 } & $25(2$ of 2$)$ & $100-1000$ & 12 & 8.8 & 0.99 \\
\cline { 2 - 6 } & 40 & $100-1000$ & 9.7 & 6.9 & 0.99 \\
\cline { 2 - 6 } & 60 & $100-1000$ & 8.1 & 5.7 & 0.99 \\
\hline \multirow{4}{*}{ Casson } & $25(1$ of 2) & $0-1000$ & 9.5 & 2.6 & 0.98 \\
\cline { 2 - 6 } & $25(2$ of 2) & $0-1000$ & 8.9 & 2.5 & 0.99 \\
\cline { 2 - 6 } & 40 & $0-1000$ & 7.2 & 1.9 & 0.99 \\
\cline { 2 - 6 } & 60 & $0-1000$ & 6.0 & 1.6 & 0.99 \\
\hline \hline
\end{tabular}

Likewise, the slurry consistency appeared to decrease with increasing temperature. The Bingham-Plastic fits indicated a consistency ranging from 5.7 to $9.5 \mathrm{mPa} \cdot \mathrm{s}$ (depending on temperature); the Casson fits found a consistency ranging from 1.6 to $2.6 \mathrm{mPa} \cdot \mathrm{s}$. Based on the Bingham-Plastic fits, the slurry consistency decreased from $8.8 \mathrm{mPa} \cdot \mathrm{s}$ to $6.9 \mathrm{mPa} \cdot \mathrm{s}$ over $25^{\circ} \mathrm{C}$ to $40^{\circ} \mathrm{C}$ and from 6.9 to $5.7 \mathrm{mPa} \cdot \mathrm{s}$ over $40^{\circ} \mathrm{C}$ to $60^{\circ} \mathrm{C}$. Both decreases exceeded the $10 \%$ limit of accuracy expected for this measurement range. Although the decrease observed in the Casson fit consistency was less (and may not be significant on a temperature-to-temperature basis), the overall decrease observed between $25^{\circ} \mathrm{C}$ and $60^{\circ} \mathrm{C}$ was large enough to be considered significant. 
WTP-RPT-170, Rev. 0

\subsection{Summary and Conclusions}

A scope of work ${ }^{(a)}$ was developed to perform caustic and oxidative leaching bench-scale tests of actual Hanford tank waste samples to address Task 4 of the M-12 External Flowsheet Review Team (EFRT) response plan. ${ }^{(b)}$ Supporting this response, eight groupings of actual waste had been developed encompassing a large fraction of the high-level waste (HLW) types present at the Hanford Site. Each waste grouping was developed to specifically address a Waste Treatment and Immobilization Plant (WTP) processing challenge. Together, the eight waste groupings represented $\sim 75 \%$ of the HLW mass expected to be processed through the WTP.

The waste group tested and discussed in this report is the ferrocyanide waste (Group 8, FeCN). This waste type was of interest because of its high iron content. Iron was expected to exist primarily as $\mathrm{Fe}(\mathrm{OH})_{3}$, and its filtration behavior was of particular concern because of the observed lower filter fluxes of iron hydroxide-rich simulants relative to more crystalline materials such as gibbsite $\left(\mathrm{Al}[\mathrm{OH}]_{3}\right)$.

Samples representative of Group 8 were retrieved from the archived tank waste sample inventory at the 222S Laboratory. Samples were transferred to the hot cells at the Radiochemical Processing Laboratory (RPL), transferred to a compositing vessel with water, homogenized, and then subdivided. The composited material was characterized for physical properties, chemical composition, and crystal habit of the insoluble solids. The remaining composite material was tested in a bench-top filtration/leaching apparatus, commonly called the crossflow ultrafilter test assembly or CUF, in the hot cells where ultrafiltration and caustic-leaching conditions that were expected to be conducted at the WTP pre-treatment facility were simulated. The filtration testing was conducted in a parametric test sequence to understand filter-flux dependency on axial velocity and trans-membrane pressure both before caustic leaching (low and high solids content) and after leaching and washing (high solids content.). The CUF system was capable of filtering HLW slurry using a cross-flow ultrafilter ( $2 \mathrm{ft}$ long with a 0.5 inch ID) rated for 0.1 - $\mu$ m-diameter particles. Caustic leaching and solids washing in conjunction with filtration were performed in the apparatus; the effectiveness of maintaining transuranic material in the HLW process stream (slurry side of the CUF) was evaluated.

The following objectives of the test plan were accomplished:

- Physical and chemical characterization (settling rate, particle-size distribution [PSD], rheology, concentrations of metal, anions, and radionuclides, and crystal habit and morphology using X-ray Diffraction [XRD], scanning electron microscopy [SEM], and transmission electron microscopy [TEM]).

(a) SK Fiskum, TP-RPP-WTP-467, Rev. 0, 2/2/07 and Rev. 17/31/07, Characterization and Small Scale Testing of Hanford Wastes to Support the Development and Demonstration of Leaching and Ultrafiltration Pretreatment Processes.

(b) WTP Doc. No. 24590-WTP-PL-ENG-06-0008, Rev 0, "Hanford Waste Treatment and Immobilization Plant (WTP) Project Response Plan for Resolution of Issues Identified by the Comprehensive Review of the WTP Flowsheet and Throughput." L Lucas, March 2006. 
- Parametric filtration testing at $5.8 \mathrm{wt} \%$ undissolved solids (UDS) and $13 \mathrm{wt} \%$ UDS before caustic leaching was performed.

- Caustic leaching at $60^{\circ} \mathrm{C}$ for $9 \mathrm{~h}$ in a 3.7-M free-hydroxide matrix while periodically sampling the aqueous fraction to evaluate $\mathrm{Al}$ and $\mathrm{P}$ dissolution as a function of time.

- Final characterization of the caustic leached and washed solids including PSD, concentrations of metal, anions, and radionuclides as well as crystal habit and morphology.

- Solids from the previous CUF test with Group 7 (tributyl phosphate [TBP] sludge) combined with AY-102 solids were blended with the residual solids from the Group 8 CUF test, resulting in a final $23 \mathrm{wt} \%$ UDS. This blended material represented the highest solids content tested in the CUF relative to all eight tank waste groupings tested in this program. The blended waste was subjected to a parametric filtration test matrix.

\subsection{Characterization}

The major analyte concentrations of the Group 8 supernatant before processing and the washed solids composition before and after processing are shown in Table 5.1 and Table 5.2. Overall, a concentration factor of $\sim 1.3$ was found in the solids following caustic leaching and washing with this waste form (based on evaluation of Fe, $\mathrm{U}, \mathrm{Mn}$, and Ni). Analytes that were partially leached during the caustic leach and wash steps included ${ }^{137} \mathrm{Cs}, \mathrm{Al}$, and $\mathrm{S}$.

The ${ }^{137} \mathrm{Cs}$ that leached into the aqueous phase would ultimately require ion exchange separation to allow recombination with the $\mathrm{HLW}$ for eventual vitrification. The $\mathrm{Pu}, \mathrm{Am}, \mathrm{U}, \mathrm{Fe}, \mathrm{Mn}$, and $\mathrm{Ni}$ remained with the solids during all processing. The $\mathrm{Cd}$ and $\mathrm{B}$ concentrations were low, and their processing fates could not be discerned.

The XRD patterns defining the crystal structures were very complex and showed that only gibbsite was removed during the caustic leaching and washing steps. All other diffraction peaks were identical to the input material and were consistent with an initial and final solids composition that included sodium uranium oxide, $\mathrm{Na}_{2} \mathrm{U}_{2} \mathrm{O}_{7}$, hematite, $\mathrm{Fe}_{2} \mathrm{O}_{3}$, sodium aluminum iron oxide, $\mathrm{Na}_{2} \mathrm{Al}_{0.5} \mathrm{Fe}_{9.5} \mathrm{O}_{15}$, hydroxycancrinite, $1.06 \mathrm{Na}_{2} \mathrm{O} \cdot \mathrm{Al}_{2} \mathrm{O}_{3} \cdot 1.60 \mathrm{SiO}_{2} \cdot 1.60 \mathrm{H}_{2} \mathrm{O}$, and other minor phases. An amorphous component appeared to also be present. 
Table 5.1. Radionuclide Content in Group 8 Before and After Caustic Leach

\begin{tabular}{|c|c|c|c|c|c|c|}
\hline \multirow{2}{*}{$\begin{array}{l}\text { Process } \\
\text { Phase }>\end{array}$} & \multicolumn{4}{|c|}{ Initial Composition } & \multirow{3}{*}{$\begin{array}{c}\begin{array}{c}\text { Composition of } \\
\text { Leached and } \\
\text { Washed Solids }^{(\mathbf{b})}\end{array} \\
08-2297^{(\mathbf{d})} \\
\end{array}$} & \multirow{4}{*}{$\begin{array}{l}\text { Analyte } \\
\text { CF }^{(\mathrm{e})}\end{array}$} \\
\hline & \multirow{2}{*}{\multicolumn{2}{|c|}{$\begin{array}{c}\text { Supernatant } \\
0^{08-01943}{ }^{(a)}\end{array}$}} & \multirow{2}{*}{\multicolumn{2}{|c|}{$\begin{array}{c}\text { Washed solids }^{(\mathbf{b})} \\
\text { 08-01946 }^{(\mathbf{a})}\end{array}$}} & & \\
\hline Sample ID> & & & & & & \\
\hline Analyte & $\mu \mathrm{Ci} / \mathrm{mL}$ & RPD & $\mu \mathrm{Ci} / \mathrm{g}$ & RPD & $\mu \mathrm{Ci} / \mathrm{g}$ & \\
\hline${ }^{137} \mathrm{Cs}$ & $4.53 \mathrm{E}+1$ & 0.66 & $3.85 \mathrm{E}+2$ & 0.26 & $1.5 \mathrm{E}+2$ & 0.39 \\
\hline${ }^{60} \mathrm{Co}$ & $<1 . \mathrm{E}-4$ & na & $9.94 \mathrm{E}-3^{(\mathrm{f})}$ & $\mathrm{na}^{(\mathrm{c})}$ & $7.8 \mathrm{E}-3$ & $n a^{(f)}$ \\
\hline${ }^{241} \mathrm{Am}$ & $<7 . \mathrm{E}-3$ & na & $1.91 \mathrm{E}-1$ & 12 & [1.8E-1] & {$[0.95]$} \\
\hline${ }^{238} \mathrm{Pu}$ & $5.58 \mathrm{E}-6$ & 24 & $1.41 \mathrm{E}-2$ & 26 & $2.9 \mathrm{E}-2$ & 2.1 \\
\hline${ }^{239+240} \mathrm{Pu}$ & $7.69 \mathrm{E}-5$ & 8.2 & $5.63 \mathrm{E}-1$ & 2.8 & $6.9 \mathrm{E}-1$ & 1.2 \\
\hline Gross alpha & $<4 . \mathrm{E}-3$ & na & $8.77 \mathrm{E}-1$ & 7.3 & $1.2 \mathrm{E}+0$ & 1.4 \\
\hline Gross beta & $4.54 \mathrm{E}+1$ & 2.0 & $2.97 \mathrm{E}+3$ & 1.7 & $3.4 \mathrm{E}+3$ & 1.1 \\
\hline${ }^{90} \mathrm{Sr}$ & $8.12 \mathrm{E}-2$ & 3.0 & $1.29 \mathrm{E}+3$ & 2.3 & $1.6 \mathrm{E}+3$ & 1.2 \\
\hline \multicolumn{7}{|l|}{ Opportunistic } \\
\hline${ }^{154} \mathrm{Eu}$ & $<5$.E-4 & na & $1.41 \mathrm{E}-1$ & 11 & $1.7 \mathrm{E}-1$ & 1.2 \\
\hline${ }^{155} \mathrm{Eu}$ & $<8 . \mathrm{E}-3$ & na & $<1$.E-1 & na & $<1 \mathrm{E}-1$ & na \\
\hline \multicolumn{7}{|c|}{$\begin{array}{l}\text { (a) ASR } 8150 \text { Reference date is July } 15,2007 \text {. } \\
\text { (b) Analyte concentrations are calculated on a dry-mass basis. } \\
\text { (c) Not calculated-the duplicate sample was }<3 \mathrm{E}-3 \text {; the result of the primary sample is reported. } \\
\text { (d) ASR } 8206 \text { reference date February } 17,2008 \text {. } \\
\text { (e) Concentration factor (CF) was calculated by dividing the final concentration by the initial } \\
\text { concentration. } \\
\text { (f) The }{ }^{60} \text { Co concentration in the duplicate sample was }<3 \mathrm{E}-3 \text {. As such, the CF could range from } \\
0.78 \text { to }>2.6 \text {. Because of the wide disparity, the CF is listed as "na." }\end{array}$} \\
\hline
\end{tabular}


Table 5.2. Inductively Coupled Plasma (ICP) Analyte Content in Group 8 Before and After Caustic Leach

\begin{tabular}{|c|c|c|c|c|c|c|}
\hline Process & \multicolumn{4}{|c|}{ Initial Composition } & $\begin{array}{c}\text { Final } \\
\text { Composition }\end{array}$ & \\
\hline Phase $>$ & \multicolumn{2}{|c|}{ Supernatant } & \multicolumn{2}{|c|}{ Washed solids $^{(\mathrm{a})}$} & $\begin{array}{c}\text { Leached and } \\
\text { Washed solids }^{(a)}\end{array}$ & \\
\hline Sample ID> & \multicolumn{2}{|c|}{ 08-01943 } & \multicolumn{2}{|c|}{ 08-01946 } & 08-2297 & Analyte \\
\hline Analyte & $\mu \mathrm{g} / \mathrm{mL}$ & RPD & $\mu \mathrm{g} / \mathrm{g}$ & RPD & $\mu \mathrm{g} / \mathrm{g}^{(\mathbf{b})}$ & $\mathbf{C F}^{(\mathbf{c})}$ \\
\hline $\mathrm{Al}$ & 1,430 & 2.8 & 89,650 & 1.7 & 50,000 & 0.56 \\
\hline $\mathrm{B}$ & 128 & 3.9 & $<100$ & na & $<100$ & na \\
\hline $\mathrm{Bi}$ & $<3.7$ & na & 5,990 & 7.8 & 7,700 & 1.3 \\
\hline $\mathrm{Cd}$ & $<0.42$ & na & $<47$ & na & {$[13]$} & na \\
\hline $\mathrm{Cr}$ & 180 & 1.1 & 2,140 & 0.2 & 2,400 & 1.1 \\
\hline $\mathrm{Fe}$ & 45.6 & 0.7 & 106,000 & 3.4 & 140,000 & 1.3 \\
\hline $\mathrm{K}$ & 1,110 & 3.6 & 1,190 & 1.5 & na & na \\
\hline $\mathrm{Mn}$ & {$[0.18]$} & na & 1,330 & 3.1 & 1,800 & 1.4 \\
\hline $\mathrm{Na}$ & 79,900 & 0.8 & 50,500 & 0.8 & 62,000 & 1.2 \\
\hline $\mathrm{Ni}$ & 125 & 1.6 & 36,150 & 0.8 & 46,000 & 1.3 \\
\hline $\mathrm{P}$ & 2,550 & 1.6 & 36,950 & 2.6 & 49,000 & 1.3 \\
\hline $\mathrm{S}$ & 2,290 & 2.6 & {$[5,900]$} & na & [770] & {$[0.13]$} \\
\hline $\mathrm{Si}$ & 25.6 & 16.8 & {$[17,000]$} & na & {$[23,000]$} & [1.4] \\
\hline $\mathrm{Sr}$ & 2.17 & 1.8 & 41,850 & 1.6 & 54,000 & 1.3 \\
\hline $\mathrm{U}$ & [7.3] & na & 121,000 & 0.4 & 150,000 & 1.2 \\
\hline $\mathrm{Zn}$ & [1.1] & na & [555] & na & 630 & 1.1 \\
\hline $\mathrm{Zr}$ & $<0.13$ & na & [106] & na & 380 & 3.6 \\
\hline U KPA & na & na & 103,000 & 8.3 & 130,000 & 1.3 \\
\hline \multicolumn{7}{|c|}{ Opportunistic } \\
\hline $\mathrm{Ca}$ & [5.8] & na & 63,450 & 0.9 & 79,000 & 1.2 \\
\hline $\mathrm{Mg}$ & $<0.28$ & na & 4490 & 7.0 & 6,100 & 1.4 \\
\hline $\mathrm{Pb}$ & $<4.5$ & na & 5860 & 6.2 & 6,300 & 1.1 \\
\hline \multicolumn{7}{|c|}{$\begin{array}{l}\text { (a) Analyte concentrations are calculated on a dry-mass basis. } \\
\text { (b) The leached solids composition was calculated from the slurry and superna } \\
\text { analyses. } \\
\text { (c) The solids concentration factor was calculated by dividing the final solids } \\
\text { concentration by the initial characterization solids concentration. } \\
\text { Notes: na = not applicable } \\
\text { Values in brackets [ ] are } \geq \text { MDL but }<\text { EQL, with errors likely to exceed } 15 \% \text {. }\end{array}$} \\
\hline
\end{tabular}

\subsection{Filtration Behavior}

The filtration behavior of the Group 8 slurry was examined by parametric filter testing and by dewatering operations of the slurry before and after caustic leaching. The parametric filtration test evaluated Group 8 with 5.9 wt\% UDS, Group 8 at 13 wt\% UDS before caustic leaching, and Group 8 blended with caustic-leached and washed Group 7 (TBP waste sludge) combined with AY-102 sludge at $15 \mathrm{wt} \%$ UDS. The slurry was dewatered before caustic leaching, after caustic 
leaching, after each washing step of the caustic leached solids, and again after adding the Group 7/AY102 slurry. The filtration results from these tests are summarized in Table 5.3 along with relevant slurry parameters such as rheology and PSD. The following general observations were made:

- Filter-flux measurements of the pre-leached slurry at baseline conditions (transmembrane pressure [TMP] at $40 \mathrm{psid}$, axial velocity [AV] at $13 \mathrm{ft} / \mathrm{s}$ ) measured the average flux at 0.03 $\mathrm{GPM} / \mathrm{ft}^{2}$ after 2 days of operation.

- Increased TMP proportionally increased the filter flux throughout the test.

- The AV appeared to have a minor impact on filter flux once the slurry UDS concentration increased over $10 \mathrm{wt} \%$.

- The filter flux showed some decay over time throughout the test. However, this effect became less pronounced after 2 days of operation. After introducing the Group 7/AY102 slurry, filter decay over time became significant again.

- Filter resistance appeared relatively constant throughout the test with no changes occurring from caustic leaching or washing.

- Dewatering the washed leached solids from the Group 8 CUF test, combined with washed leached solids from the Group 7/AY102 CUF test, showed that the UDS concentration impacted filtration at UDS concentrations above $15 \mathrm{wt} \%$. As seen in previous studies, the change in filtration could be predicted by the ratio of the slurry UDS concentration to the slurry's centrifuged solids concentration.

- Particle-size measurements showed little change in the distribution during filtration and dewatering of the blended waste when compared to initial characterization results.

- The crystallinity and morphology of the particles were not as sharp as that found in the initial characterization sample (see Section 3.0). In fact, the particles appeared to form agglomerates with sub-micron components

- Rheology measurements showed that supernate viscosity had a significant impact on filter flux. Increases in the supernate viscosity correlated to decreases in the filtration rate as predicted by the Darcy equation. The changes in supernate viscosity could be correlated to increases in the dissolved solids concentration of the supernate.

- Rheology measurements also showed a correlation to slurry flow behavior and filtration behavior. For Newtonian behavior, TMP was the most significant controlling parameter, and AV had no impact. As slurry rheology changed to more non-Newtonian behavior, AV was more significant. These changes correlated to increases in the slurry UDS concentration, which demonstrates how particle interactions in the flowing slurry will affect the formation of filter cake on the filter surface and impact filter flux as a result.

- Overall, the waste type filtered successfully before and after leaching. Decreases in the filter flux after caustic leaching were a result of increases in the supernate viscosity. Observed foaming of the waste impacted pumping efficiency, but did not directly impact filtration. 
Table 5.3. Summary of Group 8 Filtration Results

\begin{tabular}{|c|c|c|}
\hline Filtration Step & Property & Results \\
\hline \multirow{4}{*}{$\begin{array}{l}\text { Initial Characterization of } \\
\text { Group } 8 \\
\text { (Section 3.0) }\end{array}$} & Material Description & Ferrocyanide tank waste sludge \\
\hline & UDS & $11.4 \mathrm{wt} \%$ \\
\hline & $\begin{array}{l}\text { Slurry Rheology } \\
\text { @ } 25^{\circ} \mathrm{C} \\
\text { @ } 40^{\circ} \mathrm{C} \\
\text { @ } 60^{\circ} \mathrm{C}\end{array}$ & $\begin{array}{lr}\text { Newtonian } & \\
\text { Viscosity: } & 2.6-3.3 \mathrm{mPa} \cdot \mathrm{s} @ 25^{\circ} \mathrm{C} \\
& 2.2 \mathrm{mPa} \cdot \mathrm{s} @ 40^{\circ} \mathrm{C} \\
& 1.4 \mathrm{mPa} \cdot \mathrm{s} @ 60^{\circ} \mathrm{C} \\
\end{array}$ \\
\hline & $\begin{array}{l}\text { PSD } \\
\text { (3000 RPM pump speed) }\end{array}$ & $\begin{array}{l}\mathrm{d}(10): 1.3-3.5 \mu \mathrm{m} \\
\mathrm{d}(50): 7.5-9.4 \mu \mathrm{m} \\
\mathrm{d}(90): 23-140 \mu \mathrm{m}\end{array}$ \\
\hline \multirow{2}{*}{$\begin{array}{l}\text { Low Solids } \\
\text { Filtration Testing } \\
\text { (Section 4.3.1) }\end{array}$} & Material Description & $\begin{array}{l}\text { Group } 8 \text { diluted } \mathrm{w} / \text { simulant } \\
\text { supernatant and circulated in CUF }\end{array}$ \\
\hline & UDS & $5.9 \mathrm{wt} \%$ \\
\hline \multirow[t]{4}{*}{$\begin{array}{l}\text { Baseline Conditions } \\
\text { TMP: } 40 \text { psid } \\
\text { AV: } 13 \mathrm{ft} / \mathrm{s}\end{array}$} & $\begin{array}{l}\text { Slurry Rheology } \\
\text { @ } 25^{\circ} \mathrm{C} \\
\text { @ } 40^{\circ} \mathrm{C} \\
\text { (a) } 60^{\circ} \mathrm{C}\end{array}$ & $\begin{array}{ll}\text { Newtonian } & \\
\text { Viscosity: } & 3.0 \mathrm{mPa} \cdot \mathrm{s} @ 25^{\circ} \mathrm{C} \\
& 2.3 \mathrm{mPa} \cdot \mathrm{s} @ 40^{\circ} \mathrm{C} \\
& 1.1 \mathrm{mPa} \cdot \mathrm{s} @ 60^{\circ} \mathrm{C}\end{array}$ \\
\hline & $\begin{array}{l}\text { PSD } \\
\text { (3000 RPM pump speed) }\end{array}$ & $\begin{array}{l}\mathrm{d}(10): 50 \mu \mathrm{m} \\
\mathrm{d}(50): 87 \mu \mathrm{m} \\
\mathrm{d}(90): 150 \mu \mathrm{m}\end{array}$ \\
\hline & Baseline Filter Flux & $0.030 \mathrm{GPM} / \mathrm{ft}^{2}$ \\
\hline & Controlling Parameter & $\begin{array}{l}\text { Proportional to TMP } \\
\text { Slight decay with time }\end{array}$ \\
\hline \multirow{3}{*}{$\begin{array}{l}\text { Dewatering of Waste Prior } \\
\text { to Leaching } \\
\text { (Section 4.3.2) }\end{array}$} & Initial Flux & $0.029 \mathrm{GPM} / \mathrm{ft}^{2}$ \\
\hline & Final Flux & $0.024 \mathrm{GPM} / \mathrm{ft}^{2}$ \\
\hline & Final UDS & $13 \mathrm{wt} \%$ \\
\hline \multirow{2}{*}{$\begin{array}{l}\text { Filtration Conditions } \\
\text { TMP: } 40 \mathrm{psid} \\
\mathrm{AV}: 13 \mathrm{ft} / \mathrm{s}\end{array}$} & Behavior & $\begin{array}{l}\text { TMP controlling } \\
\text { Slight decay with time }\end{array}$ \\
\hline & Supernate Composition & $\begin{array}{ll}{[\mathrm{Na}]:} & 3.4 \mathrm{M} \\
{[\mathrm{OH}]:} & 0.36 \mathrm{M} \\
{[\mathrm{Al}]:} & 0.054 \mathrm{M}\end{array}$ \\
\hline \multirow[t]{6}{*}{$\begin{array}{l}\text { High Solids } \\
\text { Filtration Testing } \\
\text { (Sections 4.3.3, 4.4) }\end{array}$} & Material Description & $\begin{array}{l}\text { Dewatered Group } 8 \text { slurry diluted w/ } \\
\text { simulant supernatant and circulated in } \\
\text { CUF }\end{array}$ \\
\hline & UDS & $13 \mathrm{wt} \%$ \\
\hline & $\begin{array}{l}\text { Slurry Rheology } \\
\text { (a) } 25^{\circ} \mathrm{C} \text { to } 60^{\circ} \mathrm{C}\end{array}$ & $\begin{array}{l}\text { Borderline non-Newtonian } \\
\text { Shear Stress range: } \quad 0.2 \text { to } 0.8 \mathrm{~Pa} \\
\text { Consistency range: } \quad 1.6 \text { to } 5.1 \mathrm{mPa} \cdot \mathrm{s}\end{array}$ \\
\hline & $\begin{array}{l}\text { PSD } \\
\text { (3000 RPM pump speed) }\end{array}$ & $\begin{array}{l}\mathrm{d}(10): 1.6 \mu \mathrm{m} \\
\mathrm{d}(50): 6.1 \mu \mathrm{m} \\
\mathrm{d}(90): 29 \mu \mathrm{m}\end{array}$ \\
\hline & Baseline Filter Flux & $0.025 \mathrm{GPM} / \mathrm{ft}^{2}$ \\
\hline & Controlling Parameter & $\begin{array}{l}\text { Proportional to TMP } \\
\text { Secondary AV effects }\end{array}$ \\
\hline
\end{tabular}


Table 5.3 (contd)

\begin{tabular}{|c|c|c|}
\hline Filtration Step & Property & Results \\
\hline \multirow{2}{*}{$\begin{array}{l}\text { Caustic Leach Dewater } \\
\text { (Sections 4.5.2, 4.5.3) }\end{array}$} & Initial Flux & $0.017 \mathrm{GPM} / \mathrm{ft}^{2}$ \\
\hline & Final Filter Flux & $0.012 \mathrm{GPM} / \mathrm{ft}^{2}$ \\
\hline \multirow{3}{*}{$\begin{array}{l}\text { Filtration Conditions } \\
\text { TMP: } 40 \mathrm{psid} \\
A V: 13 \mathrm{ft} / \mathrm{s}\end{array}$} & Final UDS & $\begin{array}{l}\text { Measured at } 23 \mathrm{wt} \% \\
\text { Predicted at } 12 \mathrm{wt} \%\end{array}$ \\
\hline & Behavior & Slight decay over time \\
\hline & Supernate Composition & $\begin{array}{ll}\mathrm{Na}]: & 5.2 \mathrm{M} \\
{[\mathrm{OH}]:} & 3.6 \mathrm{M} \\
{[\mathrm{Al}]:} & 0.17 \mathrm{M} \\
\end{array}$ \\
\hline \multirow{3}{*}{$\begin{array}{l}\text { Caustic Wash } 1 \\
\text { (Section 4.5.5) } \\
\text { Filtration Conditions } \\
T M P: 40 \text { psid } \\
A V: 13 f t / s\end{array}$} & Wash Solution & $0.47 \mathrm{M} \mathrm{NaOH}$ \\
\hline & Supernate Composition & $\begin{array}{ll}{[\mathrm{Na}]:} & 3.9 \mathrm{M} \\
{[\mathrm{OH}]:} & 2.7 \mathrm{M} \\
{[\mathrm{Al}]:} & 0.096 \mathrm{M} \\
\end{array}$ \\
\hline & Filter Flux & $\begin{array}{l}0.042-0.019 \mathrm{GPM} / \mathrm{ft}^{2} \\
\text { Average: } 0.034 \mathrm{GPM} / \mathrm{ft}^{2}\end{array}$ \\
\hline \multirow{3}{*}{$\begin{array}{l}\text { Caustic Wash } 2 \\
\text { (Section 4.5.5) } \\
\text { Filtration Conditions } \\
T M P: 40 \text { psid } \\
A V: 13 f t / s\end{array}$} & Wash Solution & $0.16 \mathrm{M} \mathrm{NaOH}$ \\
\hline & Supernate Composition & $\begin{array}{ll}{[\mathrm{Na}]:} & 1.4 \mathrm{M} \\
{[\mathrm{OH}]:} & 0.96 \mathrm{M} \\
{[\mathrm{Al}]:} & 0.038 \mathrm{M} \\
\end{array}$ \\
\hline & Filter Flux & $\begin{array}{l}0.050-0.031 \mathrm{GPM} / \mathrm{ft}^{2} \\
\text { Average: } 0.040 \mathrm{GPM} / \mathrm{ft}^{2}\end{array}$ \\
\hline \multirow{3}{*}{$\begin{array}{l}\text { Caustic Wash } 3 \\
\text { (Section 4.5.5) } \\
\text { Filtration Conditions } \\
T M P: 40 \text { psid } \\
A V: 13 f t / s\end{array}$} & Wash Solution & $0.049 \mathrm{M} \mathrm{NaOH}$ \\
\hline & Supernate Composition & $\begin{array}{ll}{[\mathrm{Na}]:} & 0.64 \mathrm{M} \\
{[\mathrm{OH}]:} & 0.44 \mathrm{M} \\
{[\mathrm{Al}]:} & 0.017 \mathrm{M} \\
\end{array}$ \\
\hline & Filter Flux & $\begin{array}{l}0.057-0.031 \mathrm{GPM} / \mathrm{ft}^{2} \\
\text { Average: } 0.044 \mathrm{GPM} / \mathrm{ft}^{2}\end{array}$ \\
\hline \multirow{3}{*}{$\begin{array}{l}\text { Caustic Wash } 4 \\
\text { (Section 4.5.5) } \\
\text { Filtration Conditions } \\
T M P: 40 \text { psid } \\
A V: 13 f t / s\end{array}$} & Wash Solution & $0.014 \mathrm{M} \mathrm{NaOH}$ \\
\hline & Supernate Composition & $\begin{array}{ll}{[\mathrm{Na}]:} & 0.31 \mathrm{M} \\
{[\mathrm{OH}]:} & 0.22 \mathrm{M} \\
{[\mathrm{Al}]:} & 0.0079 \mathrm{M} \\
\end{array}$ \\
\hline & Filter Flux & $\begin{array}{l}0.059-0.030 \mathrm{GPM} / \mathrm{ft}^{2} \\
\text { Average: } 0.045 \mathrm{GPM} / \mathrm{ft}^{2}\end{array}$ \\
\hline \multirow{3}{*}{$\begin{array}{l}\text { Washed Caustic Leached } \\
\text { Slurry } \\
\text { (Section 4.6) }\end{array}$} & UDS & $\begin{array}{l}\text { Measured } 20 \mathrm{wt} \% \\
\text { Predicted } 15 \mathrm{wt} \%\end{array}$ \\
\hline & $\begin{array}{l}\text { PSD } \\
\text { (3000 RPM pump speed) }\end{array}$ & $\begin{array}{l}\mathrm{d}(10): 3.3 \mu \mathrm{m} \\
\mathrm{d}(50): 10 \mu \mathrm{m} \\
\mathrm{d}(90): 54 \mu \mathrm{m}\end{array}$ \\
\hline & $\begin{array}{l}\text { Rheology } \\
\text { (a) } 25^{\circ} \mathrm{C} \text { to } 60^{\circ} \mathrm{C}\end{array}$ & $\begin{array}{lr}\text { Non-Newtonian } & \\
\text { Yield Stress range: } & 3.4 \text { to } 6.7 \mathrm{~Pa} \\
\text { Consistency range: } & 1.7 \text { to } 6.9 \mathrm{mPa} \cdot \mathrm{s}\end{array}$ \\
\hline
\end{tabular}


Table 5.3 (contd)

\begin{tabular}{|c|c|c|}
\hline Filtration Step & Property & Results \\
\hline \multirow{4}{*}{$\begin{array}{l}\begin{array}{l}\text { Combined Solids } \\
\text { Filtration Testing } \\
\text { (Section 4.7) }\end{array} \\
\text { Baseline Conditions } \\
T M P: 40 \mathrm{psid} \\
A V: 13 \mathrm{ft} / \mathrm{s}\end{array}$} & Material Description & $\begin{array}{l}\text { Washed Caustic Leached Group } 8 \\
\text { Solids Combined with Washed } \\
\text { Caustic Leached Solids from Group } \\
\text { 7/AY-102 }\end{array}$ \\
\hline & Measured UDS & $15 \mathrm{wt} \%$ \\
\hline & Baseline Flux & $0.037-0.048 \mathrm{GPM} / \mathrm{ft}^{2}$ \\
\hline & Controlling Parameter & $\begin{array}{l}\text { Proportional to TMP } \\
\text { Secondary AV effects } \\
\text { Small Decay over Time }\end{array}$ \\
\hline \multirow{3}{*}{$\begin{array}{l}\text { Combined Leached Slurry } \\
\text { Dewatering (Section 4.7.2) }\end{array}$} & Initial Flux & $0.044 \mathrm{GPM} / \mathrm{ft}^{2}$ \\
\hline & Final Filter Flux & $0.022 \mathrm{GPM} / \mathrm{ft}^{2}$ \\
\hline & Final Measured UDS & $26 \mathrm{wt} \%$ \\
\hline \multirow{2}{*}{$\begin{array}{l}\text { Baseline Condition } \\
\text { TMP: } 40 \mathrm{psid} \\
\mathrm{AV}: 13 \mathrm{ft} / \mathrm{s}\end{array}$} & Behavior & UDS Controlling \\
\hline & $\begin{array}{l}\text { Rheology } \\
\text { (a) } 25^{\circ} \mathrm{C}-60^{\circ} \mathrm{C}\end{array}$ & $\begin{array}{l}\text { Non-Newtonian } \\
\text { Shear Stress range: } \\
\text { Consistency range: }\end{array} \quad \begin{array}{l}6.0 \text { to } 9.5 \mathrm{mPa} \cdot \mathrm{Pa} \\
\end{array}$ \\
\hline
\end{tabular}

\subsection{Leaching Behavior}

The Group 8 material was caustic leached during the CUF test. The leaching of the slurry was performed at $60^{\circ} \mathrm{C}$ for $8 \mathrm{~h}$ at a free-hydroxide concentration of $3.7 \mathrm{M}$ (the sodium concentration was $5.2 \mathrm{M}$ ) at an initial UDS concentration of $12 \mathrm{wt} \%$. The $\mathrm{Al}, \mathrm{Cr}, \mathrm{P}$, and ${ }^{137} \mathrm{Cs}$ caustic-leach factors are summarized in Table 5.4; the caustic-leached and washed solids composition is shown in Table 5.1 and Table 5.2. The following general observations were made:

- The overall dissolution of $\mathrm{Al}$ appeared kinetically fast, reaching equilibrium before the temperature of the leach slurry reached $40^{\circ} \mathrm{C}$. XRD results of the leached material showed only the absence of gibbsite, indicating that $\mathrm{Al}$ in the form of gibbsite dissolved.

- Leach factors for solid aluminum were found between 55 and 60\% from supernate and slurry ICP measurements. XRD results of the leached material indicated that aluminum that was not dissolved was largely in the form of hydroxycancrinite and sodium aluminum iron oxide.

- Phosphorus present as insoluble solids was not dissolved by the caustic leach.

- A small fraction of soluble phosphate in the supernate appeared to have precipitated during the caustic leach because of the increased sodium concentration from the caustic addition. Washing of the slurry decreased the sodium concentration and re-solubilized the phosphate. These observations matched previous results indicating how changes in sodium concentration impacted the transportation of phosphate to the low-activity waste (LAW) stream.

- The dissolution of chromium, similar to aluminum, was kinetically fast, reaching equilibrium before the temperature of the leach slurry reached $40^{\circ} \mathrm{C}$. A solid leach factor between 10 and $16 \%$ was found for chromium.

- Caustic leaching did not dissolve measureable quantities of transuranic materials from the slurry solids. 
- After four volumetric washes, only a small fraction of sodium was present in the interstitial liquid of the slurry (Figure 5.1). While half of the aluminum was removed from the CUF as a result of leaching and washing, a majority $(83 \mathrm{wt} \%)$ of the solids material remained in the slurry.

- Caustic leaching also caused 54 to $68 \%$ of the cesium present in the insoluble solids to dissolve into the aqueous phase. Considering that the Cs disposal pathway is with the HLW and not the LAW, and the total mass reduction as a result of caustic leaching was modest compared to the increase of sodium into the LAW stream, caustic leaching of the Group 8 sludge may not be considered very productive.

Table 5.4. Caustic Leaching Summary of Group 8 Slurry

\begin{tabular}{|c|c|c|c|c|}
\hline \multirow[b]{2}{*}{ Element } & \multicolumn{3}{|c|}{ Solid Leach Factors } & \multirow[b]{2}{*}{$\begin{array}{c}\text { Total Removal } \\
\text { from Slurry } \\
\text { wt } \%\end{array}$} \\
\hline & $\begin{array}{c}\text { Using Filtered } \\
\text { Supernate } \\
\text { Analysis, } \\
\text { wt\% }\end{array}$ & $\begin{array}{c}\text { Applying Total } \\
\text { Mass Balance, } \\
\text { wt \% }\end{array}$ & $\begin{array}{c}\text { Using Slurry } \\
\text { and Supernate } \\
\text { Analysis } \\
\text { wt\% }\end{array}$ & \\
\hline $\mathrm{Al}$ & 60 & 54 & $55-56$ & 63 \\
\hline $\mathrm{P}$ & $0^{(\mathrm{b})}$ & 0 & 0 & 44 \\
\hline $\mathrm{Cr}$ & 16 & 11 & $10-11$ & 41 \\
\hline${ }^{137} \mathrm{Cs}$ & not analyzed & 53 & $66-68$ & 72 \\
\hline
\end{tabular}

(a) Analyte mass percent removal includes the components in the initial supernatant phase.

(b) The data suggest approximately $10 \%$ increase in insoluble $\mathrm{P}$ due to precipitation of sodium phosphate during caustic leaching. The precipitated sodium phosphate was removed during the solids washing steps. 
WTP-RPT-170, Rev. 0

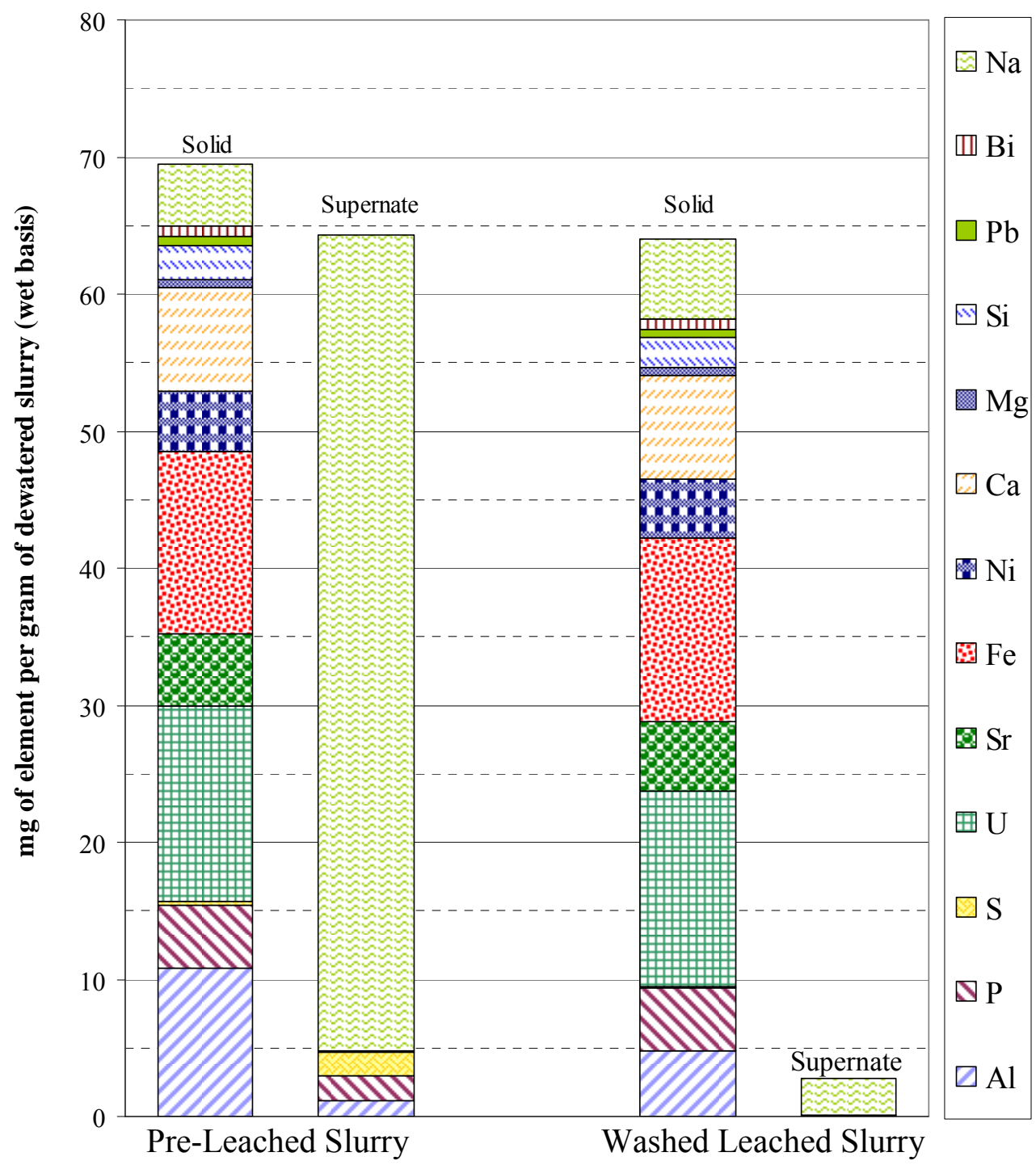

Figure 5.1. Comparison of Slurry Composition Before and After Caustic Leaching and Washing (Basis 1 gram of dewatered slurry) 
WTP-RPT-170, Rev. 0

Appendix A

Homogenization Vessel 



\section{Appendix A: Homogenization Vessel}

The homogenization vessel and mixing system used to homogenize the Group 8 ferrocyanide sludge material was designed and fabricated for use at the Pacific Northwest National Laboratory (PNNL) in the High-Level Radiochemistry Facility (HLRF). This stainless steel equipment was specifically designed for the task of tank waste homogenization and sub-division. The homogenization vessel was designed to hold and effectively mix a variable volume of 1 to $5 \mathrm{~L}$ of waste. A set of removable baffles was designed and added to enhance mixing. Industry experience shows that the best mixing is achieved when a tank height-to-diameter ratio is 1:1. For a fixed-volume batch tank, this is easy to achieve. For a variable volume tank, this presents a challenge usually solved by making the tank conical. Height restrictions and volume requirements made it unfeasible to make the entire homogenization vessel conical, so to optimize mixing, a compromise tank design was devised. The bottom of the tank with a volume capacity of $\sim 1.5$ to $2.0 \mathrm{~L}$ was conical. At low volumes, the mixing assistance from the baffles was less than at larger volumes. Therefore, the need to rigorously maintain the 1:1 ratio was achieved in this section of the tank. In the cases where the tank waste slurry volumes were above $2 \mathrm{~L}$, the baffles combined with a down-sweeping mixer blade were shown to be sufficient to maintain a good mixing profile in the non-conical portion of the tank. The bottom of the conical section sloped toward the side to facilitate good subdivision of the samples.

Figure A.1 shows photographs of the homogenization vessel along with a schematic representation of its design. The Group 8 sample material was loaded into the vessel through a Tyler sieve mounted to the top of the vessel (see right side of Figure A.1). This was done so that no chunks of material greater than $3.2 \mathrm{~mm}$ in diameter were included in the composite, which was necessary for forming a uniform composite and protecting the crossflow ultra filtration (CUF) equipment during later testing. This vessel was used to composite several groups of tank samples. Extensive cleaning was done between each group with water, $0.01 \mathrm{M} \mathrm{NaOH}$, and 0.01 $\mathrm{M} \mathrm{HNO}_{3}$.

Before the actual tank waste samples were homogenized, non-radioactive testing of this system with various simulants was performed to establish the best operating conditions and procedures and to verify the uniformity of the sub-samples obtained with this tank. Simulants with high yield stress values (clay shown in Figure A.2) and simulants with the capability to settle rapidly (Min-u-sil shown in Figure A.3) were tested to verify that good mixing could be maintained and uniform sub-samples removed. Operating conditions and guidelines that resulted in a composite with homogeneous sub-samples of the most challenging simulants were then incorporated into the test instructions for the actual waste testing.

Clay simulants were prepared with high Bingham yield stresses and cohesive properties that would make them sticky. These consisted primarily of kaolin and bentonite clay mixtures. These simulants mixed well and delivered uniform samples while the homogenization vessel was tested (Figure A.2 left and center). However, they did leave a thick film of material coating the tank, mixer, and baffle surfaces (Figure A.2, right). In compositing the actual tank waste samples, solids materials with these characteristics would need to be recovered to support CUF testing with 
extra rinses of de-ionized (DI) water after completing homogenization and sub-sampling of the bulk material.
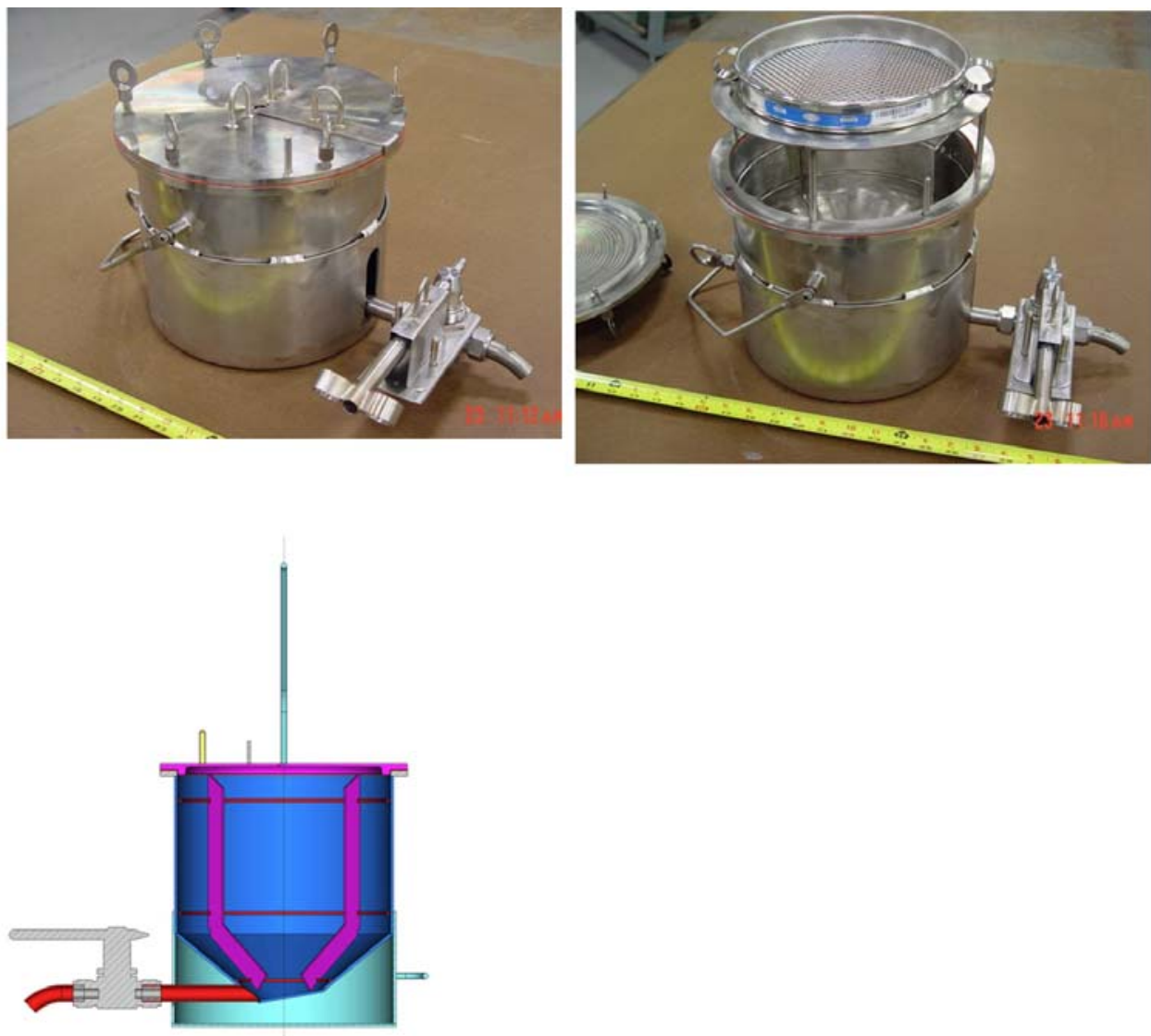

Figure A.1. Homogenization Vessel and Schematic Used to Prepare and Sub-Sample the Group 8 Composite Slurry
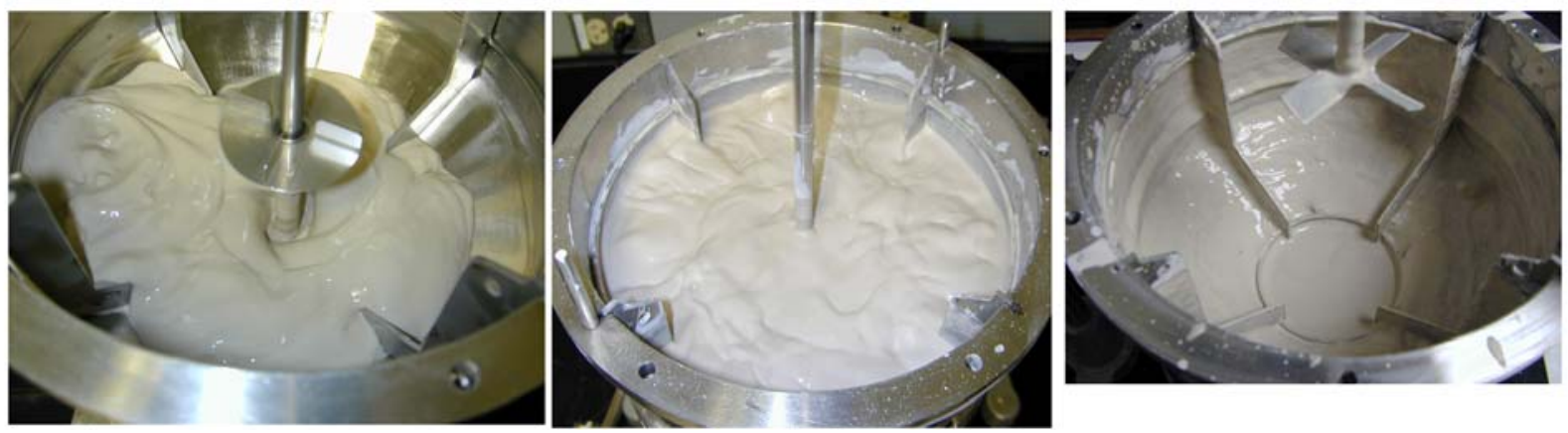

Figure A.2. Photographs of a High Yield Stress Clay Simulant in the Homogenization Vessel Used for Group 8

Min-u-sil-based simulants were used to test variable mixing speeds and propeller placement because of their tendency to settle swiftly when mixing is not sufficient. Figure A.3 shows that these simulant types could usually be cleanly and completely recovered from the tanks.

However, the sub-samples were often non-uniform with the Min-u-sil simulants. Figure A.4 
shows an example of non-uniform settling results for sub-samples taken when the mixer speed was too low. Based on these results, a hold point was inserted into the compositing test instructions such that after 3 days of settling, the settled solids of all the composite samples would be compared and statically analyzed to verify that good homogenization of the composite had been achieved and maintained during the sub-sampling process.

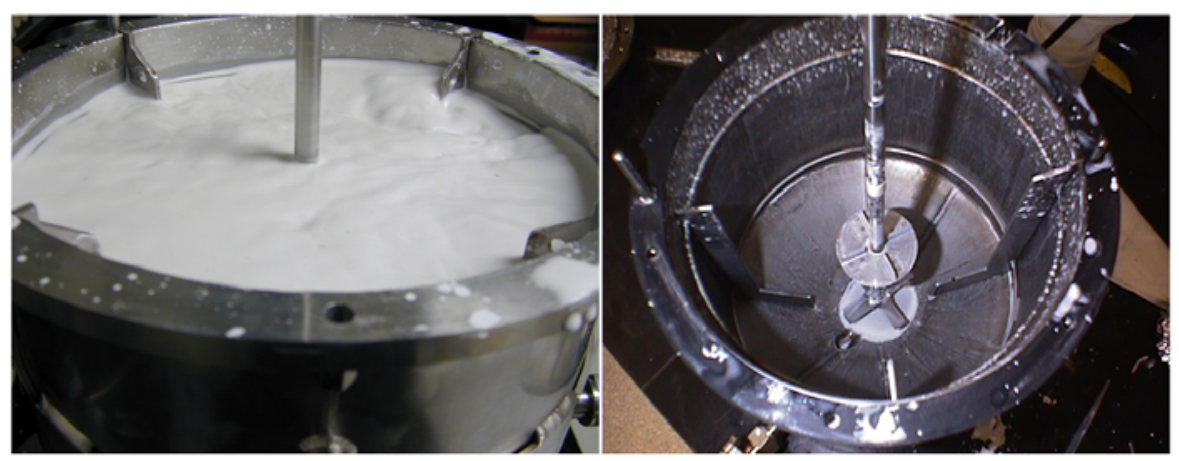

Figure A.3. Photographs of the Mixing of a Min-u-sil Simulant that Settles Rapidly in the Homogenization Vessel Used for Group 8 (left) and the Vessel After Draining of the Material (right)
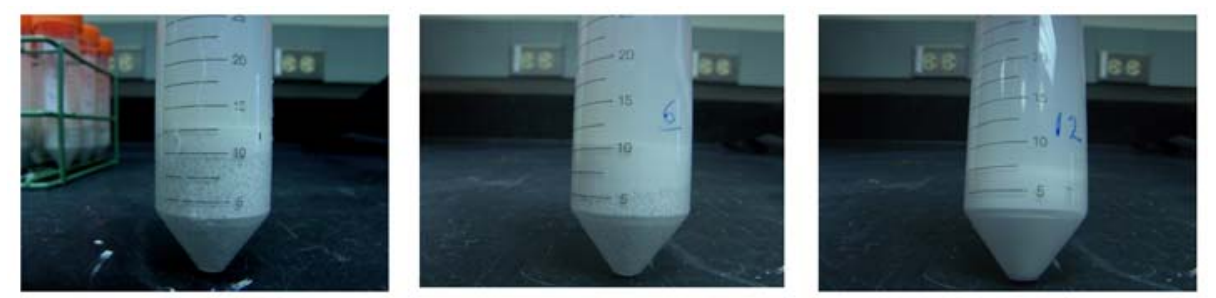

Figure A.4. Photographs of Three Different Sub-Samples Taken from the Homogenization Vessel During Non-Radioactive Testing with a Min-u-sil Simulant. Note the different degrees of settling, which indicates in-homogeneity in the slurry attributed to insufficient mixing during sampling. 

WTP-RPT-170, Rev. 0

Appendix B

\section{Analysis Methods}



WTP-RPT-170, Rev. 0

\section{Appendix B: Analysis Methods}

This section describes the methods used to determine the chemical and radiochemical composition of the sample slurries (Section B.1), crystal form and habit of the solids (Section B.2), physical properties, including density, wt $\%$ undissolved solids (UDS), etc. of the liquids and slurries, as appropriate (Section B.3), rheology (Section B.4), and particle-size attributes (Section B.5).

\section{B.1 Chemical and Radioisotope Characterization}

The following sections describe procedures used to support the chemical and radiochemical characterization of the solids and aqueous samples. Aqueous samples were distributed directly to the free-hydroxide, ion chromatrography (IC), and total inorganic carbon/total organic carbon (TIC/TOC) analytical workstations. The solids and liquids required a digestion step before distribution to the inductively coupled plasma-optical emission spectrometry (ICP-OES) and radiochemistry workstations.

\section{B.1.1 Free Hydroxide}

The free-hydroxide concentration was determined by potentiometric titration with standardized $\mathrm{HCl}$ according to procedure RPG-CMC-228, Determination of Hydroxyl $\left(\mathrm{OH}^{-}\right)$and Alkalinity of Aqueous Solutions, Leachates, and Supernates and Operation of Brinkman 636 Auto-Titrator. The free hydroxide was defined as the first inflection point on the titration curve. Quality control (QC) samples were generated at the analytical workstation and included a sample replicate determination, process blank, blank spike (BS), and matrix spike (MS).

\section{B.1.2 Anions}

Anions were determined by IC with a Dionix ICS-2500 IC system equipped with a conductivity detector according to procedure RPG-CMC-212, Determination of Common Anions by Ion Chromatography. Additional sample dilutions from $100 \times$ to $25,000 \times$ were required to accurately measure the analytes. QC samples were generated at the analytical workstation and included a sample replicate determination, process blank, BS, and MS.

\section{B.1.3 TIC/TOC}

The TIC was determined by applying silver-catalyzed hot persulfate (HP) oxidation according to procedure RPG-CMC-385, Carbon Measured in Solids, Sludge, and Liquid Matrices. The HP wet oxidation method was used. This method takes advantage of acid decomposition of the carbonate (TIC measure) followed by oxidation of organic carbon (TOC measure) with acidic potassium persulfate at 92 to $95^{\circ} \mathrm{C}$. QC samples were generated at the analytical workstation and included a sample replicate determination, process blank, BS, and MS.

\section{B.1.4 Acid Digestion}

Aqueous samples were digested with nitric and hydrochloric acids according to procedure PNL-ALO-128, $\mathrm{HNO}_{3}$-HCl Acid Extraction of Liquids for Metals Analysis Using a Dry-Block Heater. The acid-digested solutions were brought to a nominal $25-\mathrm{mL}$ volume (resulting in a nominal $25 \times$ dilution where the initial sample size was $1-\mathrm{mL}$ ); absolute volumes were determined based on final solution weights and densities. As part of the analytical preparation batch, the Analytical Support Operations 
(ASO) processed a digestion preparation blank (PB), a BS, and an MS. The spike solution contained a broad suite of stable elements; radionuclides were not included in the digestion preparation. Aliquots of the BS, MS, and PB, along with the sample aliquots, were delivered to the ICP-OES workstation for analysis; sample and PB aliquots were delivered to the radiochemical workstations for separations supporting specific radioisotope analysis.

\section{B.1.5 KOH Fusion}

The potassium hydroxide $(\mathrm{KOH})$ fusion was conducted in the shielded analytical facility (hot cells) according to PNL-ALO-115, Solubilization of Metals from Solids using $\mathrm{KOH}-\mathrm{KNO}_{3}$ Fusion. A nominal sample size of 0.1 to $0.2 \mathrm{~g}$ dry solids was combined with a $\mathrm{KOH} / \mathrm{KNO}_{3}$ flux mixture and fused at $550^{\circ} \mathrm{C}$ for $1 \mathrm{~h}$ in a nickel crucible. The fused material was acidified with $\mathrm{HNO}_{3}$, taken to a $100-\mathrm{mL}$ volume with de-ionized (DI) water, and then split for metals and radionuclide analysis. Samples were typically prepared in duplicate along with a fusion blank and a laboratory control sample (LCS) (SRM-2710, Montana Soil, purchased from the National Institute for Science and Technology [NIST]).

\section{B.1.6 HF-Assisted Acid Digestion}

The HF-assisted acid digestion was conducted in the shielded analytical facility (hot cells) according to PNL-ALO-138, $\mathrm{HNO}_{3}-\mathrm{HF}-\mathrm{HCl}$ Acid Digestion of Solids for Metals Analyses Using a Dry Block Heater. A nominal sample size of 0.1 to $0.2 \mathrm{~g}$ dry solids was contacted with a mixture of concentrated $\mathrm{HF}$ and $\mathrm{HNO}_{3}$ and evaporated to dryness in a Teflon ${ }^{\circledR}$ reaction tube. Concentrated $\mathrm{HCl}$ was then added, and the sample was evaporated to dryness a second time. Additional concentrated $\mathrm{HNO}_{3}$ and $\mathrm{HCl}$ were added, the reaction tube was capped tightly, and the mixture was heated in a dry-block heater at $95^{\circ} \mathrm{C}$ for $6.5 \mathrm{~h}$. The digestate was cooled, brought to a $50-\mathrm{mL}$ volume, and then split for metals analysis. The sample was prepared in duplicate along with a fusion blank and an LCS (SRM-2710, Montana Soil).

\section{B.1.7 Metals Analysis by ICP-OES}

Metals were measured by ICP-OES according to procedure RPG-CMC-211, Determination of Elemental Composition by Inductively Coupled Argon Plasma Optical Emission Spectrometry (ICPOES). The preparative QC samples (duplicate, $\mathrm{PB}, \mathrm{BS}, \mathrm{MS}$ ) were processed along with analytical workstation QC (post-digestion spike and serial dilution).

\section{B.1.8 U (KPA)}

Uranium was determined directly from solids samples prepared by $\mathrm{KOH}$ fusion and from aqueous samples prepared by acid digestion. Analysis was conducted with a Chem Chek Instruments KPA according to procedure RPG-CMC-4014, Rev. 1, Uranium by Kinetic Phosphorescence Analysis. The LCS did not contain U, so preparative QC was limited to the duplicate and PB. A post-digestion spike was conducted at the analytical workstation.

\section{B.1.9 Gamma Energy Analysis}

Gamma energy analysis was performed with direct or diluted samples that were prepared from acid digestion, fusion, or neat (direct or straight dilution). Sample counting was conducted according to procedure RPG-CMC-450, Gamma Energy Analysis (GEA) and Low-Energy Photon Spectroscopy (LEPS), using high-purity germanium detectors. Extended count times (up to $20 \mathrm{~h}$ ) were employed as needed to achieve low detection limits. In many cases, the Compton background from the high ${ }^{137} \mathrm{Cs}$ 
activity $(661 \mathrm{keV})$ limited the achievable detection limit of lower energy gamma emitters (e.g., ${ }^{241} \mathrm{Am}$ at $59 \mathrm{keV}$ ). The QC associated with the GEA analysis was composed of the sample duplicate and PB; because this is a direct analysis, no additional QC samples were required.

\section{B.1.10 Gross Alpha and Gross Beta}

The gross-alpha and beta activities were measured from aqueous samples prepared by acid-digestion, and washed-solids samples were prepared by $\mathrm{KOH} / \mathrm{KNO}_{3}$ fusion. Prepared sample aliquots were plated directly onto stainless steel planchets according to procedure RPG-CMC-4001, Source Preparation for Gross Alpha and Gross Beta Analysis. The mounts prepared for gross-alpha analysis were counted with Ludlum alpha scintillation counters. The gross-alpha analysis tends to be confounded by the dissolved solids in the sample matrix. The solids can absorb the alpha particles, decreasing the intensity relative to the detector, which biases the results low. The sources prepared for gross-beta analysis were counted with an LB4100 gas-proportional counter. In both cases, counting operations were conducted according to procedure RPG-CMC-408, Rev.1, Total Alpha and Total Beta Analysis. The preparative QC included the sample duplicates and the PB. The BS and MS were prepared at the analytical workstation on sample dilutions.

\section{B.1.11 Pu Isotopes: ${ }^{238} \mathrm{Pu}$ and ${ }^{239+240} \mathrm{Pu}$}

The ${ }^{238} \mathrm{Pu}$ and ${ }^{239+240} \mathrm{Pu}$ activities were measured from aqueous samples prepared by acid-digestion, and washed solids samples were prepared by $\mathrm{KOH} / \mathrm{KNO}_{3}$ fusion. Radiochemical separations were conducted according to procedure RPG-CMC-4017, Analysis of Environmental Water Samples for Actinides and Strontium-90 (analyte purification using ion exchange); source preparation was conducted according to RPG-CMC-496, Coprecipitation Mounting of Actinides for Alpha Spectroscopy (co-precipitation of $\mathrm{PuF}_{3}$ with $\mathrm{LaF}_{3}$ ); and alpha counting was conducted according to RPG-CMC-422, Rev.1, Solutions Analysis: Alpha Spectrometry. The preparative QC included the sample duplicates and the PB. The BS and MS were prepared at the analytical workstation on sample dilutions.

\section{B.1.12 Strontium-90}

The ${ }^{90} \mathrm{Sr}$ activities were measured from aqueous samples prepared by acid-digestion, and washed-solids samples were prepared by $\mathrm{KOH} / \mathrm{KNO}_{3}$ fusion. Radiochemical separation was conducted according to procedure RPG-CMC-476, Strontium-90 Separation Using Eichrom Strontium Resin; source preparation and beta counting were conducted according RPG-CMC-474, Measurement of Alpha and Beta Activity by Liquid Scintillation Spectrometry.

\section{B.2 Crystal Form and Habit}

This section describes the methods used to determine the crystal forms and habits of the tank solid samples. The solids crystal characteristics were determined on small aliquots of the solids. In all cases, the solids sample fractions were allowed to air dry at room temperature in preparation for analysis. This effort was intended to minimize morphological changes that might occur upon heating. The methods applied for X-ray diffraction (XRD), scanning electron microscopy (SEM), and transmission electron microscopy (TEM) evaluations are discussed in the following sections. 
WTP-RPT-170, Rev. 0

\section{B.2.1 X-Ray Diffraction}

The sample mounts for XRD examination were prepared from the dried solids according to procedure RPL-PIP-4, Preparing Sealed Radioactive Samples for XRD and Other Purposes. Specimens were pulverized to a powder with a boron carbide mortar and pestle, mixed with an internal standard (rutile, $\mathrm{TiO}_{2}$, or alumina, $\mathrm{Al}_{2} \mathrm{O}_{3}$ ), and mounted on a glass slide. In some cases, the internal standard was omitted to provide better clarity of the sample diffraction pattern free from potential interference from the internal standard diffraction pattern. The XRD examination was conducted according to procedure PNNL-RPG268, Solids Analysis, X-Ray Diffraction Using RGD \#34. The XRD instrument used for these samples was the Pacific Northwest National Laboratory Scintag PAD V XRD, property number WB81320. Process parameters included examination of the X-ray 2-theta range from 5 to 65 degrees with a step size of 0.02 degrees and a dwell time of 20 seconds. Copper K $\alpha$ X-rays were used. X-ray tube running conditions were $45 \mathrm{kV}$ and $40 \mathrm{~mA}$.

Phase identification was performed with JADE, Version 8.0.10 (Materials Data Inc., Livermore, CA, 2006) software search and peak match routines with comparison to the International Centre for Diffraction Data (ICDD) database PDF-2, Version 2.0704 (2007). The ICDD database included the Inorganic Crystal Structure Database (ICSD) maintained by Fachinformationszentrum, Karlsuhe, Germany. Phase identification incorporated chemistry restrictions based on the elements determined from chemical analysis.

Initial phase identification was conducted with no chemistry restrictions. Further examinations were conducted with oxygen required and with the elemental restrictions (major components identified in Table 3.6) as possible but not required. Subsequent passes were done with one of the identified major components (plus oxygen) required and the rest of the analytes possibly present. Searches were restricted to the PDF-2 and ICSD Inorganic sections.

\section{B.2.2 Scanning Electron Microscopy}

A small sample was transferred with a wooden Q-tip stem onto carbon tape supported by an aluminum pedestal mount. The sample was analyzed with the radiation-shielded Amray Model 1610T SEM according to RPL-611A-SEM, Scanning Electron Microscope Examinations. In selected cases, the mount was carbon-coated. Selected sample areas were evaluated by X-ray energy dispersive spectroscopy (EDS) for qualitative elemental composition.

\section{B.2.3 Transmission Electron Microscopy}

The TEM samples were prepared in a two-step methanol rinsing process. A small amount of the sludge slurry was mixed and transferred into methanol; a drop of the methanol slurry was transferred into a second vial containing methanol; then a drop of this second solution was deposited onto a lacey carbon TEM grid. The particles were air-dried on the lacey grid. Note that the sample drying process may have induced changes in the morphology of the particle agglomerates. However, the objective of the TEM investigation was to look at the fundamental characteristics and sizes of individual particle crystallites that are not dependent on drying effects.

Initial analysis, including the electron energy-loss analysis, was performed at the Harry Reid Center for Environmental Studies, University of Las Vegas, Nevada, on the FEI Tecnai $\mathrm{G}^{2}-30 \mathrm{~F}$ Field Emission transmission electron microscope (FEI Inc., Hillsboro, OR) operated at $300 \mathrm{keV}$. Samples were analyzed 
according to procedure TTQP-3-022, Rev. 4, Optical, Scanning, and Transmission Electron Microscope Examinations. Particles were examined with a combination of scanning transmission electron microscopy (STEM) and high-angle annular dark field (HAADF) imaging, EDS analysis, and electron energy-loss spectroscopy (EELS) and energy filtering TEM (EFTEM) imaging. Further observations were performed on an FEI Tecnai 30S-Twin at the Radiochemical Processing Laboratory at Pacific Northwest National Laboratory (PNNL) operated at $300 \mathrm{keV}$. Analysis was performed by identifying the composition with EDS and selected area electron diffraction (SAED). Images and diffraction patterns were obtained with a Gatan ORIUS digital camera. All EDS analyses were obtained with the holder tilted towards the X-ray detector by $15^{\circ}$.

\section{B.2.4 Electron Energy-Loss Spectroscopy and Imaging}

The EELS spectra were obtained with a $0.6-\mathrm{mm}$ entrance aperture and an energy dispersion of $0.1 \mathrm{eV} /$ channel. Low-loss spectra (including the zero loss peak) were acquired with an integration time of $<0.2 \mathrm{~s}$ and core-loss spectra between 2 and $5 \mathrm{~s}$. To reduce potential beam reduction, the acquisition time was kept as small as possible. The spectra were collected in the imaging mode of the transmission electron microscope and were corrected for dark current and channel-to-channel gain variation of the charge coupled device (CCD) detector.

The core-loss regime was energy calibrated, and the energy drift was measured while data were being acquired by collecting zero-loss spectra before or after core-loss spectra were collected. The position of the C-K (1s) peak at $284 \mathrm{eV}$ (arising from transitions to the $\pi^{*}$ molecular orbital) from the TEM lacy carbon support film was used to evaluate the energy calibration and as a means of roughly checking that the energy resolution was sufficient for collecting data.

\section{B.3 Physical Properties: Settling, Density, Slurry Solid Measurements}

The physical-property characterizations (settling curve, wt $\%$ UDS and $\mathrm{w} t \%$ centrifuged solids) were conducted according to procedure RPL-COLLOID-02, Rev. 1, Measurement of Physical and Rheological Properties of Solutions, Slurries and Sludges, which is consistent with the Waste Treatment and Immobilization Plant (WTP) guidelines document. ${ }^{\text {(a) }}$ Initial characterization sample sizes were generally between 8 and $9 \mathrm{~g}$ and were collected in 10-mL volume-graduated, glass, centrifuge tubes (KimbleKontes product number 45200-10). The physical-property characterization samples during crossflow ultrafiltration (CUF) testing were generally between 10 and $15 \mathrm{~g}$ and were collected in $15-\mathrm{mL}$ volumegraduated, glass, centrifuge tubes (Kimble-Kontes product number 45166-15).

Settling studies were conducted at ambient temperature by thoroughly agitating the samples and then allowing the solids to settle by gravity with periodic measurement of the settled-solids volume. The sample tubes were undisturbed over the 72-h settling period.

The samples were centrifuged at $\sim 1000 \mathrm{G}$ for $1 \mathrm{~h}$. The total sample volume and solids volume were recorded to assess the vol\% wet centrifuged solids (WCS). The supernatants were decanted from the centrifuged solids, transferred to tared graduated cylinders, and measured for mass and volume. The supernatants were then transferred to tared glass vials and dried in the oven, along with the slurry solids in the centrifuge cones at $\sim 80^{\circ} \mathrm{C}$ until visibly dry, and then at $105^{\circ} \mathrm{C}$. Once the samples reached constant

(a) 24590-WTP-GPG-RTD-001, Rev 0, "Guidelines for Performing Chemical, Physical, and Rheological Properties Measurements," G. L. Smith and K. Prindiville, May 2002. 
mass, the collected data were processed as described by Smith and Prindville ${ }^{(a)}$ to determine the volume and weight percent of wet solids (total, settled, and centrifuged), densities, total UDS, dissolved solids, and centrifuge solids content of the slurry.

Densities were also obtained from the Coriolis densitometers during CUF processing for indication only. Densities were determined in the characterization sample solution from replicate mass measures of 1-mL pipetted volume deliveries. The pipet was performance-checked daily before each use. The densities determined from the $1-\mathrm{mL}$ volume deliveries were reportable to the most (four) significant figures.

\section{B.4 Physical Properties: Rheology Measurements}

Rheological testing was conducted on the solids in contact with the supernatant generated as part of the homogenization process. Testing was conducted according to RPL-COLLIOD-02, Measurement of Physical and Rheological Properties of Solutions, Slurries and Sludges. For the current study, two regions of tank waste flow behavior are considered: 1) incipient motion in settled tank waste solids (shear strength) and 2) non-elastic flow of tank waste slurries and supernates (flow curve).

\section{B.4.1 Shear-Strength Testing}

For tank waste slurries, a finite stress must be applied before the material will begin to flow. The stress required to transition the material from elastic deformation to viscous flow is referred to as the shear strength, and its origin can be attributed to static and kinetic friction between individual particles and/or aggregates, the strength of the matrix supporting the coarse fraction (i.e., the interstitial fluid), and sludge cohesion arising from interparticle adhesive forces such as van der Waals forces.

The shear strength was measured using the vane method. For the vane technique, the stress required to begin motion is determined by slowly rotating a vane immersed in the test sample's settled solids while continuously monitoring the resisting torque as a function of time. A material's static shear strength is then associated with the maximum torque measured during the transition from initial to steady-state vane rotation.

The maximum torque required for incipient motion is dependent on vane geometry. To account for vanegeometry effects, the shear strength is expressed in terms of the uniform and isotropic stress acting over the surface area of the cylinder of rotation swept out by the vane. The shear strength is related to the maximal torque during incipient motion according to Equation B.1 (Barnes and Dzuy 2001):

$$
\tau_{S S}=\frac{M_{\max }}{4 \pi R^{3}\left(\frac{H}{2 R}+\frac{1}{3}\right)}
$$

Here, $\tau_{s s}$ is the shear strength $\left(\mathrm{N} / \mathrm{m}^{2}\right), M_{\max }$ is the maximum torque $(\mathrm{N} \cdot \mathrm{m})$, and $R$ and $H$ are the radius and height of the cylinder of rotation swept out by the vane $(\mathrm{m})$. Because the shear band observed upon slow rotation of the vane does not extend appreciably beyond the vane paddles, $R$ and $H$ are taken to be the dimensions of the vane itself. 
The proximity of the vane to the sample container inner surfaces as well as the free surface of the settled solids can impact shear-strength results. As such, certain geometric constraints must be satisfied for the test to be considered independent of container geometry. These constraints are outlined in Table B.1.

Table B.1. Vane Immersion Depth and Container Geometry Constraints for Shear-Strength Tests Using the Vane Technique

\begin{tabular}{||l|l|l||}
\hline \hline Constraint & Criterion & For $8 \times 16 \mathbf{m m}(\mathbf{R} \times \mathbf{H})$ Vane \\
\hline Vane height to radius & $\mathrm{H}<7 \mathrm{R}$ & $\mathrm{H}<56 \mathrm{~mm}$ (Satisfied) \\
\hline Container radius to vane radius & $\mathrm{R}_{\text {cont }}>2 \mathrm{R}$ & $\mathrm{R}_{\text {cont }}>16 \mathrm{~mm}$ \\
\hline Immersion depth to vane height & $\mathrm{h}>\mathrm{H}$ & $\mathrm{h}>16 \mathrm{~mm}$ \\
\hline $\begin{array}{l}\text { Separation between bottom of vane and } \\
\text { container floor }\left(\mathrm{h}_{\text {floor }}\right)\end{array}$ & $\mathrm{h}_{\text {floor }}>0.5 \mathrm{H}$ & $\mathrm{h}_{\text {floor }}>8 \mathrm{~mm}$ \\
\hline $\begin{array}{l}\mathrm{R}=\text { radius } \\
\mathrm{H}=\text { height }\end{array}$ & \\
\hline
\end{tabular}

\section{B.4.2 Flow-Curve Testing}

The non-elastic flow of tank waste slurries and supernates is characterized with rotational viscometry. The typical result of such testing is a set of flow-curve data, which shows the stress response of a material to a range of applied rates-of-deformation. Specifically, flow-curve testing allows characterization of a material's shear stress, $\tau$, which is the response as a function of applied shear rate, $\dot{\gamma}$. Once measured, the flow-curve data can be interpreted with several constitutive equations for the viscous stress/rate-ofstrain relationship. Such analysis allows the flow behavior over a broad range of conditions to be described with just a few rheological descriptors such as viscosity, yield stress, consistency, and flow index.

A concentric cylinder rotational viscometer operated in controlled-rate mode was used for flow-curve testing of tank waste slurries and supernates. Rotational viscometers operate by placing a given volume of test sample into a measurement cup of known geometry. A cylindrical rotor attached to a torque sensor is then lowered into the sample until the slurry is even with, but does not cover, the top of the rotor. A single-point determination of a fluid's flow properties is made by spinning a rotor at a known rotational speed, $\Omega$, and measuring the resisting torque, $M$, acting on the rotor. The torque acting on the rotor can be directly related to the shear stress at the rotor using the equation,

$$
\tau=\frac{M}{2 \pi H R_{I}^{2}}
$$

The shear stress has units of force per area $\left(\mathrm{N} / \mathrm{m}^{2}\right)$. The rotational rate is related to the shear rate. However, calculating the fluid shear rate at the rotor is complicated by the fact that shear rate depends on both the measurement-system geometry and the fluid rheological properties. For the simplest fluids (i.e., Newtonian fluids), the shear rate of the fluid at the rotor can be calculated given the geometry of the cup rotor shear by using the equation, 
WTP-RPT-170, Rev. 0

$$
\dot{\gamma}=\left(\frac{2 R_{O}^{2}}{R_{O}^{2}-R_{I}^{2}}\right) \Omega
$$

Here, the shear rate has units of inverse seconds $\left(\mathrm{s}^{-1}\right)$. Calculating the shear rate for materials showing more complex shear-stress versus shear-rate behavior (i.e., non-Newtonian fluids) requires estimates of yield stress and a degree of shear-thinning or shear-thickening. As the goal of rheological testing is to determine and quantify such behavior, these values are typically not known. This requirement can be circumvented by using a cup-and-rotor system with a small gap $(\sim 1 \mathrm{~mm})$ for fluid shear. For fluid flow in small-gap cup and rotor systems, shear-rate effects introduced by fluid properties are minimized such that Equation B.3 provides an accurate determination of shear rate for non-Newtonian materials. Shear rates examined in this study spanned the range from 1 to $1000 \mathrm{~s}^{-1}$.

The resistance of a fluid to flow is often described in terms of the fluid's apparent viscosity, $\eta_{a p p}$, which is defined as the ratio of the shear stress to the shear rate:

$$
\eta_{\text {app }}=\frac{\tau}{\dot{\gamma}}
$$

For Newtonian fluids, the apparent viscosity is independent of the shear rate. For non-Newtonian fluids, the apparent viscosity will vary as a function of the shear rate. The unit of apparent viscosity is $\mathrm{Pa} \cdot \mathrm{s}$, although it is typically reported in the unit of centipoise $(\mathrm{cP}$; where $1 \mathrm{cP}=1 \mathrm{mPa} \cdot \mathrm{s})$.

Flow-curve data are usually combined plots of $\tau$ and $\eta_{\text {app }}$ as a function of $\dot{\gamma}$. As stated above, flow-curve data can be interpreted with several constitutive equations (i.e., flow curves), allowing characterization of that data with just a few rheological descriptors. The behavior of tank waste sludges, slurries, and supernates can be described by four common flow-curve equations:

- Newtonian-Newtonian fluids flow as a result of any applied stress and show constant viscosity over all shear conditions. The flow curve for Newtonian fluids is,

$$
\tau=\eta \dot{\gamma}
$$

where $\eta$ is the Newtonian viscosity.

- Ostwald (Power Law) - Power-law fluids flow as a result of any applied stress and have viscosities that either increase or decrease with increasing shear rate. They are described by,

$$
\tau=m \dot{\gamma}^{n}
$$

where $m$ is the power-law consistency index, and $n$ is the power-law index. Power-law fluids with $n<1$ are referred to as pseudoplastic (shear-thinning), whereas power-law fluids with $n>1$ are referred to as dilatant (shear-thickening). 
- Bingham Plastic - Bingham plastics are fluids that show finite yield points. A finite stress (i.e., the yield stress), must be exceeded before these types of materials flow. Once flow is initiated, the stress response of the material is Newtonian over the rest of the shear-rate range. Bingham plastics are described by

$$
\tau=\tau_{O}^{B}+k_{B} \dot{\gamma}
$$

where $\tau_{O}^{B}$ is the Bingham yield index, and $k_{B}$ is the Bingham consistency index.

- Herschel-Bulkley -Fluids that behave in accordance with a Herschel-Bulkley model show a finite yield followed by power-law behavior over the rest of the shear-rate range. They are described by

$$
\tau=\tau_{O}^{H}+k_{H} \dot{\gamma}^{b}
$$

where $\tau_{O}^{H}$ is the Herschel-Bulkley yield index, $k_{H}$ is the Herschel-Bulkley consistency index, and b is the Herschel-Bulkley power-law index.

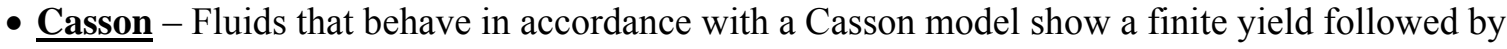
pseudoplastic behavior. They are described by,

$$
(\tau)^{0.5}=\left(\tau_{o}^{C}\right)^{0.5}+\left(k_{C} \dot{\gamma}\right)^{0.5}
$$

where $\tau_{o}^{C}$ is the Casson yield index, and $k_{C}$ is the Casson consistency index. Although more limited in the types of flow behavior that it can describe relative to the Herschel-Bulkley equation, the Casson model is popular because it is capable of accurately describing many shear-thinning fluids and because units on the parameters are more physically meaningful (e.g., the consistency is in $\mathrm{Pa} \cdot \mathrm{s}$ versus $\mathrm{Pa} \cdot \mathrm{s}^{\mathrm{n}}$ for the Herschel-Bulkley model).

Power-law fluids, Bingham plastics, Herschel-Bulkley, and Casson fluids are referred to as nonNewtonian fluids. In generally, liquids without internal and/or interconnected structures (such as tank waste supernatants) are Newtonian. Sludges and slurries are typically non-Newtonian, but their exact behavior depends on the concentration of solids and suspending phase chemistry. Sufficiently dilute slurries may show Newtonian behavior.

\section{B.4.3 Rheology Instrumentation}

Rheological characterization was accomplished using a Rotovisco ${ }^{\circ}$ RV20 Measuring System M equipped with an M5 measuring head and RC20 controller sold by HAAKE Mess-Technik GmbH u Co. (now the Thermo Electron Corporation). The M5 measuring head is a "Searle" type viscometer capable of producing rotational speeds up to $500 \mathrm{RPM}$ and measuring torques up to $0.049 \mathrm{~N} \cdot \mathrm{m}$. The minimum rotational speed and torque resolution achievable by this measuring head are $0.05 \mathrm{RPM}$ and $0.49 \mathrm{mN} \cdot \mathrm{m}$, respectively. 
Specific measurement tools, such as cup-and-rotor assemblies and shear vanes, are attached to measure selected rheological properties. Shear-strength measurements employ an $8 \mathrm{~mm} \times 16 \mathrm{~mm}(\mathrm{R} \times \mathrm{H})$ shear vane tool. Flow-curve measurements employed an MV1 stainless steel measuring cup and rotor. The dimensions of the MV1 and vane measuring systems are listed in Table B.2.

Table B.2. Vane and Cup and Rotor Measuring System Dimensions

\begin{tabular}{|l|c|c|c|c||}
\hline Measuring System & $\begin{array}{c}\text { Vane/Rotor Radius } \\
(\mathbf{m m})\end{array}$ & $\begin{array}{c}\text { Vane/Rotor Height } \\
(\mathbf{m m})\end{array}$ & $\begin{array}{c}\text { Cup Radius } \\
(\mathbf{m m})\end{array}$ & $\begin{array}{c}\text { Gap Width } \\
(\mathbf{m m})\end{array}$ \\
\hline Vane Tool & 8 & 16 & $>16^{(\text {a) }}$ & $>8^{(\text {a) }}$ \\
\hline MV1 & 20.04 & 60 & 21 & 0.96 \\
\hline (a) Vane tests must satisfy the requirements outlined in Table B.1. \\
\hline
\end{tabular}

The temperature is controlled with a combination of the standard measuring system temperature jacket and a temperature-controlled recirculator. The jacket temperature is monitored using a Type-K thermocouple calibrated over $0^{\circ}$ to $100^{\circ} \mathrm{C}$ and connected to a calibrated multichannel temperature display. The temperature control is employed only for flow-curve measurements. Shear-strength measurements are carried out at ambient cell temperature.

For measuring the Group 8 initial characterization slurry (sample TI516-G8-AR-P1), the calibrated thermocouple attached to the water jacket failed immediately before testing. Although the target temperature could still be set and monitored at the heated recirculator control interface, the temperature device monitoring the recirculator temperature was not calibrated. As a result, appropriate control of the sample temperature could not be verified for Group 8 initial characterization flow-curve measurements. The data and results derived for sample TI516-G8-AR-P1 flow curves are considered "For Information Only." Additional details are provided in NCR 38963.1. Shear-strength measurement of Group 8 settled solids was not affected by failure of the jacket thermocouple because the ambient in-cell temperature recorded for shear-strength testing was based on the calibrated thermocouple attached to the CUF slurry reservoir.

The rheometer was controlled and data were acquired with a remote computer connection using the RheoWin Pro Job Manager Software, Version 2.96. During measurement, the software automatically collects and converts rotor torque readings into shear stresses based on Equation B.1 (for vane testing) or Equation B.2 (for flow-curve testing). Likewise, the software also automatically converts the rotational rate readings into shear rates based on Equation B.3.

\section{B.4.4 Rheology Materials and Methods}

No sample treatment was performed before analysis with the exception of the mechanical agitation required to mix and sub-sample selected waste jars.

\section{Shear-Strength Testing}

Before testing, the tank waste slurries that were provided for shear-strength testing were mixed thoroughly and subsequently allowed to settle for at least 48 to $72 \mathrm{~h}$. When possible, the shear strength was measured by immersing the $8-\times 16-\mathrm{mm}$ vane tool to a depth of $15 \mathrm{~mm}$ into the settled solids. The 
WTP-RPT-170, Rev. 0

vane was slowly rotated at $0.3 \mathrm{RPM}$ for $180 \mathrm{~s}$. For the entire duration of rotation, the time, rotational rate, and vane torque were continuously monitored and recorded. At the end of the measurement, shear stress versus time data were parsed, and the maximum measured shear stress (i.e., the material's shear strength) was determined.

\section{Flow-Curve Testing}

Each flow curve was measured over a 15-min period and split into three 5-min intervals. Over the first $5 \mathrm{~min}$, the shear rate was smoothly increased from zero to $1000 \mathrm{~s}^{-1}$. For the second $5 \mathrm{~min}$, the shear rate was held constant at $1000 \mathrm{~s}^{-1}$. For the final $5 \mathrm{~min}$, the shear rate was smoothly reduced back to zero. During this time, the resisting torque and rotational rate were continuously monitored and recorded.

Before each test, the sample was left undisturbed in the measuring system for $5 \mathrm{~min}$ to allow temperature equilibration. The sample was then sheared at 200 RPM for 3 min using the MV1 measuring system rotor in an attempt to re-disperse any settled solids and to pre-shear slurries before measurement.

Flow-curve tests were run at 25,40 , and $60^{\circ} \mathrm{C}$. Because of limited sample volume, all three temperature tests were performed on the same sample. Two flow-curve measurements, an initial and replicate measurement, were performed at $25^{\circ} \mathrm{C}$ to assess reproducibility. To combat the effects of sample evaporation, a moisture barrier was installed over the opening at the top of the temperature jacket during testing, and after each test, the cup was raised so that fresh sludge/slurry filled the measurement gap.

\section{B.5 Physical Properties: Particle-Size Attributes}

Particle attributes, including size distribution and surface area, are discussed in the following sections.

\section{B.5.1 Particle-Size Distribution}

Particle sizes were characterized according to procedure RPL-COLLOID-01, Rev. 1, Particle Size Analysis Using Malvern MS2000. This procedure uses a Mastersizer 2000 (Malvern Instruments, Inc., Southborough, MA 01772 USA) with a Hydro $\mu$ P wet dispersion accessory. Malvern lists the Mastersizer particle-size measurement range as nominally 0.02 to $2000 \mu \mathrm{m}$. The actual particle-size distribution (PSD) measurement range is dependent on the accessory used as well as the properties of the solids being analyzed. When coupled with the Hydro $\mu \mathrm{P}$ wet dispersion accessory, the nominal listed measuring range is reduced to 0.02 to $150 \mu \mathrm{m}$. The Malvern 2000 uses laser diffraction technology to define PSD.

The Hydro $\mu \mathrm{P}$ wet-dispersion accessory consisted of a $20-\mathrm{mL}$ sample flow cell with a continuous variable and independent pump and ultrasound. Both flow and sonication can be controlled and altered during measurement. PSD measurements can be made before, during, and after sonication, allowing the influence of each on the sample PSD to be determined. It should be noted that the dispersion unit's sonication capability was not functioning at the time the standard or sample measurements were taken. As such, only "before sonication" data are available. The primary measurement functions of the Malvern analyzer were controlled through Mastersizer 2000 software, Version 5.1 (Malvern Instruments, Ltd. Copyright $^{\mathcal{O}}$ 1998-2002). The optical properties applied to the test samples are summarized in Table B.3.

The PSD measurements were conducted on the washed solids in a $0.01-\mathrm{M} \mathrm{NaOH}$ dispersion solution matrix. The sample dispersion was added drop-wise to the instrument (while the pump was active) until 
an $\sim 10 \%$ obscuration was reached. For all samples, less than $10 \mathrm{mg}$ of solids was required to reach the desired obscuration in the $20-\mathrm{mL}$ flow cell.

Table B.3. Optical Properties Applied To Group 8 Test Materials

\begin{tabular}{||c|c|c|c||}
\hline Sample Name & $\begin{array}{c}\text { Material Selected for } \\
\text { Optical Properties }\end{array}$ & $\begin{array}{c}\text { Refractive } \\
\text { Index (RI) }\end{array}$ & Absorption \\
\hline TI609-G8-S-WL-PSD-1 & Boehmite & 1.655 & 1.0 \\
\hline TI609-G8-S-WL-PSD-2 & Boehmite & 1.655 & 1.0 \\
\hline TI640-G8-3-PSD & Boehmite & 1.655 & 1.0 \\
\hline TI640-G8-6-PSD & Boehmite & 1.655 & 1.0 \\
\hline TI640-G8-13-PSD & Boehmite & 1.655 & 1.0 \\
\hline Suspending Phase & Water & 1.33 & $\mathrm{n} / \mathrm{a}$ \\
\hline
\end{tabular}

The size distributions of particles were measured under varying flow conditions without sonication. A typical test matrix is shown in Table B.4. For each condition, three successive 12-s measurements of PSD were taken. The analyzer software then generated an average of these measurements. Both the individual measurement and average were saved to the analyzer data file. Once measurements were complete, the next condition was set, the sample was given 30 to 60 seconds to equilibrate, and the next set of measurements was taken.

Table B.4. Prototypic Particle-Size Analysis Test Matrix

\begin{tabular}{||c|c|c|c||}
\hline \hline Condition No. & $\begin{array}{c}\text { Pump Speed } \\
\text { (RPM) }\end{array}$ & Sonic Power & Comment \\
\hline 1 & 3000 & $\mathrm{n} / \mathrm{a}$ & no sonication \\
\hline 2 & 4000 & $\mathrm{n} / \mathrm{a}$ & no sonication \\
\hline 3 & 2000 & $\mathrm{n} / \mathrm{a}$ & no sonication \\
\hline 4 & 2000 & $\mathrm{n} / \mathrm{a}$ & no sonication \\
\hline
\end{tabular}

\section{B.5.2 Surface Area-Brunauer, Emmett, and Teller (BET)}

In an effort to minimize sample solidification into a monolith upon drying, solid samples were rinsed twice with ethanol and twice again with ethyl ether according to procedure TPR-RPP-WTP-486, Procedure for BET Sample Preparation Using Ethanol and Ethyl Ether as Drying Agents. Each rinse was conducted in a centrifuge tube. The solids were well suspended in the rinse solution, and then the phases were separated by centrifuging and decanting. The final ethyl ether rinse was used to transfer the solids slurry to the sample cell. The ethyl ether was then evaporated at room temperature directly from the sample cell.

The sample was further dried and out-gassed using the Quantachrome Instruments Monosorb Model MS-21 (Boynton Beach, FL) outgassing station. This entailed pre-flushing nitrogen through the sample cell for $\sim 10 \mathrm{~min}$ and then heating and flushing for overnight $(>10 \mathrm{~h})$ at $110^{\circ} \mathrm{C}$. 
The surface-area measurements were conducted according to OCRWM-BET-01, Surface Area Measurement with a Monosorb Gas Analyzer, which is consistent with American Society for Testing and Materials (ASTM) method D5604-96, Test Method B (Single-Point Surface Area by Flowing Gas Apparatus). The flow gas used in the measurement mode was composed of $30 \%$ nitrogen in helium. The system was calibrated per manufacturer instructions. The system performance was assessed using a 29.9 $\pm 0.75 \mathrm{~m}^{2} / \mathrm{g}$ carbon surface area standard Lot D-6 obtained from Micromeritics Instrument Corporation (Norcross, GA). 

WTP-RPT-170, Rev. 0

Appendix C

\section{Quality Assurance and Quality Control}



WTP-RPT-170, Rev. 0

\section{Appendix C: Quality Assurance and Quality Control}

This appendix describes the quality assurance (QA) program and quality control (QC) measures applied to the conduct of work.

\section{C.1 Application of Waste Treatment Plant Support Project QA Requirements}

Pacific Northwest National Laboratory's (PNNL's) QA program is based on requirements defined in DOE Order 414.1C, Quality Assurance, and 10 CFR 830, Energy/Nuclear Safety Management, Subpart A-Quality Assurance Requirements (a.k.a., the Quality Rule). PNNL has chosen to implement the requirements of DOE Order 414.1C and 10 CFR 830, Subpart A by integrating them into the laboratory's management systems and daily operating processes. The procedures necessary to implement the requirements are documented through PNNL’s Standards-Based Management System.

PNNL implemented the RPP-WTP quality requirements by performing work in accordance with the River Protection Project - Waste Treatment Plant Support Program (RPP-WTP) Quality Assurance Plan (RPPWTP-QA-001, QAP). Work was performed to the quality requirements of NQA-1-1989 Part I, Basic and Supplementary Requirements, NQA-2a-1990, Part 2.7, and DOE/RW-0333P, Rev 13, Quality Assurance Requirements and Descriptions (QARD). These quality requirements are implemented through the River Protection Project - Waste Treatment Plant Support Program (RPP-WTP) Quality Assurance Manual (RPP-WTP-QA-003, QAM). The QA requirements of DOE/RW-0333P, Rev 13, QARD and DOE Order 414.1C were not identified as a requirement for this work in the test specification.

As specified in the supporting Test Specification, 24590-PTF-TSP-RT-06-0001, Rev. 0, BNI's Quality Assurance Project Plan (QAPjP), PL-24590-QA00001, was not applicable because the work was not performed in support of environmental/regulatory testing, and the data will not be used as such.

A matrix that cross-references the NQA-1, NQA-2a, and QARD requirements with PNNL's procedures for this work was given in the test plan, TP-RPP-WTP-467. ${ }^{(a)}$ It included justification for those requirements not implemented.

\section{C.2 Conduct of Experimental and Analytical Work}

Experiments that were not method-specific were performed in accordance with PNNL's procedures QA-RPP-WTP-1101 "Scientific Investigations" and QA-RPP-WTP-1201 "Calibration and Control of Measuring and Testing Equipment," verifying that sufficient data were taken with properly calibrated measuring and test equipment to obtain quality results.

Balances are calibrated annually by a certified contractor, QC Services, Portland, Oregon. A balance performance check was conducted each day the balance was used.

(a) SK Fiskum, TP-RPP-WTP-467, Rev. 0, 2/2/07 and Rev. 1 7/31/07, Characterization and Small Scale Testing of Hanford Wastes to Support the Development and Demonstration of Leaching and Ultrafiltration Pretreatment Processes, Pacific Northwest National Laboratory, Richland, WA. 
ASO conducted analytical testing according to the Statement of Work RPP-WTP-QA-005, Rev. 2, Analytical Support by the PNNL RPL Analytical Support Operation. The analytical results and raw data are traceable through the project files according to the Analytical Services Request number and Radiochemical Processing Laboratory number.

\section{3 Internal Data Verification and Validation}

PNNL addressed internal verification and validation activities by conducting an independent technical review of the final data report in accordance with PNNL's procedure QA-RPP-WTP-604. This review verified that the reported results were traceable, that inferences and conclusions were soundly based, and the reported work satisfied the Test Plan objectives. This review procedure is part of PNNL's RPP-WTP QAM.

\section{C.4 CUF Data Acquisition Collection System Software Verification and Validation}

Most of the sensors on the testing apparatus transmitted analog data to an external data acquisition collection system (DACS), manufactured by National Instruments (Austin, TX). This system relayed the analog data to a LabView data-collection program operating on a desktop computer system using Windows XP (Professional), Service Pack 2. The software program scaled the analog data and simultaneously recorded the data electronically and displayed it on the computer monitor. The software performance was verified according to RPP-WTP-QA-010, Software Test Plan: CUF Data Collection Program (8/8/2007). 


\section{Appendix D}

\section{CUF Filtration/Leaching Apparatus, Experimental Methods, Sampling, and Sample Handling}



WTP-RPT-170, Rev. 0

\section{Appendix D: CUF Filtration/Leaching Apparatus, Experimental Methods, Sampling, and Sample Handling}

This appendix describes the crossflow ultrafiltration (CUF) apparatus used to perform the bench-top filtration and leaching tests of the Group 8 composite waste sample (test results are described in Section 4 of this report). The sampling and sample handling specifically supporting the CUF processing are described in this appendix; the analytical methodologies for sample analysis are provided in Appendix B. The material processing history in this system is also discussed.

\section{D.1 Filtration/Leaching Apparatus}

The CUF is a bench-top assembly that can process up to $4 \mathrm{~L}$ of tank waste slurry through prototypic pretreatment operations, including caustic leaching, oxidative leaching, filtration, and solids washing. The CUF apparatus schematic is shown in Figure D.1. The main components of the CUF apparatus included:

- slurry reservoir tank

- pump

- heat exchanger

- cross-flow filter

- slurry recirculation loop

- permeate flow loop

- permeate back pulse tank

- data acquisition system (DACS).

All fluid-contacting components were made of stainless steel except as noted. Tubing and connections were typically $1 / 4$ - to $3 / 8$-in. inside diameter on the permeate side while the slurry side was made with $1 / 2$-in. inside-diameter tubing. The minimum operating volume for the CUF was $\sim 1.2 \mathrm{~L}$, driven primarily by the required volume of the slurry in the circulation loop to prevent air intake.

The slurry reservoir tank was a cylindrical stainless steel tank with a 4-L capacity. The bottom of the vessel was sloped at a $15^{\circ}$ angle, allowing for easy system drainage; this outlet fed into the connection piping leading to the slurry recirculation pump. Agitation in the tank was provided with an overhead mixer using a 2-in.-diameter 3-blade impeller. Baffles were installed on the walls inside the tank to aid slurry mixing. Heat tape was installed around the exterior walls of the tank to provide controlled heating (heat ramp, soak, and cooling) in support of caustic leaching. The electrical load to the heat tape was controlled via a temperature controller connected to a dual Type-K thermocouple installed inside the tank reservoir (which extended just below the overhead mixing impeller). The secondary thermocouple output was sent to the DACS. 


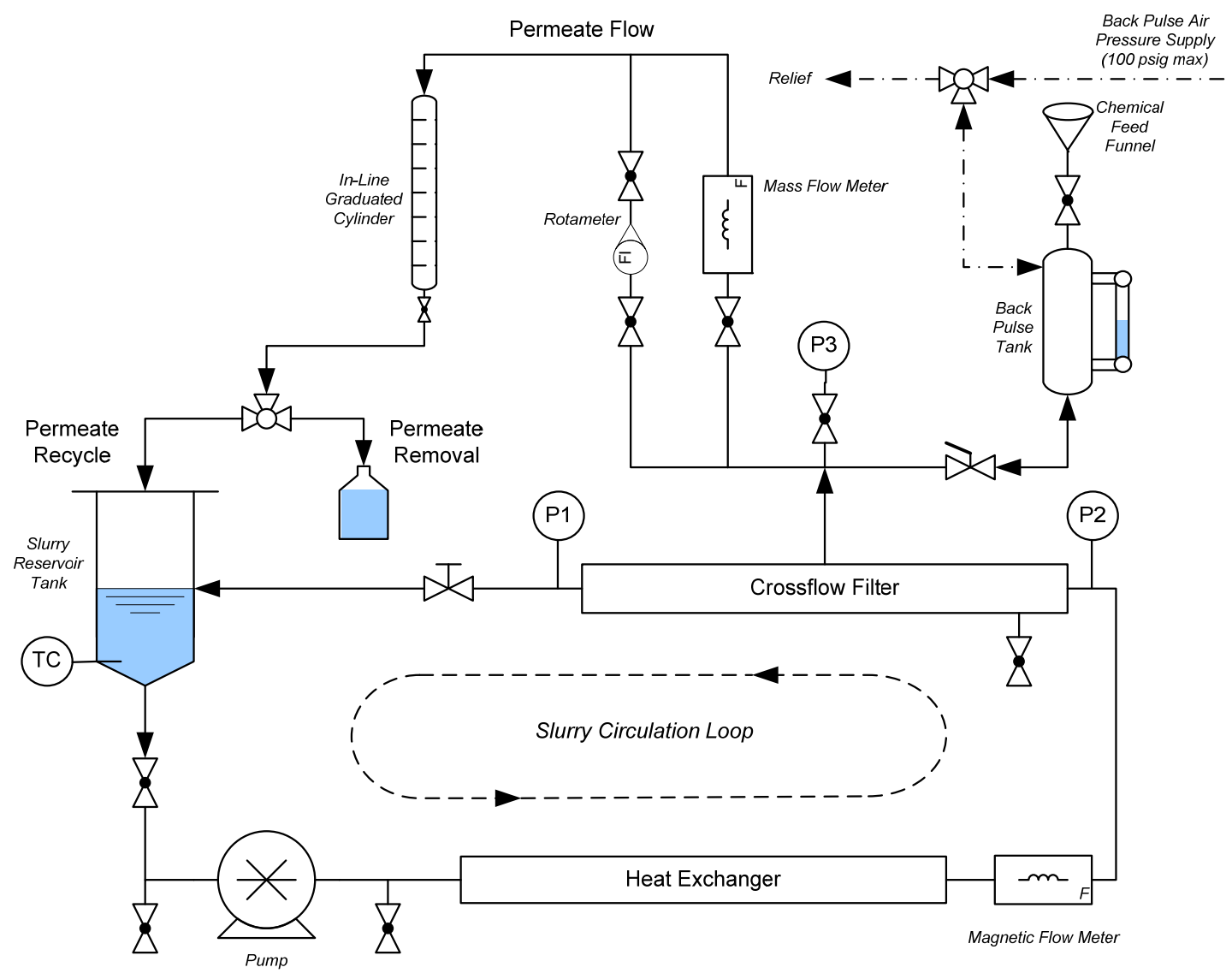

Figure D.1. Piping Diagram of CUF Apparatus (Not to Scale)

The pump was a positive-displacement rotary lobe pump (Johnson Pump, model SLAL/0059/10, Eastborne, UK) manufactured with 316 stainless steel internal components and capable of flow rates up to $60 \mathrm{~L} / \mathrm{min}$. The pump was powered using a 4-horsepower air motor (Gast Manufacturing, Model 6AMFRV-5A, Benton Harbor, MI); compressed air was supplied from an air compressor located externally to the hot cell. A regulator controlled the air pressure, which in turn controlled the pump speed. The pump speed was measured with an optical tachometer, which in turn measured the rotational speed of reflective tape fixed to the rotating connection coupling.

The heat exchanger removed excess heat from the slurry caused by mechanical mixing and frictional flow. It was constructed as a single-pass heat exchanger with counter-current flow. The HLW slurry ran through the inside tube, which was constructed of $5 / 8$-in. $\times 0.065$-in. stainless steel tubing. The outer tube was constructed of 1 -in. schedule 40 pipe (1.315 in. $\times 0.133$ in.) and was $28.5 \mathrm{in}$. long. The exterior shell of the heat exchanger was connected to a circulating chiller (VWR International, model 1179PD) located externally from the hot cell. The circulating fluid (water/anti-freeze mixture) was radiologically isolated from the hot cell. The chiller temperature was regulated with feedback control from a resistance temperature detector (RTD) installed in the heat-exchanger slurry discharge line. 
The crossflow ultra-filter was a porous sintered metal tube supplied by the Mott Corporation (Farmington, CT) under specification WTP-070110. ${ }^{\text {(a) }}$ The filter element was 24 -in. long, $1 / 2$-in. ID, and $5 / 8$-in. OD and was rated for particles of $0.1-\mu \mathrm{m}$ diameter. A schematic of the filter and dimensions are shown in Figure D.2.

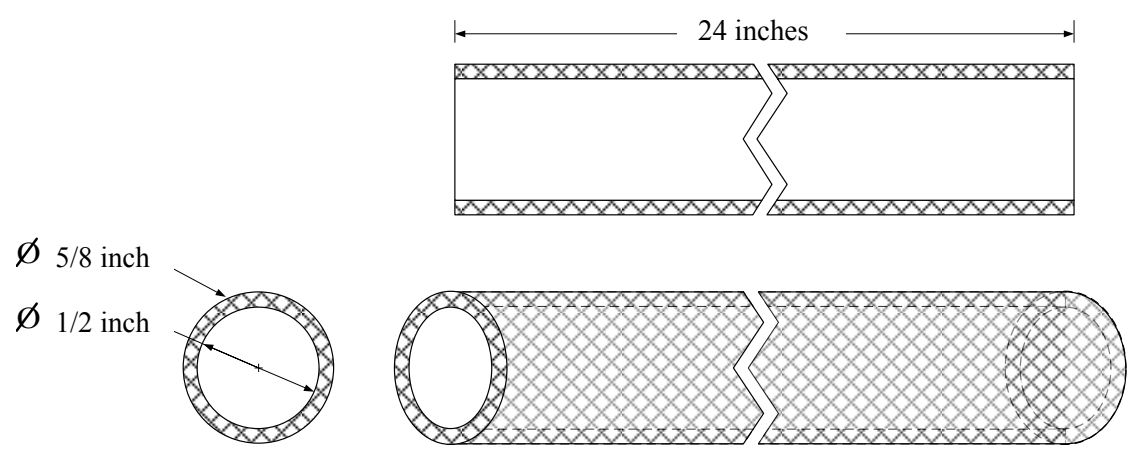

Figure D.2. Illustration of the Filter Element with Dimensions

The filter element was received in a shell-in-tube configuration. The outer tube surrounding the filter element contained the filtrate while the slurry remained in the central core. The slurry inlet and outlet were welded to steel tubing of matching outer and inner diameters that extended past the shell. The shell (or filtrate) side had two $3 / 8$-in. tubes exiting from the filter assembly; one was in the center to collect filtrate, and the other was near the slurry inlet and was used as a drain. Pressure ports equipped with digital pressure transmitters (Cecomp Electronics, Model DPG1000DR100PSIG-V, Libertyville, IL) were installed at the filter inlet and outlet to measure the slurry-side pressure. Swagelok (Swagelok Co., Solon, Ohio) $\mathrm{VCO}^{\circledR}$ fittings with O-ring face seals were placed on the inlet and outlet filter-feed-tube connections for easy in-cell connection to the rest of the apparatus. A schematic of the filter assembly is shown in Figure D.3, and a photograph is shown in Figure D.4.

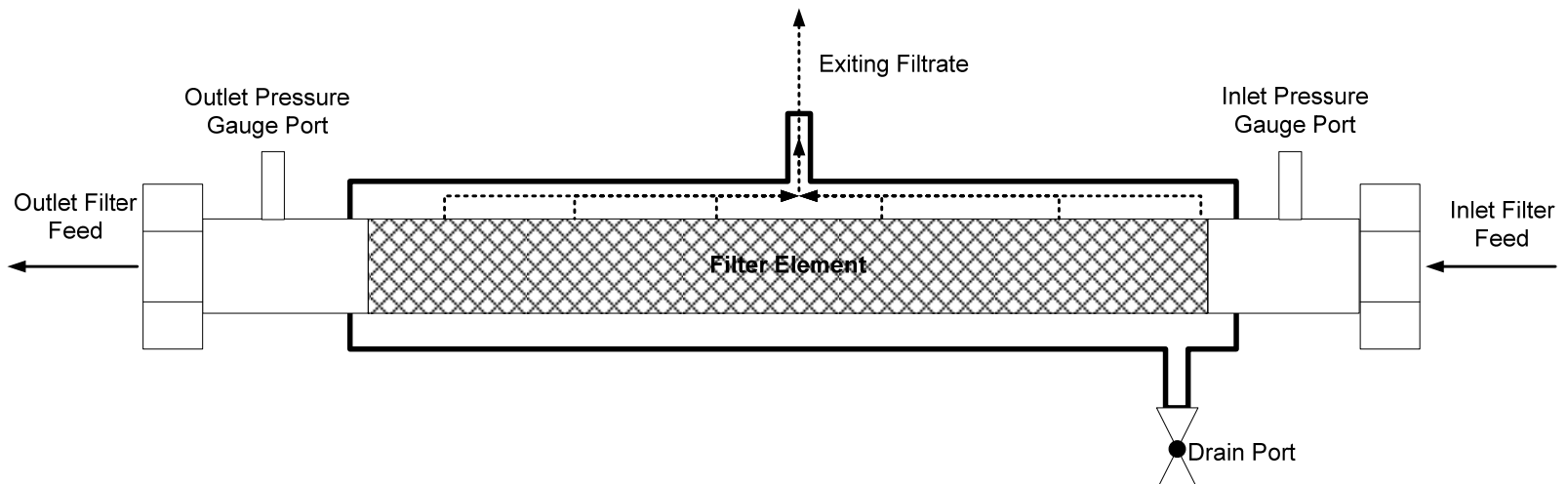

Figure D.3. Illustration of the Filter Assembly (Not to Scale)

(a) Specification WTP-070110, written by JGH Geeting for PNNL Purchase Order 38825, Feb. 2, 2007. 


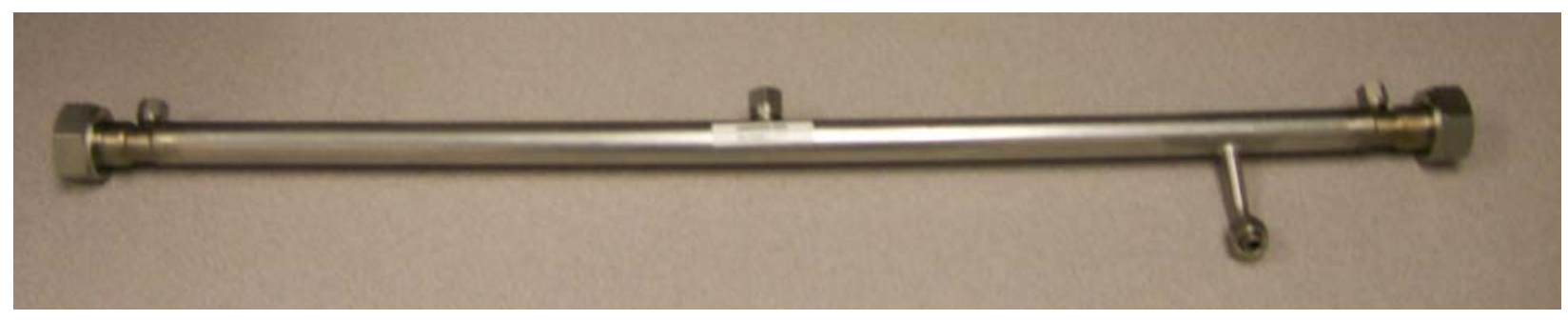

Figure D.4. Photograph of the Filter Assembly

The slurry flowed axially through the filter while the feed permeate (synonymous with filtrate) passed radially through the filter tube walls. Filtration occurred when sufficient back-pressure was applied to the slurry feed flowing through the filter element driving the aqueous component through the sintered metal walls. Because the slurry was flowing across the filter walls, solids buildup was minimized, allowing filtration to occur continuously with minimal downtime for back-pulsing (to remove solids buildup).

The slurry recirculation loop was defined as the slurry flow from the slurry reservoir tank, through the heat exchanger, through the CUF filter assembly, and back into the reservoir. Process parameters, such as flowrate (axial velocity) and pressure (trans-membrane pressure), were recorded in the slurry recirculation loop to support the filtration parametric testing. The slurry recirculation loop was equipped as follows.

1) The volumetric flow of the slurry inside the slurry recirculation loop was measured with the magnetic flow meter (Krohne, Optiflux 5000, Germany). The sensor's output was displayed on an external panel meter that generated an analog output signal monitored and recorded by the DACS. The data from this device were used to calculate the axial velocity inside the filter element.

2) Digital pressure transmitters with displays installed on the inlet and outlet port of the filter displayed the pressure in pounds per square inch, gauge (psig). The gauges also transmitted analog output signals monitored by the DACS. The data from these devices were used to calculate the average pressure inside the filter and were supported in part by the calculated axial pressure drop across the filter, also termed trans-membrane pressure (TMP).

3) A manual pinch valve was located at the discharge of the filter. Tightening the valve increased the slurry back-pressure and drove permeate flow through the filter wall. The output side was connected to the slurry reservoir tank, thus completing the circulation loop. The pinch valve was closed completely when the slurry reservoir tank was isolated for leaching.

The permeate flow loop was used to define permeate collection rates from the filtration process, aid in determining the TMP, and collect permeate from the CUF apparatus. The permeate flow loop began at the center of the filter assembly where $a 3 / 8$-in. polyethylene tube connected the filter to a manifold. The manifold was used to direct permeate through a series of measurement devices before returning it to the slurry reservoir tank or directing it to a sample collection container. The permeate flow loop was equipped as follows.

1) A digital pressure gauge was installed in the manifold to measure the pressure on the permeate side of the filter. Like the other two digital gauges, this instrument transmitted an analog output to a datacollection system. The pressure drop across the filter (TMP) was then calculated by subtracting the pressure on the permeate side of the filter from the average (input and output) pressure of the slurry inside the filter. 
2) Flow from the filter was diverted either through a calibrated mass flow meter (Brooks Instrument, Quantum QMBM4L, Hatfield, PA) or through a user-calibrated rotometer (Aalborg, P16S4-VA0A064-63-CA-VA, Orangeburg, New York). The mass flow meter measured flow rates up to $180 \mathrm{~mL} / \mathrm{min}$ as well as the permeate density. Both measurements were transmitted as two analog output signals to the DACS. The rotometer was a manual read-out device for flow rates up to $30 \mathrm{~mL} / \mathrm{s}$.

3) An in-line volumetric cylinder was installed on the discharge of both meters to support manual measurements of the permeate flowrate. Flow rates were determined after closing a valve at the bottom of the cylinder and measuring the collected permeate volume in a measured time interval. Flow was re-established after re-opening the lower valve.

4) Flow from the volumetric cylinder passed through a 3-way valve. This valve directed flow either back to the slurry reservoir tank to be mixed with the slurry or to a sampling hose that was used to direct permeate out of the system and into a collection container.

The permeate back-pulse tank was used to force solids from the filter by pushing permeate from the outer filter shell inward to the slurry side. The tank was situated adjacent to the permeate flow loop and shared the connection to the filter with the permeate flow loop via the permeate pressure gauge. The back-pulse tank was an $\sim 0.5$-L vessel equipped with a sight-glass to track the fluid volume. The tank had three entry ports:

1) $1 / 4$-in. line with a two-way toggle valve on the bottom connecting the vessel to the permeate side of the filter

2) $1 / 4$-in. line with a two-way valve connecting the top of the vessel to a funnel

3) $1 / 4$-in. line with a three-way valve connecting the top of the vessel to a compressed air line and vent line connected to the top of the slurry reservoir tank.

The bottom line was used to fill the chamber with permeate (diverted from the permeate flow loop) and then send pressurized permeate backwards to the filter as a back-pulse. The funnel on the top of the chamber was used to introduce cleaning and rinse solutions directly to the back-pulse tank. The compressed gas line was used to pressurize the back-pulse chamber to $80 \mathrm{psig}$ and to vent the chamber to atmospheric pressure.

Fluidic backpulsing through the filter was conducted in a stepwise process. Once the back-pulse chamber was half-filled with permeate (as seen through the sight-glass), the toggle valve (from entry port \#1) was closed. The three-way valve (entry port \#3) was then opened to introduce compressed gas into the chamber to pressurize the fluid for sufficient time to bring the pressure to $\sim 80 \mathrm{psig}$. The chamber was then isolated from the compressed gas line, and the slurry pressure in the CUF apparatus was dropped below the pressure back-pulse tank (under $20 \mathrm{psig}$ ). The valve at the bottom of the back-pulse tank (entry port \#2) was opened, and the pressurized permeate inside the tank flowed backwards through the filter. After the back-pulse was completed, the chamber was either vented to atmospheric pressure through the 3-way valve or re-pressurized with compressed gas to prepare for an additional back-pulse.

The CUF apparatus was mounted on a series of skids to allow entry into the hot cell facility. A photograph of the complete system (sans DACS) is shown in Figure D.5. 


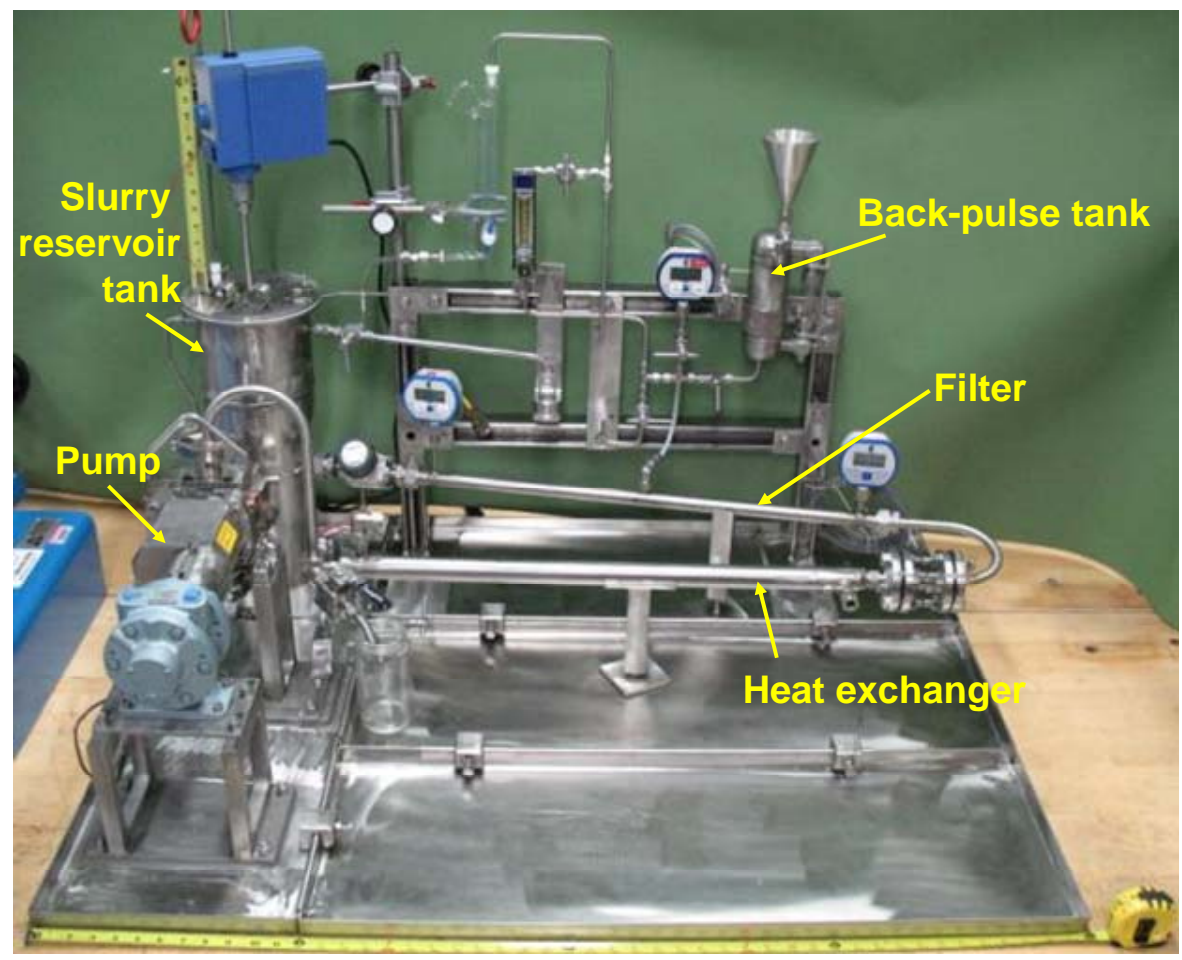

Figure D.5. Photograph of the CUF Testing Assembly Before Hot Cell Installation

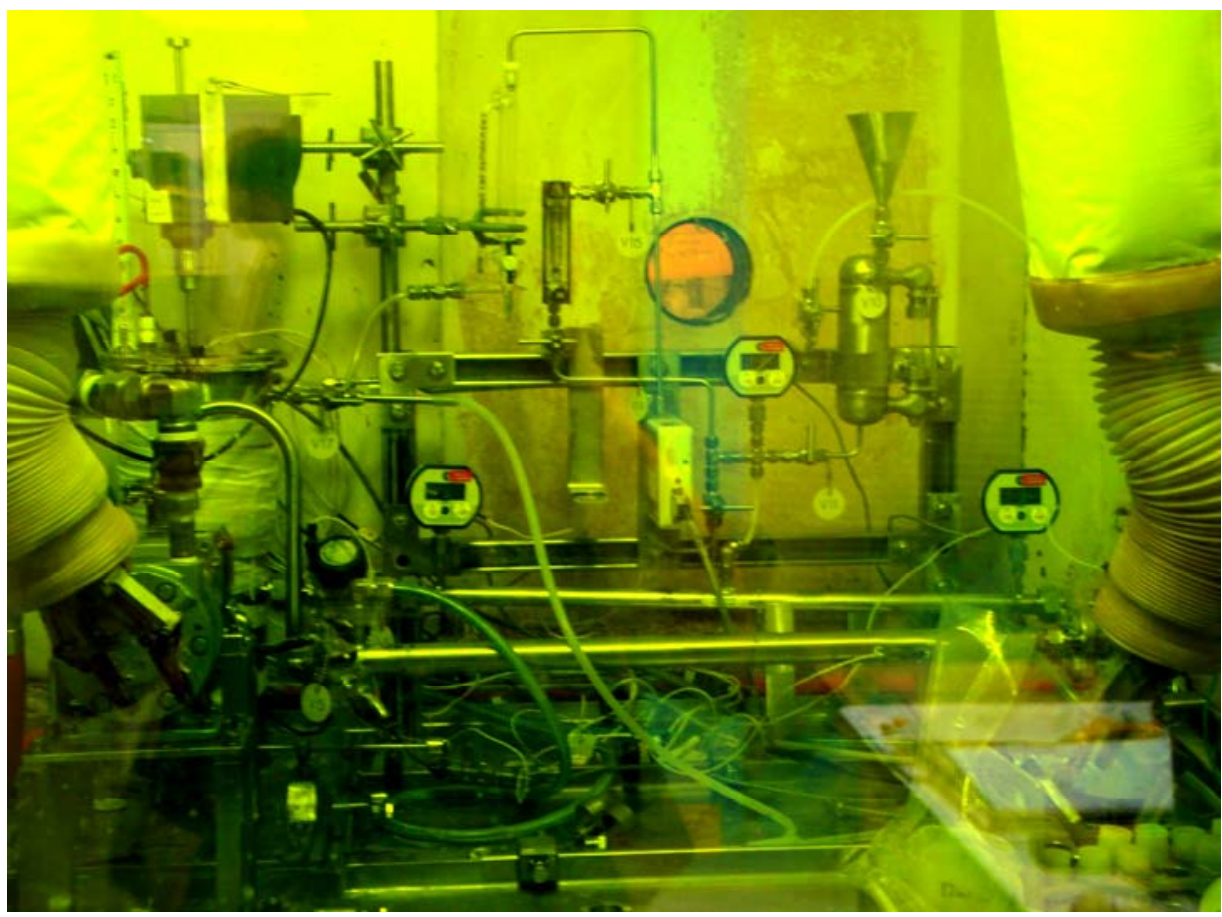

Figure D.6. Picture of Test CUF Assembly Installed in Cell 5 of the Shielded Analytical Laboratory (Note: the slurry reservoir tank is wrapped with heating tape.) 


\section{D.2 Instrumentation and Data-Acquisition System}

Because of the system complexity, one of the data-acquisition design goals was to minimize the number of manual measurements during testing and record data in an electronic format that could be analyzed readily with other approved software. Most of the sensors on the testing apparatus transmitted analog data to an external DACS, manufactured by National Instruments (Austin, TX). This system relayed the analog data to a LabView data-collection program operating on a desktop computer system using Windows XP (Professional), Service Pack 2. The software program scaled the analog data, simultaneously recorded the data electronically, and displayed it on the computer's monitor. The performance of the software was verified by test plan RPP-WTP-QA-010. All reportable data were measured on calibrated instrumentation that included the external DACS board. Figure D.7 shows a diagram of the electronic sensors attached to the DACS, and Figure D.8 displays the screen windows from the data-collection program.

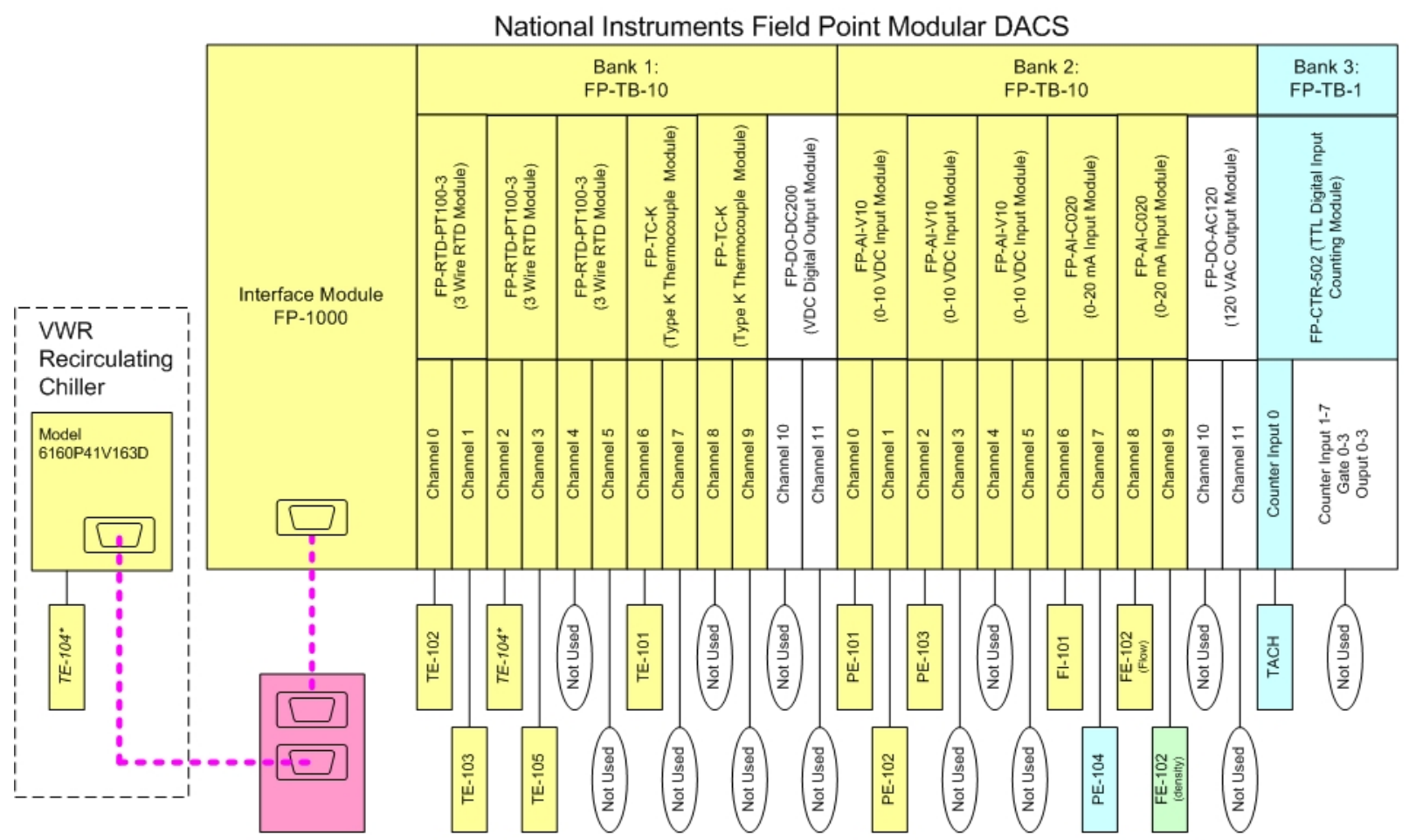

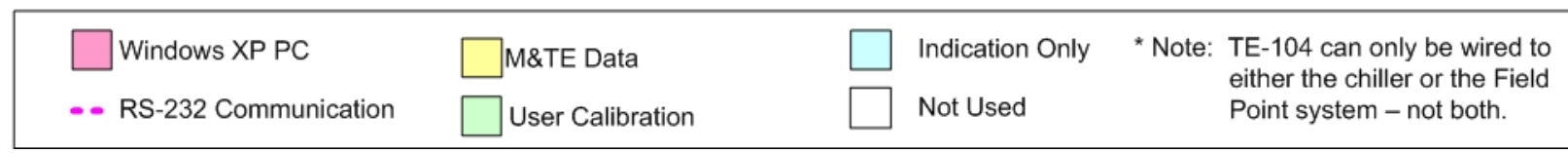

Figure D.7. Diagram of DACS System 


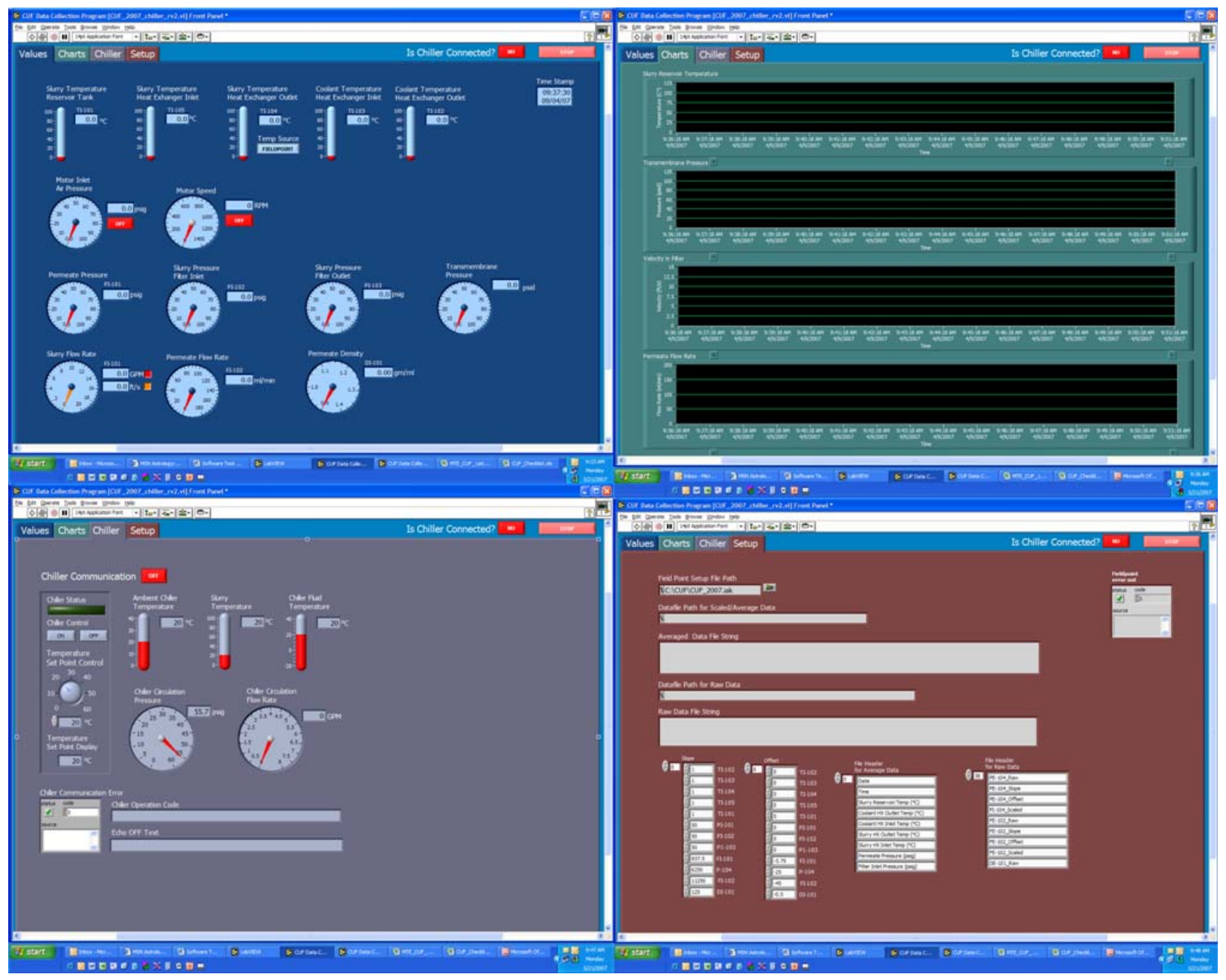

Figure D.8. Digital Images of DACS Display Windows

\section{D.3 CUF Operation and Sampling}

The following sections describe the nominal CUF processing parameters, sampling, and filtration testing during CUF operation.

\section{D.3.1 Processing Overview}

The nominal processing and sampling scheme for Group 8 is summarized in Figure 4.1. All masses into and out of the CUF were measured to track mass balance. Group 8 slurry $(2.21 \mathrm{~kg})$ was added to the slurry reservoir. Simulated supernatant $(2.33 \mathrm{~kg})$ was added to the Group 8 slurry to reduce the UDS concentration from $11 \mathrm{wt} \%$ to $5.5 \mathrm{wt} \%$. The slurry was subjected to a filter test matrix (see next section for a description of the filter test matrix). The slurry was dewatered to $12 \mathrm{wt} \%$ UDS and subjected to another filter matrix test. A quantity of $1.96 \mathrm{~kg}$ of $6.34 \mathrm{M} \mathrm{NaOH}$ was added to the slurry, which was then heated as follows: 
1) ramp from 25 to $60^{\circ} \mathrm{C}$ in $2.5 \mathrm{~h}\left(14^{\circ} \mathrm{C} / \mathrm{h}\right)$

2) soak at $60^{\circ} \mathrm{C}$ for $8 \mathrm{~h}$

3) cool from $60^{\circ} \mathrm{C}$ to $25^{\circ} \mathrm{C}$ over $5.6 \mathrm{~h}\left(6.25^{\circ} \mathrm{C} / \mathrm{h}\right)$.

Five slurry samples were taken from the slurry reservoir during the heat and soak period. The slurry was dewatered by removing $1.96 \mathrm{~L}$ of filtrate.

The caustic-leached solids were rinsed four sequential times. After adding a 1.2-L volume of rinse solution, the slurry was mixed by pumping through the slurry recirculation loop for 5 to 10 minutes and then dewatered to a 1.2- to 1.4-L slurry volume. Each rinse permeate was collected separately. The $\mathrm{NaOH}$ concentration of each added rinse solution was established to provide sufficient free-hydroxide concentration to maintain the solubility of dissolved aluminum (based on $100 \% \mathrm{Al}$ dissolution). The amount of caustic added was determined using the gibbsite solubility data reported by Li et al. (2005). The added sequential $\mathrm{NaOH}$ rinse solutions were $0.47 \mathrm{M}, 0.16 \mathrm{M}, 0.049 \mathrm{M}$, and $0.014 \mathrm{M}$.

\section{D.3.2 Filtration}

The CUF was developed to operate in several different operational modes to simulate filtration and leaching processes of the Waste Treatment and Immobilization Plant (WTP) pretreatment system. Filtration operation occurred in a recycling or dewatering mode. During recycling operations, permeate was returned to the slurry reservoir tank. By returning permeate back into the slurry, the undissolved solids (UDS) concentration in the slurry was maintained in a steady-state condition. The CUF was operated in this mode to understand how the effects of time, pressure, and axial velocity impact the filtration of slurry while maintaining the physical properties of the slurry in a constant condition (given constraints of shear effects on rheological properties). During dewatering operations, permeate from the filter was diverted to a collection vessel while operating the system at a constant transmembrane pressure and axial flow rate, allowing the UDS concentration of the slurry to change. The CUF was operated in this mode to understand how the slurry's rheological and filtration properties changed as its UDS concentration changed.

Chemical leaching occurred in the slurry reservoir tank when the slurry was isolated from the circulation loops. Before leaching was initiated, all components in the circulation loops (slurry and permeate) were drained and recombined in the isolated reservoir tank. Caustic at room temperature was introduced at the back-pulse chamber and used to rinse the piping of residual solids, which were then added back to the reservoir tank. Additional leaching agent was added as needed to the leaching reservoir to conduct the experiment.

\section{D.3.3 Filtration Test Matrix}

To understand the impact of the transmembrane pressure and axial velocity on the filter flux of the waste slurry, a filtration test matrix was developed to understand their individual effects. The waste slurry was circulated through the CUF while the slurry permeate leaving the filter was recycled back to the slurry reservoir. By recycling permeate, the UDS concentration of the slurry stayed constant. Baseline conditions were defined as $40 \mathrm{psid}$ TMP and $13 \mathrm{ft} / \mathrm{s}$ axial velocity (AV). The TMP and AV were varied to demonstrate their influence on the flux; targeted parameters are shown in Table D.1 and Figure D.9. 
Each filtration condition was maintained for at least an hour while permeate was recycled back to the slurry reservoir tank. Before the test condition was changed, a back-pulse on the filter was performed to provide the same starting conditions for each test. The initial test performed at the baseline condition was performed for a minimum of 3 hours to track how the filter flux varied with time. Deterioration of filter flux with time is an indication of filter fouling (clogging).

Table D.1. Prototypic Filtration Test Matrix Operating Conditions

\begin{tabular}{|c|c|c|c||}
\hline $\begin{array}{c}\text { Test } \\
\text { number }\end{array}$ & $\begin{array}{c}\text { Duration } \\
\text { (h) }\end{array}$ & $\begin{array}{c}\text { Target TMP } \\
\text { (psid) }\end{array}$ & $\begin{array}{c}\text { Target AV }^{(\mathbf{a})} \\
\text { (fps) }\end{array}$ \\
\hline 1 & 3 & 40 & 13 \\
\hline 2 & 1 & 30 & 11 \\
\hline 3 & 1 & 30 & 15 \\
\hline 4 & 1 & 50 & 15 \\
\hline 5 & 1 & 50 & 11 \\
\hline 6 & 1 & 40 & 13 \\
\hline 7 & 1 & 40 & 9 \\
\hline 8 & 1 & 40 & 17 \\
\hline 9 & 1 & 20 & 13 \\
\hline 10 & 1 & 60 & 13 \\
\hline 11 & 1 & 40 & 13 \\
\hline
\end{tabular}

(a) Actual conditions may vary based upon slurry volume and rheology. All conditions may not be obtainable.

Achieved conditions are described in Section 4.

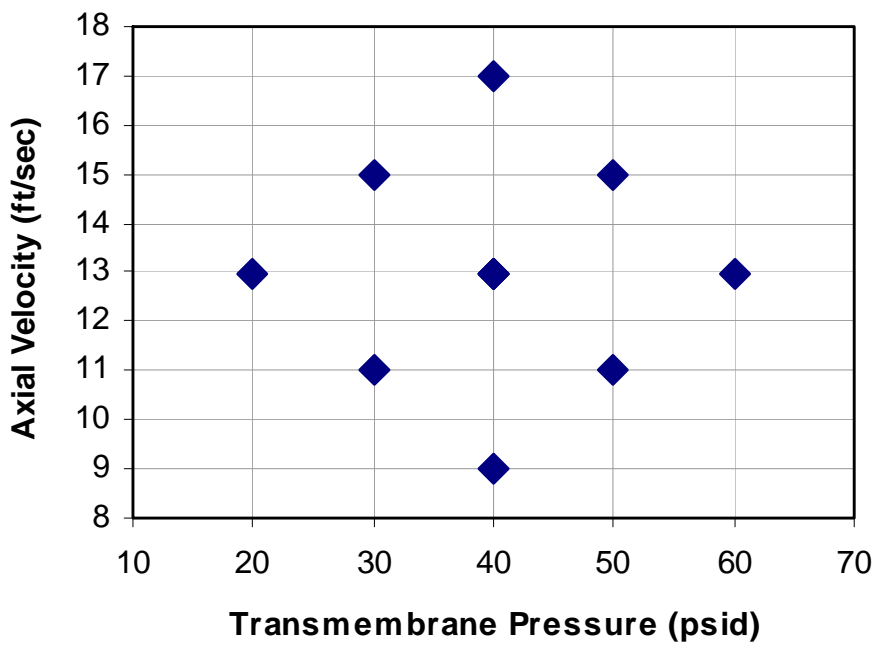

Figure D.9. Prototypic Filtration Test Matrix Configuration

When the slurry is at low concentrations, the system is expected to be controlled by the transmembrane pressure, with little impact from the axial velocity. However, once the slurry is concentrated and the flow properties change, it is expected that the axial velocity will have some effect on the filtration of the system. 
WTP-RPT-170, Rev. 0

\section{D.3.4 Sampling During CUF Operation}

Samples were collected throughout the CUF testing to measure the physical and chemical properties of the waste slurry and permeate.

Slurry samples were collected from two separate locations on the system. Small slurry samples $(\leq 20-\mathrm{mL}$ for $\mathrm{wt} \%$ UDS and chemical characterization) were collected from the top of the slurry tank reservoir with transfer pipets while the mixer was operating. The tips of the pipets were cut at an angle to minimize the potential for plugging. Larger samples $(\sim 100 \mathrm{~mL}$ for rheology) were obtained from the drain valve on the pump discharge while the pump was running. When rheology samples were available, they were subsampled to support wt $\%$ UDS, particle-size distribution (PSD), and chemical characterization in lieu of sampling from the slurry tank reservoir.

During dewatering operations, the three-way valve on the permeate collection port was positioned to divert permeate to the permeate sample line and away from recycling to the slurry reservoir. Permeate exiting the sample line was collected in 1.5-L polypropylene bottles. Permeate sub-samples were collected directly from the 1.5-L collection bottles for chemical analysis. Sampling of the aqueous-phase was more difficult during leaching operations (i.e., the samples of the leachate that were collected as a function of time to assess leach kinetics). In this case, a slurry sample was collected from the slurry reservoir tank as previously described. The sample was then transferred into a 5-mL plastic disposable syringe barrel equipped with a $0.45-\mu \mathrm{m}$ pore size nylon syringe filter in polytetrafluoroethylene (PTFE) housing. Once $\sim 5-\mathrm{mL}$ of slurry was in the syringe barrel, the syringe plunger was installed, and the contents were filtered into a plastic sample vial.

Rheological properties were measured directly on the slurry samples. Because the rheology sample size $(100 \mathrm{~mL})$ was rather large, the rheology samples were tested and then returned to the CUF for continued treatment. Samples collected for wt\% UDS determinations were processed directly, and PSD samples were diluted with $0.01 \mathrm{M} \mathrm{NaOH}$ before measurement. The aqueous-phase samples were split for direct analysis by IC for anions, potentiometric titration for free hydroxide, acid digestion followed by inductively coupled plasma-optical emission spectrometry (ICP-OES) analysis for metals, U by kinetic phosphorescence analysis (KPA), radiochemical separations, and counting for radionuclides. Characterization activities of the solids phase were conducted as shown in Figure D.10. In this case, additional solids washing on the slurry analytical sample was not conducted so the impact of the washing process on solids during the test could be better characterized. Samples of the slurry were dried and dissolved by $\mathrm{KOH}$ fusion for ICP-OES measurements and radionuclides analysis. Acid digestions (HFassisted) were performed for additional ICP-OES measurements, and deionized (DI) water leaches were performed for ion chromatography (IC) measurement to compare to IC measurement in the supernate. 
WTP-RPT-170, Rev. 0

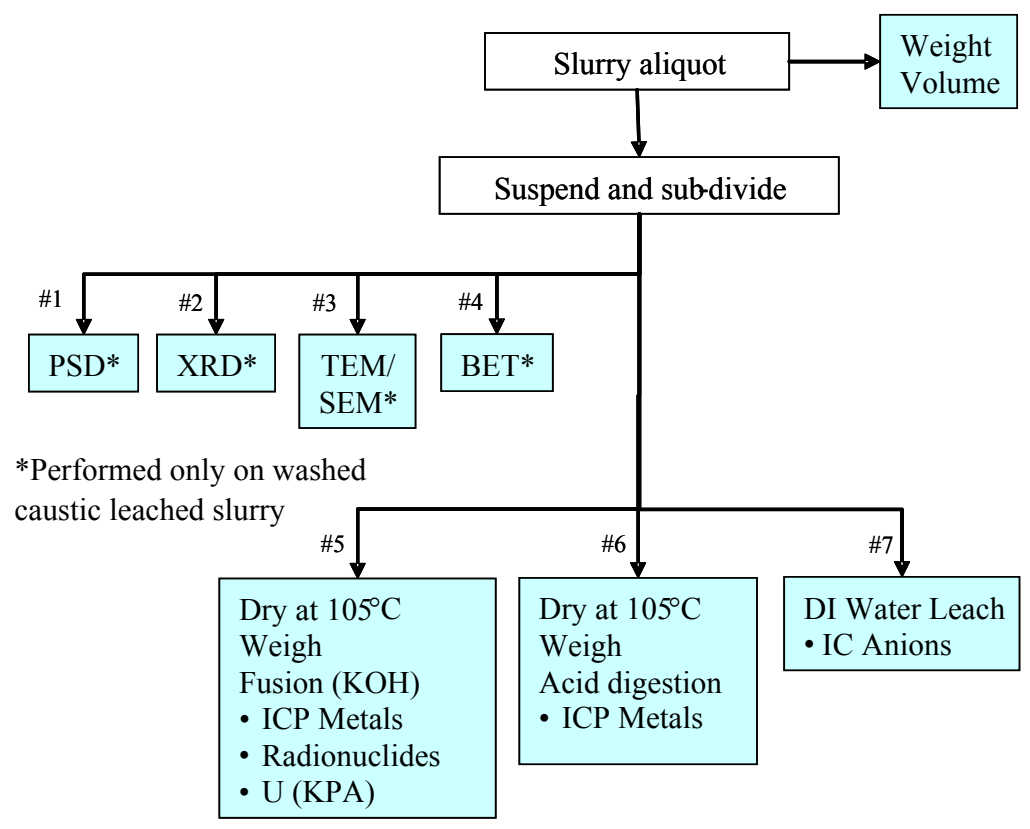

Figure D.10. CUF Slurry Characterization Scheme

\section{D.3.5 Discussion of Analytical Data Uses}

\section{D.3.5.1 Effects of Rheology and Particle Size}

During testing operations, rheology, physical property (wt\% UDS), and particle-size samples were collected to characterize the solids in the slurry and their impact on flow and filtration behavior. As slurries concentrate, their flow behavior changes and becomes more viscous and less Newtonian. This directly impacts the cross-flow behavior of the filter and the formation of filter cake. The particle size also can have an impact by affecting the gel concentration of the slurry and possibly impact fouling. Because the slurries are sheared during filtration, the particle size of the slurry can change - especially if the initial solids are agglomerated. Chemical leaching may impact the PSD and agglomeration as well.

\section{D.3.5.2 Chemical Data Analysis}

Two main goals were to be achieved from chemical and radiochemical analysis:

1) verification that transuranic (TRU) material stays in the high-level waste (HLW) stream (effective chemical and physical separations)

2) calculation of the chemical leach factors of glass-limiting compounds of interest.

During filtration, it is important to verify that TRU materials present in the waste slurry do not pass through the filtration media as a colloid or as a particle $>0.1 \mathrm{~mm}$. During leaching, it is also important to verify that TRU compounds are not chemically dissolved during operations designed only to remove glass-limiting compounds for the LAW stream. This was achieved by performing radiochemical analysis on permeate and slurry samples throughout the test to verify that the permeate streams contained minimal TRU compounds and that a mass balance on the system showed that almost all the TRU stays in the HLW slurry stream. 
WTP-RPT-170, Rev. 0

\section{D.4 CUF Processing History}

The CUF system used to process Group 8 slurry had been used previously on other wastes. This section summarizes the processing history to which it had been subjected.

\section{D.4.1 Baseline Testing of Filter}

Before testing with any of the HLW composite waste, the CUF apparatus was initially cleaned with a laboratory cleaning solution (Alconox ${ }^{(a)}$ at 1:100 dilution) and rinsed with DI water to remove residual cutting oils and soils from the fabrication process and shipping from the manufacturer. After cleaning, the filter flux was measured with a solution of $0.01 \mathrm{M} \mathrm{NaOH}$ - this is referred to as the clean water flux. Testing was performed at 10,15, and 20 transmembrane pressure (TMP) at an axial velocity of $11 \mathrm{ft} / \mathrm{s}$. Each pressure condition was held for 20 minutes, with a single back-pulse performed before changing the pressure. Next, a strontium carbonate $\left(\mathrm{SrCO}_{3}\right)$ slurry was prepared to test the filter flux with a slurry solution. As before, the $\mathrm{SrCO}_{3}$ slurry was placed in the slurry reservoir and was operated with the permeate recycling back into the slurry reservoir. Testing was performed at 10, 20, and $30 \mathrm{TMP}$ at an axial velocity of $11 \mathrm{ft} / \mathrm{s}$. A single back pulse was performed between each test condition. Afterwards, the slurry was removed and rinsed out with DI water (approximately $10 \mathrm{~L}$ ). The clean-water flux was again tested with a solution of $0.01 \mathrm{M} \mathrm{NaOH}$ to verify that the filter was clean before testing with $\mathrm{HLW}$ slurries.

The results of the baseline filter flux testing are shown in Figure D.9. Overall, the baseline flux for the filter was demonstrated to be considerably higher than the predicted flux for the waste slurries to be tested (e.g., $0.04 \mathrm{GPM} / \mathrm{ft}^{2}$ for dewatering operations). No solids were evident in the permeate during filtration of the strontium carbonate slurry, and the density of the permeate was measured at $1.12 \mathrm{~g} / \mathrm{mL}$ by the mass flow meter. A sample of the permeate was taken, and its density was measured as $1.11 \mathrm{~g} / \mathrm{mL}$ using a calibrated balance and a 50-mL volumetric flask. While the density could be measured, the volumetric flow of the permeate was beyond the range of the mass flow meter for all three tests. After a density check, permeate flow was diverted through the rotometer. For the $\mathrm{SrCO}_{3}$ flux measurements, the flow was slow enough to verify the flow rate using the in-line volumetric cylinder to measure the permeate flow.

(a) Alconox, Inc., 30 Glenn Street, Suite 309, White Plains, NY 10603 USA. 


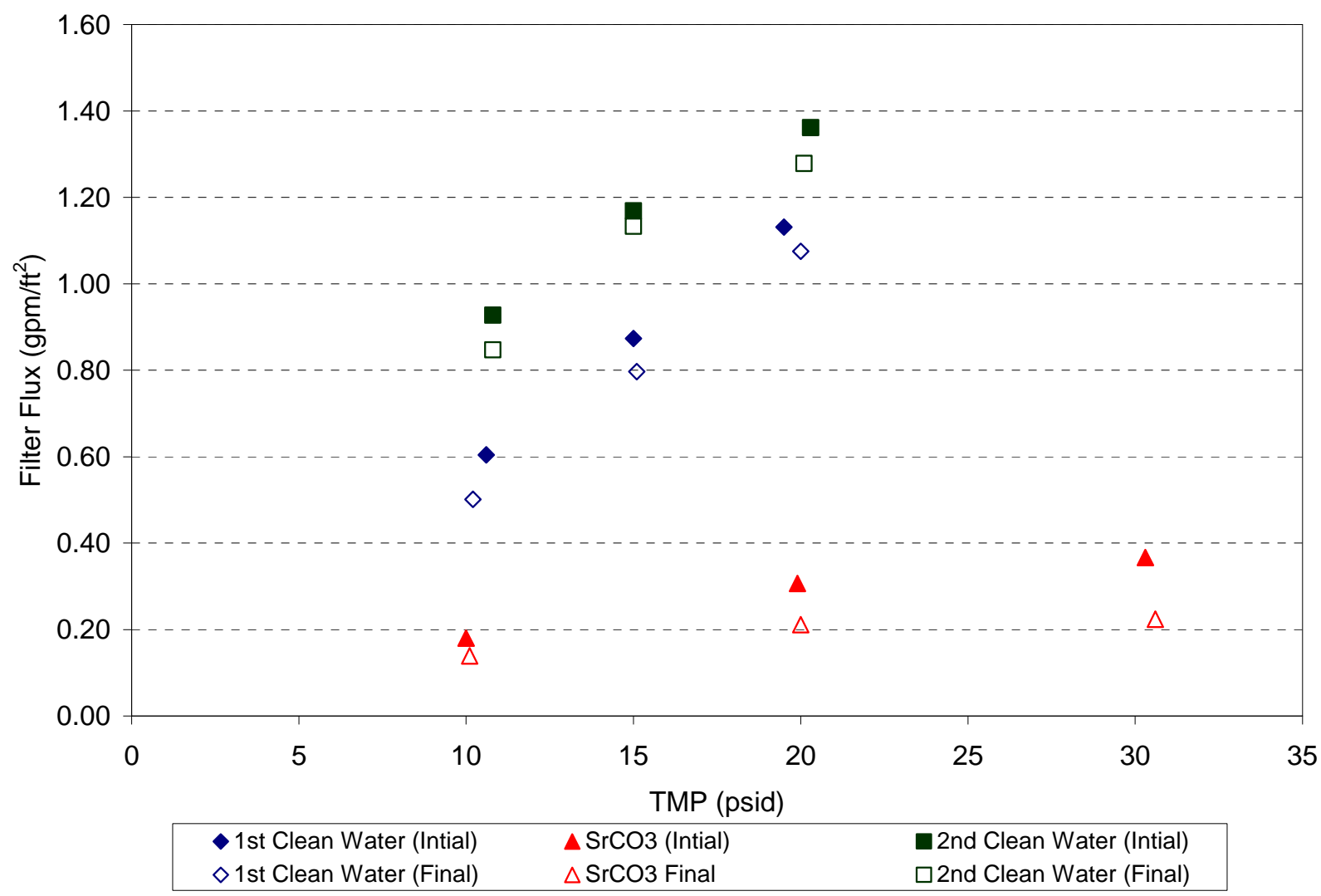

Figure D.9. Initial Clean Water/SrCO 3 Flux Measurements of Filter

After the completion of these initial filter characterization tests, the CUF had been used for a series of other actual waste process tests as shown in Table D.2. The filter was cleaned between each test with $2 \mathrm{M}$ nitric acid and $0.5 \mathrm{M}$ oxalic acid. Between each test, the filter functionality was confirmed with $0.01 \mathrm{M}$ sodium hydroxide solution. The filter was stored wet with $0.01 \mathrm{M}$ sodium hydroxide solution between tests.

Table D.2. Summary of Tank Wastes Processed through the CUF

\begin{tabular}{|c|c|c|c|l||}
\hline $\begin{array}{l}\text { Waste Test } \\
\text { Group }\end{array}$ & $\begin{array}{c}\text { Sample Mass } \\
\text { Tested (kg) }\end{array}$ & $\begin{array}{c}\text { Caustic } \\
\text { Leach }\end{array}$ & $\begin{array}{c}\text { Oxidative } \\
\text { Leach }\end{array}$ & Test Report \# \\
\hline 5 & 2.2 & $\mathrm{y}$ & $\mathrm{n}$ & WTP-RPT-172 \\
\hline $5 / 6$ & $\begin{array}{l}1.0(\text { Group 5) } \\
3.0(\text { Group 6) }\end{array}$ & $\mathrm{y}$ & $\mathrm{y}$ & $\begin{array}{l}\text { WTP-RPT-171 and } \\
\text { WTP-RPT-172 }\end{array}$ \\
\hline $1 / 2$ & $\begin{array}{l}2.3(\text { Group 1) } \\
2.9(\text { Group 2) }\end{array}$ & $\mathrm{y}$ & $\mathrm{y}$ & WTP-RPT-166 \\
\hline $3 / 4$ & $\begin{array}{l}0.6(\text { Group 3) } \\
0.7 \text { (Group 4) }\end{array}$ & $\mathrm{y}$ & $\mathrm{n}$ & WTP-RPT-167 \\
\hline 7 plus AY-102 & $\begin{array}{l}1.8(\text { Group 7) } \\
1.8(\text { AY-102) }\end{array}$ & $\mathrm{y}$ & $\mathrm{n}$ & WTP-RPT-169 \\
\hline
\end{tabular}




\section{Appendix E}

\section{Calculations Supporting CUF Filtration/Leaching}





\section{Appendix E: Calculations Supporting CUF Filtration/Leaching}

This appendix describes the calculations used to support the evaluation of cross flow ultrafiltration (CUF) processing parameters, including filter flux, solids composition, and chemical leach factors.

\section{E.1 Filtration Terms and Equations}

Filtration is examined in this report as a filter flux defined as:

$$
J=\frac{Q_{\text {permeate }}}{A_{\text {filter }}}
$$

where $J$ is the filter flux (GPM/ $\left.\mathrm{ft}^{2}\right)$, $Q_{\text {permeate }}$ is the volumetric permeate flow, and $A_{\text {filter }}$ is the filtration surface area.

In this study, the filter area is assumed as the inside area of the filter element, which is defined as:

$$
A_{\text {filter }}=\pi D i_{\text {filter }} L_{\text {filter }}
$$

where $D i_{\text {filter }}$ is the filter element inside diameter, and $L_{\text {filter }}$ is the filter element length.

The permeate volumetric flow rate is also corrected for viscosity and surface tension effects because the permeate temperature deviated from $25^{\circ} \mathrm{C}$. For a temperature, $\mathrm{T}$, the corrected permeate flow rate [Geeting, 2003] and filter flux are given as:

$$
\begin{aligned}
& Q_{25^{\circ} \mathrm{C}}=Q_{T} e^{2500\left[\frac{1}{T+273}-\frac{1}{298}\right]} \\
& J_{25^{\circ} \mathrm{C}}=J_{T} e^{2500\left[\frac{1}{T+273}-\frac{1}{298}\right]}
\end{aligned}
$$

The pressure drop across the filter (i.e., the transmembrane pressure [TMP]) was calculated in this test as:

$$
T M P=\Delta P_{m}=\frac{\left(P_{\text {inlet }}+P_{\text {outlet }}\right)}{2}-P_{\text {permeate }}
$$

where $P_{\text {inlet }}$ is the pressure at the filter inlet, $P_{\text {outlet }}$ is the pressure at the filter outlet, and $P_{\text {permeate }}$ is the pressure at the permeate side of the filter. A common unit for measurement of TMP is psid, which is pounds per square inch, differential.

The axial velocity inside the filter is calculated by dividing the volumetric slurry flow of the filter by the cross section area of the inside diameter of the filter: 


$$
A V=\frac{Q_{\text {slurry }}}{S_{a}}=\frac{Q_{\text {slurry }}}{\frac{\pi}{4} D i_{\text {filter }}^{2}}
$$

where $S_{a}$ is the cross-sectional area of axial flow, and $Q_{\text {slurry }}$ is the volumetric slurry flowrate in the axial direction.

The Darcy equation [Peterson, 2007] describes filter flux as:

$$
J=\frac{\Delta P_{m}}{\mu_{\text {permeate }} R_{m}}
$$

where $\Delta P_{m}$ is the pressure drop across the filter membrane, $\mu_{\text {permeate }}$ is the viscosity of the permeate, and $R_{m}$ is the overall resistance of the filter membrane.

The filter resistance term, which is a sum of the resistance of the actual filter, the resistance of the filter cake that forms on the surface of the filter surface, and the resistance due to fouling of the filter, is considered more complicated. For cross-flow filtration, the overall resistance of the filter membrane for low concentrated slurries is usually constant, and turbulent flow conditions exist inside the filter. The transmembrane pressure and permeate viscosity are the controlling operational parameters. During dewatering, the slurry's flow properties change, and the filter resistance becomes more significant. When the slurry's undissolved solids (UDS) concentration begins to approach a maximum limit, known as the gel concentration, the filter flux can be described as

$$
J=k \cdot \ln \left[\frac{C_{s}}{C_{g}}\right]
$$

where $C_{s}$ is the slurry UDS concentration, and $C_{g}$ is the slurry gel concentration [Peterson, 2007].

When the flux is impacted by the UDS concentration, the impact of axial velocity becomes significant as well. This is due to how the axial velocity affects the thickness of the filter cake inside the filter.

\section{E.2 Dewatering Operation Analysis}

During dewatering operations of the waste slurries, the transmembrane pressure and axial velocity were maintained at the baseline condition of 40 psid and $13 \mathrm{fps}$. By maintaining the operating conditions of the filtration constant, the only effect on filtration should be the wt\% UDS concentration. A generic chart of the filter flux during the dewatering step (and increasing slurry wt\% UDS) is shown in Figure E.1. The filter flux is initially expected to follow Equation E.6 for low-solids concentrations, which will appear as a nearly horizontal line on the chart when the TMP is held constant. However, as the slurry begins to concentrate, the filtration behavior is expected to change and begin to follow Equation E.7. With graphic analysis, the transition in filtration behavior can be understood. 


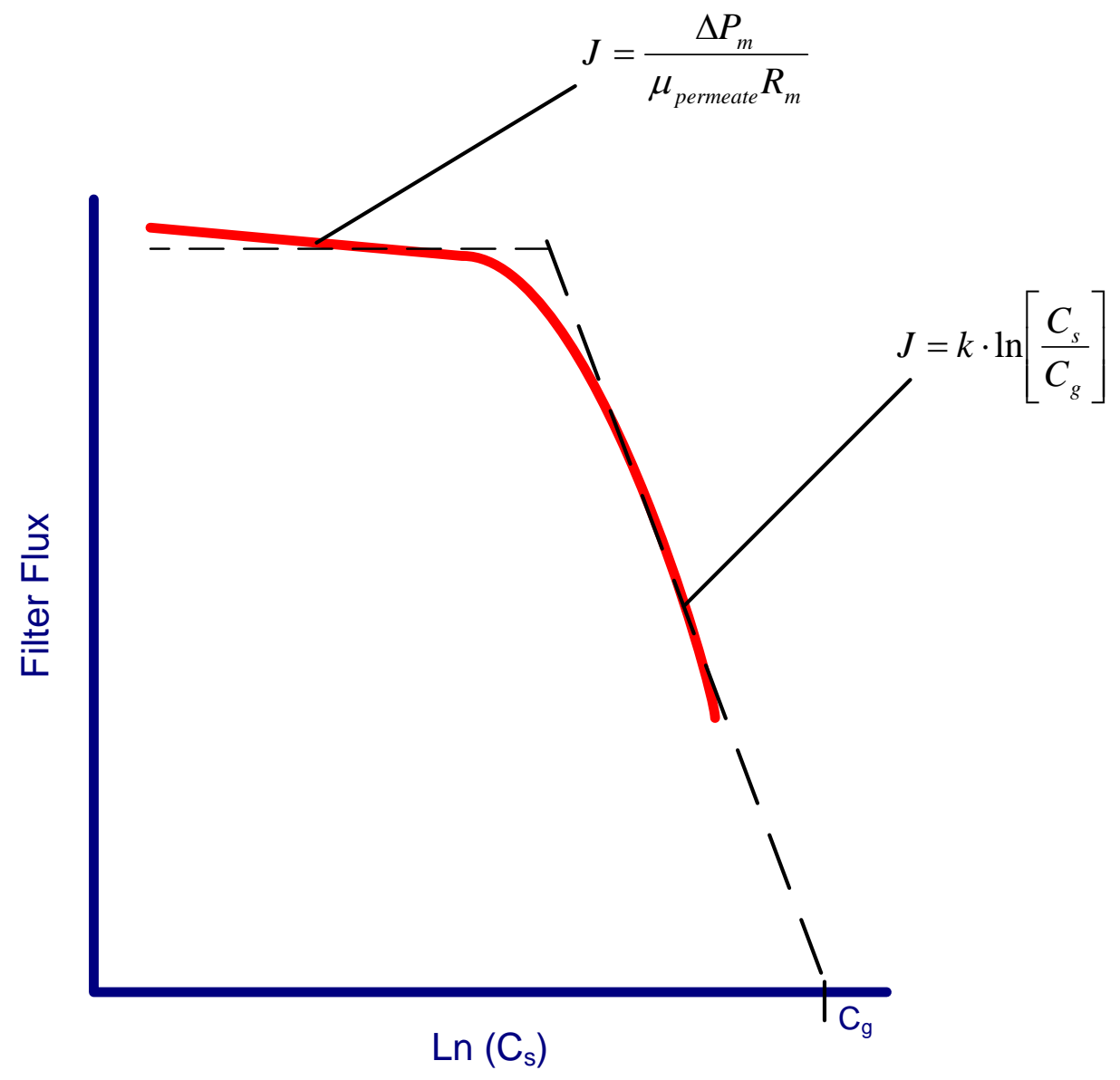

Figure E.1. Example of a Dewatering Curve 
WTP-RPT-170, Rev. 0

\section{E.3 Mass Balance Calculation}

An elemental mass ${ }^{(a)}$ balance was performed on the slurry throughout the process. The initial mass of each element in the slurry was based on initial characterization data of the slurry and the composition of the simulant added. For some components, a wash-factor term was added to account for minor component mass losses attributed to solids dissolution during initial characterization processing. The wash factors were analyte-specific and were calculated from the analyte composition in the solids wash solution relative to the calculated entrainment from the supernatant associated with the wash operation.

$$
m_{i}=M_{\text {slurry }}\left[U D S \cdot x_{i}+\frac{(1-U D S)}{\rho_{\text {sup ernate }}} y_{i}^{\text {sup ernate }}+\left(W F_{i}\right)\right]+M_{\text {simulant }}\left[\frac{y_{i}^{\text {simulant }}}{\rho_{\text {simulant }}}\right]
$$

where

$$
\begin{aligned}
& \mathrm{m}_{\mathrm{i}}=\text { mass of an analyte in the slurry (grams of analyte) } \\
& \mathrm{M}_{\text {slurry }}=\text { mass of waste sample slurry added (grams of slurry) } \\
& \mathrm{M}_{\text {simulant }}=\text { mass of waste supernate simulant added (grams of simulant) } \\
& \mathrm{WF}_{\mathrm{i}}=\text { wash factor, concentration of analyte in the wash solution higher than expected } \\
& \text { from supernate entrainment during solids washing (grams of analyte/grams of } \\
& \text { slurry) } \\
& \text { UDS = undissolved solids fraction of the slurry (grams of undissolved solids/grams of } \\
& \text { slurry) } \\
& \text { (1- UDS) = liquid fraction of the slurry (grams of supernate/grams of slurry) } \\
& \rho_{\text {supernate }}=\text { density of the slurry supernate (grams of supernate } / \mathrm{mL} \text { of supernate) } \\
& \rho_{\text {simulant }}=\text { density of the simulant supernate (grams of simulant } / \mathrm{mL} \text { of simulant) } \\
& \mathrm{x}_{\mathrm{i}}=\text { analyte concentration in the UDS, dry basis (grams of analyte/grams of } \\
& \text { undissolved solids) } \\
& \mathrm{y}_{\mathrm{i}}^{\text {supernate }}=\text { analyte concentration in the liquid phase of the slurry, wet basis. (grams of analyte } \\
& \text { /mL of supernate) } \\
& \mathrm{y}_{\mathrm{i}}^{\text {simulant }}=\text { analyte concentration in the supernate simulant, wet basis. (grams of analyte } / \mathrm{mL} \\
& \text { of simulant) }
\end{aligned}
$$

Changes in the mass of each element would occur from either sample losses of the slurry, transfer losses, or dewatering operations. Changes to the slurry analyte masses were calculated according to Equation E.9 where a slurry sample mass loss, a filtrate mass loss, and slurry transfer mass loss are accounted for, as appropriate.

$$
m_{i}^{\text {final }}=m_{i}^{\text {initial }}-M_{\text {slurrysample }}\left[T S \cdot z_{i}\right]-M_{\text {filtrate }}\left[\frac{y_{i}^{\text {sup ernate }}}{\rho_{\text {sup ernate }}}\right]-\frac{M_{\text {loss }}}{M_{\text {initial }}} m_{i}^{\text {initial }}
$$

where $\quad \mathrm{m}_{\mathrm{i}}^{\text {final }}=$ final mass of an analyte in the slurry (grams of analyte)

$$
\begin{aligned}
\mathrm{m}_{\mathrm{i}}^{\text {initial }} & =\text { initial mass of an analyte in the slurry (grams of analyte) } \\
\mathbf{M}_{\text {slurrysamle }} & =\text { mass of slurry sample slurry removed (grams of slurry) } \\
\mathbf{M}_{\text {flitrate }} & =\text { mass of filtered supernate removed from slurry (grams of }
\end{aligned}
$$

(a) Mass balance is described for purposes of discussion. The concepts applied equally to radionuclide analytes where activity balances were followed. 
WTP-RPT-170, Rev. 0

$$
\begin{aligned}
& \text { filtrated supernate) } \\
\mathrm{M}_{\text {initial }}= & \text { initial mass of slurry (grams of slurry) } \\
\mathrm{M}_{\text {loss }}= & \text { mass of slurry lossed (grams of slurry) } \\
\mathrm{TS}= & \text { total solids of the slurry (grams of dried solids in slurry / grams } \\
& \text { of slurry) } \\
\rho_{\text {supernate }=} & \begin{array}{l}
\text { density of the slurry supernate (grams of filtered supernate/mL } \\
\text { of filtered supernate) }
\end{array} \\
\mathrm{z}_{\mathrm{i}}=\begin{array}{l}
\text { analyte concentration in a slurry sample on a dry basis (grams of } \\
\text { analyte/grams of dried solids in slurry) } \\
\text { analyte concentration in the liquid phase on a wet basis (grams } \\
\text { of analyte/mL of filtered supernate) }
\end{array} &
\end{aligned}
$$

\section{E.4 Slurry Solids Composition Calculations}

The compositions of the supernate fraction of the slurry $\left(\mathrm{y}_{\mathrm{i}}\right)$ and dried slurry samples $\left(\mathrm{z}_{\mathrm{i}}\right)$ as defined in section E.3 were determined according to chemical characterization methods described in Appendix A. Calculations of the composition of the undissolved fraction of the slurry were performed as follows.

- Using the running mass balance to predict the mass of each element in the slurry $\left(\mathrm{m}_{\mathrm{i}}\right)$ at each point during the test, the mass of each element in the solids phase $\left(\mathrm{m}_{\mathrm{i}}^{\text {solid }}\right)$ is calculated by subtracting the mass of the element in the liquid phase $\left(\mathrm{m}_{\mathrm{i}}^{\text {supernate }}\right)$ using the supernate composition measurement $\left(\mathrm{y}_{\mathrm{i}}\right)$ and the mass of supernate predicted in the slurry $\left(\mathrm{M}_{\text {supernate }}\right)$. The solids composition is then calculated by dividing the mass of the element in the solids phase by the predicted mass of solids in the slurry ( $\left.\mathrm{M}_{\text {solids }}\right)$.

$$
\begin{gathered}
M_{\text {slurry }}=M_{\text {solids }}+M_{\text {sup ernate }} \\
m_{i}^{\text {solids }}=m_{i}^{\text {slurry }}-y \cdot \frac{M_{\text {sup ernate }}}{\rho_{\text {sup ernate }}} \\
X_{i}=\frac{m_{i}^{\text {solids }}}{M_{\text {solids }}}
\end{gathered}
$$

where $\quad \mathrm{M}_{\text {slurry }}=$ mass of slurry (grams of slurry)

$\mathbf{M}_{\text {solids }}=$ mass of undissolved solids in slurry (grams of solids)

$\mathrm{M}_{\text {supernate }}=$ mass of supernate (grams of supernate)

$\mathrm{m}_{\mathrm{i}}^{\text {slurry }}=$ mass of an analyte in the slurry (grams of analyte)

$\mathrm{m}_{\mathrm{i}}^{\text {solids }}=$ initial mass of an analyte in the undissolved solids of the slurry (grams of analyte)

$\mathrm{x}_{\mathrm{i}}=$ analyte composition of the undissolved solids of the slurry (grams of analyte/grams of undissolved solids)

- Using the measured dry slurry composition $\left(\mathrm{z}_{\mathrm{i}}\right)$ wet supernate composition $\left(\mathrm{y}_{\mathrm{i}}\right)$, the total solids (TS) and the UDS composition can be directly calculated by: 
WTP-RPT-170, Rev. 0

$$
x_{i}=\left[\frac{1}{U D S}\right]\left[\left(T S \cdot z_{i}\right)-(1-U D S)\left(\frac{y_{i}}{\rho_{\text {sup ernate }}}\right)\right]
$$

where $\quad \mathrm{x}_{\mathrm{i}}=$ analyte concentration in the UDS, dry basis (grams of analyte / grams of undissolved solids)

UDS = undissolved solids fraction of the slurry (grams of undissolved solids/grams of slurry)

TS = total solids of the slurry (grams of dried solids in slurry / grams of slurry)

$\mathrm{z}_{\mathrm{i}}=$ analyte concentration in a slurry sample on a dry basis (grams of analyte/grams of dried solids in slurry)

$(1-$ UDS $)=$ liquid fraction of the slurry (grams of supernate/grams of slurry)

$\mathrm{y}_{\mathrm{i}}=$ analyte concentration in the liquid phase of the slurry, wet basis. (grams of analyte $/ \mathrm{mL}$ of supernate)

$\rho_{\text {supernate }}=$ density of the slurry supernate (grams of supernate/mL of supernate)

\section{E.5 Chemical Leach Factors for Caustic Leaching}

In this report, the chemical leach factor is defined as the percentage difference in mass of a solids component in the waste before and after chemical leaching.

$$
f_{i}=1-\frac{m_{i}^{\text {final_solids }}}{m_{i}^{\text {initial_solids }}}
$$

where $f_{i}$ is the leach factor for component $\mathrm{i}, m_{i}^{\text {initial } \_ \text {solids }}$ is the initial solids mass of component $\mathrm{i}$, and $m_{i}^{\text {final_solids }}$ is the final solids mass of component $i$.

The following methods were used to calculate solids leach factors:

1) Perform a continuing analyte mass balance of the system. This approach required the assessment of masses (slurry and aqueous) in and out of the CUF along with the calculated or measured wt\% UDS in conjunction with analytical data. The analyte fractionation from the solids phase to the liquid phase can be calculated.

2) Use an inert or non-leachable component as an internal tracer in the solids fraction. Perform a mass balance of the slurry before and after leaching using insoluble components, such as uranium, to trace the fractional change in mass. Substituting dry mass compositions for leach component $i$ and inert component $j$ in Equation E.9, the leach factor becomes:

$$
f_{i}=1-\left(\frac{x_{i}^{\text {final }}}{x_{i}^{\text {initial }}}\right)\left(\frac{x_{j}^{\text {initial }}}{x_{j}^{\text {final }}}\right)
$$


The ratio between the inert compositions is commonly called a concentration factor (CF), defined as:

$$
C F=\left(\frac{x_{j}^{\text {final }}}{x_{j}^{\text {initial }}}\right)
$$

3) Equation E.15 then changes to:

$$
f_{i}=1-\left(\frac{x_{i}^{\text {final }}}{x_{i}^{\text {initial }} C F}\right)
$$

4) Perform a mass balance of the liquid phase before and after leaching to measure the analyte mobilization into the aqueous phase. This approach required the determination of total analyte in the aqueous phase before leaching and total analyte quantity in the aqueous phase after leaching. The difference was equivalent to the total mass leached from the solids phase. 

WTP-RPT-170, Rev. 0

Appendix F

Group 8 CUF Rheology 



\begin{tabular}{llll} 
& & & \\
\hline Date: & November 21, 2008 & & $\begin{array}{c}\text { PacITIC NOFCHV } \\
\text { NATIONAL LAB }\end{array}$ \\
To: & Rick Shimskey & Project No.: & 53019 \\
From: & Richard Daniel & Internal Distribution: & Rick Shimskey \\
Subject: & CUF Testing Rheology of & & Richard Daniel \\
& Ferrocyanide (FeCN) Wastes & & \\
& (Group 8) & &
\end{tabular}

\section{Acronyms and Abbreviations}

$\begin{array}{ll}\text { Acronym } & \text { Definition } \\ \text { AV } & \text { Axial Velocity } \\ \text { DI } & \text { Cells Unit Filter } \\ \text { LRB } & \text { Deionized (water) } \\ \text { NIST } & \text { Laboratory Record Book } \\ \text { RPL } & \text { National Institute of Technology } \\ \text { RPP } & \text { Radiochemical Processing Laboratory } \\ \text { SAL } & \text { River Protection Project } \\ \text { TMP } & \text { Transmembrane Pressure } \\ \text { UDS } & \text { Undissolved solids (concentration) } \\ \text { WTP } & \text { Waste Treatment Plant (Support Program) }\end{array}$

\section{Introduction}

In fulfillment of the requirements of Test Plan TP-RPP-WTP-467 [1], the rheology of select Hanford tank waste samples was characterized at the Radiochemical Processing Laboratory (RPL). This interim characterization report presents rheology test results for Ferrocyanide (FeCN) wastes (Group 8) derived from Cells Unit Filter (CUF) testing efforts. Although the studies described herein are limited to flow-curve testing of waste materials, discussion of shear strength measurements for Group 8 initial characterization (i.e., ashomogenized) samples is included for reference.

\section{Background}

Rheology is the science of material flow and deformation. For fluid systems, including pure liquids, mixtures of liquids, and suspensions of solids in liquids, the rheological properties of that system describe how it responds to an applied force or stress. When applied to solids, stress induces a strain or finite deformation in the material. When applied to pure liquids, stress causes a continuous deformation of the substance or, in simpler terms, fluid flow. Suspensions of solids in liquids or liquid mixtures with internal structure can show a combination of both solid- and liquid-like behavior. In addition, the response of materials to force and deformation may not be constant. Changes in internal structure of materials that occur as a result of mechanical and chemical processes, such as breakage, precipitation of solids, and gelation, may alter the macroscopic flow and deformation properties. For the 
current study, two regions of tank waste flow behavior are considered: 1) incipient motion in settled tank waste solids and 2) non-elastic flow of tank waste slurries and supernates.

\section{Characterization of Incipient Motion - Shear Strength Testing}

For settled tank waste slurry solids, a finite stress must be applied before the material will begin to flow. The stress required to transition the settled solids from elastic deformation to viscous flow is referred to as the shear strength, and its origin can be attributed to static and kinetic friction between individual particles and/or aggregates, strength of the matrix supporting the coarse fraction (i.e., the interstitial fluid), and sludge cohesion arising from interparticle adhesive forces such as van der Waals forces. The resistance of settled solids to motion can be quantified through shear strength testing.

In the current study, measurement of shear strength will be accomplished using the vane method. For the vane technique, the stress required to begin motion is determined by slowly rotating a vane immersed in the test sample's settled solids while continuously monitoring the resisting torque as a function of time. A material's static shear strength is then associated with the maximum torque measured during the transition from initial to steady-state vane rotation. A typical experimental setup for measuring shear strength with a vane is shown in Figure 1. An example torque versus time curve is shown in Figure 2.

The maximum torque required for incipient motion is dependent on vane geometry. To account for vane geometry effects, shear strength is expressed in terms of a uniform and isotropic stress acting over the surface area of the cylinder of rotation swept out by the vane. This uniform stress (i.e., the shear strength of the material) is related to the maximal torque during incipient motion by the equation [2]:

$$
\tau_{S S}=\frac{M_{\max }}{4 \pi R^{3}\left(\frac{H}{2 R}+\frac{1}{3}\right)}
$$

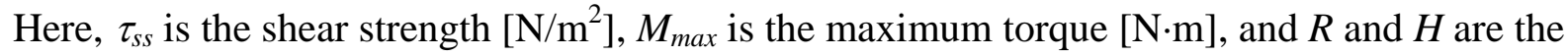
radius and height of the cylinder of rotation swept out by the vane $[\mathrm{m}]$. Because the shear band observed upon slow rotation of the vane does not extend appreciably beyond the vane paddles, $R$ and $H$ are taken to be the dimensions of the vane itself. 

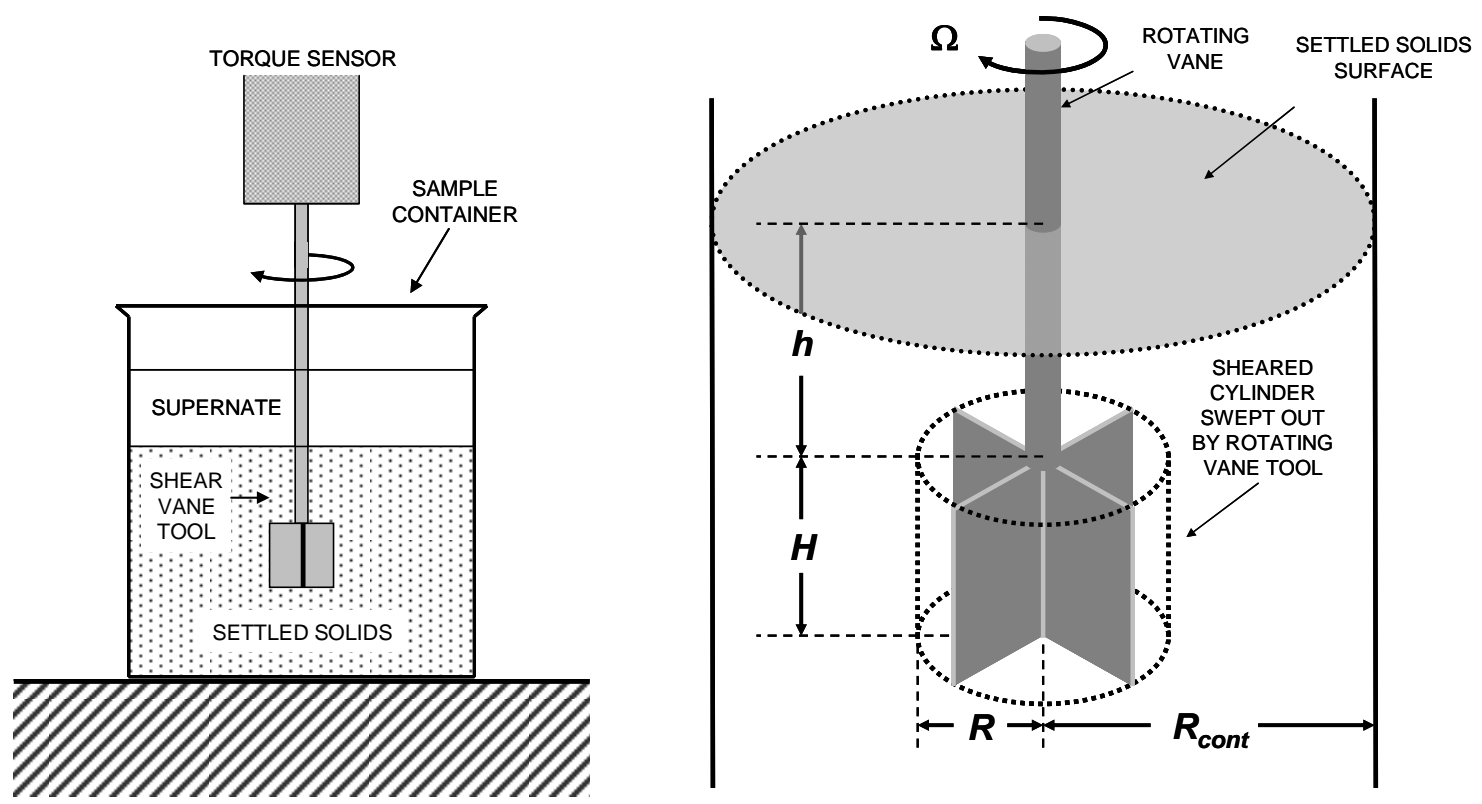

Figure 1. Typical shear strength experimental setup. A sludge / slurry sample in a container of radius $R_{\text {cont }}$ is allowed to settle over a given period of time. A vane tool attached to a viscometer (i.e., a torque sensor) is immersed into the settled solids portion of a sludge or slurry to a depth $h$ (relative to the top of the vane blades). The vane blades have a radius $R$ and a height $H$. The vane is then slowly rotated at a constant rotational speed, $\Omega$. The torque versus time profile is recorded and the maximum torque required to initiate rotation determined. The shear strength is then calculated from this maximum torque based on the assumption of a uniform stress distribution on the known vane tool geometry.

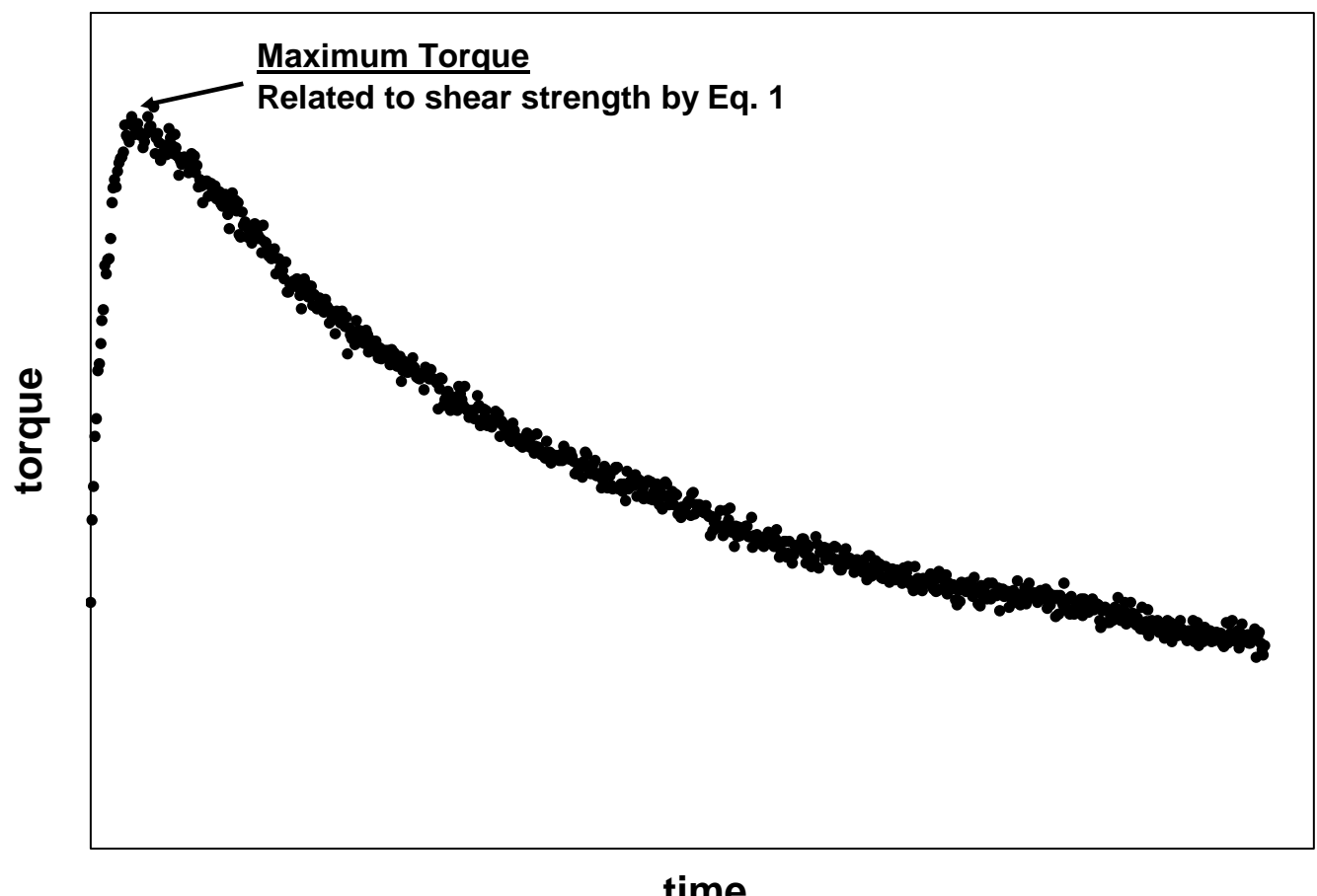

Figure 2. Example shear strength torque versus time curve. The maximum torque corresponds to the onset of motion. Here, the stress applied by vane rotation is finally sufficient to overcome frictional, cohesive, and other structural forces stabilizing the settled solids. 
Proximity of the vane to the sample container inner surfaces as well as the free surface of the settled solids can impact shear strength results. As such, certain geometric constraints must be satisfied for the test to be considered independent of container geometry. These constraints are outlined in Table 1.

Table 1. Vane immersion depth and container geometry constraints for shear strength tests using the vane technique.

\begin{tabular}{|c|c|c|}
\hline Constraint & Criterion & For $8 \times 16 \mathrm{~mm}(\mathrm{R} \times \mathrm{H})$ Vane \\
\hline Vane height to radius & $\mathrm{H}<7 \mathrm{R}$ & $\mathrm{H}<56$ mm (Satisfied) \\
\hline Container radius to vane radius & $\mathrm{R}_{\text {cont }}>2 \mathrm{R}$ & $\mathrm{R}_{\text {cont }}>16 \mathrm{~mm}$ \\
\hline Immersion depth to vane height & $\mathrm{h}>\mathrm{H}$ & $\mathrm{h}>16 \mathrm{~mm}$ \\
\hline $\begin{array}{l}\text { Separation between bottom of vane and } \\
\text { container floor }\left(\mathrm{h}_{\text {floor }}\right)\end{array}$ & $\mathrm{h}_{\text {floor }}>0.5 \mathrm{H}$ & $\mathrm{h}_{\text {floor }}>8 \mathrm{~mm}$ \\
\hline
\end{tabular}

\section{Characterization of Fluid Flow - Flow Curve Testing}

Non-elastic flow of tank waste slurries and supernatants is characterized with rotational viscometry. The goal of rotational viscometry is measurement of a material's flow curve, which describes the shear stress response, $\tau$, as a function of applied shear rate, $\dot{\gamma}$ (also called the rate-of-strain). The result of a flow curve measurement is a set of $\tau$ versus $\dot{\gamma}$ measurements, which are called flow curve data. Flow curve data can be interpreted with several constitutive equations that relate viscous stress to shear-rate. Such analysis allows the flow behavior over a broad range of conditions to be described with just a few rheological descriptors such as viscosity, yield stress, consistency, and flow index.

A concentric cylinder rotational viscometer operated in controlled-rate mode will be used for flow curve testing of tank waste slurries and supernatants. These viscometers operate by placing a given volume of test sample into a measurement cup of known geometry. A cylindrical rotor attached to a torque sensor is then lowered into the sample until the slurry is even with, but does not cover, the top of the rotor. Both the radius and height of the rotor are known such that the gap distance between cup and rotor and surface area of fluid contact can be determined. In addition, the top and bottom of the rotor have recessed surfaces such that the fluid only contacts the radial surfaces of the rotor. A filled rotor-in-cup test geometry is shown in Figure 3. Determination of the fluid flow properties of the sample is made by spinning the rotor at a known rotational speed, $\Omega$, and measuring the resisting torque, $M$, acting on the rotor. Because fluid only contacts the rotor on the radial surfaces of rotation, all of the force resisting steady-state rotation can be ascribed to shearing of the fluid in the cup-rotor gap. Assuming an isotropic fluid and cup and rotor dimensions as shown in Figure 3, the torque acting on the rotor can be directly related to the shear stress at the rotor using the equation,

$$
\tau=\frac{M}{2 \pi H R_{I}^{2}}
$$

Shear stress has units of force per area $\left[\mathrm{N} / \mathrm{m}^{2}\right]$. Calculation of the fluid shear rate at the rotor is complicated by the fact that shear rate depends on both on the measurement system geometry and the fluid rheological properties. For the simplest fluids (i.e., Newtonian fluids) the shear 
rate of the fluid at the rotor can be calculated given the geometry of the cup rotor shear (see Figure 3) by using the equation,

$$
\dot{\gamma}=\left(\frac{2 R_{O}^{2}}{R_{O}^{2}-R_{I}^{2}}\right) \Omega
$$

Here, shear rate has units of inverse seconds [ $1 / \mathrm{s}]$. Calculation of shear rate for materials showing more complex shear stress versus shear rate behavior (i.e., non-Newtonian fluids) requires input of flow curve parameters such as yield stress and degree of shear-thinning or shear-thickening. Because the required input parameters are typically not known prior to measurement, this requirement is typically circumvented by using a cup and rotor system with a small gap $(\sim 1 \mathrm{~mm})$ such that shear rate effects introduced by fluid properties are minimized. For these systems, Eq. 3 provides an accurate determination of shear rate for non-Newtonian materials.

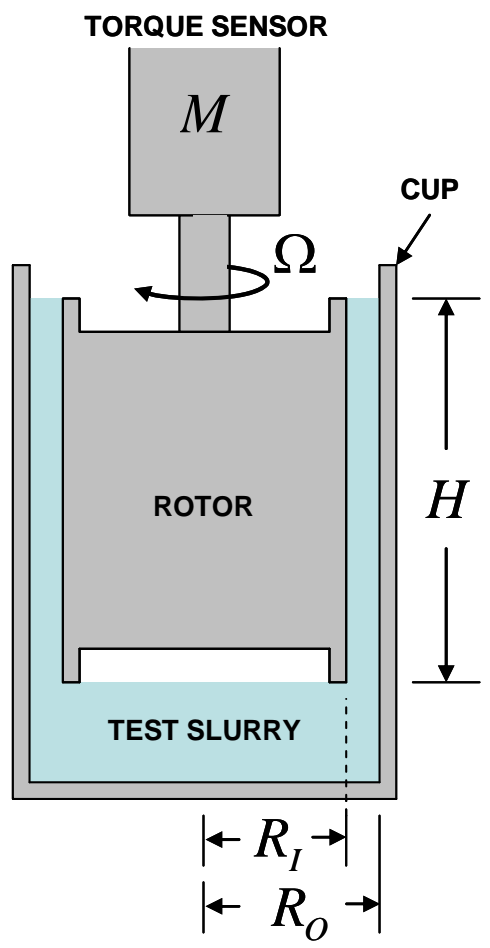

Figure 3. Rotor and cup geometry used in rotational viscometry testing.

Shear rates examined in this study will span approximately 1 to $1000 \mathrm{~s}^{-1}$ and are typical of the order of magnitude of shear rates experienced in pipeline flow [3]. Pipeline flows encountered in the Waste Treatment Plant may exceed the range studied herein. As such, mechanistic models of waste rheology shall be employed to fit shear stress versus shear rate data, allowing extension to shear rates beyond those studied herein.

The resistance of a fluid to flow can be described in terms of the fluid's apparent viscosity, $\eta_{a p p}$, which is defined as the ratio of the shear stress to shear rate: 


$$
\eta_{\text {app }}=\frac{\tau}{\dot{\gamma}}
$$

Often the shear stress and viscosity vary as a function of shear rate. Since the viscosity is defined as the ratio of shear stress to shear rate, the units of the variable are Pa·s. Typically, viscosity is reported in units of centipoise (cP; where $1 \mathrm{cP}=1 \mathrm{mPa} \cdot \mathrm{s})$.

Flow curve data are usually combined plots of $\tau$ and $\eta_{\text {app }}$ as a function of $\dot{\gamma}$. As stated above, flow curve data can be interpreted with several constitutive equations (i.e., flow curves), allowing characterization of that data with just a few rheological descriptors. The behavior of tank waste sludges, slurries, and supernates can typically be described by five common flow curve equations. These are:

- Newtonian - Newtonian fluids flow as a result of any applied stress and show constant viscosity over all shear conditions. The flow curve for Newtonian fluids is:

$$
\tau=\eta \dot{\gamma}
$$

where $\eta$ is the Newtonian viscosity.

- Power-Law (Ostwald) - Power law fluids flow as a result of any applied stress and have viscosities that either increase or decrease with increasing shear rate. The Ostwald flow curve data are described by:

$$
\tau=m \dot{\gamma}^{n}
$$

where $m$ is the power law consistency index and $n$ is the power law index. Power law fluids with $n<1$ are referred to as psuedoplastic (shear-thinning), whereas power law fluids with $n>1$ are referred to as dilatant (shear-thickening).

- Bingham Plastic - Bingham plastics are fluids that show finite yield points. This stress (i.e., the yield stress) must be exceeded before these types of materials flow. Once flow is initiated, the stress response of the material is Newtonian over the rest of the shear rate range. The Bingham-plastics flow curve data are described by:

$$
\tau=\tau_{o}^{B}+k_{B} \dot{\gamma}
$$

where $\tau_{o}^{B}$ is the Bingham yield index and $k_{B}$ is the Bingham consistency index.

- Herschel-Bulkley - Fluids that behave in accordance with a Herschel-Bulkley model show a finite yield followed by power-law behavior over the rest of the shear rate range. They are described by,

$$
\tau=\tau_{o}^{H}+k_{H} \dot{\gamma}^{b}
$$


where $\tau_{o}^{H}$ is the Herschel-Bulkley yield index, $k_{H}$ is the Herschel-Bulkley consistency index, and $b$ is the Herschel-Bulkley power law index.

- Casson - Fluids that behave in accordance with a Casson model show a finite yield followed by psuedoplastic behavior. They are described by,

$$
(\tau)^{0.5}=\left(\tau_{o}^{C}\right)^{0.5}+\left(k_{C} \dot{\gamma}\right)^{0.5}
$$

where $\tau_{o}^{C}$ is the Casson yield index and $k_{C}$ is the Casson consistency index. Although more limited in the types of flow behavior it can describe relative to the HerschelBulkley equation, the Casson model is popular because it is capable of accurately describing many shear-thinning fluids and because units on the parameters are more physically meaningful (e.g., the consistency is in Pa $\cdot s$ versus $\mathrm{Pa} \cdot \mathrm{s}^{\mathrm{n}}$ for the HerschelBulkley model).

Power-law fluids, Bingham plastics, Herschel-Bulkley, and Casson fluids are referred to as non-Newtonian fluids. In generally, liquids without internal and/or interconnected structures (such as tank waste supernatants) are Newtonian. Sludges and slurries are typically nonNewtonian, but their exact behavior depends on the concentration of solids and suspending phase chemistry. Sufficiently dilute slurries may show Newtonian behavior.

\section{Samples}

Group 8 CUF rheology samples were derived as part of bench-scale cross-flow filtration and leaching studies using actual tank waste. Source material for the studies included Group 8 [FeCN Wastes] solids was tank waste homogenization efforts. Initially, Group 8 waste solids and simulated supernate were combined in the CUF slurry reservoir to form a lowsolids concentration Group 8 tank waste slurry. This initial low-solids concentration slurry was subsequently subjected to the following operations:

1. full-recycle ultrafiltration of the low solids-concentration waste slurry at various AV and TMP

2. dewatering of the waste slurry to transform the low-concentration Group 8 slurry to a high-concentration Group 8 slurry

3. full-recycle ultrafiltration of the high solids-concentration waste slurry at various AV and TMP

4. caustic leaching of the waste slurry concentrated sodium hydroxide for 8 hours at $60^{\circ} \mathrm{C}$ (not including time for slurry heat-up, $\sim 2.5 \mathrm{hrs,} \mathrm{and} \mathrm{cool-down,} \sim 6 \mathrm{hrs}$ )

5. dewatering of the caustically leached slurry

6. washing of the caustically leached slurry (includes 4 washes with increasingly dilute sodium hydroxide solutions)

7. addition of the leached and washed Group 7 / AY-102 combined solids to form a combined-leach Group 7 / Group 8 / AY-102 waste mixture.

8. full-recycle ultrafiltration of the combined-leach waste slurry at various AV and TMP

9. dewatering of the combined-leach slurry 
For CUF rheology testing, samples were derived from various points in the ultrafiltration process outlined above. With regard to slurry samples, waste aliquots were taken:

- $\quad$ after mixing of the Group 8 solids and simulant supernate (i.e., low solids concentration initial slurry)

- after filtration of the high solids concentration initial slurry (i.e., after step 3)

- after dewatering of the caustic-leached slurry (i.e., after step 5)

- after washing of the caustic-leached slurry (i.e., after step 6)

- after dewatering of the combined-leach slurry (i.e., after step 9)

Permeate samples were collected during dewatering of the initial and caustic leached slurry.

It should be noted that the test sequence initially attempted to dewater the combinedleach slurry before the AV/TMP matrix testing (i.e., before step 8). However, after initial dewatering, the volume of concentrated combined-leach slurry was insufficient for AV/TMP matrix testing. One consequence of this was that the combined leach slurry experienced significant entrainment and retention of air, making it difficult to pump. To correct this problem, the permeate was returned to the combined leach slurry, and the matrix test was run on the dilute combined leach slurry. After matrix testing, the slurry was again dewatered to provide a concentrated slurry for rheological characterization.

For all rheology samples, approximately $60-100 \mathrm{~mL}$ of waste slurry or permeate were placed into a pre-labeled $120 \mathrm{~mL}$ Qorpak jar. Slurry samples were taken at valve V5, which is located near the slurry pump outlet. Valve V5 was selected for slurry sampling because it resides in the filtration loop and likely provides a representative sample of the slurry in-contact with the filter element. Permeate samples were taken from the dewater collection bottles. Table 2 provides a summary of the samples taken and their given sample identification number.

Table 2. Samples associated with Group 8 CUF rheology testing.

\begin{tabular}{||l|l||}
\hline \hline Sample Jar ID & Description \\
\hline TI640-G8-R1-Slurry & Slurry - low-solids Group 8 slurry before caustic leaching \\
\hline TI640-G8-R1-Perm & Permeate - initial (pre-leach) Group 8 permeate \\
\hline TI640-G8-R2-Slurry & Slurry - high-solids Group 8 slurry before caustic leaching \\
\hline TI640-G8-R3-Slurry & Slurry - dewatered Group 8 slurry after caustic leaching \\
\hline TI640-G8-R3-Perm & Permeate - final (post-leach) Group 8 permeate \\
\hline TI640-G8-R4-Slurry & Slurry - washed Group 8 slurry after caustic leaching \\
\hline TI640-G8-R5-Slurry & Slurry - combined Group 7, Group 8, and AY-102 leached solids slurry \\
\hline
\end{tabular}

\section{Analysis}

Flow curve testing of Group 8 waste slurries was run in parallel with the filtration testing, which began on June $22^{\text {nd }}$ and finished on June $27^{\text {th }}$, 2008. Both permeate samples were saved for later testing. Table 3 provides a list of sample test dates for Group 8 CUF rheology. 
Table 3. Sample testing dates for Groups 8 CUF rheology.

\begin{tabular}{|l|c|}
\hline Sample Jar ID & Date Tested \\
\hline TI640-G8-R1-Slurry & June 23, 2008 \\
\hline TI640-G8-R1-Perm & July 17, 2008 \\
\hline TI640-G8-R2-Slurry & June 24, 2008 \\
\hline TI640-G8-R3-Slurry & June 25, 2008 \\
\hline TI640-G8-R3-Perm & July 7, 2008 \\
\hline TI640-G8-R4-Slurry & June 25, 2008 \\
\hline TI640-G8-R5-Slurry & June 25, 2008 \\
\hline
\end{tabular}

Flow curve testing produced the following reportable data for the Group 8 CUF samples:

- flow curve data for Group 8 slurries at $25^{\circ} \mathrm{C}, 40^{\circ} \mathrm{C}$, and $60^{\circ} \mathrm{C}$ at various points in the filtration and leaching process

- flow curve data for Group 8 permeates at $25^{\circ} \mathrm{C}, 40^{\circ} \mathrm{C}$, and $60^{\circ} \mathrm{C}$ before and after caustic leaching

- best-fit Newtonian, Bingham Plastic, and Casson (as applicable) parameters for Group 8 waste slurries at $25^{\circ} \mathrm{C}, 40^{\circ} \mathrm{C}$, and $60^{\circ} \mathrm{C}$

- Newtonian viscosities for Group 8 permeates at $25^{\circ} \mathrm{C}, 40^{\circ} \mathrm{C}$, and $60^{\circ} \mathrm{C}$

\section{Instrumentation}

Rheological characterization was accomplished using a Rotovisco® RV20 Measuring System equipped with an M5 measuring head and RC20 controller. These components were purchased from HAAKE Mess-Technik GmbH u. Co. (now the Thermo Electron Corporation, Madison, WI 53711). This system is installed in Cell 4 of the Shielded Analytical Laboratory (SAL) at the Radiochemical Processing Laboratory (RPL). The M5 measuring head (SN\# 902398) is a "Searle" type viscometer capable of producing rotational speeds up to 500 RPM and measuring torques up to $0.049 \mathrm{~N} \cdot \mathrm{m}$. The minimum rotational speed and torque resolution achievable by this measuring head are $0.05 \mathrm{RPM}$ and $0.49 \mathrm{mN} \cdot \mathrm{m}$, respectively. Table 4 summarizes the M5 measuring system information.

Table 4. Summary of Haake RV20 system with M5 measuring head.

\begin{tabular}{||l|l||}
\hline \hline Analyzer: & $\begin{array}{l}\text { Rotorvisco }{ }^{\circledR} \text { RV20 Measuring System M with M5 } \\
\text { Measuring Head. }\end{array}$ \\
\hline Measurement principle: & Controlled Rate \\
\hline Serial Number: & 902398 \\
\hline Torque Sensor Range & 0.49 to $49 \mathrm{mN} \cdot \mathrm{s}$ \\
\hline Rotational Rate Range & 0.05 to $500 \mathrm{RPM}$ \\
\hline
\end{tabular}

Specific measurement tools such as cup and rotor assemblies and shear vanes are attached to measure selected rheological properties. Shear strength measurements employed 8 $\mathrm{mm} \times 16 \mathrm{~mm}(\mathrm{R} \times \mathrm{H})$ shear vane tool. Flow curve measurements employed an MV1 stainless steel measuring cup and rotor. The dimensions of the MV1 and vane measuring systems are listed in Table 5. 
Table 5. Vane and Cup and Rotor Measuring System Dimensions.

\begin{tabular}{||l|c|c|c|c||}
\hline Measuring System & $\begin{array}{c}\text { Vane/Rotor } \\
\text { Radius }\end{array}$ & $\begin{array}{c}\text { Vane/Rotor } \\
\text { Height }\end{array}$ & Cup Radius & Gap Width \\
\hline Vane Tool & $8 \mathrm{~mm}$ & $16 \mathrm{~mm}$ & $>16 \mathrm{~mm} \mathrm{(a)}$ & $>8 \mathrm{~mm} \mathrm{(a)}$ \\
\hline MV1 & $20.04 \mathrm{~mm}$ & $60 \mathrm{~mm}$ & $21 \mathrm{~mm}$ & $0.96 \mathrm{~mm}$ \\
\hline (a) Vane tests must satisfy the requirements outlined in Table 1. \\
\hline
\end{tabular}

Temperature control is achieved using a combination of the standard measuring system temperature jacket and a Cole-Parmer ${ }^{\circledR}$ Polystat ${ }^{\circledR}$ Temperature-Controlled Recirculator, Model Number C-12920-00. This recirculator allows heating and cooling of recirculation fluid to the rheometer over $-5^{\circ}$ to $80^{\circ} \mathrm{C}$ with a stability of $\pm 0.5^{\circ} \mathrm{C}$. The temperature jacket is used only for flow curve measurements. It connects the measuring head to the measuring system, centers the cup, and provides heat transfer area between cup and recirculating fluid. The recirculating unit is located next to, but outside, the SAL Cell 4 . The recirculator is connected to the water jacket through a combination of stainless steel piping (outside of cell) and flexible fiber reinforced plastic hose (inside cell). The desired temperature is set using the digital control interface on the recirculating unit. Fluid is circulated between the recirculator and jacket until the desired temperature is achieved at the jacket. Jacket temperature is monitored using a Type-K thermocouple (Omega Model TJ36-CASS-116-G-6-CC) calibrated over $0^{\circ}$ to $100^{\circ} \mathrm{C}$ connected to a multichannel display unit located in the SAL Gallery. Temperature control is employed only for flow curve measurements. Shear strength measurements are carried out at ambient temperature. Details of the temperature measurement and display calibration are given in Table 6. It should be noted that only the first two channels of the temperature display were calibrated. All measurements taken herein employ channel 1.

Temperature control and measurement employed thermocouple 22887 and display 22890. For shear strength measurement of Group 8 settled solids performed under initial characterization testing, the ambient in-cell temperature recorded during testing was based on the thermocouple attached to the Cells Unit Filter (CUF) slurry reservoir installed in SAL Cell 5 (Calibration Barcode 24072).

Table 6. Calibration information for temperature measurement and display systems.

\begin{tabular}{||l|c|c|c|c|c||}
\hline \hline System & Serial \# & $\begin{array}{c}\text { Calibratio } \\
\text { n Barcode }\end{array}$ & Range Calibrated & $\begin{array}{c}\text { Date } \\
\text { Calibrated }\end{array}$ & Date Due \\
\hline $\begin{array}{l}\text { Type-K } \\
\text { Thermocouple }\end{array}$ & $\mathrm{n} / \mathrm{a}$ & 22887 & $0^{\circ}$ to $100^{\circ} \mathrm{C}\left( \pm 2^{\circ} \mathrm{C}\right)$ & $4 / 4 / 2008$ & $4 / 4 / 2009$ \\
\hline $\begin{array}{l}\text { Temperature } \\
\text { Display }\end{array}$ & 6220071 & 22890 & $0^{\circ}$ to $100^{\circ} \mathrm{C}\left( \pm 2^{\circ} \mathrm{C}\right)$ & $4 / 2 / 2008$ & $4 / 2 / 2009$ \\
\hline $\begin{array}{l}\text { Type-K } \\
\text { Thermocouple }\end{array}$ & $\mathrm{n} / \mathrm{a}$ & 24072 & $0^{\circ}$ to $110^{\circ} \mathrm{C}\left( \pm 2^{\circ} \mathrm{C}\right)$ & $5 / 28 / 2008$ & $5 / 28 / 2009$ \\
\hline
\end{tabular}

Rheometer control and data acquisition are accomplished through remote computer connection using the RheoWin Pro Job Manager Software, Version 2.96. The RheoWin software serves as a central program for obtaining, processing, and recording to disk data from the RV20-M5 Measuring System. During measurement, the software automatically converted rotor torque readings into shear stresses based on the appropriate A-factor conversion, such that 


$$
\tau=A M
$$

For the cup and rotor system, the A-factor is defined by

$$
A=\frac{1}{2 \pi H R_{I}^{2}}
$$

The vane tool, the A-factor is defined as:

$$
A=\frac{1}{4 \pi R^{3}\left(\frac{H}{2 R}+\frac{1}{3}\right)}
$$

A-factors for MV1 and $8 \mathrm{~mm} \times 16 \mathrm{~mm}$ vane sensor systems are $6570 \mathrm{~m}^{-3}$ and $\sim 117,000 \mathrm{~m}^{-3}$, respectively. For flow curve testing, the RheoWin software also automatically converted the rotational rate readings into shear rates based on a factory-set "M-factor", such that:

$$
\dot{\gamma}=M_{R} \Omega
$$

where $\Omega$ is the rotational rate in radians per second, and $M_{R}$ is the "M-factor". The M-factor is defined as

$$
M=\left(\frac{2 R_{O}^{2}}{R_{O}^{2}-R_{I}^{2}}\right)
$$

For the MV1 sensor system, the M-factor is 22.350. The RheoWin software also allows postmeasurement processing and interpretation of data. Specifically, it can be used to determine maxima points in shear strength testing and fit flow curve data to any flow curve model (i.e., Eqs. 5-9).

\section{Governing Test Plan, Procedure, and Test Instructions}

The test plan governing the physical characterizations for these samples is River Protection Project - Waste Treatment Plant Support Program (RPP-WTP) document number TP-RPP-WTP-467, Revision 0 [1]. Operation of the HAAKE RV20-M5 Measurement System is governed by RPL-COLLOID-02, Revision 1 [4].

\section{Experimental}

Waste slurries were tested "as-is". No sample treatment was performed during the interval between sample extraction from the CUF and rheology testing, with exception of the mechanical agitation required to disperse any settled waste solids in the test sample jar.

\section{Instrument Performance Check}

As required by RPL-COLLOID-02, the performance of the Haake M5 rheometer must be verified at the beginning of each series of analyses (with the period between performance 
checks not to exceed 30 days during use). Checks are performed using Newtonian viscosity standards certified by methods traceable to the United States National Institute of Standards and Technology (NIST). Checks verify that the Haake M5 rheometer can measure the standard's viscosity to within $10 \%$ for fluids of $10 \mathrm{cP}$ or greater and to within $15 \%$ for fluids less than $10 \mathrm{cP}$ at the temperature listed on the certificate of analysis.

For the measurements described in this report, the performance check employed General Purpose Silicone Fluids purchased from Brookfield Engineering Laboratories, Inc. (Middleboro, Massachusetts, USA, 02346). Silicone oils are single phase liquids and have no suspended solids. For testing, two standards were used: Brookfield Fluid 10 and Brookfield Fluid 100. Tables 7 and 8 provide a summary of each viscosity standard's properties.

Table 7. Properties of Brookfield Fluid 10.

\begin{tabular}{||l|l||}
\hline Fluid & 10 \\
\hline Viscosity & $9.1 \mathrm{cP}$ \\
\hline Temperature & 25 \\
\hline Lot Number & 021308 \\
\hline Expires & April 2009 \\
\hline
\end{tabular}

Table 8. Properties of Brookfield Fluid 100.

\begin{tabular}{||l|l||}
\hline \hline Fluid & 100 \\
\hline Viscosity & $98.2 \mathrm{cP}$ \\
\hline Temperature & 25 \\
\hline Lot Number & 020108 \\
\hline Expires & April 2009 \\
\hline
\end{tabular}

Performance checks consisted of temperature controlled flow curve measurements that employed the MV1 measuring cup and rotor. The measurements reported herein were covered by two separate performance checks covering the months of June and July. Table 9 provides a summary of which performance checks cover the period of performance for measurement of the test samples listed in Table 2.

Table 9. Periods of performance for Group 8 CUF rheology.

\begin{tabular}{|c|c|c|c|}
\hline $\begin{array}{l}\text { Period of } \\
\text { Performance }\end{array}$ & $\begin{array}{c}\text { Performance } \\
\text { Check Date }\end{array}$ & Silicone Oils Used & $\begin{array}{c}\text { Applicable Sample } \\
\text { Analyses }\end{array}$ \\
\hline June 2008 & June 12, 2008 & Fluids 10 and 100 & $\begin{array}{l}\text { TI640-G8-R1-Slurry } \\
\text { TI640-G8-R2-Slurry } \\
\text { TI640-G8-R3-Slurry } \\
\text { TI640-G8-R4-Slurry } \\
\text { TI640-G8-R5-Slurry } \\
\text { TI640-G8-R3-Perm }\end{array}$ \\
\hline July 2008 & July 16, 2008 & Fluids 10 and 100 & TI640-G8-R1-Perm \\
\hline
\end{tabular}

In all cases, execution of performance verification was as follows:

1. The MVI rotor was installed on the M5 measuring head.

2. The temperature jacket was installed and the recirculator turned on and set to $25^{\circ} \mathrm{C}$. The jacket was allowed to achieve temperature equilibrium before continuing.

3. Approximately 40 to $50 \mathrm{~mL}$ of viscosity fluid was added to the MV1 cup.

4. The measuring cup was installed into the water jacket by slowly raising it on a laboratory jack stand. During installation, the cup slides into the base of the water jacket where it slides over the rotor. The rotor volume displaces the test material, forcing it to fill the gap between cup and rotor. While the cup was being raised, the liquid level relative to the top of the rotor was monitored through an opening in the top of the water jacket using a small digital video camera installed in-cell. The cup was raised until the test material was observed to spill over the top of the rotor. Before 
continuing, an attempt was made to remove the excess viscosity standard from the top of the rotor using a plastic transfer pipette. However, 1 to $3 \mathrm{~mL}$ of excess test liquid could not be retrieved and remained in the upper rotor recess during flow curve measurement.

5. The viscosity standard was left undisturbed in the measuring system for 5 minutes to allow temperature equilibration.

6. The material flow curve data were measured. Rheological analysis was performed over a 15-minute period, split into three 5-minute intervals. Over the first 5 minutes, the shear rate was smoothly increased from zero to $1000 \mathrm{~s}^{-1}$. For the second 5 minutes, the shear rate was held constant at $1000 \mathrm{~s}^{-1}$. For the final 5-minutes, the shear rate was smoothly reduced back to zero. During this time, the resisting torque and rotational rate was continuously monitored and recorded.

After the measurement, flow curve data were automatically fit to a Newtonian model (Eq. 5) by the RheoWin software. The regressed value was saved to the measurement file and was also transcribed into the LRB. The absolute relative percent difference, $E$, between the measured viscosity, $\eta_{\text {meas }}$, and that listed on the certificate of analysis, $\eta_{\text {list }}$, was calculated as:

$$
E=\left|\frac{\eta_{\text {meas }}-\eta_{\text {list }}}{\eta_{\text {list }}}\right| \times 100 \%
$$

The performance check was considered acceptable if $E$ is less than $10 \%$ for fluids with list viscosities greater than or equal to $10 \mathrm{cP}$ or is less than $15 \%$ for fluids with list viscosities less than $10 \mathrm{cP}$. Before the start of any quality affecting measurements of Group 8 CUF rheology, the RV20-M5 was verified to be in acceptable performance. Table 10 lists the results of each performance verification/check carried out in association with Group 8 CUF characterization efforts. As indicated in the table, the RV20-M5 measuring system showed acceptable performance for both test fluids.

Table 10. Results of rheometer performance checks.

\begin{tabular}{|l|c|c|c|c|c||}
\hline Fluid & $\begin{array}{c}\text { Period of } \\
\text { Performance }\end{array}$ & $\begin{array}{c}\text { List } \\
\text { Viscosity } \\
\text { (cP) }\end{array}$ & $\begin{array}{c}\text { Measured } \\
\text { Viscosity } \\
\text { (cP) }\end{array}$ & $E$ & Acceptable \\
\hline Brookfield Fluid 10 & June '08 & 9.1 & 8.5 & $6.7 \%$ & Yes \\
\hline Brookfield Fluid 100 & June '08 & 98.2 & 102 & $4.1 \%$ & Yes \\
\hline Brookfield Fluid 10 & July '08 & 9.1 & 9.9 & $2.7 \%$ & Yes \\
\hline Brookfield Fluid 100 & July '08 & 98.2 & 101 & $8.7 \%$ & Yes \\
\hline
\end{tabular}

\section{Shear Strength Testing}

No shear strength testing was performed in association with Group 8 CUF rheology testing. As such, the experimental test procedure for shear strength is not presented in detail herein. Shear strength results for the Group 8 initial characterization sample are provided for reference only. Additional details regarding how Group 8 initial characterization shear strength measurements were performed are given in TDP-WTP-323 [5]. It should be noted that because the volume of settled solids the Group 8 test samples, it was not possible to satisfy the geometric constraints outlined for vane immersion in Table 1. As such, the shear strength result reported herein is not independent of container geometry. 


\section{Flow Curve Testing}

Flow curve testing for Group 8 CUF testing samples employed an MV1 cup and rotor. Each flow curve measurement was accomplished as follows:

1. The MV1 rotor was installed on the measuring head.

2. The temperature jacket was installed and the recirculator turned on and set to $25^{\circ} \mathrm{C}$. The jacket was allowed to achieve temperature equilibrium.

3. The test sample was transferred from its source jar into the MV1 measurement cup. Sample was added to the cup until the fluid level was above the first (i.e., lowest) cup level marker but still below the second level marker. This typically required 40 to 50 $\mathrm{mL}$ of sample. Gross material transfer was accomplished by pouring the sample into the test container until a rough estimate of the required sample volume was obtained. Fine level adjustments were made by adding and removing material to and from the measuring cup using a plastic transfer pipette.

4. The measuring cup was installed into the water jacket by slowly raising it on a laboratory jack stand. The cup was raised until the test material was observed to spill over the top of the rotor. Before continuing, excess material was removed from the top of the rotor (to the extent possible) using a plastic transfer pipette. In most cases, there was approximately 1-3 mL of excess material that could not be removed from the upper rotor recess.

5. A moisture barrier was wetted and installed over the opening at the top of the temperature jacket. This barrier is a stainless steel clamshell collar lined with a sponge. It serves to minimize sample evaporation by blocking openings at the top of the water jacket (where the sample is exposed to air) and by humidifying the air space above the sample.

6. The sample was left undisturbed in the measuring system for 5 minutes to allow temperature equilibration.

7. The sample was sheared for 3 minutes to break sample structure, to attempt resuspension any settled slurry particles, and to verify that the rotor was properly centered. This shear step used a constant rotational speed of 200 RPM (470 s $\mathrm{s}^{-1}$ ). During this shear step, the rotor torque was recorded as a function of time to record any shear-induced changes in the stress-response of the sample and (in cases of certain Newtonian slurries) provide a secondary measurement of viscosity.

8. The material flow curve data were measured. Rheological analysis was performed over a 15-minute period, split into three 5-minute intervals. Over the first 5 minutes, the shear rate was smoothly increased from zero to $1000 \mathrm{~s}^{-1}$. For the second 5 minutes, the shear rate was held constant at $1000 \mathrm{~s}^{-1}$. For the final 5-minutes, the shear rate was smoothly reduced back to zero. During this time, the resisting torque and rotational rate were continuously monitored and recorded. In certain measurements, a lower maximum shear rate than $1000 \mathrm{~s}^{-1}$ was selected to avoid regions of unstable flow.

9. The flow curve data for $25^{\circ} \mathrm{C}$ were saved using the RheoWin file format and a unique filename identifier. Sample information and the associated RheoWin filename were entered into the LRB.

10. The cup was raised so that fresh sludge/slurry filled the gap. Excess sludge was pipetted from the top. The moisture guard was, removed, re-wetted, and then reinstalled.

11. The flow curve measurement at $25^{\circ} \mathrm{C}$ was repeated as per steps 7 through 9 . 
12. The temperature set point was set to $40^{\circ} \mathrm{C}$. Once, the jacket had reached the temperature set point, the sample was allowed an additional 5 minutes to reach temperature equilibrium. The cup was raised so that fresh sludge/slurry filled the gap. Excess sludge was pipetted from the top. The moisture guard was, removed, re-wetted, and then re-installed.

13. The flow curve at $40^{\circ} \mathrm{C}$ was measured as per steps 7 through 9 .

14. The temperature set point was set to $60^{\circ} \mathrm{C}$. Once, the jacket had reached the temperature set point, the sample was allowed an additional 5 minutes to reach temperature equilibrium. The cup was raised so that fresh sludge/slurry filled the gap. Excess sludge was pipetted from the top. The moisture guard was, removed, re-wetted, and then re-installed.

15. The flow curve at $60^{\circ} \mathrm{C}$ was measured as per steps 7 through 9 .

16. At the end of testing, the measuring cup was removed from the system. The test material was returned to its original container. The measuring system was disassembled. Any slurry or precipitated salt solids remaining in the cup or rotor were cleaned-off using by rinsing with copious amounts of water and by wiping down the instrument with a damp cloth.

At the end of each flow curve measurement, all information relevant to the measurement, including raw and calculated measurement results and sample information, were saved to disk using the RheoWin file format and a unique filename identifier. The filename, temperature, start and end of temperature equilibration, and a basic sample identifier were recorded in a Laboratory Record Book (LRB). A separate data file was used for each flow curve measurement.

Post-measurement analysis and review of flow curve data were accomplished using the RheoWin Pro Data Manager software, Version 2.96. For each set of measurement data, the flow curve data was characterized by determining the best-fit parameters for the constitutive equation outlined in Section 2.0 of this report (i.e., the Newtonian, Power-Law, BinghamPlastic, and Herschel-Bulkley flow models). This analysis utilized the least-squares data regression routine native to the RheoWin 2.96 software. Regressions typically included both up-ramp, constant rotation, and down-ramp portions of the flow curve, resulting in an "average" set of model parameters for the total flow curve. In a number of cases, only limit portions of the flow curve data (e.g., up-ramp only) were fit. For example, model fits were often limited to specific shear rate ranges to avoid flow curve anomalies such as Taylor Vortices (at high shear rates).

\section{Results and Discussion}

The following sections discuss the results of flow curve testing for Group 8 CUF samples. Before discussing these results, flow curve and shear strength measurements for the Group 8 source material, namely that derived from homogenization efforts, will be introduced and reviewed as a point-of-reference for discussion of the CUF flow curves. Following that discussion, the slurry flow curves for each sample will be introduced and discussed one-byone, with an emphasis on the temperature effects and flow curve behavior of each particular sample. After all flow curve measurement data have been presented, the results will be compared to one another to elucidate the effect of CUF processing on relative sample rheology. 
Next, a discussion of permeate rheology will be given. Finally, the results of flow curve testing will be summarized.

\subsection{Source Input Materials}

Before discussing the rheology results for Group 8 CUF testing, the rheology of the Group 8 source material shall be introduced in detail. The source material presented for this group correspond to that measured for the initial characterization sample derived from waste homogenization. In addition, rheology of the caustic-leached and washed Group 7 slurry shall be covered, as this slurry is added to the Group 8 CUF slurry to form the final combined leach slurry. The Group 7 leached material represents treated waste solids from both waste processing Group 7 and tank AY102.

\section{Sample TI516-G8-AR-P1: Source Material for Group 8 CUF}

Sample TI516-G8-AR-P1 was derived from homogenization efforts and is representative of the source Group 8 material used for CUF testing. The slurry sample corresponds to the Group 8 initial characterization sludge sample. It has an undissolved solids concentration of 11.4-wt\% and a supernate dissolved solids concentration of $19.0 \%$-wt\%.

The results of Group 8 initial characterization shear strength testing are shown in Table 11. Three separate observations after 72 hours of settling time indicate a shear strength ranging from 11 to $13 \mathrm{~Pa}$. The single measurement at the central location suggests a shear strength of approximately $11 \mathrm{~Pa}$. Slighter higher shear strengths of $\sim 13 \mathrm{~Pa}$ were encountered during measurements made near the container walls. Radial measurements were likely influenced by vane-wall interactions, yielding the observed increase in shear strength at these test locations.

These results should be approached with some caution. The geometric constraints required for shear strength testing could not be met because of limited settled solids volume. As a result, all reported values are likely influenced by container geometry. Proximity of the vane to the floor of the container may cause on an increase in the measurement shear strength similar to that observed in the radial measurements. This increase would be driven by coupling of stress interactions, such as the formation of linked stress chains, between the vane tool, waste particles, and container floor. On the other hand, proximity of the vane to the surface tends to reduce the measured value of shear strength. Reduction is a result of the vane no longer having to shear the volume of material above the top of the blades.

Table 11. Shear strength of Group 8 Initial Characterization settled solids at ambient hot-cell temperature (sample TI516-G8-AR-P1)

\begin{tabular}{||c|c|c|c|c||}
\hline $\begin{array}{c}\text { Test } \\
\text { Number }\end{array}$ & Location & $\begin{array}{c}\text { Temperature } \\
{\left[{ }^{\circ} \mathrm{C}\right]}\end{array}$ & Settling Time & $\begin{array}{c}\text { Shear Strength } \\
{[\mathrm{Pa}]}\end{array}$ \\
\hline 1 & Center & 27.6 & 72 hours & $11 \mathrm{~Pa}$ \\
\hline 2 & Radial (Near Wall) & 27.6 & 72 hours & $13 \mathrm{~Pa}$ \\
\hline 3 & Radial (Near Wall) & 27.6 & 72 hours & $13 \mathrm{~Pa}$ \\
\hline Average & ---- & ---- & $\sim 13 \mathrm{~Pa}$ \\
\hline
\end{tabular}

Figure 4 shows the results of flow curve measurements for the Group 8 initial characterization slurry sample, TI516-G8-AR-P1, at $25^{\circ} \mathrm{C}, 40^{\circ} \mathrm{C}$, and $60^{\circ} \mathrm{C}$. Flow curve data indicate Newtonian flow behavior. The response over shear rates of 0 to $\sim 500 \mathrm{~s}^{-1}$ is linear at all 
temperatures. At higher shear rates, flow curve data show an increase in the slope of the stress response curve that is indicative of Taylor vortex formation onset (i.e., unstable/turbulent flow). As such, flow curve data beyond $500 \mathrm{~s}^{-1}$ are unusable. Apart from Taylor vortex formation, the flow curve data are relatively free of data anomalies such as hysteresis. However, there is significant overlap between flow curve data at $25^{\circ} \mathrm{C}, 40^{\circ} \mathrm{C}$, and $60^{\circ} \mathrm{C}$, and as a result, no temperature trends are immediately identifiable. Overall, the stress response of the Group 8 slurry is weak ( $1 \mathrm{~Pa}$ at $\left.500 \mathrm{~s}^{-1}\right)$ and indicative of a low viscosity slurry. Because of the weak response, the signal-to-noise ratio observed for these flow curve measurements is low over 0 to $500 \mathrm{~s}^{-1}$.

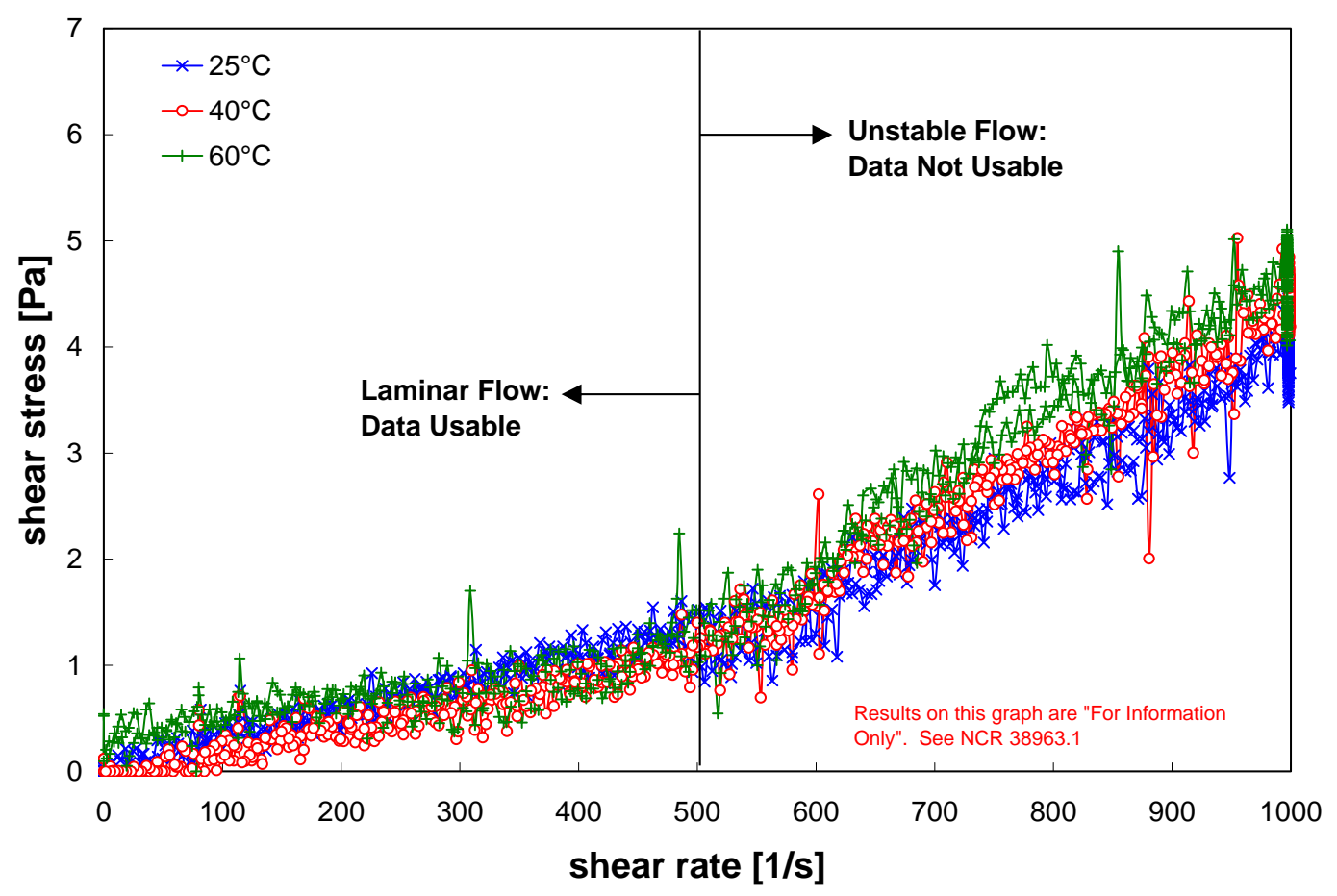

Figure 4. Flow curve (shear stress versus shear rate) for the Group 8 initial characterization slurry sample TI516-G8-AR-P1 at $25^{\circ} \mathrm{C}, 40^{\circ} \mathrm{C}$, and $60^{\circ} \mathrm{C}$. Only the repeat (second) measurement at $25^{\circ} \mathrm{C}$ is shown. The list temperatures for these measurements could not be verified. Results are "For Information Only"; see NCR 38963.1 for details.

To quantify the stress response behavior shown in Figure 4, the viscosity for slurry sample TI516-G8-AR-P1 is determined as a function of temperature by regression analysis of the flow curve data. Analysis is complicated by two factors: 1) Taylor vortex formation and 2) weak stress response coupled with small (but finite) stress offset. To exclude data affected by Taylor vortex formation, a limited shear rate range is used for fitting analysis. For the initial $25^{\circ} \mathrm{C}$, the range is restricted to 0 to $500 \mathrm{~s}^{-1}$. For the replicate $25^{\circ} \mathrm{C}$ measurement and the $60^{\circ} \mathrm{C}$ measurement, the range is limited to 0 to $400 \mathrm{~s}^{-1}$. Finally, fit of the $40^{\circ} \mathrm{C}$ measurement data is limited to 100 to $500 \mathrm{~s}^{-1}$. The lower bound of $100 \mathrm{~s}^{-1}$ in the latter fit excludes data affected by a negative torque correct (i.e., a negative stress offset). 
The flow curve data show minor stress offset (on the order of $\pm 0.2 \mathrm{~Pa}$ ). This offset results from the difficulty in zeroing the initial torque reading on the M5-system. Although this \pm 0.2 Pa stress offset is not significant in terms of the limits of accuracy of the instrument ( $\sim 0.5 \mathrm{~Pa})$, it is significant in terms of the overall stress response of the slurry ( $\sim \mathrm{Pa})$. As such, neglecting the offset can bias the regressed viscosity. Offset is present in the flow curve measurements to varying degree. The replicate $25^{\circ} \mathrm{C}$ shows little offset, where as the $60^{\circ} \mathrm{C}$ shows an offset of $\sim 0.3 \mathrm{~Pa}$. The $40^{\circ} \mathrm{C}$ measurement data appear to exhibit a negative stress offset, which the RheoWin software corrects by zeroing all stress less than zero to zero. For the fitting analysis, offset is accounted by using a Bingham-Plastic model to fit the flow curve data. It is assumed that the slurry behavior is Newtonian, and the Newtonian viscosity is associated with the regressed value for Bingham-Plastic consistency. Bingham-Plastic yield stress is neglected.

Table 12 summarizes the Newtonian viscosity results derived from flow curve data for sample TI516-G8-AR-P1. It should be stressed that these results are "For Information Only" NCR 38963.1 provides additional details regarding the quality status for this data. Table 12 indicates a Group 8 slurry viscosity that falls between 1.4 and $3.3 \mathrm{cP}$ depending on temperature. Increased temperature appears to yield a decrease in the slurry viscosity, likely as a result of suspending phase viscosity decrease. However, the initial and replicate viscosity measurement at $25^{\circ} \mathrm{C}$ do not compare, showing a significant $0.7 \mathrm{~Pa}$ difference or $20 \%$ relative percent change between initial and replicate measurement. The replicate measurement at $25^{\circ} \mathrm{C}$ occurs at the end of the measurement series, after both $40^{\circ} \mathrm{C}$ and $60^{\circ} \mathrm{C}$. Observation of lower viscosity could be a result of 1 ) changes in the slurry structure that occur after prolonged slurry shearing (i.e., thixotropy) or 2) settling of slurry solids. Because of the decrease observed in the replicate measurement, it is difficult to ascertain if the decreases observed at $40^{\circ} \mathrm{C}$ and $60^{\circ} \mathrm{C}$ are attributable to temperature alone or include both temperature and settling effects.

Table 12. Results of fitting analysis for Group 8 Initial Characterization Sample TI516-G8-AR-P1. Unless specified otherwise, flow curve viscosities are determined by fitting both up- and down-ramp data.

\begin{tabular}{||c|c|c|c|c||}
\hline \hline Model & $\begin{array}{c}\text { Temperature } \\
{\left[{ }^{\circ} \mathbf{C}\right]}\end{array}$ & Range & $\begin{array}{c}\text { Viscosity } \\
{[\mathbf{m P a} \cdot \mathbf{s}]}\end{array}$ & $\mathbf{R}$ \\
\hline \multirow{3}{*}{$\begin{array}{c}\text { Newtonian } \\
\text { (Flow Curve) }\end{array}$} & $25(1$ of 2$)$ & $0-500 \mathrm{~s}^{-1}$ & 3.3 & 0.89 \\
\cline { 2 - 5 } & $25(2$ of 2$)$ & $0-400 \mathrm{~s}^{-1}$ & 2.6 & 0.94 \\
\cline { 2 - 5 } & 40 & $100-500 \mathrm{~s}^{-1}$ & 2.2 & 0.89 \\
\cline { 2 - 5 } & 60 & $0-400 \mathrm{~s}^{-1}$ & 1.4 & 0.69 \\
\hline \multicolumn{2}{|l|}{ Results are "For Information Only". SeR 38963.1 } \\
\hline
\end{tabular}

Test Plan TP-RPP-WTP-467 requests determination of apparent viscosity at $33 \mathrm{~s}^{-1}$. For the current measurement, measurement noise and the low slurry viscosity $(<5 \mathrm{cP})$ makes determination of apparent viscosity at this shear rate difficult and subject to significant error. In terms of calculated apparent viscosities, the Newtonian results reported in Table 12 represent the apparent viscosity over the entire range of shear and should provide a reasonable estimation of the apparent viscosity at $33 \mathrm{~s}^{-1}$. Thus, determination of apparent viscosity from measurement data is forgone in favor for the results in Table 12.

In summary, flow curve analysis for Group 8 Initial Characterization slurry sample, TI516-G8-AR-P1, suggests Newtonian rheology. Regression analysis of the flow curve data 
finds a slurry viscosity of $2.6-3.3 \mathrm{cP}$ at $25^{\circ} \mathrm{C}, 2.2$ at $40^{\circ} \mathrm{C}, 1.4 \mathrm{cP}$ at $60^{\circ} \mathrm{C}$. A decrease in slurry viscosity is observed at higher temperatures; however, part of this decrease may result from settling of slurry solids over the course of the temperature series.

Sample TI624-G7-R4-Slurry: Source Material for Combined Leach Slurry

Sample TI624-G7-R4-Slurry was derived from Group 7 CUF testing and is comprised of solids from waste processing group 7 and tank AY-102 that have been caustic-leached, dewatered, and washed. This material is added to Group 8 waste solids that were leached during Group 8 CUF testing to form the Group 8 combined-leach slurry. Sample TI624-G7R4-Slurry has an undissolved solids concentration of $\sim 14$-wt $\%$ and a supernate dissolved solids concentration of $\sim 6-\mathrm{wt} \%$.

Figure 5 shows the results of flow curve testing for sample TI624-G7-R4-Slurry. The results of the measurement indicate that the flow behavior is weakly non-Newtonian. The yield stress is low $(\sim 0.5 \mathrm{~Pa})$ and near or at the instrument limit of detection. After yield, the flow curve data show a linear stress response over shear rates from zero up to $500 \mathrm{~s}^{-1}$. At higher shear rates (generally $500 \mathrm{~s}^{-1}$ and above), flow curve data show an increase in the slope of the stress response curve. This increase is likely a result of Taylor vortex formation onset (i.e., unstable/turbulent flow), which renders the affected data unusable.

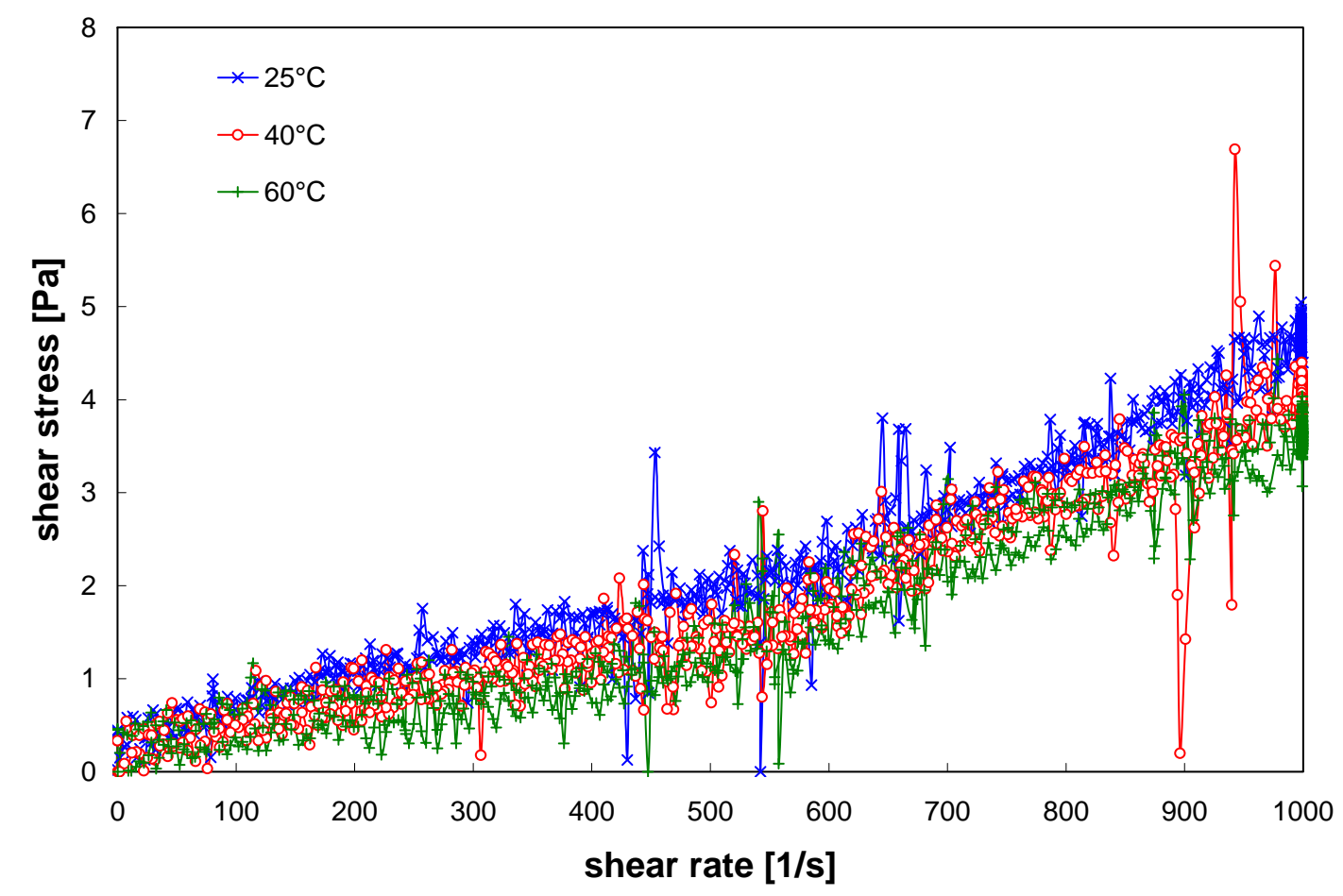

Figure 5. Flow curve for the Group 7 CUF testing slurry sample TI624-G7-R4-Slurry at $25^{\circ} \mathrm{C}, 40^{\circ} \mathrm{C}$, and $60^{\circ} \mathrm{C}$. Only the replicate flow curve measurement at $25^{\circ} \mathrm{C}$ is shown.

Flow curve data at $25^{\circ} \mathrm{C}, 40^{\circ} \mathrm{C}$, and $60^{\circ} \mathrm{C}$ were fit to both Bingham-Plastic and Casson models. Table 13 summarizes the best-fit model parameters for sample TI624-G7-R4-Slurry. An example of "how-well" the Bingham-Plastic and Casson models fit data is provided in 
Figure 6. Since the data was influenced by Taylor vortex formation, only the range of shear rates, $0-500 \mathrm{~s}^{-1}$, is employed in the Casson fitting analysis. Bingham-Plastic analysis cannot account for slurry shear thinning, and as a result, its fitting analysis is limited to $100-500 \mathrm{~s}^{-1}$ to avoid bias introduced by slurry shear thinning at low shear rates. Both models provide reasonable fits of the data up to limit of fitting analysis (i.e.,500 s${ }^{-1}$ ). Beyond $500 \mathrm{~s}^{-1}$, the model and data diverge as a result of Taylor vortex formation.

Table 13. Results of fitting analysis for rheology sample TI624-G7-R4-Slurry. Viscosities were determined by fitting both up- and down-ramp data.

\begin{tabular}{||c|c|c|c|c|c||}
\hline Model & $\begin{array}{c}\text { Temperature } \\
{\left[{ }^{\circ} \mathbf{C}\right]}\end{array}$ & Range & $\begin{array}{c}\text { Yield Stress } \\
{[\mathbf{P a}]}\end{array}$ & $\begin{array}{c}\text { Consistency } \\
{[\mathbf{m P a} \cdot \mathbf{s}]}\end{array}$ & $\mathbf{R}$ \\
\hline \multirow{3}{*}{ Bingham-Plastic } & $25(1$ of 2$)$ & $100-400 \mathrm{~s}^{-1}$ & 0.5 & 3.1 & 0.85 \\
\cline { 2 - 6 } & $25(2$ of 2$)$ & $100-400 \mathrm{~s}^{-1}$ & 0.5 & 2.8 & 0.84 \\
\cline { 2 - 6 } & 40 & $100-400 \mathrm{~s}^{-1}$ & 0.3 & 2.3 & 0.73 \\
\cline { 2 - 6 } & 60 & $100-400 \mathrm{~s}^{-1}$ & 0.4 & 1.4 & 0.46 \\
\hline \multirow{5}{*}{ Casson } & $25(1$ of 2$)$ & $0-400 \mathrm{~s}^{-1}$ & 0.1 & 2.1 & 0.93 \\
\cline { 2 - 6 } & $25(2$ of 2$)$ & $0-400 \mathrm{~s}^{-1}$ & 0.2 & 1.7 & 0.92 \\
\cline { 2 - 6 } & 40 & $0-400 \mathrm{~s}^{-1}$ & 0.1 & 1.4 & 0.84 \\
\cline { 2 - 6 } & 60 & $0-400 \mathrm{~s}^{-1}$ & 0.2 & 0.7 & 0.67 \\
\hline
\end{tabular}

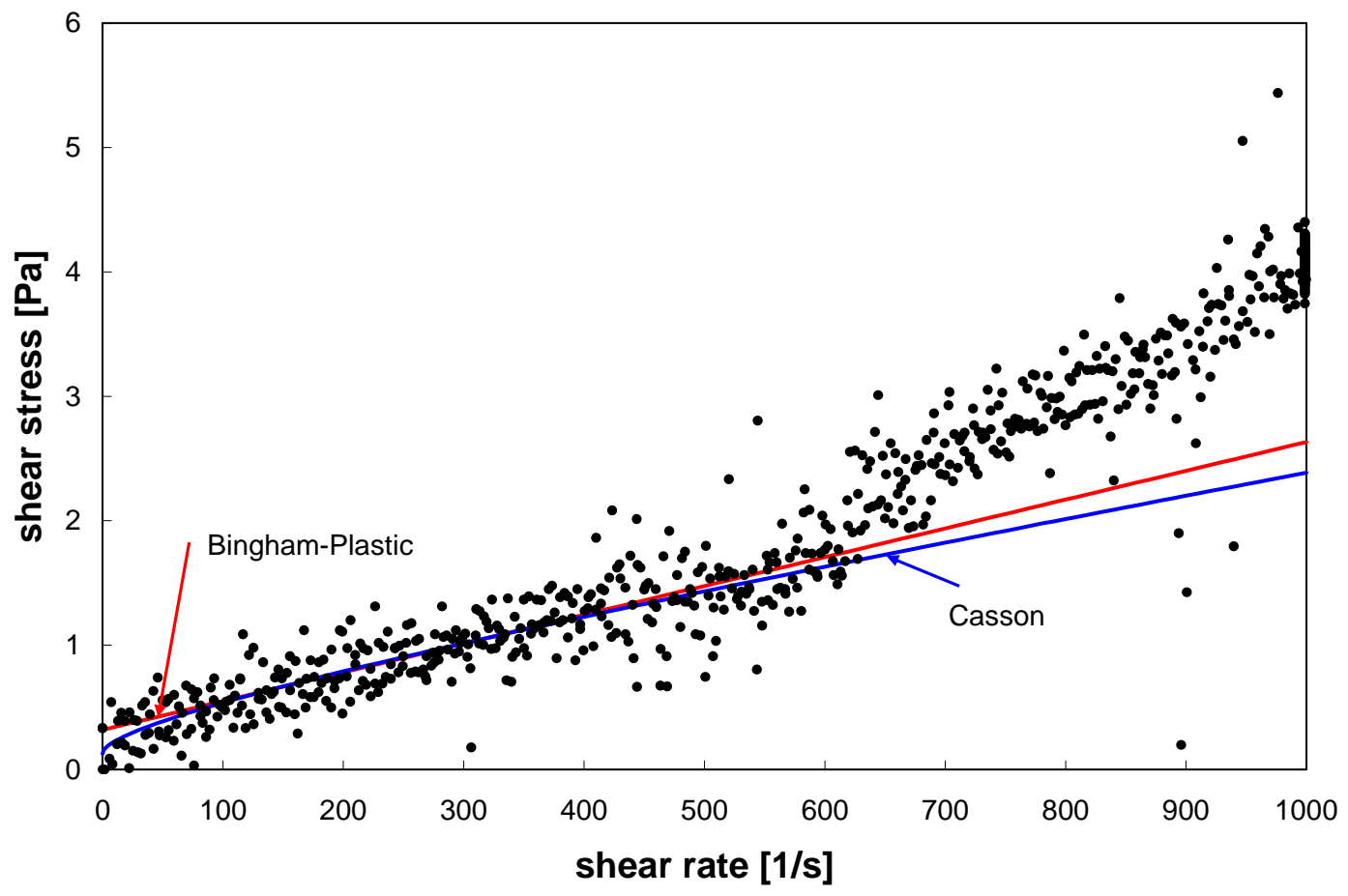

Figure 6. Example result for the fitting analysis of Group 7 CUF slurry test sample TI624-G7-R4Slurry. Data points (solid circles) correspond to the measurement at $40^{\circ} \mathrm{C}$. The solid lines correspond to the best-fit Bingham-Plastic and Casson model calculations.

Apparent viscosities at 33, 100, 500, and $1000 \mathrm{~s}^{-1}$ were derived from each measurement. For each temperature, the 33, 100, and $500 \mathrm{~s}^{-1}$ reference viscosities were determined from the average of both up-ramp and down-ramp flow curve data. The apparent viscosity at $1000 \mathrm{~s}^{-1}$ is derived from the averaging of all apparent viscosity measurements during constant rotation at $1000 \mathrm{~s}^{-1}$. As a point of comparison, apparent viscosities were also 
calculated using the Bingham-Plastic and Casson fitting parameters in Table 13. The results of these analyses are provided in Table 14.

Table 14. Select apparent viscosities for sample TI624-G7-R4-Slurry.

\begin{tabular}{|c|c|c|c|c|c|}
\hline \multirow[t]{2}{*}{ Source } & \multirow{2}{*}{$\begin{array}{c}\text { Temperature } \\
{\left[{ }^{\circ} \mathrm{C}\right]}\end{array}$} & \multicolumn{4}{|c|}{ Apparent Viscosity [cP] } \\
\hline & & @ $33 \mathrm{~s}^{-1}$ & $@ 100 \mathrm{~s}^{-1}$ & $@ 500 \mathrm{~s}^{-1}$ & @ $1000 \mathrm{~s}^{-1}$ \\
\hline \multirow[t]{4}{*}{ Measured } & 25 (1 of 2$)$ & 12 & 5.1 & $\mathrm{n} / \mathrm{a}^{*}$ & $\mathrm{n} / \mathrm{a}^{*}$ \\
\hline & $25(2$ of 2$)$ & 13 & 7.2 & 3.8 & 4.7 \\
\hline & 40 & 10 & 5.0 & 2.5 & 4.1 \\
\hline & 60 & 7.6 & 4.8 & 2.4 & 3.6 \\
\hline \multirow[t]{4}{*}{ Bingham-Plastic } & 25 (1 of 2$)$ & 17 & 7.7 & 4.0 & 3.5 \\
\hline & $25(2$ of 2$)$ & 18 & 7.7 & 3.8 & 3.3 \\
\hline & 40 & 12 & 5.5 & 3.0 & 2.6 \\
\hline & 60 & 13 & 5.2 & 2.1 & 1.7 \\
\hline \multirow[t]{4}{*}{ Casson } & 25 (1 of 2$)$ & 13 & 7.0 & 4.0 & 3.4 \\
\hline & $25(2$ of 2$)$ & 14 & 7.3 & 3.7 & 3.0 \\
\hline & 40 & 9.9 & 5.4 & 2.9 & 2.4 \\
\hline & 60 & 10 & 4.9 & 2.1 & 1.6 \\
\hline
\end{tabular}

In summary, the caustic-leached, dewatered, and washed Group 7 slurry sample TI624G7-R4-Slurry shows non-Newtonian rheology. Analysis of flow curve data against the Bingham-Plastic flow curve model suggests a yield stress ranging from 0.3 to $0.5 \mathrm{~Pa}$ and a consistency ranging from 1.4 to $3.1 \mathrm{cP}$. Similar analysis with the Casson model results in a yield and consistency that range from 0.1 to $0.2 \mathrm{~Pa}$ and 0.7 to $2.1 \mathrm{cP}$, respectively. Both fitting analyses result in yield stress below or at the limit of instrument accuracy ( $0.5 \mathrm{~Pa})$, and as such, the significance of the yield stress is questionable and the flow behavior for this slurry may be better characterized as Newtonian. For the latter case, the Newtonian viscosity would equivalent to the Bingham-Plastic consistency index (i.e., 1.4 to $3.1 \mathrm{cP}$ ). However, because Bingham-Plastic yield falls near the limit of instrument analysis, the possibility of a weakly non-Newtonian slurry cannot be completely discounted. As indicated by the results, increased slurry temperature yields lower slurry consistency. As before, this decrease is consistent with the temperature trends observed in previous Group 7 CUF testing samples.

\subsection{Rheology of Group 8 CUF Slurry Samples}

The following sub-sections discuss the rheology results for Group 8 CUF slurry test samples. A short discussion on how the measured flow curve data behave as a function of temperature is given. Next, measurement anomalies, such as Taylor vortices, slip, and rotor inertia, are identified and quantified. Finally, application of flow curve models to the data is discussed and best-fit flow curve parameters reported. In this regard, Newtonian, BinghamPlastic, and Casson constitutive equation analyses are applied. The current section focuses on flow curve data behave as a function of temperature. Section 9.3 will examine how the different sample flow curves compare to one another in an effort to highlight the effects of CUF processing on Group 8 waste mixture rheology. 


\section{Sample TI640-G8-R1-Slurry: Low Solids Concentration Group 8 Slurry}

Sample TI640-G8-R1-Slurry corresponds to the low-solids concentration (dilute)

Group 8 slurry initially run in the CUF system. It represents a chemically unmodified mixture of homogenized Group 8 wastes and simulant supernate. It has an undissolved solids concentration of $\sim 6$-wt $\%$ and a supernate dissolved solids concentration of $\sim 19$-wt $\%$.

Figure 7 shows the results of flow curve testing for sample TI640-G8-R1-Slurry. The data in Figure 7 indicate that the low solids-concentration Group 8 CUF slurry is Newtonian. In terms of overall magnitude, the stress response of the slurry is comparable to that observed for the source Group 8 material. At $25^{\circ} \mathrm{C}$ and $40^{\circ} \mathrm{C}$, the stress response is linear over the entire range of shear rates tested $\left(0\right.$ to $\left.500 \mathrm{~s}^{-1}\right)$. At $60^{\circ} \mathrm{C}$, the stress response is still linear at low shear rates but exhibits an increase in slope between $300-400 \mathrm{~s}^{-1}$ that is consistent with the formation of Taylor vortices. The data are subject to significant noise because the stress response of the slurry is approaching the M5-system's limit of measurement accuracy.

Apart from the instrument noise, the data are relatively free of hysteresis. However, rotor inertia effects yield significant negative torque correction on the down-ramp data for the initial flow curve at $25^{\circ} \mathrm{C}$. This renders that data unusable for the least-squares analysis used to determine viscosity. Likewise, rotor inertia causes part of the down-ramp data to fall below zero at low shear rates in the $60^{\circ} \mathrm{C}$ measurement. The influence of the latter correction does not prevent fitting of the $60^{\circ} \mathrm{C}$ measurement data down-ramp.

Although measurement noise yields significant variation, the data appear to indicate a decreased slurry stress response at higher temperatures. That is, the linear slope of the flow curve data decreases at higher temperature. This is consistent with decreased slurry viscosity and is consistent with the temperature trends observed in the Group 8 source material (Sample TI516-G8-AR-P1) flow curve.

Flow curve data are fit with either a Newtonian or Bingham-Plastic models, depending on the degree to which torque offset is present in the data. For both $25^{\circ} \mathrm{C}$ data sets, the Bingham-Plastic model is used to account for the small $(\sim 0.1 \mathrm{~Pa})$ but finite offset. The initial measurement is affected by negative offset, while the replicate measurement is influenced by a positive offset. Fitting analysis for the $40^{\circ} \mathrm{C}$ and $60^{\circ} \mathrm{C}$ data employ a Newtonian model.

With regard to range of shear rate ranges fit, analyses used the full range of shear rates tested (i.e., 0 to $500 \mathrm{~s}^{-1}$ ) with exception of the $60^{\circ} \mathrm{C}$ fit analysis, which used a reduced range of 0 to $250 \mathrm{~s}^{-1}$. This reduced fit range for $60^{\circ} \mathrm{C}$ is intended to exclude data affected by the formation of Taylor vortices, which render flow curve data at higher shear rates unusable for viscosity determination. Both up- and down-ramp data were included in all fitting analyses except that corresponding to the initial measurement at $25^{\circ} \mathrm{C}$. Here, only up-ramp data were considered because of significant negative torque correction on the down-ramp. 


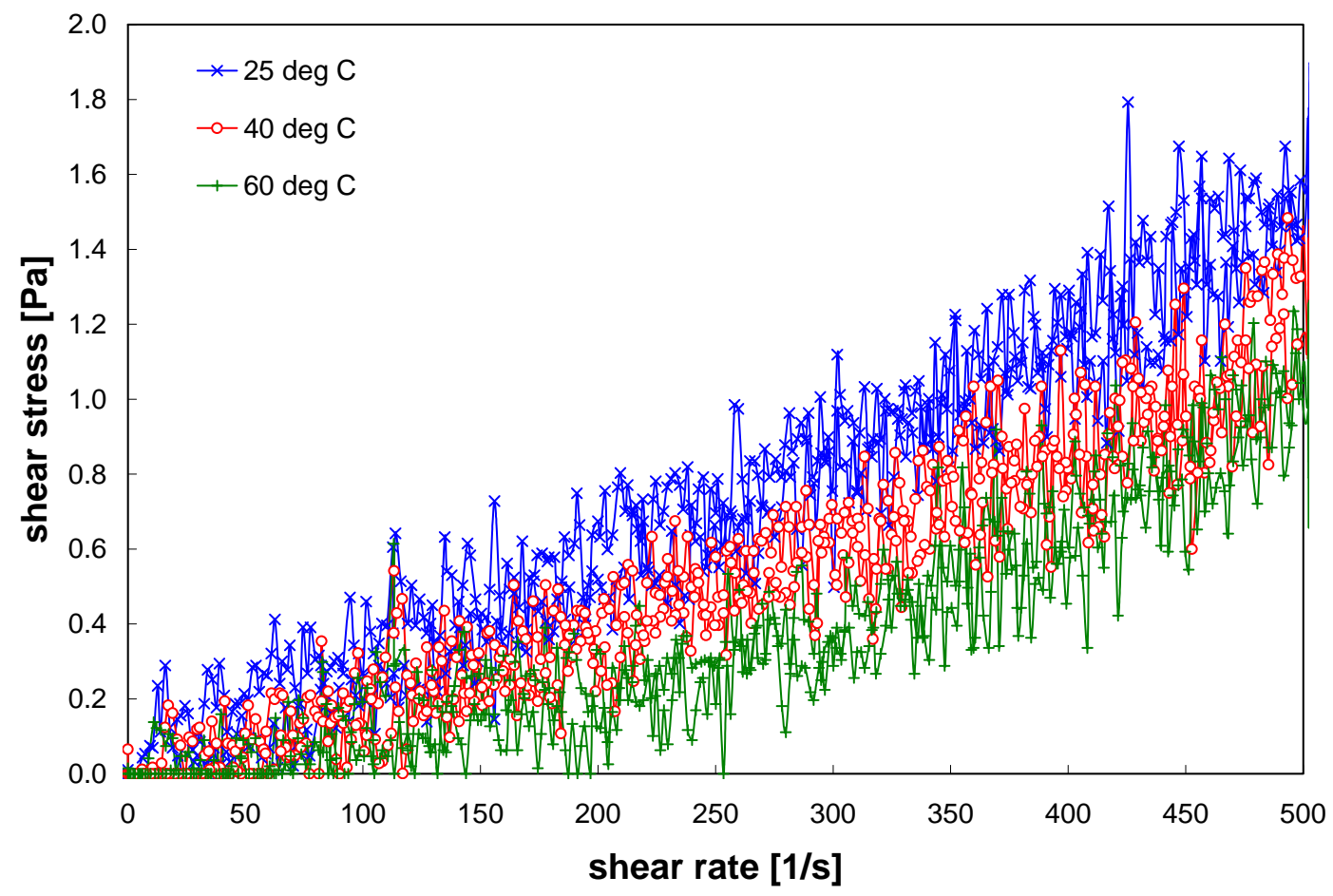

Figure 7. Flow curve for the Group 8 CUF testing slurry sample TI640-G8-R1-Slurry at $25^{\circ} \mathrm{C}, 40^{\circ}$ $\mathrm{C}$, and $60^{\circ} \mathrm{C}$. Only the replicate flow curve measurement at $25^{\circ} \mathrm{C}$ is shown.

Table 15 summarizes the best-fit Newtonian viscosities for sample TI640-G8-R1Slurry. The results indicate the slurry has a Newtonian viscosity of $3.0 \mathrm{cP}$ at $25^{\circ} \mathrm{C}, 2.3 \mathrm{cP}$ at $40^{\circ} \mathrm{C}$, and $1.1 \mathrm{cP}$ at $60^{\circ} \mathrm{C}$. Initial and replicate viscosity measurements at $25^{\circ} \mathrm{C}$ agree well. The fitting confirm the decrease in viscosity with increasing temperature observed in Figure 7. Because the difference in viscosity between adjacent temperature set points is greater than the measuring accuracy of $0.5 \mathrm{cP}$, it is likely that this temperature trend is significant.

Table 15. Results of fitting analysis for rheology sample TI640-G8-R1-Slurry.

Viscosities were determined by fitting both up- and down-ramp data.

\begin{tabular}{|c|c|c|c|c|}
\hline Model & "Temperature $\left[{ }^{\circ} \mathrm{C}\right]$ & "Range & $\begin{array}{c}\text { Viscosity } \\
\text { [mPa·s] }\end{array}$ & 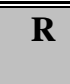 \\
\hline \multirow{4}{*}{ Newtonian } & 25 (1 of 2$)$ & $0-500 \mathrm{~s}^{-1(\mathrm{a})}$ & 3.0 & 0.97 \\
\hline & 25 (2 of 2$)$ & $0-500 \mathrm{~s}^{-1}(\mathrm{~b})$ & 3.0 & 0.97 \\
\hline & 40 & $0-500 \mathrm{~s}^{-1(\mathrm{c})}$ & 2.3 & 0.96 \\
\hline & 60 & $0-250 \mathrm{~s}^{-1(\mathrm{c})}$ & 1.1 & 0.67 \\
\hline \multicolumn{5}{|c|}{$\begin{array}{l}\mathrm{R} \text { is the correlation coefficient. } \\
\text { (a) Viscosity determined from best-fit Bingham-Plastic consistency. Only up- } \\
\text { ramp data only } \\
\text { (b) Viscosity determined from best-fit Bingham-Plastic consistency } \\
\text { (c) Viscosity determined from best-fit Newtonian viscosity }\end{array}$} \\
\hline
\end{tabular}

In summary, the initial low-solids concentration Group 8 slurry sample TI640-G8-R1Slurry shows Newtonian rheology. Viscosity ranges from $3.0 \mathrm{cP}$ at $25^{\circ} \mathrm{C}$ down to $1.1 \mathrm{cP}$ at $60^{\circ} \mathrm{C}$. Overall, viscosity of the dilute Group 8 CUF slurry appears to decrease with increasing temperature. Although there is significant measurement noise (based on the data scatter in 
Figure 7), the decrease in viscosity with increased temperature is greater than the expected measurement accuracy $(0.5 \mathrm{cP})$ and is likely significant.

\section{Sample TI640-G8-R2-Slurry: High Solids Concentration Group 8 Slurry}

Sample TI640-G8-R2-Slurry corresponds to the high-solids concentration Group 8 mixed slurry that results from dewatering of the initial low-solids concentration slurry. Like the previous sample, it represents a chemically unmodified mixture of homogenized Group 8 waste and simulant supernate. It has an undissolved solids concentration of $\sim 13-\mathrm{wt} \%$ and a supernate dissolved solids concentration of $\sim 20$-wt $\%$.

Figure 8 shows the results of flow curve testing for sample TI640-G8-R2-Slurry. The results suggest a weak non-Newtonian slurry. Specifically, the flow curve data show a yield stress of approximately $0.5 \mathrm{~Pa}$ at all temperatures. Because the measured yield stress is near the stress accuracy limit of instrument accuracy $(0.5 \mathrm{~Pa})$, it is difficult to determine if the yield is significant. Over shear rates of 0 to $100 \mathrm{~s}^{-1}$, the slurry slightly shear thinning such that the stress response has downward curvature. At higher shear rates, the stress response is typically linear. For $25^{\circ} \mathrm{C}$, the response is linear over 100 to $1000 \mathrm{~s}^{-1}$. Higher temperatures exhibit slope increases in the stress response that are indicative of Taylor vortex formation. Although, the data are relatively free of hysteresis, both $25^{\circ} \mathrm{C}$ measurements show a slightly higher stress response during the up-ramp measurement. Such hysteresis is consistent with shear induced weakening of slurry structure or could indicate settling of solids out of the slurry rheology measurement gap.

Flow curve data in Figure 8 indicate a significant drop in the stress response of the slurry with increasing temperature. At $25^{\circ} \mathrm{C}$, the stress response at $500 \mathrm{~s}^{-1}$ is approximately 3.2 Pa. This decreases to $2.6 \mathrm{~Pa}$ at $40^{\circ} \mathrm{C}$ and to $2.0 \mathrm{~Pa}$ at $60^{\circ} \mathrm{C}$. The decreased stress response is consistent with a corresponding decrease in the slurry consistency. This manifests in Figure 8 as a lowered flow curve slope at higher temperatures. With regard to previous Group 8 slurry behavior, the decrease is consistent with observations of lowered slurry viscosity in the low solids-concentration CUF slurry and source (initial characterization) material.

Flow curve data for sample TI640-G8-R2-Slurry are fit using both Bingham-Plastic and Casson constitutive equations. Both allow capture of the slurry yield stress. Because the Bingham-Plastic model is unable to capture shear thinning behavior, fitting analysis is restricted to the linear stress response region above $100 \mathrm{~s}^{-1}$. The Casson model is not subject to this limitation. Upper fitting range bounds are placed on both Casson and Bingham-Plastic models to prevent inclusion of data influenced by Taylor vortex formation. Fits at $25^{\circ} \mathrm{C}$ employ data up to and including $1000 \mathrm{~s}-1$. Fits at $40^{\circ}$ and $60^{\circ} \mathrm{C}$ are restricted to upper limits of $800 \mathrm{~s}^{-1}$ and $600 \mathrm{~s}^{-1}$, respectively.

Table 16 summarizes the best-fit Bingham-Plastic and Casson parameters for sample TI640-G8-R2-Slurry. An example of "how-well" the Bingham-Plastic and Casson models fit data is provided in Figure 9. Based on Figure 9, it appears that both Bingham-Plastic and Casson models provide a similar and reasonable fit of the data. Both fall fitting curves fall within the data scatter 


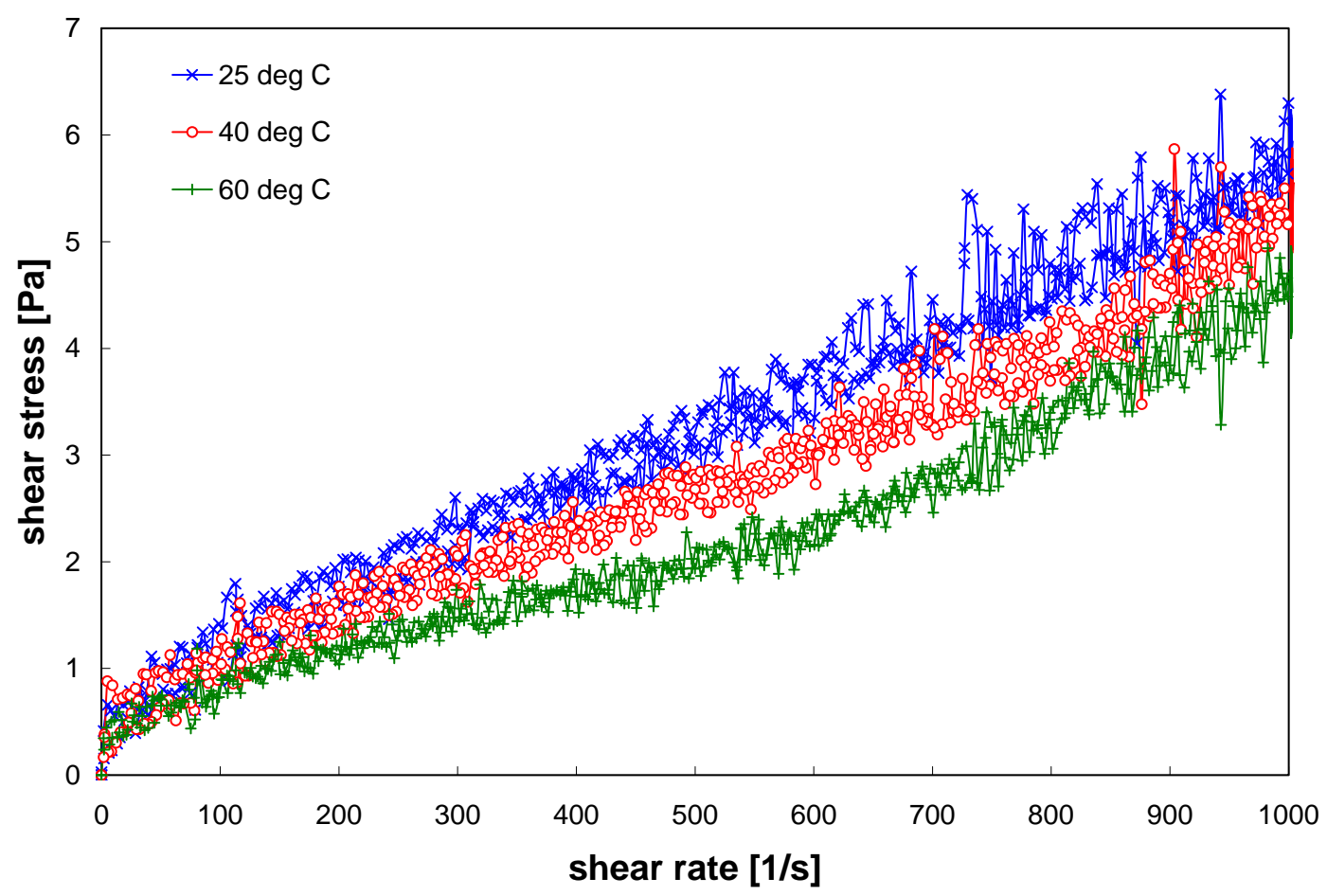

Figure 8. Flow curve for the Group 8 CUF testing slurry sample TI640-G8-R2-Slurry at $25^{\circ} \mathrm{C}, 40^{\circ}$ $\mathrm{C}$, and $60^{\circ} \mathrm{C}$. Only the replicate flow curve measurement at $25^{\circ} \mathrm{C}$ is shown.

Table 16. Results of fitting analysis for rheology sample TI640-G8-R2-Slurry. Viscosities were determined by fitting both up- and down-ramp data.

\begin{tabular}{||c|c|c|c|c|c||}
\hline \hline Model & $\begin{array}{c}\text { Temperature } \\
{\left[{ }^{\circ} \mathbf{C}\right]}\end{array}$ & Range & $\begin{array}{c}\text { Yield Stress } \\
{[\mathbf{P a}]}\end{array}$ & $\begin{array}{c}\text { Consistency } \\
{[\mathbf{m P a} \cdot \mathbf{s}]}\end{array}$ & $\mathbf{R}$ \\
\hline \multirow{3}{*}{ Bingham-Plastic } & $25(1$ of 2$)$ & $100-1000 \mathrm{~s} \mathrm{~s}^{-1}$ & 0.8 & 5.1 & 0.98 \\
\cline { 2 - 6 } & $25(2$ of 2$)$ & $100-1000 \mathrm{~s} \mathrm{~s}^{-1}$ & 0.7 & 4.9 & 0.98 \\
\cline { 2 - 6 } & 40 & $100-800 \mathrm{~s} \mathrm{~s}^{-1}$ & 0.7 & 4.0 & 0.98 \\
\cline { 2 - 6 } & 60 & $100-600 \mathrm{~s}^{-1}$ & 0.6 & 2.7 & 0.96 \\
\hline \multirow{5}{*}{ Casson } & $25(1$ of 2$)$ & $0-1000 \mathrm{~s} \mathrm{~s}^{-1}$ & 0.2 & 3.9 & 0.99 \\
\cline { 2 - 6 } & $25(2$ of 2$)$ & $0-1000 \mathrm{~s} \mathrm{~s}^{-1}$ & 0.2 & 4.0 & 0.99 \\
\cline { 2 - 6 } & 40 & $0-800 \mathrm{~s}^{-1}$ & 0.2 & 2.7 & 0.98 \\
\cline { 2 - 6 } & 60 & $0-600 \mathrm{~s}^{-1}$ & 0.3 & 1.6 & 0.98 \\
\hline
\end{tabular}

The Bingham-Plastic model indicates a yield that ranges from 0.6 to $0.8 \mathrm{~Pa}$ and a consistency that ranges from 2.7 to $5.1 \mathrm{cP}$. Likewise, the Casson model indicates a yield that ranges from 0.2 to $0.3 \mathrm{~Pa}$ and a consistency that ranges from 1.6 to $3.9 \mathrm{cP}$. It is difficult to confirm the significance of the yield stress measured for this slurry. While the BinghamPlastic yield of 0.6 to $0.8 \mathrm{~Pa}$ is significant and confirms that the fluid is non-Newtonian within the M5 systems detection capability, the Casson yield stress of 0.2 to $0.3 \mathrm{~Pa}$ falls below the detection limit. However, the finite Bingham-Plastic yield along with the downward curvature captured by the Casson model support the conclusion that this slurry is weakly nonNewtonian. 


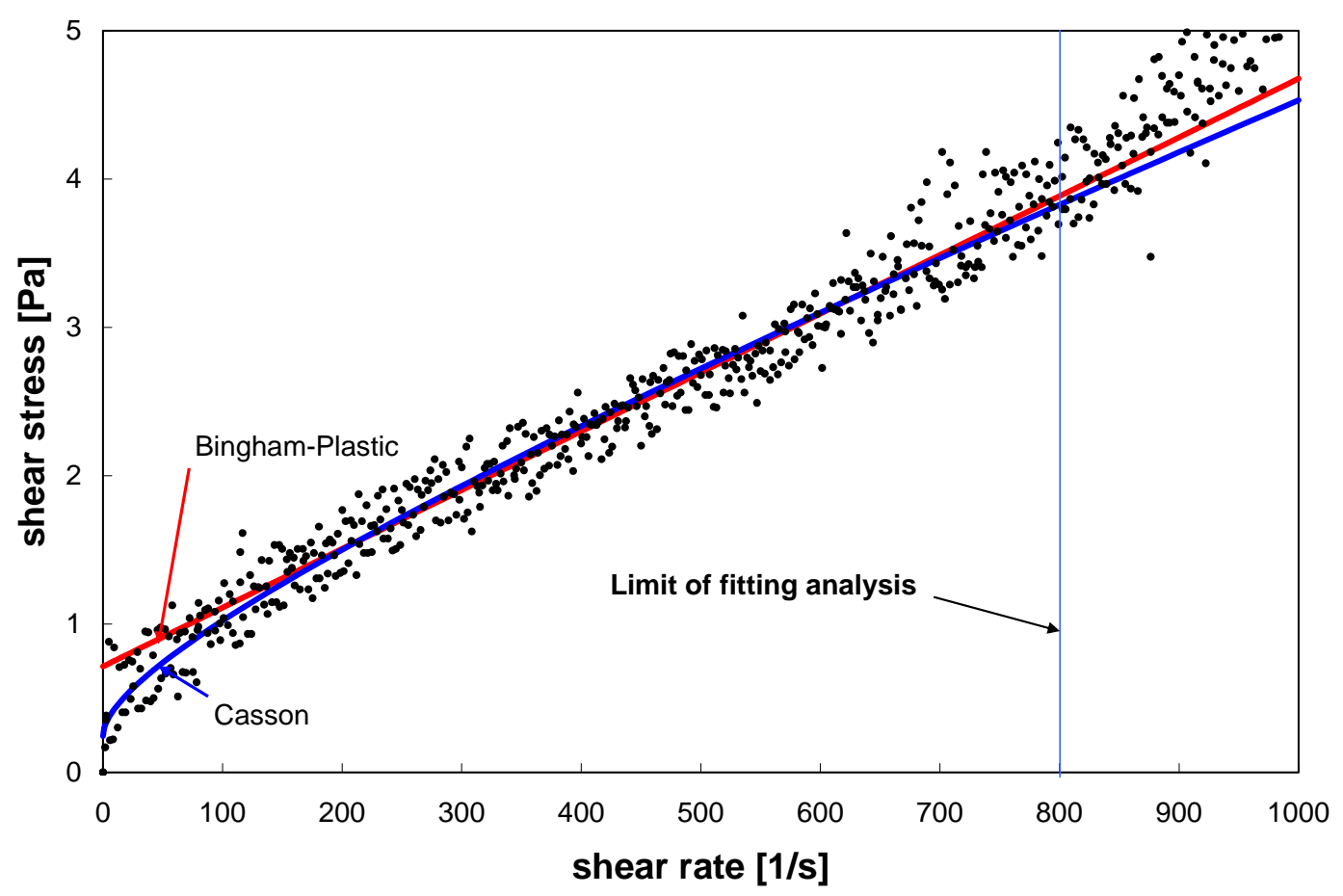

Figure 9. Example result for the fitting analysis of Group 8 CUF slurry test sample TI640-G8-R2Slurry. Data points (solid circles) correspond to the measurement at $40^{\circ} \mathrm{C}$. The solid lines correspond to the best-fit Bingham-Plastic and Casson model calculations.

Model parameters for the initial and replicate measurements at $25^{\circ} \mathrm{C}$ compare well and agree within the limits of expected instrument accuracy (i.e., $0.5 \mathrm{~Pa}$ and $0.5 \mathrm{cP}$ ). With regard to the effects of temperature, yield stress does not appear to vary significantly over $25^{\circ} \mathrm{C}$ to $60^{\circ} \mathrm{C}$ whereas consistency decreases significantly over between temperature. Yield stress for both Casson and Bingham-Plastic model fits show a smaller than 0.5 Pa variation with temperature, and as such, temperature effects cannot be differentiated from instrument and/or measurement noise. On the other hand, consistency for both Casson and Bingham-Plastic fits shows a greater than $0.5 \mathrm{cP}$ point-to-point variation with temperature. The changes here are significant and indicate that consistency decreases with increasing slurry temperature. This decrease corresponds to the decrease in flow curve data slope observed in Figure 8.

Apparent viscosities at 33, 100, 500, and $1000 \mathrm{~s}^{-1}$ were derived from each measurement. For each temperature, the 33,100 , and $500 \mathrm{~s}^{-1}$ reference viscosities were determined from the average both up-ramp and down-ramp flow curve data. The apparent viscosity at $1000 \mathrm{~s}^{-1}$ is derived from the average of all apparent viscosity measurements during constant rotation at $1000 \mathrm{~s}^{-1}$. As a point of comparison, apparent viscosities were also calculated using the Bingham-Plastic and Casson fitting parameters in Table 16. The results of these analyses are provided in Table 17. 
Table 17. Select apparent viscosities for sample TI640-G8-R2-Slurry.

\begin{tabular}{|c|c|c|c|c|c|}
\hline \multirow[t]{2}{*}{ Source } & \multirow{2}{*}{$\begin{array}{c}\text { Temperature } \\
{\left[{ }^{\circ} \mathrm{C}\right]}\end{array}$} & \multicolumn{4}{|c|}{ Apparent Viscosity [cP] } \\
\hline & & @ $33 \mathrm{~s}^{-1}$ & @ $100 \mathrm{~s}^{-1}$ & (a) $500 \mathrm{~s}^{-1}$ & (a $1000 \mathrm{~s}^{-1}$ \\
\hline \multirow[t]{4}{*}{ Measured } & 25 (1 of 2$)$ & 25 & 12 & 6.6 & 6.0 \\
\hline & $25(2$ of 2$)$ & 21 & 12 & 6.3 & 5.8 \\
\hline & 40 & 19 & 11 & 5.5 & $\mathrm{n} / \mathrm{a}^{*}$ \\
\hline & 60 & 16 & 8.2 & 4.0 & $\mathrm{n} / \mathrm{a}^{*}$ \\
\hline \multirow[t]{4}{*}{ Bingham-Plastic } & $25(1$ of 2$)$ & 29 & 13 & 6.7 & 5.9 \\
\hline & $25(2$ of 2$)$ & 27 & 12 & 6.4 & 5.7 \\
\hline & 40 & 26 & 11 & 5.4 & 4.7 \\
\hline & 60 & 22 & 9.1 & 4.0 & 3.4 \\
\hline \multirow[t]{4}{*}{ Casson } & 25 (1 of 2$)$ & 20 & 12 & 6.9 & 5.9 \\
\hline & $25(2$ of 2$)$ & 17 & 11 & 6.6 & 5.8 \\
\hline & 40 & 19 & 10 & 5.4 & 4.5 \\
\hline & 60 & 17 & 8.4 & 4.0 & 3.2 \\
\hline
\end{tabular}

In summary, the initial high-solids concentration Group 8 slurry sample TI640-G8-R2Slurry shows non-Newtonian rheology. Analysis of flow curve data against the BinghamPlastic flow curve model suggests a yield stress ranging from 0.6 to $0.8 \mathrm{~Pa}$ and a consistency ranging from 2.7 to $5.1 \mathrm{cP}$. Similar analysis with the Casson model finds a yield and consistency that range from 0.2 to $0.3 \mathrm{~Pa}$ and 1.6 to $3.9 \mathrm{cP}$, respectively. Because the magnitude of the best-fit yield stress is either below or approaches the limit of instrument accuracy $(0.5 \mathrm{~Pa})$, it is difficult to confidently conclude that the yield stress observed is significant. As such, rheology is best classified as "weakly" or borderline non-Newtonian. Based on both fitting approaches, it can be concluded that the measured yield stress does not vary significantly with temperature but that consistency decreases significantly with temperature.

Sample TI640-G8-R3-Slurry: Caustic-Leached and Dewatered Group 8 Slurry

Sample TI640-G8-R3-Slurry corresponds to the caustic-leached and dewatered Group 8 waste solids slurry. This slurry has an undissolved solids concentration of $23-\mathrm{wt} \%$ and a supernate dissolved solids concentration of $\sim 24-\mathrm{wt} \%$.

Figure 10 shows the results of flow curve testing for sample TI640-G8-R3-Slurry. Like the pre-leach concentrated slurry, the post-leach dewatered slurry shows non-Newtonian behavior. Based on visual inspection of flow curve data, the yield stress for the slurry appears to fall between 0.5 and 1.0 Pa. After yield, the stress response of this slurry is linear over the entire range of shear rates tested, with exception of the slight shear thinning region at low shear (i.e., 0 to $100 \mathrm{~s}^{-1}$ ). At all shear rates, there is significant data overlap of flow curve data between temperatures. Measurement noise and hysteresis both contribute to the observed overlap. Flow curve hysteresis is particularly significant during initial measurement at $25^{\circ} \mathrm{C}$ (not shown in Figure 10 - see Appendix A) and during the $40^{\circ} \mathrm{C}$. Hysteresis is characterized by a higher stress response on the up-ramp portion of the flow curve and suggests sample shearing effects or settling of solids out of the measurement gap. Because of the significant data overlap, temperature trends are difficult to discern from Figure 10. The data appear to indicate a decrease in flow curve slope (i.e., consistency) from 25 to $40^{\circ} \mathrm{C}$. On the other hand, flow curve at 40 and $60^{\circ} \mathrm{C}$ appear statistically similar. 


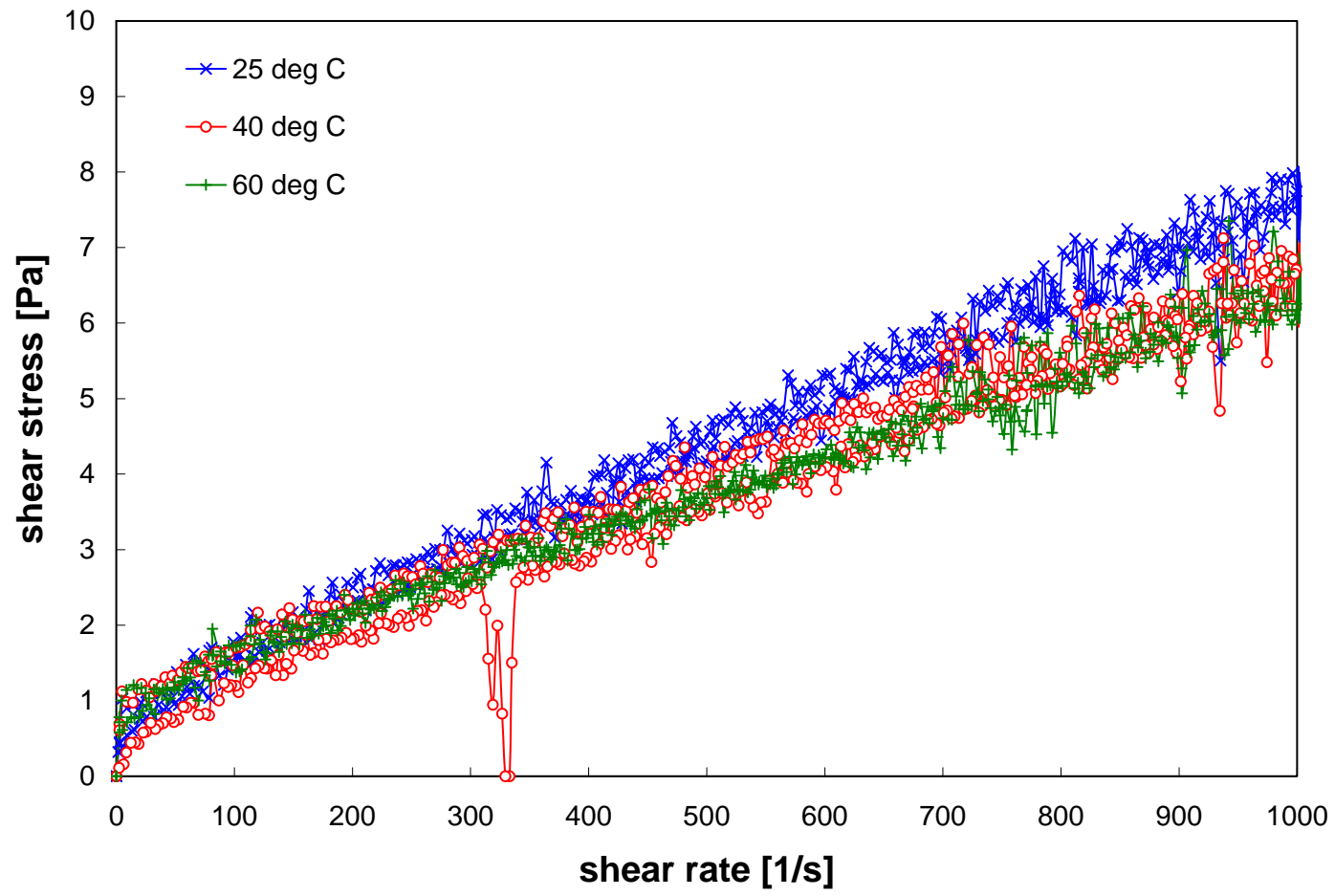

Figure 10. Flow curve for the Group 8 CUF testing slurry sample TI640-G8-R3-Slurry at $25^{\circ} \mathrm{C}, 40^{\circ}$ $\mathrm{C}$, and $60^{\circ} \mathrm{C}$. Only the replicate flow curve measurement at $25^{\circ} \mathrm{C}$ is shown.

To capture and quantify the non-Newtonian behavior show in Figure 10, flow curve data for sample TI640-G8-R3-Slurry was fit to both Bingham-Plastic and Casson models. Bingham-Plastic fits employ a shear rate range of 100 to $1000 \mathrm{~s}^{-1}$. The lower limit of $100 \mathrm{~s}^{-1}$ prevents inclusion of low shear non-linear stress response (i.e., shear thinning). The Casson fit uses the entire shear rate range of 0 to $1000 \mathrm{~s}^{-1}$. Both up- and down-ramp data are included in the fitting analysis, and as such, the parameters regressed form an average of both up- and down-ramp behaviors.

Table 18. Results of fitting analysis for rheology sample TI640-G8-R3-Slurry. Viscosities were determined by fitting both up- and down-ramp data.

\begin{tabular}{||c|c|c|c|c|c||}
\hline Model & $\begin{array}{c}\text { Temperature } \\
{\left[{ }^{\circ} \mathbf{C}\right]}\end{array}$ & Range & $\begin{array}{c}\text { Yield Stress } \\
{[\mathbf{P a}]}\end{array}$ & $\begin{array}{c}\text { Consistency } \\
{[\mathbf{m P a} \cdot \mathbf{s}]}\end{array}$ & $\mathbf{R}$ \\
\hline \multirow{3}{*}{ Bingham-Plastic } & $25(1$ of 2$)$ & $100-1000 \mathrm{~s} \mathrm{~s}^{-1}$ & 1.1 & 6.7 & 0.99 \\
\cline { 2 - 6 } & $25(2$ of 2$)$ & $100-1000 \mathrm{~s} \mathrm{~s}^{-1}$ & 1.1 & 6.6 & 0.99 \\
\cline { 2 - 6 } & 40 & $100-1000 \mathrm{~s}^{-1}$ & 0.9 & 5.6 & 0.98 \\
\cline { 2 - 6 } & 60 & $100-1000 \mathrm{~s} \mathrm{~s}^{-1}$ & 1.0 & 5.4 & 0.99 \\
\hline \multirow{5}{*}{ Casson } & $25(1$ of 2$)$ & $0-1000 \mathrm{~s} \mathrm{~s}^{-1}$ & 0.3 & 5.1 & 0.99 \\
\cline { 2 - 6 } & $25(2$ of 2$)$ & $0-1000 \mathrm{~s} \mathrm{~s}^{-1}$ & 0.3 & 5.0 & 0.99 \\
\cline { 2 - 6 } & 40 & $0-1000 \mathrm{~s}^{-1}$ & 0.3 & 4.2 & 0.99 \\
\cline { 2 - 6 } & 60 & $0-1000 \mathrm{~s} \mathrm{~s}^{-1}$ & 0.3 & 3.8 & 0.99 \\
\hline
\end{tabular}




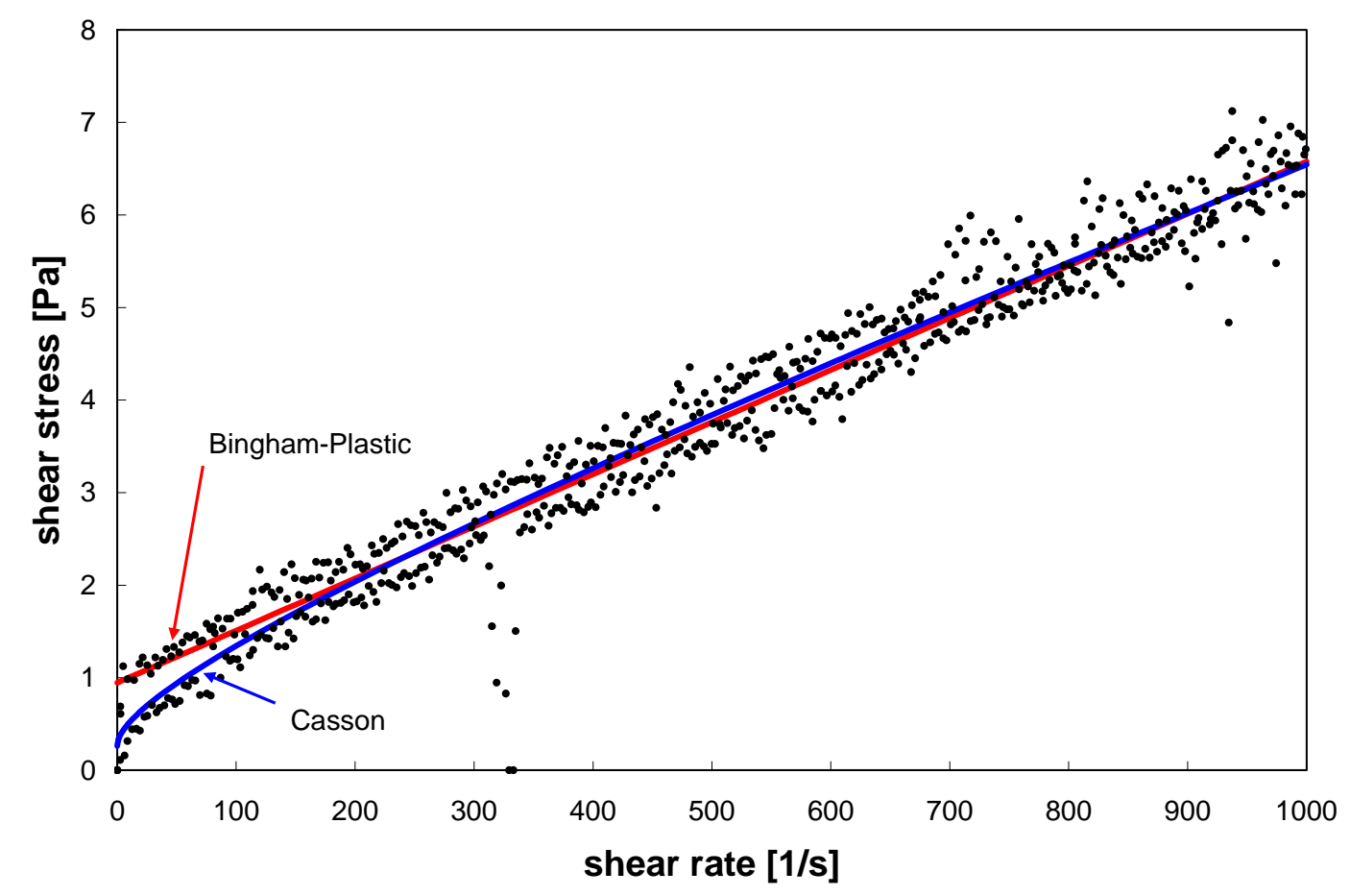

Figure 11. Example result for the fitting analysis of Group 8 CUF slurry test sample TI640-G8-R3Slurry. Data points (solid circles) correspond to the measurement at $40^{\circ} \mathrm{C}$. The solid lines correspond to the best-fit Bingham-Plastic and Casson model calculations.

Table 18 summarizes the best-fit Bingham-Plastic and Casson parameters for sample TI640-G8-R3-Slurry. An example of "how-well" the Bingham-Plastic and Casson models fit data is provided in Figure 11. The Bingham-Plastic model fits suggest a yield stress of 0.9 to 1.1 Pa and a consistency of 5.4 to $6.7 \mathrm{cP}$. Likewise, the Casson model fits suggest a yield of $0.3 \mathrm{~Pa}$ and a consistency that ranges from 3.8 to $5.1 \mathrm{cP}$. While the Bingham-Plastic result indicate a significant (greater than $0.5 \mathrm{~Pa}$ ) yield, the Casson model yield is not greater than the instrument limit of detection. Based on the result in Figure 11, it appears that both models accurately capture the magnitude and curvature of the flow curve data within the measurement variation. As a result, it is difficult to select one set of fitting results as more representative of the rheology show. The end result is that it is difficult to accurately assess if slurry sample TI640-G8-R3-Slurry is non-Newtonian with a yield or simply a Power-Law or Newtonian fluid.

Initial and replicate measurement fitting parameters compare well. Both BinghamPlastic and Casson yield stress and consistency agree to within the expected limits of instrument accuracy (0.5 Pa and $0.5 \mathrm{cP}$, respectively). With regard to temperature effects, increased slurry temperature does not appear to significantly effect yield stress but does impact consistency. Bingham-Plastic yield stress shows an insignificant 0.2 Pa variation over the range of temperatures tested. Casson yield stress shows no variation. Both Bingham-Plastic and Casson show decreases of $1.3 \mathrm{cP}$ between $25^{\circ} \mathrm{C}$ and $60^{\circ} \mathrm{C}$. Most of this decrease occurs over 25 to $40^{\circ} \mathrm{C}$, as the change in consistent between 40 and $60^{\circ} \mathrm{C}$. This behavior confirms earlier observations about the slope of the flow curve data in Figure 10. 
Apparent viscosities at 33, 100, 500, and $1000 \mathrm{~s}^{-1}$ were derived from each measurement. For each temperature, the 33, 100, and $500 \mathrm{~s}^{-1}$ reference viscosities were determined from the average both up-ramp and down-ramp flow curve data. The apparent viscosity at $1000 \mathrm{~s}^{-1}$ is derived from the average of all apparent viscosity measurements during constant rotation at $1000 \mathrm{~s}^{-1}$. As a point of comparison, apparent viscosities were also calculated using the Bingham-Plastic and Casson fitting parameters in Table 18. The results of these analyses are provided in Table 19.

Table 19. Select apparent viscosities for sample TI640-G8-R3-Slurry.

\begin{tabular}{|c|c|c|c|c|c|}
\hline \multirow[t]{2}{*}{ Source } & \multirow{2}{*}{$\begin{array}{c}\text { Temperature } \\
{\left[{ }^{\circ} \mathrm{C}\right]}\end{array}$} & \multicolumn{4}{|c|}{ Apparent Viscosity [cP] } \\
\hline & & @ $33 \mathrm{~s}^{-1}$ & (a) $100 \mathrm{~s}^{-1}$ & @ $500 \mathrm{~s}^{-1}$ & @ $1000 \mathrm{~s}^{-1}$ \\
\hline \multirow[t]{4}{*}{ Measured } & 25 (1 of 2$)$ & 29 & 16 & 8.9 & 7.7 \\
\hline & 25 (2 of 2$)$ & 30 & 16 & 8.7 & 7.6 \\
\hline & 40 & 27 & 14 & 7.4 & 6.6 \\
\hline & 60 & 31 & 16 & 7.4 & 6.5 \\
\hline \multirow[t]{4}{*}{ Bingham-Plastic } & 25 (1 of 2$)$ & 39 & 17 & 8.8 & 7.7 \\
\hline & 25 (2 of 2$)$ & 39 & 17 & 8.7 & 7.6 \\
\hline & 40 & 34 & 15 & 7.5 & 6.6 \\
\hline & 60 & 37 & 16 & 7.5 & 6.4 \\
\hline \multirow[t]{4}{*}{ Casson } & 25 (1 of 2$)$ & 27 & 15 & 9.0 & 7.7 \\
\hline & 25 (2 of 2$)$ & 26 & 15 & 8.9 & 7.6 \\
\hline & 40 & 24 & 13 & 7.7 & 6.5 \\
\hline & 60 & 26 & 14 & 7.7 & 6.4 \\
\hline
\end{tabular}

In summary, the caustic-leached and dewatered Group 8 slurry (sample TI640-G8-R3Slurry) shows non-Newtonian rheology. Analysis of flow curve data against the BinghamPlastic flow curve model suggests a yield stress ranging from 0.9 to $1.1 \mathrm{~Pa}$ and a consistency ranging from $5.4 \mathrm{cP}$ to $6.7 \mathrm{cP}$. Similar analysis with the Casson model finds a yield stress of $0.3 \mathrm{~Pa}$ and a consistency that ranges from 3.8 to $5.1 \mathrm{cP}$. Although the regressed BinghamPlastic yield is significant, the Casson yield still falls below the detection limit of $0.5 \mathrm{~Pa}$. As such, rheology of slurry sample TI640-G8-R3-Slurry is best classified as "weakly" or borderline non-Newtonian. Based on both fitting approaches, it can be concluded that the measured yield stress does not vary significantly with temperature but that consistency decreases significantly with temperature.

Sample TI640-G8-R4-Slurry: Caustic-Leached, Dewatered, and Washed Group 8 Slurry

Sample TI640-G8-R4-Slurry corresponds to the caustic-leached, dewatered, and washed Group 8 mixed slurry. This slurry has an undissolved solids concentration of 20-wt\% and a supernate dissolved solids concentration of $\sim 4 \%$.

Before measurement results for this sample are discussed, it should be noted that rheological characterization was complicated by significant air entrainment and retention in the waste sample provided. It is suspected that the yield stress of the caustic-leached, dewatered, and washed material (see Figure 12) prevented bubble migration to the surface of the slurry sample during sampling and rheology preparation activities. During testing, entrained air in the waste samples was slowly released from the sample. The release mechanism is suspected to be a combination of shear induced air bubble coalescence and yielding of the material, which allowed the bubbles to freely migrate to the surface. 
Air release was initially evidenced by a slow but significant (nearly a factor of two) decrease in the stress response of the slurry. This decrease is a consequence of the corresponding decrease in the slurry level in the measuring cup that occurs when entrained air leaves the sample. Visual inspection of the slurry level after initial testing confirmed the decrease. Subsequent observation during testing confirmed that bubbles were rising to the surface of the slurry and breaking.

To account for air entrapment, initial measurements of TI640-G8-R4-Slurry affected by air release were discarded. Subsequent measurements included significant pre-shearing of the sample to allow as much bubble release as possible. This involved monitoring torque during steady rotation of the rotor. Bubble release was assumed complete when the torque no longer showed a greater than $0.5 \mathrm{~Pa}$ change over 3 minutes. After the initial measurement at $25^{\circ} \mathrm{C}$, there was insufficient slurry in the cup to refresh the gap at higher temperatures. The measuring system was reloaded with slurry. This slurry was then sheared until most of the air was released, and measurements at $25^{\circ} \mathrm{C}$ (repeat), $40^{\circ} \mathrm{C}$, and $60^{\circ} \mathrm{C}$ completed. During the 15minute measurements, a slow transient decrease in the slurry stress response was noted. It is possible that this decrease represents continued air release, but it could also be a result of shear breakage of slurry structure (i.e., interparticle connections) and / or settling of solids out of the measurement gap.

Figure 12 shows the results of flow curve testing for sample TI640-G8-R4-Slurry. Flow curve data indicate that the slurry is non-Newtonian with a yield stress ranging from 3 to $6 \mathrm{~Pa}$. The stress response is typically non-linear over 0 to $200 \mathrm{~s}^{-1}$ and linear at higher shear rates. In addition, the stress response at higher temperatures appears to have a larger linear range, with the $60^{\circ} \mathrm{C}$ flow curve data showing linearity over 100 to $1000 \mathrm{~s}^{-1}$. Flow curve hysteresis is significant in both $25^{\circ} \mathrm{C}$ and $40^{\circ} \mathrm{C}$ data but is absent in the $60^{\circ} \mathrm{C}$. Hysteresis is characterized by a higher stress response on the up-ramp portion of the flow curve measurement relative to the down-ramp portion response. As suggested above, hysteresis appears to decrease at higher temperatures. This behavior is consistent with shearing breakage of the sample's internal (i.e., interparticle) structure or could indicate that solids are settling out of the measurement gap. Given that significant air retention and release affected the initial attempts to measure TI640-G8-R4-Slurry, the decrease could also result from longer term bubble release. Apart from hysteresis, the measurements show a relative high signal-to-noise ratio.

Temperature effects are somewhat difficult to ascertain from the data in Figure 12. Although it is clear that the stress response at $25^{\circ} \mathrm{C}$ is much higher than those at $40^{\circ} \mathrm{C}$ and $60^{\circ} \mathrm{C}$, significant overlap is observed between measurements at $40^{\circ} \mathrm{C}$ and $60^{\circ} \mathrm{C}$. Based on the data, there appears to be a significant decrease in both yield stress and consistency between $25^{\circ} \mathrm{C}$ and $40^{\circ} \mathrm{C}$. However, this decrease does not appear to continue at higher temperatures. This behavior is consistent with that observed in slurry sample TI640-G8-R3-Slurry. Good comparison between the temperature behavior of these two samples is expected, as the TI640G8-R4-Slurry is simply a washed analogue of the TI640-G8-R3-Slurry. 


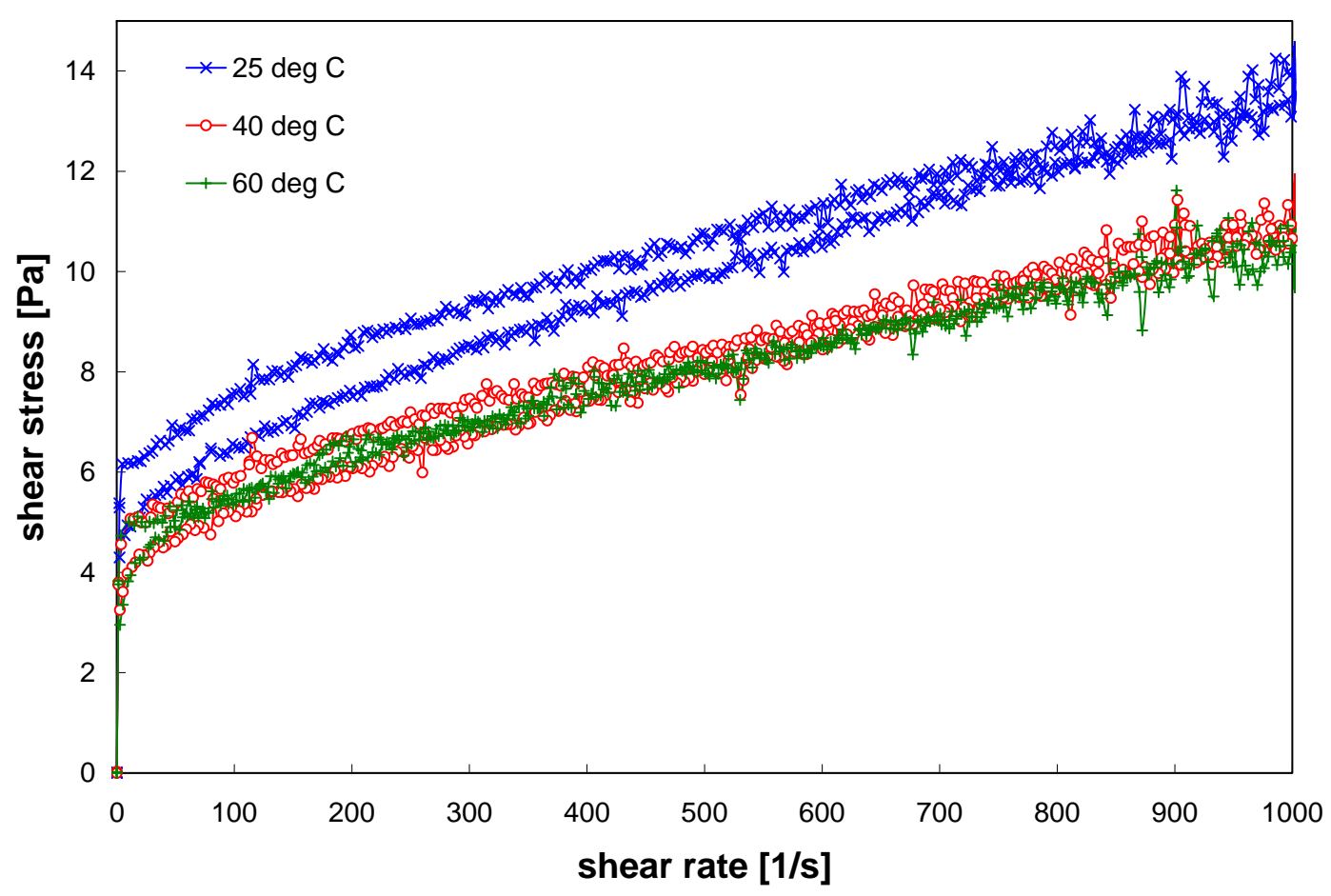

Figure 12. Flow curve for the Group 8 CUF testing slurry sample TI640-G8-R4-Slurry at $25^{\circ} \mathrm{C}, 40^{\circ}$ $\mathrm{C}$, and $60^{\circ} \mathrm{C}$. Only the replicate flow curve measurement at $25^{\circ} \mathrm{C}$ is shown.

To capture and quantify the non-Newtonian rheology of sample TI640-G8-R4-Slurry, the flow curve data are fit to both Bingham-Plastic and Casson models. Bingham-Plastic fits are limited to shear rates of 100 to $1000 \mathrm{~s}^{-1}$ to the avoid significant non-linearity observed at low shear rates. Casson model fits employ the full shear rate range of 0 to $1000 \mathrm{~s}^{-1}$. Both fitting approaches use all portions of the flow curve for fitting analysis, including the up- and down-ramps and constant rotation. Table 20 summarizes the best-fit Bingham-Plastic and Casson parameters for sample TI640-G8-R4-Slurry. An example of "how-well" the BinghamPlastic and Casson models fit data is provided in Figure 13. From the fits in Figure 13, it appears that the Casson model better captures the data over the full range of shear rates. However, beyond the region of strong curvature (0 to $\left.100 \mathrm{~s}^{-1}\right)$, both Bingham-Plastic and Casson models provide a similar fit of the data.

Table 20. Results of fitting analysis for rheology sample TI640-G8-R4-Slurry. Viscosities were determined by fitting both up- and down-ramp data.

\begin{tabular}{||c|c|c|c|c|c||}
\hline Model & $\begin{array}{c}\text { Temperature } \\
{\left[{ }^{\circ} \mathbf{C}\right]}\end{array}$ & Range & $\begin{array}{c}\text { Yield Stress } \\
{[\mathbf{P a}]}\end{array}$ & $\begin{array}{c}\text { Consistency } \\
{[\mathbf{m P a} \cdot \mathbf{s}]}\end{array}$ & $\mathbf{R}$ \\
\hline \multirow{3}{*}{ Bingham-Plastic } & $25(1$ of 2$)$ & $100-1000 \mathrm{~s} \mathrm{~s}^{-1}$ & 5.4 & 6.5 & 0.98 \\
\cline { 2 - 6 } & $25(2$ of 2$)$ & $100-1000 \mathrm{~s} \mathrm{~s}^{-1}$ & 6.7 & 6.9 & 0.99 \\
\cline { 2 - 6 } & 40 & $100-1000 \mathrm{~s}^{-1}$ & 5.3 & 5.7 & 0.98 \\
\cline { 2 - 6 } & 60 & $100-1000 \mathrm{~s} \mathrm{~s}^{-1}$ & 5.4 & 5.1 & 0.98 \\
\hline \multirow{5}{*}{ Casson } & $25(1$ of 2$)$ & $0-1000 \mathrm{~s} \mathrm{~s}^{-1}$ & 3.4 & 2.5 & 0.98 \\
\cline { 2 - 6 } & $25(2$ of 2$)$ & $0-1000 \mathrm{~s} \mathrm{~s}^{-1}$ & 4.5 & 2.4 & 0.99 \\
\cline { 2 - 6 } & 40 & $0-1000 \mathrm{~s}^{-1}$ & 3.6 & 2.0 & 0.98 \\
\cline { 2 - 6 } & 60 & $0-1000 \mathrm{~s} \mathrm{~s}^{-1}$ & 3.7 & 1.7 & 0.99 \\
\hline
\end{tabular}




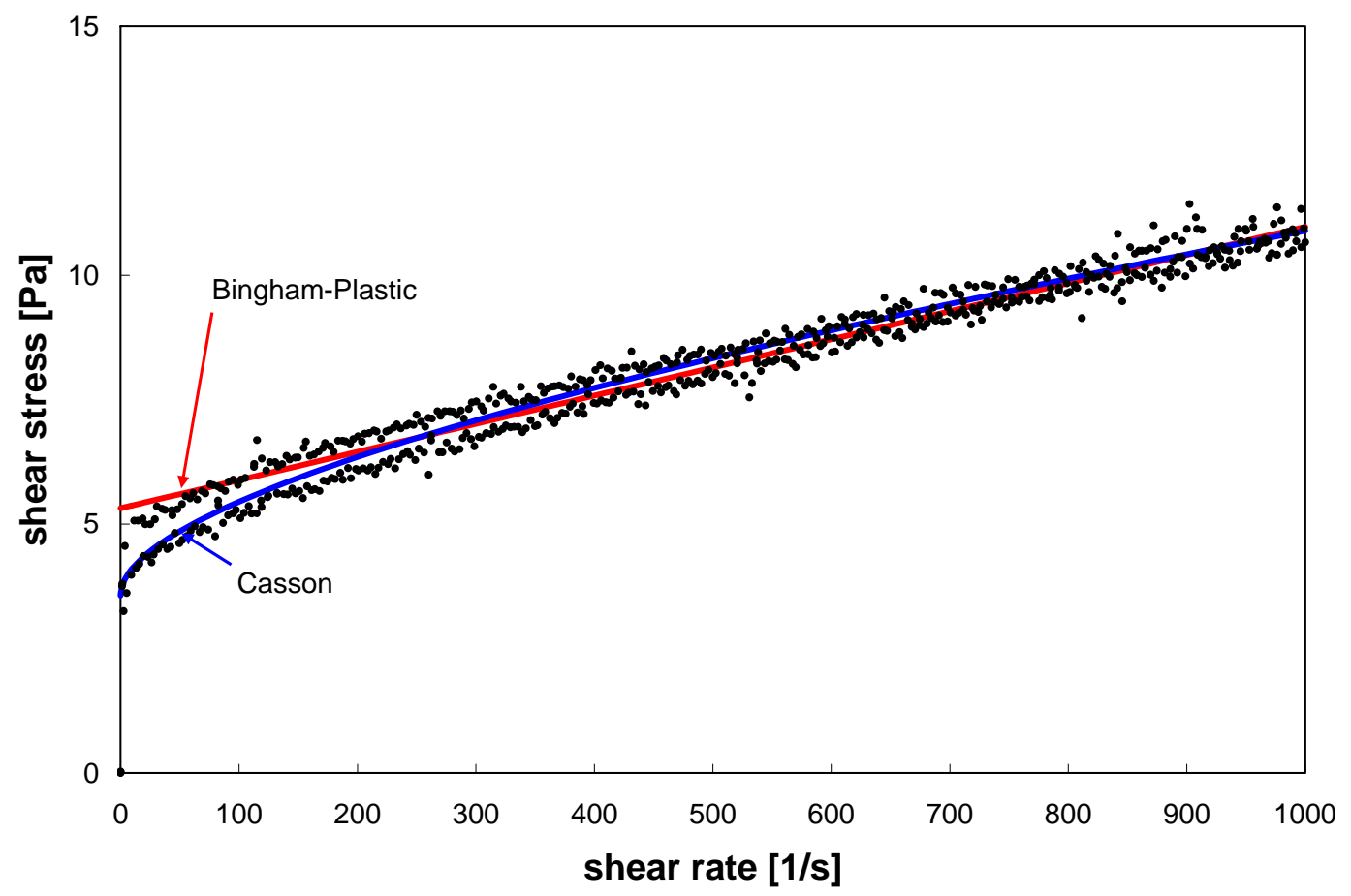

Figure 13. Example result for the fitting analysis of Group 8 CUF slurry test sample TI640-G8-R4Slurry. Data points (solid circles) correspond to the measurement at $40^{\circ} \mathrm{C}$. The solid lines correspond to the best-fit Bingham-Plastic and Casson model calculations.

The fitting results in Table 20 confirm non-Newtonian rheology. The best-fit BinghamPlastic and Casson yield stresses range from 5.3 to $6.7 \mathrm{~Pa}$ and 3.4 to $4.5 \mathrm{~Pa}$, respectively. In both cases, the replicate yield stress at $25^{\circ} \mathrm{C}$ is significantly higher than that of the initial measurement. The difference initial and replicate yield can be attributed to fresh material being added to the measurement cup for the replicate measurement to correct level decreases resulting from release of entrained air in the slurry. Apart from the disparity in the replicate measurement, yield stress at all temperatures agree within the limits of instrument accuracy $(0.5 \mathrm{~Pa})$ and do not appear to vary significantly with temperature.

The best-fit Bingham-Plastic and Casson slurry consistencies range from 5.1 to $6.9 \mathrm{cP}$ and 1.7 to $2.5 \mathrm{cP}$, respectively. Initial and replicate consistencies at $25^{\circ} \mathrm{C}$ agree within the limit of instrument accuracy $(0.5 \mathrm{cP})$. As such, it appears that the disparity affecting agreement between initial and replicate yield stress values do not affect the flow curve slope. Higher temperatures appear to effect a decrease in slurry consistency. Based on the Bingham-Plastic model parameters, there is a significant $(>0.5 \mathrm{cP})$ decrease in slurry consistency between $25^{\circ} \mathrm{C}$ and $40^{\circ} \mathrm{C}$ and between $40^{\circ} \mathrm{C}$ and $60^{\circ} \mathrm{C}$. The Casson consistencies show a reduced decrease, with the difference between consistencies at $25^{\circ} \mathrm{C}$ and $40^{\circ} \mathrm{C}$ being borderline significant and the change between $40^{\circ} \mathrm{C}$ and $60^{\circ} \mathrm{C}$ being insignificant. However, considering the change over the entire range of temperature (i.e., $25^{\circ} \mathrm{C}$ to $60^{\circ} \mathrm{C}$ ), the Casson parameters confirm that there is an overall decrease in slurry consistency with increasing temperature.

Apparent viscosities at 33, 100, 500, and $1000 \mathrm{~s}^{-1}$ were derived from each measurement. For each temperature, the 33,100 , and $500 \mathrm{~s}^{-1}$ reference viscosities were 
determined from the average both up-ramp and down-ramp flow curve data. The apparent viscosity at $1000 \mathrm{~s}^{-1}$ is derived from the average of all apparent viscosity measurements during constant rotation at $1000 \mathrm{~s}^{-1}$. As a point of comparison, apparent viscosities were also calculated using the Bingham-Plastic and Casson fitting parameters in Table 20. The results of these analyses are provided in Table 21.

Table 21. Select apparent viscosities for sample TI640-G8-R4-Slurry.

\begin{tabular}{|c|c|c|c|c|c|}
\hline \multirow[t]{2}{*}{ Source } & \multirow{2}{*}{$\begin{array}{c}\text { Temperature } \\
{\left[{ }^{\circ} \mathrm{C}\right]} \\
\end{array}$} & \multicolumn{4}{|c|}{ Apparent Viscosity [cP] } \\
\hline & & @ $33 \mathrm{~s}^{-1}$ & $@ 100 \mathrm{~s}^{-1}$ & @ $500 \mathrm{~s}^{-1}$ & @ $1000 \mathrm{~s}^{-1}$ \\
\hline \multirow[t]{4}{*}{ Measured } & $25(1$ of 2$)$ & 140 & 57 & 17 & 12 \\
\hline & $25(2$ of 2$)$ & 180 & 71 & 21 & 14 \\
\hline & 40 & 150 & 55 & 16 & 11 \\
\hline & 60 & 150 & 54 & 16 & 10 \\
\hline \multirow[t]{4}{*}{ Bingham-Plastic } & $25(1$ of 2$)$ & 170 & 60 & 17 & 12 \\
\hline & $25(2$ of 2$)$ & 210 & 74 & 20 & 14 \\
\hline & 40 & 170 & 59 & 16 & 11 \\
\hline & 60 & 170 & 59 & 16 & 10 \\
\hline \multirow[t]{4}{*}{ Casson } & 25 (1 of 2$)$ & 140 & 55 & 18 & 12 \\
\hline & $25(2$ of 2$)$ & 180 & 69 & 21 & 14 \\
\hline & 40 & 140 & 54 & 17 & 11 \\
\hline & 60 & 140 & 55 & 16 & 10 \\
\hline
\end{tabular}

In summary, the caustic-leached and dewatered Group 8 slurry (sample TI640-G8-R4Slurry) shows non-Newtonian rheology. Unlike previous samples, analysis of the leached, dewatered, and washed Group 8 slurry was complicated by the presence of significant entrained air in the samples. To obtain stable stress readings during measurement, the test slurry had to be sheared significant to release gas from the sample before measurement.

Analysis of flow curve data against the Bingham-Plastic flow curve model suggests a yield stress ranging from 5.3 to $6.7 \mathrm{~Pa}$ and a consistency ranging from 5.1 to $6.9 \mathrm{cP}$. Similar analysis with the Casson model finds a yield stress that ranges from 3.4 to $4.5 \mathrm{~Pa}$ and a consistency that ranges from 1.7 to $2.5 \mathrm{cP}$. Model fits confirm a significant yield stress and non-Newtonian behavior. The upper range of yield stress of 6.7 $\mathrm{Pa}$ and $4.5 \mathrm{~Pa}$ for BinghamPlastic and Casson fits, respectively, was uncharacteristic for the sample. That is, the majority of yield stresses derived from measurement of TI640-G8-R4-Slurry varied closely around $~ 5.4$ $\mathrm{Pa}$ (Bingham-Plastic) or $3.5 \mathrm{~Pa}$ (Casson). Increases in slurry temperature did not appear to yield changes in the slurry yield stress. On the other hand, increased temperature did lower the slurry consistency. The decrease in slurry consistency with increasing temperature is confirmed by both flow curve data (Figure 12) and by both Bingham-Plastic and Casson model fitting results.

\section{Sample TI640-G8-R5-Slurry: Group 8 CUF Combined Leach Slurry}

Sample TI640-G8-R5-Slurry corresponds to the combined-leach slurry for Group 8 CUF testing. It is a mixture of Group 7, Group 8, and AY-102 waste solids that have been caustic-leached, dewatered, and washed slurry solids. This slurry has an undissolved solids concentration of $\sim 26$-wt $\%$ and a supernate dissolved solids concentration of $\sim 3 \%$.

It should be noted that this sample also exhibited similar difficulties with regard to air entrainment as encountered in measurement of sample TI640-G8-R4-Slurry. To prevent gas 
release during flow curve measurement, the samples were pre-sheared at a constant rotational rate until the stress response changed less than 0.5 Pa change over 3 minutes. After this preshearing, the sample was measured in accordance with the typical flow curve procedure, including both the 3 minute constant rotation at $470 \mathrm{~s}^{-1}$ (200 RPM) and the 15-minute flow curve measurements at $25^{\circ} \mathrm{C}, 40^{\circ} \mathrm{C}$, and $60^{\circ} \mathrm{C}$.

Figure 14 shows the results of flow curve testing for sample TI640-G8-R5-Slurry. The data indicate a non-Newtonian slurry with significant yield stress. After yield, the stress response is generally linear although there is significant downward curvature over 0 to $100 \mathrm{~s}^{-1}$. Flow curve data exhibit hysteresis characterized by a higher stress response during the up-ramp portion of the measurement. The degree of hysteresis appears to decrease with increasing temperature (i.e., at later times in the measurement). Such hysteresis is suggestive of 1) shear induced disruption of sample structure, 2) settling of solids in the measurement gap, or 3) degassing of the sample. Despite hysteresis, the measurement is characterized by a high signal-to-noise ratio.

With regard to the effects of temperature, the data in Figure 14 suggest that rheology decreases with increasing temperature. The graph shows obvious decreases in yield stress as the temperature is raised to $40^{\circ} \mathrm{C}$ and $60^{\circ} \mathrm{C}$. The slope of the stress response (i.e., the slurry consistency) appears reduced at $40^{\circ} \mathrm{C}$ relative to that at $25^{\circ} \mathrm{C}$. This decrease may continue as the temperature is raised from $40^{\circ} \mathrm{C}$ to $60^{\circ} \mathrm{C}$, but it is difficult to tell from visual inspection of the data alone.

To capture and quantify the non-Newtonian rheology of Sample TI640-G8-R5-Slurry, the flow curve data shown in Figure 14 are fit to both Bingham-Plastic and Casson models. Bingham-Plastic fits are limited to shear rates of 100 to $1000 \mathrm{~s}^{-1}$ to the avoid significant nonlinearity at low shear rates. Casson model fits employ the full shear rate range of 0 to $1000 \mathrm{~s}^{-1}$. Both fitting approaches use all portions of the flow curve for fitting analysis, including the upand down-ramps and constant rotation. Table 22 summarizes the best-fit Bingham-Plastic and Casson parameters for sample TI640-G8-R5-Slurry. An example of "how-well” the BinghamPlastic and Casson models fit data is provided in Figure 15. As before, the fits in Figure 15 suggest that the Casson model better captures the data over the full range of shear rates. Beyond the region of strong curvature $\left(0\right.$ to $\left.100 \mathrm{~s}^{-1}\right)$, both Bingham-Plastic and Casson models provide a similar and reasonable fit of the data. 


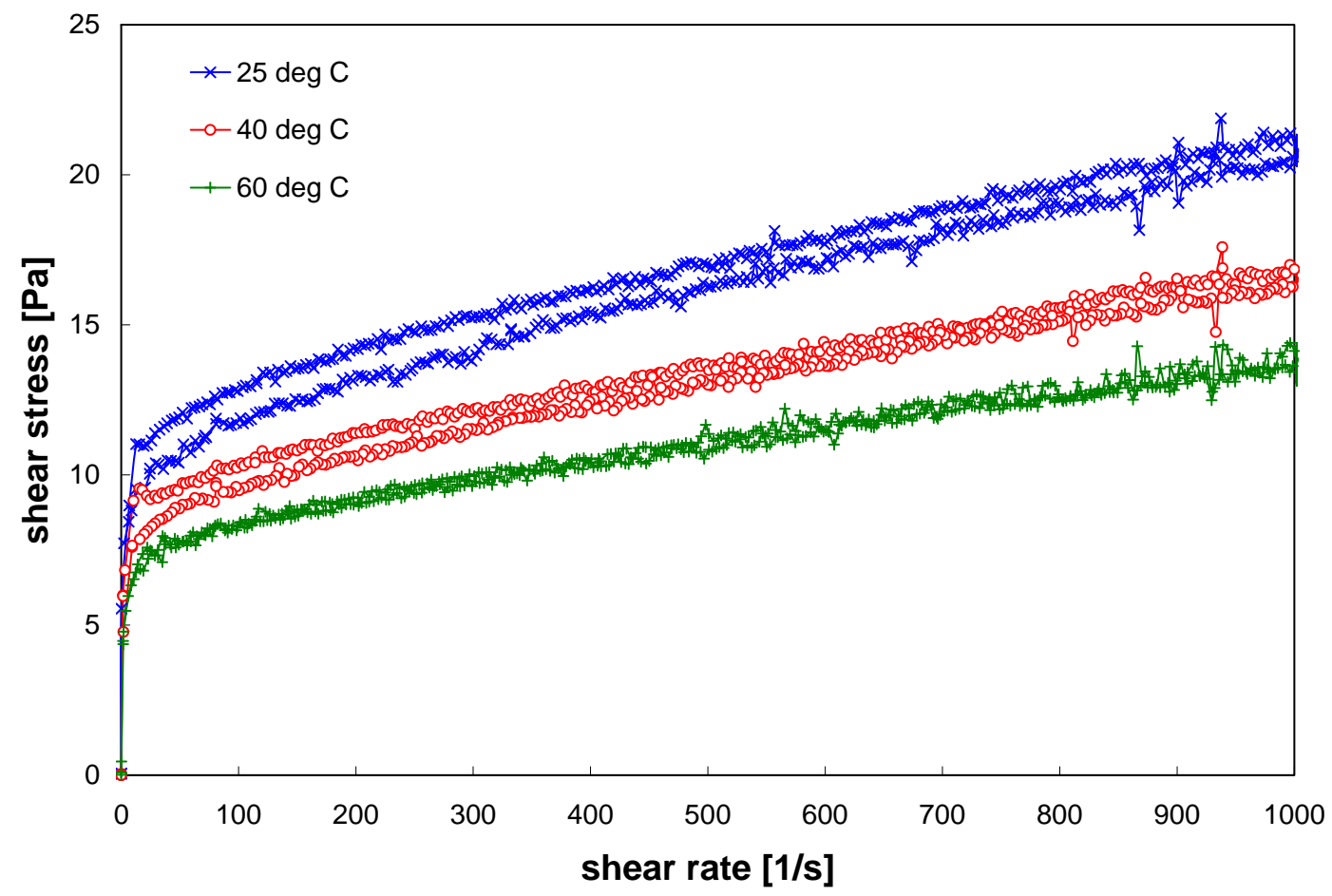

Figure 14. Flow curve for the Group 8 CUF testing slurry sample TI640-G8-R5-Slurry at $25^{\circ} \mathrm{C}, 40^{\circ}$ $\mathrm{C}$, and $60^{\circ} \mathrm{C}$. Only the replicate flow curve measurement at $25^{\circ} \mathrm{C}$ is shown.

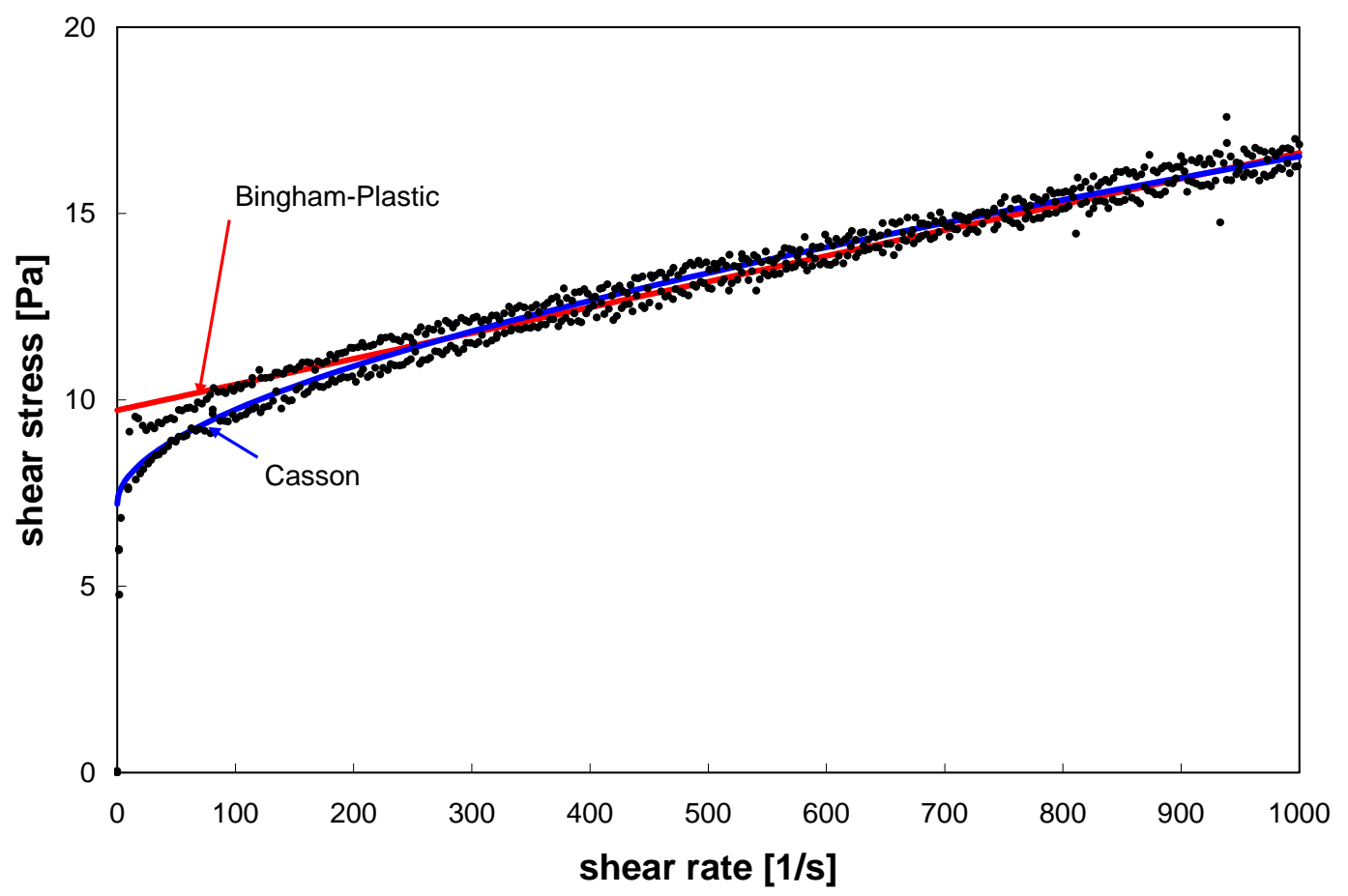

Figure 15. Example result for the fitting analysis of Group 8 CUF slurry test sample TI640-G8-R5Slurry. Data points (solid circles) correspond to the measurement at $40^{\circ} \mathrm{C}$. The solid lines correspond to the best-fit Bingham-Plastic and Casson model calculations. 
The results in Table 22 confirm non-Newtonian behavior. Both Bingham-Plastic and Casson fits indicate significant slurry yield stress. Specifically, the Bingham and Casson fits indicate a slurry yield stress of 8.1 to $13 \mathrm{~Pa}$ and 6.0 to $9.5 \mathrm{~Pa}$, respectively. Initial and replicate best-fit yield stresses agree to within $10 \%$ and as such, are comparable. Both model fits confirm that the yield stress decreases significantly with temperature. For example, the Bingham-Plastic yield stress decreases from $\sim 12 \mathrm{~Pa}$ to $9.7 \mathrm{~Pa}$ when the temperature is increased from $25^{\circ} \mathrm{C}$ to $40^{\circ} \mathrm{C}$. As the temperature is further increase to $60^{\circ} \mathrm{C}$, the yield decreases again to $8.1 \mathrm{~Pa}$. All decreases are greater than $10 \%$ of the original value and, as such, are likely significant.

Likewise, the slurry consistency appears to decrease with increasing temperature. The Bingham-Plastic fits indicate a consistency ranging from 5.7 to $9.5 \mathrm{cP}$ (depending on temperature); the Casson fits find a consistency ranging from 1.6 to $2.6 \mathrm{cP}$. Initial and replicate best-fit yield stresses agree to within $10 \%$ and as such, are comparable. Based on the Bingham-Plastic fits, slurry consistency decreased from $8.8 \mathrm{cP}$ to $6.9 \mathrm{cP}$ over $25^{\circ} \mathrm{C}$ to $40^{\circ} \mathrm{C}$ and from 6.9 to $5.7 \mathrm{cP}$ over $40^{\circ} \mathrm{C}$ to $60^{\circ} \mathrm{C}$. Both decreases exceed the $10 \%$ limit of accuracy expected for this measurement range. Although the decrease observed in the Casson fit consistency is less (and may not be significant on a temperature-to-temperature basis), the overall decrease observed between $25^{\circ} \mathrm{C}$ and $60^{\circ} \mathrm{C}$ is large enough to be considered significant.

Table 22. Results of fitting analysis for rheology sample TI640-G8-R5-Slurry. Viscosities were determined by fitting both up- and down-ramp data.

\begin{tabular}{||c|c|c|c|c|c||}
\hline Model & $\begin{array}{c}\text { Temperature } \\
{\left[{ }^{\circ} \mathbf{C}\right]}\end{array}$ & Range & $\begin{array}{c}\text { Yield Stress } \\
{[\mathbf{P a}]}\end{array}$ & $\begin{array}{c}\text { Consistency } \\
{[\mathbf{m P a} \cdot \mathbf{s}]}\end{array}$ & $\mathbf{R}$ \\
\hline \multirow{3}{*}{ Bingham-Plastic } & $25(1$ of 2$)$ & $100-1000 \mathrm{~s}^{-1}$ & 13 & 9.5 & 0.99 \\
\cline { 2 - 6 } & $25(2$ of 2$)$ & $100-1000 \mathrm{~s}^{-1}$ & 12 & 8.8 & 0.99 \\
\cline { 2 - 6 } & 40 & $100-1000 \mathrm{~s}^{-1}$ & 9.7 & 6.9 & 0.99 \\
\cline { 2 - 6 } & 60 & $100-1000 \mathrm{~s}^{-1}$ & 8.1 & 5.7 & 0.99 \\
\hline \multirow{6}{*}{ Casson } & $25(1$ of 2$)$ & $0-1000 \mathrm{~s}^{-1}$ & 9.5 & 2.6 & 0.98 \\
\cline { 2 - 6 } & $25(2$ of 2$)$ & $0-1000 \mathrm{~s}^{-1}$ & 8.9 & 2.5 & 0.99 \\
\cline { 2 - 6 } & 40 & $0-1000 \mathrm{~s}^{-1}$ & 7.2 & 1.9 & 0.99 \\
\cline { 2 - 6 } & 60 & $0-1000 \mathrm{~s}^{-1}$ & 6.0 & 1.6 & 0.99 \\
\hline
\end{tabular}

Apparent viscosities at 33, 100, 500, and $1000 \mathrm{~s}^{-1}$ were derived from each measurement. For each temperature, the 33, 100, and $500 \mathrm{~s}^{-1}$ reference viscosities were determined from the average both up-ramp and down-ramp flow curve data. The apparent viscosity at $1000 \mathrm{~s}^{-1}$ is derived from the average of all apparent viscosity measurements during constant rotation at $1000 \mathrm{~s}^{-1}$. As a point of comparison, apparent viscosities were also calculated using the Bingham-Plastic and Casson fitting parameters in Table 22. The results of these analyses are provided in Table 23. 
Table 23. Select apparent viscosities for sample TI640-G8-R5-Slurry.

\begin{tabular}{|c|c|c|c|c|c|}
\hline \multirow[t]{2}{*}{ Source } & \multirow{2}{*}{$\begin{array}{c}\text { Temperature } \\
{\left[{ }^{\circ} \mathrm{C}\right]}\end{array}$} & \multicolumn{4}{|c|}{ Apparent Viscosity [cP] } \\
\hline & & (a) $33 \mathrm{~s}^{-1}$ & @ $100 \mathrm{~s}^{-1}$ & @ $500 \mathrm{~s}^{-1}$ & @ $1000 \mathrm{~s}^{-1}$ \\
\hline \multirow[t]{4}{*}{ Measured } & 25 (1 of 2$)$ & 370 & 140 & 35 & 22 \\
\hline & $25(2$ of 2$)$ & 330 & 120 & 33 & 21 \\
\hline & 40 & 270 & 99 & 27 & 17 \\
\hline & 60 & 230 & 83 & 22 & 14 \\
\hline \multirow[t]{4}{*}{ Bingham-Plastic } & 25 (1 of 2$)$ & 400 & 140 & 35 & 22 \\
\hline & 25 (2 of 2$)$ & 370 & 130 & 33 & 21 \\
\hline & 40 & 300 & 100 & 26 & 17 \\
\hline & 60 & 250 & 87 & 22 & 14 \\
\hline \multirow[t]{4}{*}{ Casson } & 25 (1 of 2$)$ & 350 & 130 & 36 & 22 \\
\hline & 25 (2 of 2$)$ & 320 & 120 & 34 & 21 \\
\hline & 40 & 260 & 97 & 27 & 17 \\
\hline & 60 & 220 & 81 & 22 & 14 \\
\hline
\end{tabular}

In summary, the caustic-leached and dewatered Group 8 slurry (sample TI640-G8-R5Slurry) shows non-Newtonian rheology. Analysis of the data against Bingham-Plastic and Casson models indicates a slurry yield stress of 8.1 to $13 \mathrm{~Pa}$ and 6.0 to $9.5 \mathrm{~Pa}$, respectively, and a slurry consistency of 5.7 to $9.5 \mathrm{cP}$ and 1.6 to $2.6 \mathrm{cP}$, respectively. The data indicate that slurry consistency and yield decrease significantly with increasing temperature.

\subsection{Effects of CUF Processing on Group 8 Rheology}

This section examines the effect waste mixing and CUF processing has on Group 8 waste mixture rheology. Comparisons will primarily focus on the changes that occur in sample rheology between processing steps. The data analysis and discussion presented in this section details impacts to the waste slurry rheology during the following five processes:

1. dilution of the Group 8 waste solids to form the low-solids matrix

2. dewatering of the low-solids Group 8 slurry to form the high-solids matrix

3. caustic-leaching of the initial Group 8 slurry

4. washing of the caustic-leached Group8 slurry

5. mixing of the Group 8 leached solids with Group 7 CUF leached solids to form the combined leach slurry

To discuss the influence of each of these processes on the CUF slurry rheology, flow curve data along with best-fit Newtonian viscosity and Bingham-Plastic parameters shall be employed. Comparisons shall be made using best-fit parameters based on $25^{\circ} \mathrm{C}$ replicate measurement flow curve data. In addition to the processes outlined above, a general discussion of the effect of temperature for Group 8 CUF samples is given at the end of this section.

\section{Dilution of Group 8 Waste Solids}

Table 24 illustrates the effect of dilution on Group 8 rheology by comparing the rheology of the source Group 8 slurry (i.e., the initial characterization sample) to that of the low-solids matrix (dilute) Group 8 CUF slurry. The Group 8 source material has an undissolved solids concentration of $\sim 11$-wt $\%$ while the diluted CUF slurry has an undissolved solids concentration of only 6-wt\%. Despite the factor of two decrease in solids 
concentration, both slurries are Newtonian and show statistically similar viscosity (i.e., are within $0.5 \mathrm{cP}$ of each other). These results suggest that 1 ) solids concentration has minimal impact on the rheology and that 2) the viscosity of the suspending phase dominates rheology source material and dilute slurry rheology.

Table 24. Effect of dilution on Group 8 rheology (at $25^{\circ} \mathrm{C}$ ). Note: Group 8 source material (TI516-G8AR-P1) rheology result is "For Information Only". See NCR 38963.1 for details.

\begin{tabular}{||c|c|c|c|c||}
\hline Description & $\begin{array}{c}\text { Undissolved Solids } \\
\text { Concentration }\end{array}$ & Rheology & $\begin{array}{c}\text { Yield } \\
\text { Stress } \\
\text { [Pa] }\end{array}$ & $\begin{array}{c}\text { Consistency } \\
\text { [cP] }\end{array}$ \\
\hline $\begin{array}{c}\text { Group 8 Source } \\
\text { (TI516-G8-AR-P1) }\end{array}$ & $11.4-w t \%$ & Newtonian & $\mathrm{n} / \mathrm{a}$ & 2.6 \\
\hline $\begin{array}{c}\text { Dilute Group 8 CUF Slurry } \\
\text { (TI640-G8-R1-Slurry) }\end{array}$ & $\sim 6-w t \%$ & Newtonian & $\mathrm{n} / \mathrm{a}$ & 3.0 \\
\hline * Non-Newtonian properties reported are Bingham-Plastic model parameters. \\
\hline
\end{tabular}

\section{Dewatering of Group 8 CUF Slurry}

Table 25 shows the effect that dewatering has on the pre-caustic-leach rheology of the Group 8 CUF slurry. Dewatering increases the undissolved solids concentration of the slurry from $\sim 6$-wt $\%$ to $\sim 13-w t \%$. Dewatering operations are accompanied by prolonged circulation of the slurry through the filtration loop. The final dewatered slurry is highly sheared. Based on the results in Table 25, dewatering appears to effect a significant increase in slurry rheology. Before dewater, the slurry is Newtonian with a $3.0 \mathrm{cP}$ viscosity. After dewatering, the slurry is non-Newtonian with a $0.7 \mathrm{~Pa}$ yield stress (which is borderline significant) and a $4.9 \mathrm{cP}$ consistency. The increased rheology is not surprising, as increased solids concentrations leads to additional particle contact and energy dissipation.

Relative to the Group 8 source material, which was 11-wt\% and showed Newtonian rheology with a $2.6 \mathrm{cP}$ viscosity, the concentrated Group 8 initial CUF slurry shows increased rheology. Again, this is not surprising, given the higher solids concentration in the CUF testing sample. However, the concentrations are relatively close such that slight nonNewtonian behavior (or a trend toward non-Newtonian behavior, such as a 0.1 to 0.3 Pa yield stress) would be expected in the initial characterization sample based on the measured flow curve. Because no such behavior is observed in the initial characterization flow curves (Figure 4), it is speculated that prolonged shear in the CUF has caused the slurry to become more nonNewtonian. A similar consequence of CUF processing was observed during the Group 3/4 mixed slurry tests (see Reference 6).

Table 25. Effect of pre-caustic-leach dewatering on Group 8 CUF rheology (at $25^{\circ} \mathrm{C}$ )

\begin{tabular}{||c|c|c|c|c||}
\hline Description & $\begin{array}{c}\text { Undissolved Solids } \\
\text { Concentration }\end{array}$ & Rheology & $\begin{array}{c}\text { Yield Stress } \\
{[\text { Pa] }}\end{array}$ & $\begin{array}{c}\text { Consistency } \\
\text { [cP] }\end{array}$ \\
\hline $\begin{array}{c}\text { Dilute Group 8 Slurry } \\
\text { (TI640-G8-R1-Slurry) }\end{array}$ & $\sim 6-\mathrm{wt} \%$ & Newtonian & $\mathrm{n} / \mathrm{a}$ & 3.0 \\
\hline $\begin{array}{c}\text { Concentrated Group 8 Slurry } \\
\text { (TI640-G8-R2-Slurry) }\end{array}$ & $\sim 13-\mathrm{wt} \%$ & Non-Newtonian* & 0.7 & 4.9 \\
\hline * Non-Newtonian properties reported are Bingham-Plastic model parameters. \\
\hline
\end{tabular}




\section{Caustic-Leaching of Group 8 CUF Slurry}

Table 26 shows the effect of caustic-leaching and dewatering on the rheology of the Group 8 CUF slurry. Before caustic-leaching, the slurry is non-Newtonian with a yield stress of $0.7 \mathrm{~Pa}$ and a consistency of $4.9 \mathrm{cP}\left(\right.$ at $\left.25^{\circ} \mathrm{C}\right)$. The unleached slurry has an undissolved solids concentration $13-w t \%$ and a dissolved solids concentration of $20-w t \%$. After leaching, the slurry shows a strong non-Newtonian rheology. The post-leach yield stress and consistency are $1.1 \mathrm{~Pa}$ and $6.6 \mathrm{cP}$, respectively, while the post-leach undissolved solids concentration and supernate dissolved solids concentration are $23-\mathrm{wt} \%$ and $24-\mathrm{wt} \%$, respectively.

Clearly, the leached slurry shows higher yield stress and consistency although the difference in yield stress is borderline-significant. While caustic-leaching is likely to increase slurry rheology through addition of ions to the suspending solution, all of the difference in indicated in Table 26 cannot be attributed to the leaching process alone. The post-leach undissolved solids concentration is approximately $10 \%$ higher than the pre-leach, and this likely yields increased solid particle contact and collision (and increased rheology) as a result.

Table 26. Effect of caustic-leaching and dewatering on Group 8 CUF rheology (at $25^{\circ} \mathrm{C}$ )

\begin{tabular}{||c|c|c|c|c||}
\hline \hline Description & $\begin{array}{c}\text { Undissolved Solids } \\
\text { Concentration }\end{array}$ & Rheology & $\begin{array}{c}\text { Yield } \\
\text { Stress } \\
\text { [Pa] }\end{array}$ & $\begin{array}{c}\text { Consistency } \\
\text { [cP] }\end{array}$ \\
\hline $\begin{array}{c}\text { Concentrated Initial Slurry } \\
\text { (TI640-G8-R2-Slurry) }\end{array}$ & $\sim 13-$ wt\% & 0.7 & 4.9 \\
\hline $\begin{array}{c}\text { Caustic-Leached / } \\
\text { Dewatered } \\
\text { (TI640-G8-R3-Slurry) }\end{array}$ & $\sim 23-w t \%$ & $\begin{array}{c}\text { Non- } \\
\text { Newtonian* }\end{array}$ & 1.1 & 6.6 \\
\hline * Non-Newtonian properties reported are Bingham-Plastic model parameters. & & \\
\hline
\end{tabular}

\section{Washing of Caustic-Leached Group 8 CUF Slurry}

Table 27 shows the effect of post-caustic-leach washing on the rheology of the Group 8 CUF slurry. Washing appears to further increase the slurry rheology, despite a decrease in the undissolved solids concentration. Before washing, the slurry is non-Newtonian with a yield stress of $1.1 \mathrm{~Pa}$ and a consistency of $6.6 \mathrm{cP}$ at $25^{\circ} \mathrm{C}$. It has an undissolved solids concentration 23-wt\% and a supernate dissolved solids concentration of 24-wt\%. After washing, the slurry is non-Newtonian with a yield stress of $6.7 \mathrm{~Pa}$ and consistency of $6.9 \mathrm{cP}$. The undissolved solids concentration and supernate dissolved solids concentration after leaching are $20-\mathrm{wt} \%$ and $4-w t \%$, respectively.

Washing reduces both dissolved solids and undissolved solids concentrations. Therefore, the increase observed in yield stress and the minor increase observed in consistency (likely not significant) cannot be attributed to increase in the solid concentration. It can be speculated that changes in particle interactions in a lower-ionic strength suspending phase increase bulk slurry cohesion, making it more difficult to yield. 
Table 27. Effect of post-caustic-leach washing on Group 8 CUF rheology (at $25^{\circ} \mathrm{C}$ )

\begin{tabular}{||c|c|c|c|c||}
\hline \hline Description & $\begin{array}{c}\text { Undissolved Solids } \\
\text { Concentration }\end{array}$ & Rheology & $\begin{array}{c}\text { Yield Stress } \\
\text { [Pa] }\end{array}$ & $\begin{array}{c}\text { Consistency } \\
\text { [cP] }\end{array}$ \\
\hline $\begin{array}{c}\text { Caustic-Leached/Dewatered } \\
\text { (TI640-G8-R3-Slurry) }\end{array}$ & $\sim 23-w t \%$ & Non-Newtonian* & 1.1 & 6.6 \\
\hline $\begin{array}{c}\text { Caustic-Leached/Dewatered/ } \\
\text { Washed (TI640-G8-R4-Slurry) }\end{array}$ & $\sim 20-w t \%$ & Non-Newtonian* & 6.7 & 6.9 \\
\hline \multicolumn{2}{|r|}{ * Non-Newtonian properties reported are Bingham-Plastic model parameters. } \\
\hline
\end{tabular}

Mixing of Group 7 CUF and Group 8 CUF Leached and Washed Waste Solids

Table 28 compares the rheology of the source materials for the Group 8 combined leach slurry (which includes Group 7 and Group 8 CUF leached and washed solids) to that of the resulting combined leach slurry. The combined leach slurry shows both a higher yield stress and higher consistency than either Group 7 / AY-102 or Group 8 CUF slurries. Because the combined leach slurry also has a higher undissolved solids concentration than either washed /leached slurry, it is likely that the increased rheology in the combined leach sample derives from increased solids concentration. Particle interaction effects between the different waste groups may also cause part of the increase. However, without knowledge of how Group 7 / AY-102 and Group 8 leached waste slurries behave as a function of undissolved solids concentration, it is impossible to assess how much of the change is caused by particle chemistry relative to solids concentration.

Table 28. Comparison of leached and washed slurries and slurry mixture rheology for Group 7 and 8 CUF testing samples (at $25^{\circ} \mathrm{C}$ ).

\begin{tabular}{||c|c|c|c|c||}
\hline \hline Description & $\begin{array}{c}\text { Undissolved Solids } \\
\text { Concentration }\end{array}$ & Rheology & $\begin{array}{c}\text { Yield } \\
\text { Stress } \\
\text { [Pa] }\end{array}$ & $\begin{array}{c}\text { Consistency } \\
\text { [cP] }\end{array}$ \\
\hline $\begin{array}{c}\text { Group 7 Leached / Washed } \\
\text { (TI624-G7-R4-Slurry) }\end{array}$ & $\sim 14-\mathrm{wt} \%$ & Non-Newtonian* & 0.5 & 2.8 \\
\hline $\begin{array}{c}\text { Group 8 Leached / Washed } \\
\text { (TI640-G8-R4-Slurry) }\end{array}$ & $\sim 20-\mathrm{wt} \%$ & Non-Newtonian* & 6.7 & 6.9 \\
\hline $\begin{array}{c}\text { Combined Leach Slurry } \\
\text { (TI640-G8-R5-Slurry) }\end{array}$ & $\sim 26-w+\%$ & Non-Newtonian* & 12 & 8.8 \\
\hline * Non-Newtonian properties reported are Bingham-Plastic model parameters. \\
\hline
\end{tabular}

\section{Temperature Trends}

Tables 29 and 30 compare slurry yield stress and consistency (based on the BinghamPlastic model fits) as a function of test temperature for all Group 8 CUF testing samples and source materials. Yield stress does not appear to vary as a function of temperature for much of the Group 8 CUF slurries and source materials. The combined leach slurry is an exception to this generalization and shows a significant decrease in yield stress with increasing temperature. On the other hand, slurry consistency (or Newtonian viscosity) tends to decrease significantly with increasing temperature. Such decreases typically result from lowering of the permeate phase suspending viscosity (although changes in particle interactions can yield similar changes). 
Table 29. Effect of temperature on slurry Bingham-Plastic yield stress for the Group 8 source material (G8); Group 7 leached / washed solids (G7L); and the Group 8 low-solids (LS), high-solids (HS), caustic-leached and dewatered (CLD), caustic-leached dewatered and washed (CLDW), and combined leach (CLS) slurries.

\begin{tabular}{|c|c|c|c|c|c|c|c|}
\hline \multirow{2}{*}{$\begin{array}{c}\text { Temperature } \\
{\left[{ }^{\circ} \mathrm{C}\right]}\end{array}$} & \multicolumn{7}{|c|}{ Slurry Bingham-Plastic Yield Stress [Pa] } \\
\hline & G8 & G7L & LS & HS & CLD & CLDW & CLS \\
\hline 25 (replicate) & $\mathrm{n} / \mathrm{a}^{*}$ & 0.5 & $\mathrm{n} / \mathrm{a} *$ & 0.7 & 1.1 & 6.7 & 12 \\
\hline 40 & $\mathrm{n} / \mathrm{a}^{*}$ & 0.3 & $\mathrm{n} / \mathrm{a}^{*}$ & 0.7 & 0.9 & 5.3 & 9.7 \\
\hline 60 & $\mathrm{n} / \mathrm{a}^{*}$ & 0.4 & $\mathrm{n} / \mathrm{a}^{*}$ & 0.6 & 1.0 & 5.4 & 8.1 \\
\hline
\end{tabular}

Table 30. Effect of temperature on slurry Bingham-Plastic consistency for the Group 8 source material (G8); Group 7 leached / washed solids (G7L); and the Group 8 CUF low-solids (LS), high-solids (HS), caustic-leached and dewatered (CLD), caustic-leached dewatered and washed (CLDW), and combined leach (CLS) slurries.

\begin{tabular}{|c|c|c|c|c|c|c|c|}
\hline \multirow{2}{*}{$\begin{array}{c}\text { Temperature } \\
{\left[{ }^{\circ} \mathbf{C}\right]}\end{array}$} & G8 & G7L & LS & HS & CLD & CLDW & CLS \\
\cline { 2 - 8 }$y$ (replicate) & $2.6^{*}$ & 2.8 & $3.0^{*}$ & 4.9 & 6.6 & 6.9 & 8.8 \\
\hline 40 & $2.2^{*}$ & 2.3 & $2.3^{*}$ & 4.0 & 5.6 & 5.7 & 6.9 \\
\hline 60 & $1.4^{*}$ & 1.4 & $1.1^{*}$ & 2.7 & 5.4 & 5.1 & 5.7 \\
\hline * Newtonian slurry - Newtonian viscosity reported.
\end{tabular}

\subsection{Rheology of Group 8 CUF Permeate Samples}

The following sub-sections discuss the rheology results for Group 8 CUF permeate test samples TI640-G8-R1-Perm and TI640-G8-R3-Perm. A short discussion on how the measured flow curve data behave as a function of temperature is given. Next, measurement anomalies, such as Taylor vortices, slip, and rotor inertia, are identified and quantified. Finally, application of flow curve models to the data is discussed and best-fit flow curve parameters reported.

\section{Sample TI640-G8-R1-Perm: Initial (Pre-Leach) Permeate}

Sample TI640-G8-R1-Perm corresponds to permeate collected during dewatering of the initial (i.e., pre-caustic-leach) slurry. This permeate sample has a supernate dissolved solids concentration of $\sim 20$-wt $\%$. Figure 16 shows an example results of flow curve testing for this sample and corresponds to the initial flow curve measurement at $25^{\circ} \mathrm{C}$. This flow curve indicates Newtonian behavior with a weak stress response (less than $1 \mathrm{~Pa}$ at $400 \mathrm{~s}^{-1}$ ). Because of the weak response, the flow curve data are subject to significant measurement noise. The range for the measurement was limited to $400 \mathrm{~s}^{-1}$ to avoid Taylor vortex formation; however, at higher temperatures a change in flow curve slope indicated possible vortex formation even within the limited shear rate range of $0-400 \mathrm{~s}^{-1}$ (see Appendix A).

Given the scatter in the data Figure 16, the stress response appears to be relatively linear. A shear rates below $100 \mathrm{~s}^{-1}$, the data appear to be subject to negative torque correction as a result of a slight negative offset in the instrument zero. Subsequent flow curve measurements employed significant positive torque offset to allow accurate determination of viscosity at higher temperatures while avoiding negative torque correction. 
For fitting analysis, the flow behavior for Sample TI640-G8-R1-Perm is assumed Newtonian. To account for inclusion of positive torque offset, a Bingham-Plastic model was used to fit the data. The regressed yield stress associated with the torque offset is ignored, while the Newtonian viscosity is derived from (i.e., equated to) the Bingham-Plastic consistency index. Fitting of the initial flow curve data at $25^{\circ} \mathrm{C}$ employed up-ramp data only, as negative torque correction (which biases the fit) effected primarily the down ramp data. Other fits use both up- and down-ramp data. In addition, fits at $25^{\circ} \mathrm{C}$ employ the full range of shear rates tested (i.e., 0 to $400 \mathrm{~s}-1$ ) whereas fits at $40^{\circ} \mathrm{C}$ and $60^{\circ} \mathrm{C}$ employed limited shear rate ranges of 0-300 s-1 and 0-180 $\mathrm{s}^{-1}$ to avoid suspected regions of Taylor vortex formation (see Appendix A).

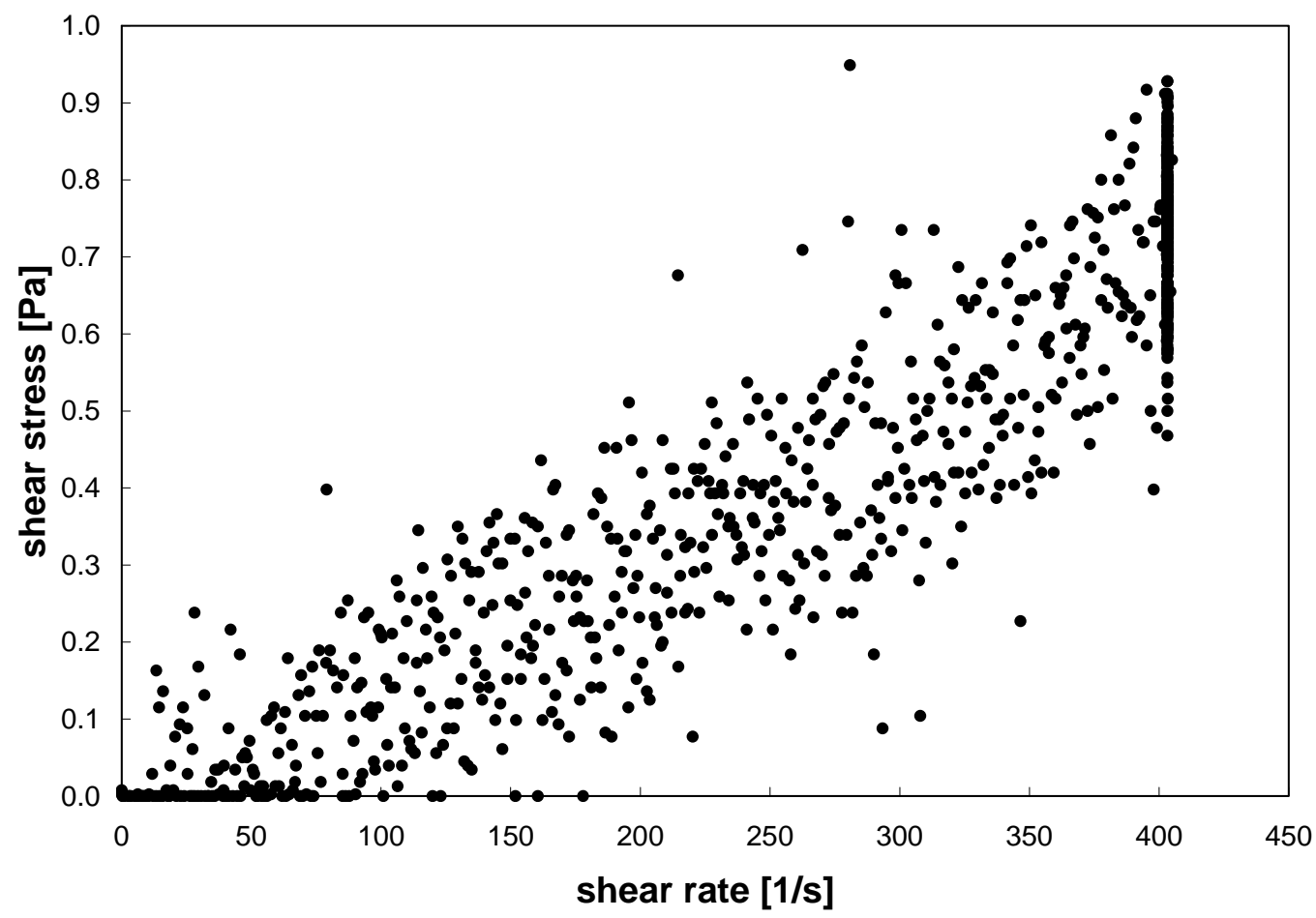

Figure 16. Sample flow curve for the Group 8 CUF testing permeate sample TI640-G8-R1-Perm. The initial flow curve measurement at $25^{\circ} \mathrm{C}$ is shown. Here, the maximum shear rate was limited to $400 \mathrm{~s}^{-1}$ to avoid the formation of Taylor vortices.

Table 31 summarizes the best-fit Newtonian viscosities for sample TI640-G8-R1-Perm. Regression analysis indicates a viscosity of $1.8-2.0 \mathrm{cP}$ at $25^{\circ} \mathrm{C}, 1.2 \mathrm{cP}$ at $40^{\circ} \mathrm{C}$, and $0.7 \mathrm{cP}$ at $60^{\circ} \mathrm{C}$. The decrease in viscosity with temperature is typical of tank waste permeate samples. The viscosity decrease that occurs between $25^{\circ} \mathrm{C}$ and $40^{\circ} \mathrm{C}$ is significant. On the other hand, the viscosity decrease between $40^{\circ} \mathrm{C}$ and $60^{\circ} \mathrm{C}$ is borderline significant, falling on the $0.5 \mathrm{cP}$ absolute limit of instrument accuracy. Finally, the initial and replicate viscosity measurements at $25^{\circ} \mathrm{C}$ compare well and agree within the $0.5 \mathrm{cP}$ reproducibility expected for viscosities in this range (i.e., 1 to $5 \mathrm{cP}$ ). 
Table 31. Results of fitting analysis for rheology sample TI640-G8-R1-Perm.

Viscosities were determined by fitting both up- and down-ramp data unless specified otherwise.

\begin{tabular}{||c|c|c|c|c||}
\hline \hline Model & $\begin{array}{c}\text { Temperature } \\
{\left[{ }^{\circ} \mathbf{C}\right]}\end{array}$ & Range & $\begin{array}{c}\text { Viscosity } \\
{[\mathbf{m P a} \cdot \mathbf{s}]}\end{array}$ & $\mathbf{R}$ \\
\hline \multirow{3}{*}{ Newtonian } & $25(1$ of 2$)$ & $0-400 \mathrm{~s}^{-1}(\mathrm{a})$ & 1.8 & 0.94 \\
\cline { 2 - 5 } & $25(2$ of 2$)$ & $0-400 \mathrm{~s}^{-1}$ & 2.0 & 0.93 \\
\cline { 2 - 5 } & 40 & $0-300 \mathrm{~s}^{-1}$ & 1.2 & 0.68 \\
\cline { 2 - 5 } & 60 & $0-180 \mathrm{~s}^{-1}$ & 0.7 & 0.35 \\
\hline \multicolumn{4}{|l|}{ (a) Fit of up-ramp data only. } \\
\hline
\end{tabular}

In short, the initial (pre-leach) Group 8 permeate sample (TI640-G8-R3-Perm) shows weak Newtonian rheology. The permeate viscosity is $1.8-2.0 \mathrm{cP}$ at $25^{\circ} \mathrm{C}, 1.2 \mathrm{cP}$ at $40^{\circ} \mathrm{C}$, and $0.7 \mathrm{cP}$ at $60^{\circ} \mathrm{C}$. The flow curve fitting results indicate a decrease in permeate viscosity with increasing temperature. The total change in viscosity over the temperature range tested is only $\sim 1 \mathrm{cP}$ and falls well above the limit of instrument accuracy $(0.5 \mathrm{cP})$. As such, this decrease is likely significant.

\section{Sample TI640-G8-R3-Perm: Post-Caustic Leach Permeate}

Sample TI640-G8-R3-Perm corresponds to permeate collected during dewatering of the caustic-leached slurry. Dewatering takes place before washing of the slurry, and the permeate collected is rich in ionic species. The sample has a supernate dissolved solids concentration of 24-wt\%.

Figure 17 shows the flow curve measurement result for the initial measurement of TI640-G8-R3-Perm at $25^{\circ} \mathrm{C}$. Here, the flow curve data indicate Newtonian behavior. The stress response does not exhibit a yield stress and is linearly over 0 to $600 \mathrm{~s}^{-1}$. At $600 \mathrm{~s}^{-1}$, the slope of the stress response increases dramatically. This increase suggests the formation of Taylor vortices (i.e., non-laminar) flow at rotor speeds greater than $600 \mathrm{~s}^{-1}$. As such, initial measurement flow curve data beyond $600 \mathrm{~s}^{-1}$ are unusable. Apart from the consequence of Taylor vortex formation, the flow curve data are relatively free of anomalies such as hysteresis. Overall, the data show a weak stress response $\left(\sim 1.5 \mathrm{~Pa}\right.$ at $\left.500 \mathrm{~s}^{-1}\right)$ and are subject to a low signal-to-noise ratio over the range of valid measurement $\left(0\right.$ to $\left.600 \mathrm{~s}^{-1}\right)$.

For the replicate measurement and measurements at higher temperature, the range of shear rates tested was limited to avoid Taylor vortex formation. The replicate $25^{\circ} \mathrm{C}$ and $40^{\circ} \mathrm{C}$ measurements employed a shear rate range of 0 to $400 \mathrm{~s}^{-1}$, whereas the $60^{\circ} \mathrm{C}$ measurement employed a shear rate range of 0 to $300 \mathrm{~s}^{-1}$. The data shown in Figure 17 appear to be subject to a slight negative offset, resulting in negative stress offset correction whereby all negative stress is set to zero by the RheoWin software. This correction interferes (and can often bias) fitting of the data to flow curve models. As such, all flow curve measurements for sample TI640-G8-R3-Perm performed after the initial measurement at $25^{\circ} \mathrm{C}$ introduced an artificial positive stress offset to avoid negative torque correction (see Appendix A). 


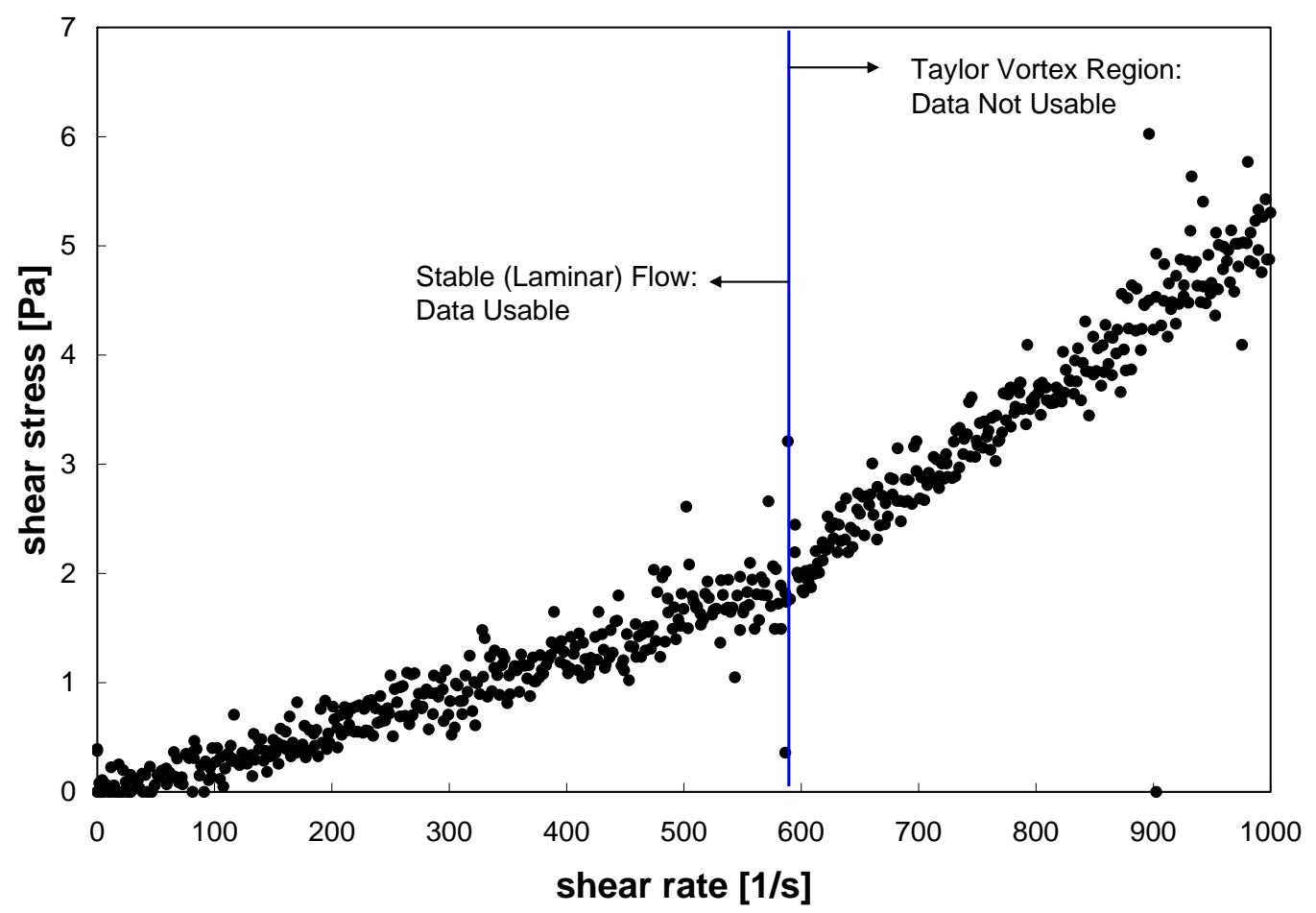

Figure 17. Sample flow curve for the Group 8 CUF testing permeate sample TI640-G8-R3-Perm. The initial flow curve measurement at $25^{\circ} \mathrm{C}$ is shown.

Least squares analysis of the $25^{\circ} \mathrm{C}, 40^{\circ} \mathrm{C}$, and $60^{\circ} \mathrm{C}$ flow curve data were performed to determine Newtonian viscosity as a function of temperature. Fitting analysis of the data assumed Newtonian permeate rheology. To account for stress offset (including artificial offset), the fitting approach employs a Bingham-Plastic model. The regressed Bingham-Plastic yield stress corresponds to the stress offset and is ignored. On the other hand, the BinghamPlastic consistency is equated to the permeate sample's Newtonian viscosity. To avoid inclusion of data influenced by Taylor vortex formation, the fit for the initial measurement data at $25^{\circ} \mathrm{C}$ use a limited shear rate range of 0 to $450 \mathrm{~s}^{-1}$. In addition, only up-ramp data were included in the initial $25^{\circ} \mathrm{C}$ measurement data fit because of significant negative stress correction on the down-ramp. Because the range of shear rates studied during flow curve measurements at higher temperatures, fits at higher temperatures use the full range of data available (i.e., $0-400 \mathrm{~s}^{-1}$ for replicate $25^{\circ} \mathrm{C}$ and $40^{\circ} \mathrm{C}$ data and $0-300 \mathrm{~s}^{-1}$ for $60^{\circ} \mathrm{C}$ data).

Table 32 summarizes the best-fit Newtonian viscosities for sample TI640-G8-R3-Perm. The analysis indicates a Newtonian viscosity of $3.1 \mathrm{cP}$ at $25^{\circ} \mathrm{C}, 2.2 \mathrm{cP}$ at $40^{\circ} \mathrm{C}$, and $1.4^{\circ} \mathrm{C}$ at $60^{\circ} \mathrm{C}$. Permeate viscosity decreases with increasing temperature. This behavior is consistent with the TI640-G8-R1-Perm sample and is expected for permeate samples. The temperatureto-temperature variation is greater than $0.5 \mathrm{cP}$, suggesting that the temperature decrease is likely significant. With regards to measurement reproducibility, the initial and replicate measurements at $25^{\circ} \mathrm{C}$ agree to within $0.5 \mathrm{cP}$. 
Table 32. Results of fitting analysis for rheology sample TI640-G8-R3-Perm.

Viscosities were determined by fitting both up- and down-ramp data.

\begin{tabular}{||c|c|c|c|c||}
\hline Model & $\begin{array}{c}\text { Temperature } \\
{\left[{ }^{\circ} \mathbf{C}\right]}\end{array}$ & Range & $\begin{array}{c}\text { Viscosity } \\
{[\mathbf{m P a} \cdot \mathbf{s}]}\end{array}$ & $\mathbf{R}$ \\
\hline \multirow{3}{*}{ Newtonian } & $25(1$ of 2$)$ & $0-450 \mathrm{~s}^{-1}(\mathrm{a})$ & 3.1 & 0.95 \\
\cline { 2 - 5 } & $25(2$ of 2$)$ & $0-400 \mathrm{~s}^{-1}$ & 3.1 & 0.96 \\
\cline { 2 - 5 } & 40 & $0-400 \mathrm{~s}^{-1}$ & 2.2 & 0.93 \\
\cline { 2 - 5 } & 60 & $0-300 \mathrm{~s}^{-1}$ & 1.4 & 0.80 \\
\hline \multicolumn{4}{|l|}{ (a) Fit of up-ramp data only } \\
\hline
\end{tabular}

Table 33 compares the viscosity of the pre- and post-caustic leaching permeate samples. Relative to the pre-leach permeate sample (TI640-G8-R1-Perm), the viscosity of the post-leach permeate is higher at all temperatures. This is expected, as the TI640-G8-R3-Perm sample has a higher concentration of dissolved solids relative to pre-leach (TI640-G8-R1Perm) sample. As indicated in the table, the pre-leach permeate has a supernate dissolved solids concentration of $\sim 20$-wt $\%$ whereas the post-leach permeate has a supernate dissolved solids concentration of $\sim 24-w t \%$. The higher dissolved solids content is both a result of caustic addition and of solid species dissolution during the leaching operation.

Table 33. Effect of caustic-leaching on Group 8 permeate (CUF) rheology

\begin{tabular}{||c|c|c|c|c|c||}
\hline \hline Description & \multirow{2}{*}{$\begin{array}{c}\text { Dissolved Solids } \\
\text { Concentration }\end{array}$} & \multirow{2}{*}{ Rheology } & \multicolumn{3}{|c|}{ Newtonian Viscosity } \\
\cline { 4 - 6 } & & & $\mathbf{2 5 ^ { \circ } \mathrm { C }}$ & $\mathbf{4 0}^{\circ} \mathbf{C}$ & $\mathbf{6 0}{ }^{\circ} \mathbf{C}$ \\
\hline $\begin{array}{c}\text { Initial Permeate (Pre-Leach) } \\
\text { (TI640-G8-R1-Perm) }\end{array}$ & $\sim 20-\mathrm{wt} \%$ & Newtonian* & 2.0 & 1.2 & 0.7 \\
\hline $\begin{array}{c}\text { Post-Leach Permeate } \\
\text { (TI640-G8-R3-Perm) }\end{array}$ & $\sim 24-w t \%$ & Newtonian* & 3.1 & 2.2 & 1.4 \\
\hline \multicolumn{1}{|l|}{ Note: reported result for $25^{\circ} \mathrm{C}$ corresponds to the replicate measurement. } \\
\hline
\end{tabular}

In short, the post-caustic leach Group 8 permeate sample (TI640-G8-R3-Perm) shows Newtonian rheology. The permeate viscosity is $3.1 \mathrm{cP}$ at $25^{\circ} \mathrm{C}, 2.2 \mathrm{cP}$ at $40^{\circ} \mathrm{C}$, and $1.4^{\circ} \mathrm{C}$ at $60^{\circ} \mathrm{C}$. The flow curve fitting results indicate a decrease in permeate viscosity with increasing temperature. Given that the variation in viscosity between temperature set points exceeds $10 \%$, it is likely that the temperature correlation observed for this sample is significant. Relative to the pre-leach permeate sample (TI640-G8-R1-Perm), the viscosity of the post-leach permeate is higher at all temperatures. The higher viscosity is a result on increased dissolved solids content.

\section{Conclusions}

The preceding sections detail the rheology of Group 8 tank waste slurries and permeates as a function of CUF processing and sample temperature. Although the initial (dilute) Group 8 CUF slurry showed Newtonian behavior, the concentrated and processed Group 8 slurries were non-Newtonian with a finite yield stress. Using the best-fit Newtonian viscosity and Bingham-Plastic parameters as a guide, the slurry rheology as a function of waste processing in the CUF may be described as follows: 
1. Group 8 Source Material (TI516-G8-AR-P1) - the source material for Group 8 has an undissolved solids concentration of $\sim 11$-wt\% and is Newtonian with a viscosity of 2.6$3.3 \mathrm{cP}$ at $25^{\circ} \mathrm{C}, 2.2 \mathrm{cP}$ at $40^{\circ} \mathrm{C}$, and $1.4 \mathrm{cP}$ at $60^{\circ} \mathrm{C}$. This result is "For Information Only”. See NCR 38963.1 for details.

2. Group 7 CUF Source Material for Combined Leach Slurry (TI624-G7-R4-Slurry) - the caustic-leached and washed solids from Group 7 CUF testing (as represented by sample TI624-G7-R4-Slurry) were mixed with caustic-leached and washed solids from Group 8 CUF testing to form the final combined leach slurry tested under Group 8 CUF activities. The Group 7 source material for the combined leach slurry has an undissolved solids concentration of $\sim 14$-wt\%. It shows very weak non-Newtonian rheology with a Bingham-Plastic yield stress of $\sim 0.5 \mathrm{~Pa}$ and a Bingham-Plastic consistency index of $2.8-3.1 \mathrm{cP}$ at $25^{\circ} \mathrm{C}, 2.3 \mathrm{cP}$ at $40^{\circ} \mathrm{C}$, and $1.4 \mathrm{cP}$ at $60^{\circ} \mathrm{C}$.

3. Group 8 CUF Initial Dilute Slurry (TI640-G8-R1-Slurry) - this is a dilute initial Group 8 slurry ( 6-wt\% UDS) created by mixing source material from Group 8 and with simulant supernate. It is Newtonian with a viscosity of $3.0 \mathrm{cP}$ at $25^{\circ} \mathrm{C}, 2.3 \mathrm{cP}$ at $40^{\circ} \mathrm{C}$, and $1.1 \mathrm{cP}$ at $60^{\circ} \mathrm{C}$.

4. Group 8 CUF Initial Concentrated Slurry (TI640-G8-R2-Slurry) - this is a concentrated Group 8 slurry ( $13-w t \%$ UDS) that results from dewatering of the initial dilute slurry. It shows non-Newtonian rheology with a Bingham-Plastic yield stress of $\sim 0.7 \mathrm{~Pa}$ and a Bingham-Plastic consistency index of $4.9-5.1 \mathrm{cP}$ at $25^{\circ} \mathrm{C}, 4.0 \mathrm{cP}$ at $40^{\circ} \mathrm{C}$, and $2.7 \mathrm{cP}$ at $60^{\circ} \mathrm{C}$.

5. Group 8 CUF Caustic-Leached and Dewatered Slurry (TI640-G4-R3-Slurry) - this is a concentrated Group 8 slurry ( 23-wt\% UDS ) that results from caustic-leaching and dewatering of the initial slurry concentrate. It shows non-Newtonian rheology with a Bingham-Plastic yield stress of $\sim 1 \mathrm{~Pa}$ and a Bingham-Plastic consistency index of 6.6$6.7 \mathrm{CP}$ at $25^{\circ} \mathrm{C}, 5.6 \mathrm{cP}$ at $40^{\circ} \mathrm{C}$, and $5.4 \mathrm{cP}$ at $60^{\circ} \mathrm{C}$.

6. Group 8 CUF Caustic-Leached, Dewatered, and Washed Slurry (TI640-G8-R4-Slurry) - this is a concentrated Group 8 slurry ( 20 -wt\%) that results from washing of the caustic-leached and dewatered slurry. It shows non-Newtonian rheology with a Bingham-Plastic yield stress of $\sim 5.4 \mathrm{~Pa}$ and a Bingham-Plastic consistency index of 6.5-6.9 $\mathrm{cP}$ at $25^{\circ} \mathrm{C}, 5.7 \mathrm{cP}$ at $40^{\circ} \mathrm{C}$, and $5.1 \mathrm{cP}$ at $60^{\circ} \mathrm{C}$.

7. Group 8 CUF Combined Leach Slurry (TI640-G8-R5-Slurry) - this is a concentrated Group 8 CUF slurry ( 26-wt\%) that results from mixing of the Group 8 CUF leached and washed solids with the Group 7 CUF leached and washed solids. It shows nonNewtonian rheology with a Bingham-Plastic yield stress of $12-13 \mathrm{~Pa}$ at $25^{\circ} \mathrm{C}, 9.7 \mathrm{~Pa}$ at $40^{\circ} \mathrm{C}$, and $8.1 \mathrm{~Pa}$ at $60^{\circ} \mathrm{C}$ and a Bingham-Plastic consistency index of 8.8-9.5 cP at $25^{\circ} \mathrm{C}, 6.9 \mathrm{cP}$ at $40^{\circ} \mathrm{C}$, and $5.7 \mathrm{cP}$ at $60^{\circ} \mathrm{C}$.

8. Group 8 CUF Initial (Pre-Leach) Permeate (TI640-G8-R1-Perm) - this is Group 8 permeate collected during dewatering of the initial slurry. It has a supernate dissolved 
solids concentration of $\sim 20-\mathrm{wt} \%$ and is Newtonian with a viscosity of $1.8-2.0 \mathrm{cP}$ at $25^{\circ} \mathrm{C}, 1.2 \mathrm{cP}$ at $40^{\circ} \mathrm{C}$, and $0.7 \mathrm{cP}$ at $60^{\circ} \mathrm{C}$.

9. Group 8 CUF Post Caustic-Leach Permeate (TI640-G8-R3-Perm) - this is Group 8 permeate collected during dewatering of the caustic-leached slurry. It has a supernate dissolved solids concentration of $\sim 24-\mathrm{wt} \%$ and is Newtonian with a viscosity of $3.1 \mathrm{cP}$ at $25^{\circ} \mathrm{C}, 2.2 \mathrm{cP}$ at $40^{\circ} \mathrm{C}$, and $1.4^{\circ} \mathrm{C}$ at $60^{\circ} \mathrm{C}$

\section{Records}

Data records relating to rheological characterization of Group 8 CUF Testing samples include Test Data Packages (TDPs), Computational Computer Programs (CCPs), and LRBs:

- $\quad$ LRB BNW 59633 - Pages 104-107, and 118-128

- TDP-WTP-323 - flow curve and shear strength measurement data, results, and graphs for sample TI516-G8-AR-P1

- TDP-WTP-321 - flow curve measurement data, results, and graphs for sample TI624G7-R4-Slurry

- CCP-WTPSP-561 - flow curve measurement data, results, and graphs for sample TI640-G8-R1-Slurry

- CCP-WTPSP-563 - flow curve measurement data, results, and graphs for sample TI640-G8-R2-Slurry

- CCP-WTPSP-564 - flow curve measurement data, results, and graphs for sample TI640-G8-R3-Slurry

- CCP-WTPSP-566 - flow curve measurement data, results, and graphs for sample TI640-G8-R4-Slurry

- CCP-WTPSP-567 - flow curve measurement data, results, and graphs for sample TI640-G8-R5-Slurry

- CCP-WTPSP-562 - flow curve measurement data, results, and graphs for sample TI640-G8-R1-Perm

- CCP-WTPSP-565 - flow curve measurement data, results, and graphs for sample TI640-G8-R3-Perm 


\section{References and Background Information}

1. Doc. No. TP-RPP-WTP-467, Revision 0, "Characterization and Small Scale Testing of Hanford Wastes to Support the Development and Demonstration of Leaching and Ultrafiltration Pretreatment Processes,” SK Fiskum, Battelle - Pacific Northwest Division, February 2007.

2. Barnes HA, and NQ Dzuy, "Rotating vane rheometry - a review,” J. Non-Newtonian Fluid Mech., 1-14 (2001).

3. Steffe JF, Rheological Methods in Food Process Engineering, Freeman Press, East Lansing (1996).

4. Doc. No. RPL-COLLOID-02, Revision 1, "Measurement of Physical and Rheological Properties of Solutions, Slurries and Sludges,” RC Daniel, Pacific Northwest National Laboratory, May 2007.

5. Doc. No. TDP-WTP-323, Revision 0, "Rheology of FeCN Wastes (Group 8): Initial Characterization,” RC Daniel, Pacific Northwest National Laboratory, November 2008.

6. Doc. No. TDP-WTP-302, Revision 0, "Rheology of PUREX Cladding Waste Sludge (Group 3) and REDOX Cladding Waste Sludge (Group 4) Mixtures,” RC Daniel, Pacific Northwest National Laboratory, October 2008. 


\section{Appendix A - Rheograms}

This appendix contains detailed rheograms (shear stress and apparent viscosity as a function of shear rate) for 8 CUF testing samples. No discussion of these results is provided.

\section{Sample TI640-G8-R1-Slurry: Initial Dilute Group 8 CUF Slurry}

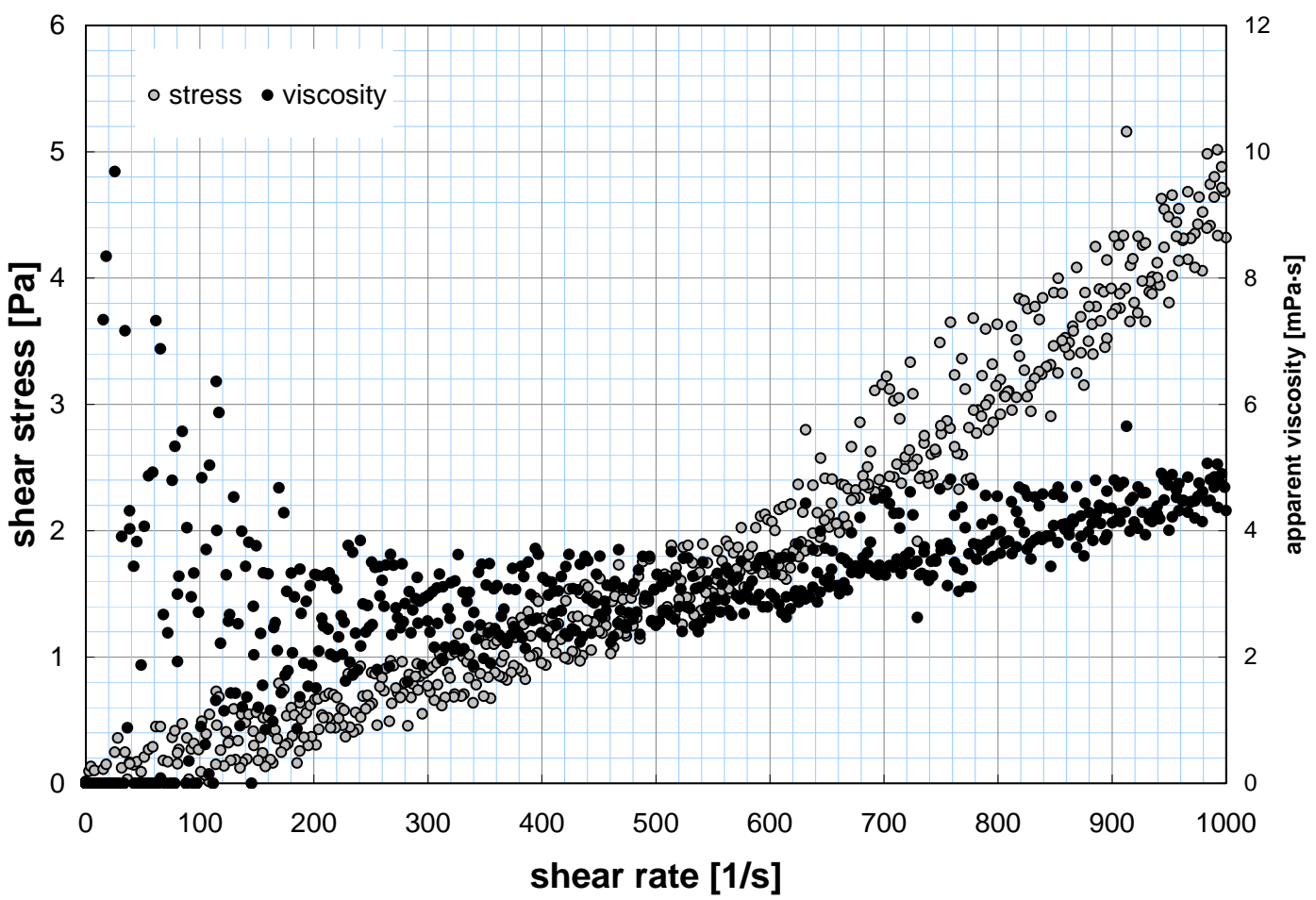

Figure A-1. Rheogram for TI640-G8-R1-Slurry at $25^{\circ} \mathrm{C}$ (measurement 1 of 2).

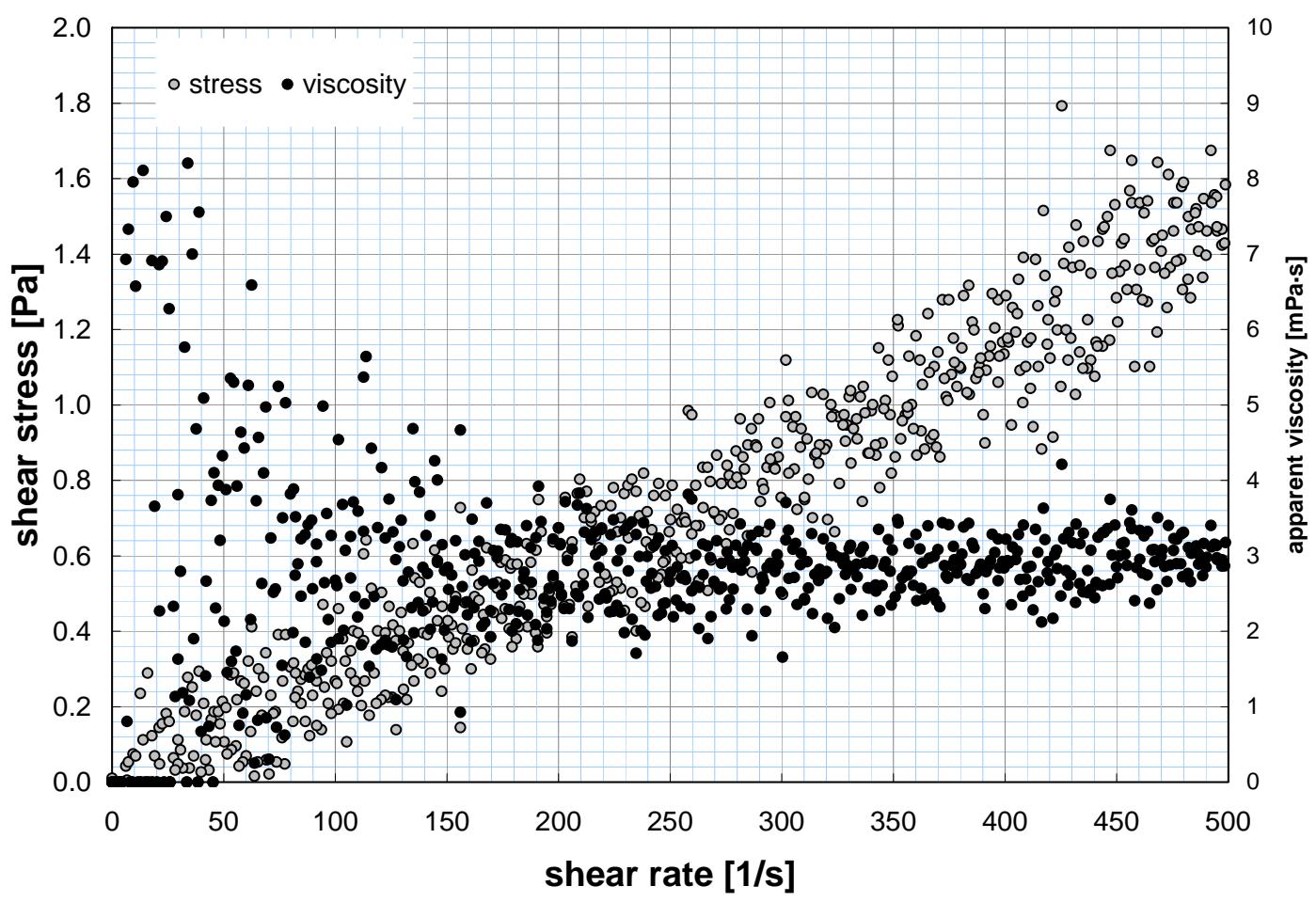

Figure A-2. Rheogram for TI640-G8-R1-Slurry at $25^{\circ} \mathrm{C}$ (measurement 2 of 2). 


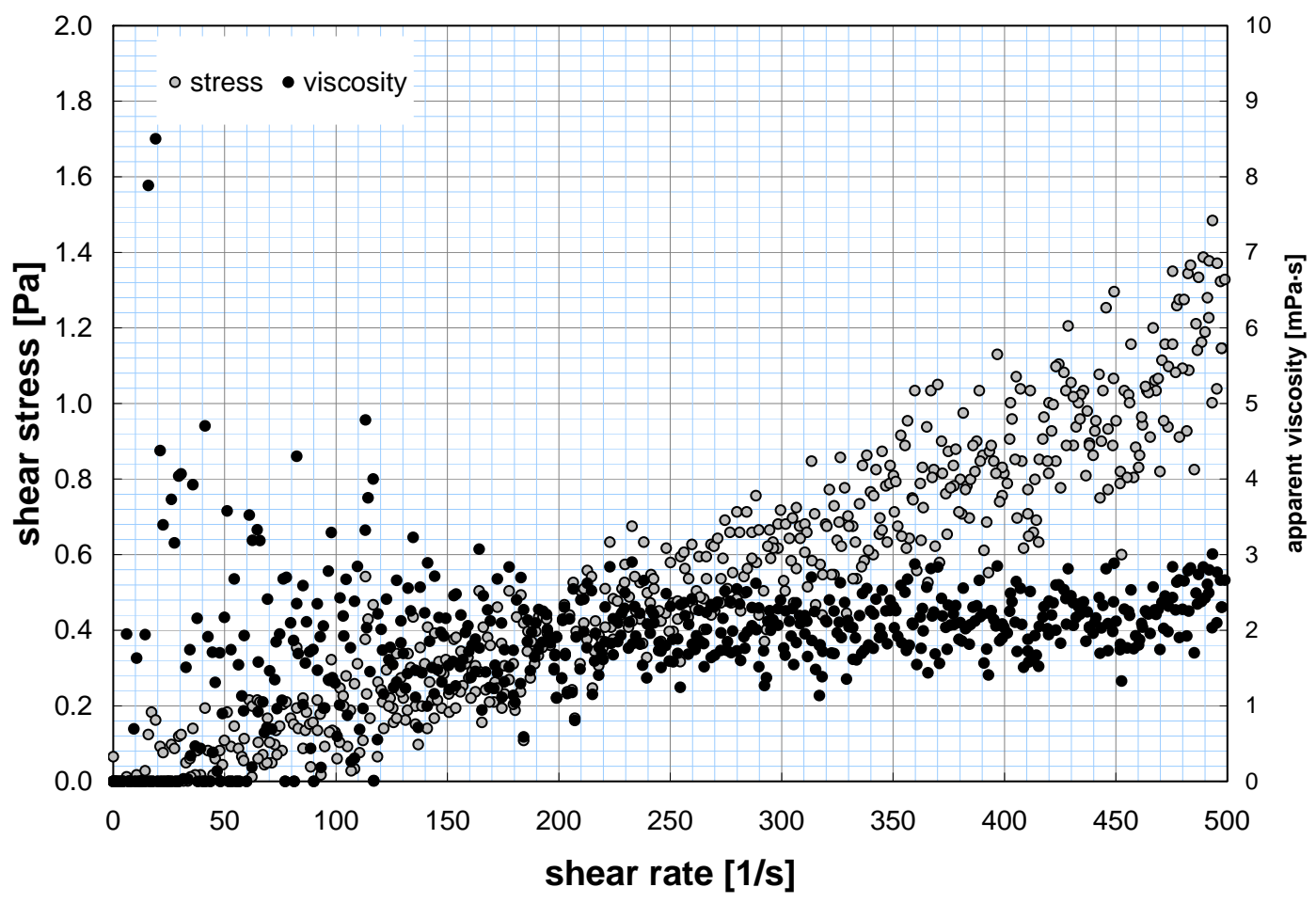

Figure A-3. Rheogram for TI640-G8-R1-Slurry at $40^{\circ} \mathrm{C}$.

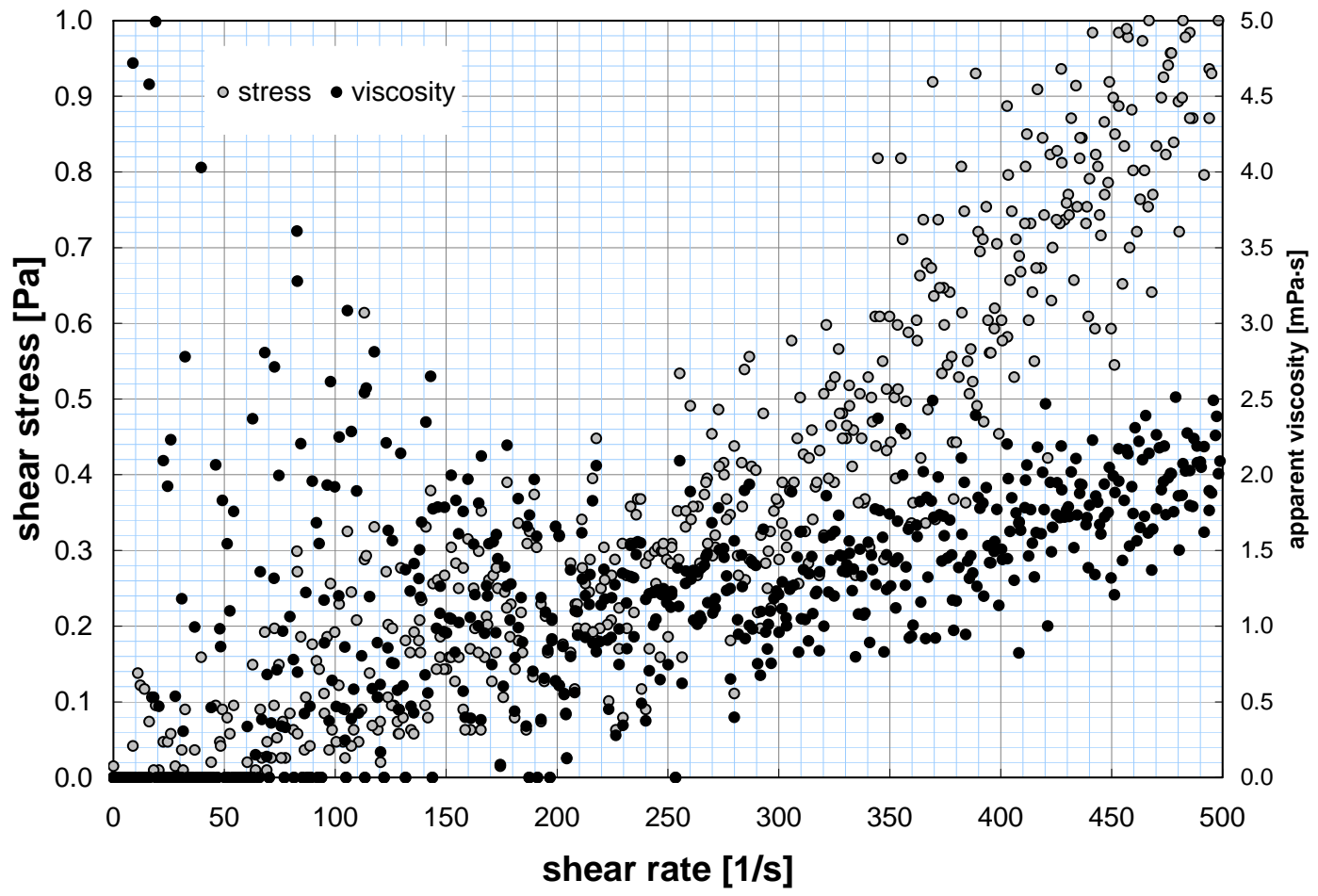

Figure A-4. Rheogram for TI640-G8-R1-Slurry at $60^{\circ} \mathrm{C}$. 
Sample TI640-G8-R2-Slurry: Initial Concentrated Group 8 CUF Slurry

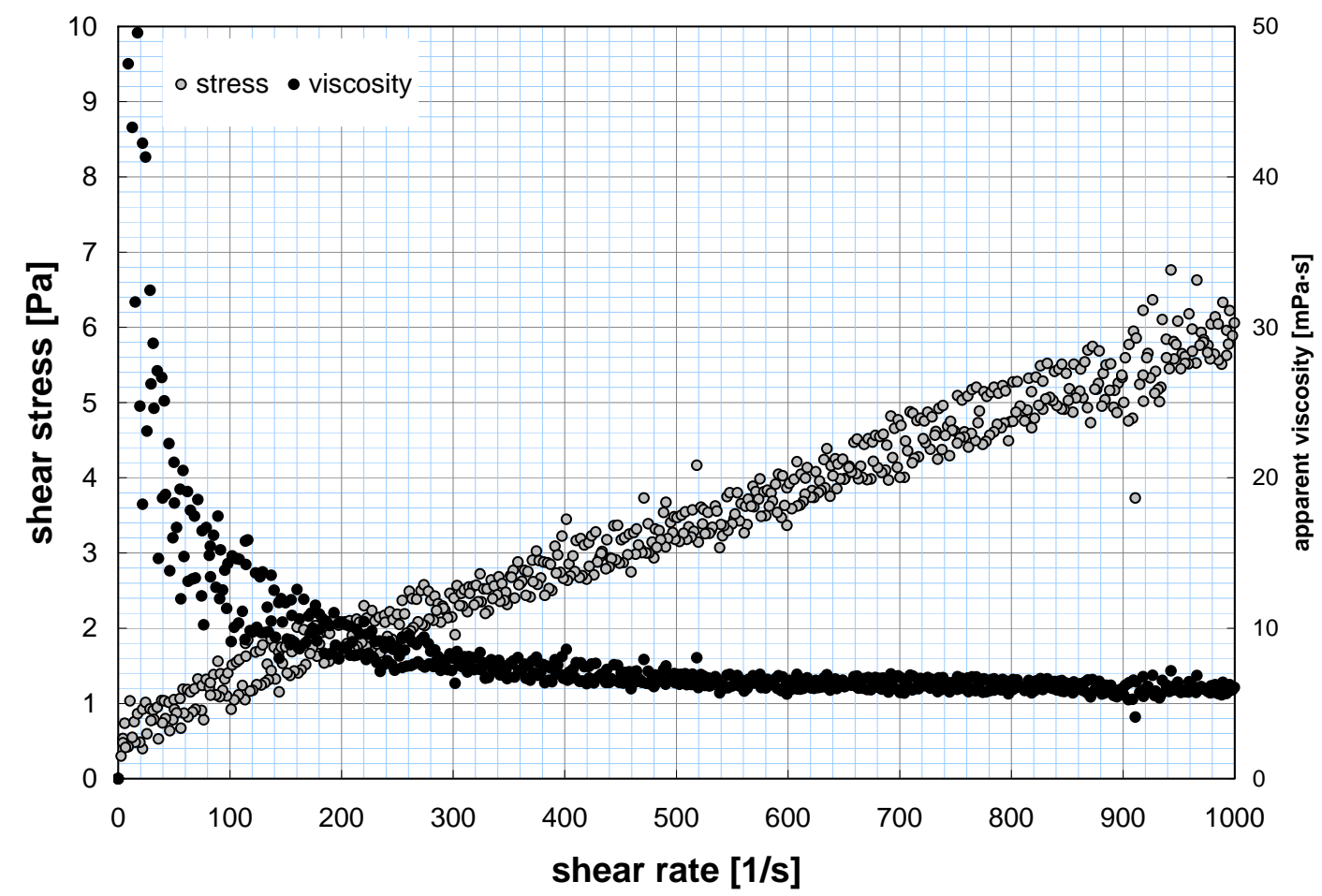

Figure A-5. Rheogram for TI640-G8-R2-Slurry at $25^{\circ} \mathrm{C}$ (measurement 1 of 2).

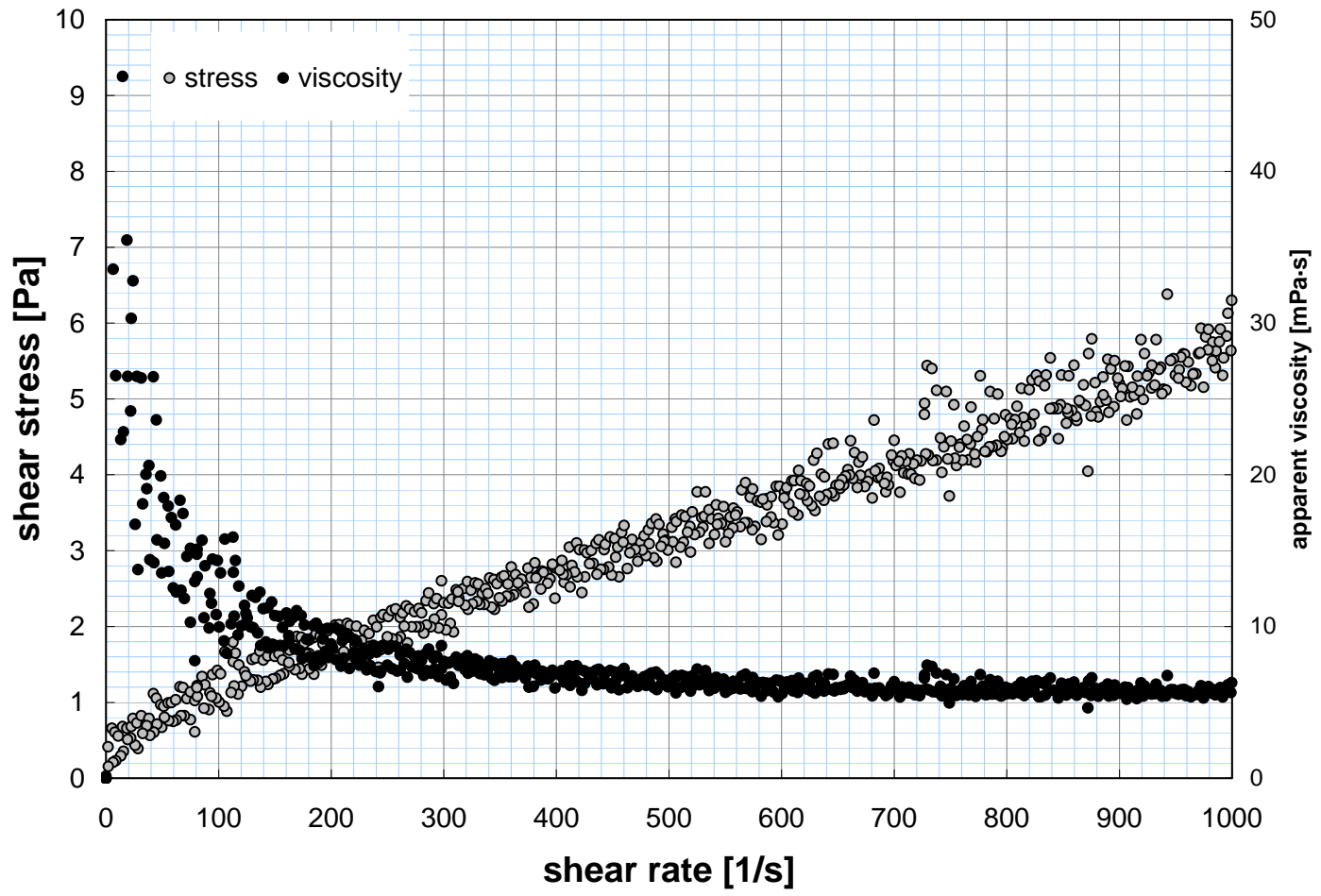

Figure A-6. Rheogram for TI640-G8-R2-Slurry at $25^{\circ} \mathrm{C}$ (measurement 2 of 2). 


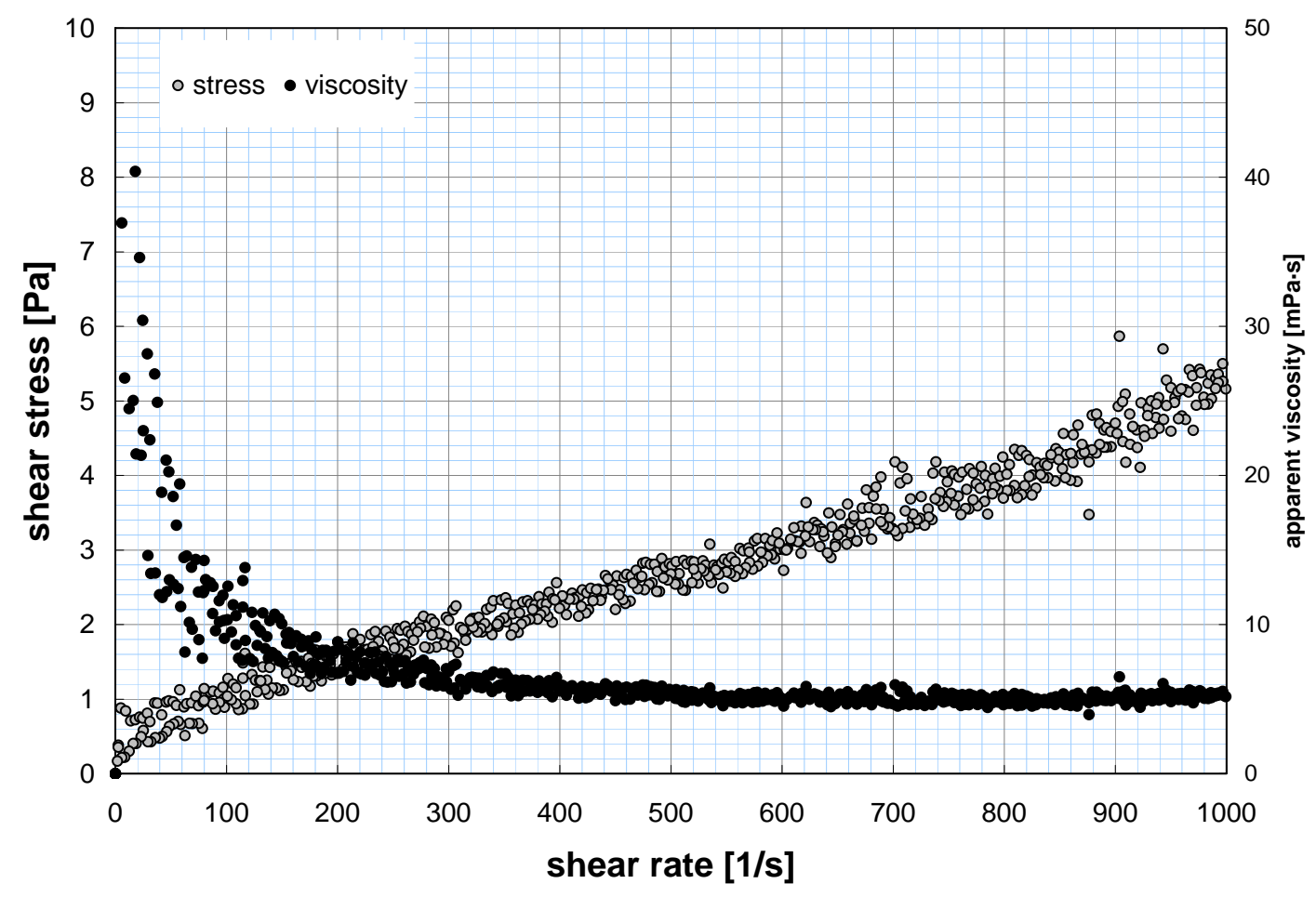

Figure A-7. Rheogram for TI640-G8-R2-Slurry at $40^{\circ} \mathrm{C}$.

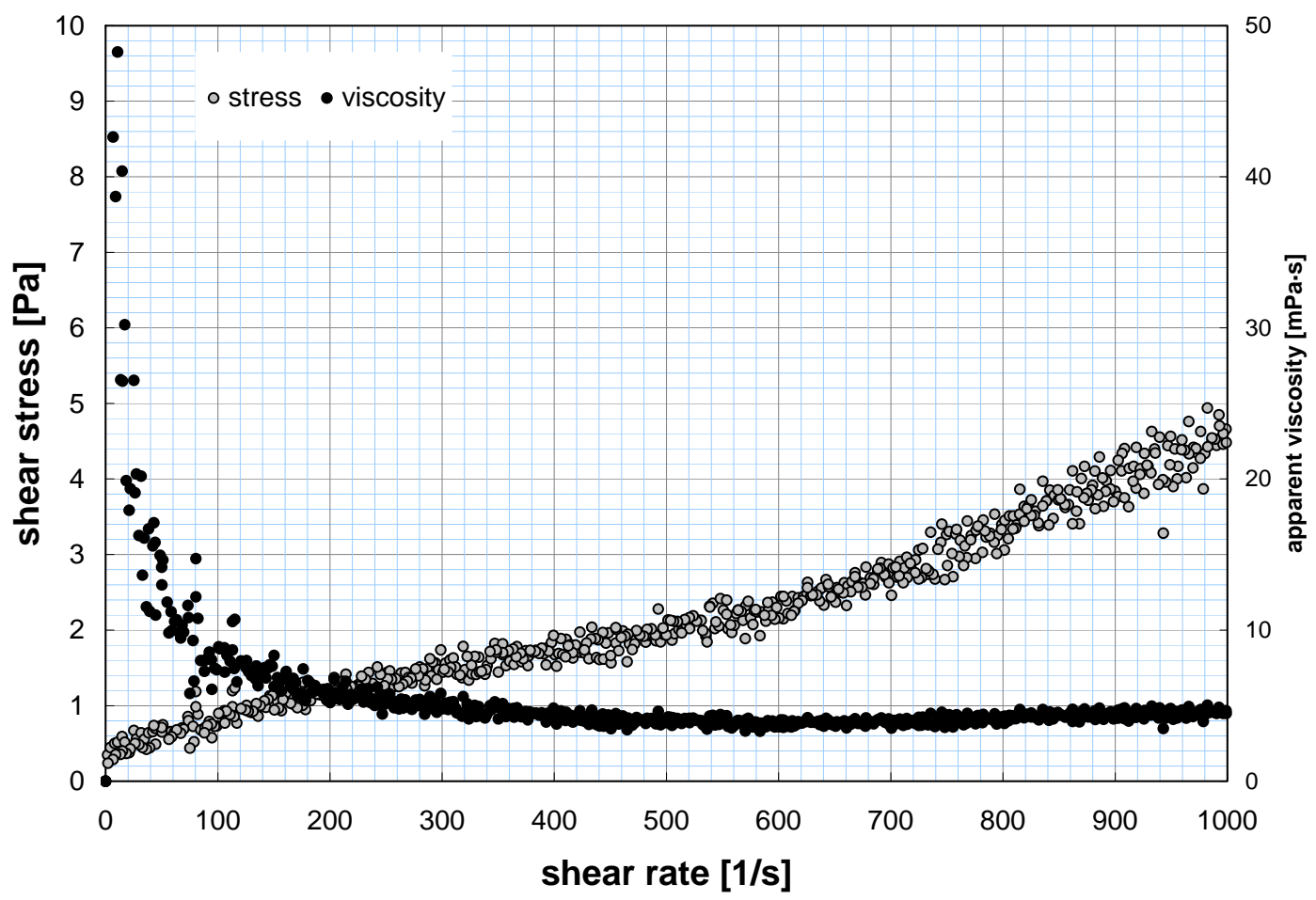

Figure A-8. Rheogram for TI640-G8-R2-Slurry at $60^{\circ} \mathrm{C}$. 
Sample TI640-G8-R3-Slurry: Caustic-Leached and Dewatered Group 8 CUF Slurry

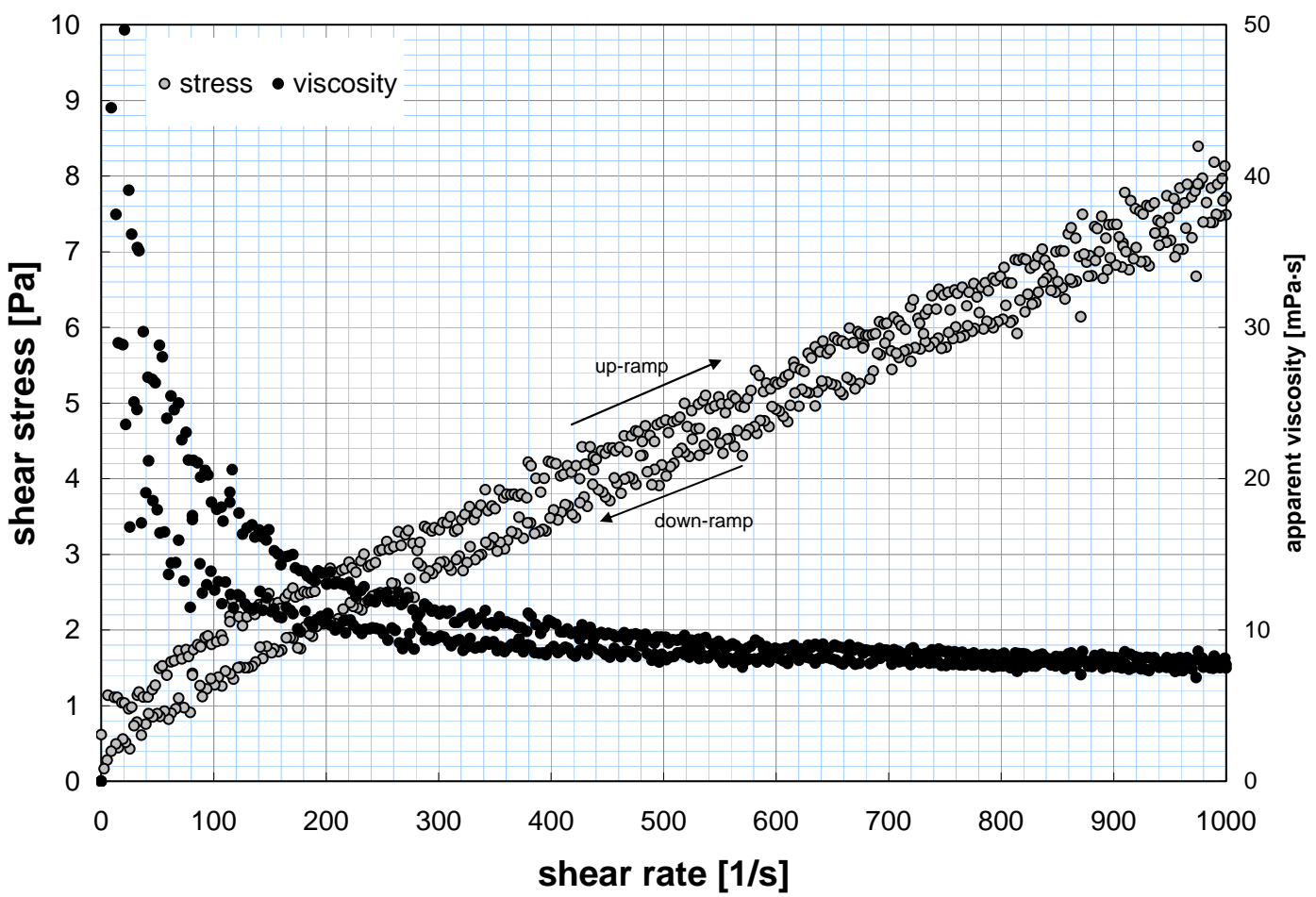

Figure A-9. Rheogram for TI640-G8-R3-Slurry at $25^{\circ} \mathrm{C}$ (measurement 1 of 2).

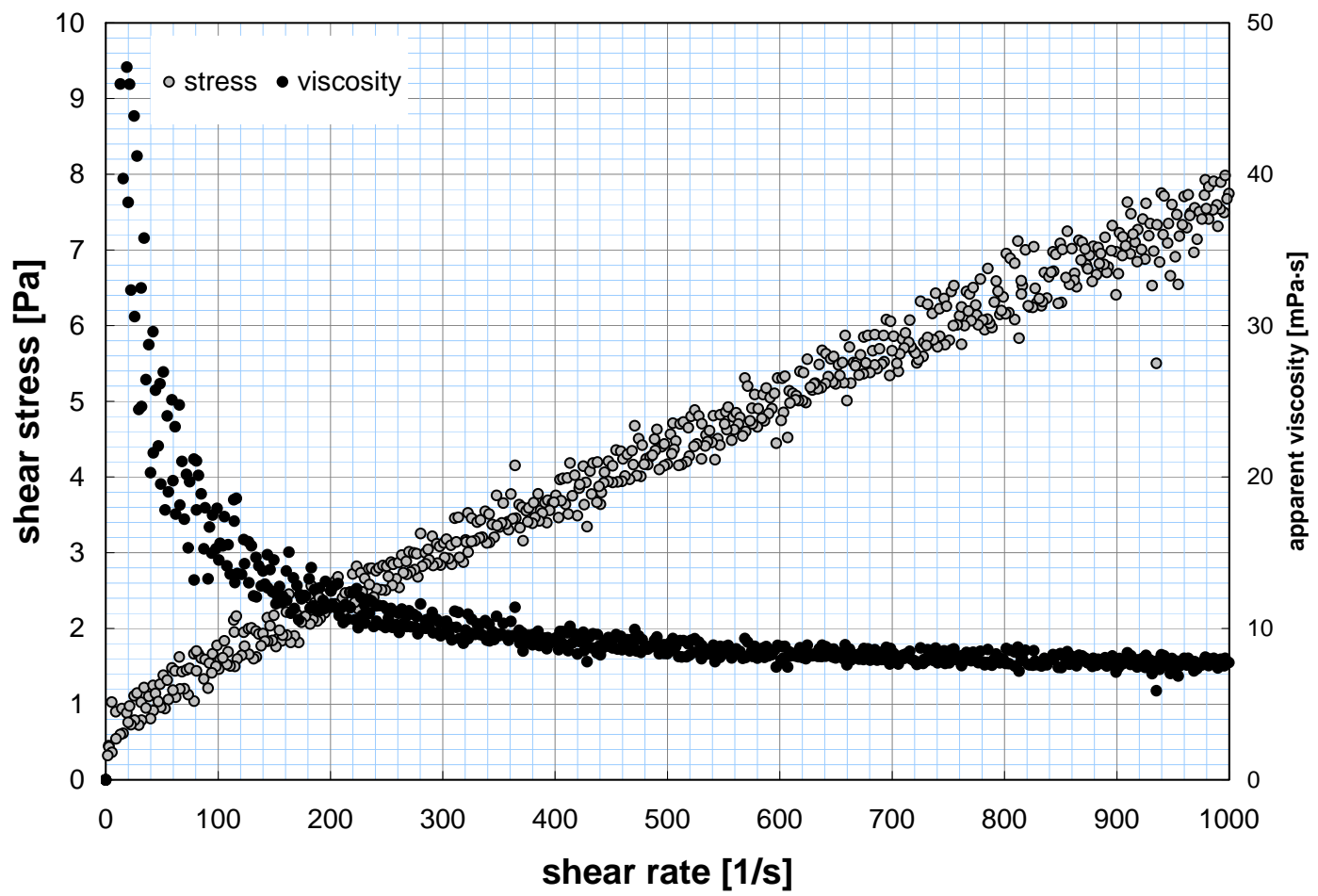

Figure A-10. Rheogram for TI640-G8-R3-Slurry at $25^{\circ} \mathrm{C}$ (measurement 2 of 2). 


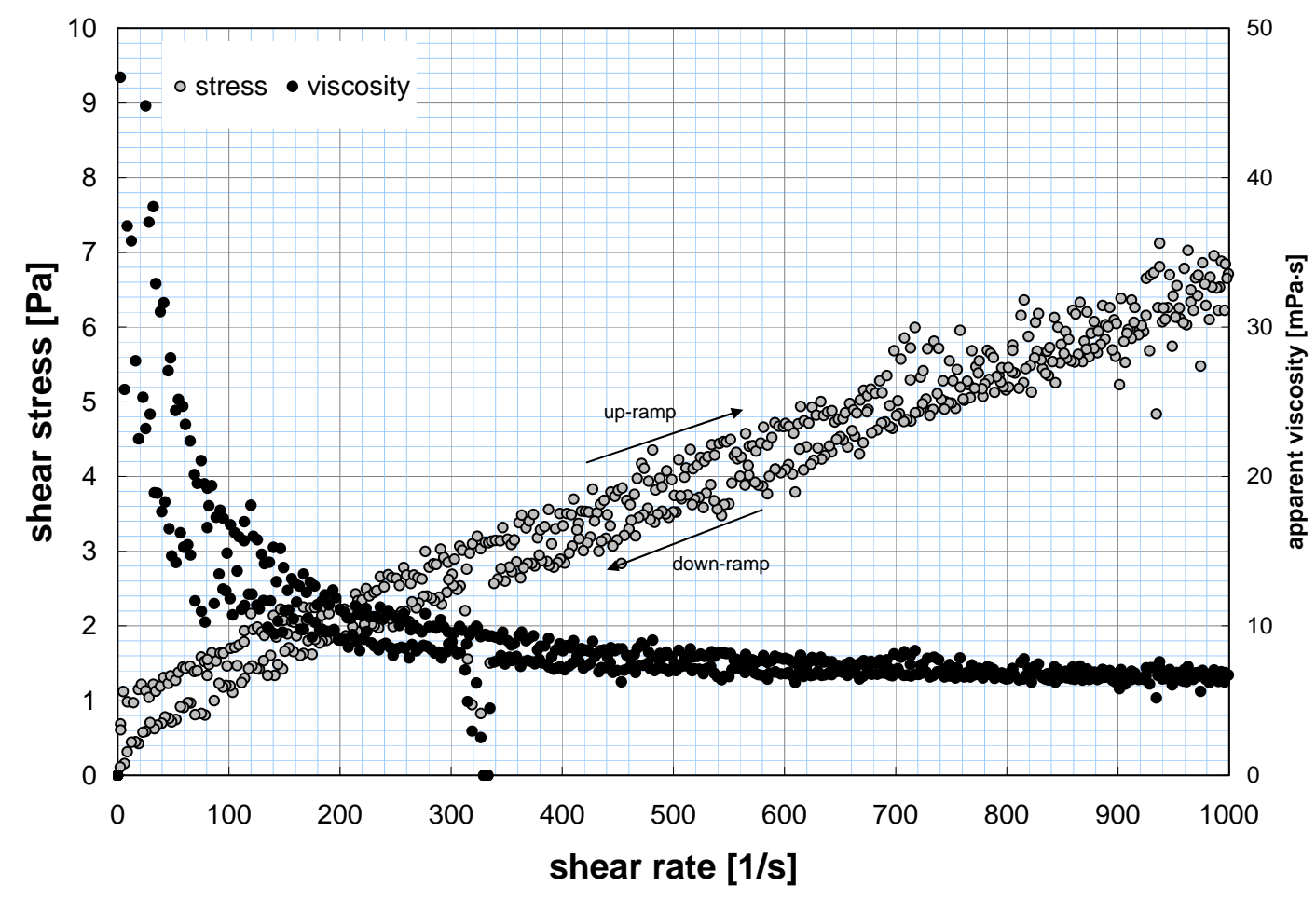

Figure A-11. Rheogram for TI640-G8-R3-Slurry at $40^{\circ} \mathrm{C}$.

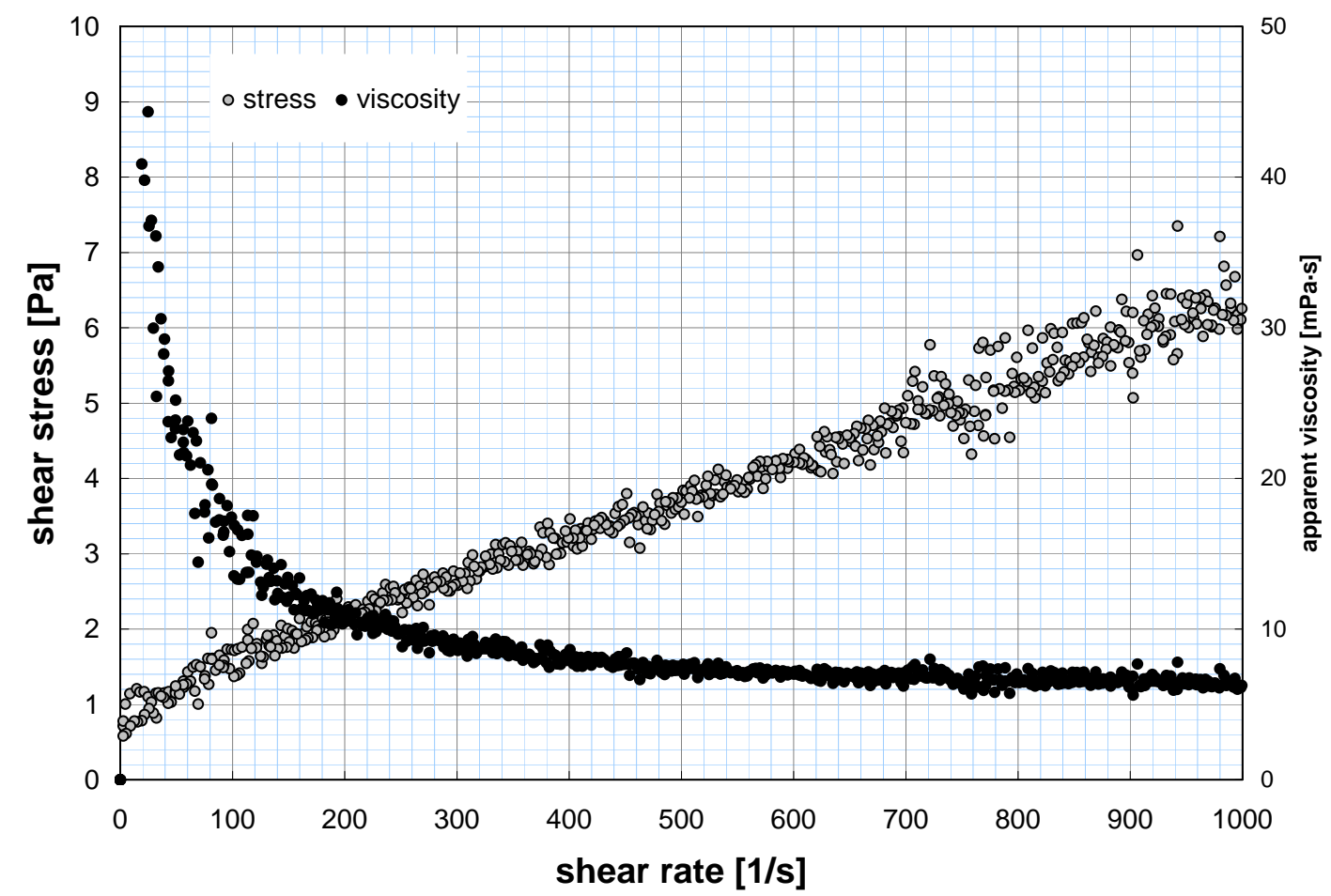

Figure A-12. Rheogram for TI640-G8-R3-Slurry at $60^{\circ} \mathrm{C}$. 
Sample TI640-G8-R4-Slurry: Caustic-Leached, Dewatered, and Washed Group 8 CUF Slurry

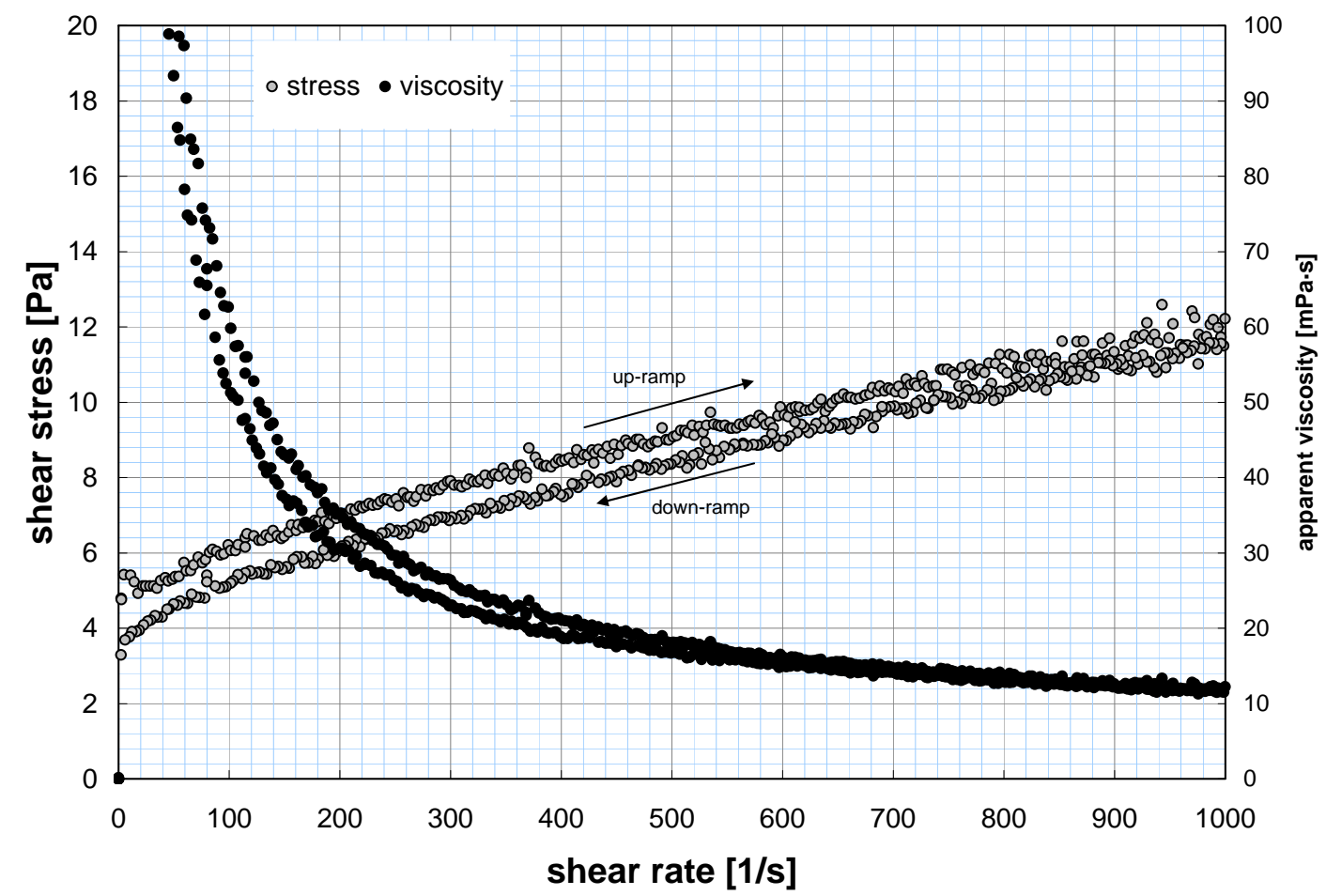

Figure A-13. Rheogram for TI640-G8-R4-Slurry at $25^{\circ} \mathrm{C}$ (measurement 1 of 2).

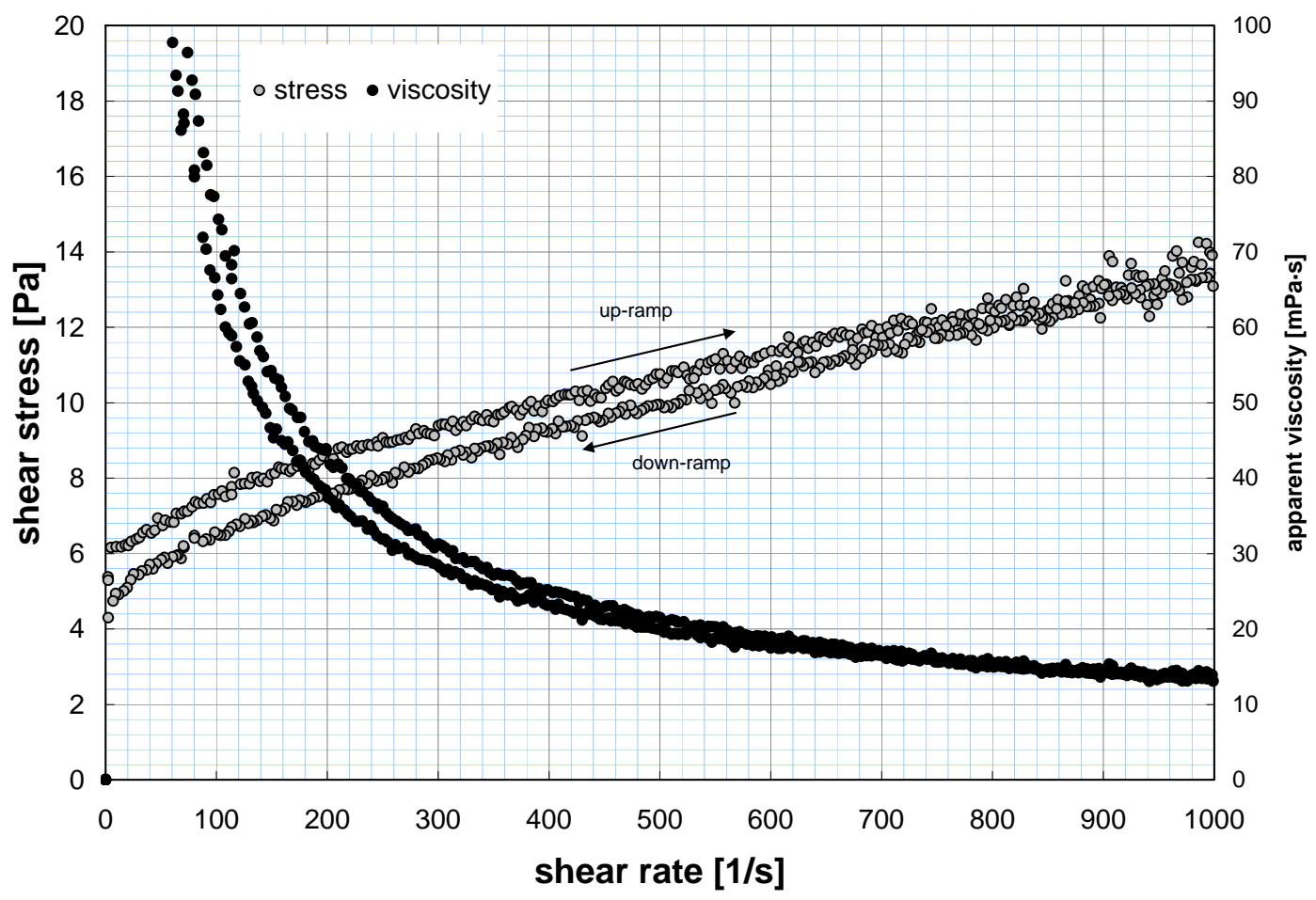

Figure A-14. Rheogram for TI640-G8-R4-Slurry at $25^{\circ} \mathrm{C}$ (measurement 2 of 2). 


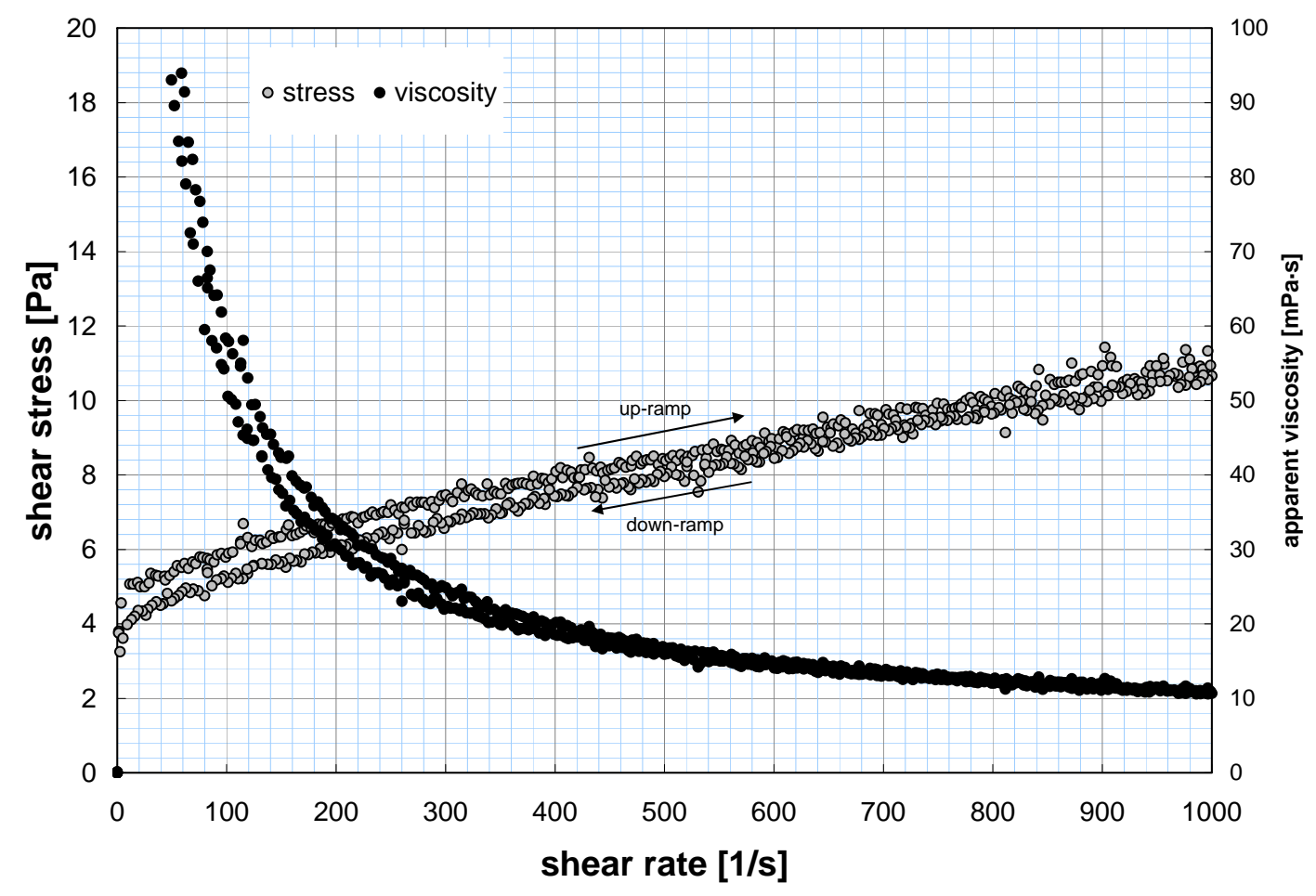

Figure A-15. Rheogram for TI640-G8-R4-Slurry at $40^{\circ} \mathrm{C}$.

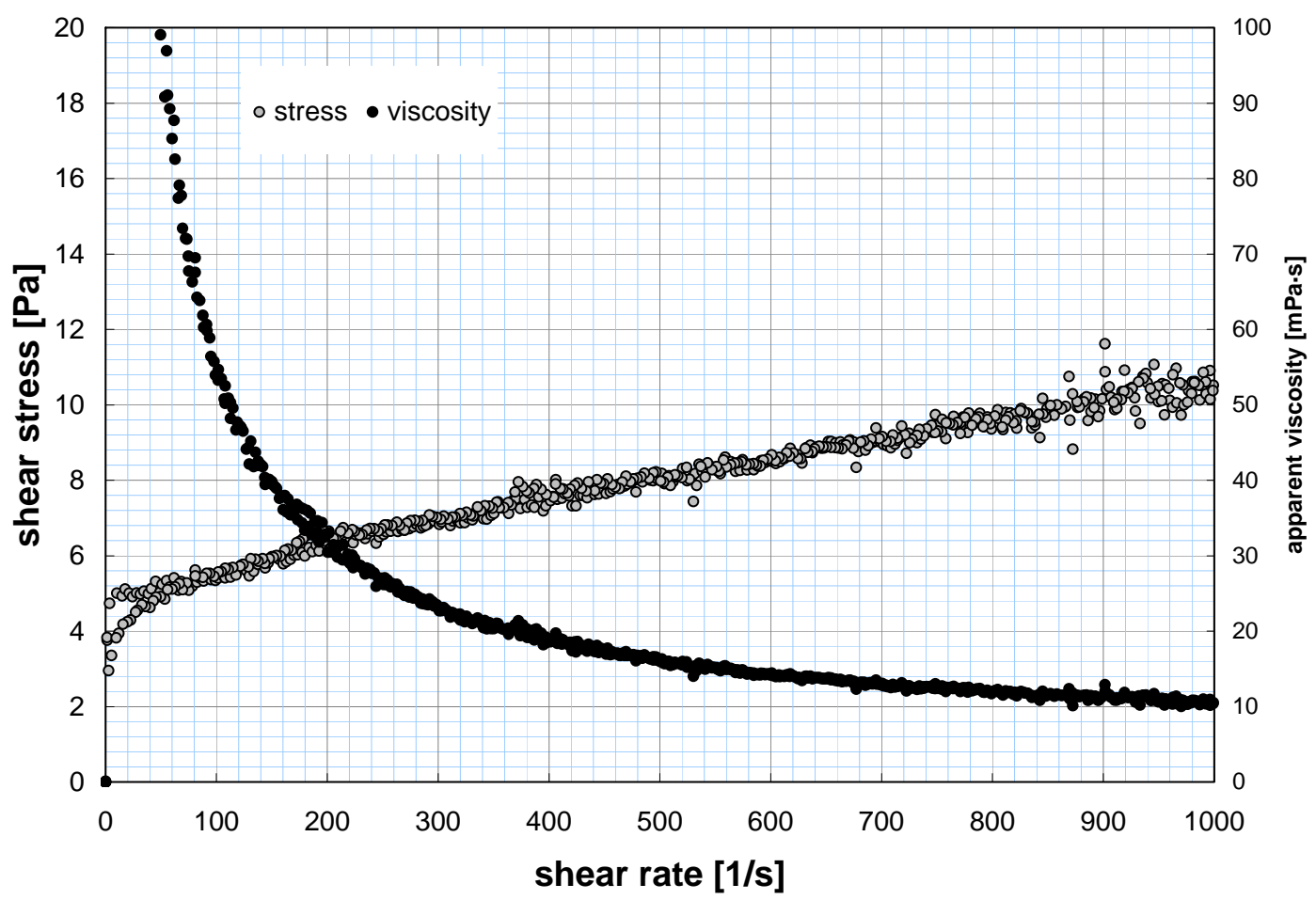

Figure A-16. Rheogram for TI640-G8-R4-Slurry at $60^{\circ} \mathrm{C}$. 


\section{Sample TI640-G8-R5-Slurry: Combined-Leach Group 8 CUF Slurry}

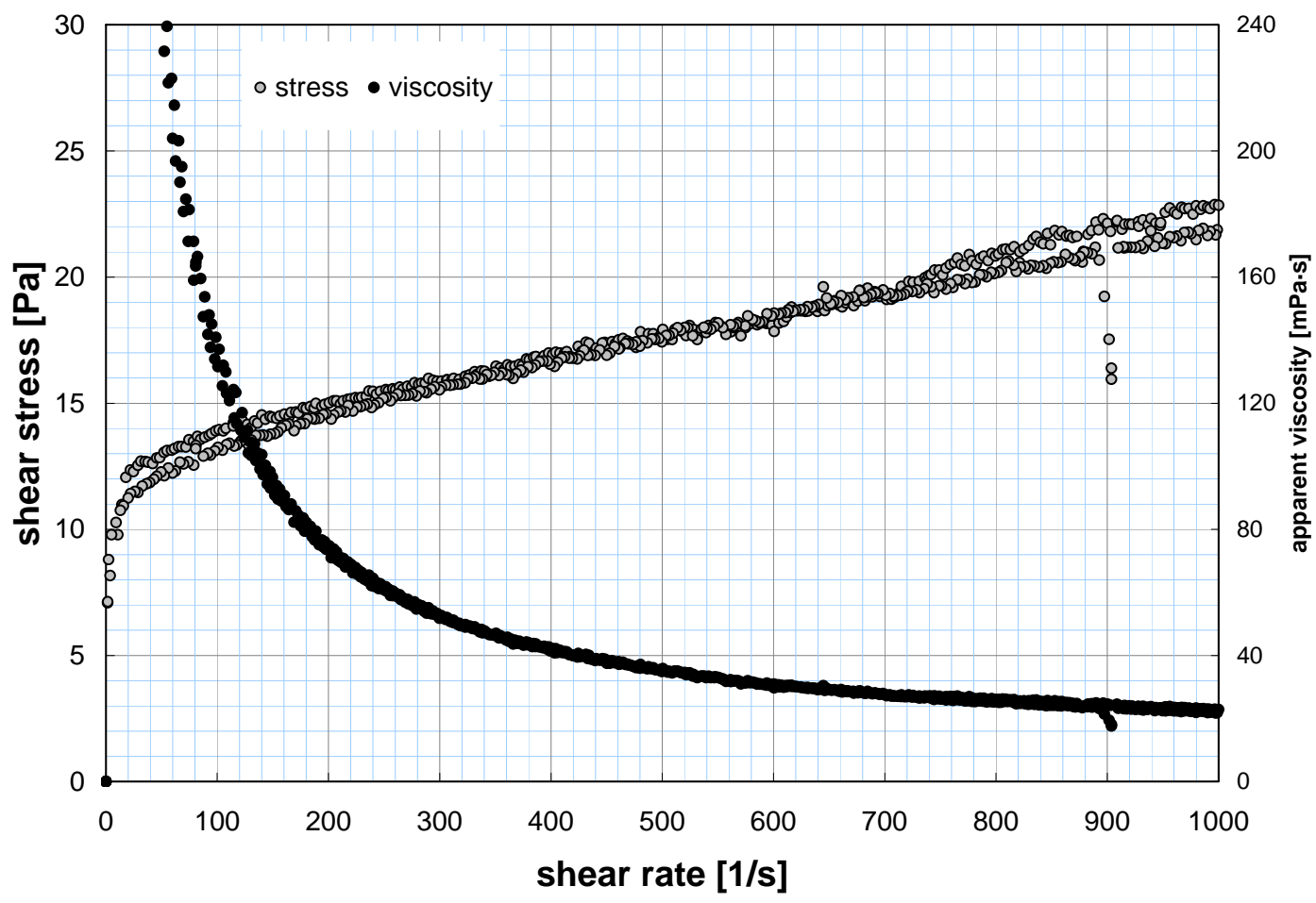

Figure A-17. Rheogram for TI640-G8-R5-Slurry at $25^{\circ} \mathrm{C}$ (measurement 1 of 2).

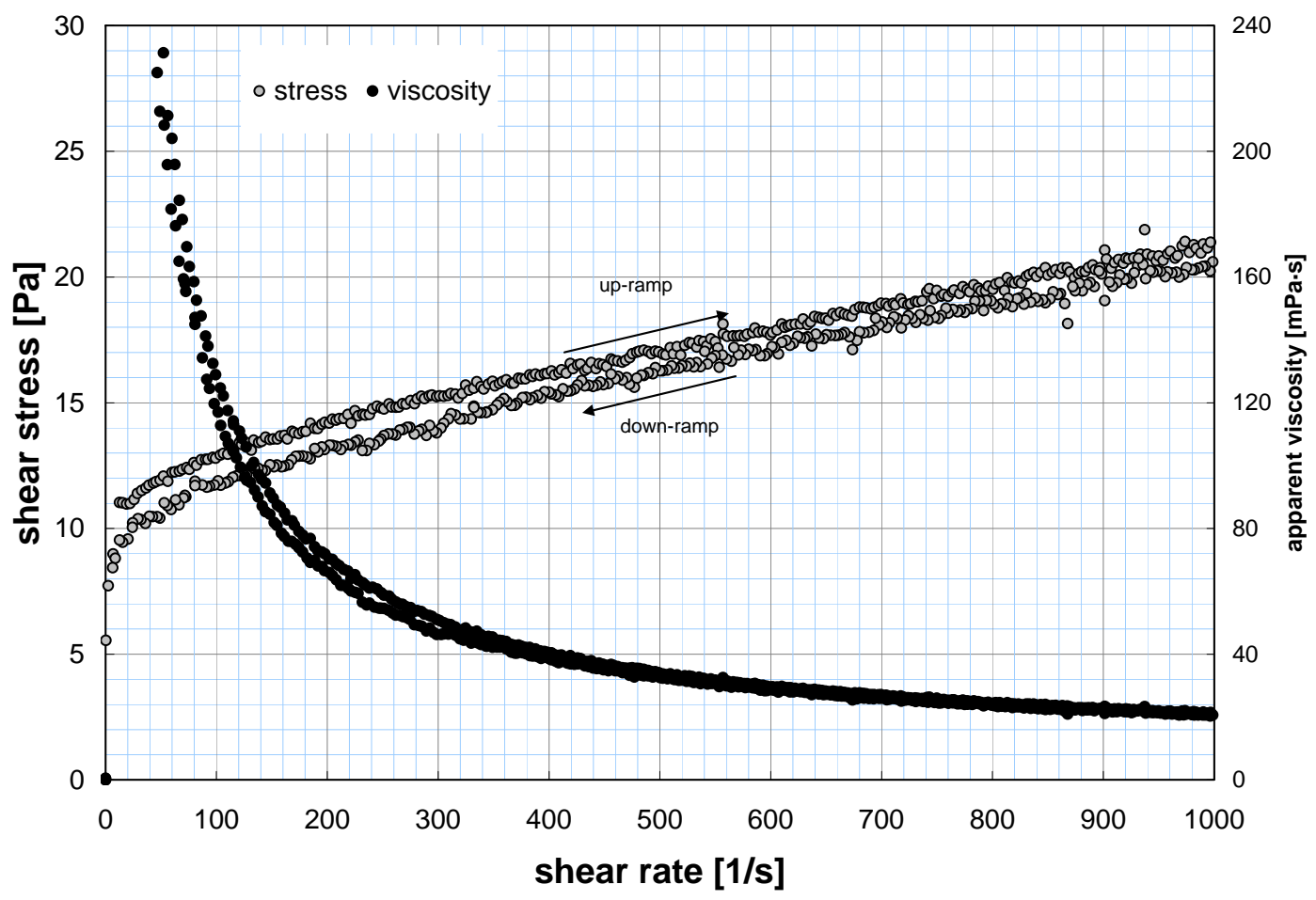

Figure A-18. Rheogram for TI640-G8-R5-Slurry at $25^{\circ} \mathrm{C}$ (measurement 2 of 2). 


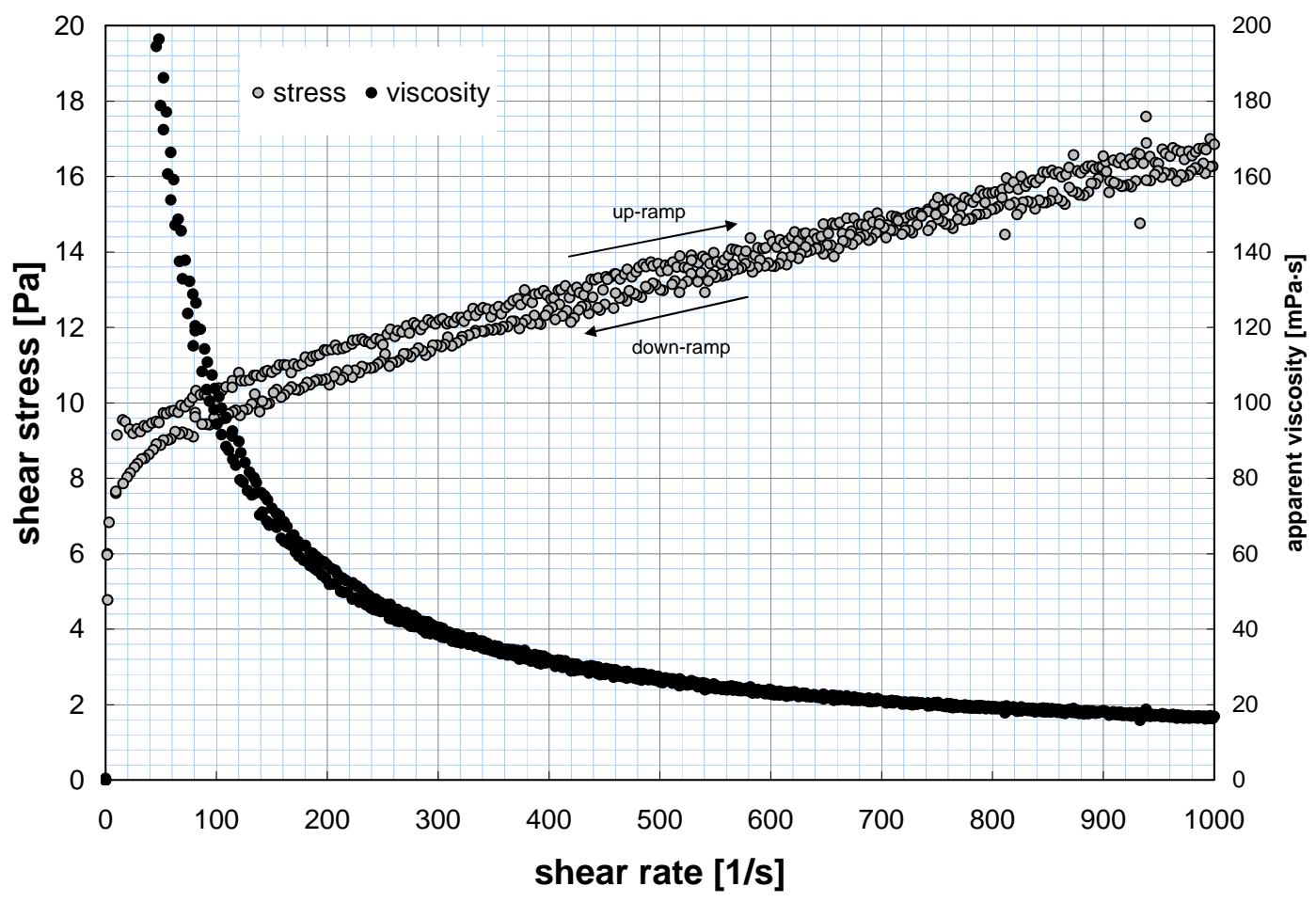

Figure A-19. Rheogram for TI640-G8-R5-Slurry at $40^{\circ} \mathrm{C}$.

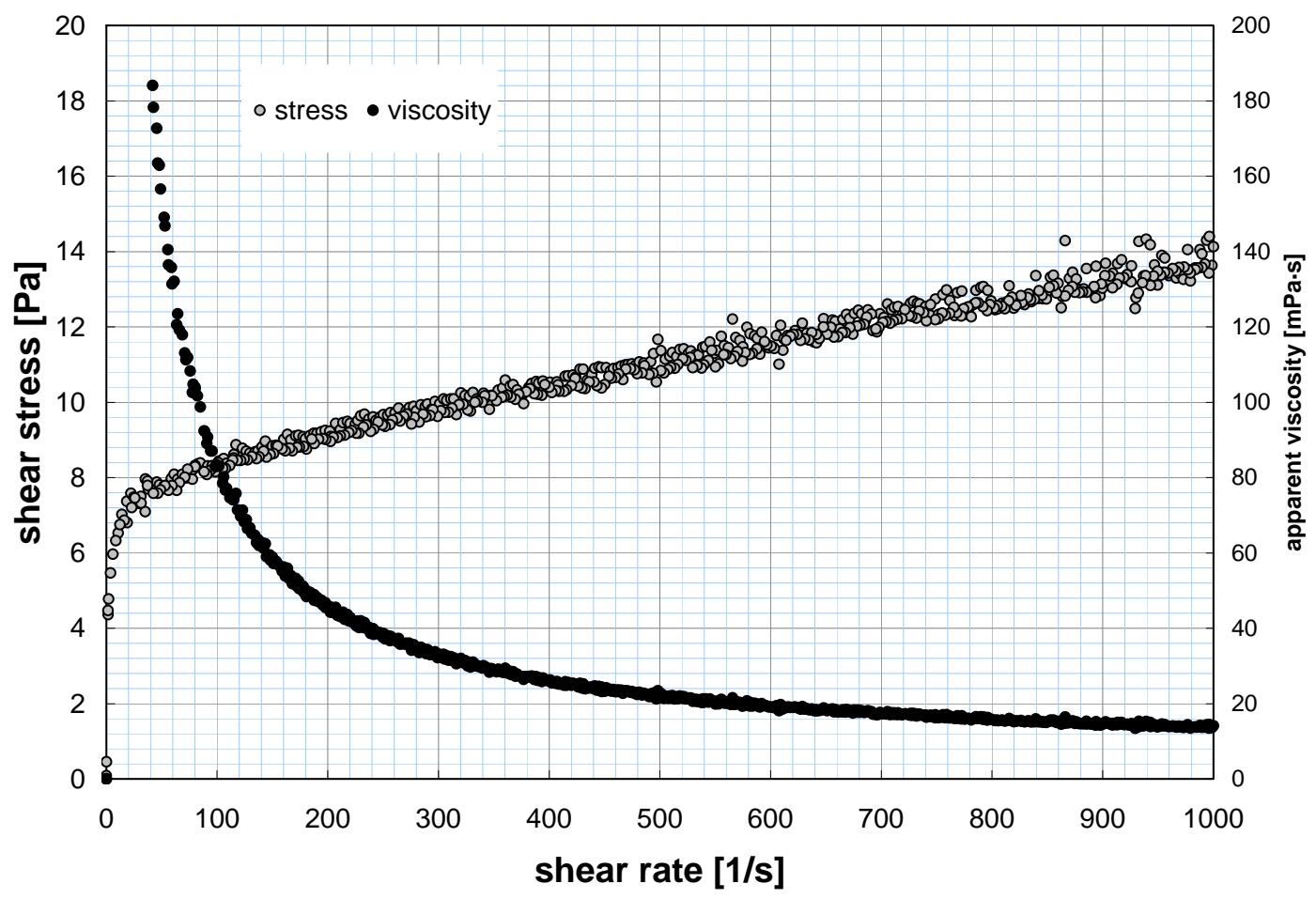

Figure A-20. Rheogram for TI640-G8-R5-Slurry at $60^{\circ} \mathrm{C}$. 


\section{Sample TI640-G8-R1-Perm: Initial (Pre-Leach) Group 8 CUF Permeate}

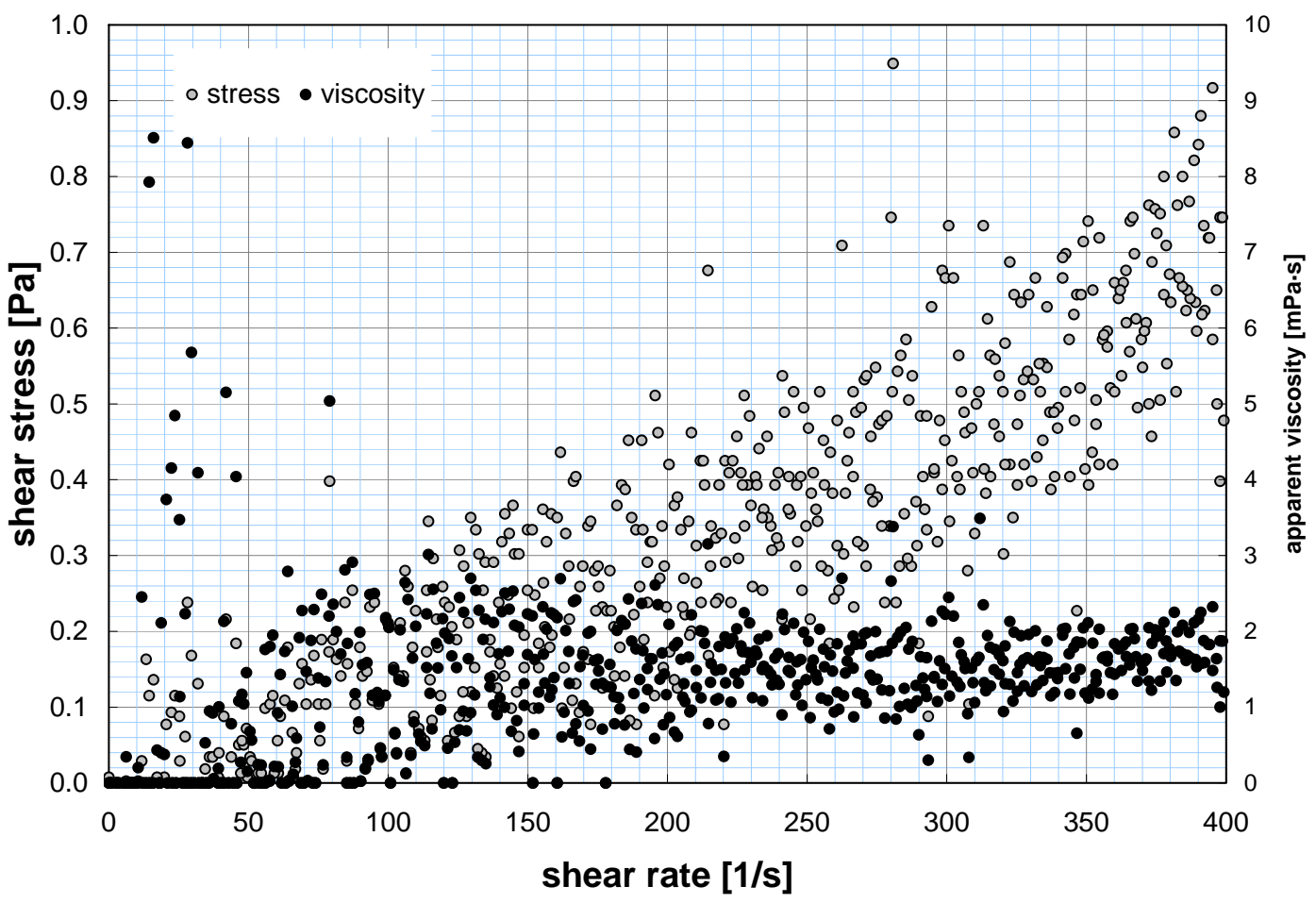

Figure A-21. Rheogram for TI640-G8-R1-Perm at $25^{\circ} \mathrm{C}$ (measurement 1 of 2).

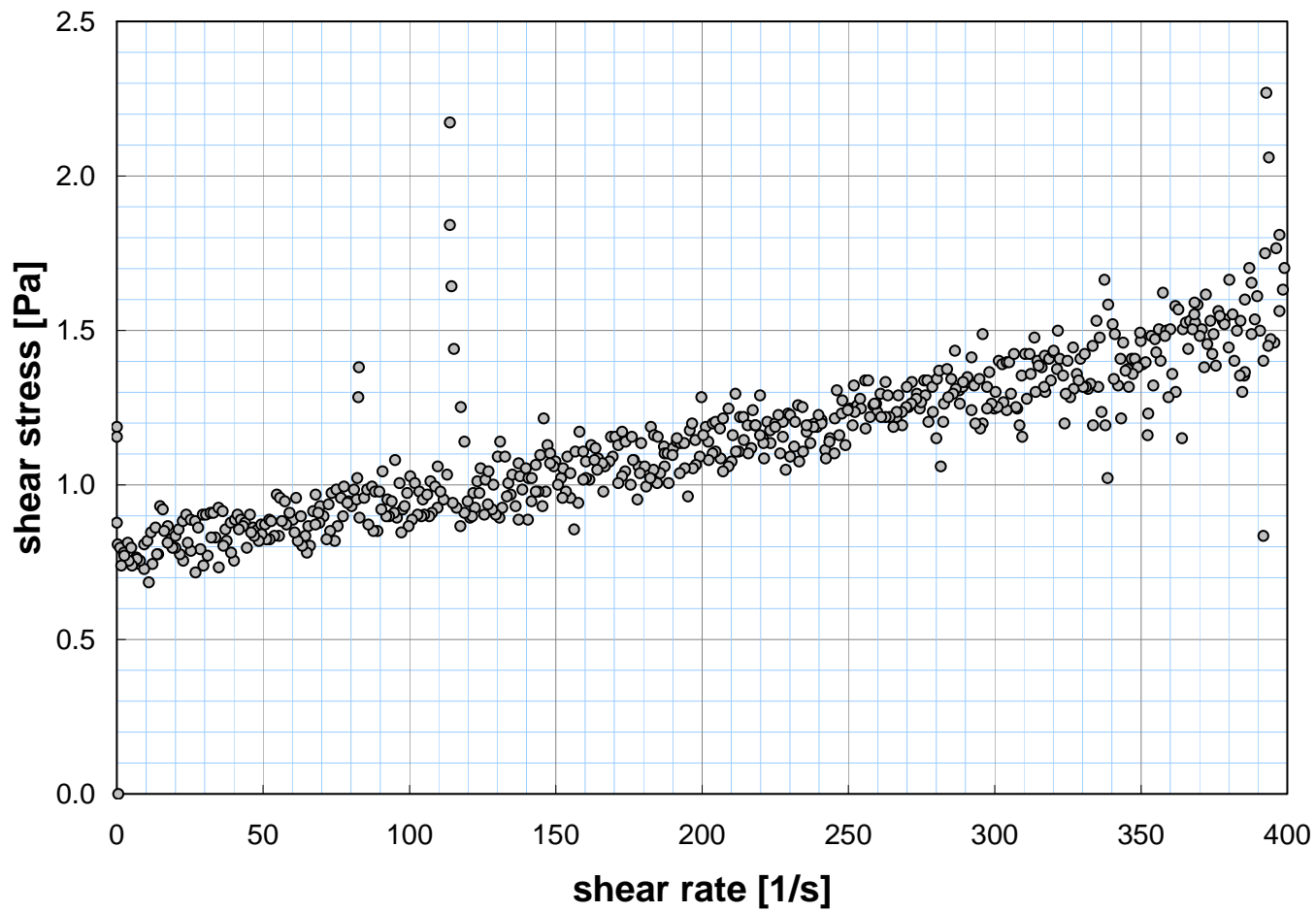

Figure A-22. Rheogram for TI640-G8-R1-Perm at $25^{\circ} \mathrm{C}$ (measurement 2 of 2). For the measurement, an artificial stress offset of $\sim 0.7 \mathrm{~Pa}$ was included to prevent negative torque correction. 


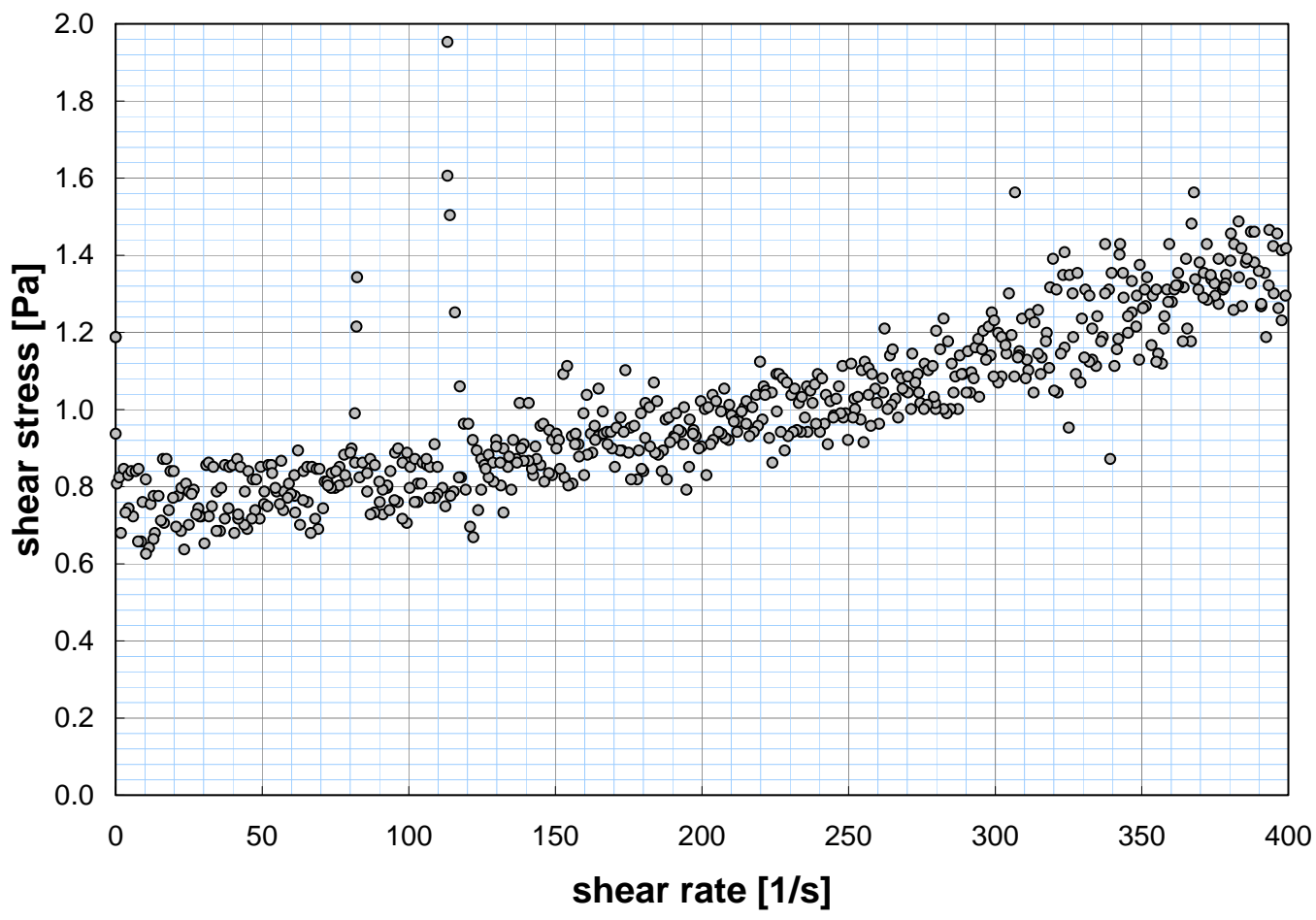

Figure A-23. Rheogram for TI640-G8-R1-Perm at $40^{\circ} \mathrm{C}$. For the measurement, an artificial stress offset of $\sim 0.7 \mathrm{~Pa}$ was included to prevent negative torque correction.

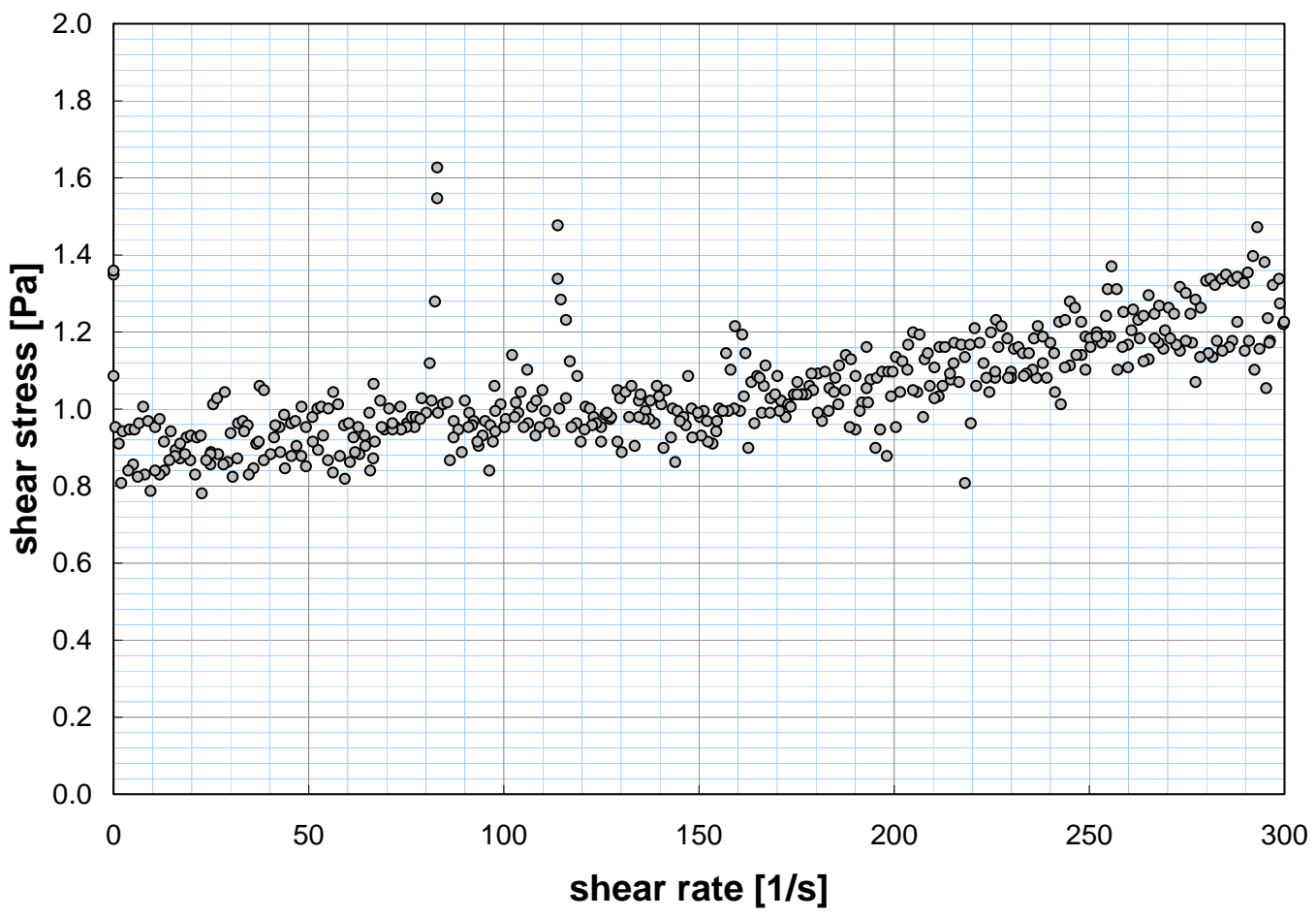

Figure A-24. Rheogram for TI640-G8-R1-Perm at $60^{\circ} \mathrm{C}$. For the measurement, an artificial stress offset of $\sim 0.9 \mathrm{~Pa}$ was included to prevent negative torque correction. 
Sample TI640-G8-R3-Perm: Post-Caustic Leach Group 8 CUF Permeate

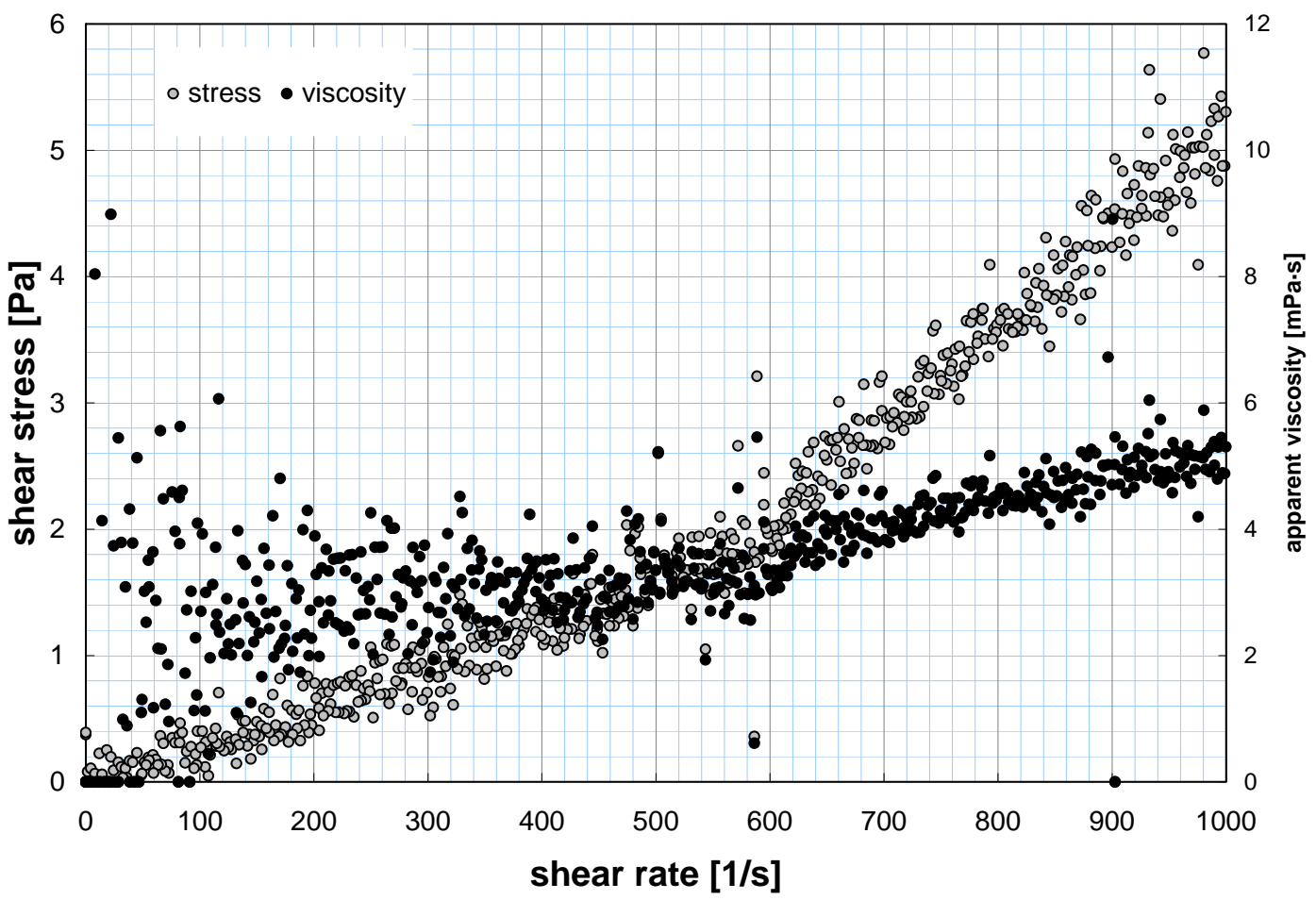

Figure A-25. Rheogram for TI640-G8-R3-Perm at $25^{\circ} \mathrm{C}$ (measurement 1 of 2).

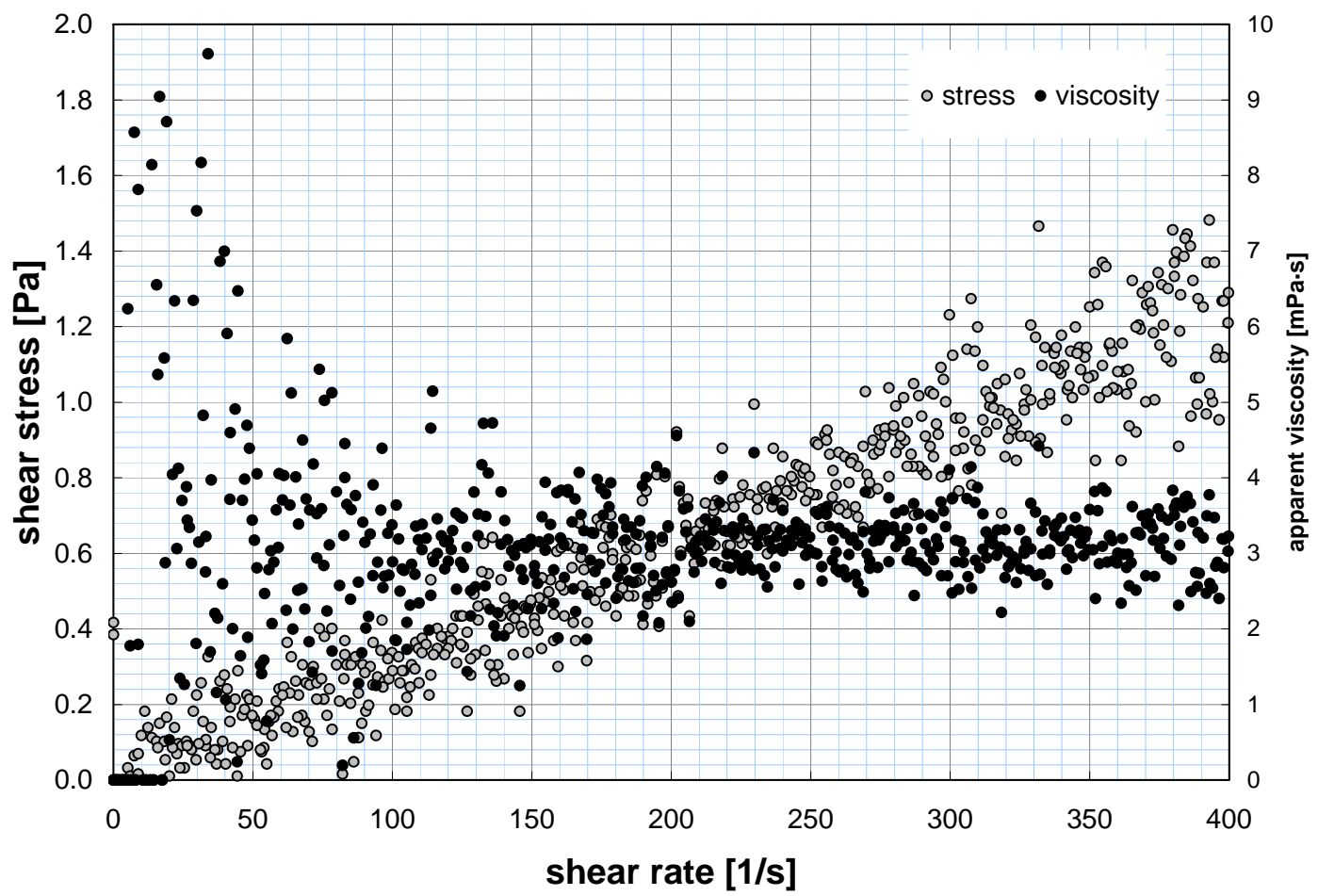

Figure A-26. Rheogram for TI640-G8-R3-Perm at $25^{\circ} \mathrm{C}$ (measurement 2 of 2). 


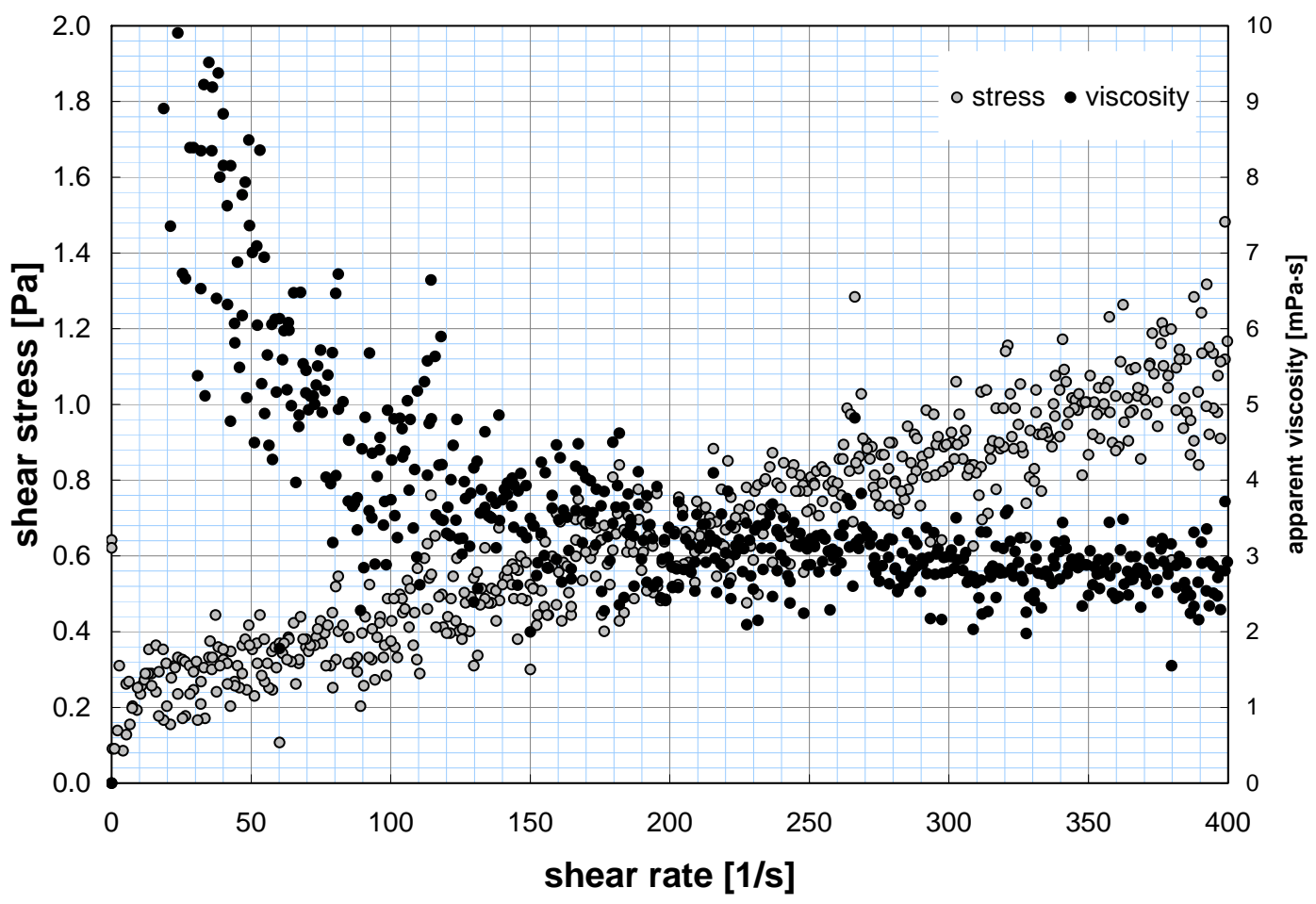

Figure A-27. Rheogram for TI640-G8-R3-Perm at $40^{\circ} \mathrm{C}$. For the measurement, an artificial stress offset of $\sim 0.2 \mathrm{~Pa}$ was included to prevent negative torque correction.

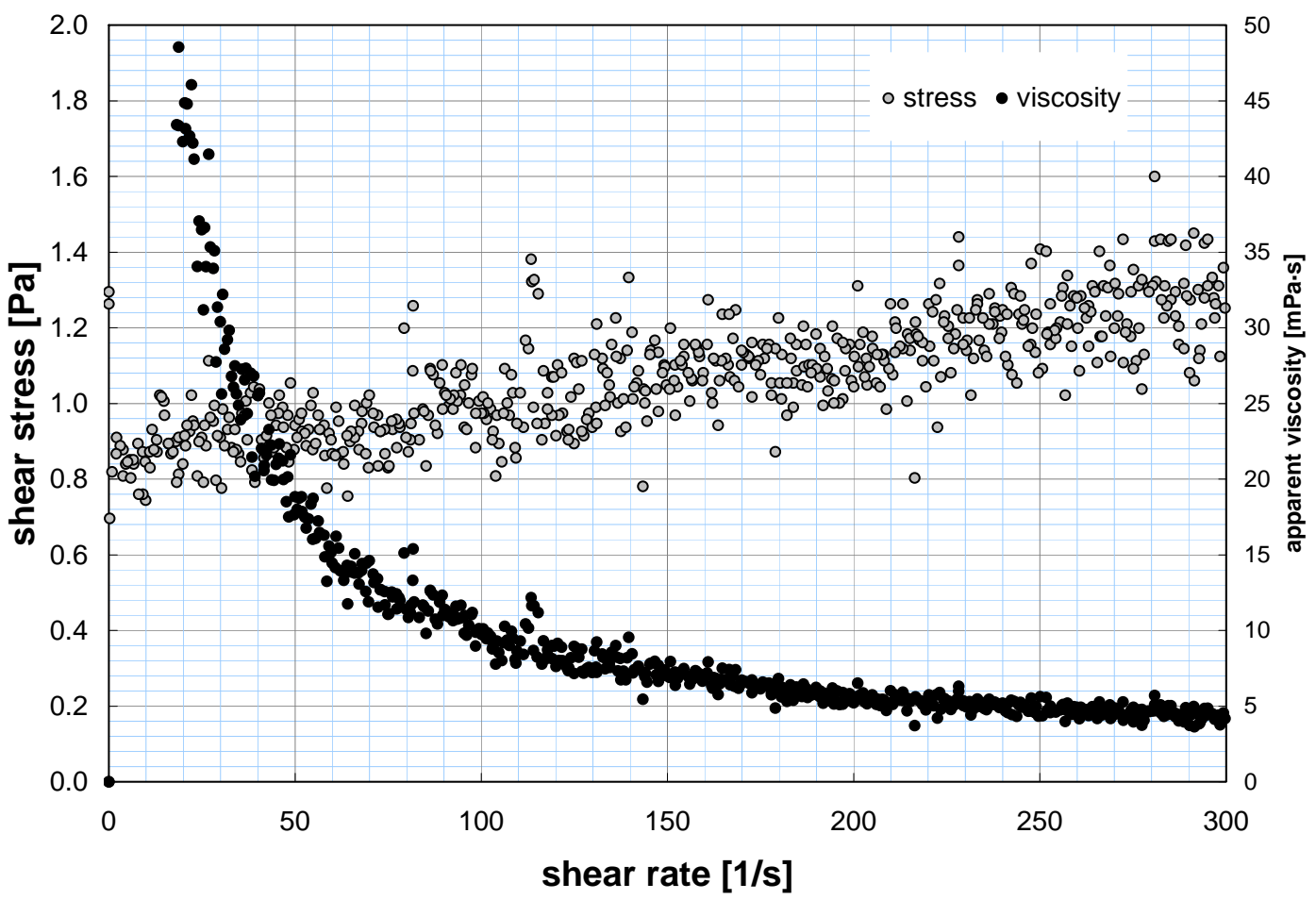

Figure A-28. Rheogram for TI640-G8-R3-Perm at $60^{\circ} \mathrm{C}$. For the measurement, an artificial stress offset of $\sim 0.8 \mathrm{~Pa}$ was included to prevent negative torque correction. 

WTP-RPT-170, Rev. 0

\section{Appendix G}

\section{Group 8 PSD Report}





\section{Appendix G: Group 8 PSD Report}

The particle-size distribution (PSD) analysis report is included in this appendix. The PSD analysis report contained appendices called Appendix A and Appendix B. All references to appendix identifications in the PSD analysis report are specific to the embedded appendices and do not reference the appendices in the overall characterization and filtration report (which are denoted as Appendix A through Appendix H). 


\title{
Battelle
}

The Business of Innovation

Date November 10, 2008

To Sandy Fiskum

Rick Shimskey

From Amanda Casella

Subject $\quad$ Particle Size Distribution for Group 8

[Ferrocyanide (FeCN) Wastes] Initial

Characteristic and CUF Samples
Internal Distribution

Sandy Fiskum

Rick Shimskey

Amanda Casella

File/LB

\section{Acronyms and Abbreviations}

\author{
AV Axial Velocity \\ CA Contamination Area \\ CCP Computational Computer Program (application) \\ CUF Cells Unit Filter \\ DI Deionized (water) \\ LRB Laboratory Record Book \\ NIST National Institute of Standards and Technology \\ PSD Particle Size Distribution \\ RI Refractive Index \\ RMA Radioactive Material Area \\ RPL Radiochemical Processing Laboratory \\ RPP River Protection Project \\ SAL Shielded Analytical Laboratory \\ TMP Transmembrane Pressure \\ UDS Undissolved Solids \\ WTP Waste Treatment Plant (Support Program)
}

\section{Introduction}

In fulfillment of the requirements of Test Plan TP-RPP-WTP-467 [1], the particle size distribution (PSD) of select Hanford tank waste water insoluble solids was characterized at the Radiochemical Processing Laboratory (RPL). This interim characterization report presents PSD results for Group 8 [Ferrocyanide ( $\mathrm{FeCN}$ ) Wastes] wastes derived during initial characterization and also wastes processed in the Cells Unit Filter (CUF) located at the RPL's Shielded Analytical Laboratory (SAL).

\section{Background}


Particle size distribution (PSD) describes the size fractionation of solid species in a given powder, dispersion, or slurry sample. PSD is typically described by either cumulative or differential population fraction versus a given particle size indicator. For example, the size distribution of particles in a slurry are often described using a histogram expressing the differential volume of particles falling between two equivalent sphere diameters over a large array of equivalent sphere diameters. PSD measurements can be accomplished using a number of approaches, such as settling experiments, microscopic imaging, and light obscuration and scattering.

The particle size measurements discussed herein are carried out on a Malvern Mastersizer 2000 particle size analyzer (Malvern Instruments, Inc., Southborough, MA). This instrument operates using the principle of laser diffraction (see Figure 1). Here, a monochromatic laser (red and/or blue) is directed through a transparent cell containing a dilute dispersion of the solid particles being analyzed. On the opposite side of the flow cell is a series of ring detectors capable of detecting the intensity of laser light at various scattering angles. If the laser does not strike a particle in the flow cell, it simply passes through the cell undisturbed and strikes the central detector. When the laser interacts with a particle, it is scattered at various angles. The scattered light is picked up across a number of rings of the detector, creating a unique "scattering pattern" that can be mapped as a function of scattered light intensity versus ring detector position. Prolonged observation of the light scattered from the dispersion allows complete sampling of the particle species contained therein. Comparison of the time-averaged scattering signal against a reference "clean" cell signal generates a scattering pattern unique to that dispersion. Given the optical properties of the particulate and dispersing phases, mathematical analysis of the averaged "scattering pattern" allows determination of size fractionation species contained in the dispersion.

flow cell filled with dilute

particle dispersion

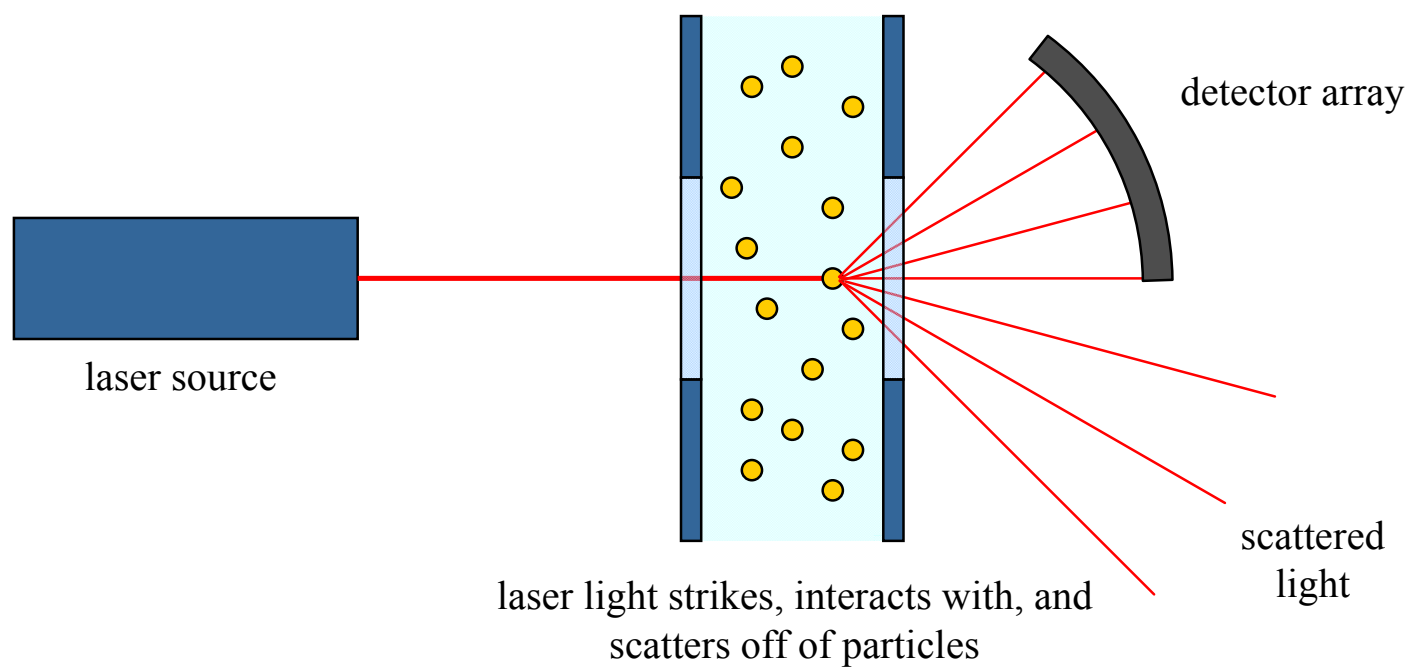

Figure 1. Schematic of a typical laser diffraction particle size analyzer.

It is important to recognize that particle size measurements by laser diffraction are intended to capture the size of a single, well-dispersed particle species. This "true" PSD captures 
all particles in the solid dispersion in an un-agglomerated primary particle state. Full dispersion at the primary particle level requires the correct selection of suspending phase chemistry, which is often further modified through the use of dispersing agents or surfactants, and sufficient flow to suspend all particles during analysis.

When dealing with complex dispersions such as Hanford tank waste, which contain multiple particle species and a broad distribution of sizes, finding the correct dispersing medium and measurement conditions is difficult (if not impossible), as individual particle species in the solids mixture may have contradictory suspending phase chemistry requirements. As such, particle size analysis of complex solids dispersions is generally performed to determine the "apparent" PSD as a function of processing conditions such as flow rate and sonication and suspending phase chemistry such as $\mathrm{pH}$. The apparent PSD differs from the true PSD in two ways: 1) particle agglomerates exist and are treated as single particle species and 2) not all particles may be suspended at the flow conditions selected. Despite these short comings, apparent PSDs provide useful information about how the PSD of the test dispersion exists in the process from which it is derived and can highlight potential difficulties in suspending large/dense particles.

\section{Samples}

Group 8 particle size measurement samples were derived as part of bench-scale leaching studies using actual tank waste. Source material for the studies included initial characterization and CUF testing of Group 8 [FeCN Wastes] solids. Five samples were submitted for analysis, including a primary and duplicate of the initial characterization (TI609-G8-S-WL-PSD-1 and TI609-G8-S-WL-PSD-2) and three CUF samples.

Group 8 CUF particle size measurement samples were derived as part of bench-scale crossflow ultrafiltration and leaching studies using actual tank waste. The Group 8 sludge samples were added to the slurry reservoir tank with two liters of a simulant supernate. The combination was initially mixed in the tank then allowed to circulate through the CUF at a high flow rate for approximately half an hour. The system was given a single backpulse to fill the permeate chamber and permeate was allowed to flow through both the rotameter and mass flow meter for another half an hour. Sample TI640-G8-3-PSD was taken after the initial slurry had been circulated in the CUF, although before any dewatering or leaching took place. Various transmembrane pressures (TMP) and axial velocities (AV) were examined, and then the slurry was subjected to the following operations:

1. dewatering of the waste slurry to transform the low-concentration Group 8 slurry to a high-concentration Group 8 slurry

2. full-recycle ultrafiltration of the high-concentration waste slurry at various AV and TMP

3. caustic-leaching of the waste slurry with $\sim 6 \mathrm{M}$ sodium hydroxide for 8 hours at $60^{\circ} \mathrm{C}$ (not including time for slurry heat-up and cool-down)

4. dewatering of the caustic-leached slurry

5. full-recycle ultrafiltration of the high-concentration caustic-leached slurry at various AV and TMP

6. washing of the caustic-leached slurry with relatively dilute sodium hydroxide solutions (includes four successive washes with increasingly dilute $\mathrm{NaOH}$ solutions) 
For CUF particle size testing, samples were derived from various points in the ultrafiltration process outlined above. With regard to slurry samples, waste aliquots for particle size were sampled after:

- after loading and circulating the sample in the CUF,

- after caustic-leaching and dewatering (i.e. after step 4)

- dewatering the initial slurry (i.e. after step 1),

- after washing the caustic-leached slurry (i.e., after step 6),

For sampling, approximately $0.5 \mathrm{~mL}$ of source slurry was taken. These slurry samples were subsequently diluted to $\sim 5 \mathrm{~mL}$ total volume with a solution of $0.01 \mathrm{M} \mathrm{NaOH}$ in water. It should be noted that this dilution step may alter both the apparent and primary particle size distributions of solids in the sample submitted for size analysis (by either particle dissolution or change in the state of particle agglomeration). As such, the PSDs measured during analysis may not correspond directly to the size distribution that exists in the CUF at a given processing step. Due to dose concerns sample TI640-G8-9-PSD was not able to be analyzed for PSD. Table 1 provides a summary of the samples analyzed and their given sample identification number. 
Table 1. Samples associated with Group 8 particle size testing.

\begin{tabular}{||c|l||}
\hline Sample Jar ID & Description \\
\hline TI609-G8-S-WL-PSD-1 & Primary Group 8 Initial Characterization Sample \\
\hline TI609-G8-S-WL-PSD-2 & Duplicate Group 8 Initial Characterization Sample \\
\hline TI640-G8-3-PSD & Slurry - Low-solids matrix Group 8 slurry before caustic leaching \\
\hline TI640-G8-6-PSD & Slurry - High-solids matrix Group 8 slurry before caustic leaching \\
\hline TI640-G8-13-PSD & Slurry - Washed Group 8 slurry after caustic leaching \\
\hline
\end{tabular}

\section{Analysis}

Particle size distributions for Group 8 samples were measured on the dates shown in Table 2. The analyses produced the following reportable data:

- particle diameters corresponding to the $10 \%, 50 \%$, and $90 \%$ cumulative weight/volume undersize percentiles

- $\quad$ volume differential distributions (mass population percentage versus diameter)

Alternate analyses of the data, such as number/surface area distributions, are available on request.

Table 2. Sample analysis dates for Group 8

\begin{tabular}{|c|c||}
\hline Sample & Date \\
\hline TI609-G8-S-WL-PSD-1 & October 7, 2008 \\
\hline TI609-G8-S-WL-PSD-2 & October 7, 2008 \\
\hline TI640-G8-3-PSD & October 16, 2008 \\
\hline TI640-G8-6-PSD & October 16, 2008 \\
\hline TI640-G8-13-PSD & October 10, 2008 \\
\hline
\end{tabular}

\section{Instrument}

Particle size characterization was accomplished using a Mastersizer 2000 (Malvern Instruments, Inc., Southborough, MA 01772 USA) with a Hydro $\mu \mathrm{P}$ wet dispersion accessory. The Mastersizer has a nominal size measurement range of $0.02-2000 \mu \mathrm{m}$. The actual range is dependent on the accessory used as well as the properties of the solids being analyzed. When coupled with the Hydro $\mu \mathrm{P}$ wet dispersion accessory, the nominal measuring range is reduced to $0.02-150 \mu \mathrm{m}$. Although particle sizes above $150 \mu \mathrm{m}$ can be observed with the Hydro $\mu \mathrm{P}$, their volume/number contribution cannot be determined reliably.

The Hydro $\mu \mathrm{P}$ wet dispersion accessory consists of a $20 \mathrm{~mL}$ sample flow cell with a continuously variable and independent pump and ultrasound. Both flow and sonication can be controlled and changed during measurement. As such, PSD measurements can be made before, during, and after sonication, allowing determination of the influence of each on the sample's PSD. The primary measurement functions of the Malvern analyzer are controlled through computer software. For the current measurements, Mastersizer 2000 software, Version 5.40 [Malvern Instruments, Ltd. Copyright (C 1998-2007] was employed. 
Table 3 provides a summary of basic information regarding the analyzer and accessory.

The Malvern Mastersizer 2000 is located in the northwest contamination area (CA) fume hood in RPL Room 302. It should be noted that the dispersion unit's sonication capability was not functioning at the time the standard or sample measurements were taken. As such, only "before sonication" data are available.

Table 3. Summary of Malvern Mastersizer 2000 instrument information.

\begin{tabular}{||l|l||}
\hline \hline Analyzer: & Mastersizer 2000 \\
\hline Measurement principle: & Laser Diffraction (Mie Scattering) \\
\hline Analyzer Accessory: & Hydro $\mu \mathrm{P}$ \\
\hline Serial Number: & MAL100406 \\
\hline Measurement Range: & $0.02-2000 \mu \mathrm{m}$ nominal $(0.02-150 \mu \mathrm{m}$ with accessory) \\
\hline Type: & $\begin{array}{l}\text { Flow cell system with continuously variable and } \\
\text { independent pump and ultrasound. }\end{array}$ \\
\hline Capacity: & $20 \mathrm{~mL}$ \\
\hline Pump Speed Range: & $0-5000$ RPM (variable) \\
\hline Ultrasound Power & $0-20 \mathrm{~W}$ (variable) \\
\hline Software Version & 5.40 \\
\hline
\end{tabular}

\section{Governing Test Plan, Procedure, and Test Instructions}

The test plan governing the physical characterizations for these samples is River Protection Project - Waste Treatment Plant Support Program (RPP-WTP) document number TPRPP-WTP-467, Revision 0 [1]. Operation of the Malvern Mastersizer 2000 is governed by RPLCOLLOID-01, Revision 1 [2].

\section{Instrument Performance Check}

As required by RPL-COLLOID-01, the performance of the Malvern analyzer must be verified at the beginning of each series of analyses (with the period between performance checks not to exceed 90 days during use). Checks are performed using particle size standards traceable to the National Institute of Standards and Technology (NIST). Checks verify that the particle size analyzer can measure a PSD standard's d(50), the 50\% volume/weight fractile and mean particle size, to within $10 \%$ of the value specified on the manufacturer's certificate of analysis.

For the measurements described in this report, the performance check employed a NIST traceable polydisperse particle size standard purchased from Whitehouse Scientific (Waverton, Chester, $\mathrm{CH} 3 \mathrm{7PB}, \mathrm{UK}$ ). Table 4 provides a summary of the standard's properties. The standard is traceable back to its certificate of analysis through a unique bottle number identifier. 
Table 4. Properties of the NIST standard used to verify performance of the Malvern Mastersizer 2000 and performance check results.

\begin{tabular}{||l|l|c|c||}
\hline Size Range: & $1-10 \mu \mathrm{m}$ & \multicolumn{3}{l||}{} \\
\hline Catalogue \#: & PS-192 & \\
\hline Bottle \# & 2103 & \multicolumn{3}{|l||}{} \\
\hline Weight: & $0.10 \mathrm{~g}$ & \multicolumn{3}{|l||}{ List } & Measured $(\mu \mathrm{m})^{*}$ & Absolute Error** \\
\hline PSD Percentiles & $2.88 \pm 0.24 \mu \mathrm{m}$ & 2.60 & $\mathrm{n} / \mathrm{a}$ \\
\hline $\mathrm{d}(10):$ & $4.18 \pm 0.34 \mu \mathrm{m}$ & 4.16 & $0.43 \%$ \\
\hline $\mathrm{d}(50):$ & $6.23 \pm 0.56 \mu \mathrm{m}$ & 6.74 & $\mathrm{n} / \mathrm{a}$ \\
\hline $\mathrm{d}(90):$ &
\end{tabular}

*As measured for the period of performance applicable for this report.

**Calculated before rounding of significant figures in List and Measured

The instrument performance check covering size analysis of samples TI609-G8-S-WLPSD-1, TI609-G8-S-WL-PSD-2, TI640-G8-3-PSD, TI640-G8-6-PSD, and TI640-G8-13-PSD was run on October 2, 2008. Performance check results for this period were recorded to the Malvern file "2008-10Oct02-G2 Para PSD.mea".

The particle size standard was supplied as a $0.10 \mathrm{~g}$ single shot of dry powder that was dispersed in $\sim 0.5 \%$ sodium hexametaphosphate in water. This dispersion was subsequently sonicated for 5 minutes in a bath sonicator. Addition of sodium hexametaphosphate and subsequent sonication helps eliminate any particle agglomerates in the initial dispersion. Before measuring the performance check standard, the Hydro $\mu \mathrm{P}$ dispersion unit was filled with $\sim 0.5 \%$ sodium hexametaphosphate in water. Next, an aliquot of the particle size standard dispersion was sampled and loaded into the Malvern using a $5 \mathrm{~mL}$ plastic transfer pipette. A continuous pump speed of 2000 RPM was set to mix the flow cell contents and the PSD was measured.

The performance check size analysis employed a particle refractive index and absorption of 1.544 and 0, respectively, and a suspending phase particle refractive index of 1.33 (for water). An average of three 2000 RPM measurements of the PSD indicated a d(50) of $4.16 \mu \mathrm{m}$. This deviates less than $1 \%$ from the $\mathrm{d}(50)$ listed on the standard's certificate of analysis from Whitehouse Scientific and is also within the range provided on the certificate. As such, acceptable instrument performance was verified for the period of performance covering samples TI609-G8-S-WL-PSD-1, TI609-G8-S-WL-PSD-2, TI640-G8-3-PSD, TI640-G8-6-PSD, and TI640-G8-13-PSD.

\section{Sample Handling}

Group 8 samples were analyzed "as-is". No additional treatment was performed except for the mechanical agitation and re-suspension of any settled solids at the time of analysis.

\section{Experimental}

Particle size measurements of waste samples TI609-G8-S-WL-PSD-1, TI609-G8-S-WLPSD-2, TI640-G8-3-PSD, TI640-G8-6-PSD, and TI640-G8-13-PSD were performed using the Malvern analyzer in RPL Room 302. All measurements were performed in $0.01 \mathrm{M}$ sodium hydroxide. Before each analysis, the analyzer was drained, flushed with $20 \mathrm{~mL}$ of deionized 
(DI) water at least three times, filled with $20 \mathrm{~mL} 0.01 \mathrm{M}$ sodium hydroxide solution, and brought into a measurement ready state. PSD characterization for each sample was accomplished as follows:

1. The analyzer flow cell pump was set to 3000 RPM with no sonication.

2. The material (sample) and suspending phase optical properties were set in the analyzer software (see Table 5).

3. The sample was prepared for analysis by re-suspending the settled solids. This was accomplished by repeatedly pulsing the samples with a $10 \mathrm{~mL}$ disposable plastic pipette until the contents were uniformly dispersed. Each pulse involved drawing off a fraction of the sample into the pipette and immediately jetting the drawn liquid back into the sample vial.

4. Immediately after re-suspension, the sample dispersion was added drop-wise to the instrument (while the pump was active) until the appropriate laser obscuration was achieved. Obscurations ranging from 3.5 to $35 \%$ were considered acceptable. For the current analyses, an obscuration of $10-20 \%$ was targeted.

5. The sample PSD was measured under the conditions outlined in the sample test matrix (see Table 6).

Table 5. Material and suspending optical properties used for analysis of Group 7 particle size distributions.

\begin{tabular}{||c|c|c|c||}
\hline Sample Name & $\begin{array}{c}\text { Material Selected for } \\
\text { Optical Properties }\end{array}$ & $\begin{array}{c}\text { Refractive } \\
\text { Index (RI) }\end{array}$ & Absorption \\
\hline TI609-G8-S-WL-PSD-1 & Boehmite & 1.655 & 1.0 \\
\hline TI609-G8-S-WL-PSD-2 & Boehmite & 1.655 & 1.0 \\
\hline TI640-G8-3-PSD & Boehmite & 1.655 & 1.0 \\
\hline TI640-G8-6-PSD & Boehmite & 1.655 & 1.0 \\
\hline TI640-G8-13-PSD & Boehmite & 1.655 & 1.0 \\
\hline Suspending Phase & Water & 1.33 & $\mathrm{n} / \mathrm{a}$ \\
\hline
\end{tabular}

Table 6. Particle size analysis test matrix used for samples TI609-G8-S-WL-PSD-1, TI609-G8-S-WL-PSD-2, TI640-G8-3-PSD, TI640-G8-6-PSD, and TI640-G8-13-PSD.

\begin{tabular}{||c|c|c|c||}
\hline \hline Condition No. & $\begin{array}{c}\text { Pump Speed } \\
\text { (RPM) }\end{array}$ & Sonic Power & Comment \\
\hline 1 & 3000 & $\mathrm{n} / \mathrm{a}$ & no sonication \\
\hline 2 & 4000 & $\mathrm{n} / \mathrm{a}$ & no sonication \\
\hline 3 & 2000 & $\mathrm{n} / \mathrm{a}$ & no sonication \\
\hline 4 & 2000 & $\mathrm{n} / \mathrm{a}$ & no sonication \\
\hline
\end{tabular}

As indicated in the analysis outline above, the optical properties, such as the refractive index (RI) of the sample and suspending phase must be entered into analyzer at the time of measurement. Because the exact optical properties of the tank waste solids are unknown, the optical properties selected were those of most abundant species. Initially Al was chosen as the major species, so optical properties for boehmite $[\mathrm{AlO}(\mathrm{OH})]$ were employed in the measurement and analysis of Group 8 samples. After PSD analysis it was determined that $U$ may be the predominate solid species, and $\mathrm{UO}_{2}$ may have been a better choice for optical properties. Upon alteration of the optical properties to those of $\mathrm{UO}_{2}$ it was determined that this difference was insignificant as shown in Appendix A. Use of the correct optical properties (in particular the RI) 
only serves to refine measured PSD. As such, the boehmite optical properties can be used while still allowing the analysis to provide a reasonable representation of the actual waste PSD.

The size distribution of particles was measured under flow conditions without sonication. Table 6 outlines the test matrix performed for all sample measurements. For each condition, three successive 20-second measurements of PSD were taken. An average of these measurements was then generated by the analyzer software. Both individual and averaged PSDs were saved to the analyzer data file. Once measurements were complete, the flow rate for the next condition was set, the sample was given approximately 30 seconds to equilibrate, and the next set of measurements was taken. Measurements for TI609-G8-S-WL-PSD-1 and TI609-G8S-WL-PSD-2 were logged to the Mastersizer 2000 file "2008-10Oct07-G8 initial char PSD.mea". Measurements for TI640-G8-3-PSD and TI640-G8-6-PSD were logged to the Mastersizer 2000 file "2008-10Oct16-G8 CUF PSD.mea". Measurements for TI640-G8-13-PSD was logged to the Mastersizer 2000 file "2008-10Oct10-G8 CUF PSD.mea".

Analysis of the raw particle size data is performed automatically by the Mastersizer software immediately after each measurement. Analysis calculates the particle size distribution based on 1) the scattered light intensity as a function of detection angle, the particle size model selected [single narrow, multiple narrow, or broad peaks] and 2) the optical properties entered into the software at the time of measurement. For the current measurements, appropriate optical properties were selected at the time of measurement for all samples.

The particle size results for Group 8 initial characterization appear largely free of defects or data artifacts caused by air/bubble entrapment in the instrument. In the Group 8 CUF testing sample TI640-G8-3-PSD a peak was observed around $1300 \mu \mathrm{m}$. As particles of this size exceed the instrument's upper measuring range boundary of $150 \mu \mathrm{m}$, the $\sim 1300 \mu \mathrm{m}$ particle population may not have been properly suspended and/or reliable sampled due to their size. Likewise, size determinations between 1000-2000 $\mu \mathrm{m}$ appear to be strongly influenced by instrument electronic background, and determination of particles in this size range can sometimes result from measurement artifacts (such as a poor background reading). For these reasons, the distribution range was limited to less than $1000 \mu \mathrm{m}$ to remove these peaks from the analysis.

\section{Results and Discussion}

\subsection{Group 8 Initial Characterization PSD Results}

\section{$\underline{\text { Results for TI609-G8-S-WL-PSD (Group } 8 \text { Initial Characterization) }}$}

Figures 2-3 and Tables 7-8 present the results of Group 8 initial characterization particle size analysis as a function of test condition. Figures 2-3 show the differential volume population distribution for the Group 8 initial characterization sample and allow a qualitative examination of the PSD behavior with respect to pump speed. Table 7 is a summary of the measured oversize diameter percentiles (by volume/weight) for the primary sample, TI609-G8-S-WL-PSD-1. Table 8 presents the same results for the duplicate sample, TI609-G8-S-WL-PSD-2. Both tables present cumulative oversize diameters corresponding to the $10^{\text {th }}, 50^{\text {th }}$, and $90^{\text {th }}$ volume/weight percentiles, hereafter referred to as $\mathrm{d}(10), \mathrm{d}(50)$, and $\mathrm{d}(90)$, respectively. More extensive 
percentile results are provided in Appendix B of this interim report. These tables will be used to quantitatively examine reproducibility and changes in particle size.

Figure 2 shows the PSD for the primary Group 8 initial characterization sample as a function of pump speed. At 2000 RPM the distribution is continuous and relatively uni-modal and ranges from $0.2-40 \mu \mathrm{m}$ with a peak centered at $10 \mu \mathrm{m}$ and a shoulder over $0.2-2 \mu \mathrm{m}$. At 3000 RPM the distribution is comprised of two separate populations which form a tri-modal range spanning $0.2-750 \mu \mathrm{m}$ with peaks at 60,110 , and $500 \mu \mathrm{m}$ and a shoulder between $0.2-2 \mu \mathrm{m}$. At 4000 RPM the distribution is continuous and bi-modal, ranging from $0.2-150 \mu \mathrm{m}$ with peaks at 5 and $60 \mu \mathrm{m}$ and a shoulder between 0.2-1 $\mu \mathrm{m}$. During the measurements (Table 6: 3000 $\mathrm{RPM} \rightarrow 4000 \mathrm{RPM} \rightarrow 2000 \mathrm{RPM}$ ), as the pump speed was increased from 3000 RPM to 4000 RPM there was a relative decrease in particles $>100 \mu \mathrm{m}$. This decrease is most likely due to shear induced disruption of agglomerates or flocculates at the higher pump speed. As the speed was reduced from 4000 to 2000 RPM there was a decrease in particles $>40 \mu \mathrm{m}$. This most likely is a result of large difficult-to-suspend particles, agglomerates, and/or flocculates settling out. The peak shift to larger diameters may also indicate recombination of agglomerates or flocculates at the lower pump speed.

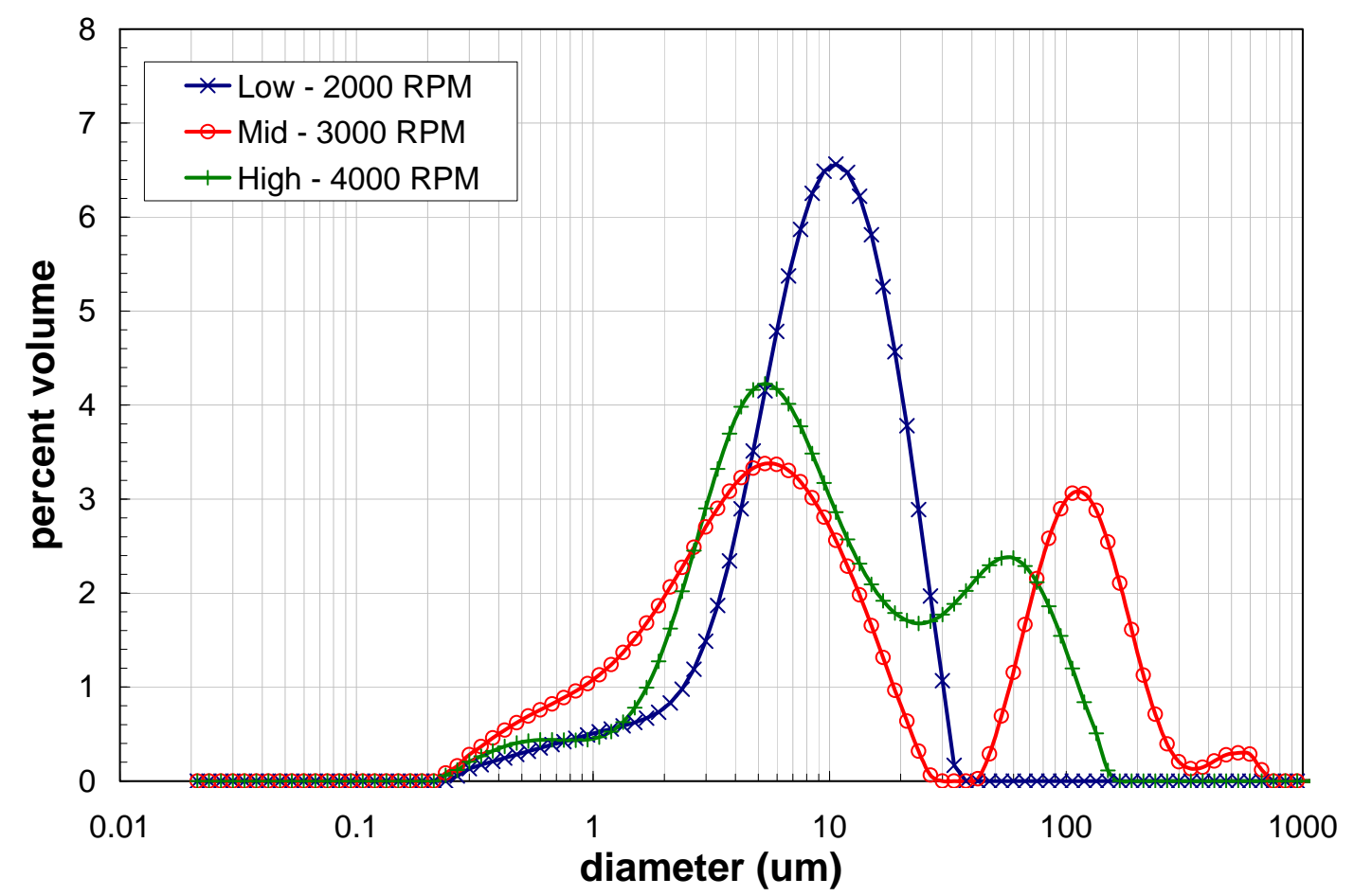

Figure 2. Volume distribution result for the primary Group 8 initial characterization sample as a function of pump speed.

Figure 3 shows the PSD for the duplicate Group 8 initial characterization sample as a function of pump speed. The distribution for all pump speeds was continuous and uni-modal with a range of $0.2-170 \mu \mathrm{m}$ with peak maximum at 30,10 , and 7 for 2000,3000 , and $4000 \mathrm{RPM}$, respectively. As the pump speed was increased from 3000 to 4000 RPM a relative increase was seen in the 20-170 $\mu \mathrm{m}$ population and the peak shifts to lower diameters. This may indicate that higher pump speeds pick up more large particles, agglomerates, and/or flocculates, but it may 
also shear some of these apart resulting in the peak shift to lower diameters. As the speed was decreased to 2000 RPM a relative increase was seen in $>10 \mu \mathrm{m}$ particles. This is most likely a result of flocculation, which had been disrupted at higher pump speeds.

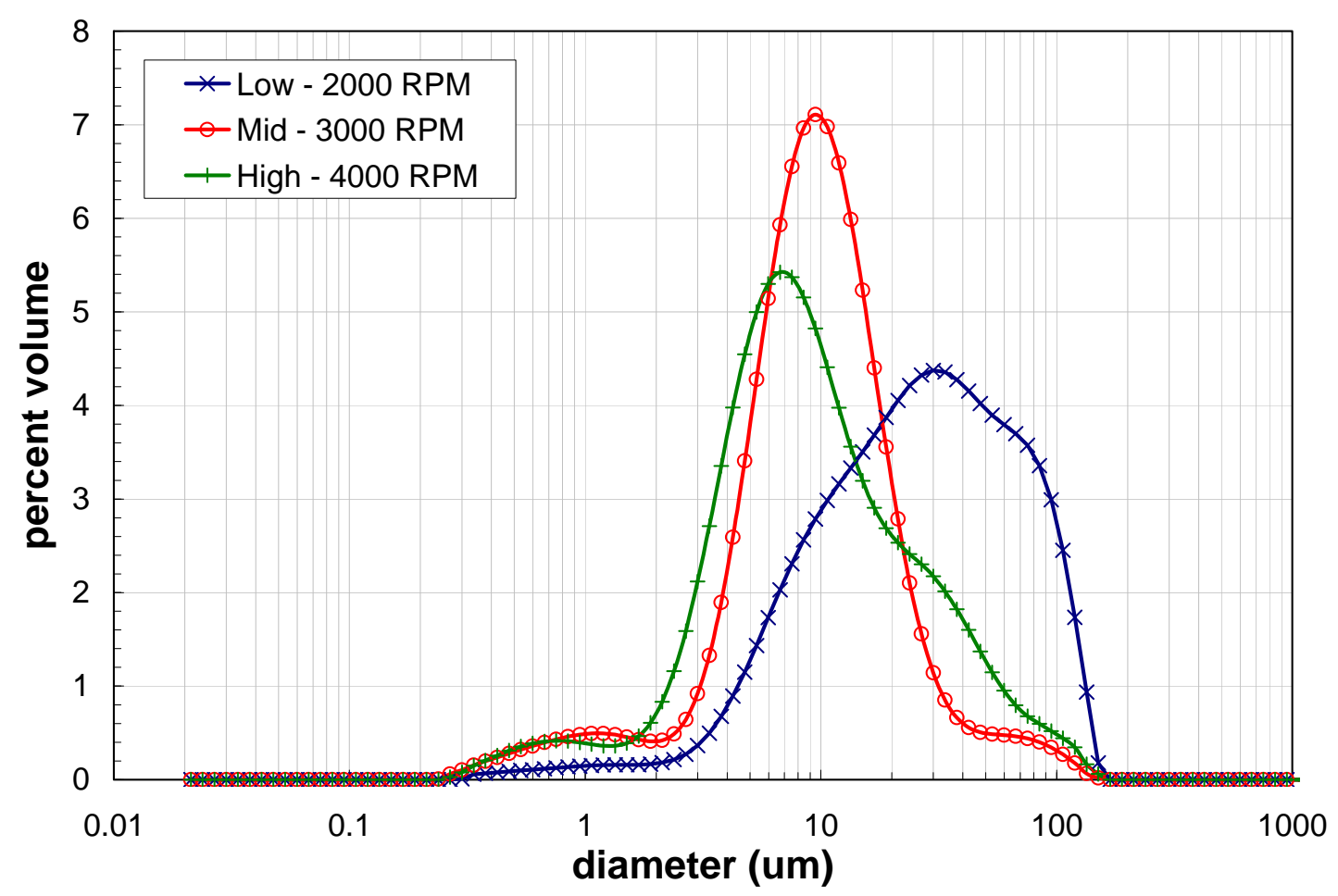

Figure 3. Volume distribution result for the duplicate Group 8 initial characterization sample as a function of pump speed.

Tables 7 and 8 show select cumulative oversize percentiles for the primary and duplicate Group 8 particle dispersions. Using the primary results as a reference, the behavior of Group 8 initial characterization particle size as a function of pump speed can be quantitatively evaluated. Specifically, the following observations can be made:

- In general, the d(10) falls between 1.3 and $2.8 \mu \mathrm{m}$, the $\mathrm{d}(50)$ between 7.5 and $9.5 \mu \mathrm{m}$, and the $\mathrm{d}(90)$ between 20 and $140 \mu \mathrm{m}$

- The listed diameter percentiles appear to be sensitive to changes in pump speed. For example, a decrease between 4000 and 2000 RPM increases the d(50) from 8.1 to 9.5 $\mu \mathrm{m}$. This is an increase of $17 \%$, which is above the instrument limit of accuracy $(10 \%)$ and is significant and not merely random noise or measurement error. 
Table 7. Particle size analysis percentile results from primary Group 8 initial characterization sample, TI609-G8-S-WL-PSD-1.

\begin{tabular}{||c|c|c|c|c|c||}
\hline $\begin{array}{c}\text { Measurement } \\
\text { Condition }\end{array}$ & Pump Speed & Sonication & $\begin{array}{c}\mathbf{d}(\mathbf{1 0}) \\
{[\boldsymbol{\mu m}]}\end{array}$ & $\begin{array}{c}\mathbf{d}(\mathbf{5 0}) \\
{[\boldsymbol{\mu m}]}\end{array}$ & $\begin{array}{c}\mathbf{d}(\mathbf{9 0}) \\
{[\boldsymbol{\mu m}]}\end{array}$ \\
\hline 1 & 3000 & $\mathrm{n} / \mathrm{a}$ & 1.3 & 7.5 & 140 \\
\hline 2 & 4000 & $\mathrm{n} / \mathrm{a}$ & 2.2 & 8.1 & 65 \\
\hline 3 & 2000 & $\mathrm{n} / \mathrm{a}$ & 2.6 & 9.5 & 110 \\
\hline 4 & 2000 & $\mathrm{n} / \mathrm{a}$ & 2.8 & 9.1 & 20 \\
\hline
\end{tabular}

Table 8. Particle size analysis percentile results from duplicate Group 8 initial characterization sample, TI609-G8-S-WL-PSD-2.

\begin{tabular}{||c|c|c|c|c|c||}
\hline $\begin{array}{c}\text { Measurement } \\
\text { Condition }\end{array}$ & Pump Speed & Sonication & $\begin{array}{c}\mathbf{d}(\mathbf{1 0}) \\
{[\boldsymbol{\mu m}]}\end{array}$ & $\begin{array}{c}\mathbf{d}(\mathbf{5 0}) \\
{[\boldsymbol{\mu m}]}\end{array}$ & $\begin{array}{c}\mathbf{d}(\mathbf{9 0}) \\
{[\boldsymbol{\mu m}]}\end{array}$ \\
\hline 1 & 3000 & $\mathrm{n} / \mathrm{a}$ & 3.5 & 9.4 & 23 \\
\hline 2 & 4000 & $\mathrm{n} / \mathrm{a}$ & 2.9 & 8.4 & 37 \\
\hline 3 & 2000 & $\mathrm{n} / \mathrm{a}$ & 4.5 & 17 & 67 \\
\hline 4 & 2000 & $\mathrm{n} / \mathrm{a}$ & 6.6 & 27 & 84 \\
\hline
\end{tabular}

Behavior of the duplicate sample PSD with respect to pump speed shows it favors larger diameters for the $\mathrm{d}(10)$ and $\mathrm{d}(50)$ than that of the primary at equivalent measurement conditions. Table 9 shows the absolute relative percent difference between the $\mathrm{d}(10), \mathrm{d}(50)$, and $\mathrm{d}(90)$ values determined for the primary and duplicate Group 8 initial characterization samples. Here, absolute relative percent difference is determined using the following equation:

$$
R P D=\left|\frac{d_{d}(n)-d_{p}(n)}{d_{p}(n)}\right|
$$

where $d_{p}(n)$ and $d_{d}(n)$ are the primary and duplicate cumulative oversize diameters corresponding to the $n^{\text {th }}$ percentile. The listed RPDs indicate that there is a significant difference between samples.

Table 9. Absolute relative percent difference between primary and duplicate Group 8 initial characterization samples.

\begin{tabular}{||c|c|c|c|c|c||}
\hline \multirow{2}{*}{$\begin{array}{c}\text { Measurement } \\
\text { Condition }\end{array}$} & \multirow{2}{*}{ Pump Speed } & \multirow{2}{*}{ Sonication } & \multicolumn{3}{|c|}{ Absolute RPD } \\
\cline { 4 - 6 } & & & $\mathbf{d}(\mathbf{1 0})$ & $\mathbf{d}(\mathbf{5 0})$ & $\mathbf{d}(\mathbf{9 0})$ \\
\hline 1 & 3000 & $\mathrm{n} / \mathrm{a}$ & $180 \%$ & $26 \%$ & $84 \%$ \\
\hline 2 & 4000 & $\mathrm{n} / \mathrm{a}$ & $35 \%$ & $3.9 \%$ & $43 \%$ \\
\hline 3 & 2000 & $\mathrm{n} / \mathrm{a}$ & $71 \%$ & $79 \%$ & $42 \%$ \\
\hline 4 & 2000 & $\mathrm{n} / \mathrm{a}$ & $140 \%$ & $190 \%$ & $320 \%$ \\
\hline
\end{tabular}

For particle size measurements on the Malvern Mastersizer 2000, RPDs of up to $10 \%$ are generally expected given the accuracy of the instrument. The results for Group 8 initial characterization samples show RPDs that range from 3.9 to $320 \%$ depending on the measurement condition and percentile examined. Based on the large number of RPDs greater than $10 \%$ in Table 9 , it is likely that there is a significant size difference in the solids species in the primary and duplicate samples. This difference may be a result of sampling difficulties due 
to large difficult-to-suspend species or flocculation and/or agglomeration taking place in the sample.

Figure 4 shows how the differences in the primary and duplicate PSDs described in the preceding paragraphs manifest in the differential volume distributions. The primary sample displays a larger $>40 \mu \mathrm{m}$ population with an extended range compared to the duplicate sample. The duplicate distribution is uni-modal with its primary peak shifted to higher diameters than the primary sample.

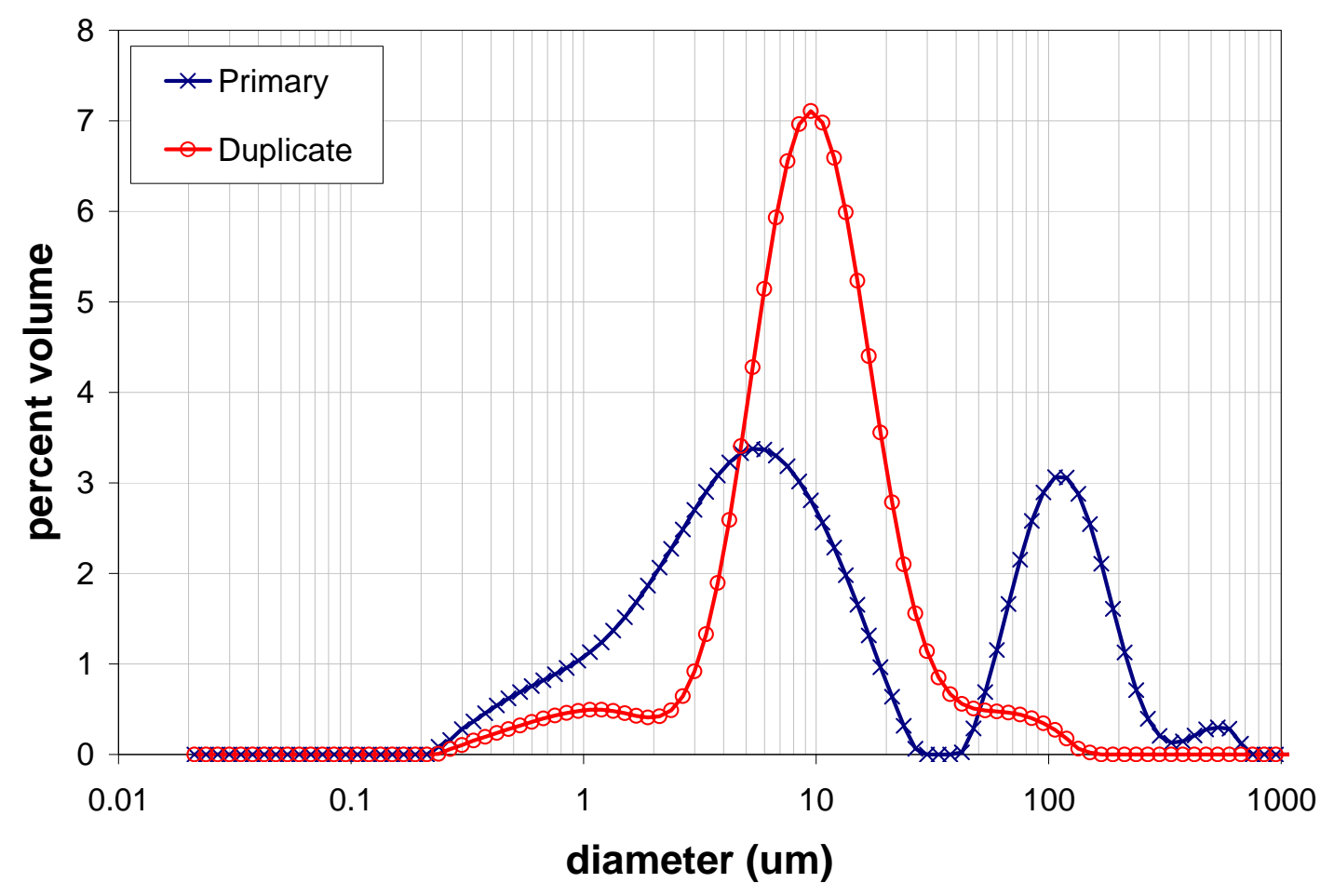

Figure 4. Comparison of primary and duplicate sample differential volume PSD of Group 8 initial characterization at 3000 RPM without sonication.

The Group 8 initial characterization particle size distribution has a broad distribution. Overall, there appears to be some large difficult-to-suspend species. These species may be flocculants, as indicated by larger diameter peak populations in the low pump speeds, which are broken apart at higher pump speeds. There is an apparent size distribution difference between the primary and duplicate sample. This may be a result of sampling difficulties due to large difficult-to-suspend species or the distribution may be significantly influenced by flocculation and/or agglomeration.

\section{$\underline{10.2 \text { Group } 8 \text { CUF Testing PSD Results }}$}

The following sub-sections discuss the PSD results for Group 8 CUF testing samples. A brief outline of how select cumulative oversize diameter percentiles behave as a function of test condition is given, and graphs of particle size distributions are given as a function of flow rate without sonication. The reproducibility of PSD for each sample in not assessed. In addition, the current section focuses on changes in the PSD with measurement condition. Comparison of PSD to one another to highlight effects of CUF processing shall be examined in Section 10.3. 
Results for TI640-G8-3-PSD (Low-Solids Matrix)

Sample TI640-G8-3-PSD is representative of the low-solids matrix (dilute) slurry that was initially run in the CUF system. Table 10 shows select cumulative undersize percentiles for sample TI640-G8-3-PSD, more extensive percentile results are shown in Appendix B. Here the $\mathrm{d}(10)$ ranges between 33 and $51 \mu \mathrm{m}$, the $\mathrm{d}(50)$ between 59 and $91 \mu \mathrm{m}$, and the $\mathrm{d}(90)$ between 110 and $160 \mu \mathrm{m}$.

Table 10. Particle size analysis percentile results the Group 8 low-solids matrix sample (TI640-G8-3-PSD).

\begin{tabular}{||c|c|c|c|c|c||}
\hline $\begin{array}{c}\text { Measurement } \\
\text { Condition }\end{array}$ & Pump Speed & Sonication & $\begin{array}{c}\mathbf{d}(\mathbf{1 0}) \\
{[\boldsymbol{\mu m}]}\end{array}$ & $\begin{array}{c}\mathbf{d}(\mathbf{5 0}) \\
{[\boldsymbol{\mu m}]}\end{array}$ & $\begin{array}{c}\mathbf{d}(\mathbf{9 0}) \\
{[\boldsymbol{\mu m}]}\end{array}$ \\
\hline 1 & 3000 & $\mathrm{n} / \mathrm{a}$ & 50 & 87 & 150 \\
\hline 2 & 4000 & $\mathrm{n} / \mathrm{a}$ & 33 & 59 & 110 \\
\hline 3 & 2000 & $\mathrm{n} / \mathrm{a}$ & 51 & 91 & 160 \\
\hline 4 & 2000 & $\mathrm{n} / \mathrm{a}$ & $\mathrm{n} / \mathrm{a}^{*}$ & $\mathrm{n} / \mathrm{a}^{*}$ & $\mathrm{n} / \mathrm{a}^{*}$ \\
\hline
\end{tabular}

*All particles appear to have settled out of the test system after prolonged operation

Figure 5 shows the PSD for Group 8 low-solids matrix (TI640-G8-3-PSD) sample as a function of pump speed. At 3000 and 4000 RPM the distribution ranges from approximately 15 300 and is continuous and uni-modal. As the pump speed is increased from 3000 to 4000 RPM the peak maximum shifts from 90 to $60 \mu \mathrm{m}$. This decrease in particle diameter may indicate some flocculate or agglomerate disruption at the higher pump speed. The distribution at 2000 RPM (condition 3 in Table 6) shows a distribution similar to that at 3000 RPM. Although for the second 2000 RPM measurement (condition 4 in Table 6) there were essentially no particles as indicated in Table 10. The most probably explanation for this is that the particles eventually settle out at 2000 RPM. 


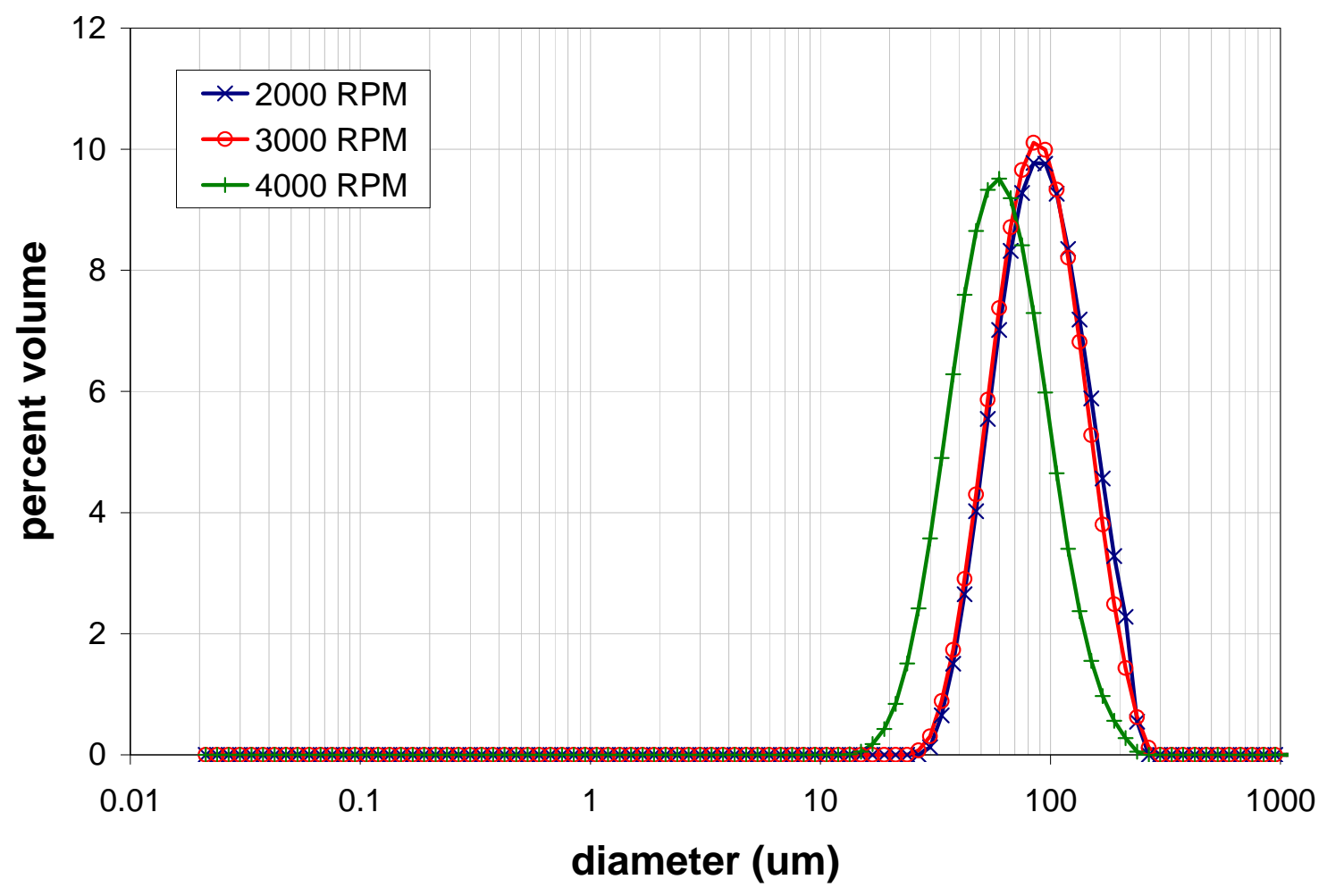

Figure 5. Volume distribution result for the Group 8 low-solids matrix (TI640-G8-3-PSD) sample as a function of pump speed.

$\underline{\text { Results for TI640-G8-6-PSD (High-solids matrix Group } 8 \text { before caustic leach) }}$

Sample TI640-G8-6-PSD is representative of the high-solids matrix slurry that results from dewatering the initial 8 CUF slurry. Table 11 shows select cumulative undersize percentiles for sample TI640-G8-6-PSD, more extensive percentile results are shown in Appendix B. Here the $\mathrm{d}(10)$ ranges between 1.6 and $5.5 \mu \mathrm{m}$, the $\mathrm{d}(50)$ between 6.1 and $38 \mu \mathrm{m}$, and the $\mathrm{d}(90)$ between 29 and $95 \mu \mathrm{m}$. With regards to pump speed effects, the $\mathrm{d}(10), \mathrm{d}(50)$ and $\mathrm{d}(90)$ percentiles show a significant increase in size as the condition numbers increase, which may indicate shear induced flocculation or agglomeration is occurring and increasing the measured diameter as time progresses.

Table 11. Particle size analysis percentile results the Group 8 high-solids matrix sample (TI640-G8-6-PSD).

\begin{tabular}{||c|c|c|c|c|c||}
\hline $\begin{array}{c}\text { Measurement } \\
\text { Condition }\end{array}$ & Pump Speed & Sonication & $\begin{array}{c}\mathbf{d}(\mathbf{1 0}) \\
{[\boldsymbol{\mu m}]}\end{array}$ & $\begin{array}{c}\mathbf{d}(\mathbf{5 0}) \\
{[\boldsymbol{\mu m}]}\end{array}$ & $\begin{array}{c}\mathbf{d}(\mathbf{9 0}) \\
{[\boldsymbol{\mu m}]}\end{array}$ \\
\hline 1 & 3000 & $\mathrm{n} / \mathrm{a}$ & 1.6 & 6.1 & 29 \\
\hline 2 & 4000 & $\mathrm{n} / \mathrm{a}$ & 2.7 & 9.8 & 60 \\
\hline 3 & 2000 & $\mathrm{n} / \mathrm{a}$ & 3.7 & 23 & 83 \\
\hline 4 & 2000 & $\mathrm{n} / \mathrm{a}$ & 5.5 & 38 & 95 \\
\hline
\end{tabular}


Figure 6 shows the PSD for Group 8 high-solids matrix (TI640-G8-6-PSD) sample as a function of pump speed. The high-solids matrix shows a continuous distribution over the range $0.2-170 \mu \mathrm{m}$. At $3000 \mathrm{RPM}$ the primary peak is at $6 \mu \mathrm{m}$ with a shoulder between $0.2-1 \mu \mathrm{m}$ and around $35 \mu \mathrm{m}$. As the speed increases to 4000 RPM the relative primary peak population decreases slightly and the $35 \mu \mathrm{m}$ shoulder becomes a secondary peak. This shift in population may be a result of increased suspension of larger difficult-to-suspend species at the higher pump speed. Another possibility is shear induced flocculation and/or agglomeration may be taking place as a result of increased interaction with other particles. As the speed is reduced from 4000 to $2000 \mathrm{RPM}$ a further increase in $>10 \mu \mathrm{m}$ is observed, with may indicate the increased flocculation and/or agglomeration is a result of increased particle interactions as a result of time the sample is in the PSD instrument.

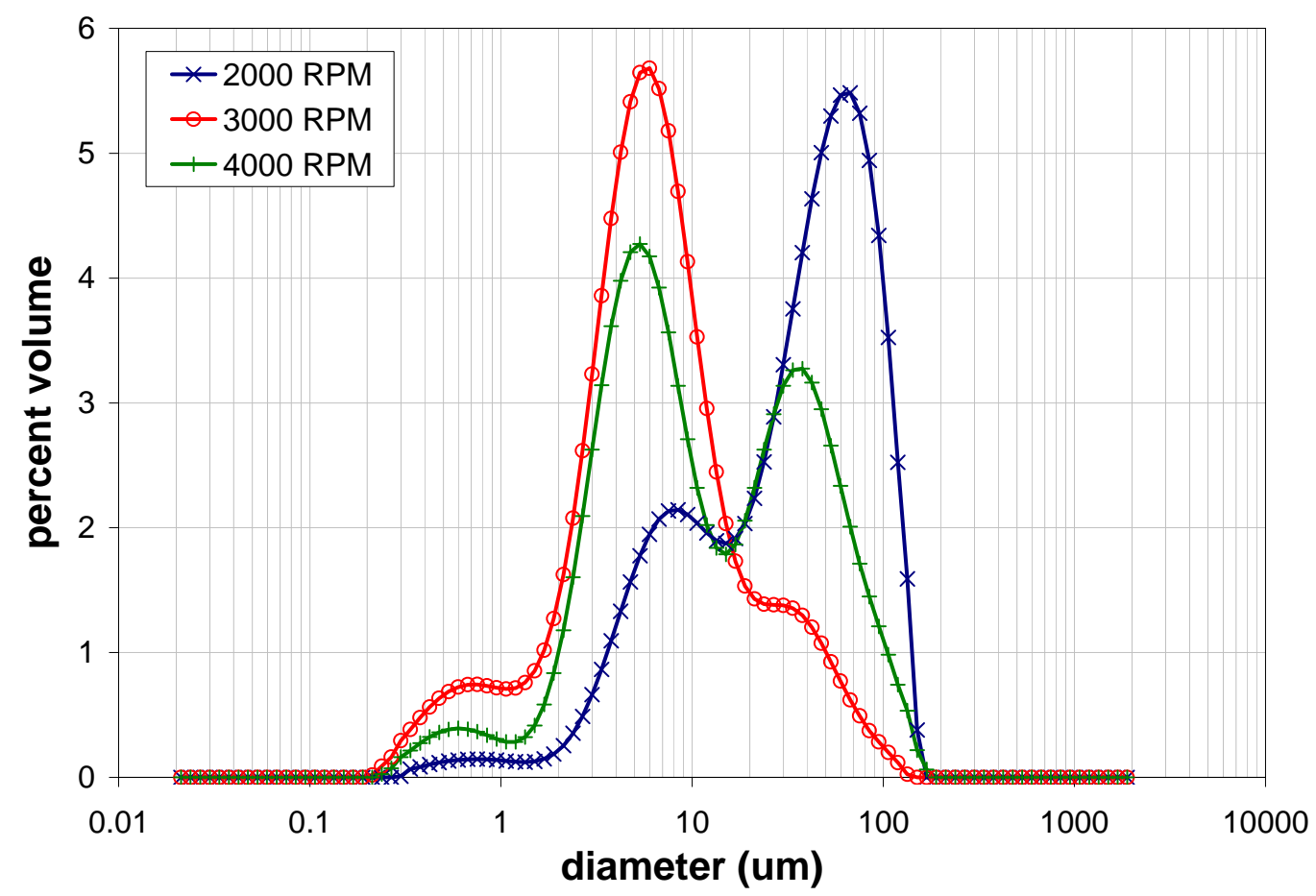

Figure 6. Volume distribution result for the Group 8 high-solids matrix (TI640-G8-6-PSD) sample as a function of pump speed.

\section{$\underline{\text { Results for TI640-G8-13-PSD (Washed Group } 8 \text { after caustic leach) }}$}

Sample TI640-G8-13-PSD is representative of waste solids that result from causticleaching, dewatering, and washing of group 8 CUF slurry. Table 12 shows select cumulative undersize percentiles for sample TI640-G4-13-PSD, more extensive percentile results are shown in Appendix B. Here the $\mathrm{d}(10)$ ranges between 3.2 and $7.3 \mu \mathrm{m}$, the $\mathrm{d}(50)$ between 10 and $38 \mu \mathrm{m}$, and the $d(90)$ between 54 and $87 \mu \mathrm{m}$. With regards to pump speed effects, the $d(10), d(50)$ and $\mathrm{d}(90)$ percentiles show a significant increase in size as the condition numbers increase, which may indicate shear induced flocculation or agglomeration is occurring and increasing the measured diameter as time progresses.

Table 12. Particle size analysis percentile results the Group 8 caustic-leached and washed sample (TI640-G8-13-PSD). 


\begin{tabular}{||c|c|c|c|c|c||}
\hline $\begin{array}{c}\text { Measurement } \\
\text { Condition }\end{array}$ & Pump Speed & Sonication & $\begin{array}{c}\mathbf{d}(\mathbf{1 0}) \\
{[\boldsymbol{\mu m}]}\end{array}$ & $\begin{array}{c}\mathbf{d}(\mathbf{5 0}) \\
{[\boldsymbol{\mu m}]}\end{array}$ & $\begin{array}{c}\mathbf{d}(\mathbf{9 0}) \\
{[\boldsymbol{\mu m}]}\end{array}$ \\
\hline 1 & 3000 & $\mathrm{n} / \mathrm{a}$ & 3.3 & 10 & 54 \\
\hline 2 & 4000 & $\mathrm{n} / \mathrm{a}$ & 3.2 & 18 & 63 \\
\hline 3 & 2000 & $\mathrm{n} / \mathrm{a}$ & 4.7 & 30 & 76 \\
\hline 4 & 2000 & $\mathrm{n} / \mathrm{a}$ & 7.3 & 38 & 87 \\
\hline
\end{tabular}

Figure 7 shows the PSD for Group 8 caustic-leached, dewatered, and washed (TI640-G813-PSD) sample as a function of pump speed. The caustic-leached, dewatered, and washed distribution was continuous and ranged from $0.2-150 \mu \mathrm{m}$. At $3000 \mathrm{RPM}$ there is a primary peak around $6 \mu \mathrm{m}$, a secondary peak around $30 \mu \mathrm{m}$ and a shoulder between 0.2-1.5 $\mu \mathrm{m}$. As the pump speed was increased to 4000 RPM the peaks remained centered around similar diameters although the $30 \mu \mathrm{m}$ peak displayed a relative increase in population. As the pump speed was decreased to 2000 RPM, the relative population in the $30 \mu \mathrm{m}$ peak further increased and the peak diameter shifted slightly to $50 \mu \mathrm{m}$. This most likely indicates that with prolonged circulation in the PSD instrument particle interactions result in flocculation and/or agglomeration producing higher percentages of larger species.

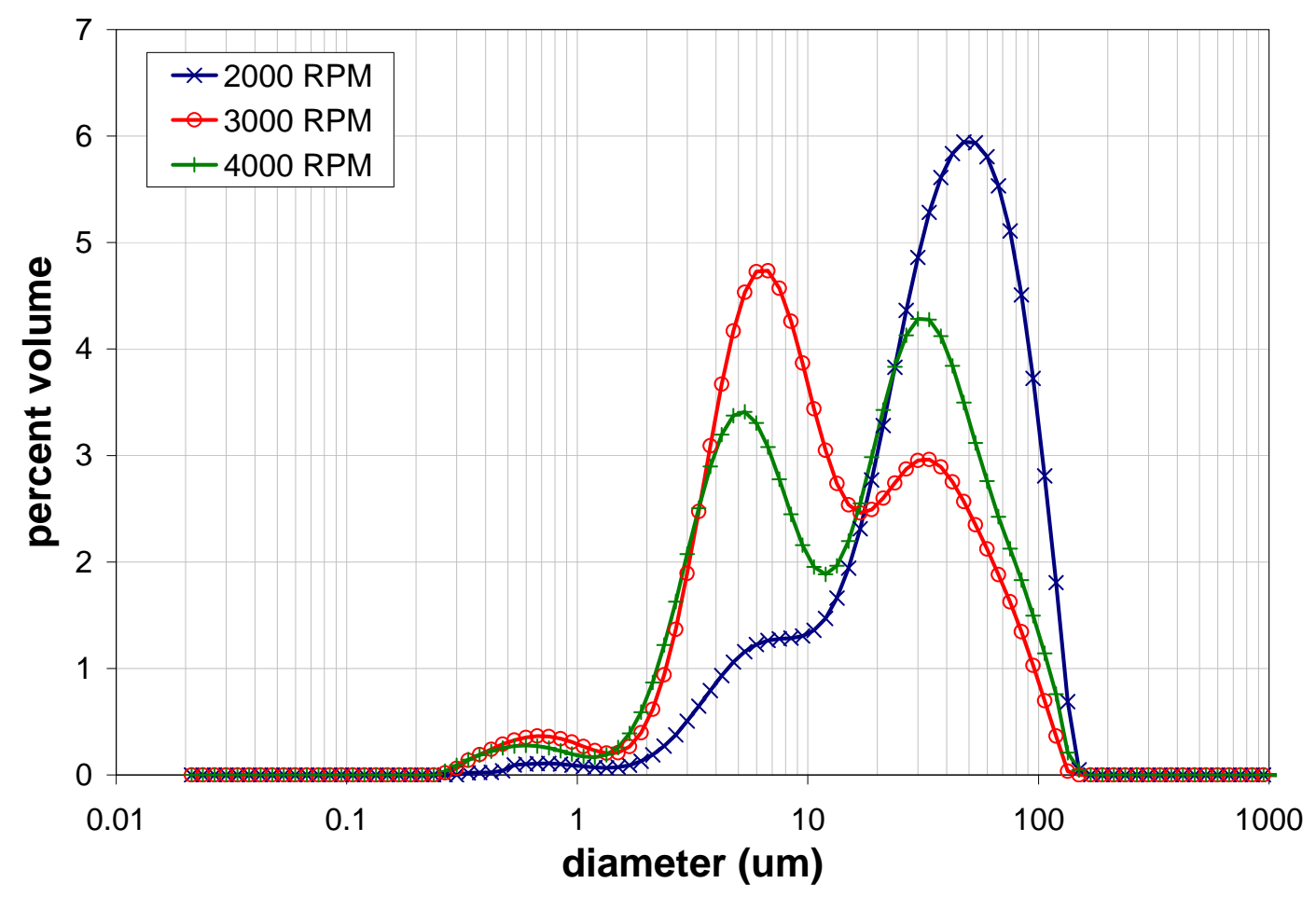

Figure 7. Volume distribution result for the Group 8 caustic-leached and washed (TI640-G8-13PSD) sample as a function of pump speed. 


\subsection{CUF Processing Effects on Group 8 Solids}

\section{Shearing Effect on Group 8 (Low-solids matrix)}

Table 13 and Figure 8 show the influence of circulation in the CUF on the PSD of Group 8 waste solids. Here, select cumulative undersize percentiles and PSD for the initial characterization (TI609-G8-S-WL-PSD-1) are compared to the low-solids matrix slurry (TI640G8-3-PSD). The low-solids matrix sample showed a significantly larger percentage of particle diameters $>30 \mu \mathrm{m}$ compared to the initial characterization. As was indicated by the high-solids matrix and caustic-leached and washed sample this may be due to particles having a high affinity for flocculation or agglomeration. Circulation in the CUF system results in numerous particle interactions, which could increase the flocculation and/or agglomeration and contribute to the larger diameters measured.

Table 13. Cumulative undersize percentiles showing the influence of circulation in the CUF on Group 8 PSD at measurement condition 1-3000 RPM (see Table 6).

\begin{tabular}{||l|c|c|c||}
\hline \hline Sample & $\begin{array}{c}\mathbf{d}(\mathbf{1 0}) \\
{[\boldsymbol{\mu m}]}\end{array}$ & $\begin{array}{c}\mathbf{d}(\mathbf{5 0}) \\
{[\boldsymbol{\mu m}]}\end{array}$ & $\begin{array}{c}\mathbf{d}(\mathbf{9 0}) \\
{[\boldsymbol{\mu m}]}\end{array}$ \\
\hline Group 8 Initial Characterization (TI609-G8-S-WL-PSD-1) & 1.3 & 7.5 & 140 \\
\hline Group 8 Low Solids Matrix Slurry (TI640-G8-3-PSD) & 50 & 87 & 150 \\
\hline
\end{tabular}

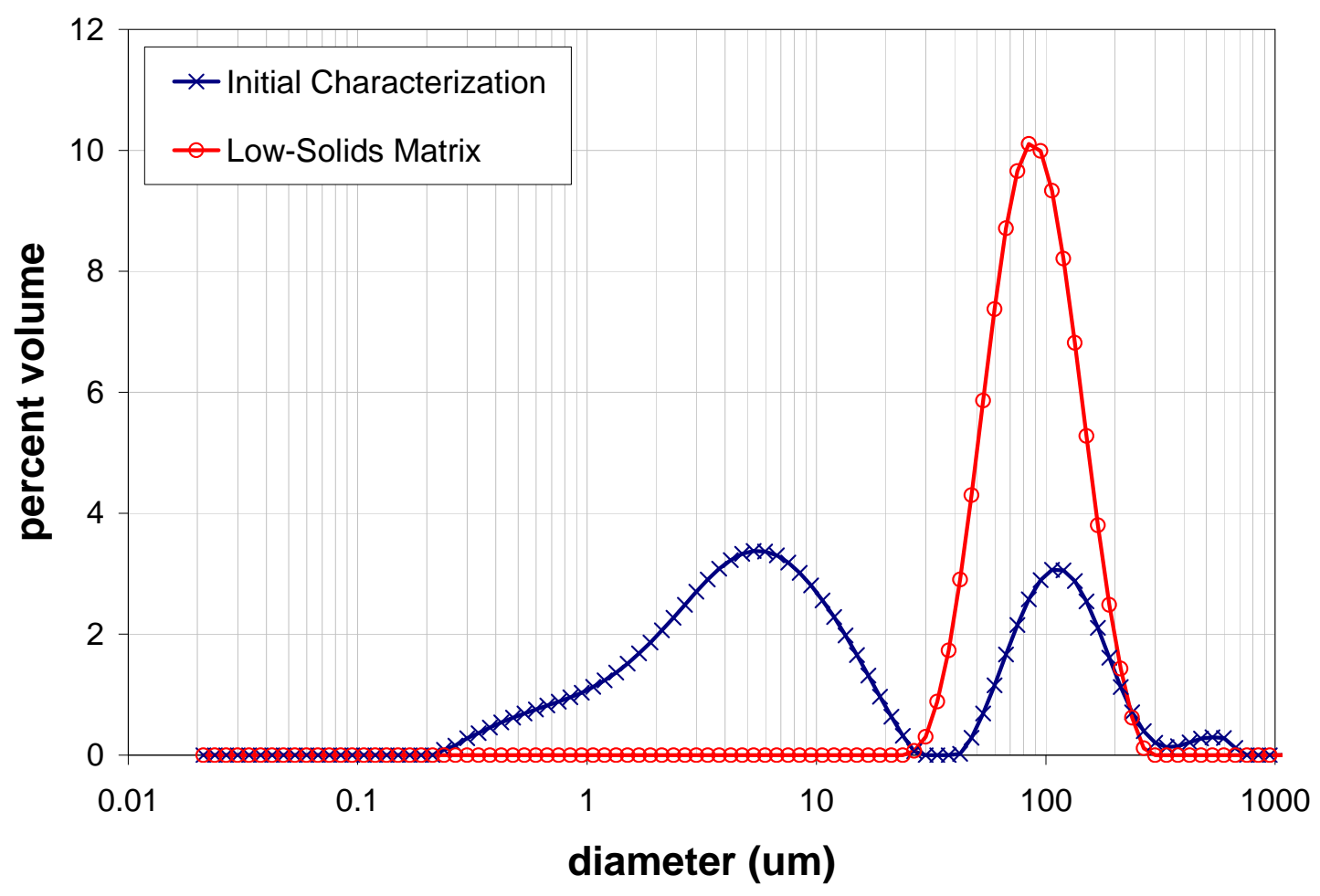

Figure 8. Influence of circulation in the CUF for Group 8. All PSDs taken at measurement condition 1-3000 RPM (see Table 6).

Filtration and Shear of Group 8 Solids 
Table 14 and Figure 9 show the influence of filtration and shearing on the PSD of Group 8 waste solids. Here, select cumulative undersize percentiles and PSD for the low-solids matrix slurry (TI640-G8-3-PSD) are compared to that of the high-solids matrix slurry (TI640-G8-6PSD). Dewatering of the low-solids matrix slurry shows a decrease in the particle size with a broader distribution. The dewatering process may have disrupted the agglomerates and/or flocculates present in the low-solids matrix. The high-solids matrix has a primary peak maximum between 5-6 $\mu \mathrm{m}$ which is similar to the primary peak in the initial characterization distribution shown in Figure 8.

Table 14. Cumulative undersize percentiles showing the influence of filtration and shear on the PSD of Group 8 solids at measurement condition 1-3000 RPM (see Table 6).

\begin{tabular}{||l|c|c|c||}
\hline \hline Sample & $\begin{array}{c}\mathbf{d}(\mathbf{1 0}) \\
{[\mathbf{\mu m}]}\end{array}$ & $\begin{array}{c}\mathbf{d}(\mathbf{5 0}) \\
{[\boldsymbol{\mu m}]}\end{array}$ & $\begin{array}{c}\mathbf{d}(\mathbf{9 0}) \\
{[\boldsymbol{\mu m}]}\end{array}$ \\
\hline Low-Solids Matrix Slurry (TI640-G8-3-PSD) & 50 & 87 & 150 \\
\hline High-Solids Matrix Slurry (TI640-G8-6-PSD) & 1.6 & 6.1 & 29 \\
\hline
\end{tabular}

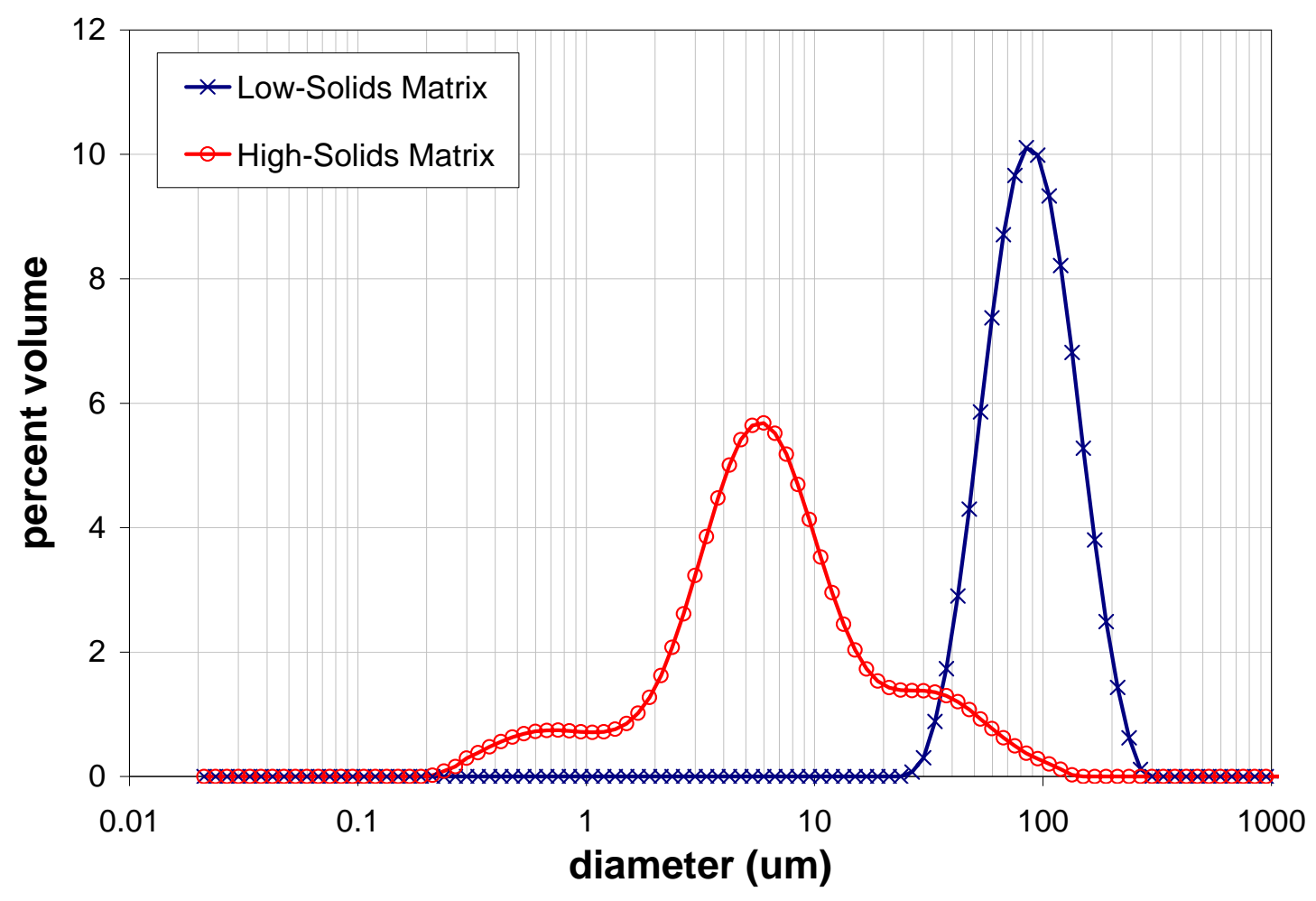

Figure 9. Influence of filtration and shearing on the PSD of Group 8 waste solids on PSD. All PSDs taken at measurement condition $1-3000$ RPM (see Table 6). 


\section{Caustic-Leaching, Washing and Dewatering of Group 8}

Table 15 and Figure 10 show the influence of caustic-leaching, dewatering, and washing on the PSD of Group 8 waste solids. Here select cumulative undersize percentiles and PSD for the high-solids matrix slurry (TI640-G8-6-PSD) are compared to that of the caustic-leached, dewatered, and washed slurry (TI640-G8-13-PSD). Both distributions have similar ranges and primary peak locations. After caustic-leaching, dewatering, and washing there is a relative increase in $>15 \mu \mathrm{m}$ particles. This increase is most likely a result of flocculation and/or agglomeration.

Table 15. Cumulative undersize percentiles showing the influence of caustic-leaching, dewatering, and washing on the PSD of Group 8 solids at measurement condition 1 - 3000 RPM (see Table 6).

\begin{tabular}{||l|c|c|c||}
\hline Sample & $\begin{array}{c}\mathbf{d}(\mathbf{1 0}) \\
{[\boldsymbol{\mu m}]}\end{array}$ & $\begin{array}{c}\mathbf{d}(\mathbf{5 0}) \\
{[\boldsymbol{\mu m}]}\end{array}$ & $\begin{array}{c}\mathbf{d}(\mathbf{9 0}) \\
{[\boldsymbol{\mu m}]}\end{array}$ \\
\hline High-Solids Matrix Slurry (TI640-G8-6-PSD) & 1.6 & 6.1 & 29 \\
\hline Caustic-Leached, Dewatered, and Washed (TI640-G4-13-PSD) & 3.3 & 10 & 54 \\
\hline
\end{tabular}

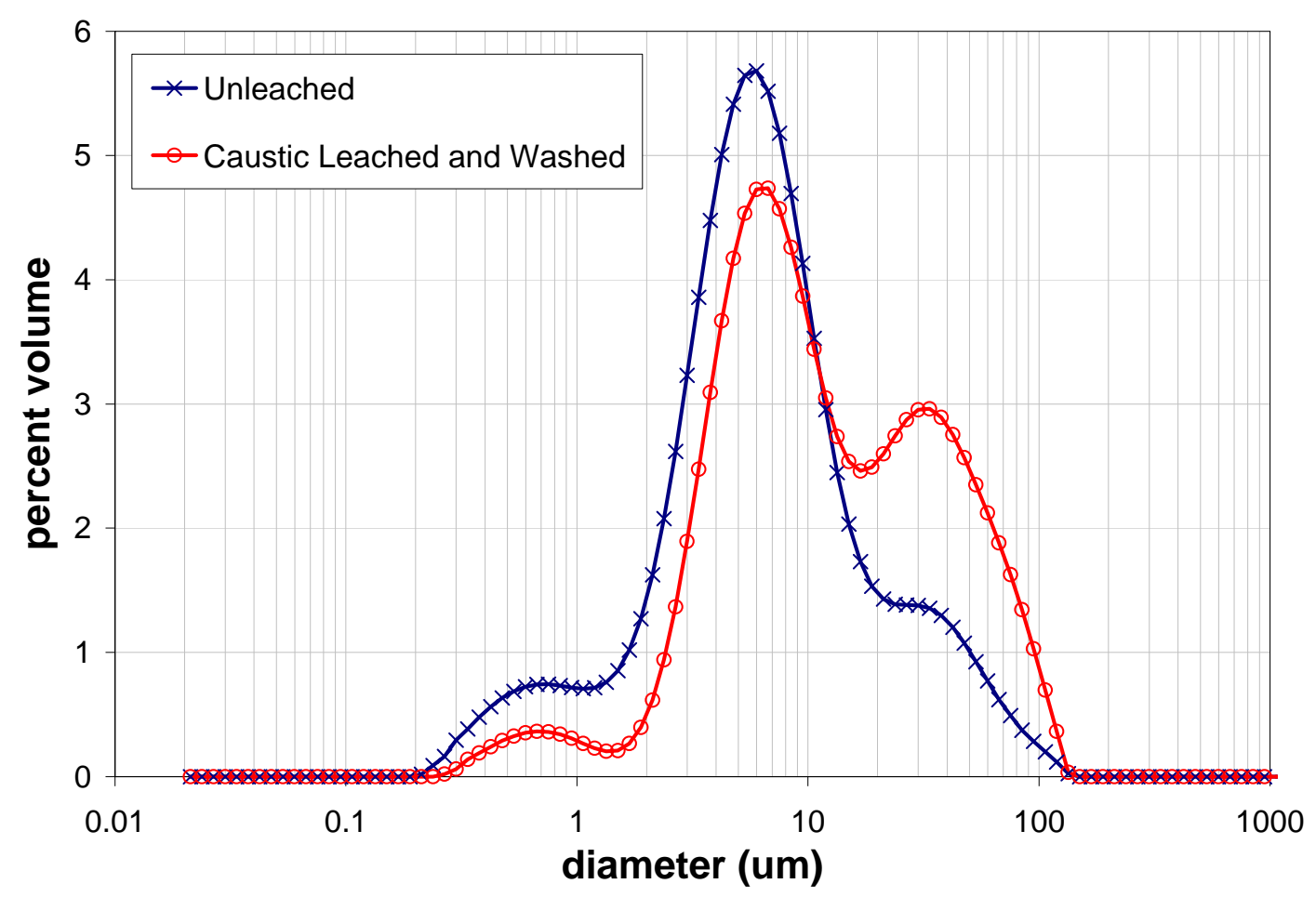

Figure 10. Influence of caustic-leaching, dewatering, and washing on the PSD of Group 8 waste solids on PSD. All PSDs taken at measurement condition 1-3000 RPM (see Table 6).

\section{Records}

Data records relating to Group 8 particle size distribution measurements and postmeasurement analysis exist in original Malvern Mastersizer 2000 data files and Laboratory Record Books (LRBs): 
- Malvern Mastersizer Files: "2008-10Oct02-G2 Para PSD.mea", "2008-10Oct10-G8 CUF PSD.mea", "2008-10Oct16-G8 CUF PSD.mea", and "2008-10Oct07-G8 initial char PSD.mea"

- LRB BNW 56933: Pages 134, 139, 144, and 145

- $\quad$ TDP-WTP-274, CCP-WTPSP-574, CCP-WTPSP-641, and CCP-WTPSP-652

\section{References}

1. Doc. No. TP-RPP-WTP-567, Revision 0, "Characterization and Small Scale Testing of Hanford Wastes to Support the Development and Demonstration of Leaching and Ultrafiltration Pretreatment Processes," SK Fiskum, Battelle - Pacific Northwest Division, February 2007.

2. Doc. No. RPL-COLLOID-01, Revision 1, "Particle Size Analysis Using Malvern MS2000," AP Poloski, Pacific Northwest National Laboratory, May 2007. 


\section{Appendix A - Optical Properties Comparison}

The optical properties for the Group 8 samples TI-609-G8-S-WL-PSD-2 taken at 3000 RPM without sonication were changed from boehmite to $\mathrm{UO}_{2}$. The results of this change are shown in Figure A-1. Use of the correct optical properties only refined the measured PSD without significantly changing the distribution. Therefore, the boehmite optical properties can be used while still allowing the analysis of Group 8 data to provide a reasonable representation of the actual waste PSD.

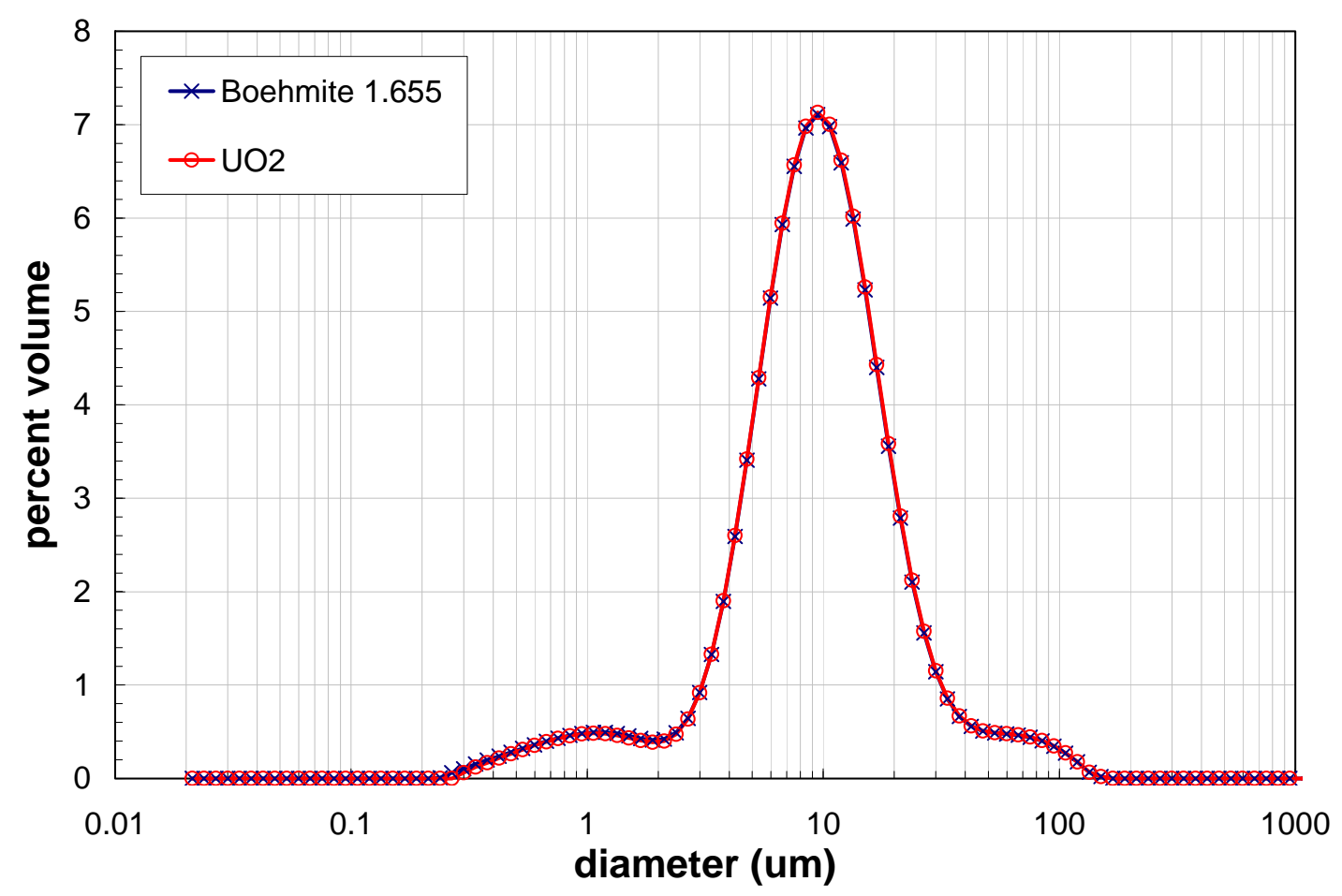

Figure A-1. Optical properties comparison for the duplicate initial characterization sample of Group 8 at 3000 RPM without sonication. 


\section{Appendix B - Detailed Cumulative PSD}

\section{Results: TI609-G8-S-WL-PSD (Group 8 Initial Characterization)}

Table B-1 and B-2 present detailed cumulative oversize distributions (by volume/weight) for Group 8 initial characterization samples TI609-G8-S-WL-PSD-1 and -2, respectively. Results are reported as a function of test condition (see Table 6). This appendix does not provide discussion of the detailed distributions; however, a portion of these results (specifically, the $10^{\text {th }}$, $50^{\text {th }}$, and $90^{\text {th }}$ diameter percentiles) are presented and discussed in the main body of this interim report.

Table B-1. Cumulative oversize diameter distributions for the primary Group 8 initial characterization sample, TI609-G8-S-WL-PSD-1.

\begin{tabular}{|c|c|c|c|c|c|c|c|c|c|c|c|c|c|c|c|}
\hline \multirow{2}{*}{$\begin{array}{l}\text { Test } \\
\text { Condition }\end{array}$} & \multicolumn{15}{|c|}{ Volume / Weight Cumulative Oversize Diameter $(\mu \mathrm{m})$} \\
\hline & $1 \%$ & $5 \%$ & $10 \%$ & $20 \%$ & $25 \%$ & $30 \%$ & $40 \%$ & $50 \%$ & $60 \%$ & $70 \%$ & $75 \%$ & $80 \%$ & $90 \%$ & $95 \%$ & $99 \%$ \\
\hline $1-3000$ & 0.37 & 0.73 & 1.3 & 2.4 & 3.0 & 3.7 & 5.3 & 7.5 & 11 & 53 & 78 & 97 & 140 & 180 & 440 \\
\hline $2-4000$ & 0.40 & 1.2 & 2.2 & 3.4 & 4.0 & 4.6 & 6.1 & 8.1 & 12 & 21 & 29 & 39 & 65 & 85 & 120 \\
\hline $3-2000$ & 0.46 & 1.5 & 2.6 & 4.3 & 5.1 & 5.8 & 7.5 & 9.5 & 12 & 16 & 19 & 25 & 110 & 160 & 520 \\
\hline $4-2000$ & 0.48 & 1.4 & 2.8 & 4.7 & 5.4 & 6.1 & 7.6 & 9.1 & 11 & 13 & 14 & 16 & 20 & 23 & 29 \\
\hline
\end{tabular}

Table B-2. Cumulative oversize diameter distributions for the duplicate Group 8 initial characterization sample, TI609-G8-S-WL-PSD-2.

\begin{tabular}{|c|c|c|c|c|c|c|c|c|c|c|c|c|c|c|c|}
\hline \multirow{2}{*}{\begin{tabular}{|l|} 
Test \\
Condition
\end{tabular}} & \multicolumn{15}{|c|}{ Volume / Weight Cumulative Oversize Diameter $(\mu \mathrm{m})$} \\
\hline & $1 \%$ & $5 \%$ & $10 \%$ & $20 \%$ & $25 \%$ & $30 \%$ & $40 \%$ & $50 \%$ & $60 \%$ & $70 \%$ & $75 \%$ & $80 \%$ & $90 \%$ & $95 \%$ & $99 \%$ \\
\hline $1-3000$ & 0.49 & 1.4 & 3.5 & 5.3 & 6.0 & 6.7 & 8.0 & 9.4 & 11 & 13 & 15 & 16 & 23 & 35 & 86 \\
\hline $2-4000$ & 0.50 & 1.6 & 2.9 & 4.3 & 4.9 & 5.5 & 6.8 & 8.4 & 11 & 15 & 18 & 22 & 37 & 54 & 100 \\
\hline $3-2000$ & 0.67 & 2.9 & 4.5 & 6.9 & 8.1 & 9.5 & 13 & 17 & 23 & 31 & 36 & 43 & 67 & 87 & 120 \\
\hline $4-2000$ & 0.98 & 4.4 & 6.6 & 10 & 13 & 15 & 20 & 27 & 35 & 46 & 53 & 61 & 84 & 100 & 130 \\
\hline
\end{tabular}

Table B-3 shows the absolute relative percent difference (RPD) between primary and duplicate results, which is calculated as:

$$
R P D=\left|\frac{d_{d}(n)-d_{p}(n)}{d_{p}(n)}\right|
$$

where $d_{p}(n)$ and $d_{d}(n)$ are the primary and duplicate cumulative oversize diameters corresponding to the $n^{t h}$ percentile. As before, this appendix does not provide discussion of the RPD results; however, the RPD for the $10^{\text {th }}, 50^{\text {th }}$, and $90^{\text {th }}$ diameter percentiles are presented and discussed in the main body of this interim report. 
Table B-3. Relative percent difference between primary and duplicate Group 8 initial characterization samples (TI609-G8-S-WL-PSD -1 and -2, respectively) as a function of test condition.

\begin{tabular}{|c|c|c|c|c|c|c|c|c|c|c|c|c|c|c|c|}
\hline \multirow[t]{2}{*}{ Test* } & \multicolumn{15}{|c|}{ Absolute RPD (\%) } \\
\hline & $1 \%$ & $5 \%$ & $10 \%$ & $20 \%$ & $25 \%$ & $30 \%$ & $40 \%$ & $50 \%$ & $60 \%$ & $70 \%$ & $75 \%$ & $80 \%$ & $90 \%$ & $95 \%$ & $99 \%$ \\
\hline 1 & $35 \%$ & $96 \%$ & $180 \%$ & $120 \%$ & $98 \%$ & $80 \%$ & $51 \%$ & $26 \%$ & $1 \%$ & $75 \%$ & $81 \%$ & $83 \%$ & $84 \%$ & $81 \%$ & $81 \%$ \\
\hline 2 & $23 \%$ & $39 \%$ & $35 \%$ & $26 \%$ & $22 \%$ & $19 \%$ & $12 \%$ & $4 \%$ & $9 \%$ & $30 \%$ & $39 \%$ & $44 \%$ & $43 \%$ & $37 \%$ & $15 \%$ \\
\hline 4 & $100 \%$ & $230 \%$ & $140 \%$ & $120 \%$ & $130 \%$ & $140 \%$ & $170 \%$ & $192 \%$ & $220 \%$ & $250 \%$ & $270 \%$ & $290 \%$ & $320 \%$ & $330 \%$ & $340 \%$ \\
\hline
\end{tabular}

*1-3000, 2-4000, 3-2000, 4-2000

\section{Results: TI640-G8-3-PSD (Low-solids matrix Group 8)}

Table B-4 presents detailed cumulative oversize distributions (by volume/weight) for Group 8 CUF testing sample TI640-G8-3-PSD. Results are reported as a function of test condition (see Table 6). This appendix does not provide discussion of the detailed distributions; however, a portion of these results (specifically, the $10^{\text {th }}, 50^{\text {th }}$, and $90^{\text {th }}$ diameter percentiles) are presented and discussed in the main body of this interim report.

Table B-4. Cumulative oversize diameter distributions for the primary Group 8 parametric testing sample, TI640G8-CL-PSD.

\begin{tabular}{|c|c|c|c|c|c|c|c|c|c|c|c|c|c|c|c|}
\hline \multirow{2}{*}{\begin{tabular}{|l|} 
Test \\
Condition
\end{tabular}} & \multicolumn{15}{|c|}{ Volume / Weight Cumulative Oversize Diameter $(\mu \mathrm{m})$} \\
\hline & $1 \%$ & $5 \%$ & $10 \%$ & $20 \%$ & $25 \%$ & $30 \%$ & $40 \%$ & $50 \%$ & $60 \%$ & $70 \%$ & $75 \%$ & $80 \%$ & $90 \%$ & $95 \%$ & $99 \%$ \\
\hline $1-3000$ & 35 & 43 & 50 & 60 & 65 & 69 & 78 & 87 & 98 & 110 & 118 & 130 & 150 & 180 & 220 \\
\hline $2-4000$ & 21 & 28 & 33 & 40 & 43 & 46 & 53 & 59 & 67 & 76 & 82 & 89 & 110 & 130 & 180 \\
\hline $3-2000$ & 36 & 45 & 51 & 62 & 67 & 71 & 80 & 91 & 100 & 120 & 120 & 130 & 160 & 180 & 220 \\
\hline $4-2000$ & 0 & 0 & 0 & 0 & 0 & 0 & 0 & 0 & 0 & 0 & 0 & 0 & 0 & 0 & 0 \\
\hline
\end{tabular}

\section{Results: TI640-G8-6-PSD (High-solids matrix Group 8)}

Table B-5 presents detailed cumulative oversize distributions (by volume/weight) for Group 8 CUF testing sample TI640-G8-6-PSD. Results are reported as a function of test condition (see Table 6). This appendix does not provide discussion of the detailed distributions; however, a portion of these results (specifically, the $10^{\text {th }}, 50^{\text {th }}$, and $90^{\text {th }}$ diameter percentiles) are presented and discussed in the main body of this interim report.

Table B-5. Cumulative oversize diameter distributions for the Group 8 CUF testing sample, TI640-G8-6-PSD.

\begin{tabular}{|c|c|c|c|c|c|c|c|c|c|c|c|c|c|c|c|}
\hline \multirow{2}{*}{$\begin{array}{l}\text { Test } \\
\text { Condition }\end{array}$} & \multicolumn{15}{|c|}{ Volume / Weight Cumulative Oversize Diameter ( $\mu \mathrm{m})$} \\
\hline & $1 \%$ & $5 \%$ & $10 \%$ & $20 \%$ & $25 \%$ & $30 \%$ & $40 \%$ & $50 \%$ & $60 \%$ & $70 \%$ & $75 \%$ & $80 \%$ & $90 \%$ & $95 \%$ & $99 \%$ \\
\hline $1-3000$ & 0.36 & 0.74 & 1.6 & 3.0 & 3.5 & 4.0 & 5.0 & 6.1 & 7.5 & 9.6 & 11 & 14 & 29 & 44 & 80 \\
\hline $2-4000$ & 0.44 & 1.6 & 2.7 & 3.9 & 4.5 & 5.2 & 6.9 & 9.8 & 17 & 28 & 34 & 40 & 60 & 81 & 120 \\
\hline $3-2000$ & 0.56 & 2.5 & 3.7 & 5.8 & 7.1 & 8.7 & 14 & 23 & 34 & 45 & 52 & 60 & 83 & 100 & 130 \\
\hline $4-2000$ & 0.83 & 3.7 & 5.5 & 9.6 & 13 & 17 & 28 & 38 & 49 & 61 & 67 & 75 & 95 & 110 & 130 \\
\hline
\end{tabular}


Results: TI640-G8-13-PSD (Caustic-leached, dewatered, and washed Group 8)

Table B-6 presents detailed cumulative oversize distributions (by volume/weight) for Group 8 CUF testing sample TI640-G8-13-PSD. Results are reported as a function of test condition (see Table 6). This appendix does not provide discussion of the detailed distributions; however, a portion of these results (specifically, the $10^{\text {th }}, 50^{\text {th }}$, and $90^{\text {th }}$ diameter percentiles) are presented and discussed in the main body of this interim report.

Table B-6. Cumulative oversize diameter distributions for the Group 8 CUF testing sample, TI640-G8-13-PSD.

\begin{tabular}{|c|c|c|c|c|c|c|c|c|c|c|c|c|c|c|c|}
\hline \multirow{2}{*}{\begin{tabular}{|l|} 
Test \\
Condition
\end{tabular}} & \multicolumn{15}{|c|}{ Volume / Weight Cumulative Oversize Diameter $(\mu \mathrm{m})$} \\
\hline & $1 \%$ & $5 \%$ & $10 \%$ & $20 \%$ & $25 \%$ & $30 \%$ & $40 \%$ & $50 \%$ & $60 \%$ & $70 \%$ & $75 \%$ & $80 \%$ & $90 \%$ & $95 \%$ & $99 \%$ \\
\hline $1-3000$ & 0.51 & 2.2 & 33 & 4.7 & 5.3 & 0 & 7.7 & 0 & 5 & 24 & 29 & 35 & 54 & 71 & 100 \\
\hline & 0.5 & 2. & 3.2 & 4.7 & 5.6 & 6.6 & 1 & 18 & 2. & 33 & 38 & 44 & 63 & 82 & 10 \\
\hline & 0.76 & 3.2 & 4.7 & 8.6 & 12 & 16 & 23 & 0 & 3 & 46 & 51 & 58 & 76 & 91 & 110 \\
\hline $4-2000$ & 1.6 & 4.5 & 7.3 & 16 & 20 & 24 & 31 & 38 & 46 & 56 & 62 & 69 & 87 & 100 & 120 \\
\hline
\end{tabular}


WTP-RPT-170, Rev. 0

\section{Appendix $\mathrm{H}$}

\section{CUF Process Request}





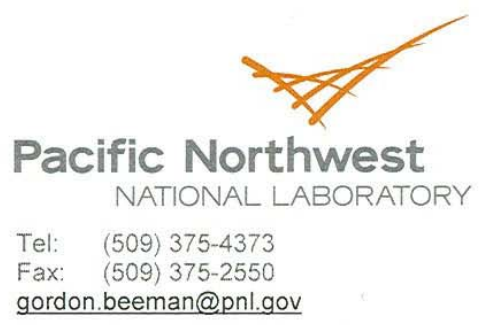

June 17, 2008

Mr. Haukur R. Hazen

WTP/RPP-MOA-PNNL-00237

Bechtel National Inc.

2435 Stevens Center Place, MSIN: H4-02

Richland WA 99352

Dear Mr. Hazen:

\section{Subcontract NO. 24590-QL-HC9-WA49-00001 - Project 53019 (WA\#2007-019) Recommendations for Filtration, and Caustic Leaching Test Matrix in the CUF for Group 8 Sample}

The purpose of this letter is to seek concurrence with the recommendation for feed composition, bench-scale testing, and CUF testing as required in Section 6.4 Item 2.0 in Test Plan TP-RPP-WTP-467, Characterization and Small Scale Testing of Hanford Wastes to Support the Development and Demonstration of Leaching and Ultrafiltration Pretreatment Processes

This test will cover the crossflow filtration and caustic leaching test for Group 8 (FeCN wastes) composite tank waste slurry. Accordingly, this work addresses the determination of filtration and leaching behavior at the bench-scale using the CUF system as described in TP-RPP-WTP467. Initial characterization of the Group 8 homogenized sample estimates that there are $\sim 250$ grams of undissolved solids (UDS) present. This will produce a final dewatered slurry $\sim 15 \mathrm{wt} \%$ undissolved solids. A caustic leach will then be performed to remove insoluble phosphorus present in the waste. While leaching conditions will be modified for a phosphorus caustic leach, the quantity of caustic added during the leach and subsequent washing steps will be based on maintaining the free hydroxide levels in the filter permeate at the aluminum solubility limit, assuming $100 \%$ dissolution of the aluminum present in the waste occurs. After leaching, it is expected that the final washed leached slurry will have a solid concentration around $10 \mathrm{wt} \%$ UDS, or lower. To produce a final slurry with a UDS concentration closer to $20 \mathrm{wt} \%$, it is proposed that the final leached slurry from the Group 7/AY102 test be added after leaching and washing of the Group 8 waste slurry is completed. Like the Group 5/6 CUF test performed in November 2007, the goal of this operation is to dewater the composite slurry to a higher undissolved solid concentration ( $20 \mathrm{wt} \%)$ to produce dewatering and filter flux data which show the impact of solid concentration. The proposed test sequence is summarized in the scheme shown in Figure 1. 
Mr. Haukur R. Hazen

WTP/RPP-MOA-PNNL-00237

Page 2

\section{Initial Test Matrix}

The initial filtration testing, low solids test matrix shown in Table 1, will be conducted with the Group 8 homogenized sample alone diluted to an estimated $5 \mathrm{wt} \%$ UDS. The inventory consists of $1.8 \mathrm{~L}$ of the waste slurry at an undissolved solids concentration of $11 \mathrm{wt} \%$. To dilute the waste slurry to $\sim 5 \mathrm{wt} \%$ UDS, a supernatant simulant will be added to give a total slurry volume of 3.8L. The supernatant simulant will be made to mimic the composition of the $\sim 3.5 \mathrm{M} \mathrm{Na}$ supernatant of Group 8 waste. While the sodium concentration of the simulant is lower than prototypic concentration of $5 \mathrm{M}$, it is more desirable to use a simulant based on the composition of the supernatant that is at equilibrium already with the waste. This will avoid precipitating species from the entrained supernatant and will allow for the formulation of a stable supernatant simulant.

\section{Dewatering Slurry and High Solids Test Matrix}

This slurry will be dewatered to a target of $15 \mathrm{wt} \%$ UDS $(\sim 1.2 \mathrm{~L})$ to generate a dewatering curve. All dewatering will be conducted at a slurry temperature of $25 \pm 5^{\circ} \mathrm{C}$, a transmembrane pressure (TMP) of $40 \pm 10$ psid and an axial velocity (AV) of $13 \pm 1 \mathrm{ft} / \mathrm{s}$.

The dewatered supernatant will be at a sodium concentration of approximately $3.5 \mathrm{M} \mathrm{Na}$ and a free hydroxide concentration of $\sim 0.3 \mathrm{M}$. Figure 2 provides a summary of sodium molarity during dewatering for the first five years of operating the Waste Treatment Plant. Inspection of this figure indicates that $3.5 \mathrm{M} \mathrm{Na}$ is within the range of conditions expected to be seen during the initial dewatering of slurry and bounds approximately $25 \%$ of the batches.

After dewatering the combined waste slurry, a high solids filtration test matrix, shown in Table 1 , will be conducted. If the slurry is unable to be pumped adequately through the system to run the test matrix proper, the slurry may be diluted with dewatered permeate as required. 
Mr. Haukur R. Hazen

WTP/RPP-MOA-PNNL-00237

Page 3
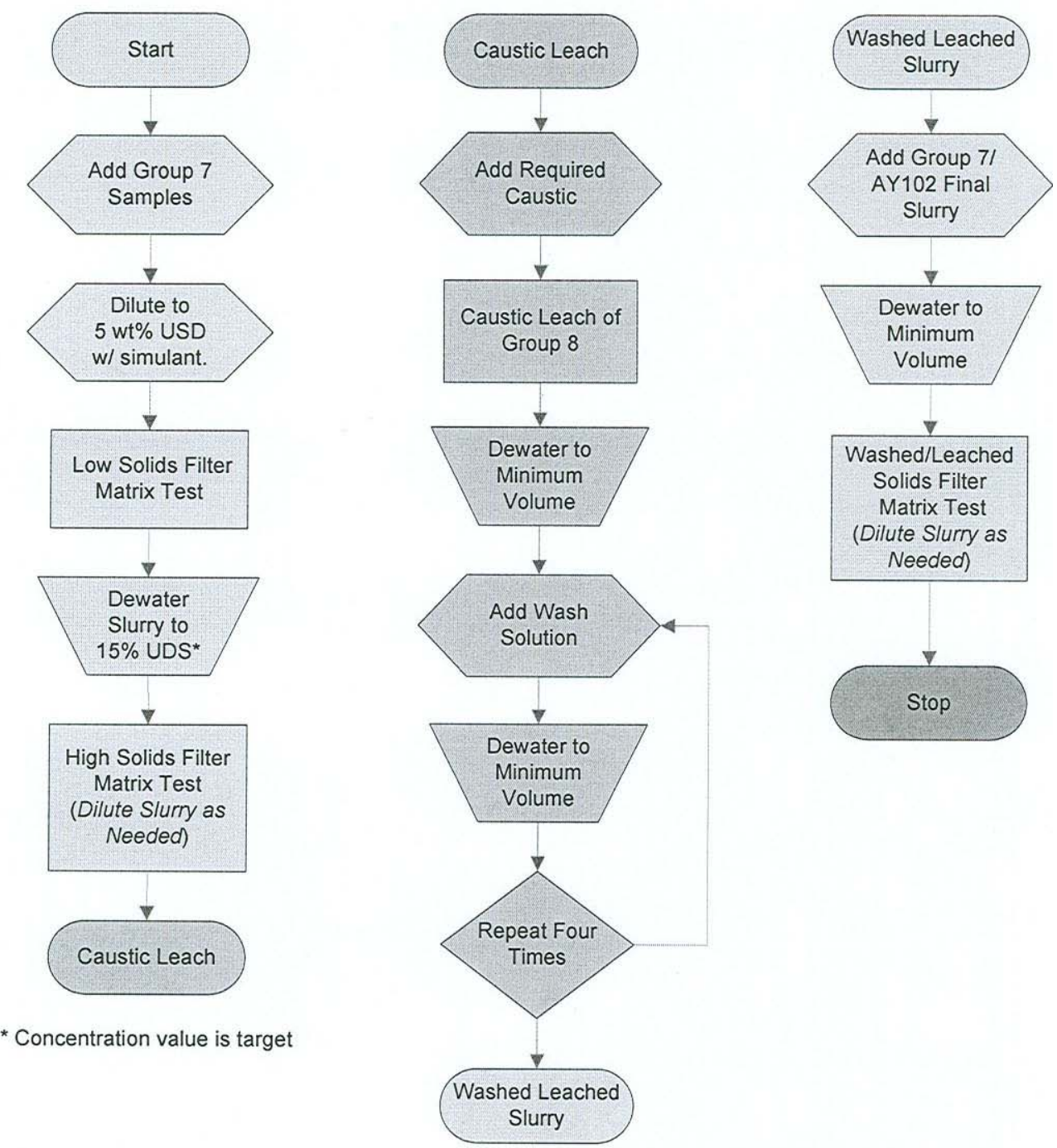

Figure 1: Proposed Test Scheme for Composite Group 8 Test 
Mr. Haukur R. Hazen

WTP/RPP-MOA-PNNL-00237

Page 4

Fraction of batches bounded by the sodium molarity during initial dewatering

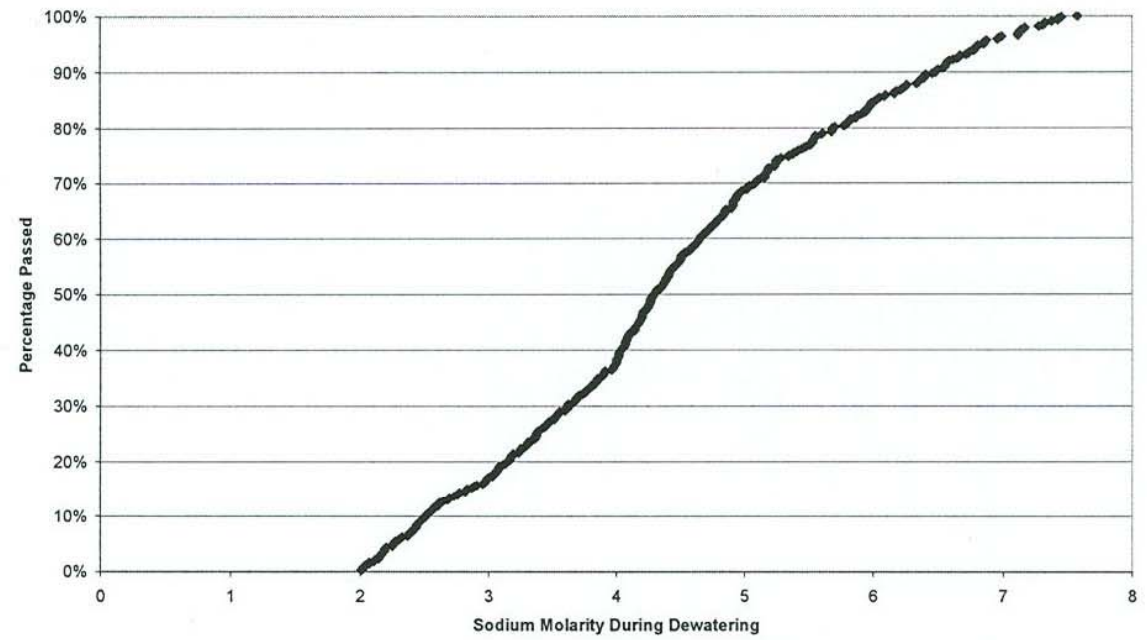

Figure 2. Projected WTP sodium molarity during initial dewatering.

\section{Dewater Process Steps (more details provided in this section)}

- First prepare the low-solids slurry by combining a supernatant simulant with the Group 8 slurry, to provide $\sim 3.8 \mathrm{~L}$ of slurry at a target of $\sim 5 \mathrm{wt} \% \mathrm{UDS}$ and $3.5 \mathrm{M}$ sodium.

- Conduct low solids filtration test matrix, Table 1.

- Dewater to target of $15 \mathrm{wt} \%$ UDS or as low volume as possible to generate a dewatering data from the Group 8 waste.

- Conduct a high solids matrix test as shown in Table 1. (If rheology, air entrainment or temperature control does not allow operation at $15 \mathrm{wt} \%$, permeate will be added back such that the test matrix could be carried out.) 
Mr. Haukur R. Hazen

WTP/RPP-MOA-PNNL-00237

Page 5

Table 1. Filtration Test Matrix

\begin{tabular}{|c|c|c|c|}
\hline Test number & $\begin{array}{c}\text { Duration } \\
\text { (hours) }\end{array}$ & $\begin{array}{c}\text { Target TMP* } \\
(\mathbf{p s i})\end{array}$ & $\begin{array}{c}\text { Target Axial } \\
\text { Velocity* } \\
\text { (ft/s) }\end{array}$ \\
\hline 1 & 3 & 40 & 13 \\
\hline 2 & 1 & 30 & 11 \\
\hline 3 & 1 & 30 & 15 \\
\hline 4 & 1 & 50 & 15 \\
\hline 5 & 1 & 50 & 13 \\
\hline 6 & 1 & 40 & 9 \\
\hline 7 & 1 & 40 & 17 ( or max) \\
\hline 8 & 1 & 40 & 13 \\
\hline 9 & 1 & 20 & 13 \\
\hline 10 & 1 & 60 & . \\
\hline 11 & 1 & 40 & cond \\
\hline
\end{tabular}

* Actual conditions may vary based upon slurry volume and rheology. All conditions may not be obtainable.

\section{Caustic Leaching}

The main goal of the caustic leach is to dissolve phosphate present in the Group 8 that is insoluble otherwise. However, aluminum present in the waste will also be removed and sufficient caustic needs to added ensure sufficient free hydroxide is present to maintain aluminum solubility in the permeate afterwards. For this test, caustic leach conditions for the blended waste slurry are proposed below based on a slurry volume of $\sim 1.4 \mathrm{~L}$ at $\sim 15 \mathrm{wt} \%$ UDS, expected phosphorus and aluminum solid concentrations, and leach factors of $100 \%$ dissolution for both phosphorus and aluminum:

Add $1.68 \mathrm{~L}$ of $6.34 \mathrm{M} \mathrm{NaOH}$ (adjust as needed for $\mathrm{Al}$ solubility at $25^{\circ} \mathrm{C}$ ), leach for 8 hours at $60^{\circ} \mathrm{C}$, and add water as needed during the caustic leach lost by evaporation to maintain a constant volume. For this test, it is assumed that the consumption of free hydroxide during phosphorous dissolution to be a 3:1 mole ratio, while the consumption ratio for aluminum to be a $1: 1$ mole ratio.

The final sodium concentration is expected to be $\sim 5.1 \mathrm{M}$. Examining Figure 3, a summary of the sodium molarity during caustic leaching for the first 5 years of WTP operation, shows that leaching at $\sim 5.1 \mathrm{M}$ sodium is at the lower end of the expected operating envelope. Because the aluminum present in the waste is relatively small ( $\sim 9 \%$ aluminum in slurry solids), the required quantity of caustic to be added is lower as well. However, the main reason for the leach is to remove insoluble phosphorus, so it is expected that the sodium concentration for this test to be low. 
Mr. Haukur R. Hazen

WTP/RPP-MOA-PNNL-00237

Page 6

Fraction of batches bounded by the sodium molarity during caustic leaching

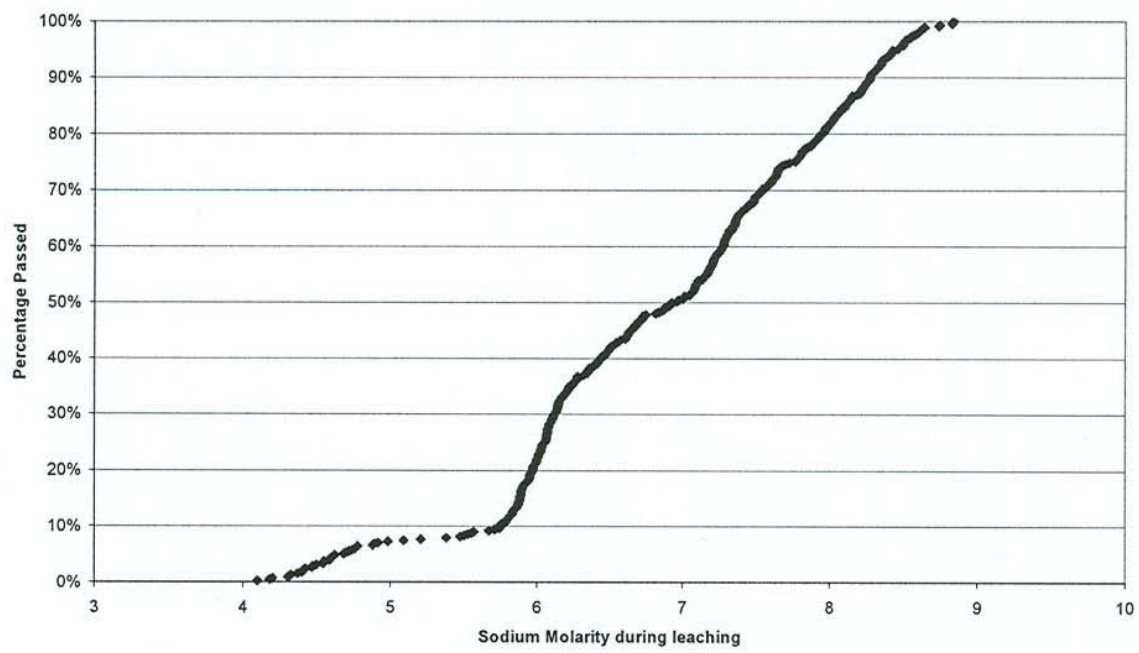

Figure 3. Projected WTP sodium molarity during caustic leaching.

\section{Caustic Leaching Process Steps (more details provided in this section)}

- Retrieve all solids from CUF and isolate in slurry feed reservoir for leaching.

- Assuming $\sim 1.4 \mathrm{~L}$ of $\sim 15 \mathrm{wt} \%$ UDS at $3.5 \mathrm{M}$ sodium, add $1.68 \mathrm{~L}$ of $6.34 \mathrm{M} \mathrm{NaOH}$. (These leaching conditions have been estimated to produce a solution saturated with $\mathrm{Al}$ at $25^{\circ} \mathrm{C}$ at the conclusion of the leaching process.)

- Based on kinetic studies of phosphate dissolution while caustic leaching, there is no need to heat the batch beyond $60^{\circ} \mathrm{C}$ while caustic leaching. Aluminum dissolution is not the sole objective for the caustic leaching of the Group 8 waste. The process, which deviates from historic WTP baseline process conditions, is as follows:

- Heat from $25^{\circ} \mathrm{C}$ to $60^{\circ} \mathrm{C}$ in 2.5 hours.

○ Leach for $8 \mathrm{~h}$ at $60(+5 /-10)^{\circ} \mathrm{C}$.

- Cool from $60^{\circ} \mathrm{C}$ to $25^{\circ} \mathrm{C}$ in 5.6 hours.

\section{Post Caustic Leach Dewater Process Steps}

- Dewater leached solids at $25 \pm 5^{\circ} \mathrm{C}, \mathrm{TMP}=40 \pm 10 \mathrm{psid}$, and $\mathrm{AV}=13 \pm 1 \mathrm{ft} / \mathrm{s}$.

- Dewater to a target of $\sim 1.2 \mathrm{~L}$ or to minimum operating volume of CUF ( $10 \mathrm{wt} \%$ undissolved solids assuming aluminum is all gibbsite and 100\% $\mathrm{Al}$ dissolution). 
Mr. Haukur R. Hazen

WTP/RPP-MOA-PNNL-00237

Page 7

\section{Post Caustic Leach Washing Process Steps}

- Four equal volume washes of the dewatered leached slurry will occur at caustic levels high enough to ensure that the solubility of $\mathrm{Al}$ is maintains in the leached slurry permeate and the dewatered wash solutions.

- Wash 1: $1.2 \mathrm{~L}$ solution of $0.47 \mathrm{M} \mathrm{NaOH}$ solution is added. Slurry is dewatered to a target of $\sim 1.2 \mathrm{~L}$ or to minimum operating volume of CUF.

- Wash 2: $\sim 1.2 \mathrm{~L}$ solution of $0.16 \mathrm{M} \mathrm{NaOH}$ solution is added. Slurry is dewatered to a target of $\sim 1.2 \mathrm{~L}$ or to minimum operating volume of CUF.

- Wash 3: 1.2L solution of $0.049 \mathrm{M} \mathrm{NaOH}$ solution is added. Slurry is dewatered to a target of $\sim 1.2 \mathrm{~L}$ or to minimum operating volume of CUF.

- Wash 4: 1.2L solution of $0.014 \mathrm{M} \mathrm{NaOH}$ solution is added. Slurry is dewatered to a target of $\sim 1.2 \mathrm{~L}$ or to minimum operating volume of CUF.

\section{Dewatering Combined Slurries and Final Test Matrix}

- After the fourth rinse, add the washed leached slurry from the Group 7/AY102 CUF test to the slurry reservoir.

- Dewater the combined slurry to a minimum volume

- Conduct a final filter matrix test as shown in Table 1. (If rheology, air entrainment or temperature control does not allow operation at the dewatered volume, permeate will be added back such that the test matrix could be carried out.)

- Drain slurry from CUF and retain for potential use, only dispose at the guidance of the client.

- Clean CUF and determine clean water $(0.01 \mathrm{M} \mathrm{NaOH})$ flux.

\section{Sample Plan}

The sample collection and analysis plan will be implemented as defined in the test plan.

If you have any questions, please contact Reid Peterson on 376-5340.

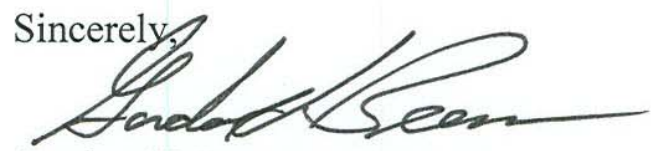

Gordon H. Beeman, Manager

RPP-WTP Support Program

GHB: $\mathrm{c}^{2}$ 
WTP-RPT-170, Rev. 0

Mr. Haukur R. Hazen

WTP/RPP-MOA-PNNL-00237

Page 8

cc: $\quad$ SK Fiskum (PNNL

RA Peterson (PNNL)

RW Shimskey (PNNL)

PS Sundar (BNI)

Project File/LB 


\section{Concurrence}

The WTP concurrence with the recommendation for filtration and leaching of the Group 8 material was provided in an e-mail and is reproduced below.

From: Sundar, Parameshwaran S [pssundar@bechtel.com]

To: Fiskum, Sandra K

Cc: Barnes, Steven M

Subject: FW: Review of Draft of the Group 8 CUF Concurrence Letter

SANDY:

We have ORP concurrence and believe PNNL has WTP's verbal approval. Steve will forward his written approval to proceed, hopefully by $\mathrm{COB}$ today. Please proceed per the plan submitted by PNNL and reviewed by us.

SUNDAR

From: Gilbert, Robert A (Rob) [mailto:Robert_A_Rob_Gilbert@RL.gov]

Sent: Thursday, June 05, 2008 6:50 AM

To: Sundar, Parameshwaran S

Cc: Bang, Ricky; Peterson, Reid A

Subject: RE: Review of Draft of the Group 8 CUF Concurrence Letter

Sundar,

Ricky Bang and I reviewed the Group 8 CUF test matrix and concur with it.

Thanks

Rob Gilbert

From: Sundar, Parameshwaran S [mailto:pssundar@bechtel.com]

Sent: Wednesday, June 04, 2008 4:31 PM

To: Gilbert, Robert A (Rob); Bang, Ricky

Cc: Peterson, Reid A; Barnes, Steven M

Subject: RE: Review of Draft of the Group 8 CUF Concurrence Letter

Importance: High

ROB:

Based on your statement during the weekly meeting yesterday, I presume we have your concurrence on the Group 8 CUF test matrix. If so, please let both Reid and I know of it by reply mail for the record.

Thanks, 
WTP-RPT-170, Rev. 0

SUNDAR

From: Sundar, Parameshwaran S

Sent: Monday, J une 02, 2008 9:35 AM

To: 'Gilbert, Robert A (Rob)'; 'Bang, Ricky'

Cc: 'Peterson, Reid A'; Barnes, Steven M

Subject: FW: Review of Draft of the Group 8 CUF Concurrence Letter

ROB, RICKY:

I am forwarding the request for approval for the CUF test with Group 8 - FeCN wastes from PNNL. Please review before our scheduled meeting tomorrow as this will be on the agenda for discussion. We would like to approve the test matrix with any changes by June 6 (COB this Friday) if at all possible. My apologies for asking an expedited response on this request.

Thanks,

SUNDAR

From: Peterson, Reid A [mailto:reid.peterson@pnl.gov]

Sent: Thursday, May 29, 2008 11:59 AM

To: Sundar, Parameshwaran S

Cc: Barnes, Steven M; Huckaby, James L; Shimskey, Rick W

Subject: FW: Review of Draft of the Group 8 CUF Concurrence Letter

Attached is the Group 8 cuf test request. I would like to have this resolved before I go on vacation - the 6th.

Thanks,

Reid 


\section{Appendix I}

\section{Group 8 CUF Analytical Results}





\title{
Appendix I: Group 8 CUF Analytical Results
}

\author{
Special Instructions for the \\ CUF Group 8 (FeCN Sludge) Treatability Study \\ Analysis Requirements
}

A blend of two HLW samples containing liquid and sludge from Hanford waste tanks was subjected to CUF process as per TI-RPP-WTP-640. The first sample is a composite blend from tanks 241-BY-104, 241-BY-105, 241-BY-106, 241-BY-108, and 241-BY-110, representing waste described as Ferrocyanide Sludge (Group 8). The start date for this treatability study is

June 22nd, 2008. Color code: Chartreuse

The processing and analysis schematic is shown by Figure 1 and Table 1 . The aqueous samples are ready to directly sub-sample for analysis and acid digestion. The solid slurry samples have yet to be split into aliquots and prepped for fusion or HF-assisted acid digestion.

\section{SAL Preparation/Analysis}

Please record observations associated with the dissolution preparations, and record the test sample being aliquotted before and after sampling to document changes in weight since the treatability study occurred. If any residual solids remain after any of the fusion and acid digestions, note on the bench sheet (include estimated quantity, color, texture, etc.) and contact RW Shimskey or MK Edwards for further instruction prior to distribution.

\section{Archive of SAL Fusion Preparation Samples}

The fusion preparations will result in a $100-\mathrm{mL}$ volume. This solution will be apportioned to the laboratory as needed to conduct work-station-specific analyses. Please prepare a 15-mL aliquot from each preparation as an archive sample. The vials need to be labeled with the following: date, ASO-ID, matrix, treatablility study, hazard, fusion prep (if applicable) and their tare, gross masses, and IDs provided to RW Shimskey or MK Edwards. The vials may be removed from the hot cells for storage. The remaining portions of the fusion preparations may be disposed of.

\section{Quality Control}

All work is to be conducted according to RPP-WTP-QA-005, Rev. 2.

Preparative or sample analysis QC includes a preparation blank, sample, sample duplicate, matrix spike, and a LCS or BS. The samples submitted for fusion are sub-aliquoted into fusion vessels in duplicate (sample, sample duplicate). If possible, the matrix spike and LCS/BS need to include all the analytes of interest to be reported for the specific analysis.

The duplicate, LCS/BS, and MS QC acceptance criteria for the aqueous phases and solid phases are provided in Table 4 . The preparation blank (PB) analyte concentration shall be less than the estimated quantitation limit (EQL) or the minimum detectable activity (MDA) of the associated sample. When the PB concentration is equal to or exceeds the EQL, then the PB concentration shall not exceed $5 \%$ of the measured concentration present in the sample. Failure of the PB, and/or duplicates, and/or LCS/BS to meet the acceptance criteria requires that affected samples in 
the processing batch be re-prepared and re-analyzed for the failed analytes, availability of samples permitting, at ASO expense.

In the case of multi-elemental methods (IC and ICP-OES), isolated QC failure(s) may be communicated to RW Shimskey or MK Edwards for an assessment of the impact on data interpretation. If the data are acceptable, RW Shimskey or MK Edwards will indicate, in writing, that the data may be reported, and the resulting limitations on the data from the QC sample failure(s) shall be included in the final report.

When the MS fails to meet the acceptance criteria, the results shall be investigated for potential sources of error. When the sources of error cannot be identified, the failure of the MS and any resulting limitations on the data shall be included in the report.

\section{Reporting Units}

Report aqueous sample results in units of $\mathrm{ug} / \mathrm{mL}$ or $\mathrm{uCi} / \mathrm{mL}$. Report solids sample results as ug/g or uCi/g; the initial dry mass of solids (as measured in each fusion crucible) will be provided. For radiochemistry, the reference date shall be February 17, 2008 for samples from TI-RPP-WTP640.

\section{Reporting}

Please prepare the analytical data report in accordance with PNL-ASO-058, Rev. 0, Section 5.3, Comprehensive Data Report. Please be sure to include action taken with respect to any identified unexpected results and discrepancies.

The following elements may be included in the final report or be traceable to the test results (usually by entry in the LRB, Test Instruction, or data sheet) and be maintained as lifetime records:

- identification of standards used

- identification of M\&TE used

- reference to the Test Plan (identified on page 1 of the ASR)

- signature and date of person who performed the test and recorded the data

- hand calculation review documentation.

Analytical results shall be reported both in hard copy and electronically. Preliminary data reports and electronic files shall be provided as soon as practical after completion of analysis. The final ASR data report shall be provided no later than the commitment date on the ASR. 
ASR 8206

Special Instructions

Page 3 of 8

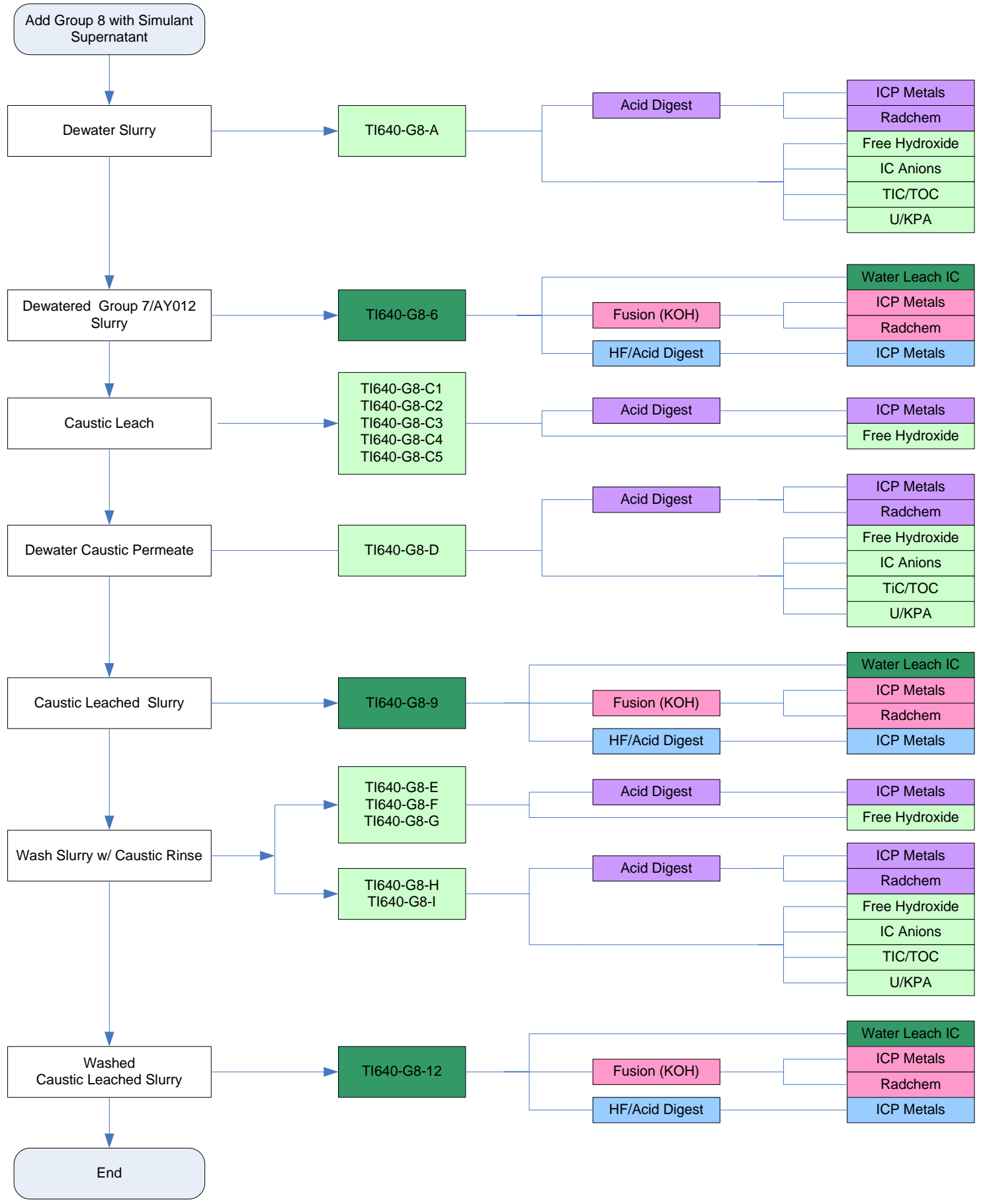

Figure 1: TI-RPP-WTP-640 Process Sampling Plan 
Table 1. Cross-Reference of Process component, Sample ID, and RPL ID

\begin{tabular}{|l|l|c|}
\hline \multicolumn{1}{|c|}{ Component } & \multicolumn{1}{c|}{ Sample ID } & ASO ID \\
\hline Group 8 Dewater filtrate & TI640-G8-A & $08-02283$ \\
\hline Dewatered Caustic Leach & TI640-G8-D & $08-02284$ \\
\hline Wash 4 Permeate & TI640-G8-H & $08-02285$ \\
\hline Composite Wash Sample & TI640-G8-I & $08-02286$ \\
\hline Caustic leach filtrate, 1 hour heat up & TI640-G8-C1 & $08-02287$ \\
\hline Caustic leach filtrate, 0 hour heat up & TI640-G8-C2 & $08-02288$ \\
\hline Caustic leach filtrate, 2 hour leach & TI640-G8-C3 & $08-02289$ \\
\hline Caustic leach filtrate, 4 hour leach & TI640-G8-C4 & $08-02290$ \\
\hline Caustic leach filtrate, 8 hour leach & TI640-G8-C5 & $08-02291$ \\
\hline Wash 1 Permeate & TI640-G8-E & $08-02292$ \\
\hline Wash 2 Permeate & TI640-G8-F & $08-02293$ \\
\hline Wash 3 Permeate & TI640-G8-G & $08-02294$ \\
\hline Dewatered Slurry & TI640-G8-6 & $08-02295$ \\
\hline Caustic Leached Slurry & TI640-G8-9 & $08-02296$ \\
\hline Washed Caustic Leached Slurry & TI640-G8-12 & $08-02297$ \\
\hline
\end{tabular}


Laboratory Analysis

The required sample analyses are shown below in Table 2 .

Table 2. Filtration and Leach Testing Characterization Plan

\begin{tabular}{|c|c|}
\hline Process Step & Analyte \\
\hline \multicolumn{2}{|c|}{ TI-RPP-WTP-640 } \\
\hline \multirow[t]{3}{*}{$\begin{array}{l}\text { Dewatered slurry } \\
\text { (TI640-G8-6) }\end{array}$} & $\begin{array}{c}\text { HF assisted Acid digestion } \\
\text { - ICP metals (Table 3) }\end{array}$ \\
\hline & $\begin{array}{l}\text { KOH fusion } \\
\text { - ICP metals (Table 3) } \\
\text { - GEA } \\
\text { - Total alpha } \\
\text { - }{ }^{238} \mathrm{Pu},{ }^{239+240} \mathrm{Pu} \\
\text { - } \mathrm{U} / \mathrm{KPA} \\
\text { - }{ }^{90} \mathrm{Sr} \\
\text { - Total beta }\end{array}$ \\
\hline & $\begin{array}{l}\text { Water Leach } \\
\text { - Anions (Table 3) }\end{array}$ \\
\hline \multirow[t]{2}{*}{$\begin{array}{l}\text { Dewater filtrate } \\
\text { (TI640-G8-A) }\end{array}$} & $\begin{array}{l}\text { Direct distribution } \\
\text { - Anions (Table 3) } \\
\text { - Free hydroxide } \\
\text { - TIC/TOC } \\
\text { - U-KPA }\end{array}$ \\
\hline & $\begin{array}{l}\text { Acid digestion } \\
\text { - ICP metals (Table 3) } \\
\text { - GEA } \\
\text { - Total alpha } \\
\text { - }{ }^{238} \mathrm{Pu},{ }^{239+240} \mathrm{Pu} \\
\text { - }{ }^{90} \mathrm{Sr} \\
\text { - Total beta }\end{array}$ \\
\hline \multirow{2}{*}{$\begin{array}{c}\text { Time interval Caustic Leach filtrates - Kinetics } \\
\text { (TI640-G8-C1, TI640-G8-C2, TI640-G8-C3, } \\
\text { TI640-G8-C4, TI640-G8-C5) }\end{array}$} & $\begin{array}{l}\text { Direct distribution } \\
\text { • Free hydroxide } \\
\end{array}$ \\
\hline & $\begin{array}{l}\text { Acid digestion } \\
\text { • ICP metals (Table 3) }\end{array}$ \\
\hline \multirow[t]{2}{*}{$\begin{array}{c}\text { Caustic-leached permeate } \\
\text { (TI640-G8-D) }\end{array}$} & $\begin{array}{l}\text { Direct distribution } \\
\text { - Anions (Table 3) } \\
\text { - Free hydroxide } \\
\text { - TIC/TOC } \\
\text { - U-KPA } \\
\end{array}$ \\
\hline & $\begin{array}{l}\text { Acid digestion } \\
\text { - ICP metals (Table 3) } \\
\text { - GEA } \\
\text { - Total alpha } \\
\text { - }{ }^{238} \mathrm{Pu},{ }^{239+240} \mathrm{Pu} \\
\text { - }{ }^{90} \mathrm{Sr} \\
\text { - Total beta }\end{array}$ \\
\hline
\end{tabular}




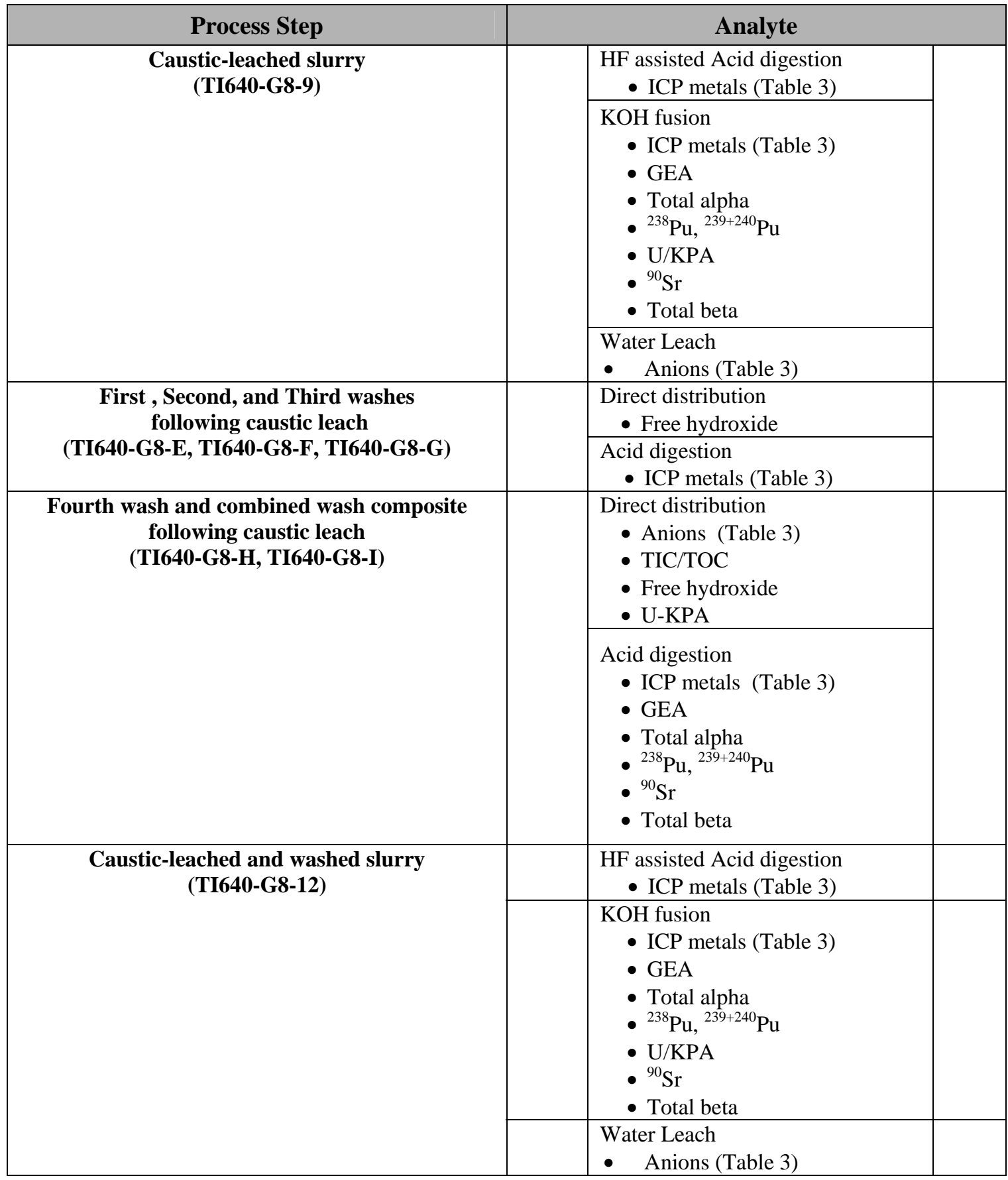

All analyses are to be conducted per approved PNNL procedures or test plans with the QC defined in the QC information Section. Table 3 defines the analytes of interest, the required detection limits, and analysis methods. 
Table 3. Method Detection Limits for Solids and Supernatants

\begin{tabular}{|c|c|c|c|}
\hline Analyte & Solids & Solutions & Analysis Method \\
\hline & $\mu \mathrm{Ci} / \mathrm{g}^{(\mathrm{a})}$ & $\mu \mathrm{Ci} / \mathrm{ml}$ & \\
\hline${ }^{137} \mathrm{Cs}$ & $6.0 \mathrm{E}-02$ & $1.0 \mathrm{E}-02$ & \multirow{5}{*}{ GEA } \\
\hline${ }^{60} \mathrm{Co}$ & $3.0 \mathrm{E}-02$ & $1.0 \mathrm{E}-02$ & \\
\hline${ }^{154} \mathrm{Eu}$ & 5.0E-03 & $4.0 \mathrm{E}-04$ & \\
\hline${ }^{155} \mathrm{Eu}$ & 8.0E-03 & $4.0 \mathrm{E}-04$ & \\
\hline${ }^{241} \mathrm{Am}$ & 3.0E-03 & 2.0E-03 & \\
\hline $\mathrm{Pu}$ & $1.0 \mathrm{E}-03$ & $1.0 \mathrm{E}-04$ & ${ }^{239+240} \mathrm{Pu}$ and ${ }^{238} \mathrm{Pu}$ by AEA \\
\hline Total alpha & $1.0 \mathrm{E}-02$ & 4.0E-03 & Proportional counting \\
\hline Total beta & 1.0E-02 & 1.0E-03 & Proportional counting \\
\hline \multirow[t]{2}{*}{${ }^{90} \mathrm{Sr}$} & $1.0 \mathrm{E}-02$ & $1.0 \mathrm{E}-03$ & Separation and proportional counting \\
\hline & $\mu g / g$ & $\mu \mathrm{g} / \mathrm{ml}$ & \\
\hline $\mathrm{Al}$ & $3.0 \mathrm{E}+02$ & $7.5 \mathrm{E}+01$ & \multirow{17}{*}{ ICP-OES } \\
\hline $\mathrm{B}$ & $2.0 \mathrm{E}+02$ & $7.5 \mathrm{E}+01$ & \\
\hline $\mathrm{Bi}$ & $4.0 \mathrm{E}+02$ & $3.0 \mathrm{E}+01$ & \\
\hline $\mathrm{Cd}$ & $7.5 \mathrm{E}+01$ & $7.5 \mathrm{E}+01$ & \\
\hline $\mathrm{Cr}$ & $1.2 \mathrm{E}+02$ & $1.5 \mathrm{E}+01$ & \\
\hline $\mathrm{Fe}$ & $3.0 \mathrm{E}+02$ & $7.5 \mathrm{E}+01$ & \\
\hline $\mathrm{K}$ & $1.0 \mathrm{E}+03^{(\mathrm{b})}$ & $5.0 \mathrm{E}+01$ & \\
\hline $\mathrm{Mn}$ & $3.0 \mathrm{E}+02$ & $1.5 \mathrm{E}+01$ & \\
\hline $\mathrm{Na}$ & $3.0 \mathrm{E}+03$ & $7.5 \mathrm{E}+01$ & \\
\hline $\mathrm{Ni}$ & $1.6 \mathrm{E}+02^{(\mathrm{b})}$ & $3.0 \mathrm{E}+01$ & \\
\hline $\mathrm{P}$ & $2.0 \mathrm{E}+02$ & $1.0 \mathrm{E}+01$ & \\
\hline $\mathrm{S}$ & $1.5 \mathrm{E}+03$ & $2.0 \mathrm{E}+2$ & \\
\hline $\mathrm{Si}$ & $3.0 \mathrm{E}+03$ & $7.5 \mathrm{E}+01$ & \\
\hline $\mathrm{Sr}$ & $3.0 \mathrm{E}+02$ & $7.5 \mathrm{E}+01$ & \\
\hline $\mathrm{Zn}$ & $3.0 \mathrm{E}+02$ & $7.5 \mathrm{E}+01$ & \\
\hline $\mathrm{Zr}$ & $3.0 \mathrm{E}+02$ & $7.5 \mathrm{E}+01$ & \\
\hline $\mathrm{U}$ & $2.5 \mathrm{E}+03$ & $7.5 \mathrm{E}+01$ & \\
\hline $\mathrm{U}$ & $6.0 \mathrm{E}+01$ & $6.0 \mathrm{E}+01$ & Kinetic Phosphorescence \\
\hline Fluoride & $2.5 \mathrm{E}+02$ & $1.2 \mathrm{E}+02$ & \multirow{6}{*}{$\begin{array}{l}\text { Ion Chromatography } \\
\text { (water-soluble species) }\end{array}$} \\
\hline Nitrite & $2.5 \mathrm{E}+02$ & $1.2 \mathrm{E}+02$ & \\
\hline Nitrate & $2.5 \mathrm{E}+02$ & $1.2 \mathrm{E}+02$ & \\
\hline Phosphate & $2.5 \mathrm{E}+02$ & $1.2 \mathrm{E}+02$ & \\
\hline Sulfate & $2.5 \mathrm{E}+02$ & $1.2 \mathrm{E}+02$ & \\
\hline Oxalate & $8.0 \mathrm{E}+02$ & $4.0 \mathrm{E}+02$ & \\
\hline Hydroxide & NA & $1 \mathrm{E}-01 \mathrm{M}$ & Titration \\
\hline Total organic carbon & NA & $4.0 \mathrm{E}+02$ (as C) & \multirow{2}{*}{ Hot persulfate method } \\
\hline Total inorganic carbon & NA & $2.0 \mathrm{E}+02$ (as C) & \\
\hline \multicolumn{4}{|c|}{$\begin{array}{l}\text { (a) KOH fusion for solid samples. } \\
\text { (b) The Ni and K cannot be measured from the KOH fusion which uses a Ni crucible. The Ni and } \mathrm{K} \text { will be } \\
\text { assessed from a separate HF-assisted acid digestion. }\end{array}$} \\
\hline
\end{tabular}


$\infty$
$\mathbb{0}$
$\infty$
$\infty$
$\infty$
$\tilde{\Xi}$

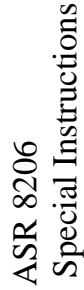

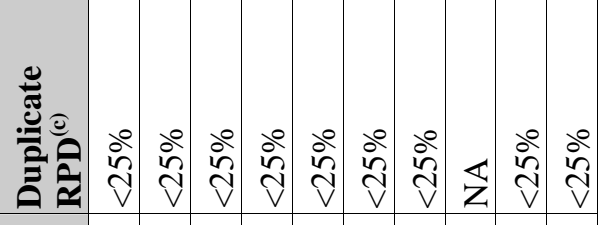
产

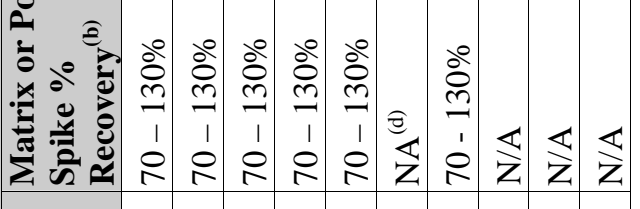

늘

离

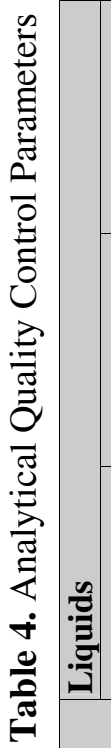

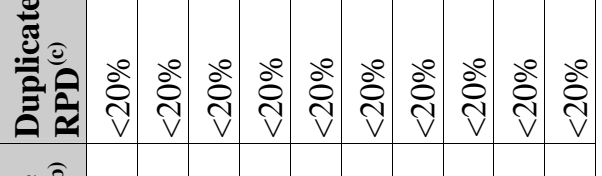

产

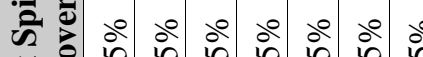

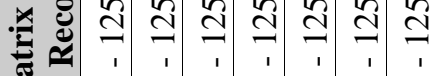

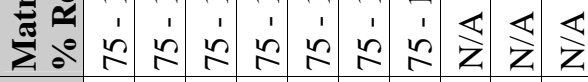

$\therefore$

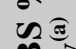

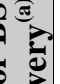

亏ํํำ

웍 궈ㄱㅝㅝㅝㅝ

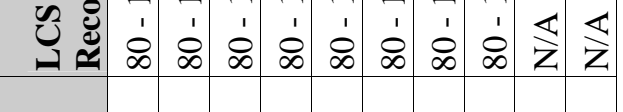

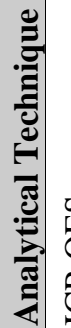

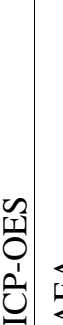

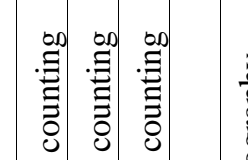

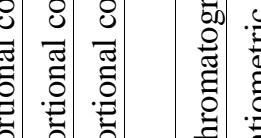

응

2

율

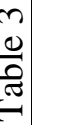

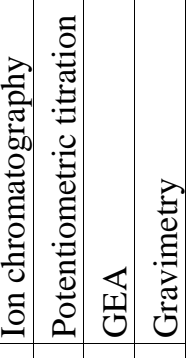

离

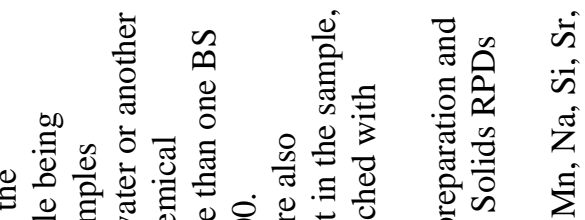

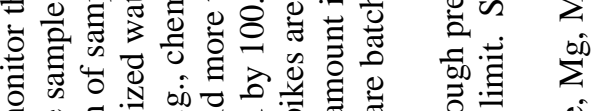
की

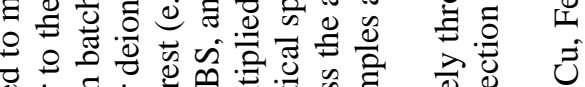

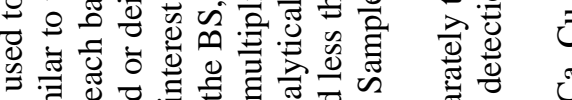

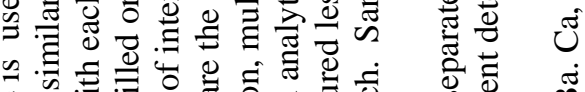

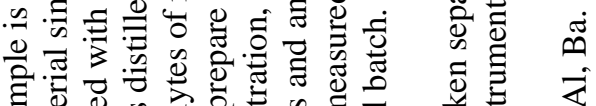

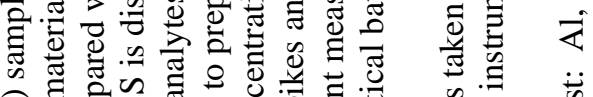

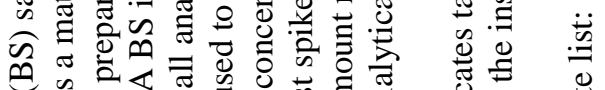

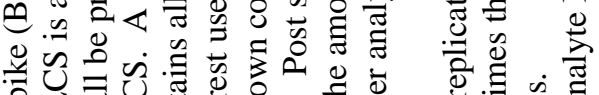

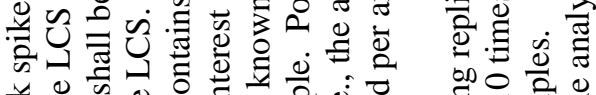

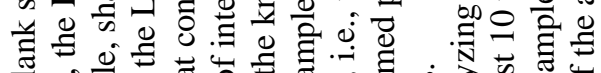

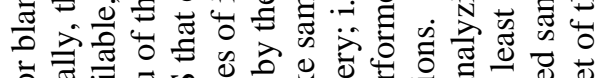
t。

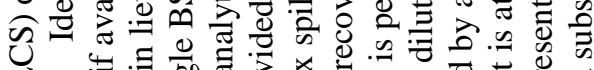

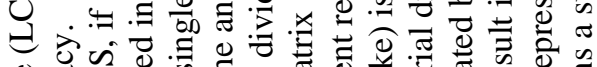

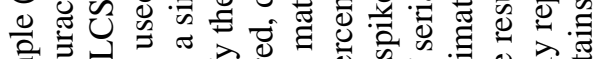

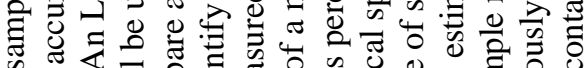

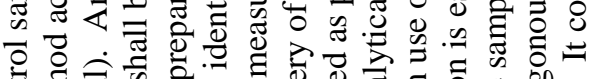

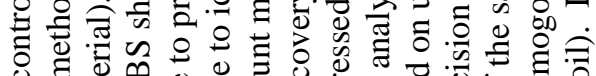
政

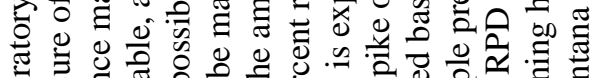
呟

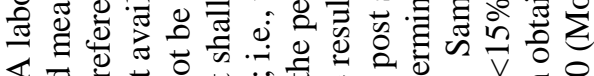

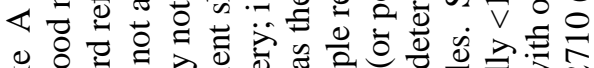

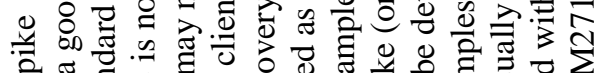

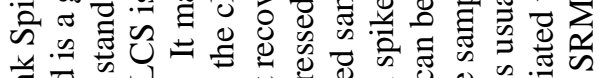

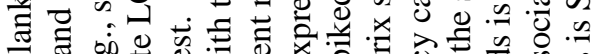
川 o

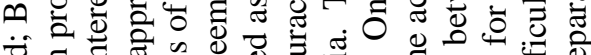

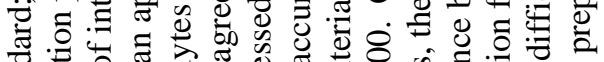

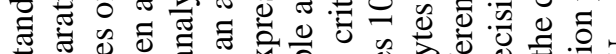
कि कूष

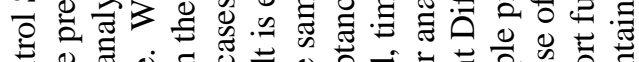

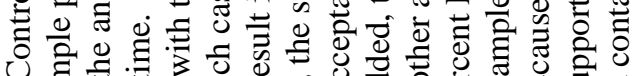

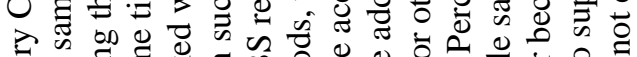

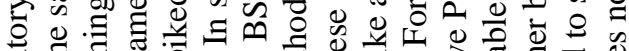

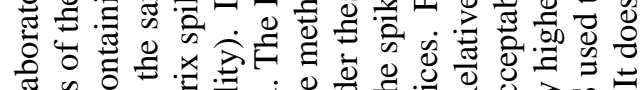

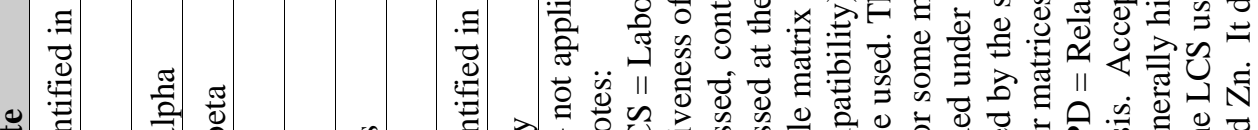

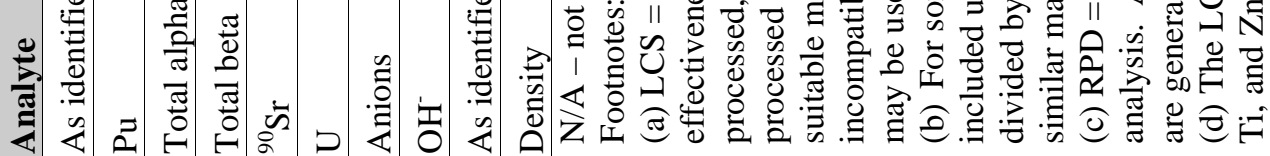


Requestor --- Complete all fields on this COVER PAGE, unless specified as optional or ASR is a revision

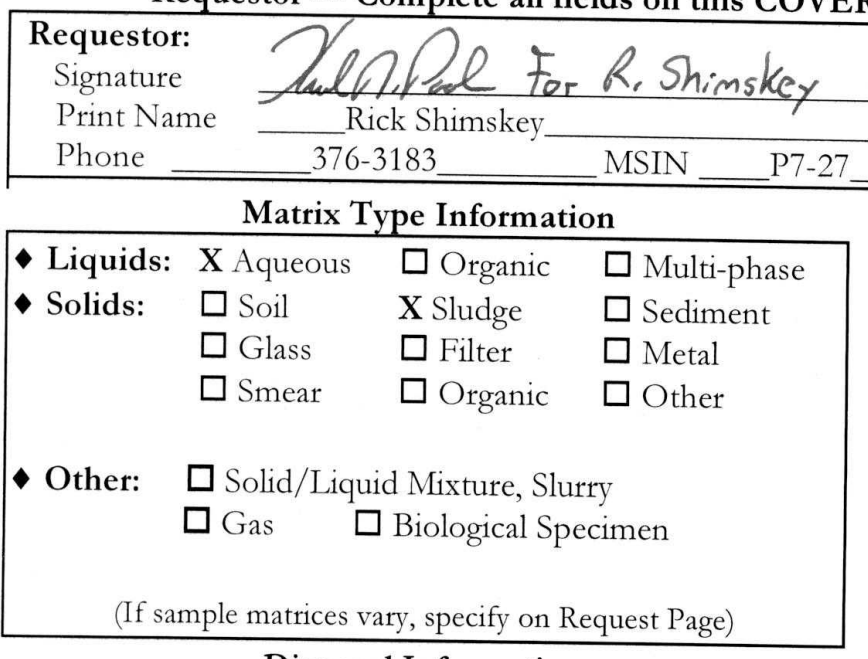

Disposal Information

- Disposition of Virgin Samples:

Virgin samples are returned to requestor unless

archiving provisions are made with receiving group!

If archiving, provide:

Archiving Reference Doc:

- Disposition of Treated Samples:

$\mathrm{X}$ Dispose $\square$ Return

Data Reporting Information

- Is Work Associated with a Fee-Based

Milestone? X No $\square$ Yes

If yes, milestone due date:

- QA Plan: $\mathrm{X}$ No $\square$ Yes

If Yes,

Contact ASO

Lead before

submitting

Samples $\square$ Minimum data report.

$\square$ Project Specific Requirements:

Contact ASO Lead or List Reference
Project Number:

Work Package:
52964

F99189

\section{QA/Special Requirements}

X ASO-QAP-001, Rev. 6 (Equivalent to HASQARD)

X Additional QA Requirements, List Document Below:

Reference Doc Number:_RPP_WTP-QA-005, Rev. 2

- Field COC Submitted? X No $\square$ Yes

- Lab COC Required? X No $\square$ Yes

- Sample/Container Inspection Documentation Required?

- Hold Time: X No $\square$ Yes

Use SW 846 (PNL-ASO-071, identify

analytes/methods where holding times apply)

- Special Storage Requirements:

X None $\square$ Refrigerate $\square$ Other, Specify:

- Data Requires ASO Quality Engineer Review? X No $\square$ Yes

\begin{tabular}{l|l} 
Data Reporting Level & $\bullet$ Requested Analytical Work Completion Date: \\
X ASO-QAP-001 (Equivalent to & \\
HASQARD). & (Note: Priority rate charge for $<10$ business day turn-around time)
\end{tabular}

- Preliminary Results Requested, As

\section{\begin{tabular}{c|c} 
Available? $\square$ No X Yes & Document: \\
\hline & Waste Designation Information
\end{tabular} Document:}

- Negotiated Commitment Date:

$$
11 / 21 / 08
$$
(To be completed by ASO Lead) SP, CZS, LPD, KJC, PKB $B M O, M B, I E B, B M O$

- Sample Information Check List Attached? X No $\square$ Yes

If no, Reference Doc Attached:

or, Previous ASR Number: 8150

Does the Waste Designation Documentation

Indicate Presence of PCBs?

$\mathrm{X}$ No $\square$ Yes

or, Previous RPL Number:

Send Report To:

Rick Shimskey

MSIN

P7-27

Matt Edwards

MSIN

P7-25

Additional or Special Instructions _The requirements of Statement of Work, RPP-WTP-QA-005, Rev. 2, apply to this work. Task-specific Quality Control criteria are attached. Reference Document (i.e., TP-RPP-WTP-

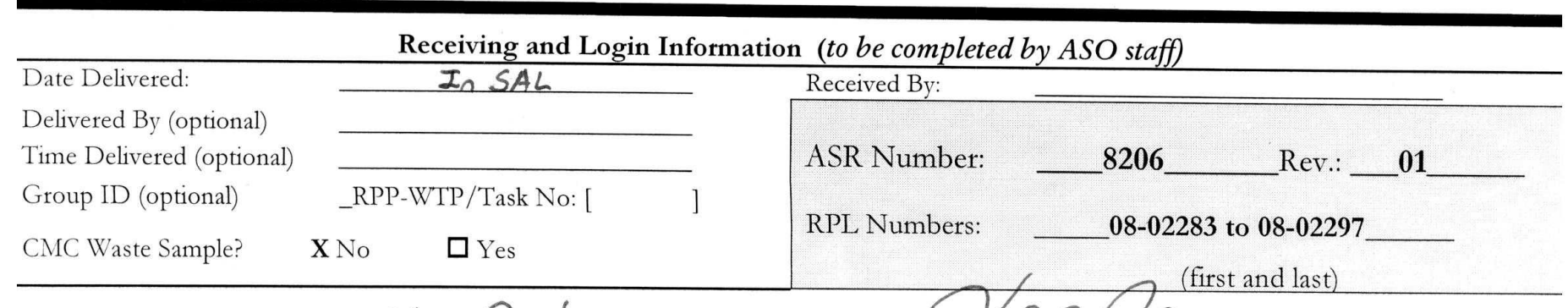




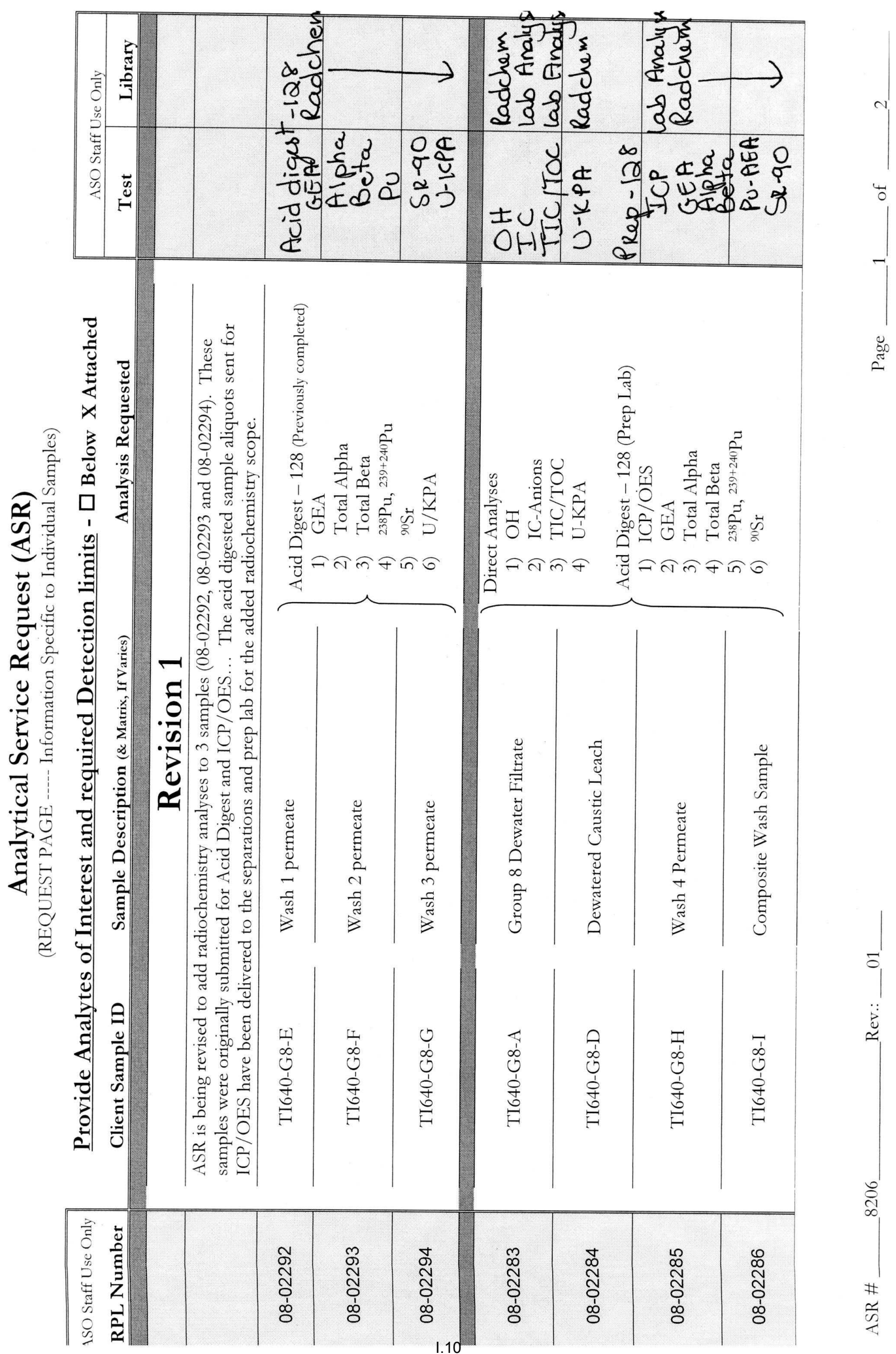



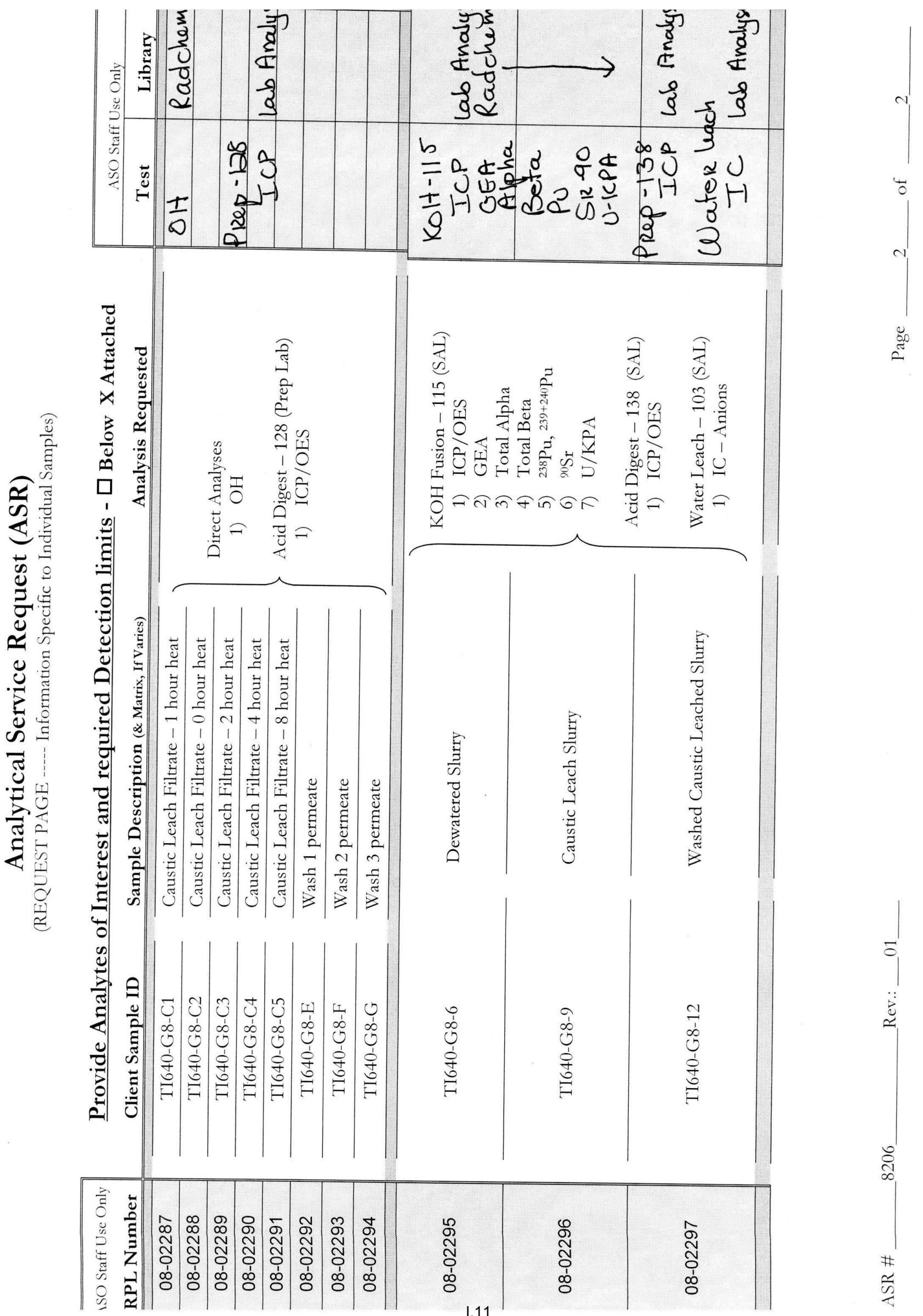
Battelle PNNL/RS\&E/Inorganic Analysis ... ICP-OES Analysis Report PO Box 999, Richland, Washington 99352

$\begin{array}{ll}\text { Project / WP\#: } & 52964 \text { / F99189 } \\ \text { ASR\#: } & 8206 \\ \text { Client: } & \text { R. Shimskey } \\ \text { Total Samples: } & 3 \text { (solid) }\end{array}$

\begin{tabular}{|l|c|c|}
\hline \multicolumn{3}{|c|}{ First } \\
\hline RPL\#: & $08-02295$ & Last \\
\hline Client ID: & T1640-G8-6 & TI6402297 \\
\hline $\begin{array}{l}\text { Sample Preparation: PNL-ALO-115, "Solubilization of Metals from Solids } \\
\text { using a KOH-KNO }\end{array}$ Fusion", 10/6/08 (SAL/ng). & \\
\hline
\end{tabular}

Procedure: $\quad$ RPG-CMC-211, "Determination of Elemental Composition by Inductively Coupled Argon Plasma Optical Emission Spectrometry (ICP-OES)", Rev 2.

Analyst: $\quad \underline{\text { M. Bonebrake and B. Oliver }}$

Analysis Date (File): $\quad \underline{10-08-2008}$ (C0173)

See Chemical Measurement Center 98620 file: $\quad$ ICP-325-405-3

(Calibration and Maintenance Records)

M\&TE Number: $\quad \underline{\text { N827583 (ICP-OES instrument) }}$ $\underline{\text { M19445 }}$ (Mettler AT400 Balance)
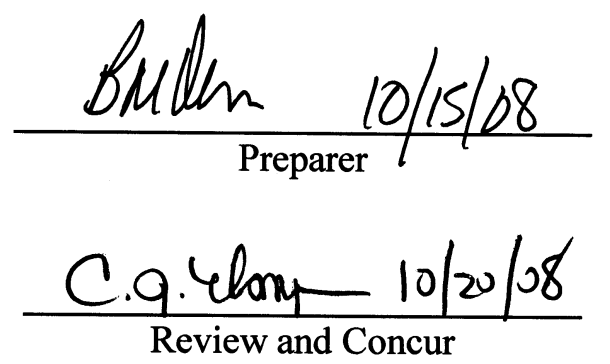


\section{Battelle PNNL/RS\&E/Inorganic Analysis ... ICP-OES Analysis Report}

Three samples submitted under Analytical Service Request (ASR) 8206 were analyzed by ICPOES. The samples were prepared in the Shielded Analytical Laboratory (SAL) following RPL fusion procedure PNL-ALO-115 using a nominal 0.2 grams of sample. The samples were dried to constant mass prior to undergoing fusion and then diluted to a final volume of $100 \mathrm{~mL}$.

Analytes of interest (AOIs) were specified in the ASR, and are listed in the upper section of the attached ICP-OES Data Report. The quality control (QC) results for these AOIs have been evaluated and are presented below. Analytes other than AOIs are reported in the bottom section of the report, but have not been fully evaluated for QC performance. The results are given as $\mu \mathrm{g} / \mathrm{g}$ for each detected analyte, and have been adjusted for all laboratory processing factors and instrument dilutions.

Calibration of the ICP-OES was done following the manufacturer's recommended calibration procedure and using multi-analyte custom standard solutions traceable to the National Institute of Standards and Technology (NIST). Midrange calibration verification standards (MCVA and MCVB) were used to verify acceptance of the two-point calibration curves obtained for each analyte, and also used for continuing calibration verification.

Minimum Method Detection Limit (MDL) values were specified in the ASR. For a number of AOIs, MDL levels were not met, including Al, Fe, Na, S, and Si. Except for sulfur, the MDL values for these analytes have been set artificially high to account for impurities in the fusion flux. It should be noted, however, that the measured levels of these analytes in the samples generally exceeded the requested MDL levels.

The controlling documents were ASO-QAP-001, and the client supplied RPP-WTP-QA-005, Rev. 2, and ASR 8206 Special Instructions. Instrument calibrations, QC checks and blanks (e.g., ICV/ICB, CCV/CCB, LLS, ICS), post-spike, laboratory control standard (LCS), duplicate, and serial dilution were conducted during the analysis run. The LCS was prepared using a nominal 0.1 grams of SRM-2710 (Montana Soil).

\section{Preparation Blank (PB):}

A preparation blank (reagents only) was prepared for the fusion process. The concentrations of all AOIs were within the acceptance criteria of $\leq \mathrm{EQL}$ (estimated quantitation level) or less than $\leq 5 \%$ of the concentration in the sample.

\section{Blank Spike (BS)/Laboratory Control Sample (LCS):}

An LCS (Montana Soil) was prepared for the fusion process. Recovery values are listed for all analytes included in the spike that were measured at or above the EQL. The recovery values were within the acceptance criterion of $80 \%$ to $120 \%$ for all AOIs meeting the above requirement.

Matrix-Spiked Sample:

No matrix spike sample was provided for analysis. 


\section{Battelle PNNL/RS\&E/Inorganic Analysis ... ICP-OES Analysis Report}

\section{Duplicate Relative Percent Difference (RPD):}

A duplicate was prepared for the sample batch. RPDs are listed for all analytes that were measured at or above the EQL. The RPDs were within the client acceptance criterion of $\leq 25 \%$ for all AOIs meeting the above requirement.

\section{Post-Spike/Analytical Spike Sample (A component):}

An analytical spike (A component) was conducted for the sample batch. Recovery values are listed for all analytes in the spike that were measured at or above the EQL, and that had a spike concentration $\geq 25 \%$ of that in the sample. The recovery values were within the client acceptance criterion of $70 \%$ to $130 \%$ for all AOIs meeting the above requirements.

\section{Post Spike/Analytical Spike Sample (B component):}

An analytical spike (B component) was conducted for the sample batch. Recovery values are listed for all analytes in the spike that were measured at or above the EQL, and that had a spike concentration $\geq 25 \%$ of that in the sample. The recovery values were within the client acceptance criterion of $70 \%$ to $130 \%$ for all AOIs meeting the above requirements.

\section{Serial dilution:}

Five-fold serial dilution was conducted for the sample batch. Percent differences (\%Ds) are listed for all analytes that had a concentration at or above the EQL in the diluted sample. The $\%$ Ds were within the acceptance criterion of $\leq 10 \%$ for all AOIs meeting the above requirement.

\section{Other QC:}

All other instrument-related QC tests for the AOIs passed within the appropriate acceptance criteria.

\section{Comments:}

1) The "Final Results" have been corrected for all laboratory dilutions performed on the samples during processing and analysis, unless specifically noted.

2) Instrument detection limits (IDL) and estimated quantitation limits (EQL) shown are for acidified water. Detection limits for other matrices may be determined if requested. Method detection limits (MDL) can be estimated by multiplying the IDL by the "Multiplier". The estimated quantitation limit (EQL) for each concentration value can be obtained by multiplying the EQL by the "Multiplier".

3) Routine precision and bias is typically $\pm 15 \%$ or better for samples in dilute, acidified water (e.g. $2 \%$ v/v $\mathrm{HNO}_{3}$ or less) at analyte concentrations $>$ EQL up to the upper calibration level. This also presumes that the total dissolved solids concentration in the sample is less than $5000 \mu \mathrm{g} / \mathrm{mL}(0.5$ per cent by weight). Note that bracketed values listed in the data report are within the MDL and the EQL, and have potential uncertainties greater than $15 \%$. Concentration values $<$ MDL are listed as ". .". Note, that calibration and QC standards are validated to a precision of $\pm 10 \%$.

4) Absolute precision, bias and detection limits may be determined on each sample if required by the client. The maximum number of significant figures for all ICP measurements is two.

5) Analytes included in the spike A component (for the AS/PS) are; Ag, Al, As, B, Ba, Be, Bi, Ca, Cd, Co, Cr, $\mathrm{Cu}, \mathrm{Fe}, \mathrm{K}, \mathrm{Li}, \mathrm{Mg}, \mathrm{Mn}, \mathrm{Mo}, \mathrm{Na}, \mathrm{Ni}, \mathrm{P}, \mathrm{Pb}, \mathrm{Sb}, \mathrm{Se}, \mathrm{Si}, \mathrm{Sn}, \mathrm{Sr}, \mathrm{Ta}, \mathrm{Ti}, \mathrm{Tl}, \mathrm{V}, \mathrm{W}, \mathrm{Y}, \mathrm{Zn}$, and Zr. Analytes included in the spike B component are; $\mathrm{Ce}, \mathrm{Dy}, \mathrm{Eu}, \mathrm{La}, \mathrm{Nd}, \mathrm{Pd}, \mathrm{Rh}, \mathrm{Ru}, \mathrm{S}, \mathrm{Te}, \mathrm{Th}$, and $\mathrm{U}$. 


\begin{tabular}{|c|c|c|c|c|c|c|c|}
\hline & Run Date > & $10 / 8 / 2008$ & $10 / 8 / 2008$ & $10 / 8 / 2008$ & $10 / 8 / 2008$ & $10 / 8 / 2008$ \\
\hline & & Multiplier > & 2602.5 & 14245.0 & 13192.6 & 11057.1 & 14092.4 \\
\hline & & RPL/LAB > & \begin{tabular}{|c|} 
08-02295-115 \\
B-R1 @5
\end{tabular} & $\begin{array}{c}\text { 08-02295-115 } \\
\text { S-R1 @25 }\end{array}$ & $\begin{array}{c}08-02295-115 \\
\text { D-R1 @25 }\end{array}$ & $\begin{array}{c}08-02296-115 \\
\text { S-R1 @25 }\end{array}$ & $\begin{array}{c}08-02297-115 \\
\text { S-R1 @25 }\end{array}$ \\
\hline $\begin{array}{l}\text { Instr. Det. } \\
\text { Limit (IDL.) }\end{array}$ & $\begin{array}{l}\text { Est. Quant. } \\
\text { Limit (EQL) }\end{array}$ & Client $|\mathrm{D}\rangle$ & Prep Blank & \multicolumn{2}{|c|}{ TI640-G8-6 } & TI640-G8-9 & T1640-G8-12 \\
\hline$(\mu \mathrm{g} / \mathrm{mL})$ & $(\mu \mathrm{g} / \mathrm{mL})$ & (Analyte) & $(\mu \mathrm{g} / \mathrm{g})$ & $(\mu \mathrm{g} / \mathrm{g})$ & $(\mu \mathrm{g} / \mathrm{g})$ & $(\mu \mathrm{g} / \mathrm{g})$ & $(\mu \mathrm{g} / \mathrm{g})$ \\
\hline 0.2900 & 2.900 & Al & -. & {$[39,000]$} & 41,300 & {$[30,000]$} & 41,000 \\
\hline 0.0077 & 0.077 & B & -- & [120] & [120] & - & -- \\
\hline 0.0240 & 0.240 & $\mathrm{Bi}$ & $-\cdot$ & {$[2,100]$} & {$[2,400]$} & 3,600 & 6,270 \\
\hline 0.0029 & 0.029 & $\mathrm{Cd}$ & -- & -- & -- & -- & 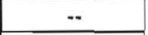 \\
\hline 0.0024 & 0.024 & $\mathrm{Cr}$ & [15] & 1,070 & 1,140 & 1,140 & 1,920 \\
\hline 0.1800 & 1.800 & $\mathrm{Fe}$ & - & 43,100 & 46,000 & 67,800 & 115,000 \\
\hline 4.0000 & 40.000 & $\mathrm{~K}$ & na & na & na & na & na \\
\hline 0.0011 & 0.011 & $\mathrm{Mn}$ & {$[6.1]$} & 540 & 586 & 864 & 1,490 \\
\hline 1.9000 & 19.000 & $\mathrm{Na}$ & -- & {$[210,000]$} & {$[210,000]$} & 212,000 & {$[78,000]$} \\
\hline 0.0400 & 0.400 & $\mathrm{Ni}$ & na & na & na & na & na \\
\hline 0.0540 & 0.540 & $\mathbf{P}$ & -- & 21,600 & 23,100 & 26,000 & 40,000 \\
\hline 0.3300 & 3.300 & $\mathrm{~s}$ & - & {$[6,800]$} & {$[6,400]$} & -- & -- \\
\hline 0.2300 & 2.300 & Si & - & {$[8,000]$} & {$[8,500]$} & {$[12,000]$} & {$[20,000]$} \\
\hline 0.0003 & 0.005 & $\mathrm{Sr}$ & {$[0.78]$} & 16,200 & 17,300 & 25,600 & 43,300 \\
\hline 0.0410 & 0.820 & $\mathrm{U}$ & -- & 46,400 & 48,600 & 71,800 & 121,000 \\
\hline 0.0032 & 0.064 & $\mathrm{Zn}$ & [72] & [120] & [130] & {$[670]$} & {$[500]$} \\
\hline 0.0035 & 0.035 & $\mathrm{Zr}$ & -- & {$[100]$} & [86] & [88] & {$[240]$} \\
\hline
\end{tabular}

\section{Other Analytes}

\begin{tabular}{|c|c|c|c|c|c|c|c|}
\hline 0.0015 & 0.015 & $\mathrm{Ag}$ &.- & .* & -. & -- & -- \\
\hline 0.0390 & 0.390 & As & -- & -- & -- & -- & - \\
\hline 0.0005 & 0.010 & $\mathrm{Ba}$ & {$[2.0]$} & 372 & 401 & 587 & 998 \\
\hline 0.0000 & 0.000 & $\mathrm{Be}$ & -- & -- & - & -. & {$[0.78]$} \\
\hline 1.1000 & 11.000 & $\mathrm{Ca}$ & - & {$[24,000]$} & {$[26,000]$} & {$[38,000]$} & {$[64,000]$} \\
\hline 0.0083 & 0.083 & $\mathrm{Ce}$ & 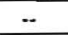 & -. & - & - & -- \\
\hline 0.0027 & 0.027 & Co & 97.7 & {$[67]$} & [65] & [69] & [53] \\
\hline 0.0020 & 0.020 & $\mathrm{Cu}$ & - & -- & -- & {$[160]$} & {$[120]$} \\
\hline 0.0029 & 0.029 & Dy & -- & 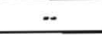 & -- & -- & - \\
\hline 0.0004 & 0.004 & $\mathrm{Eu}$ & -- & -- & -. & -- & -. \\
\hline 0.0027 & 0.027 & La & -- & [54] & [46] & [65] & [120] \\
\hline 0.0019 & 0.019 & $\mathrm{Li}$ & {$[8.2]$} & {$[40]$} & [33] & [43] & [50] \\
\hline 0.0052 & 0.052 & $\mathrm{Mg}$ & -. & 1,310 & 1,230 & 1,810 & 4,320 \\
\hline 0.0072 & 0.072 & Mo & .- & .. & -- & .. & -- \\
\hline 0.0062 & 0.062 & $\mathrm{Nd}$ & -. & $\ldots$ & -- & [82] & -- \\
\hline 0.0320 & 0.320 & $\mathrm{~Pb}$ & -- & {$[2,100]$} & {$[2,700]$} & {$[2,900]$} & 5,200 \\
\hline 0.0064 & 0.064 & $\mathrm{Pd}$ & [24] & [120] & [120] & -- & -- \\
\hline 0.0130 & 0.130 & Rh &.. & -- & -- & -- & -- \\
\hline 0.0067 & 0.067 & Ru & -- & .. & -- &.. & -- \\
\hline 0.0310 & 0.310 & $\mathrm{Sb}$ & -- & .- & -- &.- & -- \\
\hline 0.1100 & 1.100 & Se &.- & -- &.- &. &.- \\
\hline 0.0250 & 0.250 & Sn & -- & - & -- & -- & -- \\
\hline 0.0200 & 0.200 & $\mathrm{Ta}$ & -- & -- & -- & -- & -- \\
\hline 0.0260 & 0.260 & $\mathrm{Te}$ &.. & -- & -. & -- & .- \\
\hline 0.0084 & 0.084 & Th & -- & -- & -- & -- & -- \\
\hline 0.0005 & 0.005 & $\mathrm{Ti}$ & -- & 122 & 129 & 193 & 339 \\
\hline 0.0300 & 0.300 & $\mathrm{TI}$ & -- & .- & -- & - & -- \\
\hline 0.0032 & 0.032 & v & -- & .- & -- & -- & -- \\
\hline 0.0210 & 0.210 & w & -- & -. & - & -- & - \\
\hline 0.0003 & 0.003 & $Y$ & -- & {$[16]$} & [15] & [25] & [41] \\
\hline
\end{tabular}

1) "-" indicates the value is $<$ MDL. The method detection limit (MDL) $=10 L$ times the "multiplier" near the top of each column. The estimated sample quantitation limit $=E Q L$ (in Column 2) times the "multiplier". Overall error for values $\geq E Q L$ is estimated to be within $\pm 15 \%$. 2) Values in brackets [] are $\geq M D L$ but $<E Q L$, with errors likely to exceed $15 \%$. 


\begin{tabular}{|c|c|c|c|c|c|c|}
\hline Criteria > & $\leq 20 \%$ & $80 \%-120 \%$ & $75 \%-125 \%$ & $75 \%-125 \%$ & $75 \%-125 \%$ & $\leq 10 \%$ \\
\hline$Q C \mid D>$ & $\begin{array}{c}\text { 08-02295 } \\
\text { Dup }\end{array}$ & LCS/BS & MS (none) & $\begin{array}{c}08-02295+ \\
\text { AS-A }\end{array}$ & $\begin{array}{c}08-02295+ \\
\text { AS-B }\end{array}$ & $\begin{array}{c}\text { 08-02295 } \\
\text { 5-fold } \\
\text { Serial Dil }\end{array}$ \\
\hline Analytes & RPD (\%) & $\%$ Rec & $\% \operatorname{Rec}$ & $\% \operatorname{Rec}$ & $\% \operatorname{Rec}$ & $\%$ Diff \\
\hline Al & & 97 & & 105 & & \\
\hline B & & & & 109 & & \\
\hline $\mathrm{Bi}$ & & & & 97 & & \\
\hline $\mathrm{Cd}$ & & & & 105 & & \\
\hline $\mathrm{Cr}$ & 6.6 & & & 103 & & \\
\hline $\mathrm{Fe}$ & 6.6 & 99 & i & 105 & & \\
\hline $\mathrm{K}$ & na & na & na & na & na & na \\
\hline$M n$ & 8.3 & 100 & & 105 & & \\
\hline $\mathrm{Na}$ & & & & 100 & & \\
\hline $\mathrm{Ni}$ & na & na & na & na & na & na \\
\hline$P$ & 6.7 & & & 102 & & \\
\hline $\mathbf{s}$ & & & & & 101 & \\
\hline $\mathrm{Si}$ & & 93 & & 100 & & \\
\hline $\mathrm{Sr}$ & 6.3 & 96 & & 108 & & 0.7 \\
\hline $\mathrm{U}$ & 6.8 & & & & 100 & \\
\hline $\mathrm{Zn}$ & & 93 & & 106 & & \\
\hline $\mathrm{Zr}$ & & & & 105 & & \\
\hline \multicolumn{7}{|c|}{ Other Analytes } \\
\hline $\mathrm{Ag}$ & & & & 94 & & \\
\hline As & & & & 104 & & \\
\hline $\mathrm{Ba}$ & 7.7 & 93 & & 101 & & \\
\hline $\mathrm{Be}$ & & & & 101 & & \\
\hline $\mathrm{Ca}$ & & & & 101 & & \\
\hline $\mathrm{Ce}$ & & & & & 98 & \\
\hline Co & & $\mathrm{nr}$ & & 104 & & \\
\hline $\mathrm{Cu}$ & & 99 & & 108 & & \\
\hline Dy & & & & & 101 & \\
\hline Eu & & & & & 101 & \\
\hline La & & & & & 99 & \\
\hline $\mathrm{Li}$ & & & & 102 & & \\
\hline $\mathrm{Mg}$ & 6.7 & 90 & & 103 & & \\
\hline Mo & & & & 104 & & \\
\hline $\mathrm{Nd}$ & & & & & 101 & \\
\hline $\mathrm{Pb}$ & & 93 & & 104 & & \\
\hline $\mathrm{Pd}$ & & & & & 96 & \\
\hline $\mathrm{Rh}$ & & & & & 98 & \\
\hline Ru & & & & & 100 & \\
\hline $\mathrm{Sb}$ & & & & 103 & & \\
\hline $\mathrm{Se}$ & & & & 107 & & \\
\hline Sn & & & & 103 & & \\
\hline $\mathrm{Ta}$ & & & & 103 & & \\
\hline $\mathrm{Te}$ & & & & & 101 & \\
\hline Th & & & & & 101 & \\
\hline $\mathrm{Ti}$ & 5.4 & 91 & & 103 & & \\
\hline $\mathrm{TI}$ & & & & 100 & & \\
\hline v & & & & 100 & & \\
\hline $\mathbf{w}$ & & & & 104 & & \\
\hline $\mathbf{Y}$ & & 91 & & 101 & & \\
\hline
\end{tabular}

Shaded results are outside the acceptance criteria.

$n r=$ spike concentration less than $25 \%$ of sample concentration. Matrix effects can be assessed from the serial dilution.

$n a=$ not applicable; $\mathrm{KOH}$ flux and Nicrucible or $\mathrm{Na}_{2} \mathrm{O}_{2}$ flux and $\mathrm{Zr}$ crucible for fusion preparations, or Si for HF assisted digests. 
Battelle PNNL/RS\&E/Inorganic Analysis ... ICP-OES Analysis Report PO Box 999, Richland, Washington 99352

$\begin{array}{ll}\text { Project / WP\#: } & 52964 \text { / F99189 } \\ \text { ASR\#: } & 8206 \\ \text { Client: } & \text { R. Shimskey } \\ \text { Total Samples: } & 12 \text { (liquid) }\end{array}$

\begin{tabular}{|l|c|c|}
\hline \multicolumn{3}{|c|}{ First } \\
\hline RPL\#: & $08-02283$ & Last \\
\hline Client ID: & TI640-G8-A & TI640-G8-G \\
\hline Sample Preparation: RPG-CMC-128, "HNO & -HCl Acid Extraction of \\
Liquids for Metals Analysis Using a Dry-Block Heater", 9/9/08 (SRPL/ms). \\
\hline
\end{tabular}

Procedure: $\quad$ RPG-CMC-211, "Determination of Elemental Composition by Inductively Coupled Argon Plasma Optical Emission Spectrometry (ICP-OES)", Rev 2.

Analyst: $\quad \underline{\text { M. Bonebrake and B. Oliver }}$

Analysis Date (File): $\quad \underline{10-01-2008}$ (C0172)

See Chemical Measurement Center 98620 file: $\underline{\text { ICP-325-405-3 }}$

(Calibration and Maintenance Records)

M\&TE Number: $\quad \underline{\text { N827583 }}$ (ICP-OES instrument) $\underline{\text { M19445 (Mettler AT400 Balance) }}$

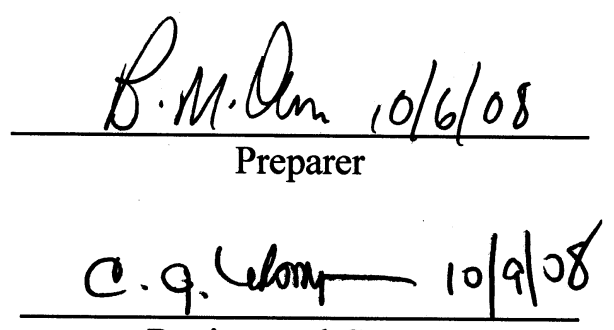

Review and Concur 
Battelle PNNL/RS\&E/Inorganic Analysis ... ICP-OES Analysis Report

Twelve samples submitted under Analytical Service Request (ASR) 8206 were analyzed by ICPOES. The samples were prepared in the RPL Sample Receiving and Preparation Laboratory (SRPL) following Procedure RPG-CMC-128 using $1 \mathrm{~mL}$ of sample and diluting to a final volume of approximately $25 \mathrm{~mL}$.

Analytes of interest (AOIs) were specified in the ASR, and are listed in the upper section of the attached ICP-OES Data Report. The quality control (QC) results for these AOIs have been evaluated and are presented below. Analytes other than AOIs are reported in the bottom section of the report, but have not been fully evaluated for QC performance. The results are given as $\mu \mathrm{g} / \mathrm{mL}$ for each detected analyte, and have been adjusted for all laboratory processing factors and instrument dilutions.

Calibration of the ICP-OES was done following the manufacturer's recommended calibration procedure and using multi-analyte custom standard solutions traceable to the National Institute of Standards and Technology (NIST). Midrange calibration verification standards (MCVA and MCVB) were used to verify acceptance of the two-point calibration curves obtained for each analyte, and also used for continuing calibration verification.

Minimum Method Detection Limit (MDL) values were specified in the ASR. MDL levels were met for all AOIs.

The controlling documents were ASO-QAP-001, and the client supplied RPP-WTP-QA-005, Rev. 2 and ASR 8206 Special Instructions. Instrument calibrations, QC checks and blanks (e.g., ICV/ICB, CCV/CCB, LLS, ICS), post-spike, blank spike, matrix spike, duplicate, and serial dilution were conducted during the analysis run. The blank spike and matrix spike were prepared using $1 \mathrm{~mL}$ each of BPNL-QC-1A and -2B solutions.

\section{Preparation Blank (PB):}

A preparation blank (reagents only) was prepared for the extraction process. The concentrations of all AOIs were within the acceptance criteria of $\leq$ EQL (estimated quantitation level) or less than $\leq 5 \%$ of the concentration in the sample.

\section{Blank Spike (BS)/Laboratory Control Sample (LCS):}

A blank spike was prepared for the extraction process. Recovery values are listed for all analytes included in the spike that were measured at or above the EQL. The recovery values were within the acceptance criterion of $80 \%$ to $120 \%$ for all AOIs meeting the above requirement.

\section{Matrix-Spiked Sample:}

A matrix spike was prepared for the extraction process. Recovery values are listed for all analytes in the spike that were measured at or above the EQL, and that had a spike concentration $\geq 25 \%$ of that in the sample. The recovery values were within the acceptance criterion of $75 \%$ to $125 \%$ for all AOIs meeting the above requirements. 


\section{Battelle PNNL/RS\&E/Inorganic Analysis ... ICP-OES Analysis Report}

\section{Duplicate Relative Percent Difference (RPD):}

A duplicate was prepared for the extraction process. RPDs are listed for all analytes that were measured at or above the EQL. The RPDs were within the acceptance criterion of $\leq 20 \%$ for all AOIs meeting the above requirement.

\section{Post-Spike/Analytical Spike Sample (A component):}

A post spike (A component) was conducted on one sample from the analysis batch. Recovery values are listed for all analytes in the spike that were measured at or above the EQL, and that had a spike concentration $\geq 25 \%$ of that in the sample. The recovery values were within the acceptance criterion of $75 \%$ to $125 \%$ for all AOIs meeting the above requirements.

Post Spike/Analytical Spike Sample (B component):

A post spike (B component) was conducted on one sample from the analysis batch. Recovery values are listed for all analytes in the spike that were measured at or above the EQL, and that had a spike concentration $\geq 25 \%$ of that in the sample. The recovery values were within the acceptance criterion of $75 \%$ to $125 \%$ for all AOIs meeting the above requirements.

\section{Serial dilution:}

Five-fold serial dilution was conducted on one sample from the analysis batch. Percent differences (\%Ds) are listed for all analytes that had a concentration at or above the EQL in the diluted sample. The $\%$ Ds were within the acceptance criterion of $\leq 10 \%$ for all AOIs meeting the above requirement.

\section{Other QC:}

Sodium was slightly outside the range of $\pm \mathrm{EQL}$ for several of the CCBs. In all cases, however, the sodium levels in the CCBs were $<1 \%$ of those measured in the samples, and thus had no statistical effect on the reported sodium data. All other instrument-related QC tests for the AOIs passed within the appropriate acceptance criteria.

\section{Comments:}

1) The "Final Results" have been corrected for all laboratory dilutions performed on the samples during processing and analysis, unless specifically noted.

2) Instrument detection limits (IDL) and estimated quantitation limits (EQL) shown are for acidified water. Detection limits for other matrices may be determined if requested. Method detection limits (MDL) can be estimated by multiplying the IDL by the "Multiplier". The estimated quantitation limit (EQL) for each concentration value can be obtained by multiplying the EQL by the "Multiplier".

3) Routine precision and bias is typically $\pm 15 \%$ or better for samples in dilute, acidified water (e.g. $2 \% \mathrm{v} / \mathrm{v}$ $\mathrm{HNO}_{3}$ or less) at analyte concentrations $>\mathrm{EQL}$ up to the upper calibration level. This also presumes that the total dissolved solids concentration in the sample is less than $5000 \mu \mathrm{g} / \mathrm{mL}(0.5$ per cent by weight). Note that bracketed values listed in the data report are within the MDL and the EQL, and have potential uncertainties greater than $15 \%$. Concentration values $<$ MDL are listed as ". .". Note, that calibration and QC standards are validated to a precision of $\pm 10 \%$.

4) Absolute precision, bias and detection limits may be determined on each sample if required by the client. The maximum number of significant figures for all ICP measurements is two. 


\section{Battelle PNNL/RS\&E/Inorganic Analysis ... ICP-OES Analysis Report}

5) Analytes included in the spike A component (for the AS/PS) are; $\mathrm{Ag}, \mathrm{Al}, \mathrm{As}, \mathrm{B}, \mathrm{Ba}, \mathrm{Be}, \mathrm{Bi}, \mathrm{Ca}, \mathrm{Cd}, \mathrm{Co}, \mathrm{Cr}$, $\mathrm{Cu}, \mathrm{Fe}, \mathrm{K}, \mathrm{Li}, \mathrm{Mg}, \mathrm{Mn}, \mathrm{Mo}, \mathrm{Na}, \mathrm{Ni}, \mathrm{P}, \mathrm{Pb}, \mathrm{Sb}, \mathrm{Se}, \mathrm{Si}, \mathrm{Sn}, \mathrm{Sr}, \mathrm{Ta}, \mathrm{Ti}, \mathrm{Tl}, \mathrm{V}, \mathrm{W}, \mathrm{Y}, \mathrm{Zn}$, and Zr. Analytes included in the spike B component are; Ce, Dy, Eu, La, Nd, Pd, Rh, Ru, S, Te, Th, and U. 


\begin{tabular}{|c|c|c|c|c|c|c|c|c|}
\hline & \\
\hline & & Run Date > & $10 / 1 / 2008$ & $10 / 1 / 2008$ & $10 / 1 / 2008$ & $10 / 1 / 2008$ & $10 / 1 / 2008$ & $10 / 1 / 2008$ \\
\hline & & Multiplier > & 24.1 & 126.7 & 125.3 & 122.6 & 126.2 & 124.3 \\
\hline & & RPL/LAB > & $\begin{array}{c}08-02283- \\
\text { PB } \\
\end{array}$ & $\begin{array}{c}08-02283 \\
@ 5\end{array}$ & $\begin{array}{c}08-02283- \\
\text { Dup @5 } \\
\end{array}$ & $\begin{array}{c}08-02284 \\
\text { @5 }\end{array}$ & $\begin{array}{c}\text { 08-02285 } \\
\text { @5 }\end{array}$ & $\begin{array}{c}08-02286 \\
@ 5 \\
\end{array}$ \\
\hline $\begin{array}{l}\text { Instr. Det. } \\
\text { Limit (IDL) } \\
\end{array}$ & $\begin{array}{l}\text { Est. Quant. } \\
\text { Limit (EQL) }\end{array}$ & Client ID > & Prep Blank & \multicolumn{2}{|c|}{ T1640-G8-A } & TI640-G8-D & $\mathrm{Tl640-G8- \textrm {H }}$ & T1640-G8-1 \\
\hline$(\mu \mathrm{g} / \mathrm{mL})$ & $(\mu \mathrm{g} / \mathrm{mL})$ & (Analyte) & $(\mu \mathrm{g} / \mathrm{mL})$ & $(\mu \mathrm{g} / \mathrm{mL})$ & $(\mu \mathrm{g} / \mathrm{mL})$ & $(\mu \mathrm{g} / \mathrm{mL})$ & $(\mu \mathrm{g} / \mathrm{mL})$ & $(\mu \mathrm{g} / \mathrm{mL})$ \\
\hline 0.0060 & 0.060 & $\mathrm{Al}$ & {$[0.25]$} & 1,470 & 1,460 & 4,570 & 213 & 3,750 \\
\hline 0.0048 & 0.096 & B & {$[0.55]$} & 65.8 & 59.7 & 31.8 & [6.1] & {$[9.8]$} \\
\hline 0.0300 & 0.300 & $\mathrm{Bi}$ & [2.1] & - & - & - & - & - \\
\hline 0.0021 & 0.021 & $\mathrm{Cd}$ & {$[0.34]$} & {$[1.6]$} & {$[1.6]$} & [1.8] & {$[1.8]$} & [1.5] \\
\hline 0.0017 & 0.017 & $\mathrm{Cr}$ & {$[0.17]$} & 80.0 & 79.3 & 63.9 & 3.26 & 146 \\
\hline 0.0009 & 0.018 & $\mathrm{Fe}$ & {$[0.27]$} & 23.8 & 23.5 & 14.2 & 3.19 & {$[2.0]$} \\
\hline 0.0720 & 0.720 & $\mathrm{~K}$ & [15] & 1,270 & 1,280 & 785 & [58] & 213 \\
\hline 0.0002 & 0.005 & $\mathrm{Mn}$ & - & {$[0.087]$} & {$[0.073]$} & {$[0,15]$} & - & - \\
\hline 0.0160 & 0.320 & $\mathrm{Na}$ & - & 78,400 & 78,700 & 119,000 & 7,140 & 63,100 \\
\hline 0.0024 & 0.024 & $\mathrm{Ni}$ & {$[0.059]$} & 54.1 & 53.8 & 19.6 & {$[1,4]$} & {$[0.45]$} \\
\hline 0.0500 & 0.500 & 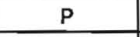 & - & 2,450 & 2,430 & 780 & 73.4 & 507 \\
\hline 0.1600 & 1.600 & $\mathrm{~s}$ & - & 2,240 & 2,220 & 1,060 & [65] & 283 \\
\hline 0.0056 & 0.056 & $\mathrm{Si}$ & {$[0.40]$} & 17.3 & 16.4 & 57.8 & 7.58 & 19.4 \\
\hline 0.0001 & 0.002 & $\mathrm{Sr}$ & {$[0.0022]$} & {$[0.10]$} & {$[0.11]$} & {$[0.18]$} & {$[0.022]$} & {$[0.020]$} \\
\hline 0.0320 & 0.320 & U & {$[0.97]$} & [13] & [10] & [13] & [9.2] & {$[6.9]$} \\
\hline 0.0028 & 0.056 & $\mathrm{Zn}$ & {$[1.0]$} & {$[1.8]$} & [1.5] & {$[4.0]$} & [1.6] & [3.2] \\
\hline 0.0011 & 0.011 & $\mathrm{Zr}$ & - & - & - & - & - & {$[0.20]$} \\
\hline \multicolumn{9}{|c|}{ Other Analytes } \\
\hline 0.0021 & 0.021 & $\mathrm{Ag}$ & - & {$[0.42]$} & {$[0.55]$} & {$[0.59]$} & - & - \\
\hline 0.0860 & 0.860 & As & - & - & - & - & - & [12] \\
\hline 0.0003 & 0.005 & $\mathrm{Ba}$ & - & {$[0.17]$} & {$[0.16]$} & {$[0.41]$} & {$[0.036]$} & {$[0.11]$} \\
\hline 0.0001 & 0.001 & $\mathrm{Be}$ & - & - & {$[0.0086]$} & {$[0.064]$} & {$[0.0079]$} & {$[0.016]$} \\
\hline 0.0120 & 0.120 & $\mathrm{Ca}$ & {$[0.73]$} & [4.5] & [5.8] & [4.2] & [2.2] & [3.8] \\
\hline 0.0100 & 0.100 & $\mathrm{Ce}$ & - & - & - & - & - & - \\
\hline 0.0024 & 0.024 & Co & - & {$[0.87]$} & {$[0.96]$} & {$[0.36]$} & - & - \\
\hline 0.0014 & 0.014 & $\mathrm{Cu}$ & - & - & - & {$[0.60]$} & - & {$[0.22]$} \\
\hline 0.0029 & 0.029 & Dy & - & - & - & -- & $=$ & - \\
\hline 0.0011 & 0.011 & Eu & - & - & - & - & - & -- \\
\hline 0.0028 & 0.028 & La & - & - & - & - & -- & - \\
\hline 0.0006 & 0.012 & $\mathrm{Li}$ & {$[0.051]$} & {$[0.50]$} & {$[0.42]$} & {$[0.36]$} & {$[0.17]$} & {$[1.4]$} \\
\hline 0.0023 & 0.023 & $\mathrm{Mg}$ & {$[0.091]$} & - & - & - & - & - \\
\hline 0.0052 & 0.052 & Mo & - & [3.2] & {$[3.0]$} & [1.6] & -- & {$[3.8]$} \\
\hline 0.0200 & 0.200 & $\mathrm{Nd}$ & - & - & - & - & $\cdots$ & - \\
\hline 0.0320 & 0.320 & $\mathrm{~Pb}$ & [1.2] & -- & - & 82.8 & 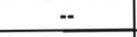 & [4.3] \\
\hline 0.0063 & 0.063 & $\mathrm{Pd}$ & {$[0.17]$} & {$[0,99]$} & - & {$[0.80]$} & -- & - \\
\hline 0.0120 & 0.120 & Rh & - & - & {$[1.5]$} & - & -- & {$[1.7]$} \\
\hline 0.0085 & 0.085 & $\mathrm{Ru}$ & - & - & - & -- & -- & {$[1.2\rceil$} \\
\hline 0.0200 & 0.200 & $\mathrm{Sb}$ & {$[0.51]$} & - & - & - & 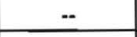 & - \\
\hline 0.0700 & 0.700 & $\mathrm{Se}$ & - & - & - & -- & - & -- \\
\hline 0.0270 & 0.270 & $\mathrm{Sn}$ & - & [9.8] & [10] & {$[6.0]$} & -- & - \\
\hline 0.0170 & 0.170 & $\mathrm{Ta}$ & - & - & - & - & - & - \\
\hline 0.0260 & 0.260 & $\mathrm{Te}$ & - & - & 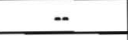 & - & -- & - \\
\hline 0.0098 & 0.098 & Th & - & - & - & - & - & - \\
\hline 0.0004 & 0.004 & $\mathrm{Ti}$ & - & - & - & - & - & - \\
\hline 0.0380 & 0.380 & $\mathrm{TI}$ & - & - & - & - & - & -- \\
\hline 0.0007 & 0.007 & V & {$[0.072]$} & {$[0.52]$} & {$[0.58]$} & {$[0.59]$} & {$[0.40]$} & {$[0.79]$} \\
\hline 0.0150 & 0.150 & $w$ & - & {$[5.0]$} & [4.3] & - & - & [7.7] \\
\hline 0.0004 & 0.004 & $Y$ & -- & - & - & - & -- & - \\
\hline
\end{tabular}

1) "--" indicates the value is $<M D L$. The method detection limit (MDL) $=I D L$ times the "multiplier" near the top of each column. The estimated sample quantitation limit $=E Q L$ (in Column 2) times the "multiplier". Overall error for values $\geq E Q L$ is estimated to be within $\pm 15 \%$.

2) Values in brackets [] are $\geq M O L$ but $<E Q L$, with errors likely to exceed $15 \%$. 


\begin{tabular}{|c|c|c|c|c|c|c|c|c|}
\hline Run Date > & $10 / 1 / 2008$ & $10 / 1 / 2008$ & $10 / 1 / 2008$ & $10 / 1 / 2008$ & $10 / 1 / 2008$ & $10 / 1 / 2008$ & $10 / 1 / 2008$ & $10 / 1 / 2008$ \\
\hline Multiplier > & 124.8 & 125.8 & 122.0 & 121.0 & 120.0 & 122.0 & 123.1 & 117.8 \\
\hline RPL/LAB > & $\begin{array}{c}08-02287 \\
@ 5\end{array}$ & $\begin{array}{c}08-02288 \\
\text { @5 }\end{array}$ & $\begin{array}{c}\text { 08-02289 } \\
\text { @5 }\end{array}$ & $\begin{array}{c}08-02290 \\
@ 5\end{array}$ & $\begin{array}{c}08-02291 \\
@ 5\end{array}$ & $\begin{array}{c}08-02292 \\
@ 5\end{array}$ & $\begin{array}{c}08-02293 \\
\text { @5 }\end{array}$ & $\begin{array}{c}08-02294 \\
@ 5\end{array}$ \\
\hline Client ID > & II640-G8-C1 & II640-G8-C2 & II640-G8-C3 & II640-G8-C4 & T1640-G8-C5 & $\mathrm{I} \mid 640-\mathrm{G} 8-\mathrm{E}$ & TI640-G8-F & T1640-G8-G \\
\hline (Analyte) & $(\mu \mathrm{g} / \mathrm{mL})$ & $(\mu \mathrm{g} / \mathrm{mL})$ & $(\mu \mathrm{g} / \mathrm{mL})$ & $(\mu \mathrm{g} / \mathrm{mL})$ & $(\mu \mathrm{g} / \mathrm{mL})$ & $(\mu \mathrm{g} / \mathrm{mL})$ & $(\mu \mathrm{g} / \mathrm{mL})$ & $(\mu \mathrm{g} / \mathrm{mL})$ \\
\hline $\mathrm{Al}$ & 4,580 & 4,600 & 4,520 & 4,600 & 4,650 & 2,600 & 1,030 & 465 \\
\hline B & 31.1 & 33.3 & 31.6 & 31.6 & 31.0 & 21.8 & {$[8.8]$} & {$[4.5]$} \\
\hline $\mathrm{Bi}$ & -- & -- & -- & - & - & - & - & - \\
\hline $\mathrm{Cd}$ & {$[1.7]$} & {$[1.6]$} & {$[1.8]$} & {$[1.7]$} & [1.6] & [1.5] & {$[1,3]$} & {$[1.6]$} \\
\hline $\mathrm{Cr}$ & 63.5 & 49.3 & 51.3 & 54.9 & 61.3 & 38.0 & 14.8 & 6.57 \\
\hline $\mathrm{Fe}$ & 13.7 & 15.3 & 14.3 & 14.3 & 14.5 & 10.2 & 4.93 & 3.71 \\
\hline $\bar{K}$ & 788 & 800 & 861 & 865 & 883 & 630 & 212 & 91.5 \\
\hline $\mathrm{Mn}$ & {$[0.094]$} & {$[0.13]$} & [0.10] & {$[0.11]$} & {$[0.072]$} & {$[0.072]$} & -- & - \\
\hline $\mathrm{Na}$ & 119,000 & 128,000 & 120,000 & 120,000 & 120,000 & 90,800 & 32,500 & 14,700 \\
\hline $\mathrm{Ni}$ & 19.5 & 21.5 & 18.8 & 18.6 & 18.0 & 15.3 & 4.71 & [2.2] \\
\hline $\mathbf{P}$ & 756 & 783 & 774 & 763 & 1,040 & 851 & 358 & 156 \\
\hline $\mathrm{s}$ & 1,030 & 1,110 & 1,050 & 1,050 & 1,030 & 737 & 241 & [120] \\
\hline $\mathrm{Si}$ & 54.3 & 90.1 & 77.4 & 74.6 & 59.4 & 43.4 & 16.9 & 9.58 \\
\hline $\mathrm{Sr}$ & {$[0.17]$} & [0.15] & [0.13] & 0.219 & [0.11] & {$[0.12]$} & {$[0.17]$} & {$[0.020]$} \\
\hline $\mathrm{u}$ & [11] & [23] & [14] & [13] & [11] & {$[14]$} & {$[9.6]$} & {$[10]$} \\
\hline $\mathrm{Zn}$ & [3.5] & [5.1] & 46.7 & {$[5.8]$} & {$[3.3]$} & [2.9] & [1.4] & {$[1.4]$} \\
\hline $\mathrm{Zr}$ & - & -- & -- & -- & - & -- & - & -- \\
\hline
\end{tabular}

\begin{tabular}{|c|c|c|c|c|c|c|c|c|}
\hline $\mathrm{Ag}$ & {$[0.78]$} & {$[0.43]$} & {$[0,60]$} & {$[0.59]$} & {$[0.47]$} & {$[0.52]$} & - & -- \\
\hline As & - & -- & -- & [12] & - & - & - & - \\
\hline $\mathrm{Ba}$ & {$[0.54]$} & 4.49 & 3.47 & 3.31 & {$[0.22]$} & 1.02 & {$[0.060]$} & {$[0.057]$} \\
\hline $\mathrm{Be}$ & {$[0.042]$} & {$[0,036]$} & {$[0.038]$} & {$[0,050]$} & {$[0.055]$} & {$[0.018]$} & {$[0.0099]$} & -- \\
\hline $\mathrm{Ca}$ & {$[1.9]$} & {$[5.8]$} & {$[3.6]$} & 40.5 & {$[9,1]$} & 18.7 & {$[1.8]$} & {$[6.9]$} \\
\hline $\mathrm{Ce}$ & - & -- & - & - & - & - & -- & -- \\
\hline Co & {$[0.50]$} & {$[0.51]$} & {$[0.47]$} & {$[0,65]$} & {$[0.54]$} & {$[0.60]$} & -- & -- \\
\hline $\mathrm{Cu}$ & {$[0.72]$} & [1.4] & [1.3] & [1.5] & {$[0.97]$} & - & -- & -- \\
\hline Dy & -- & -- & 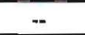 & -- & -- & -- & - & -. \\
\hline $\mathrm{Eu}$ & -- & .- & -- & -- & -- & - & -- & -- \\
\hline $\mathrm{La}$ & -- & - & - & -- & - & - & -- & -- \\
\hline $\mathrm{Li}$ & {$[0.52]$} & {$[0.48]$} & {$[0.76]$} & {$[0.36]$} & {$[0,12]$} & {$[0.61]$} & {$[0.18]$} & -- \\
\hline $\mathrm{Mg}$ & - & -- & -- & - & - & -- & -- & {$[0.66]$} \\
\hline Mo & {$[1.7]$} & {$[1.3]$} & [1.7] & [1.5] & {$[1.8]$} & [1.1] & $r$ & - \\
\hline $\mathrm{Nd}$ & -- & -- & -- & -- & - & -- & -- & - \\
\hline $\mathrm{Pb}$ & 83.0 & 97.8 & 92.9 & 94.5 & 98.6 & 45.7 & {$[6.5]$} & {$[4.6]$} \\
\hline $\mathrm{Pd}$ & -- & -- & - & -- & - & - & [1.1] & -- \\
\hline $\mathrm{Rh}$ & [2.9] & {$[2.4]$} & {$[1.7]$} & -- & {$[1.7]$} & [2.0] & -- & - \\
\hline $\mathrm{Ru}$ & -- & -- & -- & - & - & - & - & - \\
\hline $\mathrm{Sb}$ & -- & -- & - & - & - & -- & {$[3.2]$} & -- \\
\hline $\mathrm{Se}$ & {$[10]$} & - & - & {$[10]$} & -- & -- & $=$ & -- \\
\hline Sn & [6.2] & [7.3] & {$[6.5]$} & [6.6] & {$[5.8]$} & [3.5] & -- & -- \\
\hline $\mathrm{Ta}$ & -- & - & $-\cdot$ & -- & - & -- & -- & -- \\
\hline $\mathrm{Te}$ & -- & -- & -- & -- & -- & -- & -- & -- \\
\hline Th & -- & - & -- & - & - & - & -- & -- \\
\hline $\mathrm{Ti}$ & - & - & -- & -- & - & - & {$[0.054]$} & -- \\
\hline $\mathrm{TI}$ & - & -- & -- & $-\cdot$ & -- & -- & - &.- \\
\hline $\mathrm{v}$ & {$[0.67]$} & {$[0.51]$} & {$[0.54]$} & {$[0.53]$} & {$[0.65]$} & [0.55] & {$[0.41]$} & {$[0.34]$} \\
\hline$w$ & -- & [3.1] & {$[4,4]$} & [3.7] & {$[2.7]$} & {$[2.7]$} & -- & - \\
\hline$Y$ & $m$ & -- & $\cdots$ & -- & -- & -- & -- & -- \\
\hline
\end{tabular}




\begin{tabular}{|c|c|c|c|c|c|c|}
\hline Criteria > & $\leq 20 \%$ & $80 \%-120 \%$ & $75 \%-125 \%$ & $75 \%-125 \%$ & $75 \%-125 \%$ & $\leq 10 \%$ \\
\hline$Q C$ ID > & $\begin{array}{c}\text { 08-02283 } \\
\text { Dup }\end{array}$ & LCS/BS & $\begin{array}{c}08-02284 \\
\text { MS } \\
\end{array}$ & $\begin{array}{c}08-02284+ \\
\text { PS-A }\end{array}$ & $\begin{array}{c}08-02284+ \\
\text { PS-B }\end{array}$ & $\begin{array}{c}08-02283 \\
5 \text {-fold } \\
\text { Serial Dil }\end{array}$ \\
\hline Analytes & RPD (\%) & $\% \operatorname{Rec}$ & $\% \operatorname{Rec}$ & $\% \operatorname{Rec}$ & $\% \operatorname{Rec}$ & \%Diff \\
\hline $\mathrm{Al}$ & 0.8 & 103 & 104 & 107 & & 3.0 \\
\hline B & 9.7 & 110 & 103 & 111 & & 4.6 \\
\hline $\mathrm{Bi}$ & & 89 & 95 & 95 & & \\
\hline $\mathrm{Cd}$ & & 100 & 103 & 102 & & \\
\hline $\mathrm{Cr}$ & 0.9 & 99 & 99 & 103 & & 0.7 \\
\hline $\mathrm{Fe}$ & 1.5 & 100 & 102 & 102 & & 3.1 \\
\hline $\mathrm{K}$ & 0.6 & 105 & 109 & 104 & & 3.2 \\
\hline $\mathrm{Mn}$ & & 104 & 104 & 104 & & \\
\hline $\mathrm{Na}$ & 0.4 & 98 & $\mathrm{nr}$ & $\mathrm{nr}$ & & 4.8 \\
\hline $\mathrm{Ni}$ & 0.6 & 101 & 102 & 103 & & 4.9 \\
\hline P & 0.6 & 102 & 90 & 104 & & 1.5 \\
\hline $\mathbf{S}$ & 0.8 & 100 & 101 & & 101 & 1.7 \\
\hline Si & 5.1 & 97 & 113 & 112 & & \\
\hline $\mathrm{Sr}$ & & 102 & 103 & 103 & & \\
\hline $\mathrm{U}$ & & 101 & 101 & & 101 & \\
\hline $\mathrm{Zn}$ & & 99 & 103 & 105 & & \\
\hline $\mathrm{Zr}$ & & 104 & 104 & 103 & & \\
\hline \multicolumn{7}{|c|}{ Other Analytes } \\
\hline $\mathrm{Ag}$ & & & & 94 & & - \\
\hline As & & & & 103 & & \\
\hline $\mathrm{Ba}$ & & 100 & 101 & 100 & & \\
\hline $\mathrm{Be}$ & & 102 & 104 & 104 & & \\
\hline $\mathrm{Ca}$ & & 107 & 108 & 102 & & \\
\hline $\mathrm{Ce}$ & & 99 & 99 & & 100 & \\
\hline Co & & & & 103 & & \\
\hline $\mathrm{Cu}$ & & 102 & 105 & 106 & & \\
\hline Dy & & & & & 102 & \\
\hline Eu & & & & & 101 & \\
\hline La & & 99 & 101 & & 101 & \\
\hline $\mathrm{Li}$ & & 105 & 103 & 103 & & \\
\hline $\mathrm{Mg}$ & & 101 & 101 & 100 & & \\
\hline Mo & & 100 & 101 & 102 & & \\
\hline $\mathrm{Nd}$ & & 100 & 102 & & 102 & \\
\hline $\mathrm{Pb}$ & & 99 & 101 & 100 & & \\
\hline $\mathrm{Pd}$ & & & & & 95 & \\
\hline $\mathrm{Rh}$ & & & & & 99 & \\
\hline $\mathrm{Ru}$ & & & & & 99 & \\
\hline $\mathrm{Sb}$ & & & & 99 & & \\
\hline Se & & & & 103 & & \\
\hline $\mathrm{Sn}$ & & & & 100 & & \\
\hline $\mathrm{Ta}$ & & & & 104 & & \\
\hline $\mathrm{Te}$ & & & & & 99 & \\
\hline Th & & 100 & 101 & & 102 & \\
\hline $\mathrm{Ti}$ & & 102 & 102 & 100 & & \\
\hline $\mathrm{TI}$ & & & & 96 & & \\
\hline V & & 97 & 98 & 97 & & \\
\hline$w$ & & 100 & 106 & 101 & & \\
\hline Y & & & & 100 & & \\
\hline
\end{tabular}

Shaded results are outside the acceptance criteria.

$n r=$ spike concentration less than $25 \%$ of sample concentration. Matrix effects can be assessed from the serial dilution. 
Battelle PNNL/RS\&E/Inorganic Analysis ... ICP-OES Analysis Report PO Box 999, Richland, Washington 99352

$\begin{array}{ll}\text { Project / WP\#: } & 52964 \text { / F99189 } \\ \text { ASR\#: } & 8206 \\ \text { Client: } & \text { R. Shimskey } \\ \text { Total Samples: } & \text { 3 (solid) }\end{array}$

\begin{tabular}{|c|c|c|}
\hline & First & Last \\
\hline RPL\#: & $08-02295$ & $08-02297$ \\
\hline Client ID: & TI640-G8-6 & TI640-G8-12 \\
\hline
\end{tabular}

Procedure: RPG-CMC-211, "Determination of Elemental Composition by Inductively Coupled Argon Plasma Optical Emission Spectrometry (ICP-OES)", Rev 2.

Analyst: $\quad$ B. Oliver

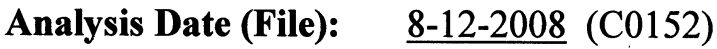

See Chemical Measurement Center 98620 file: ICP-325-405-3

(Calibration and Maintenance Records)

M\&TE Number: $\quad \underline{\text { N827583 }}$ (ICP-OES instrument)

$\underline{\text { M19445 }}$ (Mettler AT400 Balance)

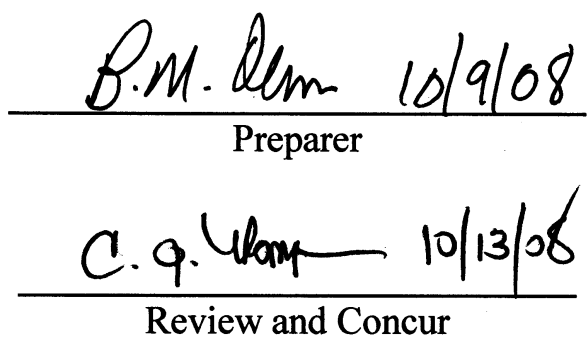




\section{Battelle PNNL/RS\&E/Inorganic Analysis ... ICP-OES Analysis Report}

Three samples submitted under Analytical Service Request (ASR) 8206 were analyzed by ICPOES. The samples were prepared following RPL procedure RPG-CMC-138 using a nominal 0.2 grams of sample and diluting to a final volume of $100 \mathrm{~mL}$.

Analytes of interest (AOIs) were specified in the ASR, and are listed in the upper section of the attached ICP-OES Data Report. The quality control (QC) results for these AOIs have been evaluated and are presented below. Analytes other than AOIs are reported in the bottom section of the report, but have not been fully evaluated for QC performance. The results are given as $\mu \mathrm{g} / \mathrm{g}$ for each detected analyte, and have been adjusted for all laboratory processing factors and instrument dilutions.

Calibration of the ICP-OES was done following the manufacturer's recommended calibration procedure and using multi-analyte custom standard solutions traceable to the National Institute of Standards and Technology (NIST). Midrange calibration verification standards (MCVA and $\mathrm{MCVB}$ ) were used to verify acceptance of the two-point calibration curves obtained for each analyte, and also used for continuing calibration verification.

Minimum Method Detection Limit (MDL) values were specified in the ASR. MDL levels were met for all AOIs.

The controlling documents were ASO-QAP-001, and the client supplied RPP-WTP-QA-005, Rev. 2 and ASR-8206 Special Instructions. Instrument calibrations, QC checks and blanks (e.g., ICV/ICB, CCV/CCB, LLS, ICS), post-spike, laboratory control standard (LCS), duplicate, and serial dilution were conducted during the analysis run. The LCS was prepared using a nominal 0.2 grams of SRM-2710 (Montana Soil).

\section{Preparation Blank (PB):}

A preparation blank (reagents only) was prepared for the digestion process. The concentrations of all AOIs were within the acceptance criteria of $\leq \mathrm{EQL}$ (estimated quantitation level) or less than $\leq 5 \%$ of the concentration in the sample.

Blank Spike (BS)/Laboratory Control Sample (LCS):

An LCS (Montana Soil) was prepared for the digestion process. Recovery values are listed for all analytes included in the spike that were measured at or above the EQL. The recovery values were within the acceptance criterion of $80 \%$ to $120 \%$ for all AOIs meeting the above requirement.

Matrix-Spiked Sample:

No matrix spike sample was provided for analysis.

Duplicate Relative Percent Difference (RPD):

A duplicate was prepared for the digestion process using Sample 08-02295. RPDs are listed for all analytes that were measured at or above the EQL. Al, $\mathrm{Na}, \mathrm{Sr}$, and several nonAOIs had RPDs that were greater than the client acceptance criteria of $\leq 25 \%$. Comparison of the duplicate sample data in this report with subsequent fusion preparation data on the 


\section{Battelle PNNL/RS\&E/Inorganic Analysis ... ICP-OES Analysis Report}

same sample indicates a problem with the acid-digest duplicate sample, most likely from issues related to sample preparation. Consequently, the duplicate sample data in this report must be considered as suspect, and the results are shaded in the attached analysis report.

\section{Post-Spike/Analytical Spike Sample (A component):}

An analytical spike (A component) was conducted for the sample batch. Recovery values are listed for all analytes in the spike that were measured at or above the EQL, and that had a spike concentration $\geq 25 \%$ of that in the sample. The recovery values were within the client acceptance criterion of $70 \%$ to $130 \%$ for all AOIs meeting the above requirements.

\section{Post Spike/Analytical Spike Sample (B component):}

An analytical spike (B component) was conducted for the sample batch. Recovery values are listed for all analytes in the spike that were measured at or above the EQL, and that had a spike concentration $\geq 25 \%$ of that in the sample. The recovery values were within the client acceptance criterion of $70 \%$ to $130 \%$ for all AOIs meeting the above requirements.

\section{Serial dilution:}

Five-fold serial dilution was conducted for the sample batch. Percent differences (\%Ds) are listed for all analytes that had a concentration at or above the EQL in the diluted sample. The $\% \mathrm{Ds}$ were within the acceptance criterion of $\leq 10 \%$ for all AOIs meeting the above requirement.

\section{Other QC:}

All other instrument-related QC tests for the AOIs passed within the appropriate acceptance criteria.

\section{Comments:}

1) The "Final Results" have been corrected for all laboratory dilutions performed on the samples during processing and analysis, unless specifically noted.

2) Instrument detection limits (IDL) and estimated quantitation limits (EQL) shown are for acidified water. Detection limits for other matrices may be determined if requested. Method detection limits (MDL) can be estimated by multiplying the IDL by the "Multiplier". The estimated quantitation limit (EQL) for each concentration value can be obtained by multiplying the EQL by the "Multiplier".

3) Routine precision and bias is typically $\pm 15 \%$ or better for samples in dilute, acidified water (e.g. $2 \% \mathrm{v} / \mathrm{v}$ $\mathrm{HNO}_{3}$ or less) at analyte concentrations $>\mathrm{EQL}$ up to the upper calibration level. This also presumes that the total dissolved solids concentration in the sample is less than $5000 \mu \mathrm{g} / \mathrm{mL}$ ( 0.5 per cent by weight). Note that bracketed values listed in the data report are within the MDL and the EQL, and have potential uncertainties greater than $15 \%$. Concentration values $<$ MDL are listed as "- -". Note, that calibration and $\mathrm{QC}$ standards are validated to a precision of $\pm 10 \%$.

4) Absolute precision, bias and detection limits may be determined on each sample if required by the client. The maximum number of significant figures for all ICP measurements is two.

5) Analytes included in the spike $\mathrm{A}$ component (for the $\mathrm{AS} / \mathrm{PS}$ ) are; $\mathrm{Ag}, \mathrm{Al}, \mathrm{As}, \mathrm{B}, \mathrm{Ba}, \mathrm{Be}, \mathrm{Bi}, \mathrm{Ca}, \mathrm{Cd}, \mathrm{Co}, \mathrm{Cr}$, $\mathrm{Cu}, \mathrm{Fe}, \mathrm{K}, \mathrm{Li}, \mathrm{Mg}, \mathrm{Mn}, \mathrm{Mo}, \mathrm{Na}, \mathrm{Ni}, \mathrm{P}, \mathrm{Pb}, \mathrm{Sb}, \mathrm{Se}, \mathrm{Si}, \mathrm{Sn}, \mathrm{Sr}, \mathrm{Ta}, \mathrm{Ti}, \mathrm{Tl}, \mathrm{V}, \mathrm{W}, \mathrm{Y}, \mathrm{Zn}$, and $\mathrm{Zr}$. Analytes included in the spike B component are; $\mathrm{Ce}, \mathrm{Dy}, \mathrm{Eu}, \mathrm{La}, \mathrm{Nd}, \mathrm{Pd}, \mathrm{Rh}, \mathrm{Ru}, \mathrm{S}, \mathrm{Te}, \mathrm{Th}$, and $\mathrm{U}$. 


\begin{tabular}{|c|c|c|c|c|c|c|c|c|c|c|c|c|}
\hline & Run Date > & Run Date $=$ & $8 / 12 / 2008$ & $8 / 12 / 2008$ & $8 / 12 / 2008$ & $8 / 12 / 2008$ & $8 / 12 / 2008$ & $8 / 12 / 2008$ & $8 / 12 / 2008$ & $8 / 12 / 2008$ & $8 / 12 / 2008$ \\
\hline & & Multiplier > & Multiplier= & 2548.4 & 2157.0 & 10785.2 & 2196.8 & 10984.2 & 3346.7 & 16733.6 & 2840.9 & 14204.5 \\
\hline & & RPLLAB > & RPLILAB \#= & $\begin{array}{l}08-02295- \\
138 \cdot B \text { @5 } \\
\end{array}$ & $\begin{array}{l}08-02295- \\
138-S @ 5 \\
\end{array}$ & $\begin{array}{c}08-02295- \\
138-5 @ 25 \\
\end{array}$ & $\begin{array}{l}08-02295- \\
138-D @ 5 \\
\end{array}$ & $\begin{array}{c}08-02295- \\
138-D @ 25 \\
\end{array}$ & $\begin{array}{l}08-02296- \\
138-S @ 5 \\
\end{array}$ & $\begin{array}{c}08-02296- \\
138-\mathrm{S} @ 25 \\
\end{array}$ & $\begin{array}{l}08-02297- \\
138-S \text { @5 } \\
\end{array}$ & $\begin{array}{c}08-02297 . \\
138-S \text { @25 } \\
\end{array}$ \\
\hline $\begin{array}{l}\text { Instr. Det. } \\
\text { Limit (IDL) }\end{array}$ & $\begin{array}{l}\text { Est. Quant. } \\
\text { Limit (EQL) }\end{array}$ & Client ID > & Client ID= & Prep Blank & \multicolumn{4}{|c|}{ T1640-G8-6 } & \multicolumn{2}{|c|}{ TI640-G8-9 } & \multicolumn{2}{|c|}{ TI640-G8-12 } \\
\hline$(\mu \mathrm{g} / \mathrm{mL})$ & $(\mu \mathrm{g} / \mathrm{mL})$ & (Analyte) & (Analyte) & $(\mu \mathrm{g} / \mathrm{g})$ & $(\mu \mathrm{g} / \mathrm{g})$ & $(\mu \mathrm{g} / \mathrm{g})$ & $(\mu \mathrm{g} / \mathrm{g})$ & $(\mu \mathrm{g} / \mathrm{g})$ & $(\mu \mathrm{g} / \mathrm{g})$ & $(\mu \mathrm{g} / \mathrm{g})$ & $(\mu \mathrm{g} / \mathrm{g})$ & $(\mu \mathrm{g} / \mathrm{g})$ \\
\hline 0.0060 & 0.060 & Al & Al & -- & 39,000 & & 52,200 & & 31,500 & & 44,700 & \\
\hline 0.0048 & 0.096 & B & B & [87] & [130] & & [120] & & [23] & & {$[73]$} & \\
\hline 0.0300 & 0.300 & $\mathrm{Bi}$ & $\mathrm{Bi}$ & -- & 2,430 & & 2,580 & & 3,760 & & 6,790 & \\
\hline 0.0021 & 0.021 & $\mathrm{Cd}$ & $\mathrm{Cd}$ & - & [12] & & [19] & & [21] & & [17] & \\
\hline 0.0017 & 0.017 & $\mathrm{Cr}$ & $\mathrm{Cr}$ & -- & 1,020 & & 977 & & 1,220 & & 2,070 & \\
\hline 0.0009 & 0.018 & $\mathrm{Fe}$ & $\mathrm{Fe}$ & [11] & 43,700 & & 49,000 & & 65,900 & & 123,000 & \\
\hline 0.0720 & 0.720 & $\mathrm{~K}$ & $\mathrm{~K}$ & 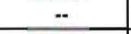 & 2,380 & & {$[1,500]$} & & [790] & & -- & \\
\hline 0.0002 & 0.005 & $\mathrm{Mn}$ & $\mathrm{Mn}$ & {$[0.79]$} & 568 & & 569 & & 858 & & 1,600 & \\
\hline 0.0160 & 0.320 & $\mathrm{Na}$ & $\mathrm{Na}$ & .- & 187,000 & & 140,000 & & 262,000 & & 97,200 & \\
\hline 0.0024 & 0.024 & $\mathrm{Ni}$ & $\mathrm{Ni}$ & $\cdots$ & 14,800 & & 14,200 & & 22,100 & & 40,600 & \\
\hline 0.0500 & 0.500 & $\mathbf{P}$ & $\mathbf{P}$ & $\ddot{*}$ & 21,200 & & 18,000 & & 26,600 & & 43,000 & \\
\hline 0.1600 & 1.600 & $\mathbf{s}$ & $\mathbf{s}$ & -- & 4,820 & & {$[3,100]$} & & {$[2,200]$} & & {$[890]$} & \\
\hline 0.0056 & 0.056 & $\mathrm{Si}$ & $\mathrm{Si}$ & na & na & na & na & na & na & na & na & na \\
\hline 0.0001 & 0.002 & $\mathrm{Sr}$ & $\mathrm{Sr}$ & -. & over-range & 17,000 & sat & 22,700 & over-range & 25,600 & sat & 47,000 \\
\hline 0.0320 & 0.320 & $u$ & $\mathbf{u}$ &.- & 46,900 & & 43,700 & & 70,600 & & 132,000 & \\
\hline 0.0028 & 0.056 & $\mathrm{Zn}$ & $\mathrm{Zn}$ & [18] & 235 & & 240 & & 334 & & 554 & \\
\hline 0.0011 & 0.011 & $\mathrm{Zr}$ & $\mathrm{Zr}$ & - & 120 & & 130 & & 185 & & 335 & \\
\hline \multicolumn{13}{|c|}{ Other Analytes } \\
\hline 0.0021 & 0.021 & $\mathrm{Ag}$ & $\mathrm{Ag}$ & -- & [12] & & {$[8.8]$} & & [18] & & {$[24]$} & \\
\hline 0.0860 & 0.860 & As & As & - &.- & & - & & - & &. & \\
\hline 0.0003 & 0.005 & $\mathrm{Ba}$ & $\mathrm{Ba}$ & {$[3.4]$} & 391 & & 510 & & 589 & & 1,080 & \\
\hline 0.0001 & 0.001 & Be & $\mathrm{Be}$ & - & {$[0.50]$} & & {$[0.59]$} & & {$[0.63]$} & & {$[1,1]$} & \\
\hline 0.0120 & 0.120 & $\mathrm{Ca}$ & $\mathrm{Ca}$ & [39] & 24,800 & & 33,100 & & 37,200 & & 69,500 & \\
\hline 0.0100 & 0.100 & $\mathrm{Ce}$ & $\mathrm{Ce}$ & -- & [35] & & [70] & & [57] & & {$[150]$} & \\
\hline 0.0024 & 0.024 & Co & Co & -. & [21] & & [23] & & [34] & & {$[50]$} & \\
\hline 0.0014 & 0.014 & $\mathrm{Cu}$ & $\mathrm{Cu}$ & [7.4] & 54.9 & & 59.7 & & 80.9 & & 134 & \\
\hline 0.0029 & 0.029 & Dy & Dy &.. & 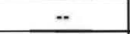 & & $\ddot{-}$ & & - & & .- & \\
\hline 0.0011 & 0.011 & Eu & Eu &.. & .. & & [2.5] & & - & & {$[3.6]$} & \\
\hline 0.0028 & 0.028 & $\mathrm{La}$ & La & 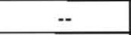 & [51] & & 71.4 & & [83] & & 141 & \\
\hline 0.0006 & 0.012 & $\mathrm{Li}$ & $\mathrm{Li}$ &.- & [12] & & {$[8.4]$} & & [15] & & [17] & \\
\hline 0.0023 & 0.023 & $\mathrm{Mg}$ & $\mathrm{Mg}$ & 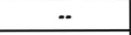 & 1,890 & & 2,560 & & 2,850 & & 5,350 & \\
\hline 0.0052 & 0.052 & Mo & Mo & -- & -- & & - & & -- & & -- & \\
\hline 0.0200 & 0.200 & Nd & Nd &.. & [65] & & [130] & & [110] & & {$[290]$} & \\
\hline 0.0320 & 0.320 & $\mathrm{~Pb}$ & $\mathrm{~Pb}$ & -- & 2,280 & & 2,260 & & 3,040 & & 5,490 & \\
\hline 0.0063 & 0.063 & $P d$ & $\mathrm{Pd}$ & -- & 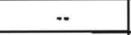 & & 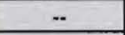 & & - & & -- & \\
\hline 0.0120 & 0.120 & Rh & $\mathrm{Rh}$ & -- & -- & & - & & -- & & - & \\
\hline 0.0085 & 0.085 & $\mathrm{Ru}$ & $\mathrm{Ru}$ & -- &.- & & -- & & [46] & & [42] & \\
\hline 0.0200 & 0.200 & Sb & Sb & 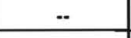 & -- & & $\ddot{-}$ & & - & & -- & \\
\hline 0.0700 & 0.700 & Se & Se & 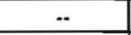 & -- & & [260] & & 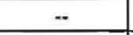 & & -- & \\
\hline 0.0270 & 0.270 & Sn & $\mathrm{Sn}$ & -- & - & & - & & - & & -- & \\
\hline 0.0170 & 0.170 & $\mathrm{Ta}$ & $\mathrm{Ta}$ & -- & - & & {$[40]$} & & - & & $\ddot{*}$ & \\
\hline 0.0260 & 0.260 & $\mathrm{Te}$ & $\mathrm{Te}$ & - & $\ddot{-}$ & & - & & - & & $\ddot{*}$ & \\
\hline 0.0098 & 0.098 & Th & Th & - & -- & & - & & [46] & & -- & \\
\hline 0.0004 & 0.004 & $\mathrm{Ti}$ & $\mathrm{Ti}$ & [1.1] & 127 & & 121 & & 195 & & 361 & \\
\hline 0.0380 & 0.380 & $\mathrm{TI}$ & TI & -- & - & & - & & - & & -- & \\
\hline 0.0007 & 0.007 & v & v & -- & [2.9] & & [5.2] & & {$[3.6]$} & & -- & \\
\hline 0.0150 & 0.150 & $w$ & $w$ & -- & -- & & [55] & & -- & & [48] & \\
\hline 0.0004 & 0.004 & $Y$ & $\mathrm{Y}$ & - & 14.8 & & 19.8 & & 22.6 & & 42.0 & \\
\hline
\end{tabular}

1) " - " indicates the value is $<$ MDL. The method detection limit (MDL) =IDL times the "multiplier"

near the top of each column. The estimated sample quantitation limit $=E Q L$ (in Column 2)

times the "multiplier". Overall error for values $\geq E Q L$ is estimated to be within $\pm 15 \%$.

2) Values in brackets [] are $\geq M D L$ but $<E Q L$, with errors likely to exceed $15 \%$.

$n a=$ not applicable; $\mathrm{KOH}$ flux and $\mathrm{Ni}$ crucible or $\mathrm{Na}_{2} \mathrm{O}_{2}$ flux and $\mathrm{Zr}$ crucible for fusion preparations, or $\mathrm{Si}$ for $\mathrm{HF}$ assisted digests.

Shaded results are suspect based on comparison with separate fusion data on the same sample (see narrative). 
QC Performance 8/12/2008

\begin{tabular}{|c|c|c|c|c|c|c|}
\hline Criteria > & $\leq 25 \%$ & $80 \%-120 \%$ & $70 \%-130 \%$ & $70 \%-130 \%$ & $70 \%-130 \%$ & $\leq 10 \%$ \\
\hline QC ID > & $\begin{array}{c}\text { 08-02295 } \\
\text { Dup }\end{array}$ & LCSIBS & MS (none) & $\begin{array}{c}08-02295+ \\
\text { PS-A }\end{array}$ & $\begin{array}{c}08-02295+ \\
\text { PS-B }\end{array}$ & $\begin{array}{l}\text { 08-02295 } \\
5 \text {-fold } \\
\text { Serial Dil }\end{array}$ \\
\hline Analytes & RPD (\%) & $\% \operatorname{Rec}$ & $\% \operatorname{Rec}$ & $\%$ Rec & $\% \operatorname{Rec}$ & $\%$ Diff \\
\hline Al & 28.9 & 101 & & 103 & & 0.9 \\
\hline$B$ & & & & 109 & & \\
\hline $\mathrm{Bi}$ & 5.9 & & & 97 & & \\
\hline Cd & & & & 104 & & \\
\hline $\mathrm{Cr}$ & 4.8 & & & 103 & & 1.5 \\
\hline $\mathrm{Fe}$ & 11.4 & 101 & & 102 & & 2.2 \\
\hline $\mathrm{K}$ & & & & 102 & & \\
\hline $\mathrm{Mn}$ & 0.1 & 105 & & 104 & & 2.0 \\
\hline $\mathrm{Na}$ & 28.7 & 100 & & 96 & & 2.8 \\
\hline $\mathrm{Ni}$ & 4.1 & & & 94 & & 2.8 \\
\hline $\mathbf{P}$ & 16.3 & & & 103 & & 0.2 \\
\hline $\mathrm{s}$ & & & & & 99 & \\
\hline $\mathrm{Si}$ & na & na & na & na & na & na \\
\hline $\mathrm{Sr}$ & 28.7 (a) & 103 & & & & \\
\hline $\mathrm{U}$ & 7.2 & & & & 96 & 1.5 \\
\hline $\mathrm{Zn}$ & 2.0 & 104 & & 106 & & \\
\hline $\mathrm{Zr}$ & 8.2 & & & 103 & & 6.0 \\
\hline
\end{tabular}

Other Analytes

\begin{tabular}{|c|c|c|c|c|c|}
\hline $\mathrm{Ag}$ & & & 96 & & \\
\hline As & & & 100 & & \\
\hline $\mathrm{Ba}$ & 26.4 & 100 & 102 & & 0.7 \\
\hline $\mathrm{Be}$ & & & 103 & & \\
\hline $\mathrm{Ca}$ & 28.6 & 100 & 100 & & 1.1 \\
\hline $\mathrm{Ce}$ & & & & 96 & \\
\hline Co & & & 103 & & \\
\hline $\mathrm{Cu}$ & 8.4 & 102 & 104 & & \\
\hline Dy & & & & 98 & \\
\hline Eu & & & & 98 & \\
\hline La & & & & 98 & \\
\hline Li & & & 104 & & \\
\hline $\mathrm{Mg}$ & 30.2 & 101 & 103 & & 2.4 \\
\hline Mo & & & 103 & & \\
\hline Nd & & & & 100 & \\
\hline $\mathrm{Pb}$ & 0.9 & 101 & 101 & & \\
\hline $\mathrm{Pd}$ & & & & 90 & \\
\hline $\mathrm{Rh}$ & & & & 95 & \\
\hline Ru & & & & 100 & \\
\hline $\mathrm{Sb}$ & & & 103 & & \\
\hline $\mathrm{Se}$ & & & 100 & & \\
\hline Sn & & & 101 & & \\
\hline $\mathrm{Ta}$ & & & 103 & & \\
\hline $\mathrm{Te}$ & & & & 97 & \\
\hline Th & & & & 98 & \\
\hline $\mathrm{Ti}$ & 5.1 & 96 & 102 & & 4.0 \\
\hline $\mathrm{TI}$ & & & 99 & & \\
\hline V & & 96 & 98 & & \\
\hline$w$ & & & 103 & & \\
\hline$Y$ & 28.4 & 82 & 100 & & \\
\hline
\end{tabular}

Shaded results are outside the acceptance criteria.

$n r=$ spike concentration less than $25 \%$ of sample concentration. Matrix effects can be assessed from the serial dilution.

na = not applicable; $\mathrm{KOH}$ flux and $\mathrm{Ni}$ crucible or $\mathrm{Na}_{2} \mathrm{O}_{2}$ flux and $\mathrm{Zr}$ crucible for fusion preparations, or Si for HF assisted digests.

(a) Data from $25 x$ dilutions. 


\section{Battelle - Pacific Northwest National Laboratory Analytical Support Operations - IC Report \\ PO Box 999, Richland, Washington 99352}

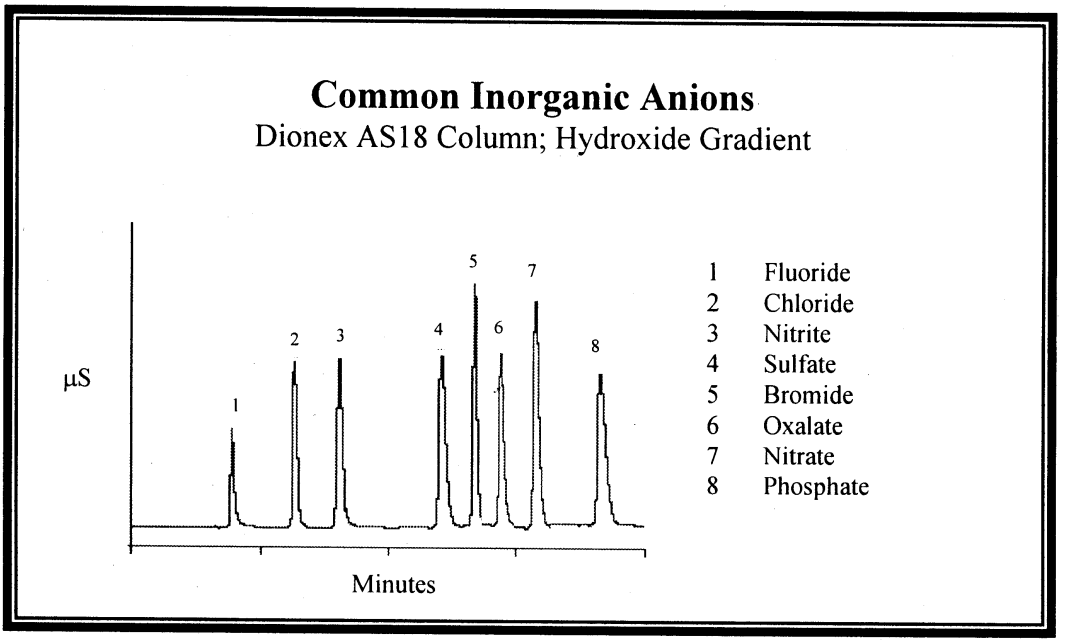

Client:

Project \#:

R. Shimskey

Charge Code: $\quad$ F99189

$\begin{array}{ll}\text { ASR \#: } & 8206.01 \\ \text { \# Samples: } & 4 \text { liquids }\end{array}$

\section{*** RPL Numbers: 08-02283 through 08-02286*** Liquid Samples Only}

\section{Procedure, Analysis, System, and Records Information}

\begin{tabular}{|l|l|}
\hline Analysis Procedure & $\begin{array}{l}\text { RPG-CMC-212, rev 1 "Determination of Inorganic Anions by Ion } \\
\text { Chromatography" }\end{array}$ \\
\hline Preparative Procedure & None \\
\hline Prep Procedure & Bench Dilution performed in lab 400 (DRK 11/26/08) \\
\hline Analyst & DR Kallsen \\
\hline Analysis Dates & $12 / 10 / 08-12 / 16 / 2008$ \\
\hline Calibration Date & $10 / 27 / 08$ \\
\hline Cal/Ver Stds Prep Date & Cal 10/24/08; Ver 12/10/08 \\
\hline Excel Data File & ResultsShimskey8206.xls \\
\hline \multirow{2}{*}{ M\&TE Numbers } & IC System (M\&TE) N830443 \\
\cline { 2 - 2 } & Balances: $360-06-01-031 / 1113052270$ \\
\hline All Analysis Records & Chemical Measurement Center 98620: RIDS IC System File (IC-0181) \\
\hline
\end{tabular}
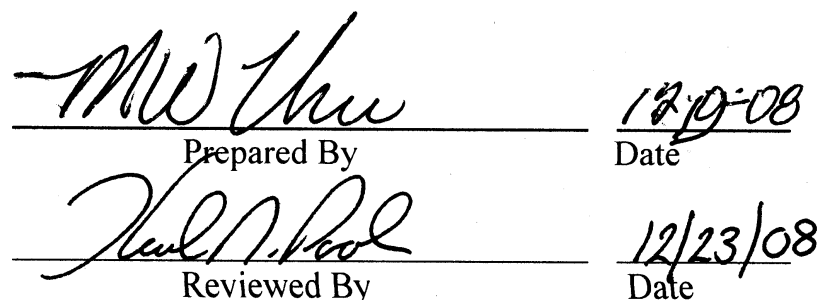


\section{IC Report}

\section{Sample Results}

See Attachment: Direct Liquid Sample Results ASR 8206.01 (Liquids Only)

\section{Sample Analysis/Results Discussion}

Four liquid samples were submitted to the ASO for analysis under ASR 8206.01. The analytes of interest are fluoride, chloride, nitrite, nitrate, oxalate, sulfate and phosphate. The samples were prepared for analysis using dilutions at the bench, which included the preparation of analytical spikes and sample replicates. The dilutions were prepared in deionized water and the water was analyzed as the process dilution sample. All sample results are reported as $\mu \mathrm{g} / \mathrm{mL}$.

The final analysis was performed using dilutions ranging from $\sim 450 \mathrm{x}$ to $\sim 6,000 \mathrm{x}$ to provide values within the calibration range. All results have been adjusted for all analytical dilutions. The preparation dilution blanks (water used to dilute samples at the IC workstation) are reported as analyzed, no dilution factors were applied to these samples. The estimated method detection limits (MDL) are provided, and are based on the estimated quantitation limit (EQL), which is one-tenth of the lowest calibration standard (adjusted for the dilutions used for reporting the results).

\section{Data Limitations}

None

\section{Quality Control Discussion}

The method performance is evaluated against the acceptance criteria established by Analytical Support Operations QA Plan ASO-QAP-001 and the client specified special instructions, RPP-WTP-QA-005 Rev 2, which has the same specification as the QA Plan.

Processing Blanks (Diluent): A process dilution blank (deionized water) was analyzed with the sample set. There were no anions detected above the method detection limit (MDL). Thus, the processing blanks met the QA Plan acceptance criteria of less than EQL for all analytes of interest.

Duplicate (Precision): One sample was analyzed in duplicate (08-02283). The relative percent difference (RPD) was $1 \%$ or less for all analytes of interest. Note: the RPD is not calculated if either the sample or duplicate result is less than EQL.

Processing Laboratory Control/Blank Spike (LCS/BS): Since no processing was performed on the samples, other than dilution, the initial Continuing Calibration Verification (CCV) standard is used as the LCS. Recoveries for the initial CCV ranged from $95 \%$ to $101 \%$ for the analytes of interest. These recoveries meet the QA Plan acceptance criteria of $80 \%$ to $120 \%$ recovery.

Matrix Spike (Accuracy): None prepared. Sample did not undergo sample preparation; therefore, an analytical spike was prepared and analyzed. 


\section{IC Report}

Analytical Spike (Accuracy): Sample 08-02283 was prepared as an analytical spike at three different dilutions and analyzed. The recovery ranged from $92 \%$ to $105 \%$ for all analytes of interest, which meets the QA Plan matrix spike recovery acceptance criteria of $75 \%$ to $125 \%$.

IC System QC Samples: Numerous calibration verification standards and calibration verification blanks were analyzed with each run day. For all data reported, the IC System QC bounding the sample analyses produced results for all analytes were within the acceptance criterion of the ASO's QA Plan (i.e., $90 \%$ to $110 \%$ recovery for verification standards and verification blank results $<\mathrm{EQL}$ or $<5 \%$ of reported sample result).

\section{Deviations from Procedure}

None

\section{General Comments}

- The reported "Final Results" have been corrected for all dilutions performed on the sample during processing or analysis.

- The MDL is set at the concentration of the lowest calibrations standard divided by 10 . The EQL is defined as the concentration of the lowest calibration standards times the sample dilution factors (processing and analysis) and assumes non-complex aqueous matrices. Matrix-specific MDLs or EQLs may be determined, if requested.

- Routine precision and bias are typically $\pm 15 \%$ or better for non-complex aqueous samples that are free of interference. 

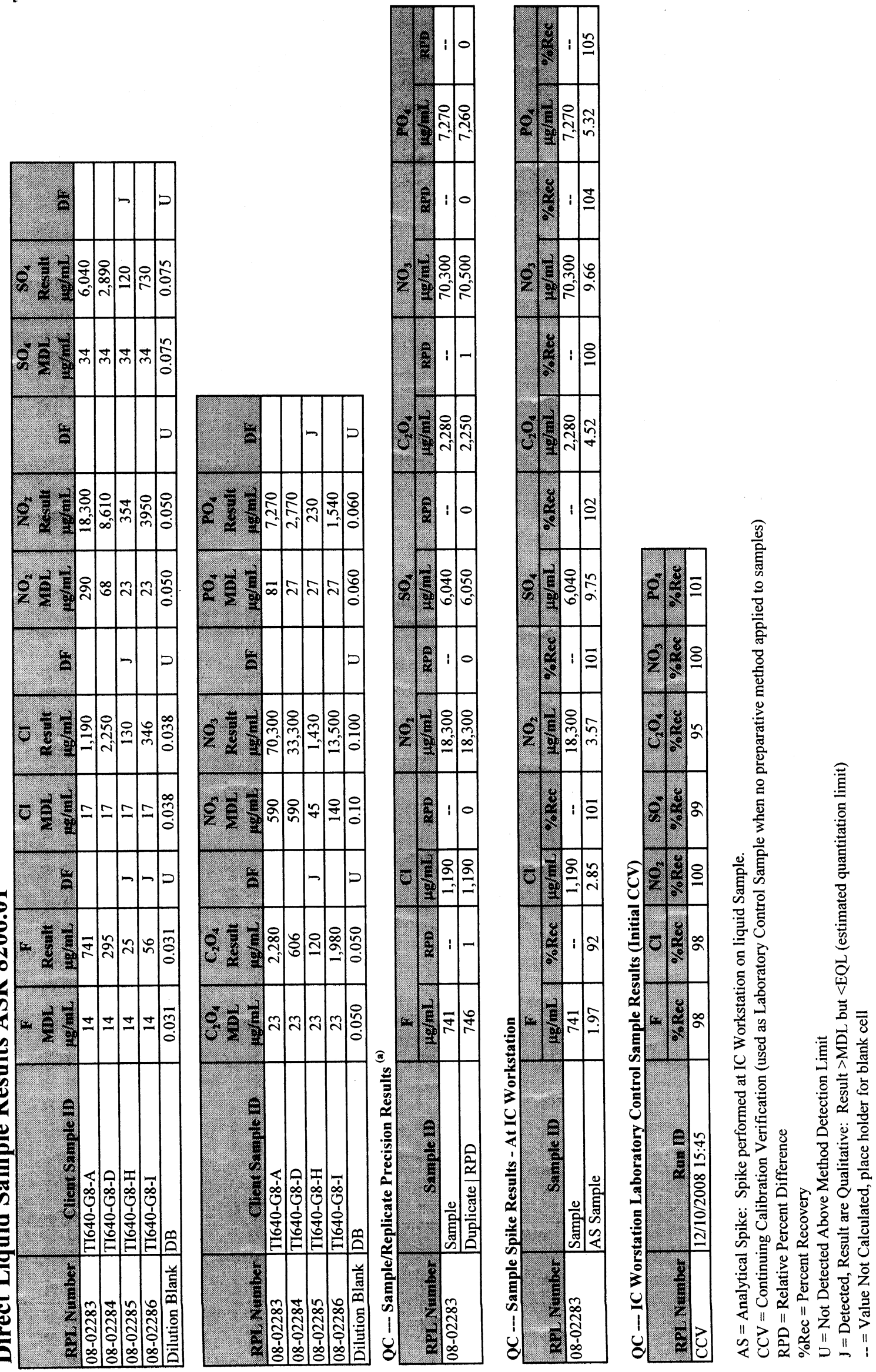


\section{Battelle - Pacific Northwest National Laboratory \\ Analytical Support Operations - IC Report \\ PO Box 999, Richland, Washington 99352}

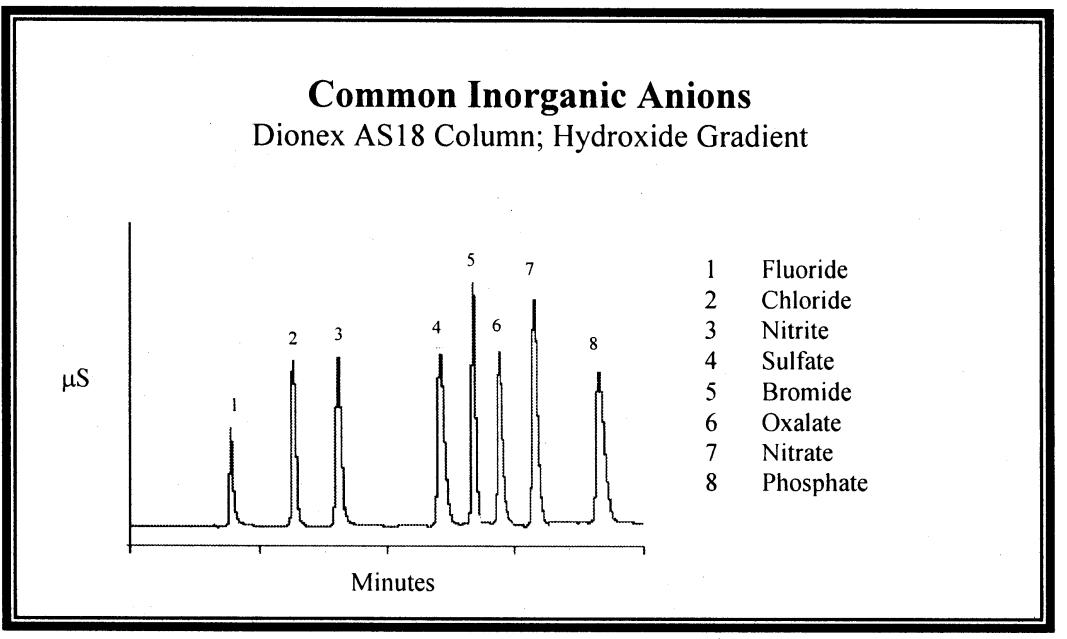

\section{Client: \\ R. Shimskey \\ Project \#: 52964 \\ Charge Code: \\ F99189 \\ ASR \#: $\quad 8206.01$ \\ \# Samples: 3 Solids \\ *** RPL Numbers: 08-02295 through 08-02297*** Water Leached Solids Samples Only}

Procedure, Analysis, System, and Records Information

\begin{tabular}{|l|l|}
\hline Analysis Procedure & $\begin{array}{l}\text { RPG-CMC-212, rev 1 "Determination of Inorganic Anions by Ion } \\
\text { Chromatography" }\end{array}$ \\
\hline Preparative Procedure & RPG-CMC-103, rev 0 "Water Leach of Sludge, Soil, and Other Solids" \\
\hline Prep Procedure & Bench Dilution performed in lab 400 (DRK 11/26/08) \\
\hline Analyst & DR Kallsen \\
\hline Analysis Dates & $12 / 10 / 08-12 / 16 / 2008$ \\
\hline Calibration Date & $10 / 27 / 08$ \\
\hline Cal/Ver Stds Prep Date & Cal 10/24/08; Ver 12/10/08 \\
\hline Excel Data File & ResultsShimskey8206.xls \\
\hline M\&TE Numbers & IC System (M\&TE) N830443 \\
\cline { 2 - 3 } & Balances: 360-06-01-031/1113052270 \\
\hline All Analysis Records & Chemical Measurement Center 98620: RIDS IC System File (IC-0181) \\
\hline
\end{tabular}




\section{IC Report}

\section{Sample Results}

See Attachment: Water Leached Solids Results ASR 8206.01 (Solids Only)

\section{Sample Analysis/Results Discussion}

Three solid/slurry samples were submitted to the ASO for analysis under ASR 8206.01. The specified analytes of are fluoride, nitrite, nitrate, sulfate, oxalate and phosphate; however, chloride has also been reported. The samples were prepared for IC analysis by drying the solids/slurry and then leaching the dry solids (from $\sim 0.9 \mathrm{~g}$ to $\sim 1.2 \mathrm{~g}$ slurry to $\sim 10 \mathrm{~mL}$ of deionized water), which included the preparation of a process blank, blank spike, matrix spike and sample duplicate. Following leaching, the samples were further diluted to bring each analyte within the calibration range. The dilutions were prepared in deionized water. Both the deionized water used to leach the solids/slurries and to make further dilutions were analyzed as a process blank sample. All sample results are reported as $\mu \mathrm{g} / \mathrm{g}$; the leach deionized water samples (referred to the process blank, PB) has been adjusted for each sample leach factor and reported with each sample.

After screening the samples, the final analysis was performed using additional dilution factors ranging from $\sim 40 \mathrm{x}$ to $\sim 1,400 \mathrm{x}$. All sample results have been adjusted for all leaching and analytical dilution factors. The estimated method detection limits (MDL) are provided for each analyte of interest measured and the MDLs have been adjusted for all analytical dilutions. The MDLs are set at one-tenth the lowest calibration standard, which is defined as the estimated quantitation limit (EQL).

\section{Data Limitations}

Oxalate recovery failed (at 73\%) for the water leach Blank Spike Laboratory Control Sample. Oxalate results are for information only.

\section{Quality Control Discussion}

The method performance is evaluated against the acceptance criteria established by Analytical Support Operations QA Plan ASO-QAP-001 and the client specified special instructions, RPPWTP-QA-005 Rev 2, which has the same specification as the QA Plan.

Dilution Blank (Diluent): A dilution blank (deionized water) were analyzed with the sample set. There were no anions detected above the method detection limit (MDL). The processing blank meets the QA Plan acceptance criteria of less than EQL for all analytes of interest.

Process Blank (Leach): A process blank (deionized water subjected to the same handling as the leached solid/slurry samples) was analyzed with the sample set. Only chloride and nitrate were detected in the process leach blank, but were below the EQL; thus meeting the QA Plan acceptance criteria for all analytes of interest.

Duplicate (Precision): Sample 08-02295 was analyzed in duplicate. The relative percent difference (RPD) is reported for those analytes where both the sample and duplicate were 


\section{IC Report}

measured at or above the EQL. The reported RPDs ranged from 2 to $15 \%$ for all analytes of interest, which meets the Project acceptance criteria (Table 4 of ASR) of $<25 \%$.

Processing Laboratory Control Sample/Blank Spike (LCS/BS): The leaching process $\mathrm{LCS} /$ blank spike was analyzed with the data set and had a recoveries ranging from $95 \%$ to $108 \%$ for the analytes of interest, except oxalate which recovered at $73 \%$. Except for oxalate (see Data Limitations), the recoveries meet the Project acceptance criteria (Table 4 of ASR) of $80 \%$ to $120 \%$ recovery. The failure of the oxalate appears to be due to the length of time the spiking solution was at hot cell temperature prior to being used.

Matrix Spike (Accuracy): A matrix spike was prepared for Sample 08-02297. However, no recoveries are reported since concentrations of all analytes of interest are greater than five times the (added) spike concentration. Post spikes were performed to evaluate accuracy.

Post Spike (Accuracy): Post spikes (i.e., standard added after leaching) were prepared at multiple dilutions for sample 08-02297 and analyzed. Sample 08-02297 was diluted by $\sim 80$, $\sim 900$ and $\sim 2,700$ in order to obtain spikes concentrations at least $20 \%$ greater than measured sample concentration. The recovery range was from $79 \%$ to $108 \%$ for all analytes of interest, which meets the Project (Table 4 of ASR) post spike recovery acceptance criteria of $70 \%$ to $130 \%$.

IC System QC Samples: Numerous calibration verification standards and calibration verification blanks were analyzed with each run day. For all data reported, the IC System QC bounding the sample analyses produced results for all analytes were within the acceptance criterion of the ASO's QA Plan (i.e., $90 \%$ to $110 \%$ recovery for verification standards and verification blank results $<\mathrm{EQL}$ or $<5 \%$ of reported sample result).

\section{Deviations from Procedure}

\section{None}

\section{General Comments}

- The reported "Final Results" have been corrected for all dilutions performed on the sample during processing or analysis.

- The MDL is set at the concentration of the lowest calibrations standard divided by 10 . The $\mathrm{EQL}$ is defined as the concentration of the lowest calibration standards times the sample dilution factors (processing and analysis) and assumes non-complex aqueous matrices. Matrix-specific MDLs or EQLs may be determined, if requested.

- Routine precision and bias are typically $\pm 15 \%$ or better for non-complex aqueous samples that are free of interference. 

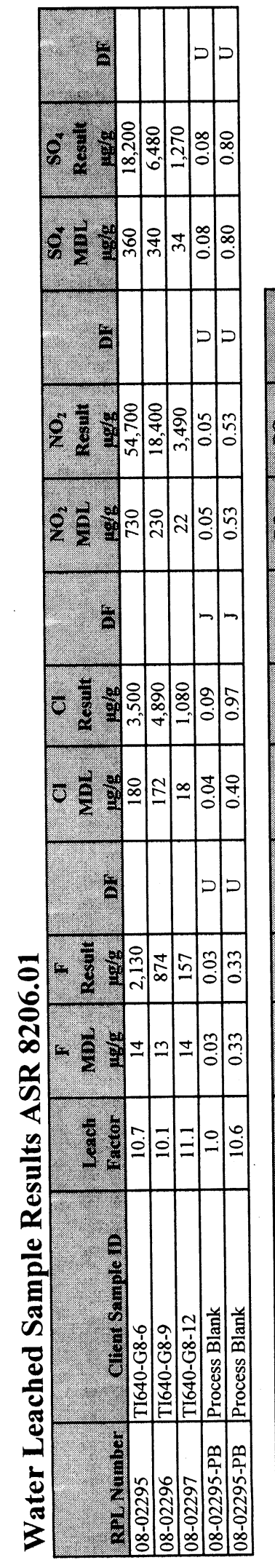

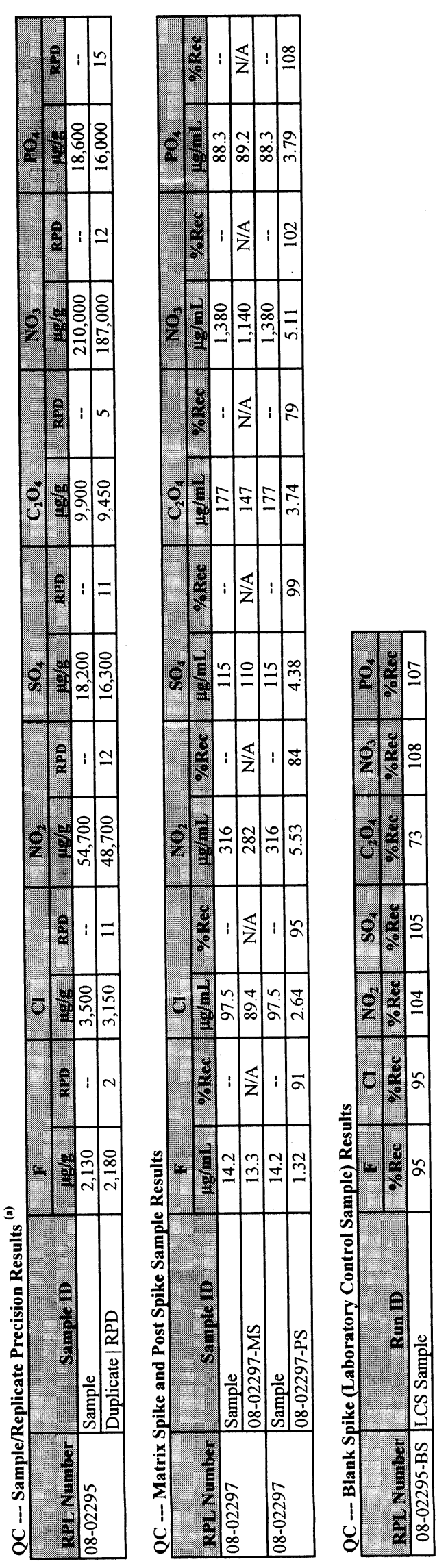

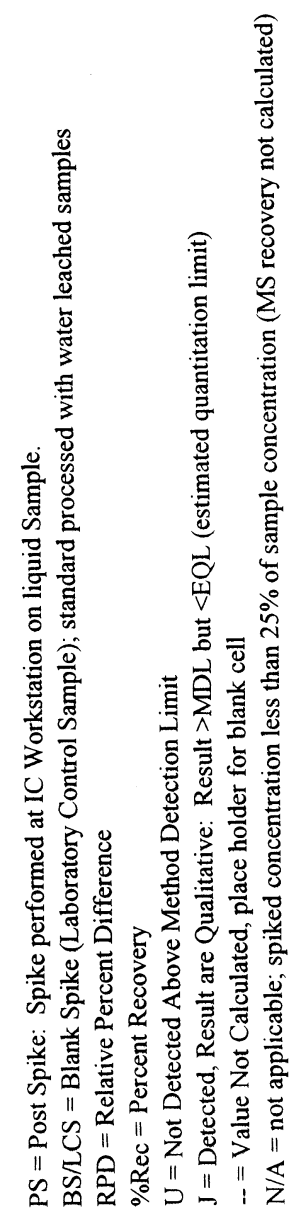




\section{2 \\ Pacific Northwest}

NATIONAL LABORATORY

\begin{tabular}{|c|c|c|c|c|c|}
\hline Client: & Rick Shim & & & $\begin{array}{r}\text { Report Date: } \\
\text { Analysis Date: }\end{array}$ & $\begin{array}{l}8 / 26 / 2008 \\
8 / 25 / 2008 \\
\end{array}$ \\
\hline Subject: & Hydroxid & lyses for: & & $\begin{array}{l}\text { Ip } 8 \text { (FeCN Sludge) } \\
\text { eatability Study }\end{array}$ & \\
\hline $\begin{array}{l}\text { ASR: } \\
\text { Sample ID. }\end{array}$ & $\begin{array}{l}8206 \\
08-02283\end{array}$ & $\begin{array}{l}\text { Rev-0 } \\
\text { thru }\end{array}$ & $08-02294$ & Procedure: RPG-CMC & 228-Rev 1 \\
\hline
\end{tabular}

Direct sample aliquots of CUF Group 8 (FeCN Sludge) Waste Treatability Study samples (see above assigned RPL Sample \#'s), 12 samples total were analyzed in duplicate for the base constituents content following procedure RPG-CMC-228, and using a Brinkman 636 Auto-Titrator. The titrant used was 0.1016 $\mathrm{M} \mathrm{HCl}$ and the base standard, $0.1118 \mathrm{M} \mathrm{NaOH}$ was used for QC verification standards and matrix spike. -See Chemrec_139 pdf imbedded in the result report.

Sample aliquots were weighed, thus density information is available -- see data page following. The hydroxide Standard recovery was $95 \%$, well within the allowed $\pm 20 \%$ recovery range. Although not required in this ASR, 2 matrix spikes were analyzed with recoveries of $95 \%$ and $95 \%$ at the neutral pH range of $\sim 7-8$. No hydroxide was detected in the reagent blank.

The initial pH is reported on attached Report Summary along with the free hydroxide molarities at an average $\mathrm{pH}$ of $10 \pm 1$. These results showed excellent Relative Percent Deviation (RPD) for the first inflection point, all $<7 \%$, well within $\pm 20 \%$ allowed range. A 2 nd inflection point around $\mathrm{pH} 7-8$, indicating final hydroxide molarity or carbonate also showed very good RPD's, well within $\pm 20 \%$ allowed range on all samples except 08-2285 and 08-2294 where the detected molarity was below the MDL. All samples also indicated a third inflection point, probably bicarbonate, around $\mathrm{pH} 4-5$, and again all RPD's were within \pm $20 \%$ allowed range except 08-2286 and 08-2294 where the detected molarity was below the MDL.

The best estimate of the MDL for this method is obtained from the reagent blank which did not show any inflection points and is consistent with a value of 0 within our measurement sensitivity. All sample hydroxide molarities were well above the MDL $(0.1 \mathrm{M})$ for this analysis. The results are accepted based on the QC data meeting the acceptance criteria as specified in the ASR.

Following is the report summary, the sample results calculated from the raw data, and the record file for the standardized acid and base used. The sample fractions provided were consumed in the analysis process.

Copies of the titration curves are available upon request.
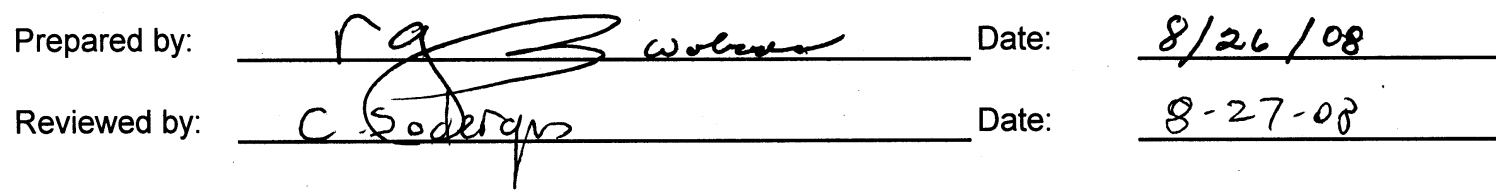
Battelle Pacific Northwest Laboratory

Radiochemical Processing Group-325 Building

Chemical Measurements Center

Hydroxide and Alkalinity Determination

Procedure: RPG-CMC-228-Rev 1

\section{ASR \# 8206}

WP

F99189

Equip \# WB76843

\begin{tabular}{rl|} 
Report Summary for ASR \# -- 8206 & $\begin{array}{r}\text { Report Date: } \\
\text { Revision \# Rev-0 } \\
\text { Analysis Date: }\end{array} \quad 8 / 25 / 2008$ \\
\hline
\end{tabular}

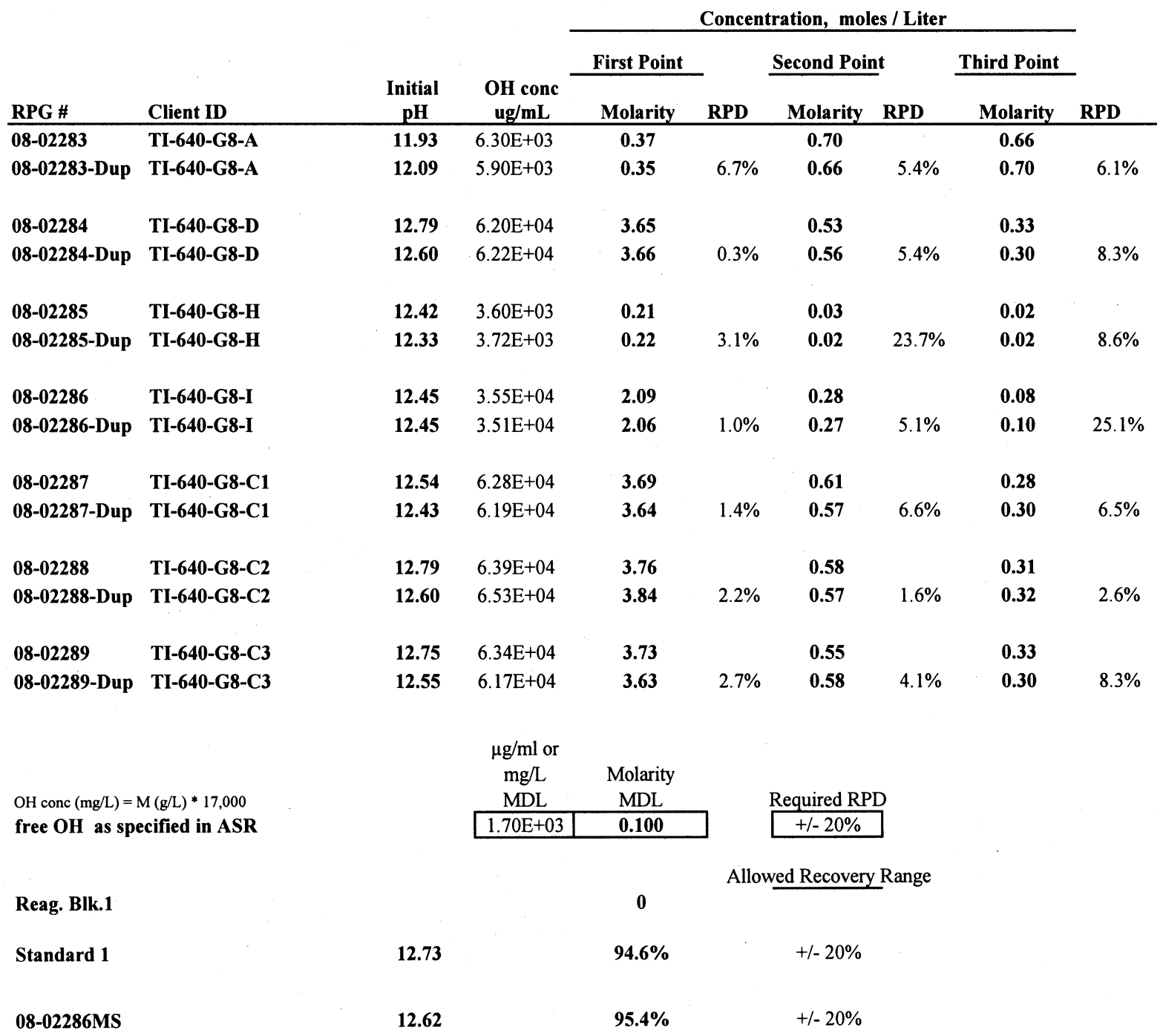

Note: Results are presented for the first, second, and third inflection points on the titration curves, as applicable. The first inflection point is generally associated with the free hydroxide concentration. The second inflection point generally represents total hydroxide, or carbonate or a combination of aluminate and carbonate. The third inflection point is usually indicative of bicarbonate or other weak acids or possibly the continued protonation of alumina.

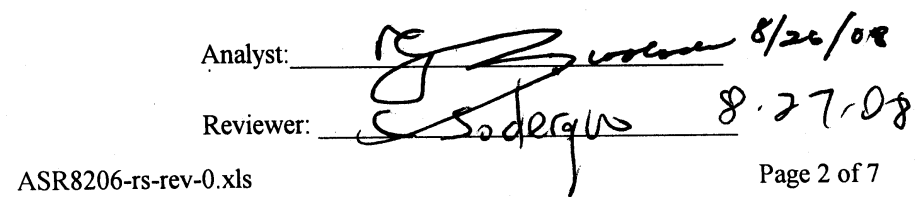


Battelle Pacific Northwest Laboratory

Radiochemical Processing Group-325 Building

Chemical Measurements Center

Hydroxide and Alkalinity Determination

Procedure: RPG-CMC-228-Rev 1
ASR \# 8206

WP\# F99189

$$
\begin{array}{rl|}
\text { Report Summary for ASR \# - } 8206 & \begin{array}{r}
\text { Report Date: } \\
\text { Revision \# }
\end{array} \text { Rev-0 } \\
\text { Analysis Date: } & 8 / 25 / 2008 \\
\hline
\end{array}
$$

Concentration, moles / Liter

\begin{tabular}{|c|c|c|c|c|c|c|c|c|c|}
\hline \multirow[b]{2}{*}{ RPG \# } & \multirow[b]{2}{*}{ Client ID } & \multirow{2}{*}{$\begin{array}{c}\text { Initial } \\
\text { pH }\end{array}$} & \multirow{2}{*}{$\begin{array}{c}\text { OH conc } \\
\text { ug/mL }\end{array}$} & \multirow{2}{*}{$\begin{array}{c}\text { First Point } \\
\text { Molarity }\end{array}$} & \multirow[b]{2}{*}{ RPD } & \multicolumn{2}{|c|}{ Second Point } & \multirow{2}{*}{$\begin{array}{c}\text { Third Point } \\
\text { Molarity }\end{array}$} & \multirow[b]{2}{*}{ RPD } \\
\hline & & & & & & Molarity & RPD & & \\
\hline 08-02290 & TI-640-G8-C4 & 12.41 & $6.15 \mathrm{E}+04$ & 3.62 & & 0.52 & & 0.27 & \\
\hline 08-02290-Dup & TI-640-G8-C4 & 12.41 & $5.86 \mathrm{E}+04$ & 3.45 & $4.8 \%$ & 0.54 & $3.5 \%$ & 0.27 & $0.7 \%$ \\
\hline 08-02291 & TI-640-G8-C5 & 12.44 & $6.35 \mathrm{E}+04$ & 3.73 & & 0.59 & & 0.28 & \\
\hline 08-02291-Dup & TI-640-G8-C5 & 12.42 & $6.02 \mathrm{E}+04$ & 3.54 & $5.4 \%$ & 0.58 & $2.1 \%$ & 0.34 & $18.2 \%$ \\
\hline 08-02292 & TI-640-G8-E & 12.10 & $4.65 \mathrm{E}+04$ & 2.74 & & 0.40 & & 0.28 & \\
\hline 08-02292-Dup & TI-640-G8-E & 12.33 & $4.60 \mathrm{E}+04$ & 2.71 & $1.0 \%$ & 0.46 & $13.6 \%$ & 0.33 & $13.3 \%$ \\
\hline 08-02293 & TI-640-G8-F & 12.35 & $1.62 \mathrm{E}+04$ & 0.95 & & 0.14 & & 0.08 & \\
\hline 08-02293-Dup & TI-640-G8-F & 12.41 & $1.65 \mathrm{E}+04$ & 0.97 & $1.9 \%$ & 0.12 & $19.4 \%$ & 0.08 & $3.1 \%$ \\
\hline 08-02294 & TI-640-G8-G & 12.16 & $7.69 \mathrm{E}+03$ & 0.45 & & 0.04 & & 0.05 & \\
\hline 08-02294-Dup & TI-640-G8-G & 12.35 & $7.32 \mathrm{E}+03$ & 0.43 & $4.8 \%$ & 0.07 & $57.3 \%$ & 0.04 & $24.9 \%$ \\
\hline
\end{tabular}

$\mathrm{OH}$ conc $(\mathrm{mg} / \mathrm{L})=\mathrm{M}(\mathrm{g} / \mathrm{L}) * 17,000$ free $\mathrm{OH}$ as specified in ASR

Reag. Blk.1

Standard 1

08-02293MS Matrix spike
12.73

12.45

\begin{tabular}{|c|c|}
\hline $\begin{array}{c}\mu \mathrm{g} / \mathrm{ml} \text { or } \\
\mathrm{mg} / \mathrm{L} \\
\mathrm{MDL}\end{array}$ & $\begin{array}{c}\text { Molarity } \\
\text { MDL }\end{array}$ \\
\hline $1.70 \mathrm{E}+03$ & 0.100 \\
\hline
\end{tabular}

Required RPD $+/-20 \%$

Allowed Recovery Range

$94.6 \%$

$+/-20 \%$

$95.3 \%$

N/A

Note: Results are presented for the first, second, and third inflection points on the titration curves, as applicable. The first inflection point is generally associated with the free hydroxide concentration. The second inflection point generally represents total hydroxide, or carbonate or a combination of aluminate and carbonate. The third inflection point is usually indicative of bicarbonate or other weak acids or possibly the continued protonation of alumina.

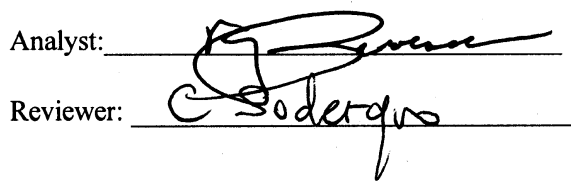

$8 / 26 / 0-$

$8-27-08$ 
号

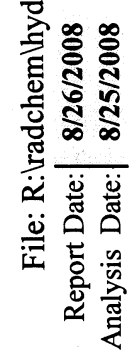

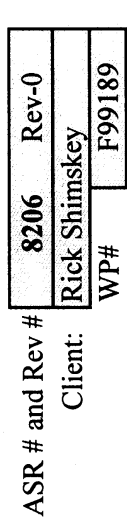

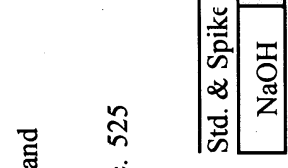

空

ह है

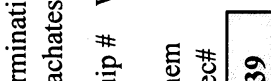

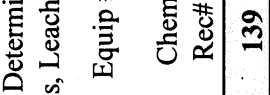

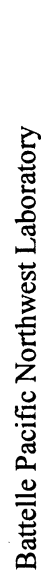

证

象

究出语

妾

节

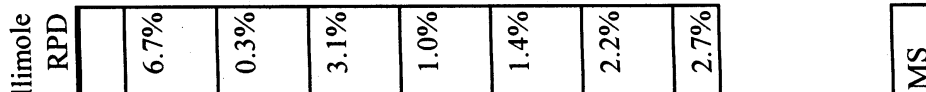

ํํㄹ

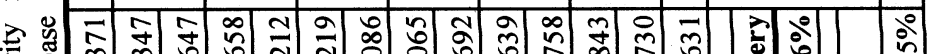
帝

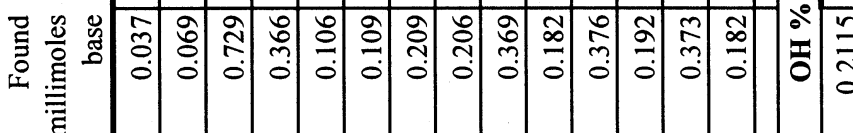

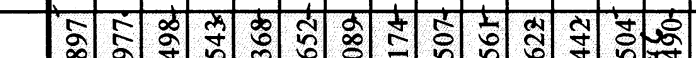

枯

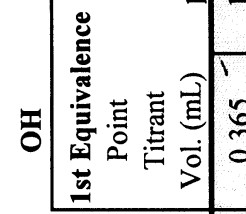

co

$\mid$\begin{tabular}{c|c|c|}
$\frac{1}{2}$ \\
aे
\end{tabular}

高

a.

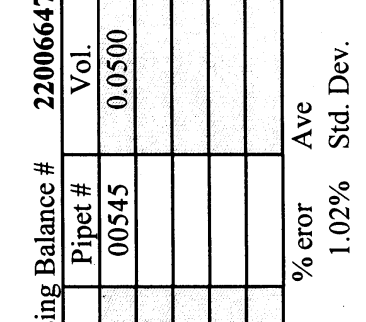

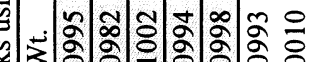

0.00000

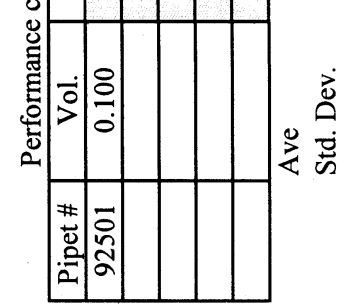

鄫言

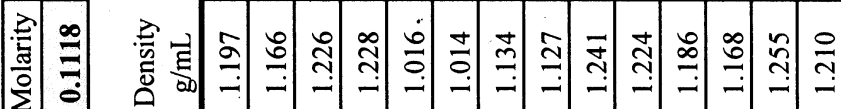

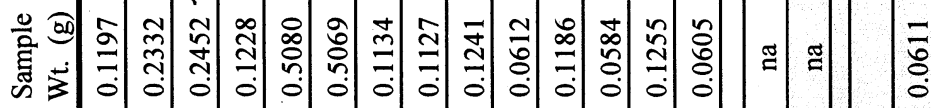

言 실

ठ̊̀े

๘

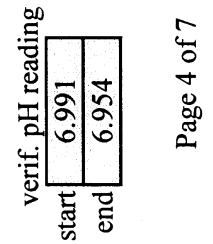

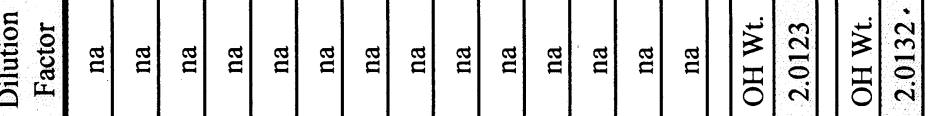
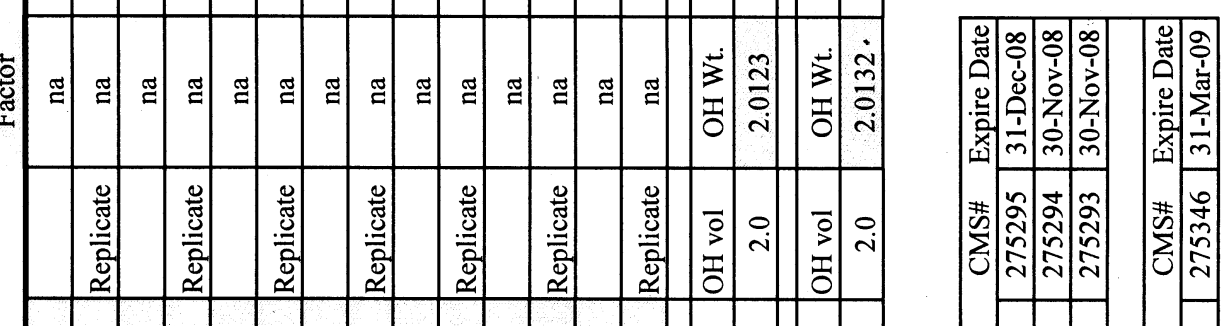

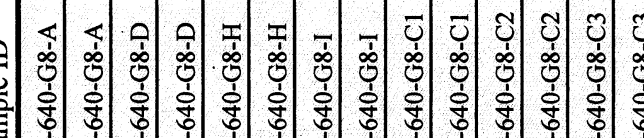

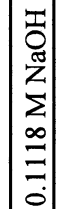

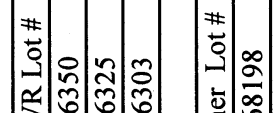

की
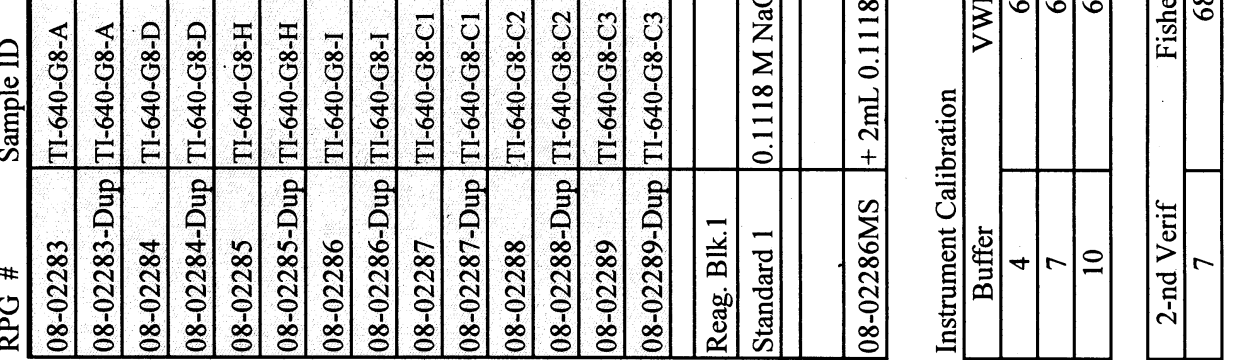

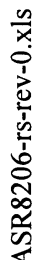


荡

亩企

¿े

๖े

亏.

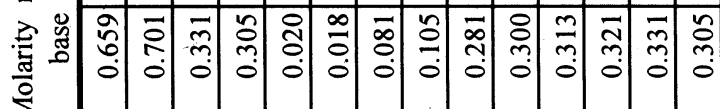

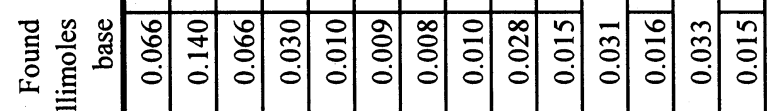
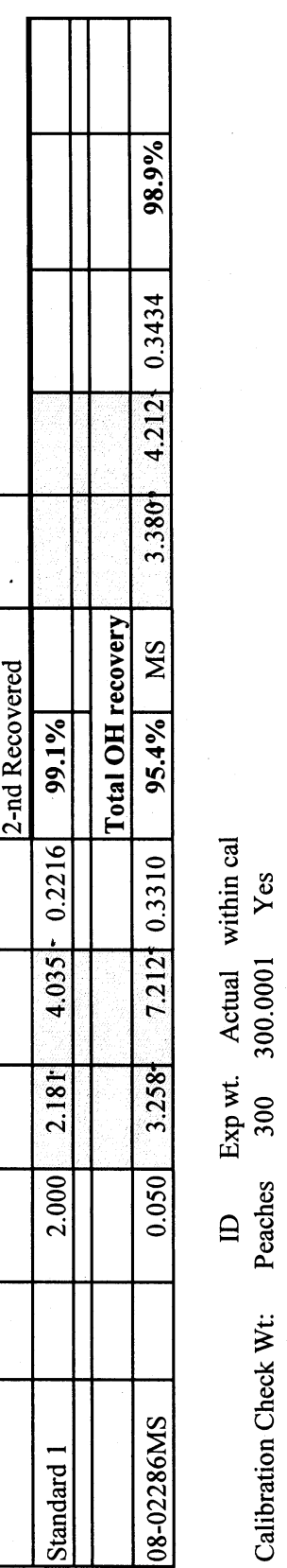

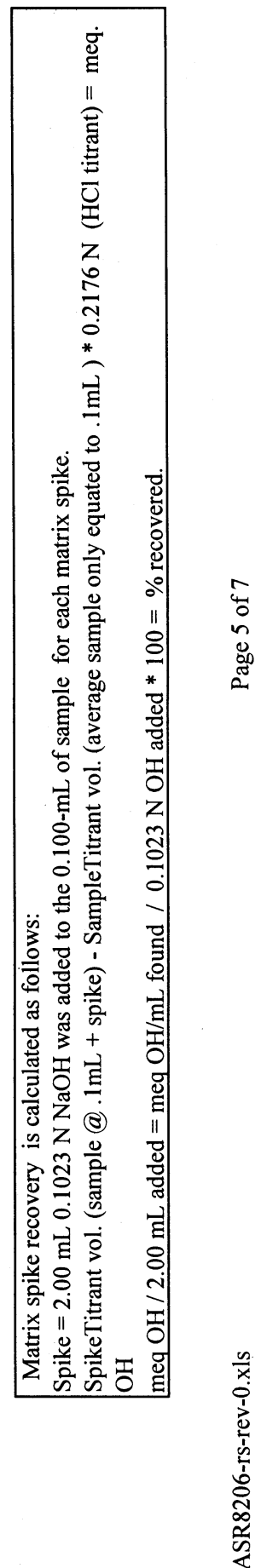

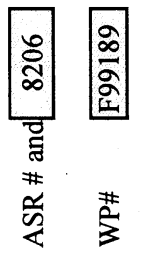

ะ :

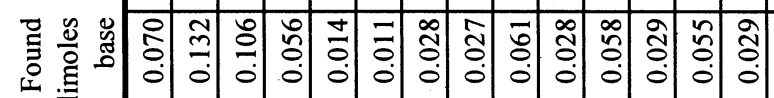
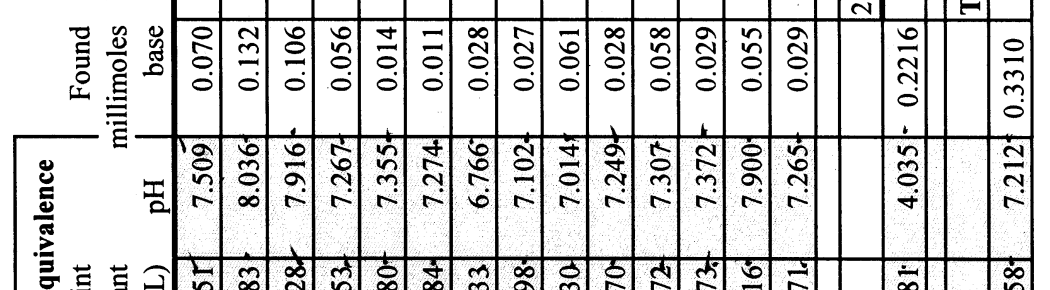

帚

क

:

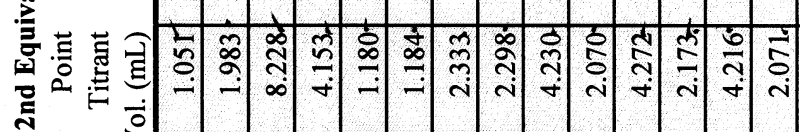

$\stackrel{\dot{\alpha}}{\sim}$

녕 영

응

窟
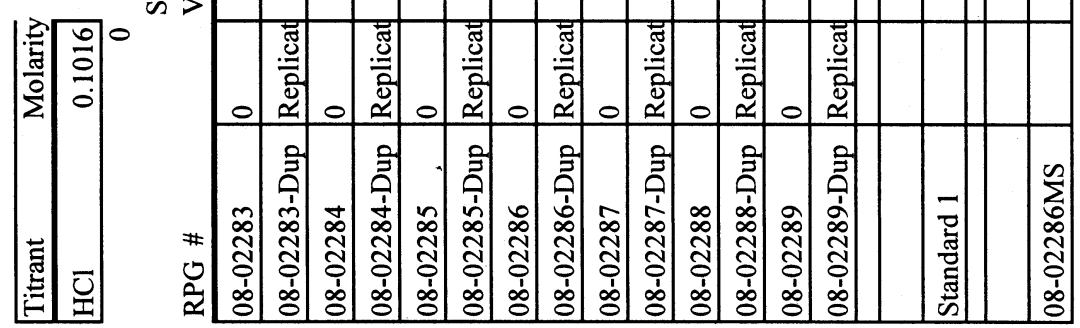
ํㅠㅁ

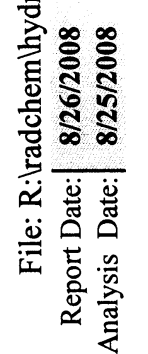

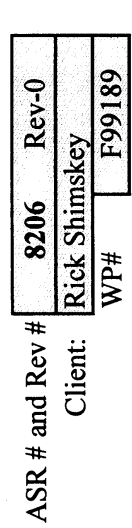

จ

害

o

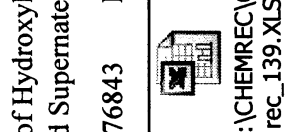

政

数

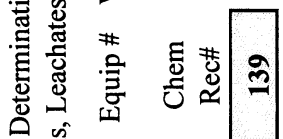

量

궁

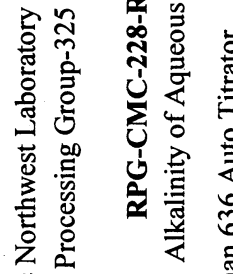

宸.

$\frac{\mathscr{8}}{\frac{\pi}{\pi}}$

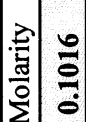

忥
衰言

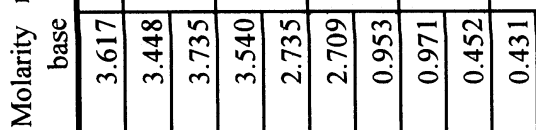

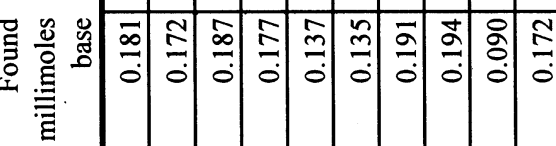

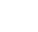

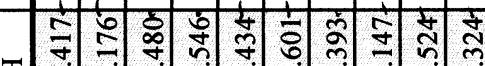

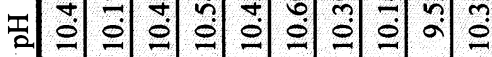

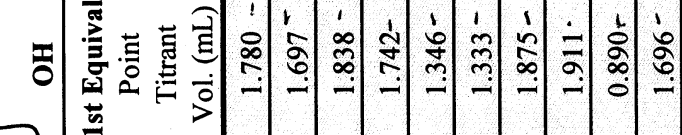

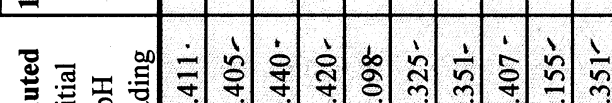

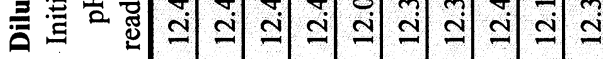

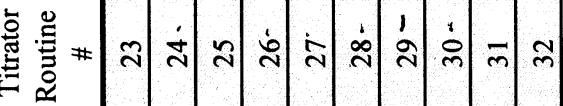

总品

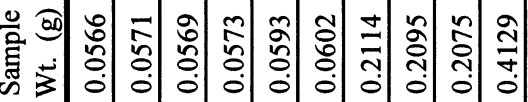

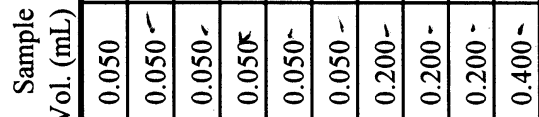

$\approx$ ฐ

雍

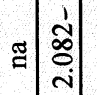

한

ธิ)

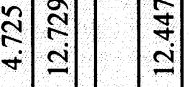

$-1$

$\dot{m}$

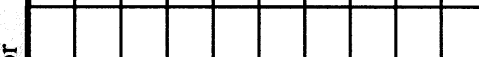

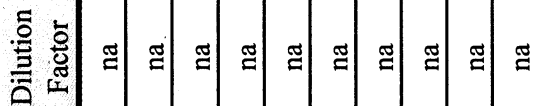

임

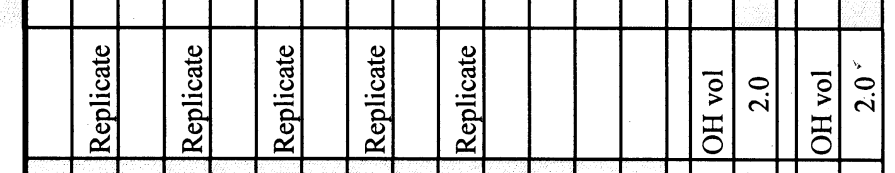

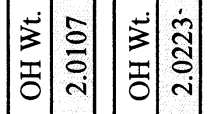

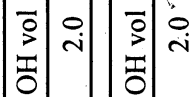

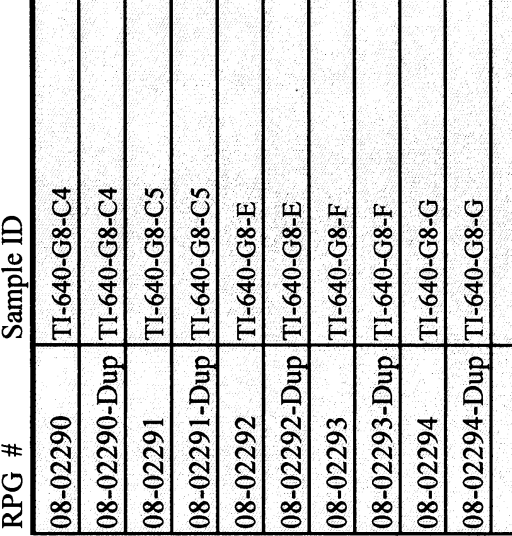

हूँ

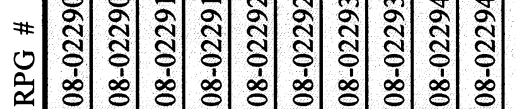

$\frac{m}{2}$

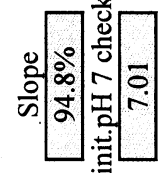

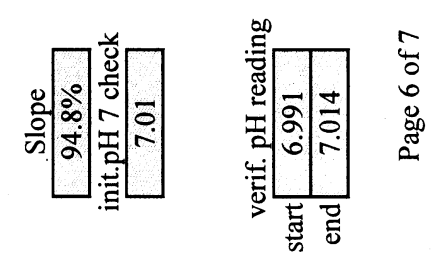

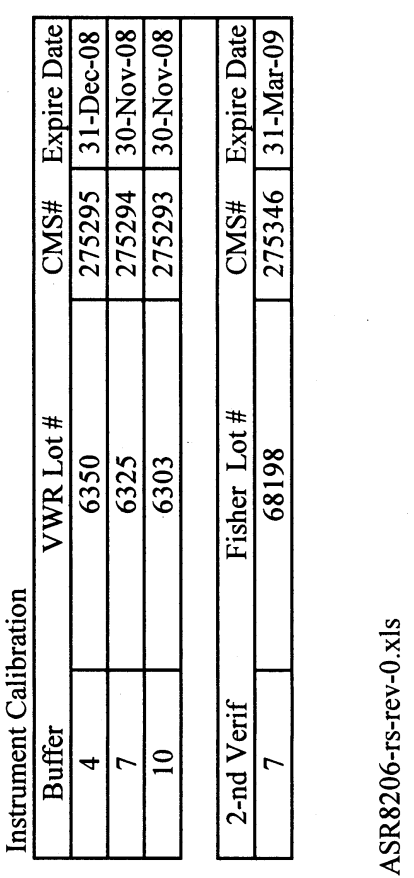

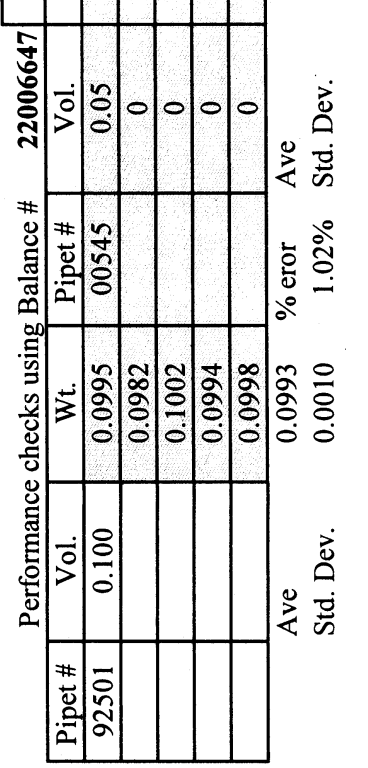

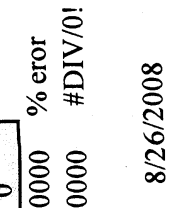



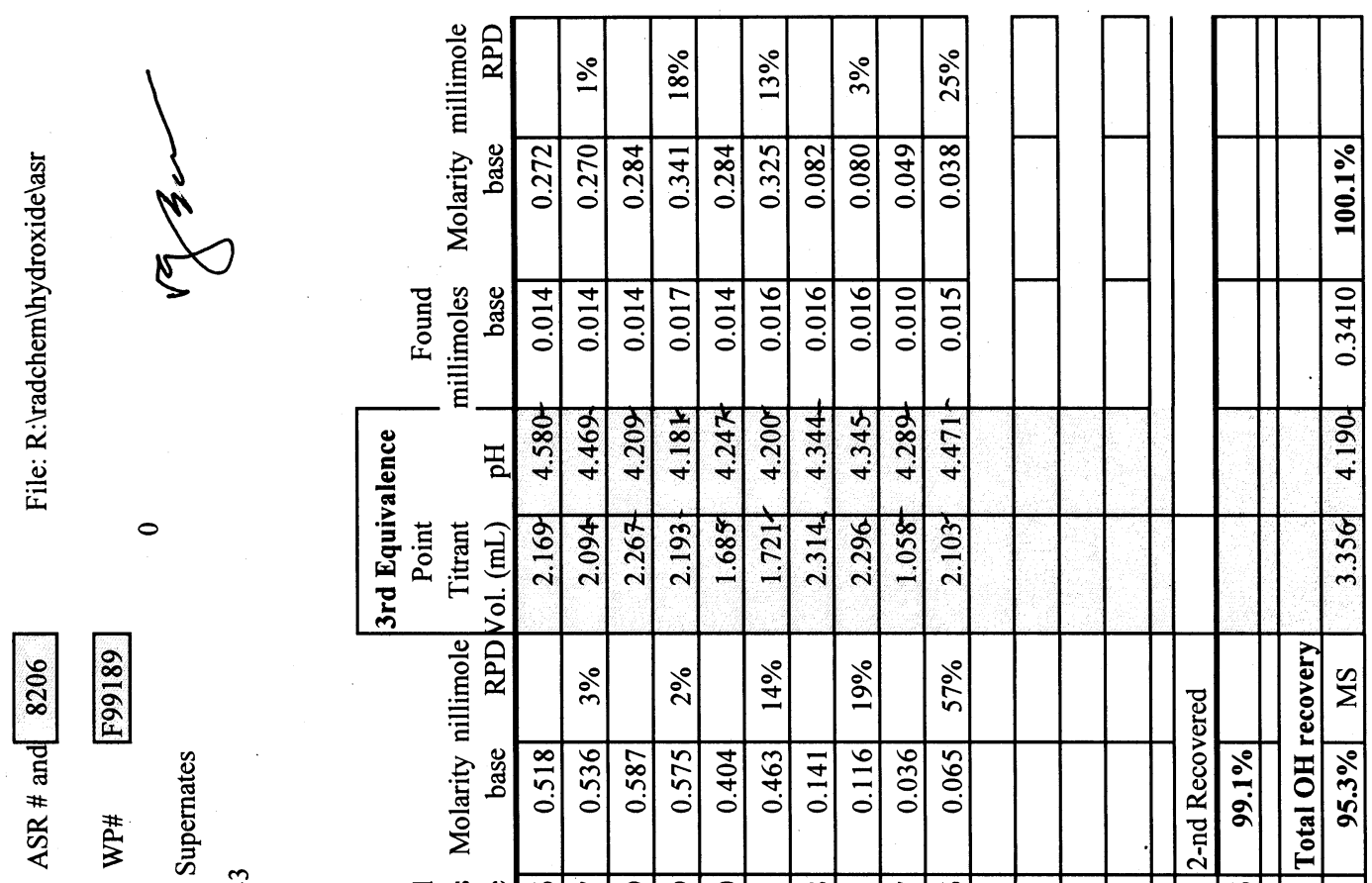

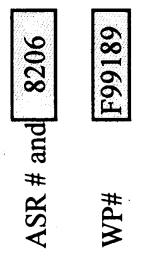

造

告

莺 1

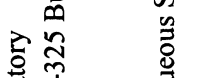

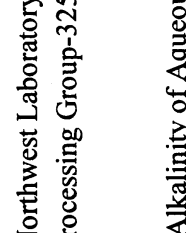
密 을 焉

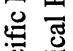

. 窇 氡

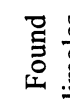

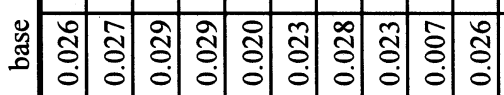

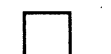

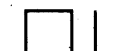

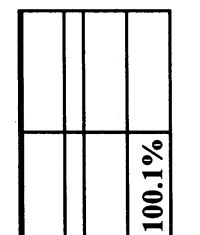


बे
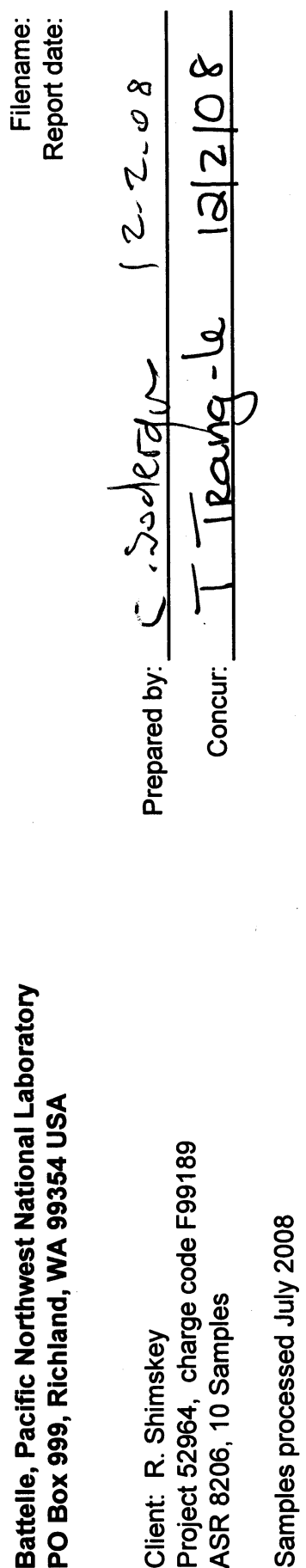

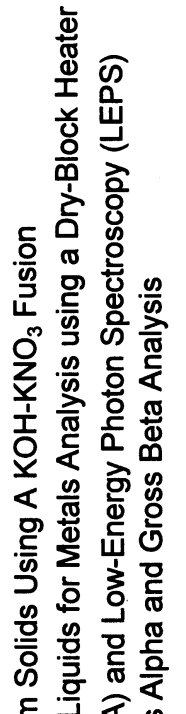

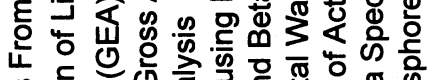

응 응

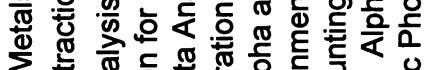

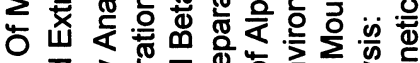

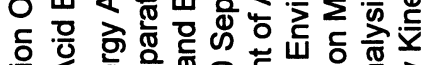

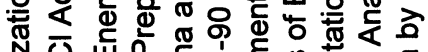

○

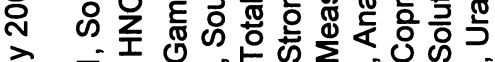
J

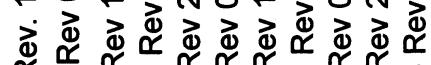

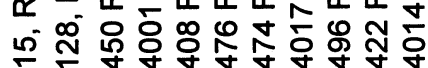
Б்َ 而施 $\sum_{0} \sum_{0} \sum_{0} \sum_{0} \sum_{0} \sum_{0} \sum_{0} \sum_{0} \sum_{0}$ 1 za $\frac{1}{x} \frac{0}{x} \frac{0}{x} \frac{0}{x} \frac{1}{x} \frac{0}{x} \frac{0}{x} \frac{1}{x} \frac{0}{x}$

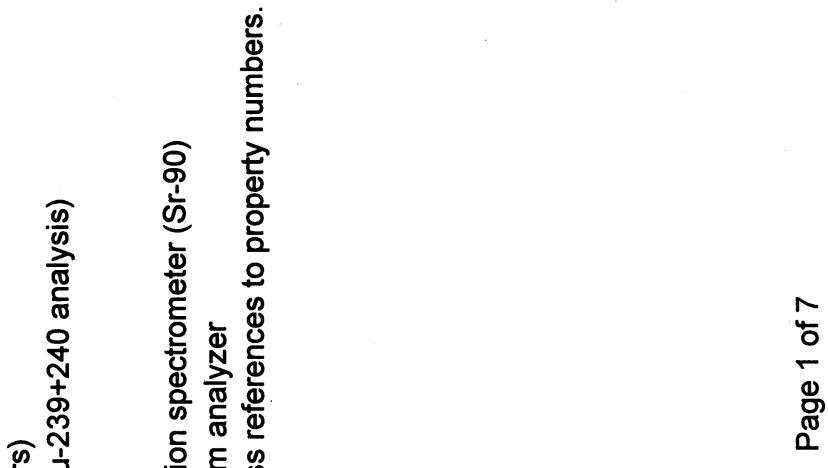

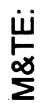

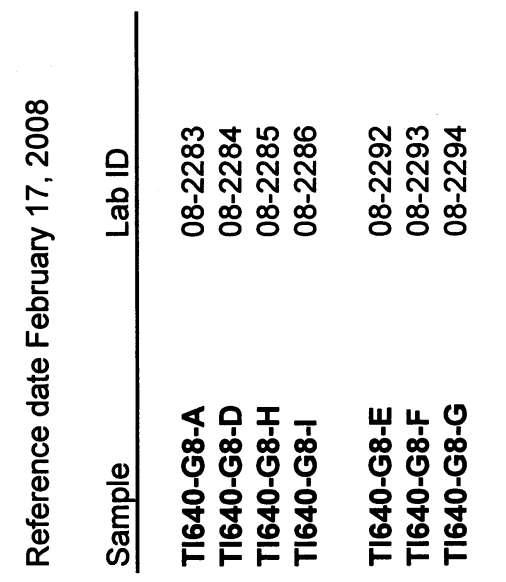


WTP-RPT-170, Rev 0
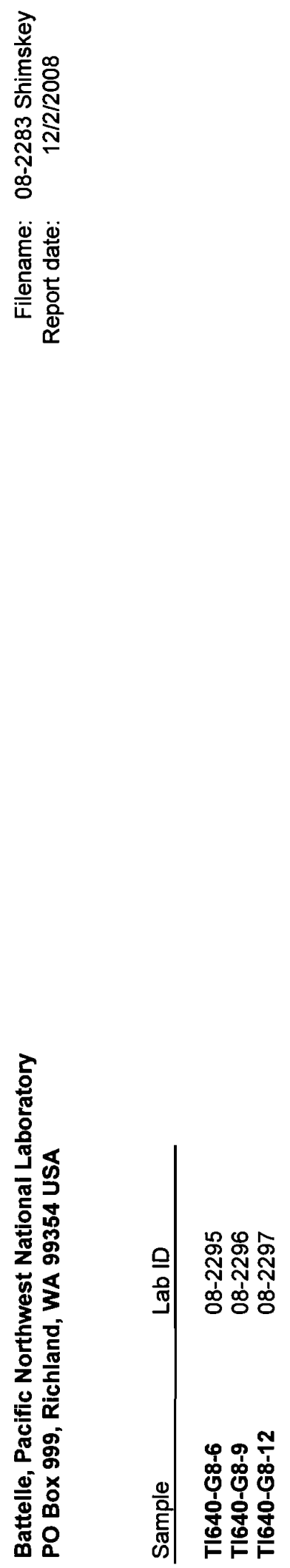
Battelle, Pacific Northwest National Laboratory
Richland, WA
Radiochemical Sciences and Engineering Group

Client: R. Shimskey

ASR 8206

\section{The Samples}

These samples originated in the hot cells and arrived in the analytical lab in June 2008. The samples required analysis of metals by ICPOES, hydroxide, anions, and several radionuclides. Only the radiochemistry data is reported here; the inorganic analytes are reported separately.

\section{Sample Preparation}

The aqueous samples were digested in dilute nitric acid (procedure RPG-CMC-128) in a laboratory fume hood. The solid samples were fused with potassium hydroxide (procedure PNL-ALO-115) in a hot cell.

\section{Quality Control Results}

All of the quality control results fell well within the limits prescribed by the project.

All of the requested detection limits were met except for Eu-155 and Am-241 in most of the samples, where the Compton background from high Cs-137 activity raised the detection limit for Eu-155 and Am-241. The hot cell blank results are small compared to the accompanying samples. All pairs of duplicates agree well (the Pu-238 results for sample T1640-G8-A are near the detection limit and have very high counting error). All of the spike recoveries fell within the limits prescribed by the project, and within expected uncertainty.

\section{Gamma Emitters (procedure RPG-CMC-450)}

Gamma emitters were measured by counting aliquots of the acid digestions and potassium hydroxide fusions. All gamma emitters that were detected were reported, except for potassium-40. Because no sample preparation or separation is done for gamma counting, no spikes are prepared.

\section{Gross Alpha and Gross Beta (procedures RPG-CMC-4001 and -408)}

To measure gross alpha, a small volume of each sample solution (the acid digestion or fusion solution) was dried onto a steel disk and counted on a Ludlum solid scintillation alpha counter.

To measure gross beta, a small volume of each sample solution was evaporated onto a planchet and counted on a gas proportional counter. Nearly all the activity is beta, not alpha, and crosstalk corrections were not necessary. Solids loading on the counting planchets was too small to affect the data. 


\section{Battelle, Pacific Northwest National Laboratory Richland, WA \\ filename $\quad 08-2283$ Shimskey \\ Radiochemical Sciences and Engineering Group

Client: R. Shimskey

ASR 8206

The aqueous samples have too little alpha to measure accurately by gross alpha counting. The sum of Pu-239+240, Pu-238, and Am-241 is a more accurate and sensitive estimate of the gross alpha activity of these samples. (Uranium contributes only a small part of the alpha activity.)

The gross beta activity agrees reasonably well with the sum of Cs-137, Sr-90, and Y-90.

Strontium-90 (procedures RPG-CMC-476 and -474)

Strontium was chemically separated from the acid digestion preparations, then measured by liquid scintillation.

Plutonium (procedures RPG-CMC-4017, -496 , and -422)

Plutonium was separated from the sample solutions by anion exchange in hydrochloric acid, then mounted for alpha spectroscopy by coprecipitation, then measured using alpha spectrometry.

Uranium (procedures RPG-CMC-4017 and -4014)

Uranium was chemically separated from the samples by anion exchange in hydrochloric acid, then measured by kinetic phosphorescence. All of the samples have easily measurable uranium, well above the blanks.

Raw aqueous sample, not the acid digestion, was used for uranium analysis. No uranium concentration is given for the acid digestion blank because the acid digestion was not used for uranium analysis. 


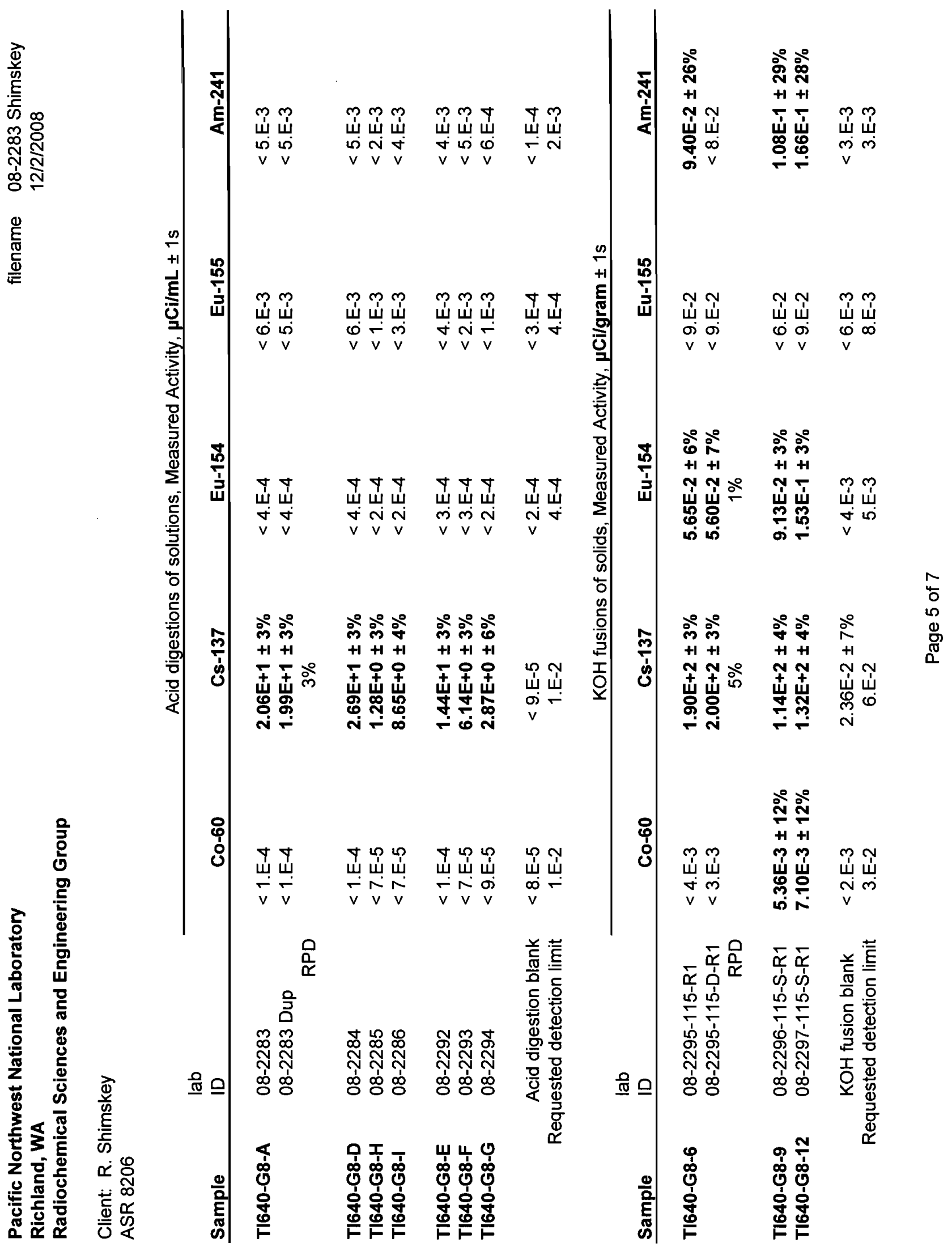




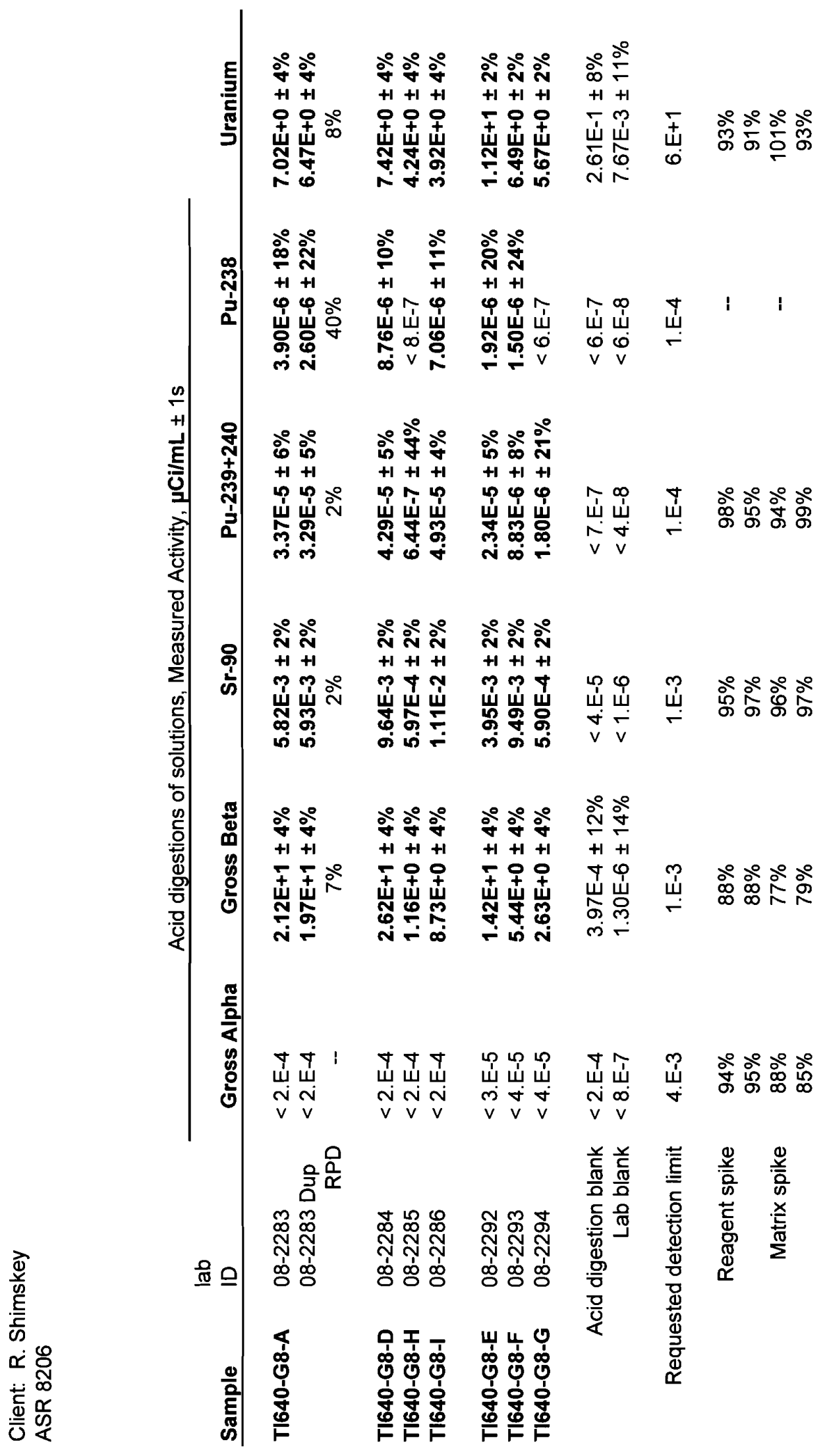


WTP-RPT-170, Rev 0
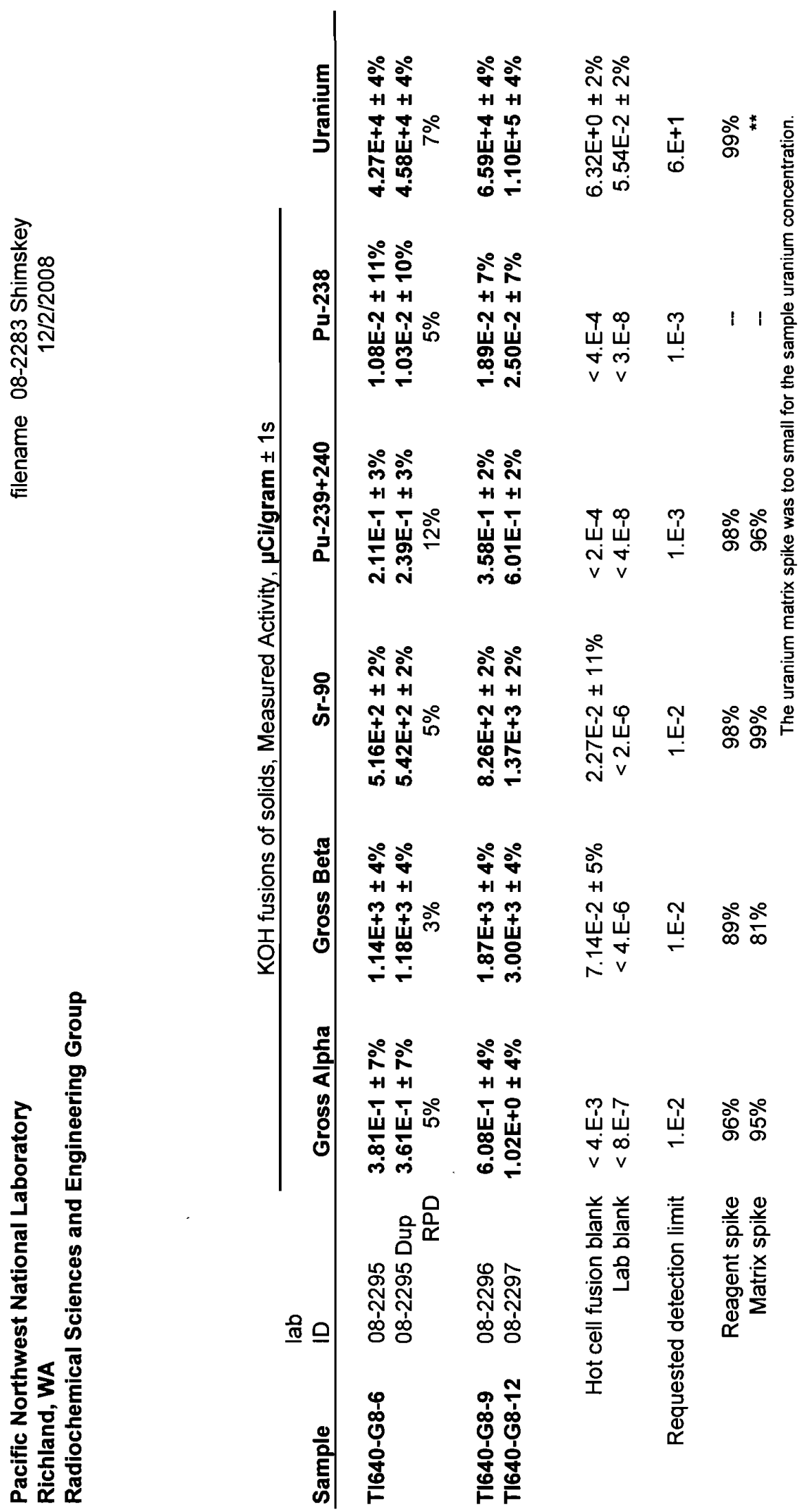


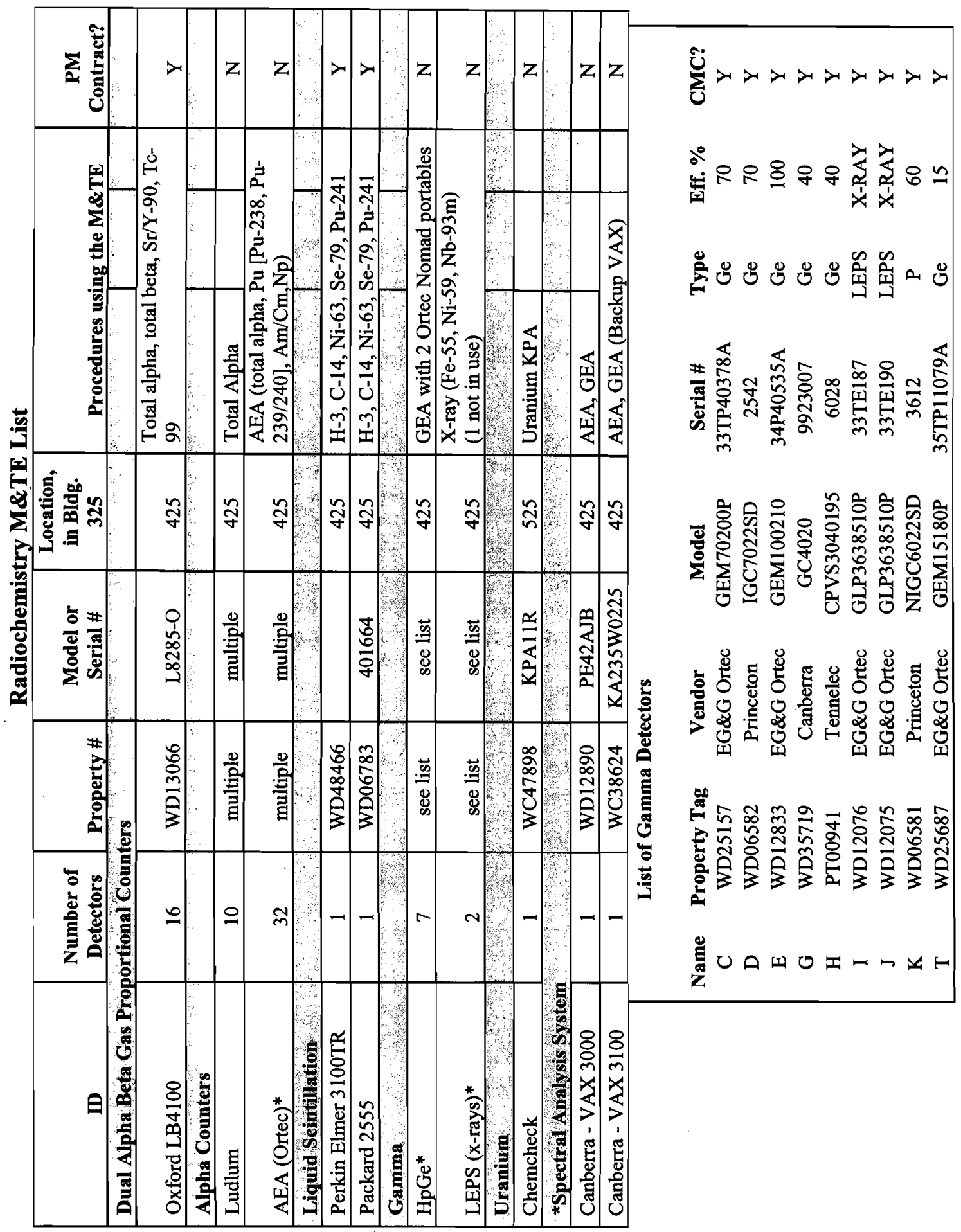




\section{Battelle - Pacific Northwest National Laboratory \\ Radiochemical Science and Technology \\ TIC/TOC Report-Hot Persulfate Method \\ PO Box 999, Richland, Washington 99352}

$\begin{array}{ll}\text { Project Number: } & 52964 \\ \text { Charge Code: } & \text { F99189 } \\ \text { ASR Number: } & 8206 \\ \text { Client: } & \text { RW Shimskey } \\ \text { Total Samples: } & 4\end{array}$

\begin{tabular}{|l|c|}
\hline & Sample \\
\hline RPL & $08-02283$ through 08-02286 \\
Numbers & TI640-G8-A through TI640-G8-I \\
\hline Client IDs &
\end{tabular}

\begin{tabular}{|l|l|}
\hline Analysis Procedure & $\begin{array}{l}\text { RPG-CMC-385 Rev. 0, "Carbon Measured in Solids, } \\
\text { Sludge, and Liquid Matrices" }\end{array}$ \\
\hline Prep Procedure & None \\
\hline Analyst & D. Kallsen \\
\hline Analysis Date & September 29, 2008 \\
\hline CCV Standards & TOC CMS-291280 TIC CMS-239430 \\
\hline BS/LCS/MS Standards & TOC CMS-291279 TIC CMS-239496 \\
\hline Excel Data File & ASR 8206 HP Shimskey.xls \\
\hline \multirow{2}{*}{ M\&TE Numbers } & Carbon System (WC01713-701) \\
\cline { 2 - 2 } & Balance (360-06-01-023/ Satorius 37050057/ 30809774) \\
\hline All Analysis Records & System Files TC-08-020 \\
\hline
\end{tabular}

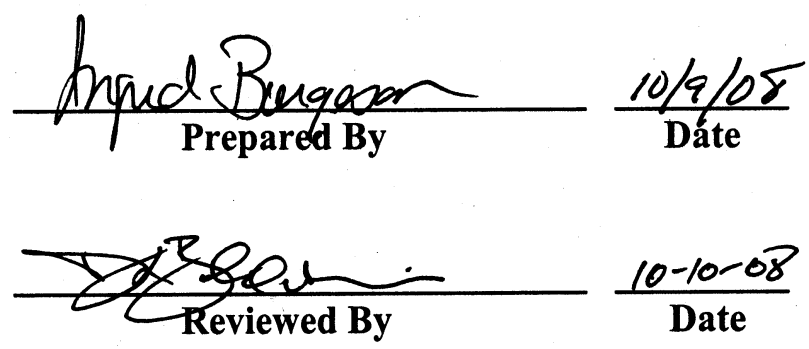




\section{TIC/TOC Report - Hot Persulfate Method}

Table 1: Carbon Final Results

\begin{tabular}{|c|c|c|c|c|c|c|c|c|c|}
\hline \multirow[b]{2}{*}{ RPL Number } & \multirow[b]{2}{*}{ Sample ID } & \multicolumn{3}{|c|}{ TIC } & \multicolumn{3}{|c|}{ TOC } & \multicolumn{2}{|l|}{$\mathrm{TC}$} \\
\hline & & $\begin{array}{c}\mathrm{MDL} \\
\mu \mathrm{g} \mathrm{C} \\
/ \mathrm{mL}\end{array}$ & $\begin{array}{c}\text { Results } \\
\mu \mathrm{g} \\
\mathrm{C} / \mathrm{mL} \\
\end{array}$ & RPD & $\begin{array}{c}\mathrm{MDL} \\
\mu \mathrm{g} \mathrm{C} / \mathrm{mL}\end{array}$ & $\begin{array}{c}\text { Results } \\
\mu \mathrm{g} \\
\mathrm{C} / \mathrm{mL}\end{array}$ & RPD & $\begin{array}{c}\text { Results } \\
\mu \mathrm{g} \mathrm{C} / \mathrm{mL}\end{array}$ & RPD \\
\hline $08-02283$ & TI-640-G8-A & 14 & 6,700 & & 143 & 1,250 & & 7,950 & \\
\hline 08-02283-Dup & TI-640-G8-A & 14 & 6,780 & $1 \%$ & 143 & 1,180 & $6 \%$ & 7,960 & $0 \%$ \\
\hline $08-02284$ & TI-640-G8-D & 14 & 3,400 & & 143 & 440 & & 3,840 & \\
\hline $08-02285$ & TI-640-G8-H & 14 & 190 & & 143 & $<143$ & & 190 & \\
\hline $08-02286$ & TI-640-G8-I & 14 & 930 & & 143 & 640 & & 1,570 & \\
\hline \multicolumn{10}{|l|}{ QC Samples } \\
\hline $08-02283$ AS & Recovery & -- & $101 \%$ & -- & -- & $103 \%$ & -- & $102 \%$ & -- \\
\hline $\begin{array}{l}\text { LCS/Blank } \\
\text { Spike }\end{array}$ & Recovery & -- & $99 \%$ & -- & -- & $101 \%$ & -- & $\mathrm{n} / \mathrm{a}$ & -- \\
\hline
\end{tabular}

TOC: total organic carbon

TC: total carbon

MDL: method detection limit

TIC: total inorganic carbon

Dup: duplicate/replicate

AS: analytical spike

RPD: relative percent difference

$\mathrm{n} / \mathrm{a}$ : RPD not calculated if results not greater than $5 \mathrm{x}$ MDL

-- indicates no information for that cell

\section{Sample Analysis/Results Discussion}

The TIC/TOC analysis of four aqueous samples submitted under Analytical Service Request (ASR) 8206 was performed using the hot persulfate wet oxidation method. The hot persulfate method uses acid decomposition for TIC and silver catalyzed acidic potassium persulfate oxidation at $92-95^{\circ} \mathrm{C}$ for TOC, all on the same sample, with TC being the sum of the TIC and TOC. The analyses were performed on September 29, 2008 following the QA Plan ASO-QAP001 and the client document RPP-WTP-QA-005 Rev. 2.

Table 1 above shows the results from the analysis. The solution samples were analyzed directly using approximately $0.50 \mathrm{~mL}$ of solution. These results are reported as $\mu \mathrm{g} \mathrm{C} / \mathrm{mL}$ sample. All sample results are corrected for average percent recovery of system calibration verification standards and are also corrected for contribution from the instrument blank, as per procedure RPG-CMC-385, Rev. 0.

\section{Quality Control Discussion}

The identification of the calibration verification standard, laboratory control sample, and analytical spike standards and identified by their respective Chemical Management System (CMS) numbers are included on the raw data benchsheets for traceability.

The QC for the method involves calibration blanks, sample duplicate (laboratory), laboratory control sample/blank spike (LCS/BS), and analytical spike (AS).

Calibration Check Standards: The calibration of the coulometer analysis system was checked by calibration check standards analyzed at the beginning and end of the analysis run. The average recovery from the calibration check standards is applied as a correction factor to the 'raw data' results obtained for the samples. The average recovery for the batch was $97.3 \%$ for TIC and $98.8 \%$ for TOC; all within the acceptance criteria for the carbon procedure. 


\section{TIC/TOC Report - Hot Persulfate Method}

Laboratory Control Sample/Blank Spike: An LCS/BS was analyzed with the samples. The TIC material is a solid and the TOC material is a liquid. The recoveries for the TIC and TOC were $99 \%$ and $101 \%$, respectively; both well within the acceptance criterion of $80 \%$ to $120 \%$.

Duplicate: Precision of the carbon measurements is demonstrated by the relative percent difference (RPD) between sample and duplicate. No duplicate sample was provided by the client; therefore laboratory duplicate were analyzed in each batch. The precision result for TIC was $1 \%$ and for TOC was $6 \%$, which is within the $\leq 20 \%$ acceptance criterion.

Analytical Spike: The accuracy of the carbon measurements can be estimated by the recovery results from the analytical spike (AS). Analytical spike was prepared for sample 08-02283. The TIC recovery was $99 \%$ and the TOC recovery was $101 \%$, both meet the QAP recovery acceptance criteria of $75 \%$ to $125 \%$.

\section{Deviation from Procedure}

None.

\section{General Comments}

1) Routine precision and bias are typically $\pm 15 \%$ or better for non-complex samples that are free of interferences.

2) The estimated quantitation limit $(\mathrm{EQL})$ is defined as 10 times the MDL. Results $<10 \mathrm{xMDL}$ have higher uncertainties, and RPDs (or RSDs, if applicable) are not calculated if the results are $<5 \times$ MDL.

3) For the TIC/TOC, the analysis MDL is based on the standard deviation calculated from the number (n) of system blanks analyzed with the batch of samples, with the standard deviation multiplied by the Student's $t$ values for $n-1$ degrees of freedom to establish the daily analysis.

4) The reported "Final Results" have been corrected for the lack of dilution performed on the sample during preparation. 
PNNL-18120

WTP-RPT-170, Rev. 0

\section{Distribution}

No. of

Copies

\section{ONSITE}

4 Bechtel National, Inc.

WTP R\&T Docs (2) H4-02

P. S. Sundar H4-02

S. Barnes H4-02

15 Pacific Northwest National Laboratory

S. K. Fiskum (2) P7-25

J. M. Billing P7-25

E. C. Buck P7-27

R. C. Daniel P7-22

M. K. Edwards P7-25

D. E. Kurath K3-52

G. J. Lumetta P7-25

L. M. Peurrung K9-09

R. A. Peterson P7-22

R. L. Russell K6-24

R. W. Shimskey P7-25

L. A. Snow P7-25

Information Release P8-55

Project File P7-28 